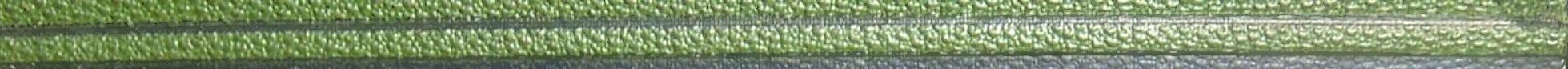

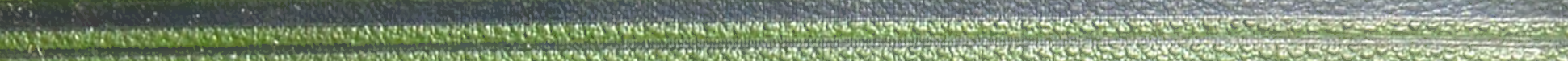
A15

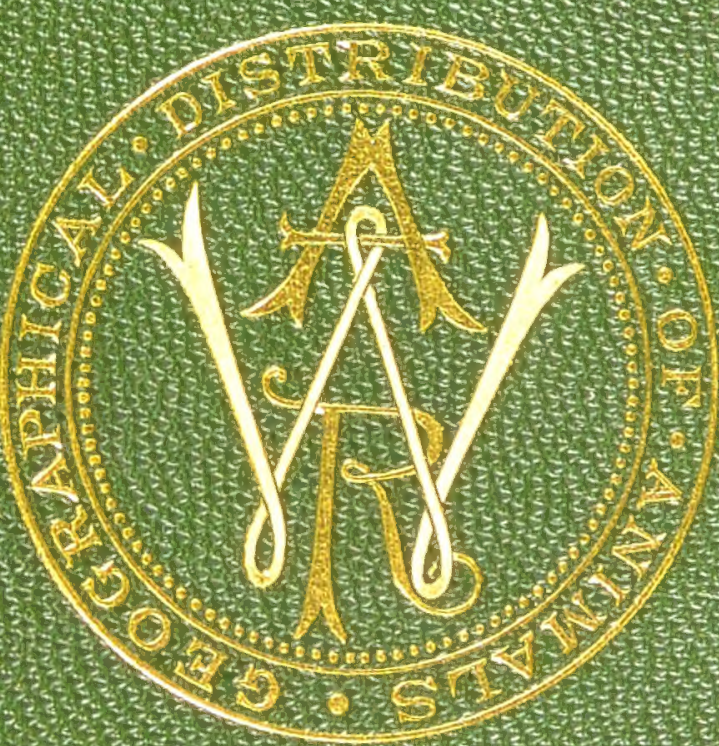

S. 


$$
\text { la.9.20 }
$$



42

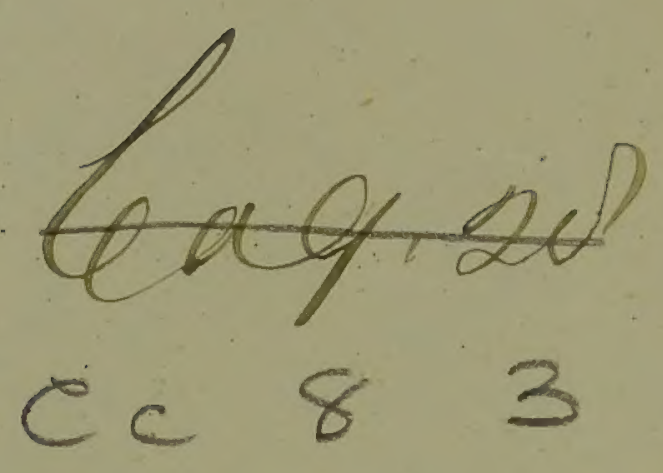

$R 32723$ 
THE GEOGRAPHICAL

\section{DISTRIBUTION OF ANIMALS.}

VOL. I. 


THE WORLD o MERCATOR'S PROJECTION SHEWTA THE ZOOGEOGRAPHICAL REGIONS, AND TIE APPROXIMATE UNILATIONS OF TIE OCEAN BED.

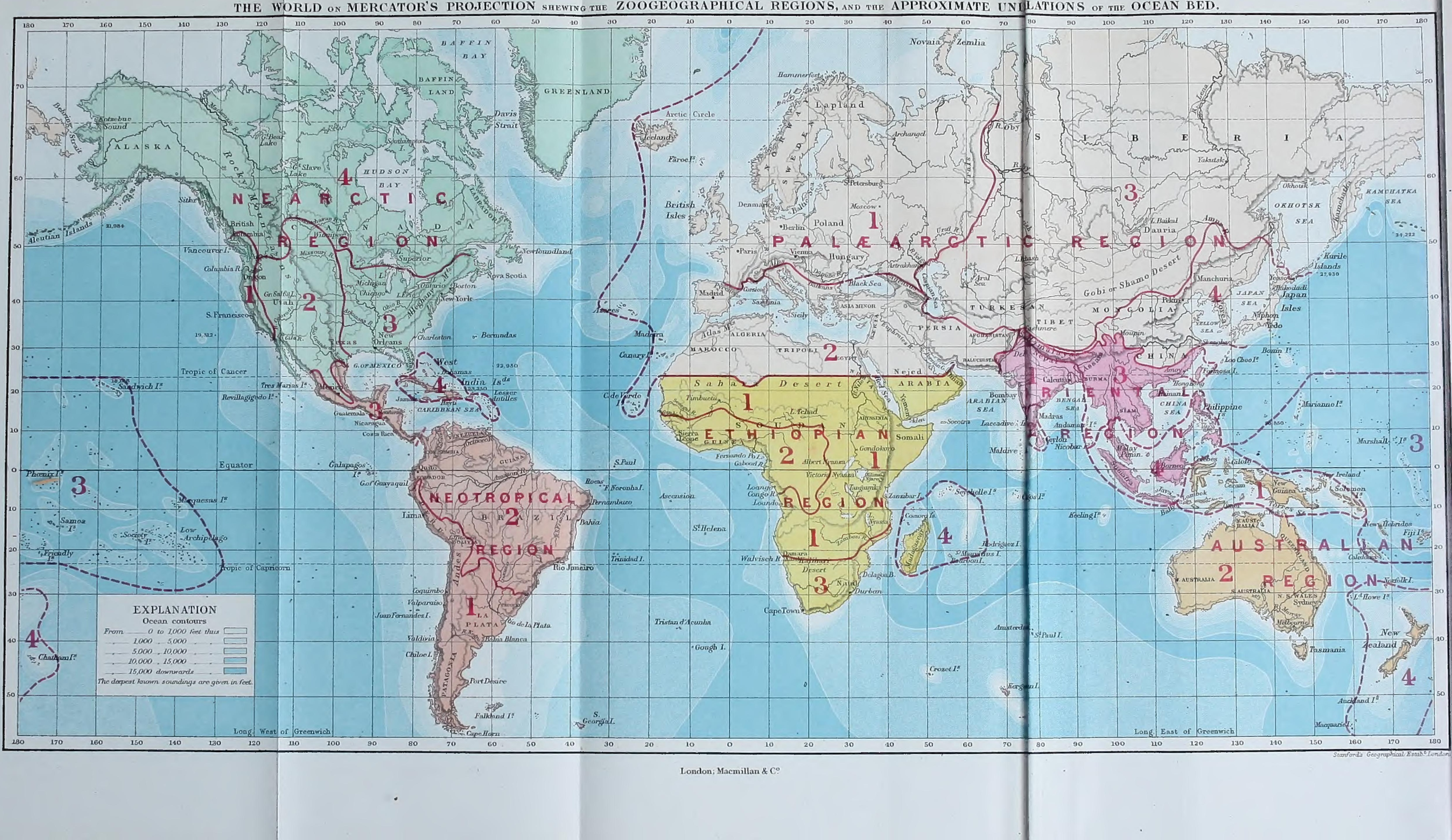




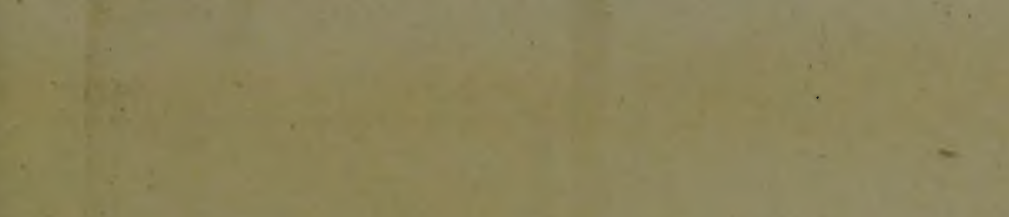
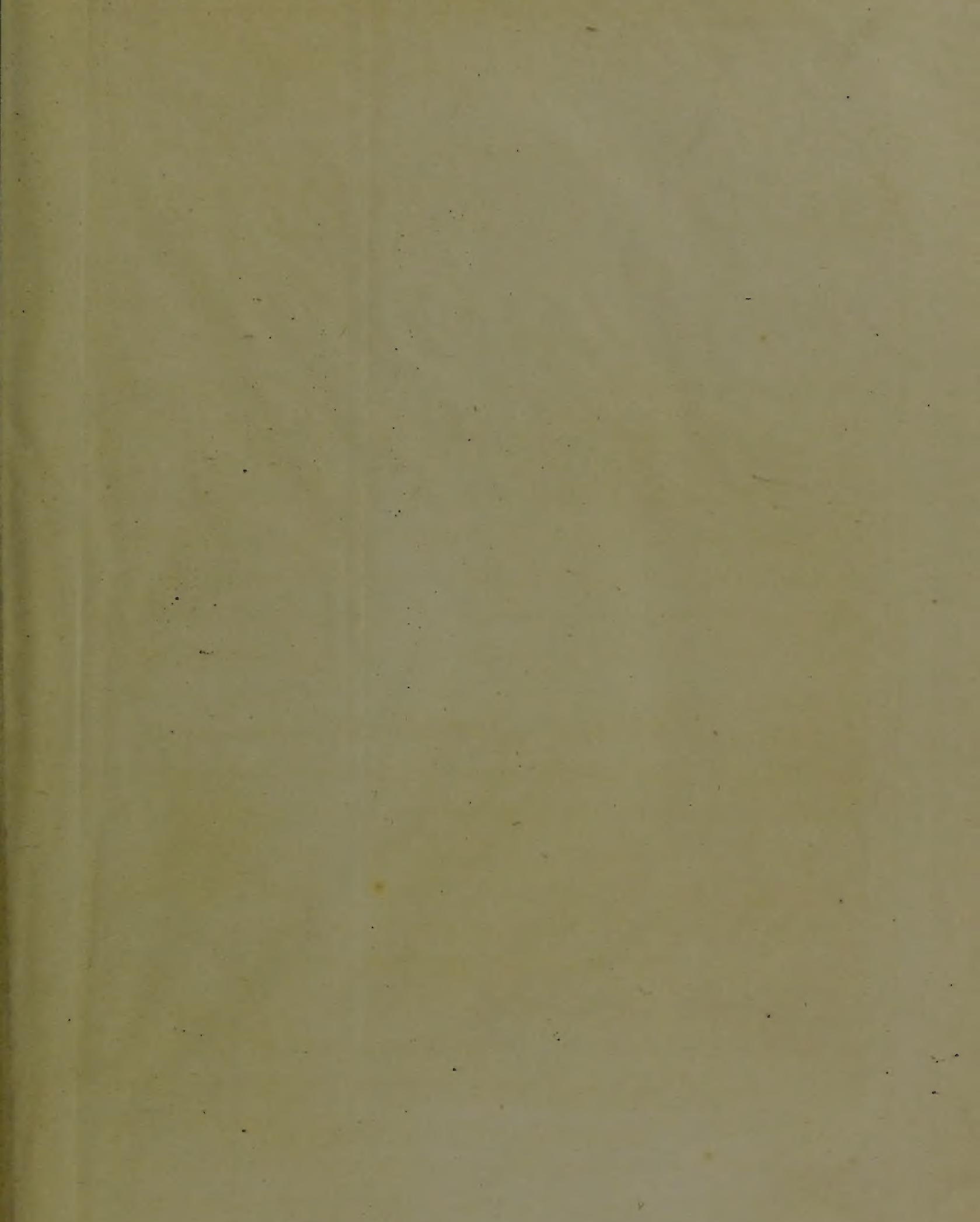

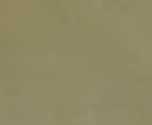

:
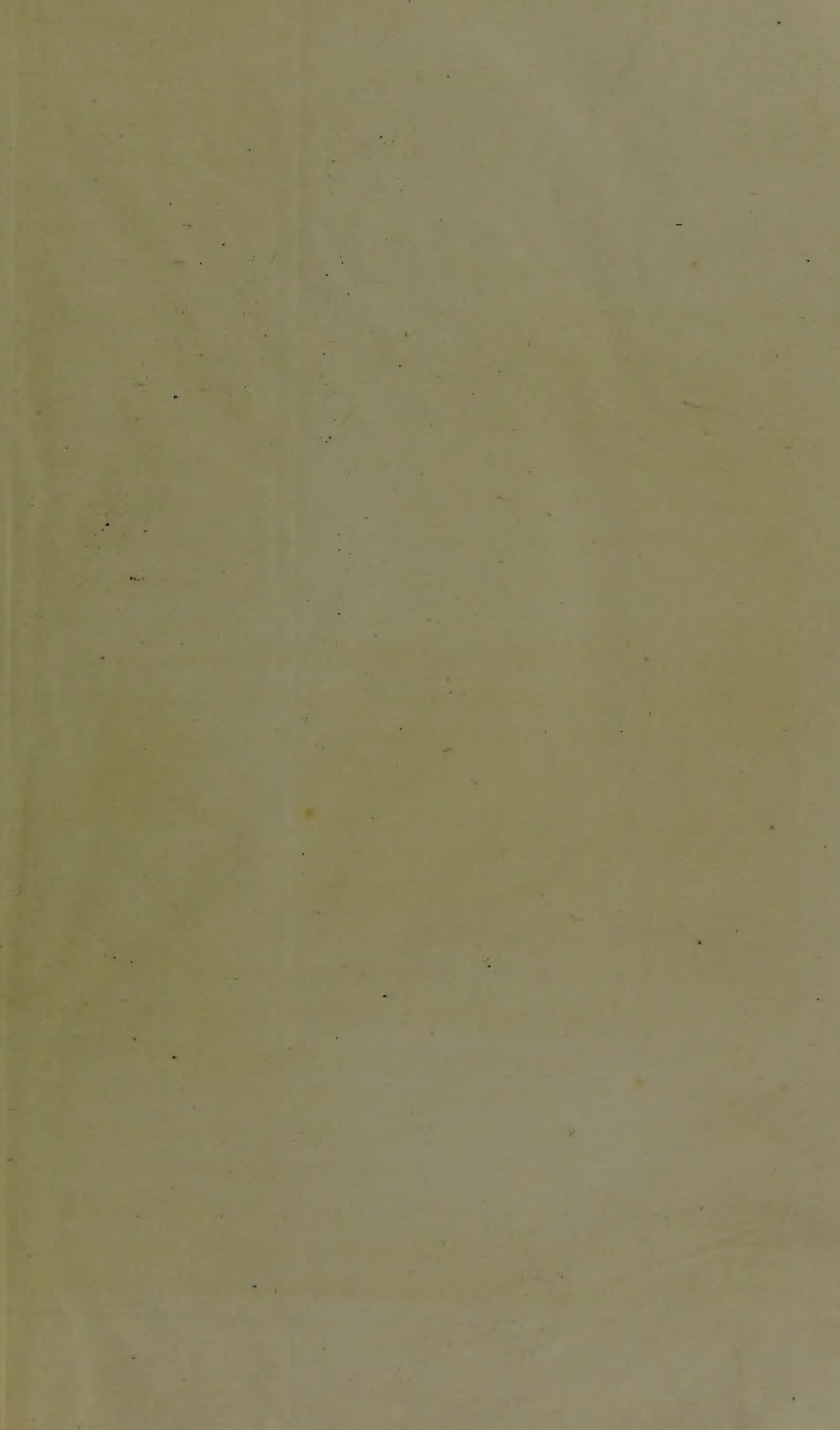



\title{
THE GEOGRAPHICAL
}

\section{DISTRIBUTION OF ANIMALS}

\author{
WI'TH A STUDY OF \\ THE RELATIONS OF LIVING AND EXTINCT FAUNAS \\ AS ELUCIDATING THE \\ PAST CHANGES OF THE EARTH'S SURFACE.
}

$\mathrm{BY}$

ALFRED RUSSEL WALLACE,

aUthor of "The shatay arohiphlago," eto.

WITH MAPS AND ILLUSTRATIONS.

IN TWO VOLUMES.-VOLUME I.

20non:

MACMILLAN AND CO.

1876 . 
LUNDUN:

R. CLAY, BUNS, AND TAYLUR, FHNILES,

BREAD STREET HILL. 


\section{P R E F A C E.}

THE present work is an attempt to collect and summarize the existing information on the Distribution of Land Animals; and to explain the more remarkable and interesting of the facts, by means of established laws of physical and organic change.

The main idea, which is here worked out in some detail for the whole earth, was stated sixteen years ago in the concluding pages of a paper on the "Zoological Geography of the Malay Archipelago," which appeared in the Journal of Proceedings of the Linnean Society for 1860 ; and again, in a paper read before the Royal Geographical Society in 1863, it was briefly summarized in the following passage :-

"My object has been to show the important bearing of researches into the natural history of every part of the world, upon the study of its past history. An accurate knowledge of any groups of birds or of insects and of their geographical distribution, may enable us to map out the islands and continents of a former epoch,- the amount of difference that exists between the animals of adjacent districts being closely related to preceding geological changes. By the collection of such minute facts, alone, can we hope to fill up a great gap in the 
past history of the earth as revealed by geology, and obtain some indications of the existence of those ancient lands. which now lie buried beneath the ocean, and have left us nothing but these living records of their former existence."

The detailed study of several groups of the birds and insects collected by myseli in the East, brought prominently before me some of the curious problems of Geographical Distribution; but I should hardly have ventured to treat the whole subject, had it not been for the kind encouragement of Mr. Darwin and Professor Newton, who, about six years ago, both suggested that I should undertake the task. I accordingly set to work; but soon became discouraged by the great dearth of materials in many groups, the absence of general systematic works, and the excessive confusion that pervaded the classification. Neither was it easy to decide on any satisfactory method of treating the subject. During the next two years, however, several important catalogues and systematic treatises appeared, which induced me to resume my work; and during the last three years it has occupied a large portion of my time.

After much consideration, and some abortive trials, an outline plan of the book was matured; and as this is, so far as I am aware, quite novel, it will be well to give a few of the reasons for adopting it.

Most of the previous writings on Geographical Distribution appeared to me to be unsatisfactory, because they drew their conclusions from a more or less extensive selection of facts; and did not clearly separate groups of facts of nnequal value, or those relating to groups of animals of unequal rank. As an example of what is meant, I may refer to Mr. Andrew Murray's large and valuable work on the Geographical Distribution of Mammalia, in which an immense number of coloured maps are 
used to illustrate the distribution of various groups of animals. These maps are not confined to groups of any fixed rank, but are devoted to a selection of groups of various grades. Some show the range of single species of a genus-as the lion, the tiger, the puma, and a species of fox ; others are devoted to sections of genera,- - as the true wolves; others to genera,--as the hyænas, and the bears; others to portions of farnilies,- -as the flying squirrels, and the oxen with the bisons; others to families, -as the Mustelidæ, and the Hystricidæ; and others to groups of families or to orders, - as the Insectivora, and the opossums with the kangaroos. But in no one grade are all the groups trcated alike. Many genera are wholly unnoticed, while several families are only treated in combination with others, or are represented by some of the more important genera.

In making these observations $I$ by no means intend to eriticise Mr. Murray's book, but merely to illustrate by an example, the method which has been hitherto employed, and which seems to me not well adapted to enable us to establish the foumdations of the science of distribution on a secure basis. To do this, uniformity of treatment appeared to me essential, both as a matter of principle, and to avoid all imputation of a partial selection of facts, which may be made to prove anything. I determined, therefore, to take in succession every well-estallished family of terrestrial vertebrates, and to give an account of the distribution of all its component genera, as far as materials were available. Species, as such, are systematically disregarded, -firstly, because they are so numerous as to be unmanageable; and, secondly, because they represent the most recent modifications of form, due to a variety of often unknown causes, and are therefore not so clearly connected with geographical changes as are the natural groups of species termed genera; which may be considered to represent the average and more permanent 
distribution of an orginic type, and to be inore clearly influenced by the various known or inferred changes in the organic and physical environment.

This systematic review of the distribution of families and genera, now forms the last part of my book-Geographical Zoology; but it was nearly the first written, and the copious materials collected for it enabled me to determine the zoogeographical divisions of the earth (regions and sub-regions) to be adopted. I next drew up tables of the families and genera found in each region and sub-region; and this afforded a basis for the geographical treatment of the subject-Zoological Geography-the most novel, and perhaps the most useful and generally interesting part of my work. While this was in progress I found it necessary to make a careful summary of the distribution of extinct Mammalia. This was a difficult task, owing to the great uncertainty that prevails as to the affinities of many of the fossils, and my want of practical acquaintance with Palæontology; but having carefully examined and combined the works of the best authors, I have given what I believe is the first connected sketch of the relation of extinct Mammalia to the distribution of living groups, and have arrived at some very interesting and suggestive results.

It will be observed that man is altogether omitted from the series of the animal kingdom as here given, and some explanation of this oinission may perhaps be required. If the genus Homo had been here treated like all other genera, nothing more than the bare statement- "universally distributed"could have been given;-and this would inevitably have provoked the criticism that it conveyed no information. If, on the other hand, I had given an outline of the distribution of the varieties or races of man, I should have departed from the plan of my work for no sufficient reason. Anthropology is a science 
by itself; and it seems better to omit it altogether from a zoological work, than to treat it in a necessarily superficial manner.

The best method of illustrating a work of this kind was a matter requiring much consideration. To have had a separate coloured or shaded map for each family would have made the work too costly, as the terrestrial vertebrates alone would have required more than three hundred maps. I had also doubts about the value of this mode of illustration, as it seemed rather to attract attention to details than to favour the development of general views. I deternined therefore to adopt a plan, suggested in conversation by Professor Newton; and to have one general map, showing the regions and sub-regions, which could be referred to by means of a series of numbers. These references I give in the form of diagrammatic headings to each family; and, when the map has become familiar, these will, I believe, convey at a glance a body of important information.

Taking advantage of the recent extension of our knowledge of the depths of the great oceans, I determined to give upon this map a summary of our knowledge of the contours of the ocean bed, by means of tints of colour increasing in intensity with the depth. Such a map, when it can be made generally accurate, will be of the greatest service in forming an estimate of the more probable changes of sea and land during the Tertiary period; and it is on the effects of such changes that any satisfactory explanation of the facts of distribution must to a great extent depend.

Other important factors in determining the actual distribution of animals are, the zones of altitude above the sea level, and the strongly contrasted character of the surface as regards vegetation - a primary condition for the support of animal life. I 
therefore designed a series of six maps of the regions, drawn on a uniform scale, on which the belts of altitude are shown by contour-shading, while the forests, pastures, deserts, and perennial snows, are exhibited by means of appropriate tints of colour.

These maps will, I trust, facilitate the study of geographical distribution as a science, by showing, in sorne cases, an adequate cause in the nature of the terrestrial surface for the actual distribution of certain groups of animals. As it is hoped they will be constantly referred to, double folding has been avoided, and they are consequently rather small; but Mr. Stanford, and his able assistant in the map department, Mr. Bolton, have taken great care in working out the details from the latest observations; and this, combined with the clearness and the beauty of their execution, will I trust render them both interesting and instructive.

In order to make the book more intelligible to those readers who have no special knowledge of systematic zoology, and to whom most of the names with which its pages are often crowded must necessarily be unmeaning, I give a series of twenty plates, each one illustrating at once the physical aspect and the special zoological character of some well-marked division of a region. Great care has been taken to associate in the pictures, such species only as do actually occur together in nature; so that each plate represents a scene which is, at all events, not an impossible one. The species figured all belong to groups which are either peculiar to, or very characteristic of, the region whose zoology they illustrate; and it is hoped that these pictures will of themselves serve to convey a notion of the varied types of the higher animals in their true geographical relations. The artist, Mr. J. B. Zwecker, to whose talent as a zoological draughtsman and great knowledge both of animal and vegetable forms we are indebted for this set of drawings, died a few weeks after he 
had put the final touches to the proofs. He is known to many readers by his vigorous illustrations of the works of Sir Samuel Baker, Livingstone, and many other travellers,--but these, his last series of plates, were, at my special request, executed with a care, delicacy, and artistic finish, which his other designs seldom exhibit. It must, however, be remembered, that the figures of animals here given are not intended to show specific or generic characters for the information of the scientific zoologist, but merely to give as accurate an idea as possible, of some of the more remarkable and more restricted types of beast and bird, amid the characteristic scenery of their native country;and in carrying out this object there are probably few artists who would have succeeded better than Mr. Zwecker has done.

The general arrangement of the separate parts of which the work is composed, has been, to some extent, determined by the illustrations and maps, which all more immediately belong to Part III. It was at first intended to place this part last, but as this arrangement would have brought all the illustrations into the second volume, its place was changed,-perhaps in other respects for the better, as it naturally follows Part II. Yet for persons not well acquainted with zoology, it will perhaps be advisable to read the more important articles of Part IV. (and especially the observations at the end of eacli order) after Part II, thus making Part III. the conclusion of the work.

Part IV. is, in fact, a book of reference, in which the distribution of all the families and most of the genera of the higher animals, is given in systematic order. Part III. is treated somewhat more popularly; and, although it is necessarily crowded with scientific rames (without which the inferences 
and conclusions would have nothing solid to rest on), these may be omittel by the non-scientific reader, or merely noted as a certain number or proportion of peculiar generic types. Many English equivalents to family and generic names are, however, given; and, assisted by these, it is believed that any reader capable of understanding Lyell's "Principles," or Darwin's "Origin," will have no difficulty in following the main arguments and appreciating the chief conclusions arrived at in the present work.

To those who are more interested in facts than in theories, the book will serve as a kind of dictionary of the geography and affinities of animals. By means of the copious Index, the native country, the systematic position, and the numerical extent of every important and well established genus of landanimal may be at once discovered;-information now scattered through hundreds of volumes.

In the difficult matters of synonymy, and the orthography of generic names, I have been guided rather by general utility than by any fixed rules. When I have taken a whole family group from a modern author of repute, I have generally followed his nomenclature throughout. In other cases, I use the names which are to be found in a majority of modern authors, rather than follow the strict rule of priority in adopting some newly discovered appellation of early date. In orthography I have adopted all such modern emendations as seem coming into general use, and which do not lead to inconvenience; but where the alteration is such as to completely change the pronunciation and appearance of a well-known word, I have not adopted it. I have also thought it best to preserve the initial letter of wellknown and old-established names, for convenience of reference, to the Indices of established works. As an example I may refer to Enicurus,-a name which has been in use nearly half a 
century, and which is to be found under the letter $E$, in Jerdon's Birds of India, Blyth's Catalogue, Bonaparte's Conspectus, and the Proceedings of the Zoological Suciety of London down to 1865. Classicists now write Henicurus as the correct form; but this seems to me one of those cases in which orthographical accuracy should give way to priority, and still more to convenience.

In combining and arranging so much detail from such varied sources, many errors and omissions must doubtless have occurred. Owing to my residence at a distance from the scientific libraries of the metropolis, I was placed at a great disadvantage; and I could hardly have completed the work at all, had I not been permitted to have a large number of volumes at once, from the library of the Zoological Society of London, and to keep them for months together; - a privilege for which I return my best thanks to Mr. Sclater the Secretary, and to the Council.

Should my book meet with the approval of working naturalists, I venture to appeal to them, to assist me in rendering any future editions more complete, by sending me (to the care of my publishers) notes of any important omissions, or corrections of any misstatements of fact; as well as copies of any of their paper's or essays, and especially of any lists, catalogues, and monographs, containing information on the classification or distribution of living or extinct animals.

To the many friends who have given me information or assistance I beg to tender my sincere thanks. Especially am I indebted to Professor Newton, who not only read through much of my rough MSS., but was so good as to make numerous corrections and critical notes. These were of great value to me, as they often contained or suggested important additional matter, or pointed out systematic and orthographical inaccuracies. 
Professor Flower was so good as to read over my chapters on extinct animals, and to point out several errors into which I had fallen.

Dr. Günther gave me much valuable information on the classification of reptiles, marking on my lists the best established and most natural genera, and referring me to reliable sources of information.

I am also greatly indebted to the following gentlemen for detailed information on special subjects :-

To Sir Victor Brooke, for a MS. arrangement of the genera of Bovidæ, with the details of their distribution:

To Mr. Dresser, for lists of the characteristic birds of Northern and Arctic Europe:

To Dr. Hooker, for information on the colours and odours of New Zealand plants:

To Mr. Kirby, for a list of the butterflies of Chili:

To Professor Mivart, for a classification of the Batrachia, and an early proof of his article on "Apes" in the Encyclopedia Britannica :

To Mr. Salvin, for correcting my list of the birds of the Galapagos, and for other assistance:

To Mr. Sharpe, for MS. lists of the birds of Madagascar and the Cape Verd Islands:

To Canon Tristram, for a detailed arrangement of the difficult. family of the warblers,-Sylviidæ:

To Viscount Walden, for notes on the systematic arrangement of the Pycnonotidæ and Timaliidæ, and for an early proof of his list of the birds of the Philippine Islands.

I also have to thank many naturalists, both in this country and abroad, who have sent me copies of their papers; and I trust they will continue to favour me in the same manner. 
An author may easily be mistaken in estimating his own work. I am well aware that this first outline of a great subject is, in parts, very meagre and sketchy; and, though perhaps overburthened with some kinds of detail, yet leaves many points most inadequately treated. It is therefore with some hesitation that I venture to express the hope that I have made some approach to the standard of excellence I have aimed at; - which was, that my book should bear a similar relation to the eleventh and twelfth chapters of the "Origin of Species," as Mr. Darwin's "Animals and Plants under Domestication" does to the first chapter of that work. Should it be judged worthy of such a rank, my long, and often wearisome labours, will be well repaid.

March, 1876. 



\title{
CONTENTS OF THE FIRST VOLUME.
}

\author{
PART I. \\ THE PRINCIPLES AND GENERAL PHENOMENA OF DISTRIBUTION.
}

\author{
CHA PTER I.
}

INTRODUCTORY.

CHAPTER II.

THE MEANS OF DISPERSAL AND THE MIGRATIONS OF ANIMALS.

Means of Dispersal of Mammalia (p. 10)-Climate as a Limit to the Range of Mammals (p. 11)-Valleys and Rivers as Barriers to Mammals (p. 12)-Arms of the Sea as Barriers to Mammals (p. 13)-Ice-floes and drift-wood as aiding the Dispersal of Mammals (p. 14)-Means of Dispersal of Birds (p. 15)-Dispersal of Birds by Winds (p. 16)-Barriers to the Dispersal of Birds (p. 17) The Phenomena of Migration (p. 18)-Migrations of Birds (p. 19)-General remarks on Migration (p. 25)-Means of Dispersal of Reptiles and Amphibia (p. 28)-Means of Dispersal of Fishes (1. 29)-Means of Dispersal of Mollusca (p. 30)-Means of Dispersal of Insects and the Barriers which limit their Range (p. 32)

\section{CHAPTER III.}

DISTRIBUTION AS AFFECTED BY THE CONDITIONS AND OHANGES OF THE EARTH'S SURFACIS.

Land and Water (p. 35)-Continental Areas (p. 36)-Recent Changes in the Continental Areas (p. 38)-The Glacial Epoch as affecting the Distribution of Animals (p. 40)-Changes of Vegetation §s affecting the Distribution of Animals (p. 43)-Organic Changes as affecting Distribution (p. 44) . $35-49$ 


\section{CHAP'TER JV.}

ON ZOOLOGICAL REGIONS.

Principles upon which Zoological Regions should be formed (p. 53)-Which class of Animals is of most importance in determining Zoological Regions (p. 56)Various Zoological Regions proposed since 1857 (p. 58)-Discussion of proposed Regions (p. 61)-Reasons for adopting the Six Regions first proposed by $\mathrm{Mr}$. Sclater (p. 63)-Objections to the system of Circumpolar Zones (p. 67)-Does the Arctic Fauna characterise an independent Region (p.68)-Palæarctic Region (p. 71)-Ethiopian Region (p. 73)-Oriental Region (p. 75)-Australian Region (p. 77)-Neotropical Region (p.78)-Nearctic Region (p. 79)-Observations on the series of Sub-regions (p. 80) . . . . . . . 50-82

\section{CHAPTER V.}

CLASSIFICATION AS AFFECTING THE STUDY OF GEOGRAPHICAL DISTRIBUTION.

Classification of the Mammalia (p. 85)-Classification of Birds (p. 92)-Classifica. tion of Reptiles (p. 98)-Classification of Amphibia (p. 100)-Classification of Fisies (p. 101)-Classification of Insects (p. 102)-Classification of Mollusca (p. 104)

\section{PART II.}

\section{ON THE DISTRIBUTION OF EXTINCT ANIMALS.}

\section{CHAPTER VI.}

THE EXTINCT MAMMALIA OF THE OLD WORLD.

Historic and Post-pliocene Period (p. 110)-Pliocene Period (p. 112)-General Conclusions as to the Pliocene and Post-pliocene Faunas of Europe (p. 113)Miocene Period (p. 114)-Extinct Auimals of Greece (p. 115)-Miocene Fauna of Central and Western Europe (p. 117)-Upper Miocene Deposits of India (p. 121)-General Observations on the Miocene Faunas of Europe and Asia (p. 123)-Eocene Period (p. 124)-General Considerations on the Extinct Mammalian Fauna of Europe (p. 126) . . . . . . 107-128 


\section{CHAPTER VII.}

EXTINCT MAMMALIA OF THE NEW WORLD.

North America-Post-pliocene Period (p. 129)-Remarks on the Post-pliocene Fauna of North America (p. 130)-Tertiary Period (p. 132)-Primates (p. 32) Insectivora (p. 133)-Carnivora (p. 134)-Ungulata (p. 135)-Proboscidea (p.138)-Tillodontia (p.139)-Rodentia (p.140)-General Relations of the Extinct Tertiary Mammalia of North America and Europe (p.140)-South America (p. 143)-Fauna of the Brazilian Caves (p. 143)-Pliocene Period of Temperate South America (p. 146)-Pliocene Mammalia of the Antilles (p. 148)-Eocene Fauna of South America (p. 148)-General Remarks on the Extinct Manmalian Fauna of the Old and New Worlds (p. 148)-The Birth-place and Migrations of some Mammalian Families and Genera (p. 153) 129-156

\section{CHAPTER VIII.}

VARIOUS EXTINCT ANIMALS; - AND ON THE ANTIQUITY OF THE GENERA OF INSECTS AND IAND-MOLLUSCA.

Extinct Mammalia of Australia (p. 157)-Mammalian Remains of the Secondary Formations (p. 159)-Extinct Birds (p. 160)-Palæarctic Region and North India (p. 161)-North America (p. 163)-South America, Madagascar, New Zealand (p. 164)-Extinct Tertiary Reptiles (p. 165)-Antiquity of the Genera of Insects (p. 166)-Antiquity of the Genera of Land and Fresh-water Shells (p. 168) - $157-170$

\section{PART III.}

ZOOLOGICAL GEOGRAPHY : A REVIEW OF THE CHIEF FORMS OF LIFE IN THE SEVERAL REGIONS AND SUB-REGIONS, WITH THE INDICATIONS THEY AFFORD OF GEOGRAPHICAL MUTATIONS.

\section{CHAPTER IX.}

THE ORDER OF SUCOESSION OF THE REGIONS.-COSMOPOLITAN GROUPS OF ANIMALS. - TABLES OF DISTRIBUTION.

Order of succession of the Regions (p. 173)-Cosmopolitan Groups (p. 175)-

Tables of Distributions of Families and Genera (p. 177) . . 173-179 
CHAP'TER X.

TIIT PAIASARCTIC; REGION.

Zoological Characteristics of the Palrearctic Brgion (p. 181)-Summary of Palrearctic Vertebrata (p. 186)-Insects (1. 187)-Iand-shells (p. 190)-The Palnarctic Sub-regions (p. 190)-Central and Northern Europe (p. 191)-North European Islands (p. 197)-Mediterranean Sub-region (p. 199)-The Mediterraneau and Atlantic Islands (p. 206)-The Siberian Sub-region, or Northern Asia (p. 216)-Japan and North China, or the Manchurian Sub-region (p. 220) -Birds (p. 223)-Insects (p. 227)--Remarks on the General Character of the Fauna of Japan (p. 230)-General Conclusions as to the Fauna of the Palæ. arctic Region (p. 231)-Table 1. Families of Animals inhabiting the Palæarctic Region (p. 234)-Table II. List of the Cenera of Terrestrial Mammalia. and Birds of the Palæarctic Region (p. 239)

$181-250$

\section{CHAPTER XI.}

THE ITHIOPIAN REGION.

Zoological Characteristics of the Ethiopian Region (p. 252)-Summary of Ethiopian Vertebrates (p. 255)-The Ethiopian Sub-regions (p. 258)-The East African Sub-region, or Central and East Africa (p. 258)-The West African Sub-region (p. 262)-Islauds of the West African Sub-region (p. 265)-South African Sub-region (p. 266)-Atlantic Islands of the Ethiopian Region;-St. Helena (p. 269)-Tristan d'Acunha (p. 271)-Madagascar and the Mascarene Islands, or the Malagasy Sub-region (p. 272)-The Mascarene Islands (p. 280) -Extinct Fauma of the Mascarene Islands and Madagascar (p. 282)-General Remarks on the Insect Fauna of Madagascar (p. 284)-On the probable Past History of the Ethiopian Region (p. 285)-Table I. Families of Animals inhabiting the Ethiopian Region (p. 294)-Table II. List of Genera of Terrestrial Mammalia and Birds of the Ethiopian Region (p. 300) . 251-313

\section{CHAPTER XII.}

THE ORIENTAL REGION.

Zoological Characteristics of the Oriental Region ( $p$. 315) - Summary of Oriental Vertebrata (p. 318)-The Oriental Sub-regions (p. 321)-Hindostan, or Indian Sub-region (p. 321) - Range of the Genera of Mammalia which inhabit the subregion of Hindostan (p. 322)-Oriental, Palæarctic, and Ethiopiau Genera of Birds in Central India (p. 224)-Sub-region of Ceylon and South India (p. 326)-The Past History of Ceylon and South India, as indicated by its Fauna (p. 328)-Himalayan or Indo-Chinese Sub-region (p. 329)-Islands of the 
Indo-Chinese Sub-region (p. 333)-Indo-Malaya, or the Malayan Sub-region (p. 334)-Malayan Insects (p. 341)-The Zoological Relations of the several Islands of the Indo-Malay Sub-region (p. 345)-Philippine Islands (p. 345)Java (p. 349)-Malacca, Sumatra, and Borneo (p. 353)-Probable recent Geographical Changes in the Indo-Malay Islands (p. 357)-Probable Origin of the Malayan Fauna (p. 359)-Concluding Remarks on the Oriental Region (p. 362) -Table I. Families of Animals inhabiting the Oriental Region (p. 365)Table II. Genera of Terrestrial Mammalia and Birds in the Oriental Region (p. 371)

- $314-386$

\section{CHAPTER XIII.}

THE AUSTRALIAN REGION.

General Zoological Characteristics of the Australian Region (p. 390)-Summary of the Australian Vertebrata (p. 397)-Supposed Land-connection between Australia and South America (p. 398)-Insects (p. 403)-Land-shells (p. 407) -dustralian Sub-regions (p. 408)-Austro-Malayan Sub-region (p. 409)Papua, or the New Guinea Group (p. 409)-The Moluccas (p. 417)-InsectsPeculiarities of the Moluccan Fauna (p. 420)-Timor Group (p. 422)Celebes Group (p. 426)-Origin of the Fauna of Celebes (p. 436)-Australia and Tasmania, or the Australian Sub-region ( $p .438)$-The Pacific Islands, or Polynesian Sub-region (p. 442)-Fiji, Tonga, and Samoa Islands (p. 443)Society and Marquesas Islands (p. 443)-I Ladrone and Caroline Islands (p. 444) -New Caledonia and the New Hebrides (p. 444)-Sandwich Islands (p. 445) -Reptiles of the Polynesian Sub-region (p.448)-New Zealand Sub-region (p. 449)-Islets of the New Zealand Sub-region (p. 453)-Reptiles, Amphibia, and Fresh-water Fishes (p. 456)-Insects (p.457)-The Ancient Fauna of New Zealand (p. 459)-The Origin of the New Zealand Fauna (p. 459)-Causes of the Poverty of Insect-life in New Zealand: its Influence on the Character of the Flora (p. 462)-Concluding Remarks on the Early History of the Australian Region (p. 464)-Table I. Families of Animals inhabiting the Australian Region (p. 468)-Table II. Genera of Terrestrial Mammalia and Birds of the Australian Region (p. 473)

- $387-485$

Index to Vol, I .

$489-503$ 



\section{MAPS AND ILLUSTRATIONS IN VOL. I.}

1. Map of the World, showing the Zoo-Geographical Regions and the contour of the Ocean-bed

- Frontispiece

2. Map of the Palæarctic Region . . . . . . 181

3. Plate I. The Alps of Central Europe with Characteristic Animals 195

4. Plate II. Characteristic Mammalia of Western Tartary * . . 218

5. Plate III. Characteristic Animals of North China . . . . 226

6. Map of the Ethiopian Region . . . . . . . . 251

7. Plate IV. Characteristic Animals of East Africa . . . . 261

8. Plate V. Scene in West Africa with Characteristic Animals . . 264

9. Plate VI. Scene in Madagascar with Charactoristic Animals , . 278

10. Map of the Oriental Region . . . . . . . . 315

11. Plate VII. Scene in Nepaul with Characteristic Animals . . . 331

12. Plate VIII. A Forest in Borneo with Characteristic Mammalia . $\quad 337$

13. Plate IX. A Malacea Forest with some of its Peculiar Birds . . 340

14. Map of the Australian Region . . . . . . . 387

15. Plate X. Scene in New Guinea with Characteristic Animals . $\quad 415$

16. Plate XI. The Characteristic Mammalia of Tasmania . . 439

17. Plate XII. The Plains of New South Wales with Characteristic Animals . . . . . . . . 442

18. Plate XIII. Scene in New Zealand with some of its Remarkable Birds 455 


\section{ERRATA IN VOL.I.}

I have detected several misprints and small crrors in the final impression, and Dr. Meyer, who has translated the work into German, has kindly communicated all that he has noticed. It is not thought necessary to give here all the smaller orthographical errors, most of which will be corrected in the Index. The following seem, however, to be of sufficient importance to justify me in asking my readers to correct them in their copies.

Page 93, 12 lines from foot, for Hocco read Hoazin.

") 97, line 2, for Hocco read Hoazin.

„147, 13 lines from foot, for three-handed read three-banded.

"177, line 6, for Lycænidæ read Zygænidæ.

"183, line 20, for third read fourth.

," 238, line 18, for Spirigidea read Sphingidea.

", 242, insert | 92a | Tamias | 1 | All Northern Asia | N. America.

, 245, last line, insert in 2nd column (6).

, 309, line 20, for Motacilla read Budytes.

, 327, 12 lines from foot, after Hindostan read and.

", 331, last line, for Icthyopsis read Icthyophis.

"340, line 15, for Edotius read Bhringa.

", 348, line 17, for Flores read New Guinea.

"371, 11 lines from foot, for and Borneo read Borneo and Philippines.

"391, 10 lines from foot, after Celebes add and the Papuan Islands.

,, 391, 9 lines from foot, omit New Guinea' or.

" 414, 6 lines from foot, for Epimachus read Seleucides.

"415, line 10 for ditto read ditto.

, 427, line 20, after Celebes add and on somo of the Philippine Islands.

"427, 5 lines from foot, for tusks read jaw.

, 462, 15 lines from foot, for p. 156 read p. 166.

, 474, 9 lines from foot, after Celebes add Papua. 
THE

\title{
GEOGRAPHICAL DISTRIBUTION OF ANIMALS.
}

\author{
PART I.
}

THE PRINCIPLES AND GENERAL PHENOMENA OF DISTRIBUTION. 



\section{CHAPTER I.}

IN T RO L U C T O R Y.

IT is a fact within the experience of most persons, that the various species of animals are not uniformly dispersed over the surface of the country. If we have a tolerable acquaintance with any district, be it a parish, a county, or a larger extent of territory, we soon become aware that each well-marked portion of it has some peculiarities in its animal productions. If we want to find certain birds or certain insects, we have not only to choose the right season but to go to the right place. If we travel beyond our district in various directions we shall almost certainly meet with something new to us; some species which we were accustomed to see almost daily will disappear, others which we have never seen before will make their appearance. If we go very far, so as to be able to measure our journey by degrees of latitude and longitude and to perceive important changes of climate and vegetation, the differences in the forms of animal life will become greater; till at length we shall come to a country where almost everything will be new, all the familiar creatures of our own district being replaced by others more or less differing from them.

If we have been observant during our several journeys, and have combined and compared the facts we have collected, it will become apparent that the change we have witnessed has been of two distinct kinds. In our own and immediately surrounding districts, particular species appeared and disappeared because 
the soil, the aspect, or the vegetation, was adapted to them or the reverse. The marshes, the heaths, the woods and forests, the chalky downs, the rocky mountains, had each their peculiar inhabitants, which reappeared again and arain as we carne to tracts of country suitable for them. But as we got further away we began to find that localities very similar to those we had left behind were inhabited by a somewhat different set of species; and this difference increased with distance, notwithstanding that almost identical external conditions might be often met with. The first class of changes is that of stations; the second that of habitats. The one is a locel, the other a geographical phenomenon. The whole area over which a particular animal is found may consist of any number of stations, but rarely of more than one habitat. Stations, however, are often so extensive as to include the entire range of many species. Such are the great seas and oceans, the Siberian or the Amazonian forests, the North African deserts, the Andean or the Himalayan highlands.

There is yet another difference in the nature of the change we have been considering. The new animals which we meet with as we travel in any direction from our starting point, are some of them very much like those we have left behind us, and can be at once referred to familiar types; while others are altogether unlike anything we have seen at home. When we reach the Alps we find another kind of squirrel, in Southern Italy a distinct mole, in Southern Europe fresh warblers and unfamiliar buntings. We meet also with totally new forms; as the glutton and the snowy owl in Northern, the genet and the hoopoe in Southern, and the saiga antelope and collared pratincole in Eastern Europe. The first series are examples of what are termed represcntative species, the seconil of distinct groups or types of animals. The one represents a comparatively recent modification, and an origin in or near the locality where it occurs; the other is a result of very ancient changes both organic and inorganic, and is connected with some of the most curious and difficult of the problems we shall have to discuss. 
Having thus defined our subject, let us glance at the opinions that have generally prevailed as to the nature and causes of the phenomena presented by the geographical distribution of animals.

It was long thought, and is still a popular notion, that the manner in which the various kinds of animals are dispersed over the globe is almost wholly due to diversities of climate and of vegetation. There is indeed much to favour this belief. The arctic regions are strongly characterised by their white bears and foxes, their reindeer, ermine, and walruses, their white ptarmigan, owls, and falcons; the temperate zone has its foxes and wolves, its rabbits, sheep, beavers, and marmots, its sparrows and its song birds; while tropical regions alone produce apes and elephants, parrots and peacocks, and a thousand strange quadrupeds and brilliant birds which are found nowhere in the cooler regions. So the camel, the gazelle and the ostrich live in the desert; the bison on the prairie; the tapir, the deer, and the jaguar in forests. Mountains and marshes, plains and rocky precipices, have each their animal inhabitants; and it might well be thought, in the absence of accurate inquiry, that these and other differences would sufficiently explain why most of the regions and countries into which the earth is popularly divided should have certain animals peculiar to them and should want others which are elsewhere abundant.

A more detailed and accurate knowledge of the productions of different portions of the earth soon showed that this explanation was quite insufficient; for it was found that countries exceedingly similar in climate and all physical features may yet have very distinct animal populations. The equatorial parts of Africa and South America, for example, are very similar in climate and are both covered with luxuriant forests, yet their animal life is widely different; elephants, apes, leopards, guinea-fowls and touracos in the one, are replaced by tapirs, prehensiletailed monkeys, jaguars, curnssows and toucans in the other. Again, parts of South Africa and Australia are wonderfully similar in their soil and climate; yet one has lions, antelopes, zebras and giraffes; the other only kangaroos, wombats, phalan- 
gers and mice. In like manner parts of North America and Europe are very similar in all essentials of soil climate and vegetation, yet the former has racoons, opossums, and hummingbirds; while the latter possesses moles, hedgehogs and true flycatchers. Equally striking are the facts presented by the distribution of many large and important groups of animals. Marsupials (opossums, phalangers \&c.) are found from temperate Van Diemen's land to the tropical islands of New Guinea and Celebes, and in America from Chili to Virginia. No crows exist in South America, while they inhabit every other part of the world, not excepting Australia. Antelopes are found only in Africa and Asia; the sloths only in South America; the true lemurs are confined to Madagascar, and the birds-of-paradise to New Guinea.

If we examine more closely the distribution of animals in any extensive region, we find that different, though closely allied species, are often found on the opposite sides of any considerable barrier to their migration. Thus, on the two sides of the Andes and Rocky Mountains in America, almost all the mammalia, birds, and insects are of distinct species. To a less extent, the Alps and Pyrenees form a similar barrier, and even great rivers and river plains, as those of the Amazon and Ganges, separate more or less distinct groups of animals. Arms of the sea are still more effective, if they are permanent; a circumstance in some measure indicated by their depth. Thus islands far away from land almost always have very peculiar animals found nowhere else; as is strikingly the case in Madagascar and New Zealand, and to a less degree in the West India islands. But shallow straits, like the English Channel or the Straits of Malacca, are not found to have the same effect, the animals being nearly or quite identical on their opposite shores. A change of climate or a change of vegetation may form an equally effective barrier to migration. Many tropical and polar animals are pretty accurately limited by certain isothermal lines; and the limits of the great forests in most parts of the world strictly determine the ranges of many species.

Naturalists have now arrived at the conclusion, that by some 
slow process of development or transmutation, all animals have been produced from those which preceded them; and the old notion that every species was specially created as they now exist, at a particular time and in a particular spot, is abandoned as opposed to many striking facts, and unsupported by any evidence. This modification of animal forms took place very slowly, so that the historical period of three or four thousand years has hardly produced any perceptible change in a single species. Even the time since the last glacial epoch, which on the very lowest estimate must be from 50,000 to 100,000 years, has only served to modify a few of the higher animals into very slightly different species. The changes of the forms of animals appear to have accompanied, and perhaps to have depended on, changes of physical geography, of climate, or of vegetation; since it is evident that an animal which is well adapted to one condition of things will require to be slightly changed in constitution or habits, and therefore generally in form, structure, or colour, in order to be equally well adapted to a changed condition of surrounding circumstances. Animals multiply so rapidly, that we may consider them as continually trying to extend their range; and thus any new land raised above the sea by geological causes becomes immediately peopled by a crowd of competing iuhabitants, the strongest and best adapted of which alone succeed in maintaining their position.

If we keep in view these facts-that the minor features of the earth's surface are everywhere slowly changing; that the forms, and structure, and habits of all living things are also slowly changing; while the great features of the earth, the continents, and oceans, and loftiest mountain ranges, only change after very long intervals and with extreme slowness; we must see that the present distribution of animals upon the several parts of the earth's surface is the final product of all these wonderful revolutions in organic and inorganic nature. The greatest and most radical differences in the productions of any part of the globe must be dependent on isolation by the most effectual and most permanent barriers. That ocean which has remained broadest and deepest from the most remote geolonical epoch 
will separate countries the productions of which inost widely and radically differ; while the most recently-depressed seas, or the last-formed mountain ranges, will separate countries the productions of which are almost or quite identical. It will be evident, therefore, that the study of the distribution of animals and plants may add greatly to our knowledge of the past history of our globe. It may reveal to us, in a manner which no other evidence can, which are the oldest and most permanent features of the earth's surface, and which the newest. It may indicate the existence of islands or continents now sunk beneath the ocean, and which have left no record of their existence save the animal and vegetable productions which have migrated to adjacent lands. It thus becomes an important adjunct to geology, which can rarely do more than determine what lands lave been raised above the waters, under what conditions and at what period; lut can seldom ascertain anything of the position or extent of those which have sunk beneath it. Our present study may often enable us, not only to say where lands must have recently disappeared, but also to form some judgment as to their extent, and the time that las elapsed since their submersion.

Having thus briefly sketched the nature and objects of the subject we have to study, it will be necessary-before entering on a detailed examination of the zoological features of the different parts of the earth, and of the distribution of the orders, families, and genera of animals - to examine certain preliminary facts and principles essential for our guidance. We must first inquire what are the powers of multiplication and dispersal of the various groups of animals, and the nature of the barriers that most effectually limit their range. We have then to consider the effects of changes in physical geography and in climate; to examine the nature and extent of such changes as have been known to occur; to determine what others are possible or probable; and to ascertain the various modes in which such changes affect the structure, the distribution, or the very existence of animals. 
Two subjects of a different nature must next engage our attention. We have to deal with two vast masses of facts, each involving countless details, and requiring subdivision and grouping to be capable of intelligible treatment. All the continents and their chief subdivisions, and all the more important islands of the globe, have to be compared as regards their various animal forms. To do this effectively we require a natural division of the earth especially adapted to our purpose; and we shall have to discuss at some length the reasons for the particular system adopted,- -a discussion which must to some extent anticipate and summarize the conclusions of the whole work. We have also to deal with many hundreds of families and many thousands of genera of animals, and here too a true and natural classification is of great importance. We must therefore give a connected view of the classification adopted in the various classes of animals dealt with.

And lastly, as the existing distribution of animals is the result and outcome of all preceding changes of the earth and of its inhabitants, we require as much knowledge as we can get of the animals of each country during past geological epochs, in order to interpret the facts we shall accumulate. We shall, therefore, enter upon a somewhat detailed sketch of the various forms of extinct animals that have lived upon the earth during the Tertiary period; discuss their migrations at various epochs, the changes of physical geography that they imply, and the extent to which they enable us to determine the birthplace of certain families and genera.

The preliminary studies above enumerated will, it is believed, enable us to see the bearing of many facts in the distribution of animals that would otherwise be insoluble problems; and, what is hardly less valuable, will teach us to estimate the comparative importance of the various groups of animals, and to avoid the common error of cutting the gordian knot of each difficulty by vast hypothetical changes in existing continents and oceans - probably the most permanent features of our globe. 


\section{CHAPTER II.}

TIE MEANS OF DISPERSAL AND THE MIGRATIONS OF ANIMALS.

ALL animals are capable of multiplying so rapidly, that if a single pair were placed in a continent with abundance of food and no enemies, they might fully stock it in a very short time. Thus, a bird which produces ten pairs of young during its lifetime (and this is far below the fertility of many birds) will, if we take its life at five years, increase to a hundred millions in about forty years, a number sufficient to stock a large country. Many fishes and insects are capable of multiplying several thousandfold each year, so that in a few years they would reach billions and trillions. Even large and slow breeding mammals, which have only one at a birth but continue to breed from eight to ten successive years, may increase from a single pair to ten millions in less than forty years.

But as animals rarely have an unoccupied country to breed in, and as the food in any one district is strictly limited, their natural tendency is to roam in every direction in search of fresh pastures, or new hunting grounds. In doing so, however, they meet with many obstacles. Rocks and mountains have to be climbed, rivers or marshes to be crossed, deserts or forests to be traversed; while narrow straits or wider arms of the sea separate islands from the main land or continents from each other. We have now to inquire what facilities the different classes of animals have for overcoming these obstacles, and what kind of barriers are most effectual in checking their progress.

Means of Disper'sal of Mammalia.-Many of the largest mammalia are able to roam over whole continents and are hardly 
stopped by any physical obstacles. The elephant is almost equally at home on plains and mountains, and it even climbs to the highest summit of Adam's Peak in Ceylon, which is so steep and rocky as to be very difficult of ascent for man. It traverses rivers with great ease and forces its way through the densest jungle. There seems therefore to be no limit to its powers of wandering, but the necessity of procuring food and its capacity of enduring changes of climate. The tiger is another animal with great powers of dispersal. It crosses rivers and sometimes even swims over narrow straits of the sea, and it can endure the severe cold of North China and Tartary as well as the heats of the plains of Bengal. The rhinoceros, the lion, and many of the ruminants have equal powers of dispersal; so that wherever there is land and sufficient food, there are no limits to their possible range. Other groups of animals are more limited in their migrations. The apes, lemurs, and many monkeys are so strictly adapted to an arboreal life that they can never roam far beyond the limits of the forest vegetation. The same may be said of the squirrels, the opossums, the arboreal cats, and the sloths, with many other groups of less importance. Deserts or open country are equally essential to the existence of others. The camel, the hare, the zebra, the giraffe and many of the antelopes could not exist in a forest country any more than could the jerboas or the prairie marmots.

There are other animals which are confined to mountains, and could not extend their range into lowlands or forests. The goats and the sheep are the most striking group of this kind, inhabiting many of the highest mountains of the globe; of which the European ibex and mouflon are striking examples. Rivers are equally necessary to the existence of others, as the beaver, otter, water-vole and capybara; and to such animals high mountainranges or deserts must form an absolutely impassable barrier.

Climate as a Limit to the Range of Mammals.-Climate appears to limit the range of many animals, though there is some reason to believe that in many cases it is not the climate itself so much as the change of vegetation consequent on climate which produces the effect. The quadrumana appear to be limited by climate, 
since they inhabit almost all the tropical regions lut do not range more than about $10^{\circ}$ beyond the southern and $12^{\circ}$ beyond the northern tropic, while the great bulk of the speecies are found only within an equatorial belt aloout $30^{\circ}$ wide. But as these animals are almost exclusively fruit-eaters, their distribution depends as much on vegetation as on temperature; and this is strikingly shown by the fact that the Semnopithecus schistaceus inhabits the Himalayan mountains to a height of 11,000 feet, where it has been seen leaping among fir-trees loaded with snow-wreaths! Some northern animals are bounded by the isothermal of $32^{\circ}$. Such are the polar bear and the walrus, which cannot live in a state of nature far beyond the limits of the frozen ocean; but as they live in confinement in temperate countries, their range is probably limited by other conditions than temperature.

We must not therefore be too hasty in concluding, that animals which we now see confined to a very hot or a very cold climate are incapable of living in any other. The tiger was once considered a purely tropical animal, but it inhabits permanently the cold plains of Manchuria and the Amoor, a country of an almost arctic winter climate. Few animals seem to us more truly inhabitants of hot countries than the elephants and rhinoceroses; yet in Post-tertiary times they roamed over the whole of the northern continents to within the arctic circle; and we know that the climate was then as cold as it is now, from their entire bodies being preserved in ice. Some change must recently have occurred either in the climate, soil, or vegetation of Northern Asia which led to the extinction of these forerunners of existing tropical species; and we must always bear in mind that similar changes may have acted upon other species which we now find restricted within narrow limits, but which may once have roamed over a wide and varied territory.

Valleys and Rivers as Barriers to Mammals.-To animals which thrive best in dry and hilly regions, a broad level and marshy valley must often prove an effectual barrier. The difference of vegetation and of insect life, together with an unhealthy atmosphere, no doubt often checks migration if it is attempted. Thus 
many animals are restricted to the slopes of the Himalayas or to the mountains of Central India, the flat valley of the Ganges forming a limit to their range. In other cases, however, it is the river rather than the valley which is the barrier. In the great Amazonian plains many species of monkeys, birds, and even insects are found up to the river banks on one side but do not cross to the other. Thus in the lower part of the Rio Negro two monkeys, the Jacchusibicolor and the Brachiurus couxiou, are found on the north bank of the river but never on the south, where a red-whiskered Pithecia is alone found. Higher up Ateles paniscus extends to the north bank of the river while Lagothrix humboldtii comes down to the south bank; the former being a native of Guiana, the latter of Ecuador. The range of the birds of the genus Psophia or trumpeters, is also limited by the rivers Amazon, Madeira, Rio Negro and some others; so that in these cases we are able to define the limits of distribution with an unusual degree of accuracy, and there is little doubt the same barriers also limit a large number of other species.

Arms of the Sea as Barriers to Mammals.-Very few mammals can swim over any considerable extent of sea, although many can swim well for short distances. The jaguar traverses the widest streams in South America, and the bear and bison cross the Mississippi ; and there can be no doubt that they could swim over equal widths of salt water, and if accidentally carried out to sea might sometimes succeed in reaching islands many miles distant. Contrary to the common notion pigs can swim remarkably well. Sir Charles Lyell tells us in his "Principles of Geology" that during the floods in Scotland in 1829, some pigs only six months old that were carried out to sea, swam five miles and got on shore again. He also states, on the authority of the late Edward Forbes, that a pig jumped overboard to escape from a terrier in the Grecian Archipelago, and swam safely to shore many miles distant. These facts render it probable that wild pigs, from their greater strength and activity, might under favourable circumstances cross arms of the sea twenty or thirty miles wide; and there are facts in the distribution of this tribe of animals which seem to indicate that they have sometimes done so. Deel. 
take boldly to the water and can swim considerable distances, but we have no evidence to show how long they could live at sea or how many miles they could traverse. Squirrels, rats, and lemmings often migrate from northern countries in bands of thousands and hundreds of thousands, and pass over rivers, lakes and even arms of the sea, but they generally perish in the saltwater. Admitting, however, the powers of most mammals to swim considerable distances, we have no reason to believe that any of them could traverse without help straits of upwards of twenty miles in width, while in most cases a channel of half that distance would prove an effectual barrier.

Ice-floes and Driftwood as Aiding the Dispersal of Mammals.In the arctic regions icebergs originate in glaciers which descend into the sea, and often bear masses of gravel, earth, and even some vegetation on their surfaces; and extensive level icefields break away and float southwards. These might often carry with them such arctic quadrupeds as frequent the ice, or even on rare occasions true land-nnimals, which might sometimes be stranded on distant continents or islands. But a more effectual because a more wide-spread agent, is to be found in the uprooted trees and rafts of driftwood often floated down great rivers and carried out to sea. Such rafts or islands are sometimes seen drifting a hundred miles from the mouth of the Ganges with living trees erect upon them; and the Amazon, the Orinoco, Mississippi, Congo, and most great rivers produce similar rafts. Spix and Martius declare that they saw at different times on the Amazon, monkeys, tiger-cats, and squirrels, being thus carried down the stream. On the Parana, pumas, squirrels, and many other quadrupeds have been seen on these rafts; and Admiral W. H. Smyth informed Sir C. Lyell that among the Philippine islands after a hurricane, he met with floating masses of wood with trees growing upon them, so that they were at first mistaken for islands till it was found that they were rapidly drifting along. Here therefore, we have ample means for carrying all the smaller and especially the arbureal mammals out to sea; and although in most cases they would perish there, yet in some favourable instances strong winds or 
uniusual tidal currents might carry them safely to shores perhaps several hundred miles from their native country. The fact of green trees so often having been seen erect on these rafts is most important; for they would act as a sail by which the raft might be propelled in one direction for several days in succession, and thus at last reach a shore to which a current alone would never have carried it.

There are two groups of mammals which have quite exceptional means of dispersal-the bats which fly, and the cetacea, seals, \&c., which swim. The former are capable of traversing considerable spaces of sea, since two North American species either regularly or occasionally visit the Bermudas, a distance of 600 miles from the mainland. The oceanic mammals (whales and porpoises) seem to have no barrier but temperature; the polar species being unable to cross the equator, while the tropical forms are equally unfitted for the cold polar waters. The shorefeeding manatees, however, can only live where they find food; and a long expanse of rocky coast would probably be as complete a barrier to them as a few hundred miles of open ocean. 'ithe amphibious seals and walruses seem many of them to be capable of making long sea journeys, some of the species being found on islands a thousand miles apart, but none of the arctic are identical with the antartic species.

The otters with one exception are freshwater animals, and we have no reason to believe they could or would traverse any great distances of salt water. In fact, they would be less liable to dispersal across arms of the sea than purely terrestrial species, since their powers of swimming would enable them to regain the shore if accidentally carried out to sea by a sudden flood.

Means of Dispersal of Birds. - It would seem at first sight that no barriers could limit the range of birds, and that they ought to be the most ubiquitous of living things, and little fitted therefore to throw any light on the laws or causes of the geographical distribution of animals. This, however, is far from being the case; many groups of birds are almost as strictly limited by barriers as the mammalia; and from their larger numbers and the avidity with which they have been collected, they furnish 
materials of the greatest value for our present study. The different groups of birds offer remarkahle contrasts in the extent of their range, some heing the most cosmopolite of the higher animals, while others are absolutely confined to single spots on the earth's surface. The petrels (Procellariidec) and the gulls (Larida) are among the greatest wanderers; but most of the species are confined to one or other of the great oceans, or to the arctic or antarctic seas, a few only being found with scarcely any variation over almost the whole globe. The sandpipers and plovers wander along the shores as far as do the petrels over the ocean. Great numbers of them breed in the arctic regions and migrate as far as India and Australia, or down to Chili and Brazil; the species of the old and new worlds, however, being generally distinct. In striking contrast to these wide ranges we find many of the smaller perching birds, with some of the parrots and pigeons, confined to small islands of a few square miles in extent, or to single valleys or mountains on the mainland.

Dispersal of Birds by Winds.-Those groups of birds which possess no powers of fight, such as the ostrich, cassowary, and apteryx, are in exactly the same position as mammalia as regards their means of dispersal, or are perhaps even inferior to them; since, although they are able to cross rivers by swimming, it is doubtful if they could remain so long in the water as most land quadrupeds. A very large number of short-winged birds, such as toucans, pittas, and wrens, are perhaps worse off; for they can fly very few miles at a time, and on falling into the water would soon be drowned. It is only the strong-flying species that can venture to cross any great width of sea; and even these rarely do so unless compelled by necessity to migrate in search of food, or to a more genial climate. Small and weak birds are, however, often carried accidentally across great widths of ocean by violent gales. This is well exemplified by the large numbers of stragglers from North America, which annually reach the Bermudas. No less than sixty-nine species of American birds have occurred in Europe, most of them in Britain and Heligoland. They consist chietly of migratory birds which in autumn 
return along the eastern coasts of the United States, and often fly from point to point across bays and inlets. They are then liable to be blown out to sea by storns, which are prevalent at this season; and it is almost always at this time of year that their occurrence has been noted on the shores of Europe. It may, however, be doubted whether this is not an altogether modern phenomenon, dependent on the number of vessels constantly on the Atlantic which afford resting-places to the winderers; as it is hardly conceivable that such birds as titlarks, cuckoos, wrens, warblers, and rails, could remain on the wing without food or rest, the time requisite to pass over 2,000 miles of ocean. It is somewhat remarkable that no European birds reach the American coast but a fer which pass by way of Iceland and Greenland; whereas a considerable number do reach the Azores, fully half way across; so that their absence can hardly be due to the prevailing winds being westerly. The case of the Azores is, however, an argument for the unassisted passage of birds for that distance; since two of the finches are peculiar 'species,' but closely allied to Europeau forms, so that their progenitors must, probably, have reached the islands before the Atlantic was a commercial highway.

Barriers to the Dispersal of Birds.-We have seen that, as a rule, wide oceans are an almost absolute barrier to the passage of most birds from one continent to another; but much narrower seas and straits are also very effectual barriers where the habits of the birds are such as to preserve them from being carried away by storms. All birds which frequent thickets and forests, and which feed near or on the ground, are secure from such accidents; and they are also restricted in their range by the extent of the forests they inhabit. In South America a large number of the birds have their ranges determined by the extent of the forest country, while others are equally limited to the open plains. Such species are also bounded by mountain ranges whenever these rise above the woody region. Great rivers, such as the Amazon, also limit the range of many birds, even when there would seem to be no difficulty in their crossing them. The supply of food, and the kind of vegetation, soil, and climate 
best suited to a bird's halbits, are probably the causes which nark out the exact limits of the range of each species; to which must be added the prevalence of enemies of either the parent birds, the eggs, or the young. In the Malay Archipelago pigeons abound most where monkeys do not occur; and in South America the same birds are comparatively scarce in the forest plains where monkeys are very abundant, while they are plentiful on the open plains and campos, and on the mountain plateaux, where these nest-hunting quadrupeds are rarely found. Some birds are confined to swamps, others to mountains; some can only live on rocky streams, others on deserts or grassy plains.

The Phenomena of Migration.-The term "migration" is often applied to the periodical or irregular movements of all animals; but it may be questioned whether there are any regular migrants but birds and fishes. The annual or periodical movements of mammalia are of a different class. Monkeys ascend the Himalayas in summer to a height of 10,000 to 12,000 feet, and descend again in winter. Wolves everywhere descend from the mountains to the lowlands in severe weather. In dry seasons great herds of antelopes move southwards towards the Cape of Good Hope. The well-known lemmings, in severe winters, at long intervals, move down from the mountains of Scandinavia in immense numbers, crossing lakes and rivers, eating their way through haystacks, and surmounting every obstacle till they reach the sea, whence very few return. The alpine hare, the arctic fox, and many other animals, exhibit similar phenomena on a smaller scale; and generally it may be said, that whenever a favourable succession of seasons has led to a great multiplication of any species, it must on the pressure of hunger seek food in fresh localities. For such movements as these we have no special term. The summer and winter movements best correspond to true migration, but they are always on a small scale, and of limited extent; the other movements are rather temporary incursions than true migrations.

The annual movements of many fishes are more strictly analogous to the migration of birds, since they take place in large bodies and often to considerable distances, and are 
immediately connected with the process of reproduction. Some, as the salmon, enter rivers; other's, as the herring and mackerel, approach the coast in the breeding season; but the exact course of their migrations is unknown, and owing to our complete ignorance of the area each species occupies in the ocean, and the absence of such barriers and of such physical diversities as occur on the land, they are of far less interest and less connected with our present study than the movements of birds, to which we shall now confine ourselves.

Migrations of Birds.-In all the temperate parts of the globe there are a considerable number of birds which reside only a part of the year, regularly arriving and leaving at tolerably fixed epochs. In our own country many northern birds visit us in winter, such as the fieldfare, redwing, snow-bunting, turnstone, and numerous ducks and waders; with a few, like the black redstart, and (according to Rev. C. A. Johns) some of the woodcocks from the south. In the summer a host of birds appear-the cuckoo, the swifts and swallows, and numerous warblers, being the most familiar,- - which stay to build their nests and rear their young, and then leave us again. These are true migrants; but a number of other birds visit us occasionally, like the waxwing, the oriole, and the bee-eater, and can only be classed as stragglers, which, perhaps from too rapid multiplication one year and want of food the next, are driven to extend their ordinary range of migration to an unusual degree. We will now endeavour to sketch the chief phenomena of migration in different countries.

Europe.-It is well ascertained that most of the birds that spend their spring and summer in the temperate parts of Europe pass the winter in North Africa and Western Asia. The winter visitants, on the other hand, pass the summer in the extreme north of Europe and Asia, many of them having been found to breed in Lapland. The arrival of migratory birds from the south is very constant as to date, seldom varying more than a week or two, without any regard to the weather at the time; but the departure is less constant, and nore dependent on the weather. Thus the swallow always comes to us about the middle 
of April, however cold it may be, while its departure may take. place from the end of September to late in Octolser, and is said by Forster to occur on the first N. or N.E. wind after the 20 th of September.

Almost all the migratory birds of Europe go southward to the Mediterranean, move along its coasts east or west, and cross over in three places only; either from the south of Spain, in the neighbourhood of Gibraltar, from Sicily over Malta, or to the east by Greece and Cyprus. They are thus always in sight of land. The passage of most small birds (and many of the larger ones too) takes place at night; and they only cross the Mediterranean when the wind is steady from near the east or west, and when there is moonlight.

It is a curious fact, but one that seems to be well authenticated, that the males often leave before the females, and both before the young birds, which in considerable numbers migrate later and alone. These latter, however, seldom go so far as the old ones; and numbers of young birds do not cross the Mediterranean, but stay in the south of Europe. The same rule applies to the northward migration; the young birds stopping short of the extreme arctic regions, to which the old birds migrate. ${ }^{1}$ When old and young go together, however, the old birds take the lead. In the south of Europe few of the migratory birds stay to breed, but pass on to more temperate zones; thus, in the south of France, out of 350 species only 60 breed there. The same species is often sedentary in one part of Europe and migratory in another; thus, the chaffinch is a constant resident in England, Germany, and the middle of France; but a migrant in the south of France and in Holland: the rook visits the south of France in winter only: the Falco tinnunculus is both a resident and a migrant in the south of France, according to M. Marcel de Serres, there being two regular passages every year, while a certain number always remain.

I Marcel de Serres states this as a general fact for wading and swimming birds. He says that the old birds arrive in the extreme north almost alone, the young remaining on the shores of the Baltic, or on the lakes of Austria, Hungary, and Russia. See his prize essiy, Des Causes des Migrations, \&c. 2nd. ed., Paris, 1845, p. 121. 
We see, then, that migration is governed by certain intelligible laws; and that it varies in many of its details, even in the same species, according to changed conditions. It may be looked upon as an exaggeration of a habit common to all locomotive animals, of moving about in search of food. This habit is greatly restricted in quadrupeds by their inability to cross the sea or even to pass through the highly-cultivated valleys of such countries as Europe; but the power of flight in birds enables them to cross every kind of country, and even moderate widths of sea; and as they mostly travel at night and high in the air, their movements are difficult to observe, and are supposed to be more mysterious than they perhaps are. In the tropics birds move about to different districts according as certain fruits become ripe, certain insects abundant, or as flooded tracts dry up. On the borders of the tropics and the temperate zone extends a belt of country of a more or less arid character, and liable to be parched at the summer solstice. In winter and early spring its northern margin is verdant, but it soon becomes burnt up, and most of its birds necessarily migrate to the more fertile regions to the north of them. They thus follow the spring or surnmer as it advances from the south towards the pole, feeding on the young flower buds, the abundance of juicy larvæ, and on the ripening fruits; and as soon as these become scarce they retrace their steps homewards to pass the winter. Others whose lome is nearer the pole are driven south by cold, hunger, and darkness, to more hospitable climes, returning northward in the early summer. As a typical example of a migratory bird, let us take the nightingale. During the winter this bird inhabits almost all North Africa, Asia Minor, and the Jordan Valley. Early in April it passes into Europe by the three routes already mentioned, and spreads over France, Britain, Denmark, and the south of Sweden, which it reaches by the beginning of May. It does not enter Brittany, the Chanuel Islands, or the western part of England, never visiting Wales, except the extreme south of Glamorganshire, and rarely extending farther north than Yorkshire. It spreads over Central Europe, through Austria and Hungary to Southern Russia and the warmer parts of Siberia, 
but it nevertheless breeds in the Jordan Valley, so that in some places it is only the surplus population that migrates. In August and September, all who can return to their winter quarters.

Migrations of this type probably date back from at least the period when there was continuous land along the route passed over; and it is a suggestive fact that this land connection is known to have existed in recent geological times. Britain was connected with the Continent during, and probably before, the glacial epoch; and Gibraltar, as well as Sicily and Malta, were also recently united with Africa, as is proved by the fossil elephants and other large mammalia found in their caverns, by the comparatively shallow water still existing in this part of the Mediterranean while the remainder is of oceanic profundity, and by the large amount of identity in the species of land animals still inhabiting the opposite shores of the Mediterranean. The submersion of these two tracts of land (which were perhaps of considerable extent) would be a slow process, and from year to year the change might be hardly perceptible. It is easy to see how the migration that had once taken place over continuous land would be kept up, first over lagoons and marshes, then over a narrow channel, and subsequently over a considerable sea, no one generation of birds ever perceiving any difference in the route.

There is, however, no doubt that the sea-passage is now very dangerous to many birds. Quails cross in immense flocks, and great numbers are drowned at sea whenever the weather is unfavourable. Some individuals always stay through the winter in the south of Europe, and a few even in England and Ireland; and were the sea to become a little wider the migration would cease, and the quail, like some other birds, would remain divided between south Europe and north Africa. Aquatic birds are observed to follow the routes of great rivers and lakes, and the shores of the sea. One great body reaches central Europe by way of the Danube from the shores of the Black Sea; another ascends the Rhone Valley from the Gulf of Lyons. 
India and China.-In the peninsula of India and in China great numbers of northern birds arrive during September and October, and leave from March to May. Among the smaller birds are wagtails, pipits, larks, stonechats, warblers, thrushes, buntings, shrikes, starlings, hoopoes, and quails. Some species of cranes und storks, many ducks, and great numbers of Scolopacidce also visit India in winter; and to prey upon these come a band of rapacious birds- the peregrine falcon, the hobby, kestrel, common sparrowhawk, hanrier, and the short-eared owl. These birds are almost all natives of Europe and Western Asia; they spread over all northern and central India, mingling with the sedentary birds of the oriental fauna, and give to the ornithology of Hindostan at this season quite a European aspect. The peculiar species of the higher Himalayas do not as a rule descend to the plains in winter, but merely come lower down the mountains; and in southern India and Ceylon comparatively few of these migratory birds appear.

In China the migratory birds follow generally the coast line, coming southwards in winter from eastern Siberia and northern Japan; while a few purely tropical forms travel northwards in summer to Japan, and on the mainland as far as the valley of the Amoor.

North America.-The migrations of birds in North America have been carefully studied by resident naturalists, and present some interesting features. The birds of the eastern parts of North America are pre-eminently migratory, a much smaller proportion being permanent residents than in corresponding latitudes in Europe. Thus, in Massachusetts there are only about 30 species of birds which are resident all the year, while the regular summer visitors are 106. Comparing with this our own country, though considerably further north, the proportions are reversed; there being 140 residents and 63 summer visitors. This difference is clearly due to the much greater length and severity of the winter, and the greater heat of summer, in America than with us. The number of permanent residents increases pretty regularly as we go southward; but the number of birds at any locality during the breeding season seems to increase as we go 
northward as firr as Cinada, where, aceonding to Mr. Allen, nore species breed than in the warm Sorthern states. Even in the extrene north, beyond the linit of forests, there are no less than 60 species which breed; in Canada about 160; while in Carolina there are only 135, and in Louisiane, 130. The extent of the migration varies greatly, some species only going a few degrees north and soutl, while others migrate anmually from the tropies to the extreme north of the continent; and every gradation occurs between these extremes. Among those which migrate furthest are the species of Dendroca, and other American flycatching warblers (Mniotiltidce), many of which breed on the shores of Hudson's Bay, and spend the winter in Mexico or the West Indian islands.

The great migratory movement of American birds is almust wholly confined to the east coast; the birds of the high central plains and of California being for the most part sedentary, or only migrating for short distances. All the species which reach South America, and most of those which winter in Mexico and Guatemala, are exclusively eastern species; though a few Rocky Mountain birds range southward along the plateaux of Mexico and Guatemala, but probably not as regular annual migrants.

In America as in Europe birds appear in spring with great regularity, while the time of the autumnal return is less constant. More curious is the fact, also observed in both hemispheres, that they do not all return by the same route followed in going northwards, some species being constant visitors to certain localities in spring but not in autumn, others in autumn but not in spring.

Some interesting cases have been observed in America of a gradual alteration in the extent of the migration of certain birds. A Mexican swallow (Hirundo lunifrons) first appeared in Ohio in 1815. Year by year it increased the extent of its range till by 1845 it had reached Maine-and Canada; and it is now quoted by Anerican writers as extending its anmual migrations to Hudson's Pay. An American wren (Troglodytes ludovicianus) is another bird which has spread considerably northwards since 
the time of the ornithologist Wilson; and the rice-bird, or "Bobo'-link," of tlie Americans, continually widens its range as rice and wheat are more extensively cultivated. This bird winters in Cuba and other West Indian Islands, and probably also in Mexico. In April it enters the Southern States and passes northward, till in June it reaches Canada and extends west to the Saskatchewan River in $54^{\circ}$ north latitude.

South Temperate Anerica.-The migratory birds of this part of the world have been observed by Mr. Hudson at Buenos Ayres. As in Europe and North America, there are winter and summer visitors, from Patagonia and the tropics respectively. Species of Pyrocephalus, Milvulus, swallows, and a hummingbird, are among the most regular of the summer visitors. They are all insectivorous birds. From Patagonia species of Toniopterc, Cinclodes, and Centrites, come in winter, with two gulls, two geese, and six snipes and plovers. Five species of swallows appear at Buenos Ayres in spring, some staying to breed, others passing on to more temperate regions farther south. As a rule the birds which come late and leave early are the most regular. Some are very irregular in their movements, the Molothrus bonariensis, for example, sometimes leaves early in autumn, sometimes remains all the winter. Some resident birds also move in winter to districts where they are never seen in summer.

General Remarks on Migration.-The preceding summary of the main facts of migration (which might have been almost indefinitely extended, owing to the grcat mass of detailed information that exists on the subject) appears to accord with the view already suggested, that the "instinct" of migration has arisen from the habit of wandering in search of food common to all animals, but greatly exaggerated in the case of birds by their powers of flight and by the necessity for procuring a large amount of soft insect food for their unfledged young. Migration in its simple form may be best studied in North America, where it takes place over a continuous land surface with a considerable change of climate from south to north. We have here (as probably in Europe and elsewhere) every grade of migration, from species which merely shift the northern and southern 
limits of their range a few hundred miles, so that in the central parts of the area the species is a permanent resident, to other's which move completely over 1,000 miles of latitude, so that in all the intervening districts they are only known as birds of passage. Now, just as the rice-bird and the Mexican swallow have extended their migrations, owing to favourable conditions induced by human agency; so we may presume that large numbers of species would extend their range where favourable conditions arose through natural causes. If we go back only as far ac the height of the glacial epoch, there is reason to believe that all North America, as far south as about $40^{\circ}$ north latitude, was covered with an almost continuous and perennial ice-sheet. At this time the migratory birds would extend up to this barrier (which would probably terminate in the midst of luxuriant vegetation, just as the glaciers of Switzerland now often terminate amid forests and corn-fields), and as the cold decreased and the ice retired almost imperceptibly year by year, would follow it up farther and farther according as the peculiarities of vegetation and insect-food were more or less suited to their several constitutions. It is an ascertained fact that many individual birds return year after year to build their nests in the same spot. This shows a strong local attachment, and is, in fact, the faculty or feeling on which their very existence probably depends. For were they to wander at random each year, they would almost certainly not meet with places so well suited to them, and might even get into districts where they or their young would inevitably perish. It is also a curious fact that in so many cases the old birds migrate first, leaving the young ones behind, who follow some short time later, but do not go so far as their parents. This is very strongly opposed to the notion of an imperative instinct. The old birds have been before, the young have not; and it is only when the old ones have all or nearly all gone that the young go too, probably following some of the latest stragglers. They wander, however, almost at random, and the majority are destroyed before the next spring. This is proved by the fact that the birds which return in spring are as a rule not more uumerous than those which came the 
preceding spring, whereas those which went away in autumn were two or three times as numerous. Those young birds that do get back, however, have learnt by experience, and the next year they take care to go with the old ones. The most striking fact in favour of the "instinct" of migration is the "agitation," or excitement, of confined birds at the time when their wild companions are migrating. It seems probable, however, that this is what may be called a social excitement, due to the anxious cries of the migrating birds; a view supported by the fact stated by Marcel de Serres, that the black swan of Australia, when domesticated in Europe, sometimes joins wild swans in their northward migration. We must remember too that migration at the proper time is in many cases absolutely essential to the existence of the species; and it is therefore not improbable that some strong social emotion should have been gradually developed in the race, by the circumstance that all who for want of such emotion did not join their fellows inevitably perished.

The mode by which a passage originally overland has been converted into one over the sea offers no insuperable difficulties, as has already been pointed out. The long flights of some birds without apparently stopping on the way is thought to be inexplicable, as well as their finding their nesting-place of the previous year from a distance of many huudreds or even a thousand miles. But the observant powers of animals are very great; and birds flying high in the air may be guided by the physical features of the country spread out beneath them in a way that would be impracticable to purely terrestrial animals.

It is assumed by some writers that the breeding-place of a species is to be considered as its true home rather than that to which it retires in winter; but this can hardly be accepted as a rule of universal application. A bird can only breed successfully where it can find sufficient food for its young; and the reason probably why so many of the smaller birds leave the warm southern regions to breed in temperate or even cold latitudes, is because caterpillars and other soft insect larvæ are there abundant at the proper time, while in their winter home the 
linvec have all changed into winged insects. But this favourable breeding district will change its position with change of climate; and as the last great change has been one of increased warnth in all the temperate zones, it is probable that many of the migratory birds are comparatively recent visitors. Other changes nay lowever have taken place, affecting the vergetation and consequently the insects of a district; and we have seldom the means of determining in any particular case in what direction the last extension of range occurrel. For the purposes of the study of geographical distribution therefore, we must, cxcept in special cases, consider the true range of a species to comprise all the area which it occupies regularly for any part of the year, while all those districts which it only visits at more or less distant intervals, apparently driven by storms or by hunger, and where it never regularly or permanently settles, should not be inclitded as forming part of its area of distribution.

Means of Dispersal of Reptiles and Amphibia.-If we leave out of consideration the true marine groups-the turtles and seasnakes-reptiles are scarcely more fitted for traversing seas and oceans than are mammalia. Wo accordingly find that in those oceanic islands which possess no indigenous mammals, land reptiles are also generally wanting. The several groups of these animals, however, differ considerably both in their means of dispersal and in their power of resisting adverse conditions. Snakes are most dependent on climate, becoming very scarce in temperate and cold elimates and entirely ceasing at $62^{\circ}$ north latitude, and they do not ascend very lofty mountains, ceasing at 6,000 feet elevation in the Alps. Some inhabit deserts, others swamps and marshes, while many are adapted for a life in forests. They swim rivers easily, but apparently have no means of passing the sea, since they are very rarely found on oceanic islands. Lizards are also essentially tropical, but they go somewhat farther north than snakes, and ascend higher on the mountains, reaching 10,000 feet in the Alps. They possess too some unknown means (probably in the egg-state) of passing over the ocean, since they are found to inhabit many islands where there are neither mammalia nor snakes. 
The amphibia are much less sensitive to cold than are true reptiles, and they accordingly extend much farther north, fross being found within the arctic circle. Their semi-aquatic life also gives them facilities for dispersal, and their eggs are no doubt sometimes carried by aquatic birds from one pond or stream to another. Salt water is fatal to them as well as to their egrgs, and hence it arises that they are seldom found in those oceanic islands from which mammalia are absent. Deserts and oceans would probably form the most effectual barriers to their dispersal; whereas both snakes and lizards abound in deserts, and have some means of occasionally passing the ocean which frogs and salamanders do not seem to possess.

Means of Dispersal of Fishes. - The fact that the same species of freshwater fish often inhabit distinct river systems, proves that they have some means of dispersal over land. 'I'he many authentic accounts of fish falling from the atmosphere, indicate one of the means by which they may be transferred from one river basin to another, viz., by hurricanes and whirlwinds, which often carry up considerable quantities of water and with it fishes of small size. In volcanic countries, also, the fishes of subterranean streams may sometimes be thrown up by volcanic explosions, as Humboldt relates happened in South America. Another mode by which fishes may be distributed is by their eggs being occasionally carried away by aquatic birds; and it is stated by Gmelin that geese and ducks during their migrations feed on the eggs of fish, and that some of these pass through their bodies with their vitality unimpaired. ${ }^{1}$ Even water-beetles flying from one pond to another might occasionally carry with them some of the smaller eggs of fishes. But it is probable that fresh-water fish are also enabled to migrate by changes of level causing streams to alter their course and carry their waters into adjacent basins. On plateaux the sources of distinct river systems often approach each other, and the same thing occurs with lateral tributaries on the lowlands near their mouths. Such changes, although small in extent, and occurring only at long intervals, would

${ }_{1}$ Quoted in Lyell's Principles of Geology (11th ed. vol. ii. p. 374), from Amon. Acad. Essay 75. 
act very powerfully in modifying the distrilution of fresh-water fish.

Sea fish would seem at first sight to have almost unlimited means of dispersal, but this is far from being the case. Temperature forms a complete barrier to a large number of species, cold water being essential to many, while others can only dwell in the warmth of the tropics. Deep water is another harrier to large numbers of species which are adapted to shores and shallows; and thus the Atlantic is quite as impassable a gulf to most fishes as it is to birds. Many sea fishes migrate to a limited extent for the purpose of depositing their spawn in favourable situations. The herring, an inhabitant of the deep sea, comes in shoals to our coast in the breeding season; while the salmon quits the northeru seas and enters our rivers, mounting upwards to the clear cold water near their sources to deposit its eggs. Keeping in mind the essential fact that changes of temperature and of depth are the main barriers to the dispersal of fish, we shall find little difficulty in tracing the causes that have determined their distribution.

Means of Dispersal of Mollusca.-The marine, fresh-water, and land mollusca are three groups whose powers of dispersal and consequent distribution are very different, and must be separately considered. The Pteropoda, the Ianthina, and other groups of floating molluses, drift about in mid-ocean, and their dispersal is probably limited chiefly by temperature, but perhaps also by the presence of enemies or the scarcity of proper food. The univalve and bivalve mollusca, of which the whelk and the cockle may be taken as types, move so slowly in their adult state, that we should expect them to have an exceedingly limited distribution; but the young of all these are free swimming embryos, and they thus have a powerful means of dispersal, and are carried by tides and currents so as ultimately to spread over every shore and shoal that offers conditions favourable for their development. The fresh water molluses, which one might at first suppose could not range beyond their own river-basin, are yet very widely distributed in common with almost all other fresh water productions; and Mr. Darwin has shown that this is 
due to the fact, that ponds and marshes are constantly frequented by wading and swimming birds which are pre-eminently wanderers, and which frequently carry away with them the seeds of plants, and the eggs of molluses and aquatic insects. Fresh water molluses just hatched were found to attach themselves to a duck's foot suspended in an aquarium; and they would thus be easily carried from one lake or river to another, and by the help of different species of aquatic birds, might soon spread all over the globe. Even a water-beetle has been caught with a small living shell (Ancylus) attached to it; and these fly long distances and are liable to be blown out to sea, one having been caught on board the Beagle when forty-five miles from land. Although fresh water molluses and their eggs must frequently be carried out to sea, yet this cannot lead to their dispersal, since salt water is almost immediately fatal to them; and we are therefore forced to conclude that the apparently insignificant and uncertain means of dispersal above alluded to are really what have led to their wide distribution. The true land-shells offer a still more difficult case, for they are exceedingly sensitive to the influence of salt water; they are not likely to be carried by aquatic birds, and yet they are more or less abundant all over the globe, inhabiting the most remote oceanic islands. It has been found, however, that land-shells have the power of lying dormant a long time. Some have lived two years and a half shut up in pill boxes; and one Egyptian desert snail came to life after having been glued down to a tablet in the British Museum for four years!

We are indebted to Mr. Darwin for experiments on the power of land shells to resist sea water, and he found that when they had formed a membranous diaphragm over the mouth of the shell they survived many days' immersion (in one case fourteen days); and another experimenter, quoted by Mr. Darwin, found that out of one hundred land shells immersed for a fortnight in the sea, twenty-seven recovered. It is therefore quite possible for them to be carried in the chinks of drift wood for many hundred miles across the sea, and this is probably one of the most effectual modes of their dispersal. Very young she!ls would also some- 
times attach themselves to the feet of birds walking or resting on the ground, and as many of the waders often go far inland, this may lave been one of the methods of distributing species of land shells; for it must always be remembered that nature can afford to writ, and that if but once in a thousand years a single bird should convey two or three minute snails to a distant island, this is all that is required for us to find that island well stocked with a great and varied population of land shells.

Means of Dispersal of Insects and the Barrier's which Limit their Range.-Winged insects, as a whole, have perhaps more varied means of dispersal over the globe than any other highly organised animals. Many of them can fly immense distances, and the more delicate ones are liable to be carried by storms and hurricanes over a wide expanse of ocean. They are often met with far out at sea. Hawk-moths frequently fly on board ships as they approach the shores of tropical countries, and they have sometimes been captured more than 250 miles from the nearest land. Dragon-flies came on board the Adventure frigate when fifty miles off the coast of South America. A southerly wind brought flies in myriads to Admiral Smyth's ship in the Mediterranean when he was 100 miles distant from the coast of Africa. A large Indian beetle (Chrysochroa ocellata) was quite recently caught alive in the Bay of Bengal by Captain Payne of the barque William Mansoon, 273 miles from the nearest land. Darwin caught a locust 370 miles from land; and in 1844 swarms of locusts several miles in extent, and as thick as the flakes in a heavy snowstorm, visited Madeira. These must have come with perfect safety more than 300 miles; and as they continued flying over the island for a long time, they could evidently have travelled to a much greater distance, Numbers of living beetles belonging to seven genera, some aquatic and some terrestrial, were caught by Mr. Darwin in the open sea, seventeen miles from the coast of South America, and they did not seem injured by the salt water. Almost all the accidental causes that lead to the dispersal of the higher animals would be still more fuvourabie for insects. Floating trees could carry hundreds of insects for one bird or mammal; and so many of the larrie, eggs, 
and pupe of insects have their abode in solid timber, that they might survive being floated immense distances. Great numbers of tropical insects have been captured in the London docks, where they have been brought in foreign timber; and some have emerged from furniture after remaining torpid for many years. Most insects have the power of existing weeks or months without food, and some are very tenacious of life. Many beetles will survive immersion for hours in strong spirit; and water a few degrees below the boiling point will not always kill them. We can therefore easily understand how, in the course of ages insects may become dispersed by means which would be quite inadequate in the case of the higher animals. The drift-wood and tropical fruits that reach Ireland and the Orkneys; the double cocoa-nuts that cross the Indian ocean from the Seychelle Islands to the coast of Sumatra; the winds that carry volcanic dust and ashes for thousands of miles; the hurricanes that travel in their revolving course over wide oceans; all indicate means by which a few insects may, at rare intervals be carried to remote regions, and become the progenitors of a group of allied forms.

But the dispersal of insects requires to be looked at from another point of view. They are, of all animals, perhaps the most wonderfully adapted for special conditions ; and are so often fitted to fill one place in nature and one only, that the barriers against their permanent displacement are almost as numerous and as effective as their means of dispersal. Hundreds of species of lepidoptera, for example, can subsist in the larva state only on one species of plant; so that even if the perfect insects were carried to a new country, the continuance of the race would depend upon the same or a closely allied plant being abundant there. Other insects require succulent vegetable food all the year round, and are therefore confined to tropical regions; some can live only in deserts, others in forests; some are dependent on water-plants, some on mountain-vegetation. Many are so intimately connected with other insects during some part of their existence that they could not live without them; such are the parasitical hymenoptera and diptera, and those mimicking species whose welfare depends upon their being 
mistaken for something else. Then again, insects have enemies in every stage of their existence-the egg, the larva, the pupa, and the perfect form; and the abundance of any one of these enemies may render their survival in possible in a country otherwise well suited to them. Ever bearing in mind these two opposing classes of facts, we shall not be surprised at the enormous range of some groups of insects, and at the extreme localization of others; and shall be able to give a rational account of many phenomena of distribution that would otherwise seen quite unintelligible. 


\section{CHAPTER III.}

DISTRIBUTION AS AFFECTED BY THE CONDITIONS AND CIIANGES OF THE EARTH'S SURFACE.

THE distribution of animals over the earth's surface, is evidently dependent in great measure upon those grand and important characteristics of our globe, the study of which is termed physical geography. The proportion of land and water; the outlines and distribution of continents; the depth of seas and oceans; the position of islands ; the height, direction, and continuity of mountain chains; the position and extent of deserts, lakes, and forests ; the direction and velocity of ocean currents, as well as of prevalent winds and hurricanes; and lastly, the distribution of heat and cold, of rain, snow, and ice, both in their means and in their extremes, have all to be considered when we endeavour to account for the often unequal and unsymmetrical manner in which animals are dispersed over the globe. But even this knowledge is insufficient unless we inquire further as to the evidence of permanence possessed by each of these features, in order that we may give due weight to the various causes that have led to the existing facts of animal distribution.

Land and Water.-The well-known fact that nearly threefourths of the surface of the earth is occupied by water, and but a little more than one-fourth by land, is important as indicating the vast extent of ocean by which many of the continents and islands are separated from each other. But there is another fact 
which greatly increases its importance, namely, that the mean height of the land is very small compared with the mean depth of the sea. It has been estimated by Humboldt that the mean height of all the land surface does not exceed a thousand feet, owing to the comparative narrowness of mountain ranges and the great extent of alluvial plains and valleys; the ocean bed, on the contrary, not only descends deeper than the tops of the highest mountains rise above its surface, but these profound depths are broad sunken plains, while the shallows correspond to the mountain ranges, so that its mean depth is, as nearly as can be estimated, twelve thousand feet. ${ }^{1}$ Hence, as the area of water is three times that of the land, the total cubical contents of the land, above the sea level, would be only $\frac{1}{36}$ that of the waters which are below that level. The important result follows, that whereas it is scarcely possible that in past times the amount of land surface should ever greatly have exceeded that which now exists, it is just possible that all the land may have been at some time submerged; and therefore in the highest degree probable that among the continual changes of land and sea that have been always going on, the amount of land surface has often been much less than it is now. For the same reason it is probable that there have been times when large masses of land have been more isolated from the rest than they are at present; just as South America would be if North America were submerged, or as Australia would become if the Malay Archipelago were to sink beneath the ocean. It is also very important to bear in mind the fact insisted on by Sir Charles Lyell, that the shallow parts of the ocean are almost always in the vicinity of land; and that an amount of elevation that would make little difference to the bed of the ocean, would raise up extensive tracts of dry land in the vicinity of existing continents. It is almost certain, therefore, that changes in the distribution of land and sea must have taken place more frequently by additions to, or

1 This estimate has been made for me by Mr. Stanford from the materials used in delineating the contours of the ocean-bed on our general map. It embodies the result of all the soundings of the C'hallenger, Tuscarora, and other vessels, obtainable up to August, 1875. 
modifications of pre-existing land, than by the upheaval of entirely new continents in mid-ocean. These two principles will throw light upon two constantly recurring groups. of facts in the distribution of animals, - the restriction of peculiar forms to areas not at present isolated,-and on the other hand, the occurrence of allied forms in lands situated on opposite shores of the great oceans.

Continental Areas.-Although the dry land of the earth's surface is distributed with so much irregularity, that there is more than twice as much north of the equator as there is south of it, and about twice as much in the Asiatic as in the American hemisphere; and, what is still more extraordinary, that on a hemisphere of which a pnint in St. George's Channel between England and Ireland is the centre, the land is nearly equal in extent to the water, while in the opposite hemisphere it is in the proportion of only one-eighth,-yet the whole of the land is almost continuous. It consists essentially of only three masses: the American, the Asia-African, and the Australian. The two former are only separated by thirty-six miles of shallow sea at Behring's Straits, so that it is possible to go from Cape Horn to Singapore or the Cape of Good Hope without ever being out of sight of land; and owing to the intervention of the numerous islands of the Malay Archipelago the journey might be continued under the same conditions as far as Melbourne and Hobart Town. This curious fact, of the almost perfect continuity of all the great masses of land notwithstanding their extremely irregular shape and distribution, is no doubt dependent on the circumstances just alluded to; that the great depth of the oceans and the slowness of the process of upheaval, has almost always produced the new lands either close to, or actually connected with pre-existing lands; and this has necessarily led to a much greater uniformity in the distribution of organic forms, than would have prevailed had the continents been more completely isolated from each other.

The isthmuses which comnect Africa with Asia, and North with South America, are, however, so small and insignificant compared with the vast extent of the countries they unite that 
we can harlly consiler thom to form more than a morninal connection. The Isthmus of Suez indeed, being itself a desert, and connecting districts which for a great distance are more or less desert also, does not effect any real union between the luxuriant forest-clad regions of intertropical Asia and $A$ frica. The Isthmus of Panama is a more effectual line of union, since it is hilly, well watered, and covered with luxuriant regetation; and we accordingly find that the main features of South American zoology are continued into Central America and Mexico. In Asia a great transverse barrier exists, dividing that continent into a northern and southern portion; and as the lowlands occur on the south and the highlands on the north of the great mountain range, which is situated not far beyond the tropic, an abrupt change of climate is prorluced; so that a belt of about a hundred miles wide, is all that intervenes between a luxuriant tropical region and an almost arctic waste. Between the northern part of Asia, and Europe, there is no barrier of importance; and it is inpossible to separate these regions as regards the main features of animal life. Africa, like Asia, has a great transverse barrier, but it is a desert instead of a mountain chain; and it is found that this desert is a more effectual barrier to the diffusion of animals than the Mediterranean Sea; partly because it coincides with the natural division of a tropical from a temperate climate, but also on account of recent geological changes which we shall presently allude to. It results then from this outline sketch of the earth's surface, that the primary divisions of the geographer correspond approximately with those of the zoologist. Some large portion of each of the popular divisions forms the nucleus of a zoological region; but the boundaries are so changed that the geographer would hardly recognise them: it has, therefore, been found necessary to give them those distinct names which will be fully explained in our next chapter.

Recent Changes in the Continental Areas.-The important fact has been now ascertained, that a considerable portion of the Sahara south of Algeria and Morocco was under water at a very recent epoch. Over much of this area sea-shells, identical with those now living in the Mediterranean, are abundantly scattered, 
not only in depressions below the level of the sea but up to a height of 900 feet above it. Borings for water made by the French government have shown, that these shells occur twenty feet deep in the sand; and the occurrence of abundance of salt, sometimes even forming considerable hills, is an additional proof of the disappearance of a large body of salt water. The common cockle is one of the most abundant of the shells found; and the Rev. H. B. Tristram discovered a new fish, in a salt lake nearly 300 miles inland, but which has since been found to inhabit the Gulf of Guinea. Connected with this proof of recent elevation in the Sahara, we have most interesting indications of subsidence in the area of the Mediterranean, which were perhaps contemporaneous. Sicily and Malta are connected with Africa by a submerged bank from 300 to 1,200 feet below the surfac ; while the depth of the Mediterranean, both to the east and west, is enormous, in some parts more than 13,000 feet; and another submerged bank with a depth of 1,000 feet occurs at the straits of Gibraltar. In caves in Sicily, remains of the living African elephant have been found by Baron Anca; and in other caves Dr. Falconer discovered remains of the Elephas antiquus and of two species of Hippopotamus. In Malta, three species of elephant have been discovered by Captain Spratt; a large one closely allied to $E$. antiquus and two smaller ones not exceeding five feet high when adult. These facts clearly indicate, that when North Africa was separated by a broad arm of the sea from the rest of the continent, it was probably connected with Europe; and this explains why zoologists find themselves obliged to place it along with Europe in the same zoological region.

Besides this change in the level of the Sahara and the Mediterranean basin, Europe has undergone many fluctuations in its physical gengraphy in very recent times. In Wales, abundance of sea-shells of living species have been found at an elevation of 1,300 feet; and in Sardinia there is proof of an elevation of 300 feet since the human epoch; and these are only samples of many such changes of level. But these changes, though very important locally and as connected with geological problems, need not be further noticed here; as they were not of a 
nature to affect the larger features of the earth's surface or to determine the boundaries of great zoological regions.

The only other other recent change of great importance which can be adduced to illustrate our present subject, is that which has taken place between North and South America. The living marine shells of the opposite coasts of the istlinus of Panama, as well as the corals and fishes, are generally of distinct species, but some are identical and many are closely allied; the West Indian fossil shells and corals of the Miocene period, however, are found to be largely identical with those of the Pacific coast. The fishes of the Atlantic and Pacific shores of America are as a rule very distinct; but Dr. Günther has recently shown that a considerable number of species inhabiting the seas on opposite sides of the isthmus are absolutely identical. These facts certainly indicate, that during the Miocene epoch a broad channel separated North and South America; and it seems probable that a series of elevations and subsidences have taken place uniting and separating them at different epochs; the most recent submersion having lasted but a short time, and thus, while allowing the passage of abundance of locomotive fishes, not admitting of much change in the comparatively stationary mollusca.

The Glacial Epoch as affecting the Distribution of Animals.The remarkable refrigeration of climate in the northern hemisphere within the epoch, of existing species, to which the term Glacial epoch is applied, together with the changes of level that accompanied and perhaps assisted to produce it, has been one of the chief agents in determining many of the details of the existing distribution of animals in temperate zones. A comparison of the effects produced by existing glaciers with certain superficial phenomena in the temperate parts of Lurope and North America, renders it certain that between the Newer Pliocene and the Recent epochs, a large portion of the northern hemisphere must have been covered with a sheet of ice several thousand feet thick, like that which now envelopes the interior of Greenland. Much further south the mountains were covered with perpetual snow, and sent glaciers down every valley; and all the 
great valleys on the southern side of the Alps poured down streams of ice which stretched far out into the plains of Northern Italy, and have left their débris in the form of huge mountainous moraines, in some cases more than a thousand feet high. In Canada and New Hampshire the marks of moving ice are found on the tops of mountains from 3,000 to 5,000 feet high; and the whole surface of the country around and to the north of the great lakes is scored by glaciers. Wherever the land was submerged during a part of this cold period, a deposit called boulder-clay, or glacial-drift has been formed. This is a mass of sand, clay, or gravel, full of angular or rounded stones of all sizes, up to huge blocks as large as a cottage; and especially characterized by these stones being distributed confusedly through it, the largest being as often near the top as near the bottom, and never sorted into layers of different sizes as in materials carried by water. Such deposits are known to be formed by glaciers and icebergs; when deposited on the land by glaciers they form moraines, when carried into water and thus spread with more regularity over a wider area they form drift. This drift is rarely found except where there is other evidence of ice-action, and never south of the 40 th parallel of latitude, to which in the northern hemisphere signs of ice-action extend. In the southern hemisphere, in Patagonia and in New Zealand, exactly similar phenomena occur.

A very interesting confirmation of the reality of this cold epoch is derived from the study of fossil remains. Both the plants and animals of the Miocene period indicate that the climate of Central Europe was decidedly warmer or more equable than it is now; since the flora closely resembled that of the Southern United States, with a likeness also to that of Eastern Asia and Australia. Many of the shells were of tropical genera; and there were numbers of large mammalia allied to the elephant, rhinoceros, and tapir. At the same time, or perhaps somewhat earlier, a temperate climate extended into the arctic regions, and allowed a magnificent vegetation of shrubs and forest trees, some of them evergreen, to flourish within twelve degrees of the Pole. In the Pliocene period we find ourselves 
among forms implying a climate very little diffurent from the present; and our own Crag formation furnishes evidence of a gradual refrigeration of climate; since its three divisions, the Coralline, Red, and Norwich Crans, show a decreasing number of sonthern, and an increasing number of northern species, as we approach the Glacial epoch. Still later than these we have the shells of the drift, almost all of which are northern and many of them aretic species. Among the mammalia indicative of cold, are the mammoth and the reindeer. In gravels and cavedeposits of Post-Pliocene date we find the same two animals, which soon disappear as the climate approached its present condition; and Professor Forbes has given a list of fifty shells which inhabited the British seas before the Glacial epoch and inhabit it still, but are all wanting in the glacial deposits. The whole of these are found in the Newer Pliocene strata of Sicily and the south of Europe, where they escaped destruction during the glacial winter.

There are also certain facts in the distribution of plants, which are so well explained by the Glacial epoch that they may be said to give an additional confirmation to it. All orer the northern hemisphere within the glaciated districts, the summits of lofty mountains produce plants identical with those of the polar regions. In the celebrated case of the White Mountains in New Hampshire, United States (latitude $45^{\circ}$ ), all the plants on the summit are arctic species, none of which exist in the lowlands for near a thousand miles further north. It has also been remarked that the plants of each mountain are more especially related to those of the countries directly north of it. Thus, those of the Pyrenees and of Scotland are Scandinarian, and those of the White Mountains are all species found in Labrador. Now, remembering that we have evidence of an exceedingly mild and uniform climate in the arctic regions during the Miocene period and a gradual refrigeration from that time, it is evident that with each degree of change more and more hardy plants would be successively driven southwards; till at last the plains of the temperate zone would be inhabited hy plants, which were once confined to alpine heights or to the aretis regions. 
As the icy mantle gradually melted off the face of the earth these plants would occupy the newly exposed soil, and would thus necessarily travel in two directions, back towards the arctic circle and up towards the alpine peaks. The facts are thus exactly explained by a cause which independent evidence has proved to be a real one, and every such explanation is an additional proof of the reality of the cause. But this explanation implies, that in cases where the Glacial epoch cannot have so acted alpine plants should not be northern plants; and a striking proof of this is to be found on the Peak of Teneriffe, a mountain 12,000 feet high. In the uppermost 4,500 feet of this mountain above the limit of trees, Von Buch found only eleven species of plants, eight of which were peculiar; but the whole were allied to those found at lower elevations. On the Alps or Pyrenees at this elevation, there would be a rich flora comprising hundreds of arctic plants; and the absence of anything corresponding to them in this case, in which their ingress was cut off by the sea, is exactly what the theory leads us to expect.

Changes of Vegetation as affecting the Distribution of Animals. - As so many animals are dependent on vegetation, its changes immediately affect their distribution. A remarkable example of this is afforded by the pre-historic condition of Denmark, as interpreted by means of the peat-bogs and kitchen-middens. This country is now celebrated for its beech-trees; oaks and pines being scarce; and it is known to have had the same vegetation in the time of the Romans. In the peat-bogs, however, are found deposits of oak trees; and deeper still pines alone occur. Now the kitchen-middens tell us much of the natural history of Denmark in the early Stone period; and a curious confirmation of the fact that Denmark like Norway was then chiefly covered with pine forests is obtained by the discovery, that the Capercailzie was then abundant, a bird which feeds almost exclusively on the young shoots and seeds of pines and allied plants. The cause of this change in the vegetation is unknown; but from the known fact that when forests are destroyed trees, of a different kind usually occupy the ground, we may suppose that some such change as a temporary submergence might cause an entirely 
different vegetation and a considerably modified fauna to occupy the country.

Organic Changes as affecting Distribution.-We have now briefly touched on some of the direct effects of clianges in physical geography, climate, and vegetation, on the distribution of animals; but the indirect effects of such changes are probalibly of quite equal, if not of greater importance. Fvery change becomes the centre of an ever-widening circle of effects. The different members of the organic world are so bound together by complex relations, that any one change generally involves numerous other changes, often of the most unexpected kind. We know comparatively little of the way in which one animal or plant is bound up with others, but we know enough to assure us that groups the most apparently disconnected are often dependent on each other. We know, for example, that the introduction of goats into St. Helena utterly destroyed a whole flora of forest trees; and with them all the insects, mollusca, and perhaps birds directly or indirectly dependent on them. Swine, which ran wild in Mauritius, exterminated the Dodo. The same animals are known to be the greatest enemies of venomous serpents. Cattle will, in many districts, wholly provent the growth of trees; and with the trees the numerous insects dependent on those trees, and the birds which ferl upon the insects, must disappear, as well as the small mammalia which feed on the fruits, seeds, leaves, or roots. Insects again have the most wonderful influence on the range of mammalia. In Paraguay a certain species of fly abounds which destroys new-born cattle and horses; and thus neither of these animals have run wild in that country, although they abound both north and south of it. This inevitably leads to a great difference in the vegetation of Paraguay, and through that to a difference in its insects, birds, reptiles, and wild mammalia. On what causes the existence of the fly depends we do not know, but it is not improbable that some comparatively slight changes in the temperature or humidity of the air at a particular season, or the introduction of some enemy might lead to its extinction or banishment. The whole face of the country would then soon be changed: new species would 
come in, while many others would be unable to live there; and the immediate cause of this great alteration would probably be quite imperceptible to us, even if we could watch it in progress year by year. So, in South Africa, the celebrated Tsetse fly inhabits certain districts having well defined limits; and where it abounds no horses, dogs, or cattle can live. Yet asses, zebras, and antelopes are unaffected by it. So long as this fly continues to exist, there is a living barrier to the entrance of certain animals, quite as effectual as a lofty mountain range or a wide arm of the sea. The complex relations of one form of life with others is nowhere better illustrated than in $\mathrm{Mr}$. Darwin's celebrated case of the cats and clover, as given in his Crigin of Species, 6th ed., p. 57. He has observed that both wild heartsease and red-clover are fertilized in this country by humble-bees only, so that the production of seed depends on the visits of these insects. A gentleman who has specially studied humble-bees finds that they are largely kept down by field-mice, which destroy their combs and nests. Field-mice in their turn are kept down by cats; and probably also by owls; so that these carnivorous animals are really the agents in rendering possible the continued existence of red-clover and wild heartsease. For if they were absent, the field-mice having no enemies, would multiply to such an extent as to destroy all the humble-bees; and these two plants would then produce no seed and soon become extinct.

Mr. Darwin has also shown that one species often exterminates another closely allied to it, when the two are brought into contact. One species of swallow and thrush are known to have increased at the expense of allied species. Rats, carried all over the world by commerce, are continually extirpating other species of rats. The imported hive-bee is, in Australia, rapicily exterminating a native stingless bee. Any slight change, therefore, of physical geography or of climate, which allows allied species hitherto inhabiting distinct areas to come into contact, will often lead to the extermination of ore of them; and this extermination will be effected by no external force, by no actual enemy, but merely because the one is slightly better 
adapted to live, to increase, and to maintain itself under adverse circumstances, than the other.

Now if we consider carchilly the few sugrestive facts here referred to (and many other's of like import are to be found in Mr. Darwin's various works), we shall be led to conclude that the several species, genera, families, and orders, both of animals and vegetables which inhabit any extensive region, are bound together by a series of complex relations; so that the increase, diminution, or extermination of any one, nay set in motion a series of actions and reactions more or less affecting a large portion of the whole, and requiring perhaps centuries of fluctuation before the balance is restored. The range of any species or group in such a region, will in many cases (perhaps in most) be determined, not by physical barriers, but by the competition of other organisms. Where barriers have existed from a remote epoch, they will at first have kept back certain animals from coming in contact with each other; but when the assemblage of organisms on the two sides of the barrier have, after many ages, come to form a balanced organic whole, the destruction of the barrier may lead to a very partial intermingling of the peculiar forms of the two regions. Each will have become modified in special ways adapted to the orgauic and physical conditions of the country, and will form a living barrier to the entrance of animals less perfectly adapted to those conditions. Thus while the abolition of ancient barriers will always lead to much intermixture of forms, much extermination and widespread alteration in some families of animals; other important groups will be unable materially to alter their range; or they may make temporary incursions into the new territory, and be ultimately driven back to very near their ancient limits.

In order to make this somewhat difficult subject more intelligible, it may be well to consider the probable effects of certain hypothetical conditions of the earth's surface:-

1. If the dry land of the globe had been from the first continuous, and nowhere divided up by such boundaries as lofty mountain ranges, wide deserts, or arms of the sea, it seems probable that none of the larger groups (as orders, tribes, or 
fumilics,) would have a limited range; but, as is to some extent the case in tropical America east of the Andes, every such group would be represented over the whole area, by countless minute modifications of form adapted to local conditions.

2. One great physical barrier would, however, even then exist; the hot equatorial zone would divide the faunas and floras of the colder regions of the northern and southern hemispheres from any chance of intermixture. This one barrier would be more effectual than it is now, since there would be no lofty mountain ranges to serve as a bridge for the partial interchange of northern and southern forms.

3. If such a condition of the earth as here supposed continued for very long periods, we may conceive that the action and reaction of the various organisms on each other, combined with the influence of very slowly changing physical conditions, would result in an almost perfect organic balance, which would be manifested by a great stability in the average numbers, the local range, and the peculiar characteristics of every species.

4. Under such a condition of things it is not improbable that the total number of clearly differentiated specific forms might be much greater than it is now, though the number of generic and family types might perhaps be less; for dominant species would have had ample time to spread into every locality where they could exist, and would then become everywhere modified into forms best suited to the permanent local conditions.

5. Now let us consider what would be the probable effect of the introduction of a barrier, cutting off a portion of this homogeneous and well-balanced world. Suppose, for instance, that a subsidence took place, cuttiug off by a wide arm of the sea a large and tolerably varied island. The first and most obvious result would be that the individuals of a number of species would be divided into two portions, while others, the limits of whose range agreed approximately with the line of subsidence, would exist in unimpaired numbers on the new island or on the main land. But the species whose numbers were diminished and whose original area was also absolutely diminished by the portion now under the sea, would not be able to hold their 
ground against the rival forms whose numbers were intact. Sone would probably diminish and rapidly die out; other's which produced favourable varieties, might be so modified by natural selection as to maintain their existence under a different form; and such changes would take place in varying modes on the two sides of the new strait.

6. But the progress of these changes would necessarily affect the other species in contact with them. New places would be opened in the economy of nature which many would struggrle to obtain; and modification would go on in ever-widening circle and very long periods of time might be required to bring the whole again into a state of equilibrium.

7. A new set of factors would in the meantime have come into play. The sinking of land and the influx of a large body of water could hardly take place without producing important climatal chinges. The temperature, the winds, the rains, might all be affected, and more or less changed in duration and amount. This would lead to a quite distinct movement in the organic world. Vegetation would certainly be considerably affected, and through this the insect tribes. We have seen how closely the life of the higher animals is often bound up with that of insects; and thus a set of changes might arise that would modify the numerical proportions, and even the forms and liabits of a great. number of species, would completely exterminate some, and raise others from a subordinate to a dominant position. And all these changes would occur differently on opposite sides of the strait, since the insular climate could not fail to differ considerably from that of the continent.

8. But the two sets of changes, as above indicated, produced by different modes of action of the same primary cause, would act and react on each other; and thus lead to such a far-spreading disturbarice of the organic equilibrium as ultimately perhaps to affect in one way or another, every form of life upon the earth.

This hypothetical case is useful as enabling us better to realize how wide-spreading might be the cffects of one of the simplest changes of physical geography, upon a compact mass of mutually 
adapted organisms. In the actual state of things, the physical changes that occur and have occurred through all geological epochs are larger and more varied. Almost every mile of land surface has been again and again depressed beneath the ocean; most of the great mountain chains have either originated or greatly increased in height during the Tertiary period; marvellous alterations of climate and vegetation have taken place over half the land-surface of the earth; and all these vast changes have influenced a globe so cut up by seas and oceans, by deserts and snow-clad mountains, that in many of its more isolated land-masses ancient forms of life have been preserved, which, in the more extensive and more varied continents have long given way to higher types. How complex then must have been the actions and reactions such a state of things would bring about; and how impossible must it be for us to guess, in most cases, at the exact nature of the forces that limit the range of some species and cause others to be rare or to become extinct! All that we can in general hope to do is, to trace out, more or less hypothetically, some of the larger changes in physical geography that have occurred during the ages immediately preceeding our own, and to estimate the effect they will probably have produced on animal distribution. We may then, by the aid of such knowledge as to past organic mutations as the geological record supplies us with, be able to determine the probable birthplace and subsequent migrations of the more important genera and families; and thus obtain some conception of that grand series of co-ordinated changes in the earth and its inhabitants, whose final result is seen in the forms and the geographical distribution of existing animals. 


\section{CHAPTER IV.}

\section{ON ZOOLOGICAL REGIONS.}

To the older school of Naturalists the native country of an animal was of little importance, except in as far as climates differed. Animals were supposed to be specially adapted to live in certain zones or under certain physical conditions, and it was hardly recognised that apart from these conditions there was any influence in locality which could materially affect them. It was believed that, while the animals of tropical, temperate, and arctic climates, essentially differed; those of the tropics were essentially alike all over the world. A group of animals was said to inliabit the "Indies;" and important differences of structure were often overlooked from the idea, that creatures equally adapted to live in hot countries and with certain general resemblances, would naturally be related to each other. Thus the Toucans and Hornbills, the Humming-Birds and SunBirds, and even the Tapirs and the Elephants, came to be popularly associated as slightly modified varieties of tropical forms of life; while to naturalists, who were acquainted with the essential differences of structure, it was a never-failing source of surprise, that under climates and conditions so apparently identical, such strangely divergent forms should be produced.

To the modern naturalist, on the other hand, the native country (or "habitat" as it is technically termed) of an animal 
or a group of animals, is a matter of the first importance; and, as regards the general history of life upon the globe, may be considered to be one of its essential characters. The structure, affinities, and habits of a species, now form only a part of its natural history. We require also to know its exact range at the present day and in prehistoric times, and to have some knowledge of its geological age, the place of its earliest appearance on the globe, and of the various extinct forms most nearly allied to it. To those who accept the theory of development as worked out by Mr. Darwin, and the views as to the general permanence and immense antiquity of the great continents and oceans so ably developed by Sir Charles Lyell, it ceases to be a matter of surprise that the tropics of Africa, Asia, and America should differ in their productions, but rather that they should have anything in common. Their similarity, not their diversity, is the fact that most frequently puzzles us.

The more accurate knowledge we have of late years obtained of the productions of many remote regions, combined with the greater approaches that have been made to a natural classification of the higher animals, has shown, that every continent or well-marked division of a continent, every archipelago and even every island, presents problems of more or less complexity to the student of the geographical distribution of animals. If we take up the subject from the zoological side, and study any family, order, or even extensive genus, we are almost sure to meet with some anomalies either in the present or past distribution of the various forms. Let us adduce a few examples of these problems.

Deer have a wonderfully wide range, over the whole of Europe, Asia, and North and South America; yet in Africa south of the great desert there are none. Bears range over the whole of Europe, Asia, and North America, and true pigs of the genus Sus, over all Europe and Asia and as far as New Guinea; yet both bears and pigs, like deer, are absent from Tropical and South Africa.

Again, the West Indian islands possess very few Mammalia, all of small size and allied to those of America, except one 
genus; and that belongs to an Order, "Insectivora," entirely absent from South America, and to a family, "Centetide," all the other species of which inhabit Madagascar only. And as if to add force to this singular correspondence we have one Madagascar species of a beautiful day-flying Moth, Urania, all the other species of which inhabit tropical America. These inscets are gorgeously arrayed in green and gold, and are quite unlike any other Lepidoptera upon the globe.

The island of Ceylon generally agrees in its productions with the Southern part of India; yet it has several birds which are allied to Malayan and not to Indian groups, and a fine butterfly of the genus Hestia, as well as several genera of beetles, which are purely Malayan.

Various important groups of animals are distributed in a way not easy to explain. The anthropoid apes in West Africa and Borneo; the tapirs in Malaya and South America; the camel tribe in the deserts of Asia and the Andes; the trogons in South America and Tropical Asia, with one species in Africa; the marsupials in Australia and Anerica, are examples.

The cases here adduced (and they might be greatly multiplied) are merely to show the kind of problems with which the naturalist now has to deal; and in order to do so he requires some system of geographical arrangement, which shall serve the double purpose of affording a convenient subdivision of his subject, and at the same time of giving expression to the main results at which he has arrived. Hence the recent discussions on "Zoological Regions," or, what are the most natural primary divisions of the earth as regards its forms of animal life.

The divisions in use till quite recently were of two kinds; either those ready made by geographers, more especially the quarters or continents of the globe; or those determined by climate and marked out by certain parallels of latitude or by isothermal lines. Either of these methods was bettel than none at all; but from the various considerations explained in the preceding chapters, it will be evident, that such divisions must have often been very unuatural, and have disguised many 
of the most important and interesting phenomena which a study of the distribution of animals presents to us.

The merit of initiating a more natural system, that of determining zoological regions, not by any arbitrary or a priori consideration but by studying the actual ranges of the more important groups of animals, is due to Mr. Sclater, who, in 1857, established six primary zoological regions from a detailed examination of the distribution of the chief genera and families of Birds. Before stating what these regions are, what objections have been made to them, what other divisions have been since proposed, and what are those which we shall adopt in this work, it will be well to consider the general principles which should guide us in the choice between rival systems.

Principles on which Zoological Regions should be formed.It will be evident in the first place that nothing like a pe?fect zoological division of the earth is possible. The causes that have led to the present distribution of animal life are so varied, their action and reaction have been so complex, that anomalies and irregularities are sure to exist which will mar the symmetry of any rigid system. On two main points every system yet proposed, or that probably can be proposed, is open to objection; they are,-1stly, that the several regions are not of equal rank;-2ndly, that they are not equally applicable to all classes of animals. As to the first objection, it will be found impossible to form any three or more regions, each of which differs from the rest in an equal degree or in the same manner. One will surpass all others in the possession of peculiar families; another will have many characteristic genera; while a third will be mainly distinguished by negative characters. There will also be found many intermediate districts, which possess some of the characteristics of two well-marked regions, with a few special features of their own, or perhaps with none; and it will be a difficult question to decide in all cases which region should possess this doubtful territory, or whether it should be formed into a primary region itself. Again, two regions which have now well-marked points of difference, may be shown to have been much more alike at a comparatively recent geological epoch; 
and this, it may be saill, proves their fundamental nuity and that they ought to form lut one primary region. To obviate some of these difficulties a binary or dichotomous division is sometimes proposed; that portion of the earth which differs most from the rest being cut off as a region equal in rank to all that remains, which is subjected again and again to the same process.

To decile these various points it scems advisable that convenience, intelligibility, and custom, should largely guicle us. The first essential is, a broally marked and easily remembered set of regions; which correspond, as nearly as truth to nature will allow, with the distribution of the nost important groups of animals. What these groups are we shall presently explain. In determining the number, extent, and boundaries of these regions, we must be guided by a variety of indications, since the application of fixed rules is impossible. They should evidently be of a moderate number, corresponding as far as practicable with the great natural divisions of the globe marked out by nature, and which have always been recognized by geographers. There should be some approximation to equality of size, since there is reason to believe that a tolerably extensive area has been an essential condition for the development of most animal forms; and it is found that, other things being equal, the numbers, variety and importance of the forms of animal and vegetable life, do hear some approximate relation to extent of area. Although the possession of peculiar families or genera is the main character of a primary zoological region, yet the negative character of the absence of certain families or genera is of equal importance, when this absence does not manifestly depend on unsuitability to the support of the group, and especially when there is now no physical barrier preventing their entrance. This will become evident when we consider that the importance of the possession of a group by one region depends on its absence from the adjoining regions; and if there is now no barricr to its entrance, we may be sure that there has once been one; and that the possession of the area by a distinct and well balanced set of organisms, which must have been slowly 
developed and adjusted, is the living barrier that now keeps out intruders.

When it is ascertained that the chief differences which now obtain between two areas did not exist in Miocene or Pliocene times, the fact is one of great interest, and enables us to speculate with some degree of probability as to the causes that have brought about the present state of things; but it is not a reason for uniting these two areas into one region. Our object is to represent as nearly as possible the main features of the distribution of existing animals, not those of any or all past geological epochs. Should we ever obtain sufficient information as to the geography and biology of the earth at past epochs, we might indeed determine approximately what were the Pliocene or Miocene or Eocene zoological regions; but any attempt to exhibit all these in combination with those of our own period, must lead to confusion.

The binary or dichotomous system, although it brings out the fundamental differences of the respective regions, is an inconvenient one in its application, and rather increases than obviates the difficulty as to equality or inequality of regions; for although $a, b, c$, and $d$, may be areas of unequal zoological rank, $a$ being the most important, and $d$ the least, yet this inequality will probably be still greater if we first divide them into $a$, on one side, and $b, c$, and $d$, on the other, and then, by another division, make $b$, an area of the second, and $c$, and $d$, of the third rank only.

Coming to the second objection, the often incompatilile distribution of different groups of animals, affords ground for opposition to any proposed scheme of zoological regions. There is first the radical difference between land and sea animals; the most complete barriers to the dispersal of the one, sometimes offering the greatest facilities for the emigration of the other, and vice versa. A large number of marine animals, however, frequent shallow water only; and these, keeping near the coasts, will agree generally in their distribution with those inhabiting the land. But among land animals themselves there are very great differences of distribution, due to certain specialities 
in their organization or mole of life. These act mainly in two ways,-1stly, by affecting the facilities with which they can be dispersed, either voluntarily or involuntarily; - 2ndly, by the conditions which enalule them to multiply and establish themseives in certain areas and not in others. When both these means of diffusion are at a maximum, the dispersal of a group becomes universal, and ceases to have much interest for us. This is the case with certain groups of fungi and lichens, as well as with some of the lower animals; and in a less degree, as has been shown by Mr. Darwin, with many fresh-water plants and animals. At the other extreme we may place certain arboreal vertebrata such as sloths and lemurs, which have no means of passing such barriers as narrow straits or moderately high mountains, and whose survival in any new country they might reach, would be dependent on the presence of suitable forests and the absence of dangerous enemies. Almost equally, or perhaps even more restricted, are the means of permanent diffusion of terrestrial molluses; since these are without any but very rare and accidental means of being safely transported across the sea; their individual powers of locomotion are highly restricted; they are especially subject to the attacks of enemies; and they often depend not only on a peculiar vegetation, but on the geological character of the country, their abundance being almost in direct proportion to the presence of some form of calcareous rocks. Between these extremes we find animals possessed of an infinite gradation of powers to disperse and to maintain themselves; and it will evidently be impossilule that the limits which best define the distribution of one group, should be equally true for all others.

Which class of Animals is of most importance in determining Zoological Regions.-To decide this question we have to consider which groups of animals are best adapted to exhibit, by their existing distribution, the past changes and present physical condition of the earth's surface; and at the same time, by the abundance of their remains in the various tertiary formations will best enable us to trace out the more recent of the series of changes, both of the earth's surface and 
of its inhabitants, by which the present state of things has been brought about. For this purpose we require a group which shall be dependent for its means of dispersal on the distribution of land and water, and on the presence or absence of lofty mountains, desert plains or plateaux, and great forests; since these are the chief physical features of the earth's surface whose modifications at successive periods we wish to discover. It is also essential that they should not be subject to dispersal hy many accidental causes; as this would inevitably in time tend to obliterate the effect of natural barriers, and produce a scattered distribution, the causes of which we could only guess at. Again, it is necessary that they should be so highly organized as not to be absolutely dependent on other groups of animals, and with so much power of adaptation as to be able to exist in one form or another over the whole globe. And lastly, it is highly important that the whole group should be pretty well known, and that a fairly natural classification, especially of its minor divisions such as families and genera, should have been arrived at; the reason for which last proviso is explained in our next chapter, on classification.

Now in every one of these points the mammalia are preemi. nent; and they possess the additional advantage of being the most highly developed class of organized beings, and that to which we ourselves belong. We should therefore construct our typical or standard Zoological Regions in the first place, from a consideration of the distribution of mammalia, only bringing to our aid the distribution of other groups to determine doubtful points. Regions so established will be most closely in accordance with those long-enduring features of physical geography, on which the distribution of all forms of life fundamentally depend; and all discrepancies in the distribution of other classes of animals must be capable of being explained, either by their exceptional means of dispersion or by special conditions affecting their perpetuation and increase in each locality.

If these considerations are well founded, the objections of those who study insects or molluscs, for example,- that our regions are not true for their departments of nature-cannot be 
maintained. For they will find, that a careful consideration of the exceptional means of dispersal and conditions of existence of each group, will explain most of the divergences from the normal distribution of higher animals.

We shall thus be led to an intelligent comprehension of the phenomena of distribution in all groups, which would not he the case if every specialist formed regions for his own particular study. In many cases we should find that no satisfactory division of the earth could be made to correspond with the distribution even of an entire class; but we should have the coleopterist and the lepidopterist each with his own Geography. And even this would probably not suffice, for it is very doubtful if the detailed distribution of the Longicornes, so closely dependent on woody vegetation, could be made to agree with that of the Staphylinidæ or the Carahidæ which abound in many of the most barren regions, or with that of the Scarabeidæ, largely dependent on the presence of herbivorous mammalia. And when each of these enquirers had settled a division of the earth into "regions" which exhibited with tolerable accuracy the phenomena of distribution of his own group, we should have gained nothing whatever but a very complex mode of exhibiting the bare facts of distribution. We should then have to begin to work out the causes of the divergence of one group from another in this respect; but as each worker would refer to his own set of regions as the type, the whole subject would become involved in inextricable confusion. These considerations seem to make it imperative that one set of "regions" should be established as typical for Zoology; and it is hoped the reasons here advanced will satisfy most naturalists that these regions can be best determined, in the first place, by a study of the distribution of the mammalia, supplemented in doubtful cases by that of the other vertebrates. We will now proceed to a discussion of what these regions are.

Various Zoological Regions moposed since 1857.- It has already been pointed out that a very large number of birds are limited by the same kind of barriers as mammalia; it will therefore not be surprising that a system of regions formed to suit the 
one, should very nearly represent the distribution of the other. Mr. Sclater's regions are as follows:-

1. The Palæaretic Region; including Europe, Temperate Asia, and N. Africa to the Atlas mountains.

2. The Ethiopian Region; Africa south of the Atlas, Madagascar, and the Mascarene Islands, with Southern Arabia.

3. The Indian Region; including India south of the Himalayas, to South China, and to Borneo and Java.

4. The Australian Region; including Celebes and Lombock, eastward to Australia and the Pacific Islands.

5. The Nearctic Region; including Greenland, and N. America, to Northern Mexico.

6. The Neotropical Region; including South America, the Antilles, and Southern Mexico.

This division of the earth received great support from Dr. Guinther, who, in the Proceedings of the Zoological Society for 1858, showed that the geographical distribution of Reptiles agreed with it very closely, the principal difference being that the reptiles of Japan have a more Indian character than the birds, this being especially the case with the snakes. In the volume for 1868 of the same work, Professor Huxley discusses at considerable length the primary and secondary zoological divisions of the earth. He gives reasons for thinking that the most radical primary division, both as regards birds and mammals, is into a Northern and Southern hemisphere (Arctogra and Notogra), the former, however, embracing all Africa, while the latter includes only Australasia and the Neotropical or Austro-Columbian region. Mr. Sclater had grouped his regions primarily into Palrogra and Neogra, the old and New Worlds of geographers; a division which strikingly accords with the distribution of the passerine birds, but not so well with that of mammalia or reptiles. Professor Huxley points out that the Nearctic, Palrarctic, Indian, and Ethiopian regions of Mr. Sclater have a much greater resemblance to each other than any one of them his to Australia or to South America; and he further suggests that New Zealand alone has peculiarities which might entitle it to rank as a primary region 
along with Australasia and South America; and that a Circumpolar Province might be conveniently recognised as of equal rank with the Palæarctic and Nearctic provinces.

In 1866, Mr. Andrew Murray published a large and copiously illustrated volume on the Geographical Distribution of Mammals, in which he maintains that the great and primary mammalian regions are only four: 1st. The Palæarctic region of Mr. Sclater, extended to include the Sahara and Nubia; 2nd. the Indo-African region, including the Indian and Ethiopian regions of Mr. Sclater; 3rd. the Australian region (unaltered); 4th. the American region, including both North and South America. These are the regions as deseribed by Mr. Murray, but his coloured map of "Great Mammalian Regions" shows all Arctic America to a little south of the Isothermal of $32^{\circ}$ Fahr. as forming with Europe and North Asia one great region.

At the meeting of the British Association at Exeter in 1869, Mr. W. T. Blanford read a paper on the Fauna of British India, in which he maintained that a large portion of the peninsula of India had derived its Fauna mainly from Africa; and that the term "Indian region" of Mr. Sclater was misleading, because India proper, if it belongs to it at all, is the least typical portion of it. He therefore proposes to call it the "Malayan region," because in the Malay countries it is most highly developed. Ceylon and the mountain ranges of Southern India have marked Malay affinities.

In 1871 Mr. E. Blyth published in Nature "A suggested new Division of the Earth into Zoological Regions," in which he indicates seven primary divisions or regions, subdivided into twenty-six sub-regions. The seven regions are defined as follows: 1. The Boreal region; including the whole of the Palæarctic and Nearctic regions of Mr. Sclater along with the West Indies, Central America, the whole chain of the Andes, with Chili and Patagonia. 2. The Columbian region; consisting of the remaining part of South America. 3. The Ethiopian region; comprising besides that region of Mr. Sclater, the valley of the Jordan, Arabia, and the desert country towards India, with all the plains and table lands of India and the northern 
half of Ceylon. 4. The Lemurian region; consisting of Madagascar and its adjacent islands. 5. The Austral-Asian region; which is the Indian region of Mr. Sclater without the portion taken to be added to the Ethiopian region. 6. The Melanesian region; which is the Australian region of $\mathrm{Mr}$. Sclater without New Zealand and the Pacific Islands, which form 7. the Polynesian region. Mr. Blyth thinks this is "a true classification of zoological regions as regards mammalia and birds."

In an elaborate paper on the birds of Eastern North America, their distribution and migrations (Bulletin of Museum of Comparative Zoology, Cambridge, Massachusetts, Vol. 2), Mr. J. A. Allen proposes a division of the earth in accordance with what he terms, "the law of circumpolar distribution of life in zones," as follows: 1. Arctic realm. 2. North temperate realm. 3. American tropical realm. 4. Indo-African tropical realm. 5. South American tropical realm. 6. African temperate realm. 7. Antarctic realm. 8. Australian realm. Some of these are subdivided into regions; (2) consisting of the American and the Europæo-Asiatic regions; (4) into the African and Iudian regions; (8) into the tropical Australian region, and one comprising the southern part of Australia and New Zealand. The other realms each form a single region.

Discussion of proposed Regions.-Before proceeding to define the regions adopted in this work, it may be as well to make a few remarks on some of the preceding classifications, and to give the reasons which seem to render it advisable to adopt very few of the suggested improvements on Mr. Sclater's original proposal. Mr. Blyth's scheme is one of the least natural, and also the most inconvenient. There can be little use in the knowledge that a group of animals is found in the Boreal Region, if their habitat might still be either Patagonia, the West Indies, or Japan; and it is difficult to see on what principle the Madagascar group of islands is made of equal rank with this enormous region, seeing that its forms of life have marked African affinities. Neither does it seem advisable to adopt the Polynesian Region, or that comprising New Zealand alone (as hinted at by Professor Huxley and since adopted by 
Mr. Sclater in his Lectures on Geomraphical Distribution at the Zoological Gardens in May 1874), because it is absolutely without indigenous mammalia and very poor in all forms of life, and therefore by no means prominent or important enough to form a primary region of the earth.

It may be as well here to notice what appears to be a serious oljection to making New Zealand, or any similar isolated district, one of the great zoological regions, comparable to South Amcrica, Australia, or Ethiopia; which is, that its claim to that distinction rests on grounds which are liable to fail. It is because New Zealand, in addition to its negative merits, possesses three families of birds (Apterygidæ living, Dinornithidæ and Palapterygidxe extinct), and a peculiar lizard-like reptile, Hatteria, which has to be classed in a distinct order, Rhynchoceplalina, that the rank of a Region is claimed for it. But supposing, what is not at all improbable, that other Rhynchocephalina should be discovered in the interior of Australia or in New Guinea, and that Apterygidæ or Palapterygidæ should be found to have inhalited Australia in Post-Pliocene times, (as Dinornithidæ have already been proved to have done) the claims of New Zealand would entirely fail, and it would be universally acknowledgred to be a part of the great Australian region. No such reversal can take place in the case of the other regions; because they rest, not upon one or two, but upon a large number of peculiarities, of such a nature that there is no room unon the globe for discoveries that can seriously modify them. Even if one or two peculiar types, like Apterygida or Hatteria, should permanently remain characteristic of New Zealand alone, we can account for these by the extreme isolation of the country, and the absence of enemies, which have enabled these defenceless birds and reptiles to continue their existence; just as the isulation and protection of the caverns of Carniola have enabled the Proteus to survive in Europe. But supposing that the Proteus was the sole representative of an order of Batrachia, and that two or three other equally curious and isolated forms occurred with it, no one would propose that these caverns or the district containing them, should form one of the 
primary divisions of the earth. Neither can much stress be laid on the negative characteristics of New Zealand, since they are found to an almost equal extent in every oceanic island.

Again, it is both inconvenient and misleading to pick out certain tracts from the midst of one region or sub-region and to place them in another, on account of certain isolated affinities which may often be accounted for by local peculiarities. Even if the resemblance of the fauna of Chili and Patagonia to that of the Palæarctic and Nearctic regions was much greater than it is, this mode of dealing with it would be objectionable; but it is still more so, when we find that these countries have a strongly marked South American character, and that the northern affinities are altogether exceptional. The Rodentia, which comprise a large portion of the mammalia of these countries, are wholly South American in type, and the birds are almost all allied to forms characteristic of tropical America.

For analogous reasons the Ethiopian must not be made to include any part of India or Ceylon; for although the Fauna of Central India has some African affinities, these do not preponderate; and it will not be difficult to show that to follow Mr. Andrew Murray in uniting bodily the Ethiopian and Indian regions of Mr. Sclater, is both unnatural and inconvenient. The resemblances between them are of the same character as those which would unite them both with the Palæarctic and Nearctic regions; and although it may be admitted, that, as Professor Huxley maintains, this group forms one of the great primary divisions of the globe, it is far too extensive and too heterogeneous to subserve the practical uses for which we require a division of the world into zoological regions.

Reasons for adopting the six Reaions first proposed by Mrr. Sclater. - So that we do not violate any clear affinities or produce any glaring irregularities, it is a positive, and by no means an unimportant, advantage to have our named regions approximately equal in size, and with easily defined, and therefore easily remembered, boundaries. All elaborate definitions of interpenetrating frontiers, as well as regions extending over three-fourths of the land surface of the globe, and including places which are 
the antipodes of each other, would be most inconvenient, even if there were not such difference of opinion about them. There can be little doubt, for example, that the most radical zoological division of the earth is made by separating the Australian region from the rest; but although it is sometling useful and definite to know that a group of animals is peculiar to Australia, it is exceedingly vague and unsatisfactory to say of any other group merely that it is extra-Australian. Neither can it be said that, from any point of view, these two divisions are of equal importance. The next great natural division that can be made is the separation of the Neotropical Region of Mr. Sclater from the rest of the world. We thus have three primary divisions, which Professor Huxley seems inclined to consider as of tolerably equal zoological importance. But a consideration of all the facts, zoological and palæontological, indicates, that the great northern division (Arctogæa) is fully as much more important than either Australia or South America, as its four component parts are less important; and if so, convenience requircs us to adopt the smaller rather than the larger divisions.

This question, of comparative importance or equivalence of value, is very difficult to determine. It may be considered from the point of view of speciality or isolation, or from that of richness and variety of animal forms. In isolation and speciality, determined by what they want as well as what they possess, the Australian and Neotropical regions are undoubtedly each comparable with the rest of the earth (Arctogra). But in richness and variety of forms, they are both very much inferior, and are much more nearly comparable with the separate regions which compose it. Taking the families of mammalia as established by the best authors, and leaving out the Cetacea and the Bats, which are almost universally distributed, and about whose classification there is much uncertainty, the number of families represented in each of Mr. Sclater's regions is as follows:

I. Palæarctic region has 31 families of terrestrial mammalia.

\begin{tabular}{|c|c|c|}
\hline II. Ethiopian & " & \\
\hline III. Indian & $y$ & " \\
\hline IV. Australian & $"$ & $"$ \\
\hline V. Neotropical & & $"$ \\
\hline VI. Nearctic & & $"$ \\
\hline
\end{tabular}


$\mathrm{W}^{\top}$ e see, then, that even the exceedingly rich and isolated Neotropical region is less rich and diversified in its forms of mammalian life than the very much smaller area of the Indian region, or the temperate Palæarctic, and very much less so than the Ethiopian region; while even the comparatively poor Nearctic region, is nearly equal to it in the number of its family types. If these were united they would possess fifty-five families, a number very disproportionate to those of the remaining two. Another consideration is, that although the absence of certain forms of life makes a region more isolated, it does not make it zoologically more important; for we have only to suppose some five or six families, now common to both, to become extinct either in the Ethiopian or the Indian regions, and they would become as strongly differentiated from all other regions as South America, while still remaining as rich in family types. In birds exactly the same phenomenon recurs, the family types being less numerous in South America than in either of the other tropical regions of the earth, but a larger proportion of them are restricted to it. It will be shown further on, that the Ethiopian and Indian, (or, as I propose to call it in this work, Oriental) regions, are sufficiently differentiated by very important groups of animals peculiar to each; and that, on strict zoological principles they are entitled to rank as regions of equal value with the Neotropical and Australian. It is perhaps less clear whether the Palæarctic should be separated from the Oriental region, with which it has undoubtedly much in common; but there are many and powerful reasons for keeping it distinct. There is an unmistakably different facies in the animal forms of the two regions; and although no families of mammalia or birds, and not many genera, are wholly confined to the Palæarctic region, a very considerable number of both have their metropolis in it, and are very richly represented. The distinction between the characteristic forms of life in tropical and cold countries is, on the whole, very strongly marked in the northern hemisphere; and to refuse to recognise this in a subdivision of the earth which is established for the very purpose of expressing such contrusts more clearly and concisely thau by ordinary geographical terminology, would be both illogical and 
inconvenient. The one question then remains, whether the Nearctic region should be kept separate, or whether it should form part of the Paliarctic or of the Neotropical regions. Professor Huxley and Mr. Blyth advocate the former course; Mr. Andrew Murray (for mammalia) and I'rofessor Newton (for birds) think the latter would be more natural. No doult inuch is to he said for both views, but both cannot be right; and it will be shown in the latter part of this chapter that the Nearctic rerion is, on the whole, fully as well defined as the Palæarctic, by positive characters which differentiate it from both the adjacent regions. More evidence in the same direction will be found in the Second Part of this work, in which the extinct faunas of the several regions are discussed.

A confirmation of the general views here set forth, as to the distinctness and approximate equivalence of the six regions, is to be found in the fact, that if any-two or more of them are combined they themselves become divisions of the next lower rank, or "sub-regions;" - -and these will be very much more important, both zoologically and geographically, than the subdivisions of the remaining regions. It is admitted then that these six regions are by no means of precisely equal rank, and that some of them are far more isolated and better characterized than others; but it is maintained that, looked at from every point of view, they are more equal in rank than any others that can be formed; while in geographical equality, compactness of area, and facility of definition, they are beyond all comparison better than any others that have yet been proposed for the purpose of facilitating the study of geographical distribution. They may be arranged and grouped as follows, so as to exhibit their various relations and affinities.

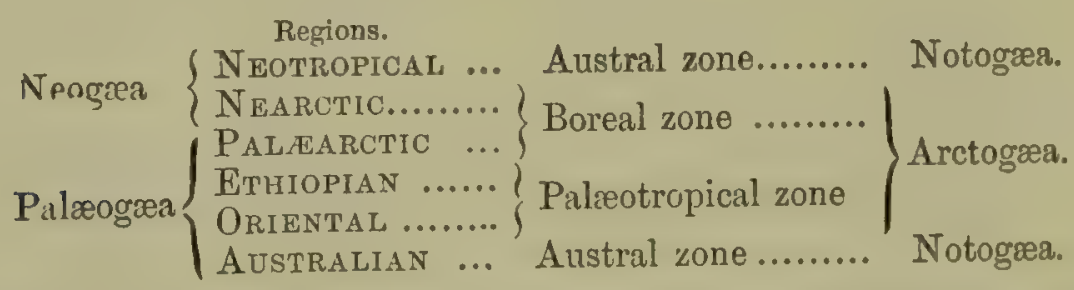

The above table shows the regions placed in the order followed in the Fourth Part of this work, and the reasons for which are 
explained in Chapter IX. As a matter of convenience, and for other reasons adduced in the same chapter, the detailed exposition of the geographical distribution of the animals of the several regions in Part III. commences with the Palæarctic and terminates with the Nearctic region.

Objections to the system of Circumpolar Zones.-Mr. Allen's system of "realms" founded on climatic zones (given at p. 61), having recently appeared in an ornithological work of considerable detail and research, calls for a few remarks. The author continually refers to the "law of the distribution of life in circumpolar zones," as if it were one generally accepted and that admits of no dispute. But this supposed "law" only applies to the smallest details of distribution-to the range and increasing or decreasing numbers of species as we pass from north to south, or the reverse ; while it has little bearing on the great features of zoological geography-the limitation of groups of genera and families to certain areas. It is analogous to the "law of adaptation" in the organisation of animals, by which members of various groups are suited for an aerial, an aquatic, a desert, or an arboreal life; are herbivorous, carnivorous, or insectivorous; are fitted to live underground, or in fresh waters, or on polar ice. It was once thought that these adaptive peculiarities were suitable foundations for a classification,- - that whales were fishes, and bats birds; and even to this day there are naturalists who cannot recognise the essential diversity of structure in such groups as swifts and swallows, sun-birds and humming-birds, under the superficial disguise caused by adaptation to a similar mode of life. The application of Mr. Allen's principle leads to equally erroneous results, as may be well seen by considering his separation of "the southern third of Australia" to unite it with New Zealand as one of his secondary zoological divisions. If there is one country in the world whose fauna is strictly homogeneous, that country is Australia; while New Guinea on the one hand, and New Zealand on the other, are as sharply differentiated from Australia as any adjacent parts of the same primary zoological division can possibly be. Yet the "law of circumpolar distribution" leads to the division of 
Australia by an arbitrary cast and west line, and a union of the northern two-thirds with New Guinea, the southern third with New Zealand. Hardly less unnatural is the supposed equivalence of South Africa (the African temperate realm) to all tropical Africa and Asia, including Madargascar (the IndoAfrican tropical realm). South Africa has, it is true, some striking peculiarities; but they are absolutely unimportant as compared with the great and radical differences between tropical Africa and tropical Asia. On these examples we may fairly rest our rejection of Mr. Allen's scheme.

We must however say a few words on the zoo-geographical nomenclature proposed in the same paper, which seems also very objectionable. The following terms are proposed: realm, region, province, district, fauna and flora; the first being the highest, the last the lowest and smallest sub-division. Considering that most of these terms have been used in very different senses already, and that no means of settling their equivalence in different parts of the globe has been even suggested, such a complex system must lead to endless confusion. Until the whole subject is far better known and its first principles agreed upon, the simpler and the fewer the terms employed the better: and as "region" was employed for the primary divisions by Mr. Sclater, eighteen years ago, and again by Mr. Andrew Murray, in his Geographical Distribution of Mammals; nothing but obscurity can result from each writer using some new, and doubtfully better, term. For the sub-divisions of the regions no advantage is gained by the use of a distinct term-" province"-which has been used (by Swainson) for the primary divisious, and which does not itself tell you what rauk it holds; whereas the term "sub-region" speaks for itself as being unmistakably next in subordination to region, and this clearness of meaning gives it the preference over ary indepeudent term. As to minor named sub-divisions, they seem at present uncalled for; and till the greater divisions are themselves generally agreed on, it seems better to adopt no technical names for what must, for a long time to come, be indeterminate.

Does the Arctic Fauna characterize an indeprudent Region.- 
The proposal to consider the Arctic regions as constituting one of the primary zoological divisions of the globe, has been advocated by many naturalists. Professor Huxley seems to consider it advisable, and Mr. Allen unhesitatingly adopts it, as well as an "antarctic" region to balance it in the southern hemisphere. The reason why an "Arctic Region" finds no place in this work may therefore be here stated.

No species or group of animals can properly be classed as " arctic," which does not exclusively inhabit or greatly preponderate in arctic lands. For the purpose of establishing the need of an "arctic" zoological region, we should consider chiefly such groups as are circumpolar as well as arctic; because, if they are confined to, or greatly preponderate in, either the eastern or western hemispheres, they can be at once allocated to the Nearctic or Palæarctic regions, and can therefore afford no justification for establishing a new primary division of the globe.

Thus restricted, only three genera of land mammalia are truly arctic: Gulo, Myodes, and Rangifer. Two species of widely dispersed genera are also exclusively arctic, Ursus maritimus and $V$ ulpes lagopus.

Exclusively arctic birds are not much more numerous. Of land birds there are only three genera (each consisting of but a single species), Pinicola, Nyctea, and Surnia. Lagopus is circumpolar, but the genus has too wide an extension in the temperate zone to be considered arctic. Among aquatic birds we have the genus of ducks, Somateria; three genera of Uriidæ, Uria, Catarractes, and Mergulus; and the small family Alcidæ, consisting of the genera Alca and Fratercula. Our total then is, three genera of mammalia, three of land, and six of aquatic birds, including one peculiar family.

In the southern hemisphere there is only the single genus Aptenodytes that can be classed as antarctic; and even that is more properly south temperate.

In dealing with this arctic fauna we have two courses open to us; we must either group them with the other species and genera which are common to the two northern regions, or we 
must form a separate prinary regrion for them. $\Lambda$ s a matter of convenience the former plan seems the best; and it is that which is in accordance with our treatment of other intermediate tracts which contain special forms of life. The great desert zone, extending from the Atlantic shores of the Saliara across Arabia to Central Asia, is a connecting link between the Palæarctic, Ethiopian, and Oriental regions, and contaius a number of "desert" forms wholly or almost wholly restricted to it; but the attempt to define it as a separate region would introduce difficulty and confusion. Neither to the "desert" nor to the "arctic" regions could any defined limits, either geographical or zoological, be placed; and the attempt to determine what species or genera should be allotted to them would prove an insoluble problem. The reason perhaps is, that both are essentially unstable, to a much greater extent than those great masses of land with more or less defined barriers, which constitute our six regions. The Arctic Zone has been, within a recent geological period, both vastly more extensive and vastly less extensive than it is at present. At a not distant epoch it extended over half of Europe and of North America. At an earlier date it appears to have vanished altogether; since a luxuriant vegetation of tall deciduous trees and broad-leaved evergreens Hourished within ten degrees of the Pole! The great deserts have not improbably been equally fluctuating; hence neither the one nor the other can present that marked individuality in their forms of life, which seems to have arisen only when extensive tracts of land have retained some considerable stability both of surface and climatal conditions, during periods sufficient for the development and co-adaptation of their several assemblages of plants and animals.

We must also consider that there is no geographical difficulty in dividing the Arctic Zone between the two northern regions. The only debateable lands, Greenland and Iceland, are generally admitted to belong respectively to America and Europe. Neither is there any zoological difficulty; for the land mammalia and birds are on the whole wonderfully restricted to their respective regions even in high latitudes; and the aquatic forms 
are, for our present purpose, of much less importance. As a primary division the "Arctic region" would be out of all proportion to the other six, whether as regards its few peculiar. types or the limited number of forms and species actually inhabiting it; but it comes in well as a counecting link between two regions, where the peculiar forms of both are specially modified; and is in this respect quite analogous to the great desert zone above referred to.

I now proceed to characterize briefly the six regions adopted in the present work, together with the sub-regions into which they may be most conveniently and naturally divided, as shown in our general map.

Pulocarctic Region.-This very extensive region comprises all temperate Europe and Asia, from Iceland to Behring's Straits and from the Azores to Japan. Its southern boundary is somewhat indefinite, but it seems advisable to comprise in it all the extra-tropical part of the Sahara and Arahia, and all Persia, Cabul, and Beloochistan to the Indus. It comes down to a little below the upper limit of forests in the Himalayas, and includes the larger northern half of China, not quite so far down the coast as Amoy. It has been said that this region differs from the Oriental by negative characters only; a host of tropical families and genera being absent, while there is little or nothing but peculiar species to characterize it absolutely. This however is not true. The Palæarctic region is well characterized by possessing 3 families of vertebrata peculiar to it, as well as 35 peculiar genera of mammalia, and 57 of birds, constituting about one-third of the total number it possesses. These are amply sufficient to characterize a region positively; but we must also consider the absence of many important groups of the Oriental, Ethiopian, and Nearctic regions; and we shall then find, that taking positive and negative characters together, and making some allowance for the necessary poverty of a temperate as compared with tropical regions, the Palæarctic is almost as strongly marked and well defined as any other.

Sub-divisions of the Palaarctic Region:-These are by no means 
so clearly indicated as in some of the other regions, and they are adopted more for convenience than because they are very natural or strongly marked.

The first, or European sub-region, comprises Central and Northern Europe as far South as the I'yrenees, the Maritime and Dinaric Alps, the Balkan mountains, the Black Sea, and the Caucasus. On the east the Caspian sea and the Ural mountains scem the most obvious limit; but it is doubtful if they form the actual boundary, which is perhaps better marked by the valley of the Irtish, where a pre-glacial sea almost certainly connected the Aral and Caspian seas with the Arctic ocean, and formed an effective barrier which must still, to some extent, influence the distribution of animals.

The next, or Mediterranean sub-region, comprises South Europe, North Africa with the extra-tropical portion of the Sahara, and Egypt to about the first or second cataracts; and enstward through Asia Minor, Persia, and Cabul, to the deserts of the Indus.

The third, or Siberian sub-region, consists of all north and central Asia north of Herat, as far as the eastern limits of the great desert plateau of Mongolia, and southward to about the upper limit of trees on the Himalayas.

The fourth, or Manchurian sub-region, consists of Japan and North China with the lower valley of the Amoor; and it should probably be extended westward in a narrow strip along the Himalayas, embracing about 1,000 or 2,000 feet of vertical distance below the upper limit of trees, till it meets an eastern extension of the Mediterranean sub-region a little beyond Sinula. These extensions are necessary to avoid passing from the Oriental region, which is essentially tropical, directly to the Siberian subregion, which has an extreme northern character; whereas the Mediterranean and Manchurian sub-regions are more temperate in climate. It will be found that between the upper limit of most of the typical Oriental groups and the Thibetan or Siberian fauna, there is a zone in which many forms occur common to temperate China. This is especially the case among the pheasants and finches. 
Ethiopian Region.-The limits of this region have been indicated by the definition of the Palæarctic region. Besides Africa south of the tropic of Cancer, and its islands, it comprises the southern half of Arabia.

This region has been said to be identical in the main characters of its mammalian fauna with the Oriental region, and has therefore been united with it by Mr. A. Murray. Most important differences have however been overlooked, as the following summary of the peculiarities of the Ethiopian region will, I think, show.

It possesses 22 peculiar families of vertebrates; 90 peculiar genera of mammalia, being two-thirds of its whole number; and 179 peculiar genera of birds, being three-fifths of all it possesses. It is further characterized by the absence of several families and genera which range over the whole northern hemisphere, details of which will be found in the chapter treating of the region. There are, it is true, many points of resemblance, not to be wondered at between two tropical regions in the same hemisphere, and which have evidently been at one time more nearly connected, both by intervening lands and by a different condition of the lands that even now connect them. But these resemblances only render the differences more remarkable; since they show that there has been an ancient and long-continued separation of the two regions, developing a distinct fauna in each, and establishing marked specialities which the temporary intercommunication and immigration has not sufficed to remove. The entire absence of such wide-spread groups as bears and deer, from a country many parts of which are well adapted to them, and in close proximity to regions where they abound, would alone mark out the Ethiopian region as one of the primary divisions of the earth, even if it possessed a less number than it actually does of peculiar family and generic groups.

Sub-divisions of the Ethiopian Region.-The African continent south of the tropic of Cancer is more homogeneous in its prominent and superficial zoological features than most of the other regions, but there are nevertheless important and deep- 
seated local peculiarities. Two portions can be marked off as possessing many peculiar forms; the luxuriant forest district of equatorial West Africa, and the southern extremity or Cape district. The remaining portion has 110 well-rnarked divisions, and a large proportion of its animal forms range over it from Nubia and Abyssinia, to Senegal on the one side and to the Zambesi on the other; this forms our first or East-African sub-region.

The second, or West African sub-region extends along the coast from Senegal to Angola, and inland to the sources of the Shary and the Congo.

The third, or South African sub-region, comprises the Cape Colony and Natal, and is roughly limited by a line from Delagoa Bay to Walvish Bay.

The fourth, or Malagasy sub-region, consists of Madagascar and the adjacent islands, from Rodriguez to the Seychelles; and this differs so remarkably from the continent that it has been proposed to form a distinct primary region for its reception. Its productions are indeed highly interesting; since it possesses 3 families, and 2 sub-families of mammals peculiar to itself, while almost all its genera are peculiar. Of these a few show Oriental or Ethiopian affinities, but the remainder are quite isolated. Turning to other classes of animals, we find that the birds are almost as remarkable; but, as might be expected, a larger number of genera are common to surrounding countries. More than 30 genera are altogether peculial, and some of these are so isolated as to require to be classed in separate families or sub-families. The African affinity is however here more strongly shown by the considerable number (13) of peculiar Ethiopian genera which in Madagascar have representative species. There can be no doubt therefore about Madagascar being more nearly related to the Ethiopian than to any other region; but its peculiarities are so great, that, were it not for its small size and the limited extent of its fauna, its claim to rank as a separate region might not seem unreasonable. It is true that it is not poorer in mammals than Australia; but that country is far more isolated, and cannot be so decidedly and 
naturally associated with any other region as Madagascar can be with the Ethiopian. It is therefore the better and more natural course to keep it as a sub-region; the peculiarities it exhibits being of exactly the same kind as those presented by the Antilles, by New Zealand, and even by Celebes and Ceylon, but in a much greater degree.

Oriental Region.-On account of the numerous objections that have been made to naming a region from the least characteristic portion of it, and not thinking "Malayan," proposed by Mr. Blanford, a good term, (as it has a very circumscribed and definite meaning, and especially because the "Malay" archipelago is half of it in the Australian region,) I propose to use the word "Oriental " instead of "Indian," as being geographically applicable to the whole of the countries included in the region and to very few beyond it; as being euphonious, and as being free from all confusion with terms already used in zoological geography. I trust therefore that it may meet with general acceptance.

This small, compact, but rich and varied reyion, consists of all India and China from the limits of the Palæarctic region; all the Malay peninsula and islands as far east as Java and Baly, Borneo and the Philippine Islands; and Formosa. It is positively characterized by possessing 12 peculiar families of vertebrata; by 55 genera of land mammalia, and 165 genera of land birds, altogether confined to it; these peculiar genera forming in each case about one half of the total number it possesses.

Sub-divisions of the Oriental region.-First we have the Indian sub-region, consisting of Central India from the foot of the Himalayas in the west, and south of the Ganges to the east, as far as a line drawn from Goa curving south and up to the Kistna river; this is the portion which has most affinity
with Africa.

The second, or Ceylonese sub-region, consists of the southern extremity of India with Ceylon; this is a mountainous forest region, and possesses several peculiar forms as well as some Malayan types not found in the first sub-region. 
Next we have the Indo-Chinese sub-rexrion, comprising South China and Burmah, extending westward along the Ilimalayan range to an altitude of about 9,000 or 10,000 feet, and southward to Tavoy or Tenasserim.

The last is the Indo-Malayan sub-region, comprising the Teninsula of Malacca and the Malay Islands to Baly, Burneo, and the Philippines.

On account of the absence from the first sub-region of many of the forms most characteristic of the other three, and the numiver of families and genera of mammalia and birds which occur in it and also in Africa, it has been thought by some naturalists that this part of India has at least an equal claim to be classed as a part of the Ethiopian region. This question will be found fully discussed in Chapter XII. devoted to the Oriental region, where it is shown that the African affinity is far less than has leen represented, and that in all its essential features Central India is wholly Oriental in its fauna.

Before leaving this region a few words may be said about Lemuria, a name proposed by Mr. Sclater for the site of a supposed submerged continent extending from Madagascar to Ceylou and Sumatra, in which the Lemuroid type of animals was developed. This is undoubtedly a legitimate and highly probable supposition, and it is an example of the way in which a study of the geographical distribution of animals may enable us to reconstruct the geography of a bygone age. But we must not, as Mr. Blyth proposed, make this hypothetical land one of our actual ZooIngical regions. It represents what was probably a primary Zoological region in some past geological epoch; but what that epoch was and what were the limits of the region in question, we are quite unable to say. If we are to suppose that it comprised the whole area now inhabited by Lemuroid animals, we must make it extend from West Africa to Burmah, South China, and Celebes; an area which it possibly did once occupy, but which cannot be formed into a modern Zoological region without violating much more important affinities. If, on the other hand, we leave out all those areas which undoubtedly belong to other regions, we reduce I.emuria to Madagascar and its adjacent 
islands, which, for reasons already stated, it is not advisable to treat as a primary Zoological region. The theory of this ancient continent and the light it may throw on existing anomalies of distribution, will be more fully considered in the geographical part of this work.

Australian Region.-Mr. Sclater's original name seems preferable to Professor Huxley's, "Austral-Asian;" the inconvenience of which alteration is sufficiently shown by the fact that Mr. Blyth proposed to use the very same term as an appropriate substitute for the "Indian region" of Mr. Sclater. Australia is the great central mass of the region; it is by far the richest in varied and highly remarkable forms of life; and it therefore seems in every way fitted to give a name to the region of which it is the essential element. The limits of this region in the Pacific are somewhat obscure, but as so many of the Pacific Islands are extremely poor zoologically, this is not of great importance.

Sub-divisions of the Australian Region.-The first sub-region is the Austro-Malayan, including the islands from Celebes and Lombock on the west to the Solomon Islands on the east. The Australian sub-region comes next, consisting of Australia and Tasmania. The third, or Polynesian sub-region, will consist of all the tropical Pacific Islands, and is characterized by several peculiar genera of birds which are all allied to Australian types. The fourth, consists of New Zealand with Auckland, Chatham, and Norfolk Islands, and must be called the New Zealand sub-region.

The extreme peculiarities of New Zealand, due no doubt to its great isolation and to its being the remains of a more extensive land, have induced several naturalists to suggest that it ought justly to form a Zoological region by itself. But the inconveniences of such a procedure have been already pointed out; and when we look at its birds as a whole (they being the only class sufficiently well represented to found any conclusion upon) we find that the majority of them belong to Australian genera, and where the genera are peculiar they are most nearly related to Australian types. The preservation in these islands 
of a single representative of a unique order of reptiles, is, as before remarked, of the same character as the preservation of the Proteus in the caverns of Carniola ; and can give the locality where it happens to have survived no claim to form a primary Zoological region, unless supported by a tolerably varied and distinctly characterized fuuna, such as never exists in a very restricted and insular area.

Neotropical Region.-Mr. Sclater's original name for this region is preserved, because change of nomenclature is always an evil; and neither Professor Huxley's suggested alteration "Austro-Columbia," nor Mr. Sclater's new term "Dendrogæa," appear to be improvements. The region is essentially a tropical one, and the extra-tropical portion of it is not important enough to make the name inappropriate. That proposed by Professor Huxley is not free from the same kind of criticism, since it would imply that the region was exclusively South American, whereas a considerable tract of North America belongs to it. This region includes South America, the Antilles and tropical North America; and it possesses more peculiar families of vertebrates and genera of birds and mammalia than any other region.

Subdivisions of the Neotropical Region.-The great central mass of South America, from the shores of Venezuela to Paraguay and Eastern Peru, constitutes the chief division, and may be termed the Brazilian sub-region. It is on the whole a forest country; its most remarkable forms are highly developed arboreal types; and it exhibits all the characteristics of this rich and varied continent in their highest development.

The second, or Chilian sub-region, consists of the open plains, pampas, and mountains of the southern extremity of the continent; and we must include in it the west side of the Andes as far as the limits of the forest near Payta, and the whole of the high Andean plateaus as far as $4^{\circ}$ of south latitude; which makes it coincide with the range of the Camelidæ and Chinchillidæ.

The third, or Mexican sub-region, consists of Central America and Southern Mexico, but it has no distinguishing character- 
istics except the absence of some of the more highly specialized Neotropical groups. It is, however, a convenient division as comprising the portion of the North American continent which belongs zoologically to South America.

The fourth, or Antillean sub-region, consists of the West India islands (except Trinidad and Tobago, which are detached portions of the continent and must be grouped in the first subregion); and these reproduce, in a much less marked degree, the phenomena presented by Madagascar. Terrestrial mammals are almost entirely wanting, but the larger islands possess three genera which are altogether peculiar to them. The birds are of South American forms, but comprise many peculiar genera. Terrestrial molluscs are more abundant and varied than in any part of the globe of equal extent; and if these alone were considered, the Antilles would constitute an important Zoological region.

Nearctic Region.-This region comprises all temperate North America and Greenland. The arctic lands and islands beyond the limit of trees form a transitional territory to the Palæarctic region, but even here there are some characteristic species. The southern limit between this region and the Neotropical is a little uncertain; but it may be drawn at about the Rio Grande del Norte on the east coast, and a little north of Mazatlan on the west; while on the central plateau it descends much farther south, and should perhaps include all the open highlands of Mexico and Guatemala. This would coincide with the range of several characteristic Nearctic genera.

Distinction of the Nearctic from the Palocarctic Region.-The Nearctic region possesses twelve peculiar families of vertebrates or one-tenth of its whole number. It has also twenty-four peculiar genera of mammalia and fifty-two of birds, in each case nearly one-third of all it possesses. This proportion is very nearly the same as in the Palæarctic region, while the number of peculiar families of vertebrata is very much greater. It has been already seen that both Mr. Blyth and Professor Huxley are disposed to unite this region with the Palæarctic, while Professor Newton, in his article on birds in the new edition of the 
Encyclopredia Britamnica, thinks that as regards that class it can hardly claim to be more than a sub-region of the Neotropical. These views are mutually destructive, but it will be shown in the proper place, that on independent grounds the Nearctic region can very properly be maintained.

Subdivisions of the Nearctic Region.-The sub-regions here depend on the great physical features of the country, and have been in some cases accurately defined by American naturalists. First we have the Californian sub-region, consisting of California and Oregon-a narrow tract between the Sierra Nevada and the Pacific, but characterized by a number of peculiar species and by several genera found nowhere else in the region.

The second, or Rocky Mountain sub-region, consists of this great mountain range with its plateaus, and the central plains and prairies to about $100^{\circ}$ west longitude, but including New Mexico and Texas in the South.

The third and most important sub-region, which may be termed the Alleghanian, extends eastward to the Atlantic, including the Mississippi Valley, the Alleghany Mountains, and the Eastern United States. This is an old forest district, and contains most of the characteristic animal types of the region.

The fourth, or Canadian sub-region, comprises all the northern part of the continent from the great lakes to the Arctic ocean; a land of pine-forests and barren wastes, characterized by Arctic types and the absence of many of the genera which distinguish the more southern portions of the region.

Observations on the series of Sub-regions. - The twenty-four subregions here adopted were arrived at by a careful consideration of the distribution of the more important genera, and of the materials, both zoological and geographical, available for their determination; and it was not till they were almost finally decided on, that they were found to be equal in number throughout all the regions-four in each. As this uniformity is of great advantage in tabular and diagrammatic presentations of the distribution of the several families, I decided not to disturb it unless very strong reasons should appear for adopting a greater or less number in any particular case. Such however have not 
arisen; and it is hoped that these divisions will prove as satisfactory and useful to naturalists in general as they have been to the author. Of course, in a detailed study of any region much more minute sub-division may be required; but even in that case it is believed that the sub-regions here adopted, will be found, with slight modifications, permanently available for exhibiting general results.

I give here a table showing the proportionate richness and speciality of each region as determined by its families of vertebrates and genera of mammalia and birds; and also a general table of the regions and sub-regions, arranged in the order that seems best to show their mutual relations.

Comparative Richness of the Six Regions.

\begin{tabular}{|c|c|c|c|c|c|c|c|c|}
\hline \multirow{2}{*}{ REGIONs. } & \multicolumn{2}{|c|}{ Vertebrata. } & \multicolumn{3}{|c|}{ Mammatia. } & \multicolumn{3}{|c|}{ BirDs. } \\
\hline & $\begin{array}{l}\text { Fanui- } \\
\text { lies. }\end{array}$ & $\begin{array}{l}\text { Peculiar } \\
\text { families }\end{array}$ & Genera. & $\begin{array}{l}\text { Peculiar } \\
\text { genera. }\end{array}$ & $\begin{array}{c}\text { Per } \\
\text { centage }\end{array}$ & Genera. & $\begin{array}{l}\text { Peculiar } \\
\text { genera. }\end{array}$ & $\begin{array}{c}\mathrm{Per} \\
\text { centage }\end{array}$ \\
\hline Palæarctic... & 136 & 3 & 100 & 35 & 35 & 174 & 57 & 33 \\
\hline Ethiopian & 174 & 22 & 140 & 90 & 64 & 294 & 179 & 60 \\
\hline Oriental.. & $16 \pm$ & 12 & $\lfloor 18$ & 55 & 46 & 340 & 165 & 48 \\
\hline A ustralian. & 141 & 30 & 72 & 44 & 61 & 298 & 189 & 64 \\
\hline Neotropical. & 168 & 44 & 130 & 103 & 79 & 683 & 576 & 86 \\
\hline Nearctic ..... & 122 & 12 & 74 & 24 & 32 & 169 & 52 & 31 \\
\hline
\end{tabular}

Table of Regions and Sub-Regions.

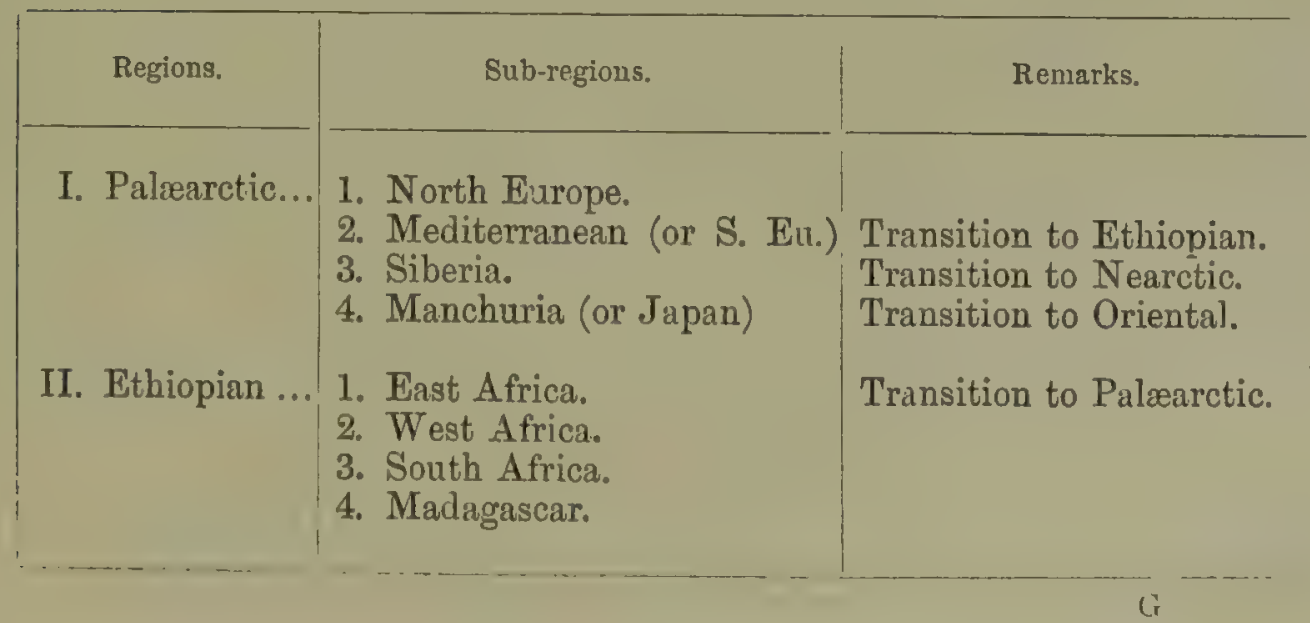


TABle of Regions and Sub-Reglons-continuerl.

\begin{tabular}{|c|c|c|}
\hline Regions. & Sub-regions. & Remarks, \\
\hline III. Oriental ...... & $\begin{array}{l}\text { 1. Hindostan (or Central Ind.) } \\
\text { 2. Ceylon. } \\
\text { 3. Indo-China (or Himalayas) } \\
\text { 4. Indo-Malaya. }\end{array}$ & $\begin{array}{l}\text { Transition to Ethiopian. } \\
\text { Transition to Palparctic. } \\
\text { Transition to Australian. }\end{array}$ \\
\hline IV. Australian... & $\begin{array}{l}\text { 1. Austro-Mulaya. } \\
\text { 2. Australia. } \\
\text { 3. Polynesia. } \\
\text { 4. New Zealand. }\end{array}$ & $\begin{array}{l}\text { Transition to Oriental. } \\
\text { Transition to Neotropical. }\end{array}$ \\
\hline V. Neotropical. & $\begin{array}{l}\text { 1. Chili (or S. Temp. Am.) } \\
\text { 2. Brazil. } \\
\text { 3. Mexico (or Trop. N. Am.) } \\
\text { 4. Antilles. }\end{array}$ & $\begin{array}{l}\text { Transition to Australian. } \\
\text { Transition to Nearctic. }\end{array}$ \\
\hline VI. Nearctic... & $\begin{array}{l}\text { 1. California. } \\
\text { 2. Rocky Mountains. } \\
\text { 3. Alleghanies (or East U.S.) } \\
\text { 4. Canada. }\end{array}$ & $\begin{array}{l}\text { Transition to Neotropical. } \\
\text { Transition to Palæarctic. }\end{array}$ \\
\hline
\end{tabular}




\section{CHAPTER V.}

CLASSIFICATION AS AFFECTING THE STUDY OF GEOGRAPIICAL DISTRIBUTION.

A LITTLE consideration will convince us, that no inquiry into the causes and laws which determine the geographical distribution of animals or plants can lead to satisfactory results, unless we have a tolerably accurate knowledge of the affinities of the several species, genera, and families to each other; in other words, we require a natural classification to work upon. Let us, for example, take three animals- $\alpha, b$, and $c$-which have a general external resemblance to each other, and are usually considered to be really allied; and let us suppose that $a$ and $b$ inhabit the same or adjacent districts, while $c$ is found far away on the other side of the globe, with no animals at all resembling it in any of the intervening countries. We should here have a difficult problem to solve; for we should have to show that the general laws by which we account for the main features of distribution, will explain this exceptional case. But now, suppose some comparative anatomist takes these animals in hand, and finds that the rescmblance of $c$ to $a$ and $b$ is only superficial, while their internal structure exhibits marked and important differences; and that $c$ really belongs to another group of animals, $d$, which inhabits the very region in which $c$ was found-and we should no longer have anything to explain. This is no imaginary case. Up to a very few years ago a curious Mexican animal, Bassaris astuta, was almost always classed in the civet family (Viverridr), a group entirely con- 
fined to Africa and Asia; but it has now been conclusively shown by Professor Flower that its real affinities are with the racoons (Procyonidre), a group confined to North and South America. In another case, however, an equally careful examination shows, that an animal peculiar to the Himalayas (Ailurus fulgens) has its nearest ally in the Cercoleptes of South America. Here, therefore, the geographical difficulty really exists, and any satisfactory theory of the causes that have led to the existing distribution of living things, must be able to account, more or less definitely, for this and other anomalies. From these cases it will be evident, that if any class or order of animals is very imperfectly known and its classification altogether artificial, it is useless to attempt to account for the anomalies its distribution may present; since those anomalies may be, to a great extent, due to false notions as to the affinities of its component species.

According to the laws and causes of distribution discussed in the preceding chapters, we should find limited and definell distribution to be the rule, universal or indefinite distribution to be the exception, in every natural group corresponding to what are usually regarded as families and genera; and so much is this the case in nature, that when we find a group of this nominal rank scattered as it were at random over the earth, we have a strong presumption that it is not natural; but is, to a considerable extent, a haphazard collection of species. Of course this reasoning will only apply, in cases where there are no unusual means of dispersal, nor any exceptional causes which might determine a scattered distribution.

From the considerations now adduced it becomes evident, that it is of the first importance for the success of our inquiry to secure a natural classification of animals, especially as regards the families and genera. The higher groups, such as classes and orders, are of less importance for our purpose; because they are almost always widely and often universally distributed, except those which are so small as to be evidently the nearly extinct representatives of a once more extensive series of forms. We now proceed to explain the classification to be adopited, as luw down as the suries of families. To these, equivilent English 
names are given wherever they exist, in order that readers possessing no technical knowledge, may form some conception of the meaning of the term "family" in zoology.

The primary divisions of the animal kingdom according to two eminent modern authorities are as follows :

\begin{tabular}{|c|c|c|c|c|}
\hline \multicolumn{2}{|c|}{$\begin{array}{l}\text { HuXLEY: } \\
\text { Classification of Animals (1869). }\end{array}$} & \multicolumn{3}{|c|}{$\begin{array}{l}\text { CARUS AND GERSTAEKER. } \\
\text { Handbuch der Zoologie (1868) }\end{array}$} \\
\hline & $\ldots$ & $\cdots$ & $\ldots$ & 1. Protozoa. \\
\hline $\begin{array}{l}\text { 3. Cœlenterata } \\
\text { 4. Annuloida }\end{array}$ & $\ldots$ & & & $\begin{array}{l}\text { 2. Coelenterata. } \\
\text { 3. Echinodermata. }\end{array}$ \\
\hline 5. Annulosa & & & & \\
\hline $\begin{array}{l}\text { 6. Molluscoida } \\
\text { 7. Mollusca } \\
\text { 8. Vertebrata }\end{array}$ & $\begin{array}{l}\cdots \\
\cdots \\
\cdots\end{array}$ & & $\begin{array}{l}\cdots \\
\cdots\end{array}$ & $\begin{array}{l}\text { 6. Molluscoida. } \\
\text { 7. Mollusca. } \\
\text { 8. Vertebrata. }\end{array}$ \\
\hline
\end{tabular}

For reasons already stated it is only with the fifth, seventh, and eighth of these groups that the present work proposes to deal; and even with the fifth and seventh only partially and in the most general way.

The classes of the vertebrata, according to both the authors above quoted, are: 1. Mammalia. 2. Aves. 3. Reptilia. 4. Amphibia. 5. Pisces, in which order they will be taken here.

The sub-classes and orders of mammalia are as follows:

\section{MAMMALIA.}

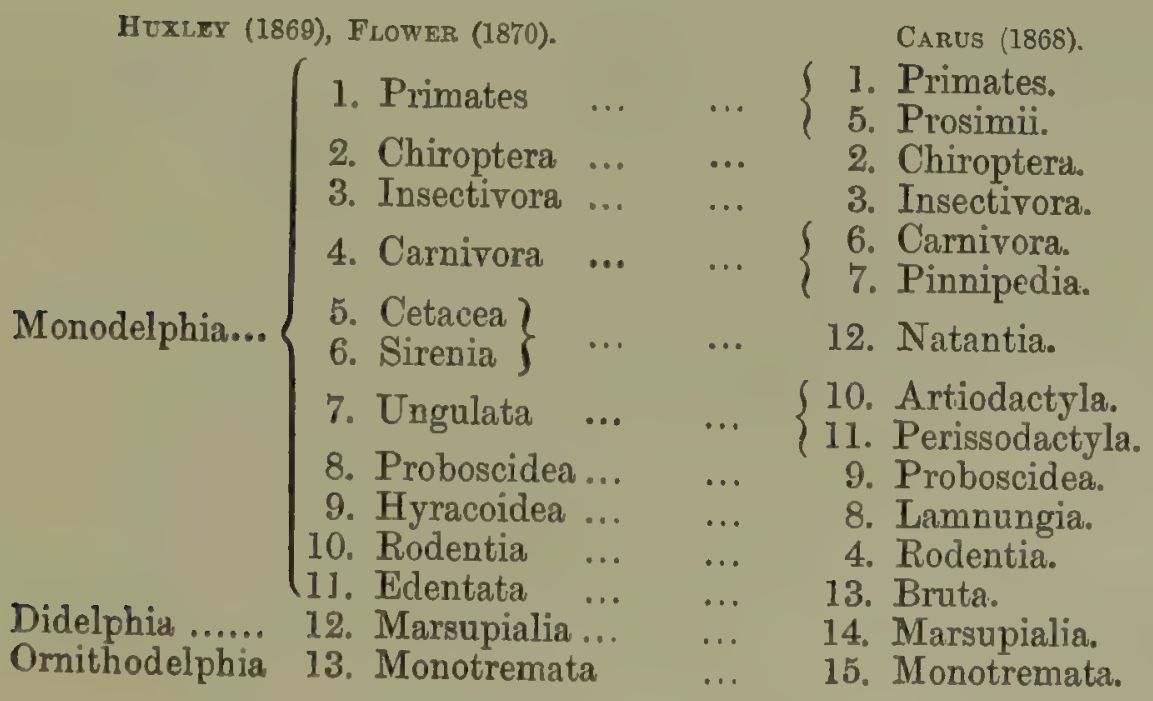


The above series of orters is armanged according to Professor Flower's Ostcology of Menmalin, and they will follow in this succession throughout my work. Professor IIuxley arranges the same orders in a different series.

In determining the manner in which the several orders shall be subdivided into families, I have been guider in my choice of classifications mainly by the degree of attention the author appaars to have paid to the group, and his known ability as a systematic zoclogist; and in a less degrec by considerations of convenience as regards the special purposes of geographical distribution. In many cases it is a matter of great doubt whether a certain group should form several distinct families or be united into one or two; but one method may bring out the peculiarities of distribution much better than the other, and this is, in our case, a sufficient reason for adopting it.

For the Primates I follow, with some modifications, the classification of Mr. St. George Mivart given in his article "Apes" in the new edition of the Encyclopoctia Britannica, and in his paper in the Proceedings of the Zoological Society of London, $1865, \mathrm{p} .547$. It is as follows:

Order-PRIMATES, divided into two Sub-orders :

I. Anthropoidea.

II. Lemuroidea.

Sub-order-ANTUROPOIDEA. Hominidæ ... ... Man.

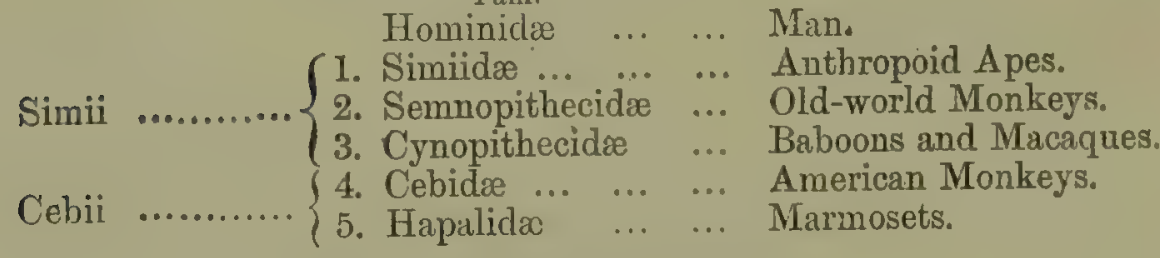

Sub-order- LEMURoideA.

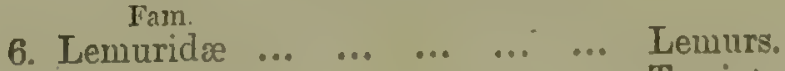

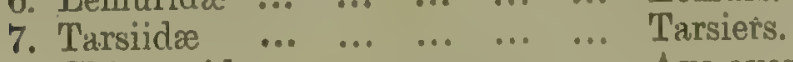

8. Chiromyidæ $\quad \ldots \quad \ldots \quad \ldots \quad \ldots$ Aye-ayes.

Omitting man (for reasons stated in the preface) the three first families are considered by Professor Mivart to be subfamilies of Simiidæ; but as the geographical distribution of the Old World apes is especially interesting, it is thought 
better to treat them as families, a rank which is claimed for the anthropoid apes by many naturalists.

As no good systematic work on the genera and species of bats has been yet published, I adopt the five families as generally used in this country, with the genera as given in the papers of Jr. J. E. Gray and Mr. Tomes. A monograph by Dr. Peters has long been promised, and his outline arrangement was published in 1865 , but this will perhaps be materially altered when the work appears.

\section{Order-CHIROPTERA.}

Frugivora $\left\{\begin{array}{l}\text { Instiophora } \\ \text { Gymnorhini }\end{array} \quad\left\{\begin{array}{lll}\text { 10. Phyllostomidæ } & \ldots & \text { Fruit-eating Bats. } \\ \text { 11. Rhinolophidæ } & \ldots & \text { Leaf-nosed Bats. } \\ \text { 12. Vespertilionidæe } & \ldots & \text { Horse-shoe Bats. } \\ \text { 13. Noctilionidæ } & \ldots & \text { True Bats. }\end{array}\right.\right.$

'The genera of Chiroptera are in a state of great confusion, the names used by different authors being often not at all comparable, so that the few details given of the distribution of the bats are not trustworthy. We have therefore made little use of this order in the theoretical part of the work.

The osteology of the Insectivora has been very carefully worked out by Professor Mivart in the Jounral of Anatomy and Physiology (Vol. ii., p. 380), and I follow his classification as given there, and in the Froccedings of the Zoological Society (1871).

\section{Fam. Order-INSECTIVORA.}

14. Galeopithecidæe

15.

16. Tuphant Shrews.

17. $\begin{array}{llllll}\text { 17. } & & & & & \\ \text { 18. }\end{array}$

18. Centetidæ $\quad \ldots . \quad \ldots \quad \ldots$ Hedgehogs.

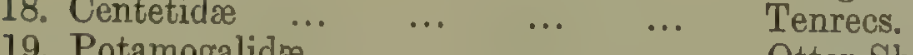

19. Potamogalidæ $\quad \ldots \quad \ldots \quad$... $\quad$ Otter Shrew.

20. Chrysochloridx $\quad \ldots \quad \ldots . \quad \ldots$ Golden Moles.

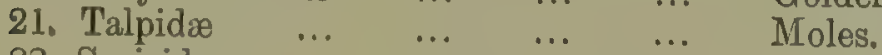

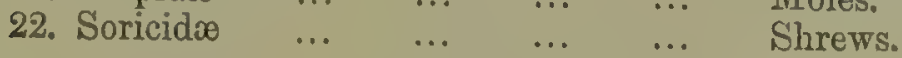

The next order, Carnivora, has been studied in detail by Professor Flower; and I adopt the classification given by him in the Proceedings of the Zoological Society, 1869, p. 4. 


\section{Orier-CidRiJVOR.A.}

\begin{tabular}{|c|c|c|c|c|}
\hline & & ratu. & & \\
\hline & & 23. Felidx & & Cats, Lion, \&c. \\
\hline & Flurnico & 24. Cryptoproctidx & & Cryptoprocta. \\
\hline & 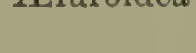 & 26. Frotelidxe & $\begin{array}{l}\cdots \\
\cdots\end{array}$ & Aard-wolf. \\
\hline sipedia? & & (27. Iyxnidxo & . & Hyænas. \\
\hline sipentas & Cynoidea & 28. Canidre ... & $\ldots$ & Dogs, Foxes, \&c. \\
\hline & & $\begin{array}{l}\text { 29. Mustelidie } \\
\text { 30. Procyonidx }\end{array}$ & $\begin{array}{l}\cdots \\
\cdots\end{array}$ & $\begin{array}{l}\text { Weasels. } \\
\text { Racoons. }\end{array}$ \\
\hline & Arctoldea & 31. AEluridx... & & Pandas. \\
\hline & & (32. Ursidæ ... & . & Bears. \\
\hline nnipedia & & 34. Trichechidær & & Walrus. \\
\hline & & 35. Phocidæ.... & & Sople \\
\hline
\end{tabular}

The Cetacea is one of those orders the classification of which is very unsettled. The animals comprising it are so huge, and there is so much difficulty in preserving them, that only a very few species are known with anything like completeness. A considerable number of genera and species have been described or indicated; but as many of these are founded on imperfect specimens of perhaps a single individual, it is not to be wondered at that those few naturalists who occupy themselves with the study of these large animals, cannot agree as to the proper mode of grouping them into natural families. They are, however, of but little importance to us, as almost all the species inhabit the ocean, and of only a few of them can it be said that anything is accurately known of their distribution. I therefore consider it best to follow Professor Carus, who makes a smaller number of families; but I give also the arrangement of Dr. Gray in his British Museum catalogue of whales and seals, as modified subsequently in the Proceedings of Zoological Society, 1870, p. 772. The Zeuglodontidæ, a family of extinct tertiary whales, are classed by Professors Owen and Carus between Cetacea and Sirenia, while Professor Huxley considers them to have been carnivorous and allied to the seals. 


\section{Order-CETACEA.}

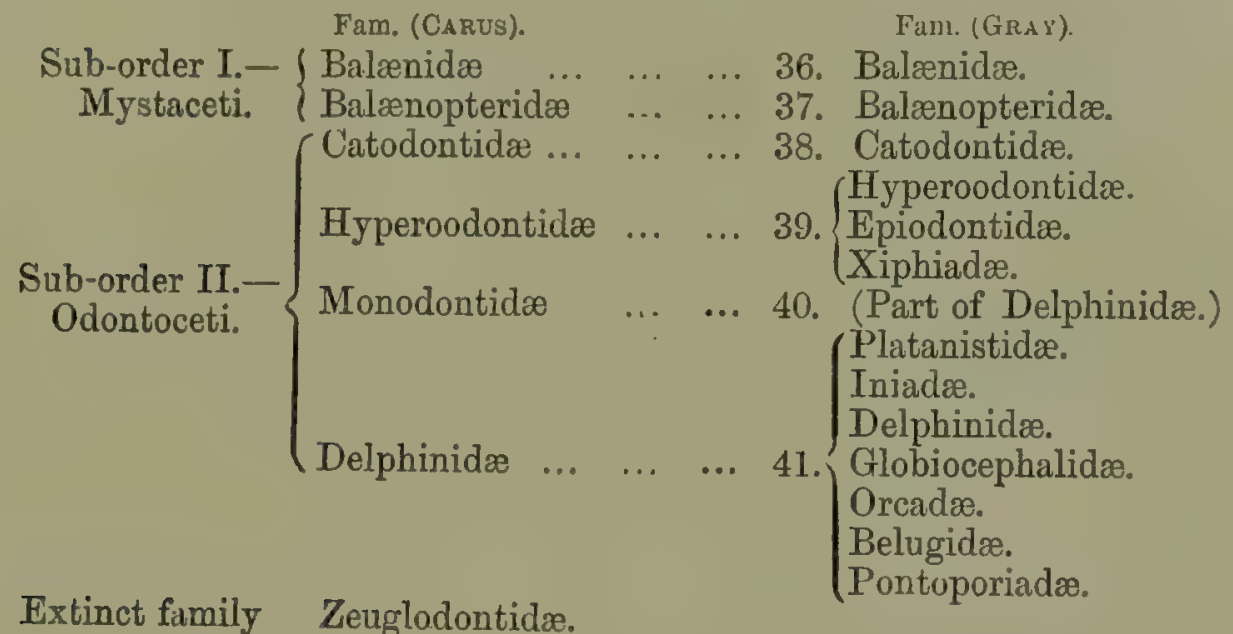

\section{Order-SIRENIA.}

The order Sirenia, comprising the sea-cows, consists of a single family:

\section{Family 42, Manatidæ.}

The extensive order Ungulata comprises the three orders Pachydermata, Solidungula, and Ruminantia of the older naturalists. The following classification is that now generally adopted, the only difference of opinion being as to whether some of the groups should be classed as families or sub-families, a matter of little importance for our purpose:

\section{Order-UNGULATA.}

Fam.

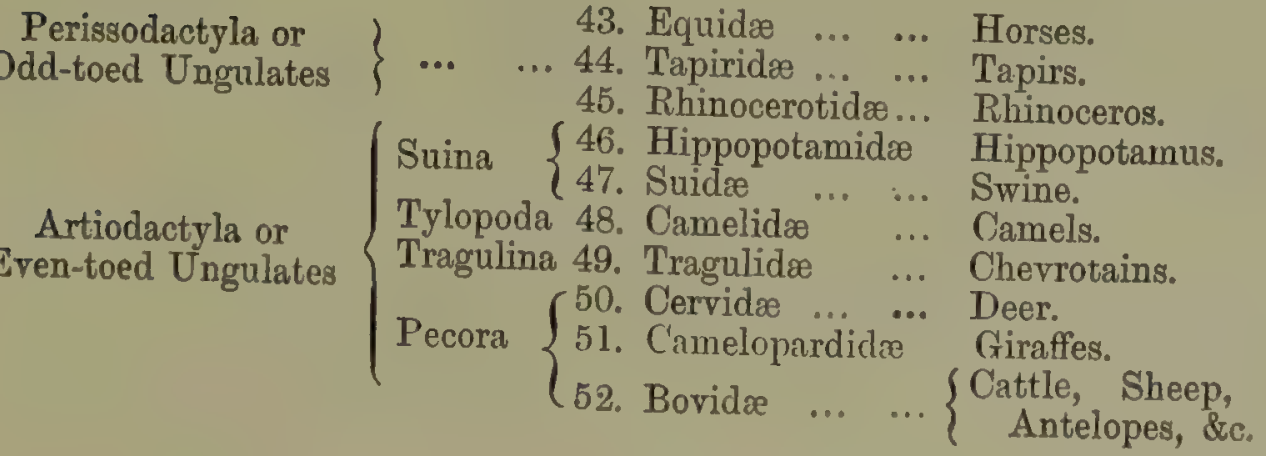


The two next orders consist of but a single family cach, viz.

\begin{tabular}{llllll}
\multicolumn{1}{c}{ Orier } & \multicolumn{5}{c}{ Fan. } \\
PROBOSCIDEA & $\ldots$ & 53. Elephantidæ & $\ldots$ & $\ldots$ & Elephants. \\
HYRACOIDEA & $\ldots$ & 54. Hyracidø & $\ldots$ & $\ldots$ & Rock-rabbits.
\end{tabular}

We now come to the Rodentia, a very extensive and difficult order, in which there is still much difference of opinion as to the details of classification, although the main outlines are pretty well settled. The foundations of a true classification of this order were laid by MIr. G. R. Waterhouse more than thirty years ago, and succeeding authors have done little more than follow his arrangement with unimportant modifications. Professor Lilljeborg, of Upsala, has however made a special study of this group of animals, and has given an original and detailed classification of all the genera. (Systematisk Öfversigt af de Gnagande Däggdjuren, Glires. Upsala, 1866.) I follow this arrangement with a few slight modifications suggested by other naturalists, and which make it better adapted for the purposes of this work.

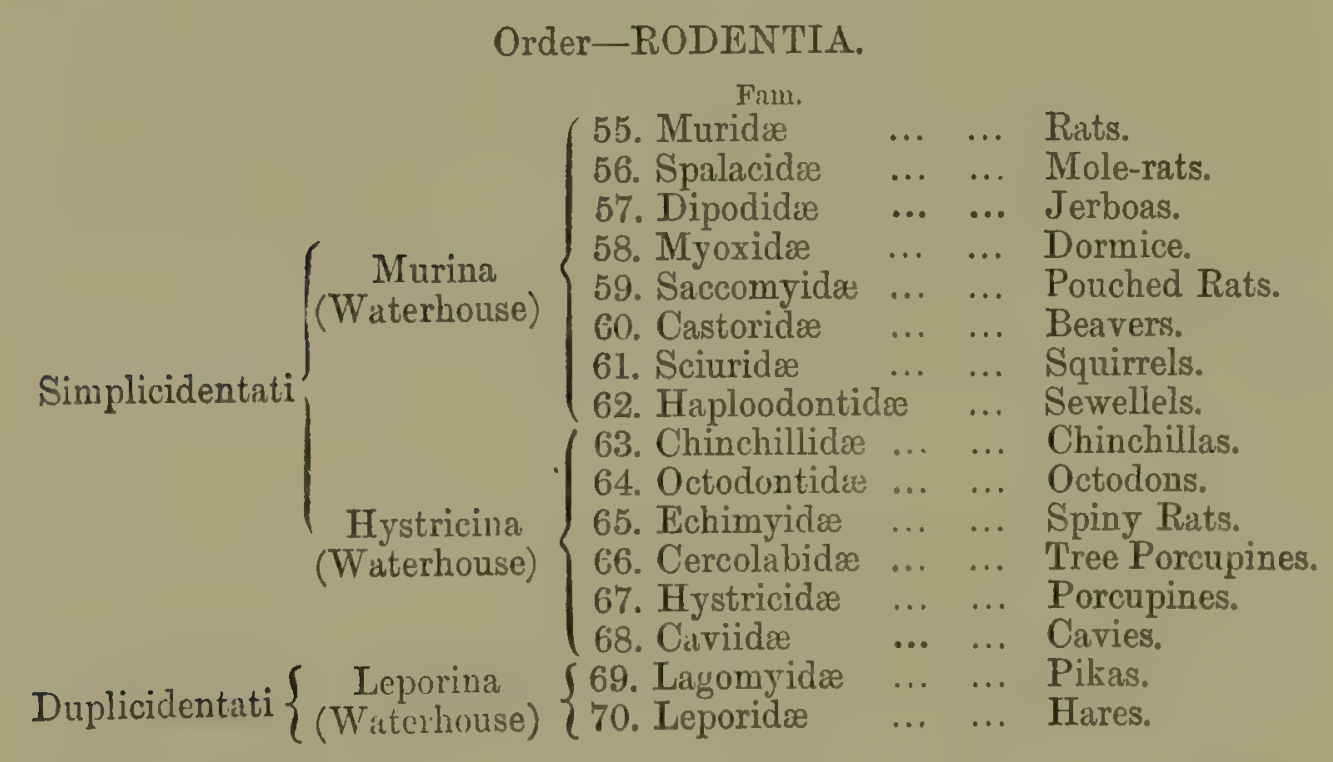

The Edentata have been classified by Mr. Turner, in the Procecdings of the Zoological Society (1851, p. 205), by Dr. Gray in the British Museum Catalogue, and by Professor Carus in his Handbuch. The former takes a middle course between 
the numerous fimilies of Dr. Gray, seven in number, and the two families to which Professor Carus restricts the existing species. I therefore follow Mr. Turner.

Order-EDENTA'TA.

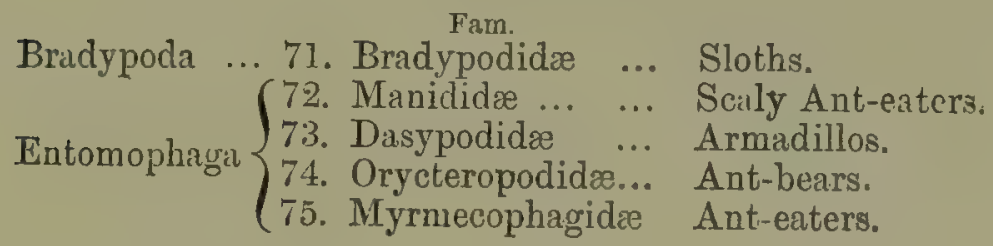

The Marsupials have been well classified and described by Mr. Waterhouse in the first volume of his Natural History of Mammalia, and his arrangement is here followed. The suborders adopted by Professor Carus are also given.

\section{Order-MARSUPIALIA.}

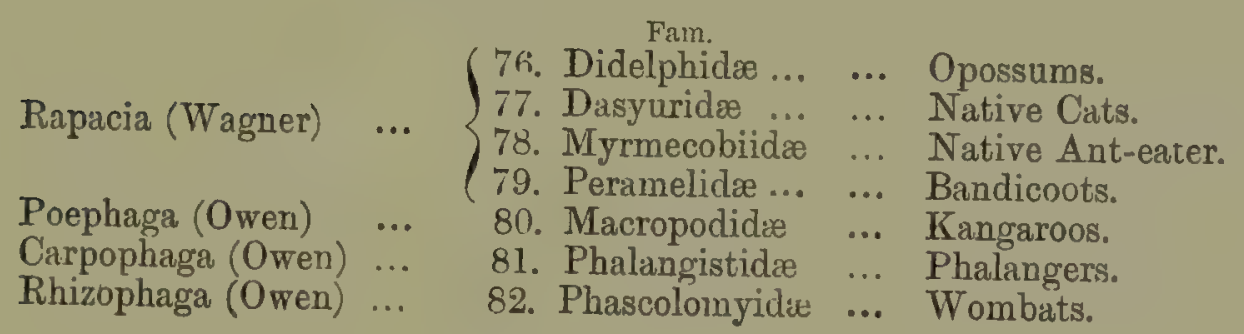

\section{Order-MONOTREMATA.}

The last order, the Monotremata, consist of two families, which Professor Carus combines into one, but which it seems more natural to keep separate.

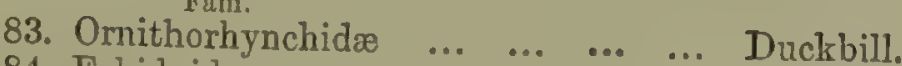

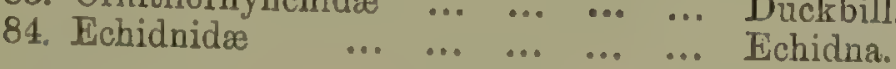




\section{BIRISS.}

Birds are perhaps the most difficult to classify of all the divisions of the vertebrata. The species and genera are exceedingly numerous, and there is such a great uniformity in general structure and even in the details of external form, that it is exceedingly difficult to find characters by which orders and families can be characterised. For a long time the system of Vigors and Swainson was followed; but this wholly ignored anatomical characters and in many cases plainly violated wellmarked affinities. Characters derived from the form of the sternum, the scutellation of the tarsi, and the arrangement of the feathers, have all assisted in determining natural groups. More recently Professor Huxley has applied the variations of the bony palate to the general arrangement of birds; and still more recently Professor Garrod has studied certain leg-muscles for the same purpose. The condition of the young as regards plumage, and even the form, texture, and coloration of the egg, have also been applied to solve doubtful cases of affinity; yet the problem is not settled, and it will probably remain for another generation of ornithologists to determine with any approach to accuracy what are the most natural divisions of the class into orders and families. In a work like the present it is evidently not advisable to adopt all the recent classifications; since experience has shown that no arrangement in which one set of characters is mainly relied on, long holds its ground. Such modifications of the old system as seem to be well established will be adopted; but the older groups will be adhered to in cases where the most recent classifications are open. to doubt, or seem inconvenient as separating families, which, owing to their similarity in general structure, form and habits are best kept together for the purposes of geographical distribution.

The old plan of putting the birds of prey at the head of the class, is now almost wholly given up; both because they are not 
the most highly organised, but only one of the most specialised forms of birds, and because their affinities are not with the Passeres, but rather with the cormorants and some other of the aquatic groups. The Passeres therefore are placed first; and the series of families is begun by the thrushes, which are certainly the most typical and generally well-organised form of birds. Instead of the Scansores and Fissirostres of the older authors, the orler Picarie, which includes them both, is adopted, but with some reluctance; as the former are, generally speaking, well marked and strougly contrasted groups, although certain families have been shown to be intermediate. In the Picariæ are included the goat-suckers, swifts, and humming-birds, sometimes separated as a distinct order, Macrochires. The parrots and the pigeons form each a separate order. The old groups of Grallæ and Anseres are preserved, as more convenient than breaking them up into widely separated parts; for though the latter plan may in some cases more strictly represent their affinities, its details are not yet established, nor is it much used by ornithologists. In accordance with these views the following is the series of rders and families of birds adopted in this work:

Orders.

Class-AVES.

1. Passeres ... \{ Including the greit mass of the smaller birds-Crows,

2. Picaria $\left\{\begin{array}{c}\text { Finches, Flycatchers, Creepers, Honeysuckers, \&c., \&c. } \\ \text { Including Woodpeckers, Cuctroo, Ton }\end{array}\right.$

2. Picaria $\cdots\left\{\begin{array}{l}\text { Including } \\ \text { Swifts, \&c., \&c. }\end{array}\right.$

3. Psittaci … Parrots only.

4. Columbre ... Pigeons and the Dodo.

5. Gallinæ … Grouse, Pheassants, Curassows, Mound-builders, \&c.
6. Opisthocomi The Hocco only.

7. Accipitres … Eagles, Owls, and Vultures.

8. Grallœ … Herons, Plovers, Rails, \&c.

9. Anseres $\quad \ldots$ Gulls, Ducks, Divers, \&c

10. Struthiones ... Ostrich, Cassowary, Apteryx, \&c.

The Passeres consist of fifty families, which may be arranged and grouped in series as follows. It must however be remembered that the first family in each series is not always that which is most allied to the last family of the preceding series. All extensive natural groups consist of divergent or branching alliances, which renders it impossible to arrange the whule in one continuous series. 


\section{A. - Typical or turdord Passeres.}

1. Turdida

2. Sylviidæ

Thrushes.

3. Timaliidx

4. Panuridæ

Warlilers.

5. Cinclida

6. Troylodytido

7. Chameida

8. Certhiidre

9. Sittidæ

10. Paridæ

11. Liotrichida

12. Phyllornithidxe.

13. Pycnonotidæ

14. Oriolidx

15. Campephagidæ .

16. Dicrurid $x$

17. Muscicapidæe ... $\ldots$

18. Pachycephalidæ $\ldots$...

19. Laniidæ

20. Corvidæ

21. Paradiseida

22. Meliphagidæ $\ldots \quad$...

23. Nectarineid $\approx$...

\section{B.-Tayagroid Passeres.}

24. Dicæidæ

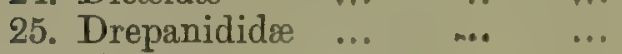

26. Cærebidæ $\quad \ldots \quad \ldots, \quad \ldots$

27. Mniotiltidæ $\quad \ldots \quad \ldots \quad \ldots$

28. Vireonidæ $\quad \ldots \quad \ldots, \quad \ldots$

29, Ampelidø $\ldots \quad \ldots . \quad \ldots$

30. Hirundinidæ $\ldots \quad \ldots$....

31. Icteridæ $\ldots \quad \ldots \quad \ldots$

32. Tanagridæ $\quad \ldots \quad \ldots \ldots$ Hangnests

33. Fringillidæ $\ldots \quad \ldots \quad \ldots$ Finches.

\section{C.-Sturnoid Passeres.}

34. Ploceidæ

35. Sturnidæ

36. Artamidæ

37. Alaudidæ

38. Motacillidæ

$\begin{array}{cccl}\ldots & \ldots & \ldots & \text { Weaver-birds. } \\ \ldots & \ldots & \ldots & \text { Starlings. } \\ \ldots & \ldots & \ldots & \text { Swallow-shrikes. } \\ \ldots & \ldots & \ldots & \text { Larks. } \\ \ldots & \ldots & \ldots & \text { Wagtails. }\end{array}$

\section{D.-Formicaroid Passeres.}

39. Tyrannidø

40. Pipridæ

41. Cotingidro

42. Phytotomidø

43. Eurylæmidæ

44. Dendrocolaptidr

45. Formicariida
... ... ... Tyrants.

$\begin{array}{llll}\ldots & \ldots & \ldots & \text { Tyrants. } \\ \ldots & \ldots & \ldots & \text { Manakins. }\end{array}$

$\begin{array}{llll}\ldots & \ldots & \ldots & \text { Manakins. } \\ \ldots & \ldots & \ldots & \text { Chatterers. }\end{array}$

... $\quad . . \quad$.. $\quad$ Plant-cutters.

.. $\quad \ldots \quad$... $\quad$ Broad-bills.

... $\quad$... $\quad$ American Creepers.

Ant-thrushes. 


$$
\text { D.-Formicaroid Passeres-continued. }
$$

46. Pteroptochidx

47. Pittidæ

48. Paictidæ

$$
\begin{array}{llll}
\cdots & \cdots & \cdots & \\
\cdots & \cdots & \cdots & \text { Pittas. }
\end{array}
$$

$$
\text { E.-Anomalous Passeres. }
$$

49. Menuridæ

50. Atrichidæ

$$
\begin{array}{cccc}
\ldots & \ldots & \ldots & \text { Lyre-birds. } \\
\ldots & \ldots & \ldots & \text { Scrub-birds. }
\end{array}
$$

The preceding arrangement is a modification of that proposed by myself in the Ibis (1874, p. 406). The principal alterations are adding the families Panuridæ and Sittidæ in series A, commencing series B with Dicæidæ; bringing Vireonidæ next to the allied American family Mniotiltidæ; and placing Motacillidæ in series C next to Alaudidæ. At the suggestion of Professor Newton I place Menuridæ and Atrichidæ apart from the other Passercs, as they both possess striking peculiarities of anatomical structure.

The heterogeneous families constituting the order Picariæ may be conveniently arranged as follows:

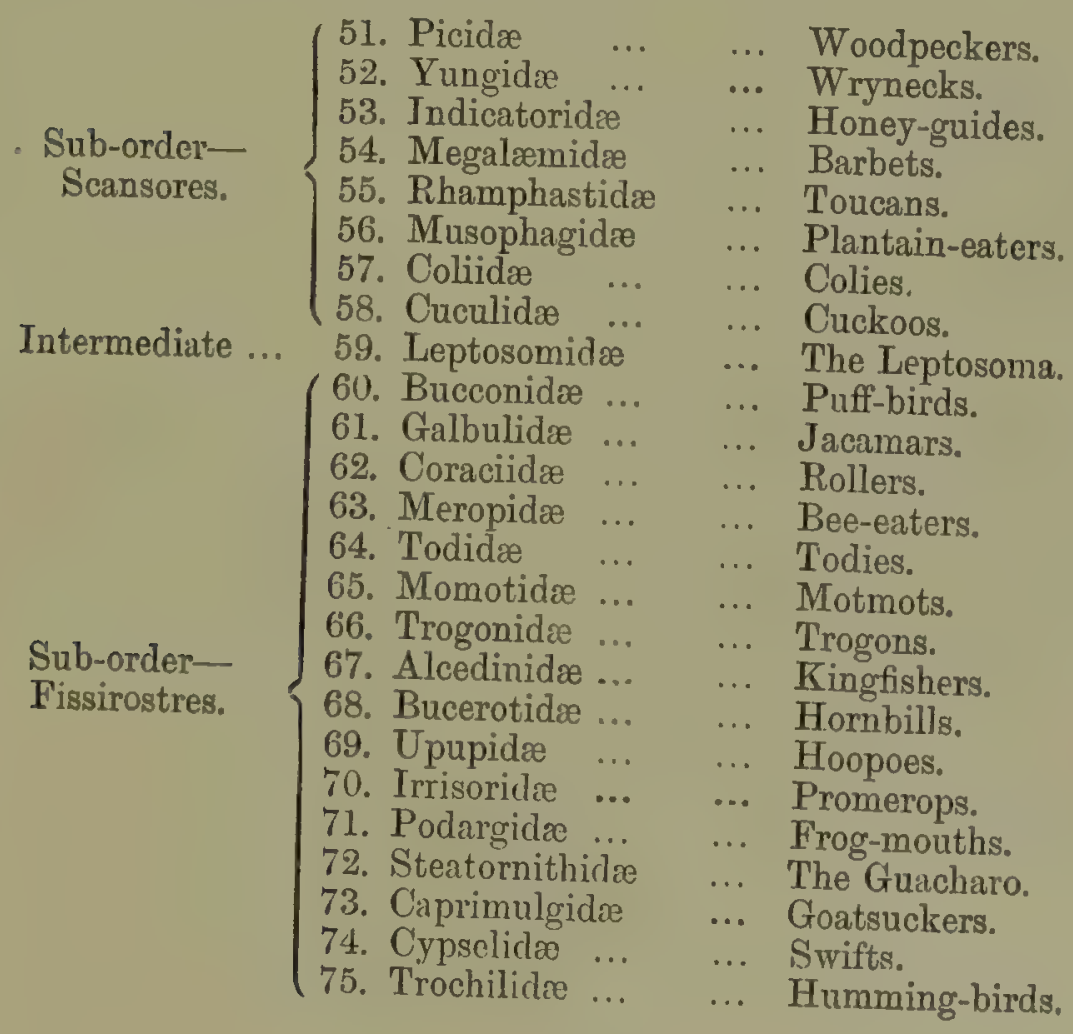


The Psittaci or parrot tribe are still in a very unsettled state of classification; that recently proposerl by Professor Garrod differing widely from the arrangement adopter in Dr. Finsch's monograph of the orler. Taking arlvantage of the researches of these and other authors, the following families are adopted as the most convenient in the present state of our knowledge:

76. Cacatuidæe...

77. Platycercidœ

78. Palæornithidæ

79. Trichoglossidæ

80. Conuridæ ...

81. Psittacidæ ...

82. Nestoridæ ...

83. Stringopidæ
... The Cockatoos.

... The Broad-tailed Paroquets of Australia.

... The Oriental Parrots and Paroquets.

... The Brush-tongued Paroquets and Lories.

... The Macaws and their allies.

... The African and South American Parrots.

... The Nestors of New Zealand.

... The Owl-parrots of New Zealind.

The Columbr, or pigeons, are also in a very unsatisfactory state as regards a natural classification. The families, subfumilies, and genera proposed by various authors are very numerous, and often quite irreconcilable. I therefore adopt only two families; and generally follow Mr. G. R. Gray's handlist for the genera, except where trustworthy authorities exist for a different arrangement. The families are:

84. Columbidre

... Pigeons and Doves.

85. Dididæ

... The extinct Dodo and allies.

The Gallinæ, or game-birds, may be divided into seven families :

\begin{tabular}{|c|c|c|c|}
\hline \multirow{3}{*}{$\begin{array}{l}\text { Fam. } \\
\text { 86. Pteroclidæ } \\
\text { 87. Tetraonidæ }\end{array}$} & Sulb. fiumi. & & \multirow{8}{*}{$\begin{array}{l}\text { Sand-grouse. } \\
\text { Partridges and Grouse. } \\
\text { Peafowl. } \\
\text { Tragopans, \&c. } \\
\text { Pheasants. } \\
\text { Fire-backed Pheasants, \&c. } \\
\text { Jungle-fowl. } \\
\text { Turkeys. } \\
\text { Guinea-fowl. }\end{array}$} \\
\hline & $\ldots$ & $\ldots$ & \\
\hline & $\ldots$ & $\ldots$ & \\
\hline & $\begin{array}{l}\text { Pavonina ... } \\
\text { Lophophorina }\end{array}$ & $\cdots$ & \\
\hline & Phasianinæ... & $\cdots$ & \\
\hline 29. & $\begin{array}{l}\text { Euplocaminæ } \\
\text { Gallinæ } \quad \ldots\end{array}$ & $\cdots$ & \\
\hline & Meleagrinæ... & ... & \\
\hline & e... & $\cdots$ & \\
\hline idn & $\cdots$ & $\cdots$ & pakers. \\
\hline & rCracinx & & \\
\hline : & $\begin{array}{l}\text { Penelopina ... } \\
\text { Oreoplitsinit }\end{array}$ & $\begin{array}{l}\ldots \\
\ldots\end{array}$ & tain-pheasant. \\
\hline$d æ$ & $\ldots$ & $\ldots$ & mo \\
\hline
\end{tabular}


The Opisthocomi consist of one family containing a single species, the "Hocco" of Guiana.

\section{Family 93. Opisthocomidx.}

The Accipitres, or birds of prey, which were long considered to be the highest and most perfect order of birds, are now properly placed lower down in the series, their affinities being more with the aquatic than with the perching birds. The following is the arrangement adopted by Mr. Sharpe in his recently published British Museum catalogue of diurnal birds of prey :-

Sub-orders.

Fam.

Sub-families.

Falcones

91. Vulturida

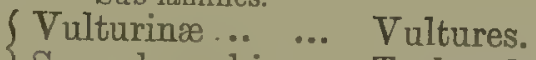

95. Serpentariidæ ...

Sarcorhamphinie Turkey-buzzards.

96. Falconidæ

Polybornia $\quad \ldots$ Caracaras.

Accipitrinæ $\quad \ldots$ Hawks.

Buteoninæ … Buzzards.

Aquilina $\ldots . . . . \quad$ Eagles.

Pandiones...97. Pandionidæ

Falconinæ $\quad \ldots$ Falcons.

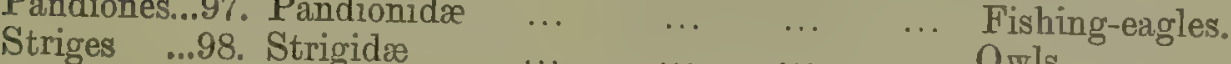

The Grallæe or Grallatores are in a very unsettled state. The following series of families is in accordance with the views of some of the best modern ornithologists :

99. Rallidæ

1(10. Scolopacidæ

101. Chionididæ

102. Thinocoridæ

103. Parridæ

104. Glareolidæ

105. Charadriidæe

106. Otididæ ...

107. Gruidæ ...

108. Cariamidæ

109. Aramidæ...

110. Psophiidae

111. Eurypyyidie

112. Rhinochotid $x$

113. Ardeidæ ...

114. Plataleidse

115. Ciconiidæ

116. Palamedeidæ

117. Phænicopterirl

$$
\begin{array}{cccl}
\ldots & \ldots & \ldots & \text { Rails, \&c. } \\
\ldots & \ldots & \ldots & \text { Sandpipers and Snipes } \\
\ldots & \ldots & \ldots & \text { Sheath-bills. } \\
\ldots & \ldots & \ldots & \text { Quail-snipes. } \\
\ldots & \ldots & \ldots & \text { Jicanas. } \\
\ldots & \ldots & \ldots & \text { Pratincoles. } \\
\ldots & \ldots & \ldots & \text { Plovers. } \\
\ldots & \ldots & \ldots & \text { Bustards. } \\
\ldots & \ldots & \ldots & \text { Cranes. } \\
\ldots & \ldots & \ldots & \text { Tariamas. } \\
\ldots & \ldots & \ldots & \text { Guaraunas. } \\
\ldots & \ldots & \ldots & \text { Trumpeters. } \\
\ldots & \ldots & \ldots & \text { Sun-litterns. } \\
\ldots & \ldots & \ldots & \text { Kagus. } \\
\ldots & \ldots & \ldots & \text { Herons. } \\
\ldots & \ldots & \ldots & \text { Spoonbills and Ibis. } \\
\ldots & \ldots & \ldots & \text { Storks. } \\
\ldots & \ldots & \ldots & \text { Screamers. } \\
\ldots & \ldots & \ldots & \text { Flamingoes. }
\end{array}
$$


The Anscres or Natatores are almost equally unsettled. The flamingoes are usually placerl in this order, but their habits best assort with those of the waders.

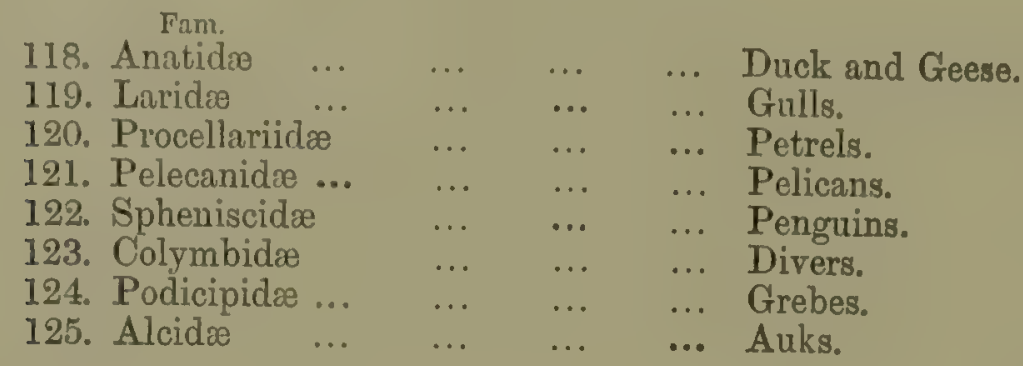

The last order of birds is the Struthiones or Ratitæ, considered by many naturalists to form a distinct sub-class. It consists of comparatively few species, either living or recently extinct.

\begin{tabular}{|c|c|c|c|}
\hline & $\begin{array}{l}\text { Fam. } \\
\text { 126. Struthionidiz }\end{array}$ & & Usti \\
\hline Living & 127. Casuariidæ ... & & Cassowarie \\
\hline & 128. Apterygidæ ... & & Apteryx. \\
\hline & 129. Dinornithidæ & & Dinornis. \\
\hline & 130. Palapterygidæ & $\cdots$ & Palapteryx \\
\hline & & & \\
\hline
\end{tabular}

\section{REPTILES.}

In reptiles I follow the classification of Dr. Günther as given in the Philosophical Transactions, vol. clvii., p. 625. He divides the class into five orders as follows:-

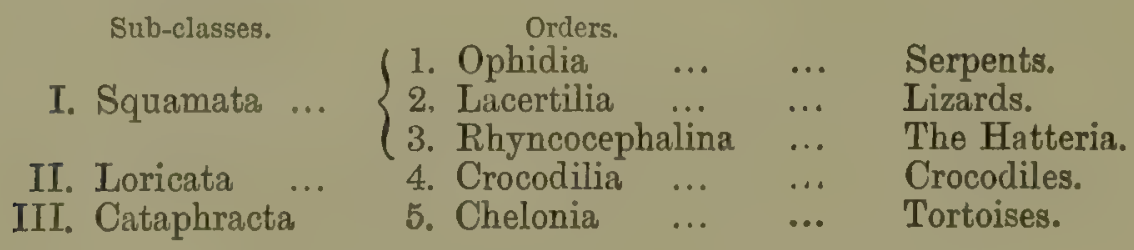

In the arrangement of the families comprised in each of these orders I also follow the arrangement of Dr. Guinther and Dr. J. E. Gray, as given in the British Museum Catalogue, or as modified by the former gentleman who has kindly given me much personal information. 
The Ophidia, or Snakes, form the first order and are classified as follows :-

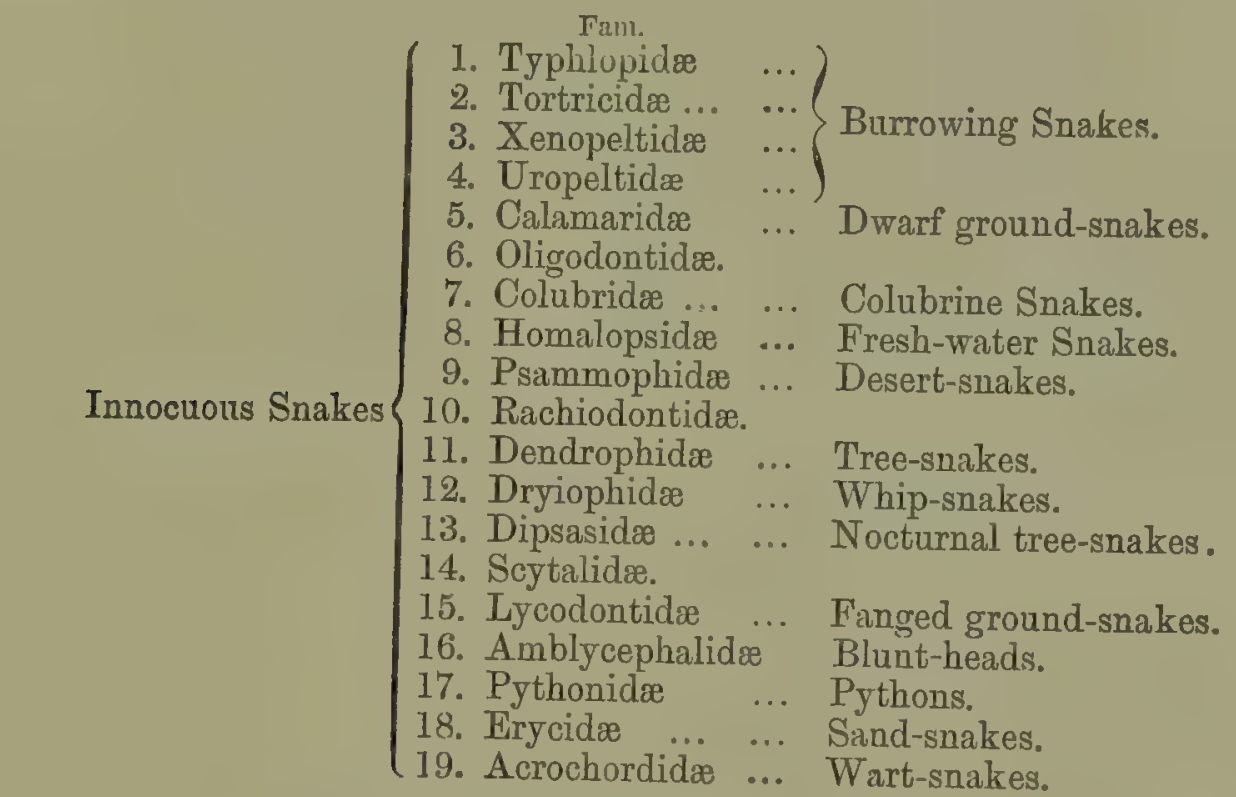

Venomous Colubrine
Snakes ...

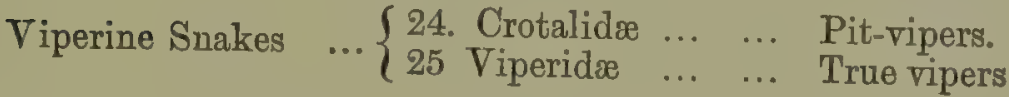

The second order, Lacertilia, are arranged as follows :-

Fam.

26. Trogonophidæ

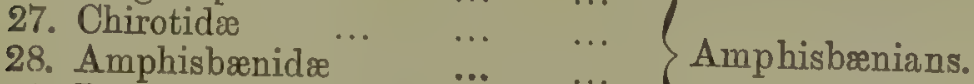

29. Lepidosternidæ

30. Varanidx

31. Helodermidæ.

32. Teidæ

33. Lacertidæ

34. Zonuridæ

35. Chalcidæ.

36. Anadiadæ.

37. Chirocolidæ.

38. Iphisadæ.

39. Cercosauridæ.

40. Chamæsauridæ.

41. Gymnopthalmidæ $\quad . . \quad$... Gape-eyed Scinks.

42. Pygopodidx $\quad . .6 \quad \ldots . \quad \ldots \quad$ Two-legged Lizards.

43. Aprasiads. 


\section{Frm.}

44. Lialidx.

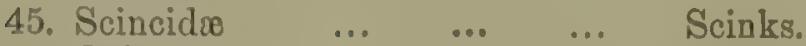

46. Ophiomoridæ ... $\quad \ldots \quad \ldots . \quad$ Snake-lizards.

47. Sepidr $\ldots \quad$... $\quad \ldots \quad$... Sand-lizards.

48. Acontiadx.

49. Geckotidre ... … ... Geckoes.

50. Iguanidæ $\quad \ldots \quad \ldots \quad \ldots \quad$ Iguanas,

51. Agamidæ $\quad . . \quad \ldots \quad \ldots \quad$ Fringed Lizards.

52. Chameleonidæ ... ... ... Chameleons.

The third order, Rhyncocephalina consists of a single family :-

53. Rhyncocephalidæ $\ldots$... The Hatteria of New Zealand.

The fourth order, Crocodilia or Loricata, consists of three families :-

54. Gavialidæ $\quad \ldots \quad \ldots \quad \ldots \quad$ Gavials.

55. Crocodilidæ $\quad \ldots \quad \ldots \quad \ldots \quad \ldots \quad$ Crocodiles.

56. Alligatoridæ $\ldots$. $\quad \ldots \quad \ldots \quad$ Alligators.

The fifth order, Chelonia, consists of four families :-

$\begin{array}{llll}\text { 57. Testudinidæ } & \ldots & \ldots & \text { Land and fresh-water Tortoises. } \\ \text { 58. Chelydidæ } & \ldots & \ldots & \text { Fresh-water Turtles. } \\ \text { 59. Trionychidæ } & \ldots & \ldots & \text { Soft Turtles. } \\ \text { 60. Cheloniidæ } & \ldots & \ldots & \text { Sea Turtles. }\end{array}$

\section{AMPHIBIA.}

In the Amplibia I follow the classification of Professor Mivart, as given for a large part of the order in the Proceedings of the Zoological Socicty for 1869. For the remainder I follow J)r. Strauch, Dr. Giinther, and a MSS. arrangement kindly furnished me by Professor Mivart.

The class is first divided into three groups or orders, and then into families as follows:- 
Order I.-PSEUDOPHIDIA.

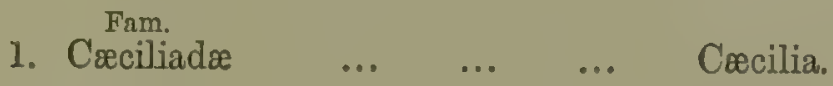

Order II.--BATRACHIA URODELA.

2. Sirenide $\ldots \quad \ldots \quad$ Siren.

3. Proteidæ ... ... Proteus.

4. Amphiumidæ … Amphiuma.

5. Menopomidse ... Giant Salamanders.

6. Salamandridæ $\quad . . \quad$ Salamanders and Newts.

Order III. BATRACHIA ANOURA.
7. Ram.
8. Phryniscidæ
9. Hylaplesidæ
10. Bufonidæ... ... Toads
11. Xenorhinidæ ...
12. Engystomidæ ...
13. Bombinatoridæ
14. Plectromantidæ
15. Alytidæ ... ... $\}$ Frogs.

Fam.

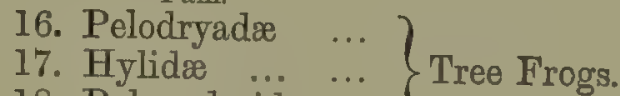

18. Polypedatidx ....

19. Ranidæ … …

21. Pipidæe … ... Tongueless

22. Dactylethridx...

\section{FISHES.}

These are arranged according to the classification of Dr. Günther, whose great work "The British Museum Catalogue of Fishes," has furnished almost all the material for our account of the distribution of the class.

In that work all existing fishes are arranged in six sub-classes and thirteen orders. A study of the extraordinary Ceratodus from Australia has induced Dr. Günther to unite three of his sub-classes; but as his catalogue will long remain a handbook for every student of fishes, it seems better to follow the arrangement there given, indicating his later views by bracketing together the groups he now thinks should be united. 


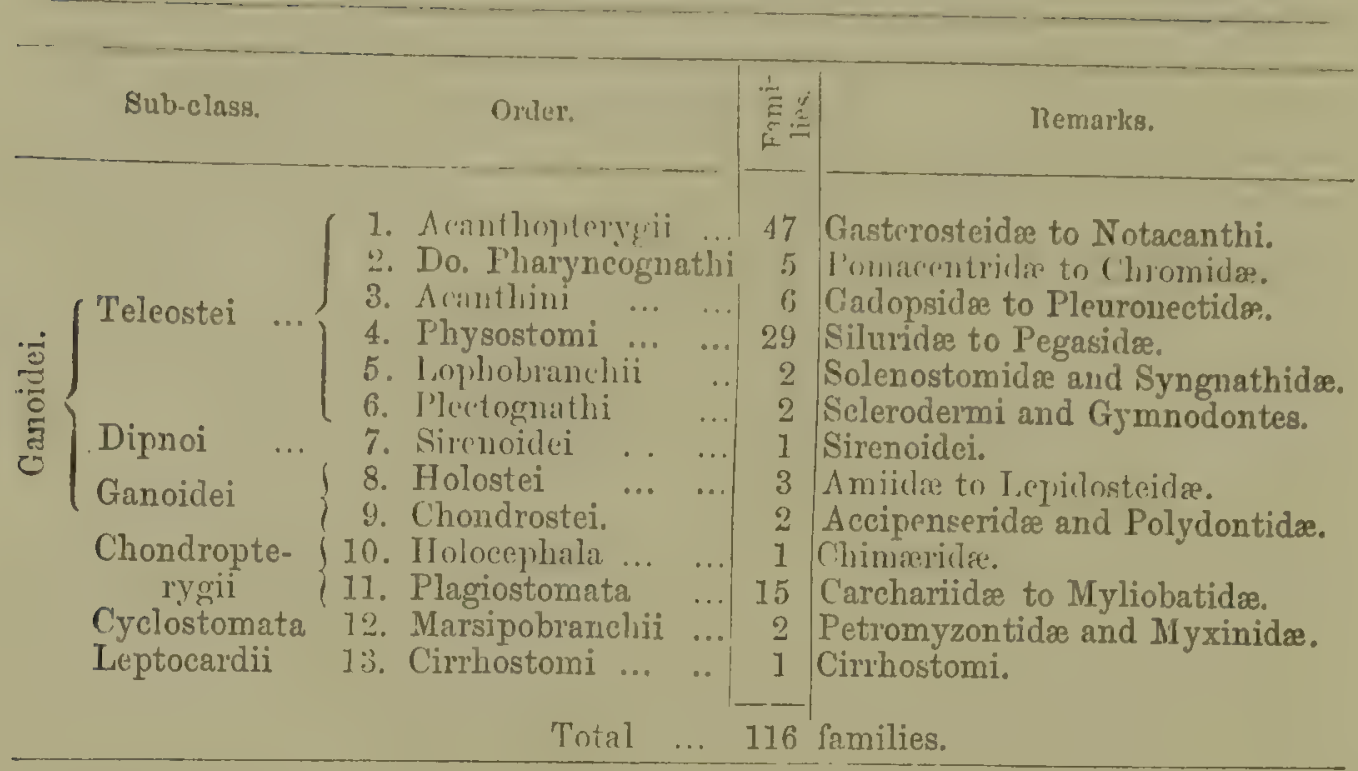

\section{INSECTS.}

The families and genera of insects are so immensely numerous, probably exceeding fifty-fold those of all other land animals, that for this cause alone it would be impossible to enter fully into their distribution. It is also quite unnecessary, because many of the groups are so liable to be transported by accidental causes, that they afford no useful information for our subject; while others are so obscure and uninteresting that they have been very partially collected and studied, and are for this reason equally ineligible. I have therefore selected a few of the largest and most conspicuous families, which have been so assiduously coliected in every part of the globe, and so carefully studied at home, as to afford valuable materials for comparison with the vertebrate groups, when we have made due allowance for the dependence of many insects on peculiar forms of vegetation, and the facility with which many of them are transported either in the egrr, larva, or perfect state, by winds, currents, and other less known means.

I confine myself then, almost exclusively, to the sixteen families of Diumal Lepidoptera or butterflies, and to six of the most extensive, conspicuous, and popular families of Coleoptera. 
The number of species of Butterflies is about the same as that of Birds, while the six families of Coleoptera selected, comprise more than twenty thousand species, far exceeding the number of all other vertebrates. These families have all been recently catalogued, so that we have very complete information as to their arrangement and distribution.

\section{LEPIDOPTERA DIURNA, OR BUTTERFLIES.}
1. Danaidæ.
2. Satyridæ.
3. Elymniidæ.
4. Morphidæ.
5. Brassolidæ.
6. Acræidæ.
7. Heliconidæ.
8. Nymphalidæ.

Fam.

9. Libythæidæ.

10. Nemeobiidx.

11. Eurygonidæ.

12. Erycinidæ.

13. Lycænidx.

14. Pieridæ.

15. Papilionidæ.

16. Hesperidæ.

\section{COLEOPTERA, OR BEETLES.}
1. Cicindelidæ... Tiger-beetles.
2. Carabidæ ... Ground-beetles.
3. Lucanidæ ... Stag-beetles.

4. Cetoniidæ ... Rose-chafers.

5. Buprestidæ... Metallic Beetles.

6. Longicornia ... Long-horned Beetles.

The above families comprise the extensive series of ground beetles (Carabidæ) containing about 9,000 species, and the Longicorns, which are nearly as numerous and surpass them in variety of form and colour as well as in beauty. The Cetoniidæe and Buprestidæ are among the largest and most brilliant of beetles; the Lucanidæ are pre-eminent for remarkable form, and the Cicindelidæ for elegance; and all the families are especial favourites with entomologists, so that the whole earth has been ransacked to procure fresh species.

Results deduced from a study of these will, therefore, fairly represent the phenomena of distribution of Coleoptera, and, as they are very varied in their habits, perhups of insects in general. 


\section{MOLLUSCA.}

The Mollusca are usually divided into five classes as follows :-

$$
\begin{array}{cccl}
\text { I. Classes. } & & & \\
\text { I. Cephalopoda } & \ldots & \ldots & \text { Cuttle-fish. } \\
\text { II. Gasteropoda } & \ldots & \ldots & \text { Snails and aquatic Univalves. } \\
\text { III. Pteropoda } & \ldots & \ldots & \text { Oceanic Snails. } \\
\text { IV. Brachiopoda } & \ldots & \ldots & \text { Symmetrical Bivalves. } \\
\text { V. Conchifera } & \ldots & \ldots & \text { Unsymmetrical Bivalves. }
\end{array}
$$

The Gasteropoda and Conchifera alone contain land and freshwater forms, and to these we shall chiefly confine our illustrations of the geographical distribution of the Mollusca. The classification followed is that of Dr. Pfeiffer for the Operculata and Dr. Von Martens for the Helicidæ. The families chiefly referred to are:-

\section{Class II.-GASTEROPODA.}

Order 2.-Pulmonifera. Fain.

$\begin{array}{ll}\text { In-operculata } & \ldots\end{array} \quad \ldots\left\{\begin{array}{l}\text { 1. Helicidæ. } \\ \text { 2. Limacidæ. } \\ \text { 3. Oncidiadæ. } \\ \text { 4. Limnæidæ. } \\ \text { 5. Auriculidæ. } \\ \text { 6. Aciculidæ. } \\ \text { 7. Diplommatinidæ. }\end{array}\right.$


PART II.

ON THE DISTRIBUTION OF EXTINCT ANIMALS. 



\section{CHAPTER VI.}

\section{THE EXTINCT MAMMALIA OF THE OLD WORLD.}

Although it may seem somewhat out of place to begin the systematic treatment of our subject with extinct rather than with living animals, it is necessary to do so in order that we may see the meaning and trace the causes of the existing distribution of animal forms. It is true, that the animals found fossil in a country are very generally allied to those which still inhabit it; but this is by no means universally the case. If it were, the attempt to elucidate our sulject by Palæontology would be hopeless, since the past would show us the same puzzling diversities of faunas and floras that now exist. We find however very numerous exceptions to this rule, and it is these exceptions which tell us of the past migrations of whole groups of animals. We are thus enabled to determine what portion of the existing races of animals in a country are descendants of its ancient fauna, and which are comparatively modern immigrants; and combining these movements of the forms of life with known or probable changes in the distribution of land and sea, we shall sometimes be able to trace approximately the long series of changes which hilve resulted in the actual state of things. To gain this knowledge is our object in studying the "Gengraphical Distribution of Animals," and our plan of study must be determined, mainly, by the facilities it affords us for attaining this object. In discussing the countless details of distribution we shall meet with in our survey of the zoological regions, we shall often find it useful to refer to the evidence we possess of the range of the group in question in 
past times; and when we attempt to generalise the phenomena on a large scale, with the details fresh in our mennory, we shall find a reference to the extinct faunas of various epochs to be absolutely necessary.

The degree of our lnowleilge of the Palæontology of various parts of the world is so unequal, that it will not be advisable to treat the subject under each of our six regions. Yet some subdivision must be made, and it seems best to consider separately the extinct animals of the Old and of the New Worlds. Those of Europe and Asia are intimately connected, and throw light on the past changes which have led to the establishment of the three great continental Old World regions, with their various subdivisions. The wonderful extinct fauna recently discovered in North America, with what was previously known from South temperate America, not only elucidates the past history of the whole continent, but also gives indications of the mutual relations of the eastern and western hemispheres.

The materials to be dealt with are enormous; and it will be necessary to confine ourselves to a general summary, with fuller details on those points which directly bear upon our special subject. The objects of most interest to the pure zoologist and to the geologist- those strange forms which are farthest removed from any now living - are of least interest to us, since we aim at tracing the local origin or birthplace of existing genera and families; and for this purpose animals whose affinities with living forms are altogether doubtful, are of no value whatever.

The great mass of the vertebrate fossils of the tertiary period consist of mammalia, and this is precisely the class which is of most value in the determination of zoological regions. The animals of the secondary period, though of the highest interest to the zoologist are of little importance to us; both because of their very uncertain affinitics for any existing groups, and also because we can form no adequate notion of the distribution of land and sea in those remote epochs. Our great olject is to trace back, step by step, the varying distribution of the chief forms of life; and to deduce, wherever possible, the physical changes which must have accompanied or caused such changes. 
The natural division of our subject therefore is into geological periods. We first go back to the Post-Pliocene period, which includes that of the caves and gravels of Europe containing flint implements, and extends back to the deposit of the glacial drift in the concluding phase of the glacial epoch. Next we have the Pliocene period, divided into its later portion (the Newer Pliocene) which includes the Glacial epoch of the northern hemisphere; and its earlier portion (the Older Pliocene), represented by the red and coralline crag of England, and deposits of similar age in the continent. During this earlier epoch the climate was not very dissimilar from that which now prevails; but we next get evidence of a still earlier period, the Miocene, when a warmer climate prevailed in Europe, and the whole fauna and flora were very different. This is perhaps the most interesting portion of the tertiary deposits, and furnishes us with the most valuable materials for our present study. Further back still we have the Eocene period, with apparently an almost tropical climate in Europe; and here we find a clue to some of the most puzzling facts in the distribution of living animals. Our knowledge of this epoch is however very imperfect; and we wait for discoveries that will elucidate some of the mystery that still hangs over the origin and migrations of many important families. Beyond this there is a great chasm in the geological record as regards land animals; and we have to go so far back into the past, that when we again meet with mammalia, birds, and land-reptiles, they appear under such archaic forms that they cease to have any local or geographical significance, and we can only refer them to wide-spread classes and orders. For the purpose of elucidating geographical distrihution, therefore, it is, in the present state of our knowledge, unnecessary to go back beyond the tertiary period of geology.

The remains of Mammalia being so much more numerous and important than those of other classes, we shall at first confine oursolves almost exclusively to these. What is known of the birls, reptilcs, and fishes of the tertiary epoch will be best indicated by a brief connected sketch of their fossils in all parts of the globe, which we shall give in a subsequent chapter. 
Historic Period.-In tracing hack the history of the organic world we fint, even within the limits of the historical period, that some animals have become extinct, while the distrilution of others has been materially changed. The Riytina of the North Pacitic, the dodo of Mauritius, and the great auk of the North Atlantic coasts, have been exterminated almost in our own times. The kitchen-middens of Denmark contain remains of the capercailzie, the Bos primigenius, and the beaver. The first still abounds farther north, the second is extinct, and the third is becoming so in Europe. The great Irish elk, a huge-antlered deer, probably existed almost down to historic times.

Pleistocene or Post-Pliocene Period.-We first meet with proofs of important changes in the character of the European fauna, in studying the remains found in the caverns of England and France, which have recently been so well explored. These cave-remains are probably all subsequent to the Glacial epoch, and they all come within the period of mau's occupation of the country. Yet we find clear proofs of two distinct kinds of change in the forms of animal life. First we have a change clearly traceable to a difference of climate. We find such arctic forms as the rein-deer, the musk-sheep, the glutton, and the lemming, with the mammoth and the woolly rhinoceros of the Siberian ice-cliffs, inhabiting this country and even the south of France. This is held to be good proof that a sub-arctic climate prevailed over all Central Europe ; and this climate, together with the continental condition of Britain, will sufficiently explain such a southward range of what are now arctic forms.

But together with this change we have another that seems at first sight to be in an exactly opposite direction. We meet with numerous animals which now only inhabit Africa, or South Europe, or the warmer parts of Asia. Such are, large felinessome closely related to the lion (Felis speloce), others of altogether extinct type (Machairodus) and forming the extreme development of the feline race; - hyænas; horses of two or more species; and a hippopotamus. If we go a little further back, to the remains furnished by the gravels and brick-earths, we still find the same association of forms. The reindeer, the glutton, 
the musk-sheep, and the woolly rhinoceros, are associated with several other species of rhinoceros and elephant; with numerous civets, now abundant only in warm countries; and with antelopes of several species. We also meet here with a great extension of range of forms now limited to small areas. The Saiga antelope of Eastern Europe occurs in France, where wild sheep and goats and the chamois were then found, together with several species of deer, of bear, and of hyæna. A few extinct genera even come down to this late period, such as the great sabre-toothed tiger, Machairodus; Galeotherium, a form of Viverridæ; Palcoospalax, allied to the mole; and Trogontherium, a gigantic form of beaver.

We find then, that even at so early a stage of our inquiries we meet with a problem in distribution by no means easy to solve. How are we to explain the banishment from Europe in so short a space of time (geologically speaking) of so many forms of life now characteristic of warmer countries, and this too during a period when the climate of Central Europe was itself becoming warmer? Such a change must almost certainly have been due to changes of physical geography, which we shall be better able to understand when we have examined the preceding Pliocene period. We may here notice, however, that so far as we yet know, this great recent change in the character of the fauna is confined to the western part of the Palæarctic region. In caves in the Altai Mountains examined by Prof. Brandt, a great collection of fossil bones was discovered. These comprised the Siberian rhinoceros and mammoth, and the cave hyæna; but all the others, more than thirty distinct species, are now living in or near the same regions. We may perhaps impute this difference to the fact that the migration of Southern types into this part of Siberia was prevented by the great mountain and desert barrier of the Central Asiatic plateau; whereas in Europe there was at this time a land connection with Africa. Postpliocene deposits and caverns in Algeria have yielded remains resembling the more southern European types of the Postpliocene period, but without any admixture of Arctic forms; showing, as we might expect, that the glacial cold did not 
extend so firr south. We have here remains of Eiquus, Bos, Antilope, Mrimopotrmus, Elephles, Rhinoceros, Ursus, Canis, and ITyena, together with Placochoerus, an African type of swine which has not occurred in the European deposits.

It is perhaps to the earlier portion of this period that the Merycotherium of the Siberian drift belongs. This was an animal related to the living camel, thus supporting the view that the Camctida are essentially denizens of the extra-tropical zone.

\section{Pliocene Period.}

Primates.-We here first meet with evidence of the existence of monkeys in Central Europe. Species of Macacus have left remains not only in the Newer Pliocene of the Val d'Arno in Italy, but in beds of the same age at Grays in Essex; while Semnopithecus and Cercopithecus, genera now confined to the Oriental and Ethiopian regious respectively, have been found in the Pliocene deposits of the South of France and Italy.

Carnivora.-Most of the genera which occurred in the Post Pliocene are found here also, and many of the same species. Few new forms appear, except Hycenarctos, a large bear with characters approaching the hyænas, and Pristiphoca, a new form of seal, both from the Older Pliocene of France; and Galecynus, a foxlike animal intermediate between Canis and Viverra, from the Pliocene of AEninghen in Switzerland.

Cetacea.-Species of Baloena, Physeter, and Delphinus occur in the Older Pliocene of England and France, and with these the remains of many extinct forms, Balcenodon and Hoplocetus (Balænidæ); Belemnoziphius and Choneziphius (Hyperoodontidæ), and Halitherium, an extinct form of the next order-Sirenia, now confined to the tropics, although the recently extinct Rytinc of the N. W. Pacific shows that it is also adlapted for temperate climates.

Ungulata.-The Pliocene deposits are not very rich in this order. The horses (Equide) are represented by the genus Equns; and here we first meet with Hipnarion, in which small lateral toes appear. Both genera occur in British deposits of this age. 
A more interesting fact for us is the occurrence of the genus Tapinus in the Newer Pliocene of France and in the older beds of both France and England, since this genus is now isolated in the remotest parts of the eastern and western tropics. The genera Rhinoceros, Hippopotamus, and Sus, occur here as in the preceding epoch.

We next come to the deer genus (Cervus), which appears to have been at its maximum in this period, no less than eight species occurring in the Norwich Crag, and Forest-beds. Among the Bovidæ, the antelopes, ox, and bison, are the only forms represented here, as in the Post-Pliocene period. Passing on to the Proboscidea, we find three species of elephants and two of $\mathrm{Mas}_{-}$ todon preserved in European beds of this period, all distinct from those of Post-Pliocene times.

Rodentia.-In this order we find representatives of many living European forms; as Cricetus (hamster), Arvicola (vole), Castor (beaver), Arctomys (marmot), Hystrix (porcupine), Lepus (hare), and Lagomys (pika); and a few that are extinct, the most important being Chalicomys, allied to the beaver; and Issiodromys, said to come nearest to the remarkable Pedetes of South Africa, both found in the Pliocene formations of France.

General Conclusions as to Pliocene and Post-Pliocene Faunas of Europe.-This completes the series of fossil forms of the Pliocene deposits of Europe. They show us that the presence of numerous large carnivora and ungulates (now almost wholly tropical) in the Post-Pliocene period, was due to no exceptional or temporary cause, but was the result of a natural succession from similar races which had inhabited the same countries for long preceding ages. In order to understand the vast periods of time covered by the Pliocene and Post-Pliocene formations, the works of Sir Charles Lyell must be studied. We shall then come to see, that the present condition of the fauna of Europe is wholly new and exceptional. For a long succession of ages, various forms of monkeys, hyænas, lions, horses, hipparions, tapirs, rhinoceroses, hippopotami, elephants, mastodons, deer, and antelopes, together 
with almost all the forms now living, produced a rich and varied faun such as we now see only in the open country of tropical Africa. During all this period we have no reason to believe that the climate or other physical conditions of Europe were more favourable to the existence of these animals than now. We must look upon them, therefore, as true indigenes of the country, and their comparatively recent extinction or banishment as a remarkable phenomenon for which there must have been some adequate cause. What this cause was we can only conjecture; but it seems most probable that it was due to the combined action of the Glacial period, and the subsidence of large areas of land once connecting Europe with Africa. The existence, in the small island of Malta, of no less than three extinct species of elephant (two of very small stature), of a gigantic dormouse, an extinct hippopotamus, and other mammalia, together with the occurrence of remains of hippopotamus in the caves of Gibraltar, indicate very clearly that during the Pliocene epoch, and perhaps during a considerable part of the Post-Pliocene, a connection existed between South Europe and North Africa in at least these two localities. At the same time we have every reason to believe that Britain was united to the Continent, what is now the German Ocean constituting a great river-valley. During the height of the Glacial epoch, these large animals would probably retire into this Mediterranean land and into North Africa, making annual migrations northwards during the summer. But as the connecting land sank and became narrower and narrower, the migrating herds would diminish, and at last cease altogether; and when the glacial cold had passed away would be altogether prevented from returning to their former haunts.

\section{Mrocene Period.}

We now come to a period which was wonderfully rich in all forms of life, and of which the geological record is exceptionally complete. Various lacustrine, estuarine, and other deposits in Europe, North India, and North America, have furnished such a 
vast number of remains of extinet mammalia, as to solve many zoological problems, and to throw great light on the early distribution and centres of dispersal of various grcups of animals. In order to show the bearing of these remains on our special subject, we will first give an account of the extinct fauna of Greece, of the Upper Miocene period; since this, being nearest to Africa and Asia, best exhibits the relations of the old European fauna to those countries. We shall then pass to the Miocene fauna of France and Central Europe; and conclude with the remarkable Siwalik and other Indian extinct faunas, which throw an additional light on the early history of the animal life of the great old-world continents.

\section{Extinct Animals of Greece.}

These are from the Upper Miocene deposits at Pikermi, near Athens, and were collected by M. Gaudry a few years ago. They comprise ten living and eighteen extinct genera of mainmalia, with a few birds and reptiles.

Primates.-These are represented by Mesopithecus, a genus believed to be intermediate between the two Indian genera of monkeys, Semnopithecus and Macacus.

Curnivora.-These were abundant. Of Felis there were four species, ranging from the size of a cat to that of a jaguar, a large hycena, and a large weasel (Mustela). Besides these there were the huge Machairodus, larger than any existing lion or tiger, and with enormously developed canine teeth; Hyonictis and Lycona, extinct forms of Hyænida; Thalassictis=Ictitherium, an extinct genus of Viverridæ but with resemblances to the hyænas, represented by three species, some of which were larger than any existing Viverridæ; Promephytis, an extinct form of Mustelidæ, having resemblances to the European marten, to the otters, and to the S. African Zorilla ; and lastly, Simocyon, an extraordinary carnivore of the size of a small panther, but having the canines of a cat, the molars of a dog, and the jaws shaped like those of a bear.

Ungulata. - These are numerous and very interesting. The Equidæ are represented by the three-toed Hipparion, which con- 
tinued to exist till the Older Pliocene period. There are three large species of Ritinuceros, as well as a species of the extinct genus Leptodon of smaller size. Remains of a very large wild boar (Sus) were found. Very interesting is the occurrence of a species of giraffe (Camelopardalis) as tall as the African species but more slender; and also an extinct genus Helladotherium, not quite so tall as the giraffe but much more robust, and showing some approach to the Antilopidr in its dentition. Antelopes were abundant, ranging from the size of the gazelle to that of the largest living species. Three or four seem referable to living genera, but the majority are of extinct types, and are classed in the genera Palocotragus, Palcooryx, Tragocerus, and Palceoreas; while Dremotherium is an ancient generalized form of Cervida or deer.

Proboscidea.-These are represented by two species of Mastodon, and two of Dinotherium, an extraordinary extinct form supposed to be, to some extent, intermediate between the elephants and the aquatic manatees (Sirenia.)

Rodentia.-This order is represented by a species of Hystrix, larger than living porcupines.

Edentata. - This order, now almost confined to South America, was represented in the Miocene period by several European species. Ancylotherium and Macrotherium, belonging to an extinct family but remotely allied to the African ant-bear (Orycteropus), occur in Greece.

Birds.-Species of Phasianus and Gallus were found; the latter especially interesting as being now confined to India.

Reptiles.-These are few and unimportant, consisting of a tortoise (Testudo) and a large lizard allied to Varanus.

Summary of the Miocene Fauna of Greece.-Although we cannot consider that the preceding enumeration gives us by any means a complete view of the actual inhabitants of this part of Europe during the later portion of the Miocene period, we yet obtain some important information. The resemblance that appeared in the Pliocene fauna of Europe, to that of the open country of tropical Africa, is now still more remarkable. We 
not only find great felines, surpassing in size and destructive power the lions and leopards of Africa, with hyænas of a size and in a variety not to be equalled now, but also huge rhinoceroses and elephants, two forms of giraffes, and a host of antelopes, which, from the sample here obtained, were probably quite as numerous and varied as they now are in Africa. Joined with this abundance of antelopes we have the absence of deer, which probably indicates that the country was open and somewhat of a desert character, since there were deer in other parts of Europe at this epoch. The occurrence of but a single species of monkey is also favourable to this view, since a well-wooded country would most likely have supplied many forms of these animals.

\section{Miocene Fauna of Central and Western Europe.}

We have now to consider the Miocene fauna of Europe generally, of which we have very full information from numerous deposits of this age in France, Switzerland, Italy, Germany, and Hungary.

Primates.-Three distinct forms of monkeys have been found in Europe-in the South of France, in Switzerland, and Wurtemberg; one was very like Colobus or Semnopithecus; the othersPliopithecus and Dryopithecus-were of higher type, and belonged to the anthropomorphous apes, being nearest to the genus Hylobates or gibbons. Both have occurred in the South of France. The Dryopithecus was a very large animal (equal to the gorilla), and M. Lartet considers that in the character of its dentition it approached nearer to man than any of the existing anthropoid apes.

Insectivora.-These small animals are represented by numerous remains belonging to four families and a dozen genera. Of Erinaceus (hedgehog) several species are found in the Upper Miocene; and in the Lower Miocene of Auvergne two extinct genera of the same family-Amphechinus and Tetracus-have been discovered. Several species of Talpa (mole) occur in the Upper Miocene of France, while the extinct Dinylus is from Germany, and Palocospalax from the Lower Miocene of the Isle of 
Wight. The Malayan family Tupaiide or squirrel-shrews, is believed to be represented by Oxygomphus, a fossil discovered in South Germany (Wiesenau) by H. von Meyer. The Soricidxe or shrews, are represented by several extinct genera-l'lesinsorex, Mysarachne and Galeospalax; as well as by Amphisorex and Myogale still living. Echinogale, a genus of Centetidx now confined to Madagascar, is said to occur in the Lower Miocene of Auvergne, a most interesting determination, if correct, as it would form a transition to the Solenodon of the Antilles belonging to the same family; but I am informed by Prof. Flower that the affinities of the animals described under this name are very doubtful.

Carnivora.-Besides Felis and Machaircdus, which extend back to the Upper Miocene, there are two other genera of Felidx, Pseudicelurus in the Upper Miocene of France, and Hycenodon, which occurs in the Upper and Lower Miocene of France, named from some resemblance in its teeth to the hyænas, and considered by some Palæontologists to form a distinct family, Hyænodontidæ. The Viverridie, or civets, were very numerous, consisting of the living genus Viverra, and three extinct forms-Thalassictis= Ictitherium, as large as a panther, aud Soricictis, a smaller form, occurring both in France and Hungary. Of Hycenido, there was the living genus Hycena, and the extinct Hyonictis, which has occurred in Hungary as well as in Greece. The Canidæ, or wolf and fox family, were represented by Pseudocyon, near to Canis; Hemicyon, intermediate between dogs and gluttons; and Amphicyon, of which several species occur in the Upper and Lower Miocene of France, some of them larger than a tiger. The Mustelidæ, or weasels, were represented by five genera, the existing genera Lutra (otter) and Mustela (weascl); Potanotherium, an extinct form of otter; Taxodon, allied to the badger and otter; Palcomephitis in Germany, and the Promephytis (already noticed) in Greece. The bears were represented only by Hyicinarctos, which has been noticed as occurring in the Pliocene, and first appears in the Upper Miocene of France. Seals are represented by a form resembling the Antarctic Otaria, remains of which occur in the Upper Miocene of France. 
Cetacea (whales).-These occur frequently in the Miocene deposits, four living, and five extinct genera having been described; but these marine forms are not of much importance for our purpose.

Sirenia (sea-cows).-These are represented by two extinct genera, Halitherium and Trachytherium. Several species of the former have been discovered, but the latter has occurred in France only, and its affinities are doubtful.

Ungulata.-Horses are represented by Hipparion and Anchitherium, the latter cccurring in both Upper and Lower Miocene and Eocene; while Hipparion, which is more nearly allied to living horses, first appears in the Upper Miocene and continues in the Pliocene.

Hippotherium, in the Upper Miocene of the Vienna basin, forms a transition to Paloplotherium, an Eocene genus of Tapiridæ or Palæotheridæ. Tapirs, allied to living forms, occur in both Upper and Lower Miocene. Rhinoceroses are still found in the Upper Miocene, and here first appear the four-toed hormless rhinoceros, Acerotherium. The Suidæ (swine) are rather numerous. Sus (wild boar) continued as far back as the Upper Miocene; but now there first appear a number of extinct forms which have been named Hyotherium, Palocochorus, Chœromorus, all of a small or moderate size; Hyopotamus, nearly as large as a tapir; and Anthracotherium, nearly the size of a hippopotamus and, according to Dr. Leidy, the type of a distinct family. Listriodon, from the Upper Miocene of the Vienna basin, is sometimes classed with the tapirs.

We now come to a well-marked new family of Artiodactyle or even-toed Ungulata, the Anoplotheriidce, which consisted of more slender long-tailed animals, allied to the swine but with indications of a transition towards the camels. The only genera that appear in the Miocene formation are, Chalicotherium, nearly as large as a rhinoceros, of which three species have been found in Germany and France; and Synaphodus, known only from its teeth, which differ somewhat from those of the Anoplotherium which appears earlier in the Focene formation. Anouher extinct, family, Amphimericidoe or Xiphodontidoe, is represented by two 
genera, Cainotherium and Microtherium, in the Miocene of France. They were of very small size, and are supjosed to be intermediate between the Suidæ and Tragulidæ.

The Camelopardalidx, or giraffes, were represented in Europe in Miocene times by the gigantic Helladotherium, which has been found in the south of France, and in Hungary, as well as in Greece. The chevrotains (Tragulidx) are represented by the extinct genus Hyomoschus.

The Cervidæ do not seem to have appeared in Europe before the Upper Miocene epoch, when they were represented by Dorcatherium and Amphimoschus, allied to Moschus, and also by true Cervus, as well as by small allied forms, Dremotherium, Amphitragalus (in the Lower Miocene), Micromeryx, Palcomeryx, and Dicrocerus.

The Bovidæ, or hollow-horned ruminants, were not well represented in Central Europe in Miocene times. There were no sheep, goats, or oxen, and only a few antelopes of the genus Tragocemus, and one allied to Hippotragus; and these all lived in the Upper Miocene period, as did the more numerous forms of Greece.

Proboscidca.-The true elephants do not extend back to the Miocene period, but they are represented by the Mastodons, which had less cornplex teeth. These first appear in the Upper Miocene of Europe, five species being known from France, Germany, Switzerland, and Greece. Dinotherium, already noticed as occurring in Greece, extended also to Germany and France, where remains of three species have been found.

Rodentia.-A considerable number of generic forms of this order have been obtained from the Miocene strata. The principal genera are C'ricetodon, allied to the hamsters, numerous in both the Upper and Lower Miocene period of France; Myoxus (the dormice) in France, and an allied genus, Brachymys, in Germany. The beavers were represented by the still living genus Castor, and the extinct Stencofiber in France. The squirrels by the existing Scuirus and Spermophilus; and by extinct forms, Lithomys and Aulacodon, in Germany, the latter resembling the African genus Aulacodes. The hares, by Lagomys and an 
extinct form Titanomys. Besides these, remains referred to the South American genera, Cavia (cavy) and Dasyprocta (agouti), have been found, the former in the Upper Miocene of Switzerland, the latter in the Lower Miocene of Auvergne. Palcomys, allied to the West Indian Capromys, has been found in the same deposits; as well as Theridomys, said by Gervais to be allied to Anomalurus and Echimys, the former now living in W. Africa, the latter in S. America.

Edentata.-These are only represented by the Macrotherium and Ancylotherium of the Grecian deposits, the former occurring also in France and Germany in Upper Miocene strata.

Marsupials.-These consist of numerous species related to the opossums (Didelphys), but separated by Gervais under the name Peratherium. They occur in both Upper and Lower Miocene beds.

\section{Upper Miocene Deposits of the Siwalik Hills and other Localities in N.W. India.}

These remarkable fresh-water deposits form a range of hills at the foot of the Himalayas, a little south of Simla. They were investigated for many years by Sir P. Cautley and Dr. Falconer, and add greatly to our knowledge of the early fauna of the Old World continent.

Primates.-Remains of the genera Semnopithecus and Macacus were found, with other forms of intermediate character; and some teeth indicated animals allied to the orang-utan of Borneo, and of similar size.

Carnivora.-These consisted of species of Felis and Machairodus of large size; Hycena, Canis, Mellivora, and an allied genus Ursitaxus; Ursus, in the deposits of the Nerbudda valley (of Pliocene age); Hyonarctos as large as the cave bear; Amphicyon of the size of a polar bear (in the deposits of the Indus valley, west of Cashmere); Lutra, and an extinct allied genus Enhydrion.

Ungulata. - These are very numerous, and constitute the most important feature of this ancient fauna. Horses are represented by a species of Equus from the Siwalik Hills and the Irawaddy 
deposits in Burmal, and by two others from the Pliocene of the Nerbudda Valley; while Hippotherium-a slender, antelope-like animal, found in the Siwalik Hills and in Europe-is surposed to form a transition from the Equidæ to the Tapiridæ. These latter are found in the Upper Indus deposits, where there is a species of Tapirus, and one of an extinct genus Antelotherium. Of Rhinoceros, five extinct species liave been found-in the Siwalik Hills, in Perim Island, and one at an elevation of 16,000 feet in the deserts of Thibet. Hippopotamus occurs in the Pliocene of the Nerbudda, and is represented in the older Miocene deposits by Hexaprotodon, of which three species have been found in various parts of India. Another remarkable genus, Merycnpotamus, connects Hippopotamus with Anthracotherium, one of the extinct European forms allied to the swine. These last are represented by several large species of Sus, and by the extinct European genus Cherotherium.

The extinct Anoplotheridx are represented by a species of the European genus Chalicotherium, larger than a horse.

An extinct camel, larger than the living species, was found in the Siwalik Hills.

Three species of deer (Cemns) have been found in the Siwaliks, and one in the Nerbudda deposits.

A large and a small species of giraffe (Camelopardalis) were found in the Siwalik Hills and at Perim Island.

The Bovidæe are represented by numerous species of Bos, and by the extinct genera Hemibos and Amphibos. There are also three species of antelopes, one of which is allied to the African Alsephalus.

We now come to an extraordinary group of extinct animals, probably forming a new family intermediate between the antelope and the giraffe. The Sivatherium was an enormous four-horned ruminant, larger than a rhinoceros. It had a short trunk like a tapir, the lower horns on the forehead were simple, the upper pair palmated. The Bramatherium, an allied form from Perim Island, showed somewhat more affinity for the giraffe.

Proboscidea.-No less than seven species of elephants and four 
of mastodons ranged over India, their remains being found in all the deposits from the Siwalik Hills to Burmah. A large Dinotherinm has also been found at Perim Island.

Reptiles.-Many remains of birds were found, but these have not been determined. Reptiles were numerous and interesting, the most remarkable being the huge tortoise, Colossochelys, whose shell was twelve feet long and head and neck eight feet more. Other small tortoises of the genera Testudo, Emys, Trionys and Emydida were found, the Emys being a living species. There were three extinct and one living species of crocodile, and one of them was larger than any now living. The only other reptile of importance was a large lizard of the genus Varanus.

General Observations on the Miocene faunas of Europe and Asia.-Comparing the three faunas of approximately the same period, and allowing for the necessarily imperfect record of each, we find a wonderful similarity of general type over the enormous area between France on the west and the Irawadly river in Burmah on the east. We may even extend our comparison to Northern China, where remains of Hyona, Tapir, Rhinoceros, Chalicotherium, and Eiephas, have been recently found, closely resembling those from the Miocene or Pliocene deposits of Europe or India, and showing that the Palaarctic region had then the same grent extent from west to east that it has now. Of about forty genera comprised in the Indian Miocene fauna, no less than twenty-seven inhabited Central and Western Europe during the same epoch. The Indian Miocene fossils are much what we should expect as the forerunners of the existing fauna, the giraffes and hippopotami being the only additions from the present Ethiopian fauna. The numerous forms of the restricted bovine type, show that these probably originated in India; while the monkeys appear to be altogether of Oriental types.

In Europe, lowever, we meet with a totally different assemblage of animals from those that form the existing fauna. We find apes and monkeys, many large Felidæ, numerous civets 
and hyænas, tapirs, rhinoceros, hippopotamus, elephants, giraffes, and antelopes, such as now characterise the tropics of Africa and Asia. Along with these we meet with less familiar types, showing relations with the Centetidæ of Madagascar, the Tupaiidæ of the Malay Islands, the Capromys, of the West Indies, and the Echimys of South America. And besides all these living types we have a host of extinct forms,--ten or twelve genera allied to swine; nine genera of tapir-like animals; four of horses; nine of wolves; with many distinct forms of the long-extinct families of Anoplotheridæ, Xiphodontidæ, and the edentate Macrotheridx. It is almost certain that during the Miocene period Europe was not only far richer than it is now in the higher forms of life, but not improbably richer than any part of the globe now is, not excepting tropical Africa and tropical Asia.

\section{EOCENe Period.}

The deposits of Eocene age are less numerous, and spread over a far more limited area, than those of the Miocene period, and only restricted portions of them furnish any remains of land animals. Our knowledge of the Eocene mammalian fauna is therefore very imperfect and will not occupy us long, as most of the new types it furnishes are of more interest to the zoologist than to the student of distribution. Some of the Eocene mammalia of Europe are, however, of interest in comparison with those of North America of the same age; while others show that ancestral types of groups now confined to Australia or to South America, then inhabited Europe.

Primates.-The only undoubted Eocene examples of this order, are the Cocnopithecus lemuroides from the Jura, which has points of resemblance to the South American marmosets and howlers, and also to the Lemuridx; and a cranium recently discovered in the Department of Lot (S.W. France), undoubtedly belonging to the Lemuridæ, and which most resembles that of the West African "Potto" (Perodicticus). This discovery has led to another, for it is now believed that remains formerly 
referred to the Anoplotheridæ (Adapis and Aphelotherium from the Upper Eocene of Paris) were also Lemurs. Some remains from the Lower Eocene of Suffolk were at first supposed to be allied to Macacus, but were subsequently referred to the Ungulate, Hyracothcrium. There is still, however, some doubt as to its true affinities.

Chiropterc.-In the Upper Eocene of Paris remains of bats have been found, so closely resembling living forms as to be referred to the genus Vespertitio.

Carnivora.-The only feline remains, are those of Hyoenodon in the Upper Eocene of Hampshire, and Pterodon, an allied form from beds of the same age in France; with Allurogale, found in the South of France in deposits of phosphate of lime of uncertain age, but probably belonging to this period. Viverridæ (civets) are represented by two genera, Tylodon, the size of a glutton from the Upper Eocene, and Palconyctis, allied to Viverra, from the Middle Eocene of France. The Canidæ (wolves and foxes) appear to have been the most ancient of the existing types of Carnivora, five genera being represented by Eocene remains. Of these, Galethylax and Cyotherium were small, and with the existing genus Canis are found in the Upper Eocene of France. Arctocyon, about the size of a wolf, is a very ancient and generalised form of carnivore which can not be placed in any existing family. It is found in the Lower Eocene of France, and is thus the oldest known member of the Carnivora.

Ungulata.-These are more numerous. Equidæ (horses) are represented by the Miocene Anchitherium in the Lower, and by a more ancient form, Anchilophus, in the Middle Eocene of France. Tapiridæ and Palæotheridæ were very numerous. Paloeotherium and the allied genus Paloplotherium, were abundant in France and England in Upper Eocene times. They somewhat resembled the tapir, with affinities for the horse and rhinoceros. A new genus, Cadurcotherium, allied to the rhinoceros and equally large, has been found in the same deposits of phosphate of lime as the lemur and AElurogale. In the Middle Eocene of both England and France are found Lophiodon allied to the tapir, 
but in some of the species reaching a larger size; Propalcentherium and Pachynoloplus of smaller size and laving affinities for the other genera named; and Plagiolophus, a small, slender animal which Professor Huxley thirks may have been a direct ancestor of the horse. In the Lower Eocene we meet with Coryphoilon, much larger than the tapir, and armed with largo canine teetl ; Pliolophus, a generailised type, allied to the tapir and horse; and Hyracotherium, a small animal from the Lower Eocene of England, remotely allied to the tapir.

Among the Artiodactyla, or even-toed ungulates, the swine are represented by several extinct genera, of moderate or small size-Acotherium, Choeropotamus, C'ebocincerus and Dichobune, all from the Upper and the last also from the Middle Eocene of France; but Eutelodon, from the phosphate of lime deposits is large. The Dichobune was the most generalised type, presenting the characters of many of the other genera combined, and was believed by I)r. Falconer to approach the musk-deer. The Cainotherium of the Miocene also occurs here, and an allied genus Plesiomeryx from the same deposits as Euteledon.

The Eocene Anoplotheridæe were numerous. The Anoplotherium was a two-toed, long-tailed Pachyderm, ranging from the size of a hog to that of an ass; the allied Eurytherium was four-toed; and there are one or two others of doubtful aftinity. All are from the Upper Eocene of France and England.

Rodentia.-Remains referred to the genera Myoxus (dormouse) and Sciurus (squirrel) have been found in the Upper Eocene of France; as well as Plesiarctornys, an extinct, genus between the marmots and squirrels. The Miocene Theridomys is also found here.

Marsupials. - The Didelphys (opossum) of Cuvier, now referred to an extinct genus Pcratherium, is found in the Upper Eocene of France and England.

General Considerations on the Extinct Mammalian Fanna of Europe-It is a curious fact that no family, and hardly a genus, of European mammalia occurs in the Pliocene deposits, without extending back also into those of Miocene age. There are, how- 
ever, a few groups which seem to be late developments or recent importations into the Palæarctic region, as they occur only in Post-Pliocene deposits. The most important of these are the badger, glutton, elk, reindeer, chamois, goat, and sheep, which only occur in caves and other deposits of Post-Pliocene age. Camels only occur in the Post-Pliocene of Siberia (Merycotherium), although a true Camelus of large size appear's to have inhabited some part of Central Asia in the Upper Miocene period, being found in the Siwalik beds. The only exclusively Pliocene genera in Europe are Ursus, Equ.s, Hippopotamus, Bos, Elephas, Arvicola, Trogontherium, Arctomys, Hystrix and Lepus; but of these Equus, Hippopotamus, Bos, and Elcphas are found in the Miocene deposits of India. Owing, no doubt, in part to the superior productiveness of the various Miocene beds, large numbers of groups appear to have their origin or earliest appearance here. Such are Insectivora, Felidæ, Hyænidæ, Mustelidie, Ursus, Equidæ, Tapirus, Rhinocerotidæ, Hippopotamidæ, Anthracotheridæ (extinct), Sus, Camelopardidæe, Tragulidæ, Cervidæ, Bovidæ, Elephantidæ, and Edentata.

Groups which go back to the Eocene period, are, Primates allied to South American monkeys, as well as sone of the Lemuridæ; bats of the living genus Vespertilio; Hyænodontidæ, an ancestral form of Carnivore; Viverridæ; Canidæ (to the Upper Eocene), and the ancestral Arctocyonidæ to the Lower Focene; Hyoenarctos, an ancestral type of bears and hyænas; Anchitheridæ, ancestral horses, to the Middle Eocene; Palæotheridæe, comprising numerous generalised forms, ancestors of the rhinoceros, horse, and tapir; Suidre, with numerous generalised forms, to the Middle Eocene; Anoplotheridx and Xiphodontidx, ancestral families of even-toed Ungulates, connecting the ruminants with the swine; and lastly, several groups of Rodents, and a Marsupial, in the Upper Eocene. We thus find all the great types of Mammalia well developed in the earliest portion of the tertiary period; and the occurrence of Quadrumana, of the highly specialized bats (Vespertilio), of various forms of Carnivora, and of Ungulates, clearly differentiated into the odd and even-toed series, associated with such lower forms as 
Lemurs and Marsupials-proves, that we have here hardly made an approach towards the epoch when the mammalian type itself began to diverge into its various modifications. Some of the Carnivora and Ungulates do, indeed, exhibit a less specialised structure than later forms; yet so far back as the Upper Miocene the most specialised of all carnivora, the great sabretoothed Machairodus, makes its appearance.

The Miocene is, for our special study, the most valuable and instructive of the Tertiary periods, both on account of its superior richness, and because we here meet with many types now confined to separate regions. Such facts as the occurrence in Europe during this period of hippopotami, tapirs, giraffes, Tragulidæ, Edentata, and Marsupials-will assist us in solving many of the problems we shall meet with in reviewing the actual distribution of living forms of those groups. Still more light will, however, be thrown on the subject by the fossil forms of the American continent, which we will now proceed to examine. 


\section{CHAPTER VII.}

\section{EXTINCT MAMMAIIA OF THE NEW WORLD.}

THE discoveries of very rich deposits of mammalian remains in various parts of the United States have thrown great light on the relations of the faunas of very distant regions. North America now makes a near approach to Europe in the number and variety of its extinct mammalia, and in no part of the world have such perfect specimens been discovered. In what are called the "Mauvaises terres" of Nebraska (the dried-up mud of an ancient lake), thousands of entire crania and some almost entire skeletons of ancient animals have been found, their teeth absolutely perfect, and altogether more resembling the preparations of the anatomist, than time-worn fossils such as we are accustomed to see in the museums of Europe. Other deposits have been discovered in Oregon, California, Virginia, South Carolina, Texas, and Utah, ranging over all the Tertiary epuchs, from Post-Pliocene to Eocene, and furnishing a remarkable picture of the numerous strange mammalia which inhabited the ancient North American continent.

\section{North America-Post-Pliocene Period.}

Insectivora.-The only indications of this order yet discovered, consists of a single tooth of some insectivorous animal found in Illinois, but which cannot be referred to any known group.

Carnivora.-These are fairly represented. Two species of Felis as large as a lion; the equally large extinct Trucifelis, found only in Texas; four species of Canis, some of them larger 
than wolves; two species of Galera, a genus now confined to the Neotropical region; two bears, and an extinct genus, Arctodus; an extinct species of racoon (Procyon), and an allied extinct genus, Myxophagus-show, that at a very recent period North America was better supplied with Carnivora than it is now. Remains of the walrus (Trichechus) have also been found as far south as Virginia.

Cetacea.-Three species of dolphins belonging to existing genera, have been found in the Eastern States; and two species of Manatus, or sea-cow, in Florida and South Carolina.

Ungulata.-Six extinct horses (Equus), and one Hipparion; the living South American tapir, and a larger extinct species; a Dicotyles, or peccary, and an allied genus, Platygonus; a species of the South American llamas (Auchenia), and one of a kind of camel, Procamelus; two extinct bisons ; a sheep, and two musksheep (Ovibos); with three living and one extinct deer (Cervus), show an important increase in its Herbivora.

Proboscide.a.-Two elephants and two mastodons, added to this remarkable assemblage of large vegetable-feeding quadrupeds.

Rodentia.--These consist mainly of genera and species still living in North America; the only important exceptions being a species of the South American capybara (Hydrochoerus) in South Carolina; and Praotherium, an extinct form of hare, found in a bone cave in Pennsylvania.

Fidentata.-Here we meet with a wonderful assemblage, of six species belonging to four extinct genera, mostly of gigantic size. A species of Megatherium, three of Megalonyx, and one of Mylodon-huge terrestrial sloths as large as the rhinoceros or even as the largest elephants-ranged over the Southern States to Pennsylvania, the latter (Mylodon) going as far as the great lakes and Oregon. Another form, Ereptodon, has been found in the Mississippi Valley.

Marsupiatia.-The living American genus of opossums, Didelphys, has been found in deposits of this age in South Carolina.

Remarks on the Post-Pliocene fauna of North America.-The assemblage of animals proved, by these remains, to have 
inhabited North America at a comparatively recent epoch, is most remarkable. In Europe, we found a striking change in the fauna at the same period; but that consisted almost wholly in the presence of animals now inhabiting countries immediately to the north or south. Here we have the appearance of two new assemblages of animals, the one now confined to the Old World-horses, camels, and elephants; the other exclusively of South American type-llamas, tapirs, capybaras, Galerc, and gigantic Edentata. The age of the various deposits in which these remains are found is somewhat uncertain, and probably extends over a considerable period of time, inclusive of the Glacial epoch, and perhaps both anterior and subsequent to it. We have here, as in Europe, the presence and apparent co-existence in the same area, of Arctic and Southern forms-the walrus and the manatee-the musksheep and the gigantic sloths. Unfortunately, as we shall see, the immediately preceding Pliocene deposits of North America are rather poor in organic remains; yet it can hardly be owing to the imperfection of the record of this period, that not one of the South American types above numerated occurs there, while a considerable number of old World forms are represented. Neither in the preceding wonderfully rich Miocene or Eocene periods, does any one of these forms occur; or, with the exception of Morotherium, from Pliocene deposits west of the Rocky Mountains, any apparent ancestor of them! We have here unmistakable evidence of an extensive immigration from South into North America, not very long before the beginning of the Glacial epoch. It was an immigration of types altogether new to the country, which spread over all the southern and central portions of it, and established themselves sufficiently to leave abundance of remains in the few detached localities where they have been discovered. How such large yet defenceless animals as tapirs and great terrestrial sloths, could have made their way into a country abounding in large felines equal in size and destructiveness to the lion and the tiger, with numerous wolves and bears of the largest size, is a great mystery. But it is nevertheless certain that they did so ; and the fact that no such 
migration had occurred for countless preceding ages, proves that some great barrier to the entrance of terrestrial mammalia which had previously existed, must for a time have been removed. We must defer further discussion of this subject till we have examined the relations of the existing faunas of North and South America.

\section{Tertiary Period.}

When we get to remains of the Tertiary age, especially those of the Miocene and Eocene epochs, we meet with so many interesting and connected types, and such curious relations. with living forms in Europe, that it will be clearer to trace the history of each order and family throughout the Tertiary period, instead of considering each of the subdivisions of that period separately.

It will be well however first to note the few American PostPliocene or living genera that are found in the Pliocene beds. These consist of several species of Canis, from the size of a fox to that of a large wolf; a Felis as large as a tiger; an Otter (Lutra); several species of Hipparion; a peccary (Dicotyles); a deer (Cervus); several species of Procamelus; a mastodon; an elephant; and a beaver (Castor). It thus appears that out of nearly forty genera found in the Post-Pliocene deposits, only ten are found in the preceding Pliocene period. About twelve additional genera, however, appear there, as we shall see in going over the various orders.

Primates.-Among the vast number of extinct mammalia discovered in the Tertiary deposits of North America, no example of this order had been recognized up to 1872 , when the discovery of more perfect remains showed, that a number of small animals of obscure affinities from the Lower Eocene of Wyoming, were really allied to the lemurs and perhaps also to the marmosets, the lowest form of American monkeys, but having a larger number of teeth than either. A number of other remains of small animals from the same formation, previously supposed to be allied to the Ungulata, are now shown to 
belong to the Primates; so that no less than twelve genera of these animals are recognized by Mr. Marsh, who classes them in two families-Limnotheridæ, comprising the genera Limnotherium, (which had larger canine teeth), Thinolestes, Telmatolestes, Mesacodon, Bathrodon, and Antiacodon of Marsh, with Notharctos, Hipposyus, Microsyops, and Palceacodon previously described by Leidy;-and I.emuravidæ, consisting of the genera Lemuravus (Marsh) and Hyopsodus (Leidy). The animals of the latter family were most allied to existing lemurs, but were a more generalized form, Lemuravus having forty-four teeth, the greatest number known in the order. These numerous forms ranged from the size of a small squirrel to that of a racoon. It is especially interesting to find these peculiar lemuroid forms in America, just when a lemur has been discovered of about the same age in Europe; and as the American forms are said to show an affinity with the South American marmosets, while the European animal is most allied to a West African group, we have evidently not yet got back far enough to find the primeval or ancestral type from which all the Primates sprang.

About the same time, in the succeeding Miocene formation, true monkeys were discovered. Mr. Marsh describes Laopithecus as an animal nearly the size of the largest South American monkeys, and allied both to the Cebidx and the Eocene Limnotheridæ. Mr. Cope has described Menotherium from the Miocene of Colorado, as a lemuroid animal, the size of a cat, and perhaps allied to Limnotherium. More Miocene remains will, no doubt, be discovered, by which we shall be enabled to trace the origin of some of the existing forms of South American monkeys; and perhaps help to decide the question (now in dispute among anatomists) whether the lemurs are really Primates, or form an altogether distinct and isolated order of mammalia.

Insectivora.-This order is represented by comparatively few forms in the tertiary beds, and these are all very different from existing types. In the Upper Miocene of Dakota are found remains indicating two extinct genera, Lepictis and Ictops. In the Miocene of Colorado, Professor Cope has recently discovered four new genera, Isccis; allied to the preceding, but as large as a 
Mephitis or skunk; Herpetotherium, near the moles; Embasis, more allied to the shrews; and Dommina, of uncertain affinities. Two others have been found in the Eocene of Wyoming; Amomys, having some resemblance to hedgehogs and to the Eastern Tupaia; and Washakins, of doubtful affinities.

Far back in the Triassic coal of North Carolina has been found the jaw of a small mammal (Dromotherium), the teeth of which somewhat resemble those of the Australian Myrmecobius, and may belong either to the Insectivora or Marsupials; if indeed, at that early period these orders were differentiated.

Carnivora.-The most ancient forms of this order are some remains found in the Middle Eocene of Wyoming, and others recently described by Professor Cope (1875) from the Eocene of New Mexico, of perhaps earlier date. The former consist of three genera, Patriofelis, Uintacyon, and Sinopa,-animals of large size but which cannot be classed in any existing family; and two others, Mesonyx and Synoplotherium, believed by Mr. Cope to be allied to Hycenodon. The latter consist of four genera,-Oxycena, consisting of several species, some as large as a jaguar, was allied to Hycenodon and Pterodon; Pachycena, allied to the last; Prototomus, allied to Amphicyon and the Viverridx; and Limnocyon, a civet-like carnivore with resemblances to the Canidæ.

In the Miocene formations we find the Feline type well developed. The wonderful Machairodus, which in Europe lived down to Post-Pliocene times, is found in the Upper Miocene of Dakota ; and perfect crania have been discovered, showing that the chin was lengthened downwards to receive and protect the enormous canines. Dinyctis was allied both to Machairodus and to the weasels. Three new genera have been lately described by Professor Cope from the Miocene of Colorado,-Buncelurus, with characters of both cats and weasels; Daptophilus, allied to Dinyctis; and Hoplophoneus, more allied to Machairodus. The Canidæ are represented by Amphicyon, which occurs in deposits of the same age in Europe; and by Canis, four species of which genus are recorded by Professor Cope from the Miocene of Colorado, and it also occurs in the Pliocene. The Hycenodon is represented by three species in the Miocene of Dakota and Colorado. It occurs 
also in the European Miocene and Upper Eocene formations, and constitutes a distinct family Hyænodontidæ, allied, according to Dr. Leidy, to wolves, cats, hyænas and weasels. The Ursidæ are represented by only one species of an extinct genus, Leptarchus, from the Pliocene of Nebraska. From the Pliocene of Colorado, Prof. Cope has recently described Tomarctos, as a "short-faced type of dog;" as well as species of Canis and Martes.

Ungulata.-The animals belonging to this order being usually of large size and accustomed to feed and travel in herds, are liable to wholesale destruction by floods, bogs, precipices, drought or hunger. It is for these reasons, probably, that their remains are almost always more numerous than those of other orders of mammalia. In America they are especially abundant; and the number of new and intermediate types about whose position there is much difference of opinion among Palæontologists, renders it very difficult to give a connected summary of them with any approach to systematic accuracy.

Beginning with the Perissodactyla, or odd-toed ungulates, we find the Equine animals remarkably numerous and interesting. The true horses of the genus Equns, so abundant in the PostPliocene formations, are represented in the Pliocene by several ancestral forms. The most nearly allied to Equus is Pliohippus, consisting of animals about the size of an ass, with the lateral toes not externally developed, but with some differences of dentition. Next come Protohippus and Hipparion, in which the lateral toes are developed but are small and functionless. Then we have the allied genera, Anchippus, Merychippus, and Hyohippus, related to the European Hippotherium, which were all still smaller animals, Protohippus being only $2 \frac{1}{2}$ feet high. In the older deposits we come to a series of forms, still unmistakably equine, but with three or more toes used for locomotion and with numerous differentiations in form, proportions, and dentition. These constitute the family Anchitheridæ. In the Miocene we have the genera Anchitherium (found also in the European Miocene), Miohippus and Mesohippus, all with three toes on each foot, and about the size of a sheep or large goat. In the Eocene of 
Utah and Wyoming, we get a step further back, several species having been discovered about the size of a fox with four toes in front and three behind. These form the genus Orohippus, and are the oldest ancestral horse known. Prof. Marsh points out the remarkably perfect series of forms in America, which, beginning with this minute ancient type, is gradually modified by gaining increased size, increased speed by concentration of the limb-bones, elongation of the head and neck, the canine teeth decreased in size, the molars becoming longer and being coated with cementtill we at last come to animals hardly distinguishable, specifically, from the living horse.

Allied to these, are a series of forms showing a transition to the tapirs, and to the Palocotherium of the European Eocene. In the Pliocene we have Parahippus; in the Miocene Lophiodon, found in the same formation and in the Eocene of Europe, and allied to the tapir; and in the Eocene, Palocosyops, as large as a rhinoceros, which had large canines and was allied to the tapir and Palcotherium; Limnohyus, forming the type of a family Limnohyidæ, which included the last genus and some others mentioned further on ; and Hyrachyus, allied to Lophiodon, and to Hyracodon an extinct form of rhinoceros. Besides these we have Lophioticerium (also from the Eocene of Europe); Diplacodon allied to Limnohyus, but with affinities to modern Perissodactyla and nearly as large as a rhinoceros; and Colonoceras, also belonging to the Limnohyidæ, an animal which was the size of a sheep, and had divergent protuberances or horms on its nose. A remarkable genus, Bathmodon, lately described by Professor Cope, and of which five species have been found in the Eocene of New Mexico and Wyoming, is believed to form the type of a new family, having some affinity to Paloosyops and to the extinct Brontotheridæ. It had large canine tusks but no horns.

The Rhinocerotidæ are represented in America by the genus Rhinoceros in the Pliocene and Miocene, and by Accratherium and Hyracodon in the Miocene. Both the latter were hornless, and Hyracodon was allied to the Eocene Hyrachyus, one of the Lophiodontidx. In the Eocene and Miocene deposits of Utah, and Operon, several remarkable extinct rhinoceroses have been 
recently discovered, forming the genus Diceratherium. These had a pair of nasal horns placed side by side on the snout, not behind each other as in existing two-horned rhinoceroses, the rest of their skeleton resembling the hornless Aceratherium. They were of rather small size.

Next to these extinct rhinoceroses come the Brontotheridæ, an extraordinary family of large mammalia, some of which exceeded in bulk the largest living rhinoceros. They had four toes to the front and three to the hind feet, with a pair of large divergent horns on the front of the head, in both sexes. Professor Marsh and Dr. Leidy have described four genera, Brontotherium, Titanotherium, Megacerops, and Anisacodon, distinguished by peculiarities of dentition. Though most nearly allied to the rhinoceroses, they show some affinity for the gigantic Dinocerata of the Eocene to be noticed further on. Professor Cope has since described another genus, Symborodon, from the Miocene of Colorado, with no less than seven species, one nearly the size of an elephant. He thinks they had a short tapir-like proboscis. The species differ greatly in the form of the cranium and development of the horn-bearing processes.

We commence the Artiodactyla, or even-toed Ungulates, with the hog tribe. These are represented by species of peccaries, (Dicotyles) from the Pliocene of Nebraska and Oregon; and by an allied form Thinohyus, very like Dicotyles, but having an additional premolar tooth and a much smaller brain-cavity. From the Miocene are three allied genera, Nanohyus, Leptochoerus, and Perchcerus. Professor Cope, however, thinks Leptochoerus may be Lemuroid, and allied to Menotherium. The Anthracotheridæ, a family which connects the Hippopotamidæ and Ruminants, and which occurs in the Miocene of Europe and India, are represented in America by the genus Hyopotamus from the Miocene of Dakota, and Elotherium from the Miocene of Oregon and the Eocene of Wyoming; the latter genus being sometimes classed with the preceding family, and lately placed by Professor Marsh, in the new order, Tillodontia. Professor Cope has since described three other genera from the Eocene of New 
Mexico: Meniscotherium, having resemblances to Palocosyops, Hyopotamus, and the Limnotheridx; Phenacodus, the size of a hog, of doubtful position, but perhaps near Elotherium; and Achanodon, as large as a cow, but more hog-like than the preceding. Another new genus from the Miocene of ColoradoPelonax-is said by Professor Cope to come between Elotherium and Hippopotamus.

The Camelidæ are very abundant, and form one of the most striking features of the ancient fauna of Arnerica. Procamelus, Homocamelus, and Megalomeryx, are extinct genera found in the Pliocene formation; the first very closely allied to the old World camel, the last smaller and more sheep-like. In the Miocene two other genera occur, Pcebrotherium and Protomeryx, the former allied to both the camel and the llama.

Deer are represented by a single species of Cervus in the Pliocene, while two extinct genera, Leptomeryx and Merycodus, are found in the Miocene deposits, the latter indicating a transition between camels and deer. Two other genera, Hypisodus and Hypertragulus, of very small size, are said by Professor Cope to be allied to the Tragulidæ and to Leptomeryx.

The Bovidæ, or hollow-horned ruminants, are only represented in the Newer Pliocene by a single species of an extinct genus, Casoryx, said to be intermediate between antelopes and deer.

We now come to an exclusively American family, the Oreodontidoe, which consisted of small animals termed by Dr. Leidy, "ruminating hogs," and which had some general structural resemblances to deer and camels. They abounded in North America during the Pliocene, and especially during the Miocene epoch, no less than six genera and twenty species having been discovered. Merychus contains the Pliocene forms; while Oreodon, Eporeodon, Merychochorus, Leptauchenia, and Agriochcerus are Miocene. The last genus extends back into the Eocene period, and shows affinity to the European Anoplotheridæ of the same epoch.

Proboscidea. - The Elephantidæ are only represented in America by one species of Mastodon and one of Elephas, in the Newer Pliocene deposits. In the Older Pliocene, Miocene, 
and Upper Eocene, no remains of this order have been found; and in 1869, Dr. Leidy remarked on the small average size of the extinct North American mammalia, which were almost all smaller than their living analogues. Since then, however, wonderful discoveries have been made in deposits of Middle Eocene age in Wyoming and Colorado, of a group of huge animals not only rivalling the elephants in size, but of so remarkable and peculiar a structure as to require the formation of a new order of mammals-Dinocerata-for their reception.

This order consists of animals with generalised Ungulate and Proboscidean affinities. The lower jaw resembles that of the hippopotamus; they had five toes on the anterior feet and four on the posterior; three pairs of horns, the first pair on the top of the head, large and perhaps palmated, the second pair above the eyes, while the third and smallest stood out sideways on the snout. They had enormous upper canines, of which the roots entered the middle horn cores, no upper incisors, and small molars. Professor Marsh believes that they had no trunk. The remains discovered indicate four genera, Dinoceras (3 sp.), Tinoceras (2 sp.), Uintatherium (1 sp.), and Eobasileus (2 sp.). Many other names have been given to fragments of these animals, and even those here given may not be all distinct.

Another new order, Tillodontia, recently established by Professor Marsh, is perhaps yet more remarkable in a zoological point of view, since it combines the characters of Carnivora, Ungulata, and Rodents. These animals have been formed into two families, Tillotheridæ and Stylinodontidx; and three genera, Tillotherium, Anchippodus, and Stylinodontia. All are from the Eocene of Wyoming and New Jersey. Perhaps to these must be added Elotherium from the Miocene of Dakota, the other forms being all Eocene. They were mostly animals of small size, between that of the capybara and tapir. The skull resembled in form that of a bear; the molar teeth were of Ungulate type, and the incisors like those of a Rodent; but the skeleton was more that of the Ursidæ, the feet being plantigrade. Professor Cope has since described three new genera from the Eocene of New Mexico, Ectoganus, Calamodon, and Esthonys, comprising 
seven species allied to Tillotherium and Anchippodus, and having also relations, as P'rofessor Cope believes, with the South $\Lambda$ merican Toxodontidr.

Rodentia.-This order is represented in the Pliocene by a beaver, a porcupine, and an American mouse (Hesperomys), all extinct species of living genera, the Hystrix being an Old World type; and Professor Cope has recently described Panolax, a new genus of hares from the Pliocene of New Mexico. The Miocene deposits have furnished an extinct genus allied to the hares-Palocolagus; one of the squirrel family-Ischyromys; a small extinct form of beaver-Palococastor; and an extinct mouse-Eumys. The Eocene strata of Wyoming have lately furnished two extinct forms of squirrel, Paramys and Sciuravus; and another of the Muridæ (or mouse family), Mysops.

Cetacea.-Numerous remains of dolphins and whales, belonging to no less than twelve genera, mostly extinct, have been found in the Miocene deposits of the Atlantic and Gulf States, from New Jersey to South Carolina and Louisiana; while seven genera of the extinct family, Zeuglodontidæ, have been found in Miocene and Eocene beds of the same districts. Some remains associated with these are doubtfully referred to the Seal family (Phocidæ) among the Carnivora.

Edentatc.-Till quite recently no remains of this order have occurred in any North American deposits below the Post-Pliocene; but in 1874 Prof. Marsh described some remains allied to Megalonyx and Mylodon, from the Pliocene beds of California and Idaho, and forming a new genus, Morotherium. As these remains have only occurred to the west of the Rocky Mountains, and in Pliocene deposits whose exact age is not ascertained, they hardly affect the remarkable absence of this group from the whole of the exceedingly rich Tertiary deposits in all other parts of North America.

General Relations of the extinct Tertiary Mammalia of North America and Europe--Having now given a sketch of the extinct Mammalia which inhabited Europe and North America during the Tertiary period, we are enabled by comparing them, 
to ascertain their relations to each other, and to see how far they elucidate the problem of the birth-place and subsequent migrations of the several families and genera. We have already pointed out the remarkable features of the Quaternary (or PostPliocene) fauna of North America, and now proceed to discuss that of the various Tertiary periods, which is closely connected with the extinct fauna of Europe.

The Tertiary Mammalia of North America at present described belong to from eighty to one hundred genera, while those of Europe are nearly double that number; yet only eighteen genera are common to the two faunas, and of these eight are living and belong chiefly to the Pliocene period. Taking first, the genera which in America do not go back beyond the Pliocene period (ten in number), we find that eight of them in Europe go back to the Upper Miocene. These are Felis, Pseudoclurus, Hipparion, Cervus, Mastodon, Elephas (in India), Castor and Hystrix; while another, Canis, goes back to the Upper Eocene and the tenth, Equus, confined to the newer Pliocene or perhaps to the Post-Pliocene in America, extends back to the older Pliocene in Europe. Of the seven European genera which are confined to the Miocene period in America, three, Hycenodon, Anchitherium, and Lophiodon go back to the Eocene in Europe; three others, Machairodus, Rhinoceros, and Aceratherium, are also of Miocene age in Europe; Amphicyon goes back to the Lower Miocene of Europe. Lophiotherium belongs to the Eocene of both countries.

If we turn now to families instead of genera, we find that the same general rule prevails. Mustelidæ (weasels), Ursidæ (bears), true Equidæ (horses), and Bovidæ (oxen \&c.), go no further back in America than the Pliocene, while they all go back to the Miocene in Europe. Suidæ (swine) and Anoplotheridæ (extinct) are found in the American Miocene and in the European Eocene. Anchitheridæ (extinct) reach the Upper Eocene in America, while in Europe they range through Upper, Middle, and Lower Eocene. Cervidæ (deer) alone are Miocene in both countries. There remain two families in which America has the preeminence. Camelidæ (camels) were wonderfully developed in 
the American Pliocene and Miocene periods, abounding in genern and species; whereas in Europe the group only exists in the Post-Pliocene or Lower Pliocene, with one Upper Miocene species of Camelus in N. India. The Anthracotheridæ (extinct), found only in the Upper Miocene of France and India, reach even the Lower Eocene in America.

These facts may be due, in part, to a want of strict co-ordination between the Tertiary deposits of Europe and North America, -in part to the imperfection of the record in the latter country. Yet it does not seem probable that they are altogether due to these causes, because the Miocene beds, which are by far the best known in America as in Europe, exhibit deficiencies of the same kind as the less known Eocene deposits. The fossil fauna of both countries is so rich, that we can hardly impute great and well marked differences to imperfect knowledge; yet we find such important families as the Civets, Hyænas, Giraffes, and Hippopotami absent from America, with the Weasels, and Antelopes almost so ; while America possesses almost all the Camelidæ, two peculiar orders, Dinocerata and Tillodontia, and four remarkably peculiar families, Limnotheridæ, Lemuravidæ, Oreodontidæ and Brontotheridæ. If then the facts at present known represent approximately the real time-relations of the groups in question on the two continents, they render it probable that weasels, bears, true horses, swine, oxen, sheep and antelopes, originated on the old World continent, and were transmitted to America during some part of the Miocene period; while camels originated in the New World, and somewhere about the same time passed over to Europe. Of the extinct families common to the two hemispheres, the Anthracotheridx alone seem to have had an American origin. Of the genera common to the two countries, almost all seem to have had a European origin, the only genera of equal date being the two rhinoceroses and three Anchitheridæ; but if the Brontotheridæ are allied to the Rhinocerotidæ, these latter may have originated in America, although now an exclusively old World type. These conclusions are not improbable when we consider the much greater size of the Old World continents, extending far into the tropics and probably 
always more or less united to the tropical areas; while the evidence of the extinct mammalia themselves shows, that South America has been for the most part isolated from the northern continent, and did not take part in the development of its characteristic Tertiary fauna.

Before speculating further on this subject, it will be well to lay before our readers a summary of South American palæontology, after which we shall be in a better position to draw correct inferences from the whole body of the evidence.

\section{SOUTH AMerica.}

Unfortunately, our knowledge of the interesting fossil fauna of this continent, is almost wholly confined to the Post-Pliocene and Pliocene periods. A few remains have been discovered in deposits believed to be of Eocene age, but nothing whatever representing the vast intervening period, so rich in peculiar forms of animal life both in North America and Europe.

Fauna of the Brazilian caves.-What we know of the PostPliocene period is chiefly due to the long-continued researches of Dr. Lund in the caves of Central Brazil, mostly situated in a district near the head waters of the San Francisco river in the Province of Minas Geraes. The caves are formed in limestone rocks, and are so numerous that Dr. Lund visited thousands, but only sixty contained bones in any quantity. These caves have a floor of reddish earth, often crowded with bones. In one experiment, half a cubic foot of this earth contained jaws of 400 opossums, 2,000 mice, besides remains of bats, porcupines and small birds. In another trial, the whole of the earth in a cavern was carried out for examination, amounting to 6,552 firkins; and, from a calculation made by measured sarnples, it was estimated to contain nearly seven millions of jaw-bones of cavies, opossums, porcupines, and mice, besides small birds, lizards, and frogs. This immense accumulation is believed to have been formed from the bodies of animals brought into the cavern by owls; and, as these are unsocial birds, the quantity found insplies an 
immense lapse of time, probably some thousands of years. More than 100 species of Mammalia, in all, were obtained in these caves. Some were living species or closely allied to such; but the majority were extinct, and a considerable number, about one-fourth, belonged to extinct genera, or genera not now inhabiting South America. Stnne implements and human remains were found in several of the caves with extinct animals. The following enumeration of these remains is from the corrected list of M. Gervais.

Primates.-Extinct species of Cebus, Callithrix, and JacchusSouth American genera of monkeys; with an extinct genus, Protopithecus - an animal of large size but belonging to the American family Cebidæ.

Chiroptera.--Species belonging to the South American Phyllostomidæ, and to two South American genera of other families.

Carnivora.-Five species of Felis, some allied to living animals, others extinct; a species of the widespread extinct genus Machairodus; and a small species referred to Cynoclurus, the genus containing the hunting leopard now found only in Africa and India. Canidæ are represented by Canis and Icticyon (a living Brazilian species of the latter genus), and the extinct genus Speothos. Mustelidæ are represented by extinct species of the South American genera Mephitis and Galictis. Procyonidæ, by a species of Nasua. Ursidæ, by Arctotherium, a genus closely resembling, if not identical with, that containing the "spectacled bear" of Chili.

Ungulata.-Equus, Tapirus, Dicotyles, Auchenia, Cervus, Leptotherium, and Antilope, are the cave-genera of this order. Equus and Antelope are particularly interesting, as representing groups forming no part of existing South American zoology; while the presence also of Leptotherium, an extinct genus of antelopes, shows that the group was fairly represented in South America at this comparatively recent period.

Proboscidea.-A species of Mastodon, found also in the Pliocene of La Plata, represents this order.

Rodentia.-These abound. Dasyprocta, Calogenys, Cavia, Kerodon, all living genera of Caviidæ, are represented by 
extinct specics. Cercolcubs, the 'tree poreupine' (Cercolabidie) has two species, one as large as a peccary; Myopotamus, Loncheres, Carterodon, are existing genera of spiny rats (Echimyidie); aud there are two extinct genera of the same family, Lonchophorus and Phyllomys. Lagostomus (Chinchillidx), the viscacha of the Pampas, is represented by an extinct species. There is also an extinct species of Lepus; sereral species of Itesperomys and Oxymycterus; and a large Arvicola, a genus not living in South America.

Edentata. -These, which constitute the great feature of the existing South American fauna, were still more abundant and varied in the Cave period, and it is remarkable that most of them are extinct genera. The armadillos are alone represented thy living forms, Dasypus, and Xcnumes; Eurydon and Hetcrodon, are extinct genera of the same family, as well as Chlamydotherium-huge armadillos the size of a tapir or rhinoceros, and Pachytherium, which was nearly as large. The ant-eaters are represented ouly by Glnssotherium, an extinct form allied to Myrmecophaga and Manis. The sloths were more numerous, being represented by the extinct genera Calodon, Splkenodon and Ochotherium, the last of large size. The huge terrestrial sloths-Megatheridx, also abounded; there being species of Megatherium and Megalonyx, as well as the allied Scclidothcrium, supposed to have some affinity for the African Orycteropus.

Marsupials.-No new forms of these appear, but numerous species of Didelphygs, all closely allied to opossums still living in South America.

The preceding sketch of the wonderful cave fauna of Central Irazil, is sufficient to show that it represents, in the main, a period of great antiquity. Not only are almost the whole of the species extinct, but there are twenty extinct genera, and three others not now inhabitants of South America. The fact that so few remains of the living animals of the country are found in these caves, indicates that some change of physical conditions has occurred since they were the receptacles of so many of the larger animals; and the presence of many extinct genera of 
large size, especially among the Fidentata and $\Lambda$ merican families of liodents, are aclditional proofs of a very high antiguity. Yet many of these cave animals are closely allied to those which are found in North America in the Post.Pliocene deposits only, so that we have no reason to suppose the cave-fauna to be of mucls earlier date. But the great amount of organic change it implies, must give us an enlarged idea of the vast jeriods of time, as measured by years, which are included in this, the most recent of all geological epochs.

\section{Pliocene Period of Temperate South Americc.- We have now} to consider the numerous remains of extinct animals found in various deposits in the Pampas, and in Patagonia, and a few in Bolivia. The age of these is uncertain; but as they are very similar to the cave-fauna, though containing a somewhat larger proportion of extinct genera and some very remarkable new forms, they cannot be very much older, and are perhaps best referred at present to the newer portion of the Pliocene formation.

Carnivora.-The genus Machairodus or sahre-toothed tigers, represents the Felidx. There are several species of wolves (Canis); a weasel (Mustela); two bears of the Brazilian cavegenus Arctotherium; and the extinct European genus Hycenarctos.

Ungulata.-There are two species of Equus, found in the Pampas, Chili, and Bolivia; two of Macrauchenia, an extraordinary extinct group allied to the tapir and Palocotherium, but with the long neck, and general size of a camel. A second species found on the highlands of Bolivia is much smaller.

A more recent discovery, in Patagonia, is the almost perfect series of teeth of a large animal named Homalodontotherium; and which is believed by Professor Flower, who has described it, to have been allied to Rhinoceros, and still more to the Miocene Hyracolon from North America; and also to present some resemblances to Macrauchenia, and though much more remotely, to the curious genus Nesodon mentioned further on.

The Artiodactyla, or even-toed Ungulates, are represented by a species of Dicotyles, or peccary, found in the deposits of the 
Pampas; by Auchcnia, or llama, of which three extinct species inhabited Bolivia, in which country two allied but extinct genera, Palcolama and Camelotherium, have also been found. Three species of deer (Cervus), from the Pampas deposits, complete the list of Pliocene Ungulates.

Proboscidea.-The cave species of Mastodon is found also in the Pampas deposits, and another in the Andes of Chili and Bolivia.

Rodents.-These are not so numerous as in the caves. There are species of the existing genera, Kerodon and C'aria (Caviidæ); Lagostomus (Chinchillidæ); Ctenomys (Octodontidæ); Lepus (hare); Hesperomys and Oxymycterus (Muridæ); Arvicola, a genus not living in South Ainerica; and an extinct genus, Cardiodus. There is also a remarkable extinct form, Typotherium, larger than the capybara, and having affinities to Edentates and Ungulates. Three species have been found in the Pampas deposits.

Fidentata.-These are as abundant and remarkable as in the cave deposits. Scelidotherium, Meyatherium, Megalonya, Glossotherium and Dasypus, have already been noticed as from the Brazilian caves. We have here, in addition, the huge Mylodon allied to the Megatherium, and the allied genera-Gnathopsis and Lestodon. We then come to the huge extinct armadillos, Glyptodon and Schistopleurum, the former consisting of numerous species; some of which were as large as an elephant. Another genus, Eutatus, is allied to the living three-handed armadillos; and a species of the existing genus Euphractus has been found in Bolivia.

Toxodontidce.-There remain a number of huge animals rivalling the Megatherium in size, and forming the genera Toxodon and $\Lambda^{\top}$ esodon, but whose position is doubtful. Several species have been found in the deposits of the Panpas and J'atagyonia. They are allied at once to Ungulates, Iiodents, Edentates, and the aquatic Sircnia, in so puzzling a manner that it is impossible to determine to what order they belong; or whether. they require a new order to be formed for their reception. Some are believed to date back to the Miocene period, and they indicate what strange forms may still be discoverel, should any 
productive deprosits be found in South Ancrica of mirldle 'Tertiary age.

Pliocene Mammalia of the Antilles.-These may be noticed lere, as they are of special interest, proving the connection of the linrer West Indian Islands with the Continent some time in the later Tertiary perior. They consist of remains of two large mimals belonging to the South American Chincliblidx, found in cave deposits in the island of Anguilla, and forming two new crencra, Amblynhiza and Loxomylus; and remain allied to Megalony. from Cuba, which have been named Megalocnus and Myomorphus.

Evecue founc of South America.-The few remains yet discovered in the Tertiary deposits of the Pampas which are believed to be of Eocene age, are exceedingly interesting, because they show us another change in the scenery of the great drama of life; there being apparently a considerable resemblance, at this epoch, between South America and Europe. They consist of a large extinct feline animal, Eutemnodus; of Palcothcrium and Anoplotherium, the well-known extinct Ungulates of the European Tertiaries, and which have never been found in North America; and of three genera of Rodents,-Theridromys, allied to Echimys, and found also in the Eocene and Miocene of France; Megamys, allied to the living Carromys of the Antilles, and also to Palcomys, an extinct form of the French Miocene; and a very large animal referred to Arvicola, a genus found also in the Pliocene deposits of South America, and abundant in the northern hemisphere. No Edentates have been found.

The resemblances of this fauna to that of Europe rather than to any part of America, are so strong, that they can hardly be accidenial. We greatly want, however, more information on this point, as well as some corresponding evidences as to the condition of West and South Africa about the same epoch, before we can venture to speculate on their bearing as regards the early migrations of organic forms.

General Remarks on the Extinct Mammatian Fauna of the Old 
and New Worlds.-Leaving the more special applications of palrontological evidence to be made after discussing the relations of the existing fauna of the severnl regions, we propose here to indicate briefly, some of the more general deductions from the evidence which has now been laid before our readers.

The first, and perhaps the most startling face brought out by our systematic review, is the very recent and almost universal change that has taken place in the character of the fauna, over all the areas we have been considering; a change which seems to be altogrether unprecedented in the past history of the same countries as revealed by the geological record. In Europe; in North America, and in South America, we have evidence that a very similar change occurred about the same time. In all three we find, in the most recent deposits-cave-earths, pcat-bogs, and gravels-the remains of a whole series of large animals, which have since become wholly extinct or only survive in far-distant lands. In Europe, the great Irish elk, the Machairodus and care-lion, the rhinoceros, hippopotamus, and elephant;-in North America, equally large felines, horses and tapirs larger than any now living, a llama as large as a camel, great mastodons and elephants, and abundance of huge megatheroid animals of almost equal size;-in South America these same megatheroids in greater variety, numerous huge armadillos, a mastodon, large horses and tapirs, large porcupines, two forms of antelope, numerous bears and felines, including a Machairodus, and a large monkey,--have all become extinct since the deposition of the most recent of the fossilbearing strata. This is certainly not a great while ago, geologically; and it is almost certain that this great organic revolution, implying physical changes of such vast proportions that they must have been due to causes of adequate intensity and proportionate range, has taken place since man lived on the earth. This is proved to have been the case in Europe, and is supported by much evidence both as regards North and South America.

It is clear that so complete and sudden a change in the higher forms of life, does not represent the normal state of things. Species and genera have not, at all times, become so rapillly extinct. The time occupied by the "Recent period," that is the 
time since these chamges took place is, geolngically, mimute. The time of the whole of the P'ust-P'liocene period, as measured by the amount of physical and generel organic clange known to have taken place, is exceedingly small when compared with the duration of the l'lincene period, and still smaller, probubly, as compared with the Miocene. Yet during these two periorls we mect with no such break in the continuity of the forms of life, no such radical change in the cheracter of the fauna (though the numlier of specific and generic changes may be as great) as we find in passing from the Post-Pliocene to recent times. For example, in Central Europe numerous hyrnas, rhinoceroses, and antelopes, with the great Machairodus, continued from Miocene all throngh Pliocene into Post-Pliocene times; while hippopotami and elephants continued to live through a good part of the Pliocene and Post-Pliocene periods,-and then all suddenly became extinct or left the country. In North America there has been more movement of the fauna in all the periods; but we have similar great felines, horses, mastodons, and elephants, in the Pliocene and Post-Pliocene periods, while Rhinoceros is common to the Miocene and Pliocene, and camels range continuously from Miocene, through Pliocene, to Post-Pliocene times; - when all alike became extinct. Even in South America the evidence is, as far as it goes, all the same way. We find Machairodus, Equus, Maslodon, Megatherium, Scelidotherium, Megalonyx, and numerous gigantic armadillos, alike in the caves and in the stratified tertiary deposits of the Pampas; - yet all have since passed away.

It is clear, therefore, that we are now in an altogether exceptional period of the earth's history. We live in a zoologically impoverished world, from which all the hugest, and fiercest, and strangest forms liave recently disappeared; and it is, no doubt, a much better world for us now they have gone. Tet it is surely a marvellous fact, and one that has hardly been sufficiently dwelt upon, this sudden dying out of so many large mammalia, not in one place only but orer half the land surface of the globe. We cannot but believe that there must have been some physical cause for this great change; and it must have ween a cause capable of acting almost simultaneously orer large 
portions of the eartl's surface, and one which, as far as the Tertiary period at least is concerned, was of an exceptional character. Such a cause exists in the great and recent physical change known as "the Glacial epoch." We have proof in both Europe and North America, that just about the time these large animals were disappearing, all the northern parts of these continents were wrapped in a mantle of ice; and we have every reason to believe that the presence of this large quantity of ice (known to have been thousands of feet if not some miles in thickness) must have acted in various ways to have produced alterations of level of the ocean as well as vast local floods, which would have combined with the excessive cold to destroy animal life. There is great difference of opinion among geologists and plysicists as to the extent, nature, and duration of the Glacial epoch. Some believe it to have prevailed alternately in the northern and southern hemispheres; others that it was simultaneous in hoth. Some think there was a succession of cold periods, each lasting many thousands of years, but with intercalated warm periods of equal duration; others deny that there is any evidence of such changes, and maintain that the Glacial epoch was one continuous period of arctic conditions in the temperate zones, with some fluctuations perhaps but with no regular alternations of warm periods. Some believe in a huge ice-cap covering the whole northern hemisphere from the pole to near $50^{\circ}$ north latitude in the eastern, and $40^{\circ}$ in the western hemisplere; while others impute the observed effects either to glaciers from local centres, or to floating icebergs of vast size passing over the surface during a period of submersion.

Without venturing to decide which of these various theories will be ultimately proved to be correct, we may state, that there is an increasing belief among geologists in the long duration of this ice-period, and the vast extent and great thickness attained by the ice-sheet. One of the most recent, and not the least able, of the writers on this question (Mr. Belt) shows strong reasons for adopting the view that the ice-period was simultaneous in both hemispheres; and he calculates that the vast amount of water abstracted from the ocean and locked up 
in mountains of ice aromul the two poles, would lower the ereneral level of the ocean about 2,000 fect. This would be equivalent to a general clevalion of the land to the same amomit, and would thus tent to intensify the cold; and this elevation may enalse, us to understand the recent discoveries of signs of glacial action at moderate elevations in Central America and Israzil, far within the tropics. At the same time, the weiglit of ice pilerl up in the north would cause the land surfuce to sink there, perhaps unequally, according to the varying nature of the interior crust of the earth; and since the weight lias been removed land would rise again, still somewhat irregularly; and thus the phenomenis of raisecl beds of aretic shells in temperate latitudes, are explained.

Now, it is evident, that the hhenonnen wo lave been considering-of the recent changes of the mammalian fauna in Europe, North America, South Temperate America, and the highlands of Brazil-are such as might be explained by the most extreme views as to the extent aud vastness of the ice-sheet, and especially as to its simultaneous occurrence in the northern and southern hemispheres; and where two such completely independent sets of fucts are found to combine harmoniously, and supplement each other on a particular hypothesis, the evidence in favour of that hypothesis is greatly strengthener. An objection that will occur to zoologists, may here be noticed. If the Glacial epoch extended over so much of the temperate and even parts of the tropical zone, and led to the extinction of so many forms of life even within the tropics, how is it that so much of the purely tropical fauna of South America has maintained itself, and that there are still such a vast number of forms, both of mamnalia, birds, reptiles, and insects, that seem organized for an exclusive existence in tropical forests? Now Mr. Belt's theory, of the subsidence of the occan to the extent of about 2,000 feet, smpplies an answer to this oljection; for we should thus have a tract of lowland of an average sidth of some hundreds of miles, added to the whole east const of Central and South Anerica. This tract would, no doubt, become covereal with forests as it was slowly formed, would enjoy a perfectly 
tropical climate, and would thus afford an ample area for the contimed existence and development of the typical Suuth American fauna; even had glaciers descended in places so low as what is now the level of the sea, which, however, there is no reason to believe they ever did. It is probable too, that this low tract, which all round the Gulf of Mexico would be of considerable width, offered that passage for intermigration between North and South America, which led to the sudden appearance in the former country in Post-Pliocene times, of the liuge Megatheroids from the latter; a migration which took place in opposite directions as we shall presently show.

The birth-place and migrations of some mammatian families and generd.-We have now to consider a few of those cases in which the evidence already at our command, is sufficiently definite and complete, to enable us to promounce with some confidence as to the last movements of several important groups of mammalia.

Primates.-The occurrence in North America of numerous forms of Lemuroidea, forming two extinct families, which are believed by American palcontologists to present gencralized features of both Lemuridæe and Hapalidæ, while in Europe only Lemurine forms allied to those of Africa have occurred in deposits of the same are (Eocene), renders it possible that the Primates may have originated in America, and sent one branch to South America to form the Hapalidæ and Cebidæ, and another to the Old World, giving rise to the lemurs and true apes. But the fact that apes of a high degree of organization occur in the European Miocene, while in the Eocene, a monkey beliered to have relations to the Lemuroids and Cebidæ has also been discovered, make it more probable that the ancestral forms of this order originated in the Old World at a still earlier period. The absence of any early tertiary remains from the tropical parts of the two hemispheres, renders it impossible to arrive at any definite conclusions as to the origin of groups which were, no doubt, always best developed in tropical regions.

Carnivora.-This is a very ancient and wide-spread group, the families and genera of which had an extensive range in very 
early times. The true bears (Ursus) are almost the only important genus that seems to lave recently migrated. In Europe it dates back to the Older Pliocene, while in Forth Anerica it is Post-Pliocene only. Bears, therefore, seem to have passed into America from the Palæaretic region in the latter part of the l'liocene period. They probably came in on the north-west, and passed down the Andes into South Anerica, where one isolated species still exists.

Ungulata.-Horses are very interesting. In Europe they date back under various forms to the Miocene period, and true Equus to the Older Pliocene. In North America they are chicfly Pliocene, true Equus being Post-Pliocene, with perhaps one or two species Newrer Pliocene; but numerous ancestral forms date back to the Miocene and Eocene, giving a more perfect "pedigree of the horse" than the European forms, and going back to a more primitive type-Orohippus. In South America, Equus is the only genus, and is Post-Pliocene or at most Newer Pliocene. While, therefore, the ancient progenitors of the Equidæ were common to North America and Europe, in Miocene and even Eocene times, true horses appear to have arisen in the Palæarctis region, to have passed into North America in the latter part of the Pliocene period, and thence to have spread over all suitalle districts in South America. They were not, however, able to maintain themselves permanently in their new territory, and all became extinct; while in their birth-place, the Old World, they continue to exist under several varied forms.

True tapirs are an old World group. They go back to the Lnwer Miocene in Europe, while in both North and South America they are exclusively Post-Pliocene. They occur in France down to the Newer Pliocene, and must, alout that time, have entered America. The land connection by which this and so many other animals passed between the old and New Worlds in late Tertiary times, was almost certainly in the North Pacific, south of Behring's Straits, where, as will be seen by our general map, there is a large expanse of shallow water, which a moderate elevation would convert into dry land, in a sufficiently temperate latitude. 
The peccary (Dicotyles), now a characteristic South American genus, is a recent immigrant from North America, where it appears to have been developed from ancestral forms of swine dating back to the Miocene period.

Antelopes are an Old World type, but a few of them appear to have entered North, and reached South America in late Pliocene times. Camels, strange to say, are a special North American type, since they abounded in that continent under various ancient forms in the Miocene perind. Towards the end of that period they appear to have entered eastern Asia, and developed into the Siberian Merycotherium and the North Indian Camelus, while in the Pliocene age the ancestral llamas entered South America.

Cervida are a wide-spread northern type in their generalized form, but true deer (Cervus) are Palæarctic. They abounded in Europe in Miocene times, but only appear in North and South America in the later Pliocene and Post-Pliocene periods.

True oxen (Bovince) seem to be an Oriental type (Miocene), while they appear in Europe only late in the Pliocene period, and in America are confined to the Post-Pliocene.

Elephants (Elephantidce) are an Old World type, abounding in the Miocene period in Europe and Iudia, and first appearing in America in Post-Pliocene or later Pliocene times. Ancestral forms, duubtfully Proboscidean (Dinocerata), existed in North America in the Eocene period, but these became extinct without leaving any direct descendants, unless the Brontotheridce and rhinoceroses may be so considered.

Marsupials are almost certainly a recent introduction into South and North America from Asia. They existed in Europe in Eocene and Miocene times, and presumably over a considerable part of the Old World; but no trace of them appears in North or South America before the Post-Pliocene period.

Edentata.-These offer a most curious and difficult problem. In South America they abound, and were so much more numerous and varied in the Post-Pliocene and Pliocene, that we may be sure tlicy lived also in the precedin Miocene period. A few living Edentates are scattered over Africa and Asia, and 
they flourished in Europe during the Miocene age-animals as large (in some species) as a rhinoceros, and most allied to living African forms. In North America no trace of Edentata lias heen found earlier than the Post-Pliocene period, or perhaps the Newer Pliocene on the west coast. Neither is there any trace of them in South America in the Eocene formations; but this may well be owing to our very imperfect knowledge of the forms of that epoch. Their absence from North America is, however, probably real; and we have to account for their presence in the old World and in South America. Their antiquity is no doubt very great, and the point of divergence of the Old WTorld and South American groups, may take ris back to early Eocene, or even to Pre-Eocene times. The distribution of land and sea may then have been very different from what it is now; and to those who would create a continent to account for the migrations of a beetle, nothing would seem more probable than that a South Atlantic continent, then united parts of what are now Africa and South America. There is, hcwever, so much evidence for the general permanence of what are now the great continents and deep oceans, that Professor Huxley's supposition of a considerable extension of land round the borders of the North Pacific Ocean in Mesozoic times, hest indicates the probable area in which the Edentate type originated, and thence spread over much of the Old World and South America. But while in the latter country it flourished and increased with little check, in the other great continents it was soon overcome by the competition of higher forms, only leaving a few small-sized representatives in Africa and Asia. 


\title{
CHAPTER VIIT.
}

\author{
VARIOUS EXTINCT ANINALS;-AND ON TIE ANTIQUTTY OF THE \\ GENERA OF INSECTS AND LAND MOLLUSCA.
}

EXTINCT MAMMALIA OF AUSTRALIA.

THese have all been obtained from caves and late Tertiary or Post-Tertiary deposits, and consist of a large number of extinct forms, some of gigantic size, but all marsupials and allied to the existing fauna. There are numerous forms of kangaroos, some larger than any living species; and among these are two genera, Protemnodon and Sthenurus, which Professor Garrod has lately shown to have been allied, not to any Australian forms, but to the Dendrolagi or tree-kangaroos of New Guinea. We have also remains of Thylacinus and Dasynurus, which now only exist in Tasmania; and extinct species of Hypsiprymnus and Phascolomys, the latter as large as a tapir. Among the more remarkable extinct genera are Diprotodon, a huge thick-limbed animal allied to the kangaroos, but nearly as large as an elephant; Nototherium, having characters of Macropus and Phascolarctos combined, and as large as a rhinoceros; and Thylacolco, a phalauger-like marsupial nearly as large as a lion, and supposed by Professor Owen to have been of carnivorous habits, though this opinion is not held by other naturalists.

Here then we find the same phenomena as in the other countries we have already discusser, - - the very recent disappcarance of a large number of pesuliar forms, many of them far surpassing in size any that continue to exist. It hardly seems probable that in this case their disappearance can have been due to the direct effects of the Glacial epoch, since no very extensive glacia- 
tion could have occurred in a comntry like Australia; but if the ocean sank 2,000 feet, the great castern nountain range might have given rise to local glaciers. It is, however, almost certain that during late Tertiary times Australia must have heen much more extensive than it is now. This is necessary to allow of the development of its peculiar and extensive fauna, especially as we sce that that fauna comprised animals rivalling in bulk those of the great continents. It is further indicated by the relations with New Guinca, already alluded to, and by the general character of the various faunas which compose the Australian region, details of which will be found in the succeeding part of this work. The lowering of the ocean during the Glacial period would be favourable to the still further development of the fauna of such a country; and it is to the unfavourable conditions produced by its subsequent rising-equivalent to a depression of the land to the amount of two thousand feet-that we must impute the extinction of so many remarkable groups of animals. It is not improbable, that the disappearance of the ice and the consequent (apparent) subsidence of the land, might have been rapid as compared with the rate at which large animals can become modified to meet new conditions. Extensive tracts of fertile land might have been submerged, and the consequent crowding of large numbers of species and individuals on limited areas would have led to a struggle for existence in which the less adapted and less easily modifiable, not the physically weaker, would succumb.

There is, however, another cause for the extinction of large rather than small animals whenever an important change of conditions occurs, which has been suggested to me by a correspondent, 1 but which has not, I believe, been adduced by Mr. Darwin or by any other writer on the subject. It is dependent on the fact, that large animals as compared with small ones are almost invariably slow breeders, and as they also necessarily cxist in much smaller numbers in a given area, they offer fir less materials for favourable variations than do smaller animals. In such an extreme case as that of the rabbit and elephant, the

1 Mr. John Hickman of Desborough. 
young born each year in the world are probably as some millions to one; and it is very easily conceivable that in a thousand years the former might, under pressure of rapidly changing conditions, become modified into a distinct species, while the latter, not offering enough favourable variations to effect a suitable adaptation, would become extinct. We must also remember the extreme specialization of many of the large animals that have become extinct-a specialization which would necessarily render modification in any new direction difficult, since the inherited tendency of variation would probably be to increase the specialization in the sime directions which had heretofore been beneficial. If to these two causes we add the difficulty of obtaining sufficient food for such large animals, and perhaps the injurious effects of changes of climate, we shall not find it difficult to understand how such a vast physical revolution as the Glacial epoch, with its attendant phenomena of elevations and subsidences, icy winds, and sudden floods by the bursting of lake barriers, might have led to the total extinction of a vast number of the most bulky forms of mammalia, while the less bulky were able to survive, either by greater hardiness of constitution or by becoming more or less modified. The result is apparent in the comparatively small or moderate size of the species constituting the ternperate fauna, in all parts of the globe.

It is much to be regretted that no mammalian remains of earlier date have been found in Australia, as we should then see if it is really the case that marsupials have always formed its highest type of mammalian life. At present its fossil fauna is chiefly interestiug to the zoologist, but throws little light on the past relations of this isolated country with other parts of the globe.

\section{Mamnalian ReNains in the Secondary Formations.}

In the oldest Tertiary beds of Europe and North America, we have (even with our present imperfect record) a rich and varied mammalian fauna. As compared with our living or recent highly specialized forms, it may be said to consist of generalised types; but as compared with any primeval mammalian type, it must be pronounced highly specialiscd. Not only are such dirersified 
(nroups as Camivora, Perrissoductyle and Artiolacty]e Ungrulates, T'rimates, Chiropteri, Rorlents, and Marsupials alrealy well marked, but in many of these there is a differentiation into numerous families and genern of diverse character. It is impessible therefore to doubt, that many peculiar furms of mammalia must have lived long anterior to the Eocene period; but there is unfortunately a great gap in the record between the Focene and Cietaceous beds, and these latter being for the most part marine continue the gap as regards mammals over an enormous lapse of time. Yet far beyond both these chasms in the Upper Oolitic strata, remains of small mammalia have been found; again, in the Stonesfield slate, a member of the Lower Oolite, other forms appear. Then comes the marine Lias formation with another huge gap; but beyond this again in the Upper Trias, the oldest of the secondary formations, inammalian tecth have been discovered in both England and Germany, and these are, as nearly as can be ascertained, of the same age as the Dromatherium already noticed, from North America. They have been named Microlestes, and show some resemblance to those of the West Australian Myrnecobius. In the Oolitic strata numerous small jawbones have been found, which have served to characterise eight genera, all of which are believed to have been Marsupials, and in some of them a resemblance can be traced to some of the smaller living Australian species. These, however, are mere indications of the number of mammalia that must have lived in the sccondary period, so long thought to be exclusively "the age of reptiles;" and the fact that the few yet found are at all comparable with such specialised forms as still exist, must convince us, that we shall have to seek far beyond even the earliest of these remains, for the first appearance of the mammalian type of vertebrata.

\section{LXTinCt BiRDS.}

Compared with those of mammalia, the remains of birds are excecdingly scarce in Furope and America; and from the wandering halits of so many of this class, they are of much less value 
as indications of past changes in physical geography. A large proportion of the remains belong to aquatic or wading types, and as these have now often a world-wide range, the occurrence of extinct forms can have little bearing on our present inquiry. There are, however, a few interesting cases of extinct land-birds belonging to groups now quite strangers to the country in which they are found; and others scarcely less interesting, in which groups now peculiar to certain areas are shown to have been preceded by allied species or genera of gigantic size.

Palcearctic Region and $N$. India. -In the caves and other Post-Pliocene deposits of these countries, the remains of birds almost all belong to genera now inhabiting the same districts. Almost the only exceptions are, the great auk and the capercailzie, already mentioned as being found in the Danish mounds; the latter bird, with Tetrco albus, in Italian caverns; and a species of pheasant (Phasianus) said to have occurred in the Post-Pliocene of France, considerably west of the existing range of the genus in a wild state.

In the preceding Pliocene deposits, but few remains have been found, and all of existing genera but one, a gallinaceous bird (Gallus bravardi) aliied to the domestic fowl and peacock.

The Miocene beds of France and Central Europe have produced many more remains of birds, but these, too, are mostly of existing European genera, though there are some notable exceptions. Along with forms undistinguishable from crows (Corvus), shrikes (Lanius), wagtails (Motacilla), and woodpeckers (Picus), are found remains allied to the Oriental edible-nest swift (Collocalia) and Trogon; a parrot resembling the African genus Psittacus; an extinct form Necronnis, perhaps allied to the plantain-eaters (Musophaga); Homalophus, doubtfully allied to woodpeckers, and Limnatornis to the hoopoes. The gallinaceous birds are represented by three species of pheasants, some very close to the domesticated species; Palcooperdix allied to the partridges; and Palcoortyx, small birds allied to the American genus Ortyx, but with larger wings. There are also species of Pterocles allied to living birds, and a small pigeon. There are numerous living genera of Accipitres; such as engle (Aquila), 
lite (Ifilmus), eagle-owl (Bubo), and screech-owl (Stris); with the African secretary-bird (Serpentarius), and sorne extinct forms, as Palococercus, Palocohierix and Palceetus.

Aquatic and wading birds were aloundant, including numerous mils, bustards, herons, sandpipers, gulls, divers, and pelicans. There were also many ducks, some allied to the genus Dendrocygna; the Oriental genus of storks, Leptoptitus; Ibitipoctiu, a remarkable form allied to Ibis and Ciconia; Elornis, near Limosa; Pelagornis, a large bird allierl to gannets and pelicans; Hydrornis, allied to the ducks and petrels; Dolichonterus, allied to plovers. Perhaps the most interesting of these extinct bircls are, however, the flamingoes, represented by forms hardly distinguishable from living species, and by one extinct genus Palolodus, which had very long toes, and probably walked on aquatic plants like the tropical jacanas.

The Miocene beds of North India have furnished few birds; the only one of geographical interest being an extinct species of ostrich, not very different from that now iuhabiting Arabia.

On the whole, the birds of Europe at this period were very Jike those now living, with the addition of a few tropical forms. These latter were, however, perhaps more numerous and important than they appear to be, as they belong to inland and foresthaunting types, which would not be so frequently preserved as the marsh and lake-dwelling species. Taking this into consideration, the assemblage of Miocene hirds accords well with what we know of the mammalian fauna. We have the same indications of a luxuriant vegetation and subtropical climate, and the same appearance of Oriental and especially of African types. Trogon is perhaps the most interesting of all the forms ret discovered, since it furnishes us with a central point whence the living trogons of Asia, Africa, and South America might have diverged.

In the Eocene we find ourselves almost wholly among extinct forms of birds. The earliest known Passerine bird is here met with, in Protornis, somewhat similar to a lark, found in the Lower Eocene of Switzerland; while annther Passerine form, Falagithalus, and one allied to the nuthatch (Sittr), hare been 
discovered in the Upper Eocene of Paris. Picarix of equal antiquity are found. Cryptornis, from the Paris Eocene, and Halcyornis from the Lower Eocene of the Isle of Sheppey, were both allied to kingfishers; while a form allied to Centropus a genus of cuckoos, or, as Milne-Edwards thinks, to the Madagascar Leptosomus, has been found in the Upper Eocene of France. Several Accipitres of somewhat doubtful aflinities have been found in the same country; while Lithomis, from the Lower Eocene of the Isle of sheppey, was a small vulturine bird supposed to be allied to the American group, Cathartes. Among the waders, some extinct forms of plovers have been found, and a genus (Agnopterus), allied to the flamingoes; while there are many swimming birds, such as pelicans, divers, and several extinct types of doubtful affinities. Most intersting of all is a portion of a cranium discovered in the Lower Eocene of Sheppey, and lately pronounced by Professor Owen to belong to a large Struthious bird, allied to the New Zealand Dinomis and also perhaps to the ostrich. Another gigantic bird is the Gastornis, from the Lower Eocene of Paris, which was as large as an ostrich, but which is believed to have been a generalised ty'pe, allied to wading and swimming lirds as well as to the Struthiones.

Beyond this epoch we have no remains of birds in European strata till we come to the wonderful Archooptemy from the Upper Oolite of Bavaria; a bird of a totally new type, with a bony tail, longer tlian the body, each vertebra of which carried a pair of diverging feathers.

North America.-A number of bird-renains have lately been found in the rich Tertiary and Cretaceous deposits of the United States; lut here, too, comparatively few are terrestrial forms. No I'asserine bird has yet been found. The Picariæ are represented by Uintornis, an extinct form allied to woodpeckers, from the Eocene of Wyoming. Species of turkey (Meleagris) occur in the Post-Pliocene and as far back as the Miocene strata, showing that this interesting type is a true denizen of temperate North America. The other birds are, Accipitres; waders and aquatics of existing genera; and a number of extinct forms of the two latter ordens-such as, Aletornis an Eocene wader; 
Palcotringa, allied to the sandpipers, and Telmatobius to the rails, both Cretaceous; with Graculavus, allied to Graculus; Laornis allied to the swans; Hesperornis a gigantic diver; and Icthyornis a very low form, with biconcave vertebra, such as are only found in fishes and some reptiles-also from Cretaceous deposits.

South America.-The caverns of Brazil produced thirty-four species of birds, most of them referable to Brazilian genera, and many to still existing species. The most interesting were two species of American ostrich (Flcea), one larger than either of the living species; a large turkey-buzzard (C'athartes); a new species of the very isolated South American genus Opisthocomus; and a Cariama, or allied new genus.

Madagascar and the Mascurene Istands.-We have here only evidence of birds that have become extinct in the historical period or very little earlier. First we have a group of birds incapable of flight, allied to pigeons, but forming a separate family, Dididee; and which, so far as we yet know, inhabited Mauritius, Rodriguez, and probably Bourbon. Aphanapteryx, an extinct genus of rails, inhabited Mauritius; and another genus, (Erythromachus), Rodriguez. A large parrot, said by Prof. Milne Edwards to be allied to Ara and Microglossus, also inhabited Mauritius; and another allied to Eclectus, the island of Liodriguez. None of these have been found in Madagascar; but a gigantic Struthious bird, Aspyomis, furming a peculiar family distinct both from the ostriches of Africa and the Dinornis of New Zealand inhabited that island; and there is reason to believe that this may have lived less than 200 years ago.

New Zealand.-A number of extinct Struthious birds, forming two families, Dinornithidce and Palapterygida, have been found in New Zealand. Some were of gigantic size. They seem allied both to the living Apteryx of New Zealand and the emu of Australia. They are quite recent, and some of them have probably lived within the last few centuries. Remains of Dinomis have also been found in a Post-Pliocene deposit in Queensland, N. F. Australia ${ }^{1}$ - a very important discovery, as it 1 Trans, Zool, Soc. of London, rol, viii. p. 381. 
gives support to the theory of a great eastward extension of Australia in Tertiary times.

\section{Extinct Tertiary Reptiles.}

These will not occupy us long, as no very great number are known, and most of them belong to a few principal forms of comparatively little geographical interest.

Tortoises are perhaps the most abundant of the Tertiary reptiles. They are numerous in the Eocene and Miocene formations both in Europe and North America. The genera Emys and Trionyx abound in both countries, as well as in the Miocene of India. Land tortoises occur in the Eocene of North America and in the Miocene of Europe and India, where the huge Colossochclys, twelve feet long, has been found. In the Pliocene deposits of Switzerland the living American genus Chelydra has been met with. These facts, together with the occurrence of a living species in the Miocene of India, show that this order of reptiles is of great antiquity, and that most of the genera once had a wider range than now.

Crocodiles, allied to the three forms now characteristic of India, Africa, and America, have baen found in the Eocene of our own country, and several species of Crocodilus have occurred in beds of the same age in North America.

Lizards are very ancient, many small terrestrial forms occurring in all the Tertiary deposits. A species of the genus Chanceleo is recorded from the Eocene of North America, together with several extinct genera.

Snakes were well developed in the Eocene period, where remains of several have been found which must have been from twelve to twenty feet long. An extinct species of true viper has occurred in the Miocene of France, and one of the Pythonidro in the Miocene brown coal of Germany.

Batrachia occur but sparingly in a fossil state in the Tertiary deposits. The most remarkable is the large Salamander Andreas) from the Tpper Miocene of Switzerland, which 
is allied to the Henopona living in North America. Species of frog $(\operatorname{Ran} \alpha)$, and I'alaophryus an extinct genus of toads, have been found in the Miocune deposits of Germany and Switzerland.

Fresh water fish are almost unknown in the Tertiary deposits of Europe, although most of the families and some genera of living marine lish are represented from the Eucene downwards.

\section{Antiquity of the Genera of Insects.}

Fossil insects are far too rarely found, to aid us in our determination of difficult questions of geographical distribution; but in discussing these questions it will be important to know, whether we are to look upon the existing generic forms of insects as of great or small antiquity, compared with the higher vertebrates; and to decide this question the materials at our command are ample.

The conditions requisite for the preservation of insects in a fossil state are no doubt very local and peculiar; the result being, that it is only at long intervals in the geological record that we meet with remains of insects in a recognisable condition. None appear to have been found in the Pliocene formation; but in the Upper Miocene of Eninghen in Switzerland, associated with the wonderfully rich fossil flora, are found immense quantities of insects. Prof. Heer examined more than 5,000 specimens belonging to over 800 species, and many have been found in other localities in Switzerland; so that more than 1,300 species of Miocene insects have now been determined. Most of the orders are represented, but the bcetles (Colcoptera) are far the most abundant. Almost all belong to existing genera, and the majority of these genera now inhabit Europe, only three or four being exclusively Indian, African, or American.

In the Lower Miocene of Croatia there is another rich deposit of insects, somewhat more tropical in character, comprising large white-ants and dragon-flies differently marked from any 
now inhabiting Europe. A buttertly is also well preserved, with all the markings of the wings; and it seems to be a Junonia, a tropical genus, though it may be a $V$ anessa, which is European, but the fossil most resembles Indian species of Junonia.

The Eocene formations seem to have produced no insect remains; but they occur again in the Upper Cretaceous at Aix-la.Chapelle, where two butterflies have been found, Cyllo sepulta and Satyrites Reynesii, both belonging to the Satyridre, and the former to a genus now spread over Africa, India, and Australia.

A little earlier, in the Wealden formation of our own country, numerous insects have been found, principally dragon flies (Libellula, Ashna); aquatic Hemiptera (Velia Hydrometra); crickets cockroaches, and cicadas, of familiar types.

Further back in the Upper Oolite of Bavaria-which produced the wonderful long-tailed bird, Archoeopteryx-insects of all orders have been found, including a moth referred to the existing genus Sphinx.

In the Lower Oolite of Oxfordshire many fossil beetles have been found whose affinities are shown by their names:-Buprestidium, Curculionidium, Blapsidium, Melolonthidium, and Prionidium; a wing of a butterfly has also been found, allied to the Brassolidæ now confined to tropical America, and named Paloontina oolitica.

Still more remote are the insects of the Lias of Gloucestershire, yet they too can be referred to well-known family typesCarabidæ, Melolonthidæ, Telephoridæ, Elateridæ, and Curculionidæ, among beetles; Gryllidæ and Blattidæ among Orthoptera; with Libellula, Agrion, Ashna, Ephemera, and soine extinct genera. When we consider that almost the only vertebrata of this period were huge Saurian repliles like the Icthyosaurus, Plesiosaurus, and Dinosaurus, with the flying Pterodactyles; and that the great mass of our existing genera, and even families, of tish and reptiles had almost certainly not come into existence, we see at once that types of insect-form are, proportionately, far more ancient. At this remote epocls we timl the chicl family types (the genera of the time of Limnus) perfectly differentiated 
and recognisable. It is only when we go further back still, into the Palæozoic formations, that the insect forms begin to show that generalization of type which render's it impossible to classify them in any existing groups. Yet even in the coal formation of Nova Scotia and Durham, the fossil insects are said by competent entomologists to be "allied to Ephemeru," "near Blatta," "near Phasmidce;" and in deposits of the same age at Saarbruick near Trèves, a well-preserved wing of a grasshopper or locust has been found, as well as a beetle referred to the Scarabeidie. More remarkable, however, is the recent discovery in the carboniferous shales of Belgium, of the clearly-defined wing of a large moth (Breyeria borinensis), closely resembling some of the Saturniidæ; so that we have now all the chief orders of Insects-including those supposed to be the most highly developed and the most recent-well represented at this very remote epoch. Even the oldest insects, from the Devonian rocks of North America, can mostly be classed as Neuroptera or Myriapoda, but appear to form new families.

We may consider it, therefore, as proved, that many of the larger and more important genera of insects date back to the beginning of the Tertiary period, or perhaps beyond it; but the family types are far older, and must have been differentiated very early in the Secondary period, while some of them perhaps go back to Palæozoic times. The great comparative antiquity of the generc is however the important fact for us, and we shall have occasion often to refer to it, in endeavouring to ascertain the true bearing of the facts of insect distribution, as elucidating or invalidating the conclusions arrived at from a study of the distribution of the higher animals.

\section{Antigutty of thf Gexelia of Land and Fresh-Water SHELLS.}

The remains of land and fresh-water shells are not much more frequent than those of insects. Like them, too, their forms are very stable, contiuuing unchanged through several geological 
periors. In the Pliocene and Miocene formations, most of the shells are very similar to living species, and some are quite identical. In the Eocene we meet with ordinary forms of the genera Helix, Clansitia, Pupa, Bulimus, Glandina, Cyclostoma, Megalostoma, Planorbis, Paludina and Limnae, some resembling European species, others more like tropical forms. A British Eocene species of Heliz is still living in Texas; and in the South of France are found species of the Brazilian sub-genera Megaspira and Anastoma. In the secondary formation no true land shells have been found, but fresh water shells are tolerably abundant, and almost all are still of living forms. In the Wealden (Lower Cretaceous) and Purbeck (Upper Oolite) are found Unio, Melania, Paludina, Planorbis, and Limncea; while the last named genus occurs even in the Lias.

The notion that land shells were really not in existence during the secondary period is, however, proved to be erroneous by the startling discovery, in the Palæozoic coal measures of Nova Scotia, of two species of Helicidæ, both of living genera-Pupa vetusta, and Zonites priscus. They have been found in the hollow trunk of a Sigillaria, and in great quantities in a bed full of Stigmarian rootlets. The most minute examination detects no important differences of form or of microscopic structure, between these shells and living species of the same genera! These mollusca were the contemporaries of Labyrinthodonts and strange Ganoid fishes, which formed almost the whole vertebrate fauna. This unexpected discovery renders it almost certain, that numbers of other existing genera, of which we have found no traces, lived with these two through the whole secondary period; and we are thus obliged to assume as a probability, that any particular genus has lived through a long succession of geological ages. In estimating the importance of any peculiarities or anomalies in the gengraphical distribution of land shells as compared with the higher vertebrates, we shall, therefore, have to keep this possible, and even probable high antiquity, constantly in mind.

We have now concluded our sketch of Tertiary Palæontology as a preparation for the intelligent study of the Gengraphical 
Distribution of Land Animals; and however imperfectly the task has been performed, the reader will at all events have been convinced that some such preliminary investigation is an essential and most important part of our work. So much of palieontology is at present tentative and conjectural, that in combining the information derived from numerous writers, many errors of detail must have been made. The main conclusions have, however, been drawn from as large a basis of facts as possible; and although fresh discoveries may show that our views as to the past history of some of the less important genera or families are erroneous, they can hardly invalidate our results to any important degree, either as regards the intercommunications between separate regions in the various geological epochs, or as to the centres from which some of the more important groups have been dispersed. 


\section{PART III.}

\section{ZOOLOGICAL GEOGRAPHY:}

A REVIEW OF THE CHIEF FORMS OF ANIMAL LIFE IN THE SEVERAL REGIONS AND SUB-REGIONS, WITH THE INDICATIONS THEY AFFORD OF GEOGRAPHICAL MUTATIONS. 



\section{CHAPTER IX.}

THE ORDER OF SUCCESSION OF THE REGIONS.-COSMOPOLITAN GROUPS OF ANIMALS.-TABLES OF DISTRIBUTION.

Having discussed, in our First Part, such general and preliminary matters as are necessary to a proper comprehension of our subject; and having made ourselves acquainted, in our Second Part, with the most important results of Palæontology, we now come to our more immediate subject, which we propose to treat first under its geographical aspect. Taking each of our six regions in succession, we shall point out in some detail the chief zoological features they present, as influenced by climate, vegetation, and other physical features. We shall then treat each of the sub-regions by itself, as well as such of the islands or other sub-divisions as present features of special interest; endeavouring to ascertain their true relations to each other, and the more important changes of physical geography that seem necessary to account for their present zoological condition.

Order of Succession of the Regions.- We may here explain the reason for taking the several regions in a different succession from that in which they appear in the tabular or diagrammatic headings to each family, in the Fourth, and concluding part of this work. It will have been seen, by our examination of extinct animals (and it will be made still clearer during our study of the several regions) that all the chief types of animal life appear to have originated in the great north temperate or northern continents; while the southern continents-now represented by 
South America, Australia, and South Africa with Madagascarhave been more or less completely isolated, during long periods, both from the northern continent and from each other. These latter countries have, however, veen sulject to more or less immigration from the north during rare epochs of approximation to, or partial union with it. In the northern, nore extensive, and probably more ancient land, the process of development has been more rapid, and has resulted in more varied and ligher types; while the southern lands, for the most part, seem to have produced numerous diverging modifications of the lower grades of organization, the original types of which they derived either from the north, or from some of the ancient continents in Mesozoic or Palrozoic times. Hence those curious resemblances in the fauna of South America, Australia, and, to a less extent, Madagascar, which have led to a somewhat general belief that these distant countries must at one tirne or other have been united; a belief which, after a careful examination of all the facts, does not seem to the author of this work to be well founded. On the other hand, there is the most satisfactory evidence that each southern region has been more or less closely united (during the tertiary or later secondary epoch) with the great northern continents, leading to numerous resemblances and affinities in their productions.

In endeavouring to present at a glance in the most convenient manner, the distribution of the families in the several regions and sub-regions, it was necessary to arrange them, so that those whose relations to each other were closest should stand side by side; the first and last being those between which the relations were least numerous and least important. Influenced by the usual opinions as to the relations between Australia and South America, the series was at first begun with the Nearctic, and terminated with the Australian and Neotropical regions; and it was not till the whole of the vertebrate families had been gone through, and their distribution carefully studied, that these last two regions were seen to be really widcr apart than any others of the series. It was therefore decided to alter the arrangement, beginning with the Neotropical, and ending with the Australian 
regions; and a careful inspection of the diagrams themselves, taken in their entirety, will, it is believed, show that this is the most natural plan, and most truly exhibits the relations of the several regions.

In the portion of our work now commencing, we are not, however, by any means bound to begin at either end of this series. Each region is studied by itself, but reference will often have to be made to all the other regions; and wherever we begin, we must occasionally refer to facts which will be given further on. As, however, the great northern continents form the central mass from which the southern regions, as it were, diverge, and as the Palæarctic region is both more extensive and much better known than any other, it undoubtedly forms the most convenient starting-point for our proposed survey of the zoological history of the earth. We thus pass from the better known to the less known-from Europe to Africa and tropical Asia, and thence to Australia, completing the series of regions of the Eastern Hemisphere. Beginning again with the Neotropical region, we pass to the Nearctic, which has such striking relations with the preceding and with the Palæarctic region, that it can only be properly understood by constant reference to both. We thus keep separate the Eastern and Western hemispheres, which form, from our point of view, the most radical and most suggestive division of terrestrial faunas; and as we are able to make this also the dividing point of our two volumes, reference to the work will be thereby facilitated.

Cosmopolitan Groups.-Before proceeding to sketch the zoological features of the several Pegions it will be well to notice those fanily groups which belong to the earth as a whole, and which are so widely and universally distributed over it that it will be unnecessary, in some cases, to do more than refer to them under the separate geographical divisions.

The only absolutely cosmopolitan families of Mammalia are those which are aerial or marine; and this is one of the striking proofs that their distribution has been effected by natural causes, and that the permanence of barriers is one of the chief 
ngencies in the limitation of their range. Even among the aerial bats, however, only one family-the Vespertilionidæ-is truly cosmopolitan, the others having a more or less restricted range. Neither are the Cetacea necessarily cosmopolitan, most of the families being restricted either to warm or to cold seas; but one family, the dolphins (Delphinidx), is truly so. This order however will not require further notice, as, being exclusively marine the groups do not enter into any of our terrestrial regions. The only other family of mammals that may be considered to be cosmopolitan, is the Muridxe (rats and mice); yet these are not entirely so, since none are known to be truly indigenous in any part of the Australian region except Australia itself.

In the class of Birds, a number of families are cosmopolites, if we reckon as such all which are found in each region and sub-region; but several of these are so abundant in some parts, while they are so sparingly represented in others, that they cannot fairly be considered so. We shall confine that term therefore, to such as, there is reason to believe, inhabit every important sub-division of each region. Such are, among the Passerine birds the crows (Corvidx), and swallows (Hirundinidæ); among the Picariæ the kingfishers (Alcedinidæ); among other Land birds the pigeons (Columbidx), grouse and partridges (Tetraonidæ), hawks (Falconidæ), and owls (Strigidæ); among the Waders the rails (Rallidæ), snipes (Scolopacidæ), plovers (Charadriadæ), and herons (Ardeidæ); and among the Swimmers the ducks (Anatidæ), gulls (Laridæ), petrels (Procellariidæ), pelicans (Pelecanidæ), and grebes (Podicipidæ).

In the class of Reptiles there are few absolutely cosmopolitan families, owing to the scarcity of members of this group in some insular sub-regions, such as New Zealand and the Pacific Islands. Those which are most nearly so are the Colubrida among snakes. and the Scincidæ among lizards.

There is no cosmopolitan family of Amphibia, the true frogs (Ranidæ) being the most widely distributed.

Neither is any family of Freshwater Fishes cosmopolitan, the Siluridæ, which have the widest range, being confined 
to warm regions, and becoming very scarce in the temperate zones.

Among the Diumal and Crepuscular Lepidoptera (butterflies and sphinges) the following families are cosmopolitan :- Satyridæ, Nymphalida, Lycænidæ, Pieridæ, Papilionidæ, Hesperidæ, Lycænidæ, and Sphingidæ.

Of the Coleoptera almost all, except some of the small and obscure families, are cosmopolitan.

Of the terrestrial Mollusca, the Helicidæ alone are true cosmopolites.

Tables of Distribution of Familics and Generc.-Having been obliged to construct numerous tables of the distribution of the various groups for the purposes of the descriptive part of the work, I have thought it well to append the most important of them, in a convenient form, to the chapter on each region; as much information will thereby be given, which can oniy be obtained from existing works at the cost of great labour. All these tables are drawn up on a uniform plan, the same generic and family names being used in each; and all are arranged in the same systematic order, so as to be readily comparable with each other. This, although it seems a simple and natural thing to do, has involved a very great amount of labour, because hardly two authors use the same names or follow the same arrangement. Hence comparison between them is impossible, till all their work has been picked to pieces, their synonymy unravelled, their differences accounted for, and the materials recast; and this has to be done, not for two or three authors only, but for the majority of those whose works have been consulted on the zoology of any part of the globe.

Except in the two higher orders-Mammalia and Birdsmaterials do not exist for complete tables of the genera brought down to the present time. We have given therefore, first, a complete table of all the families of Vertebrata and Dinnal Lepidoptera found in each region, showing the sub-regions in which they occur, and their range heyond the limits of the recrion. Families which are wholly peculiar to the region, or 
very characteristic and almost exclusively confined to it, are in ilaties. The number prefixed to each finnily corresponds to that of the series of fimilies in the Fourth Lart of this work, so that if further information is repuired it can be readily referred to withont consulting the indox. Names incloser in parentheses-( . . . ) thus-indicate fimilies which only just enter a region from an arljacent one, to which they properly belong. The eye is thus directed to the more, and the less inportant families; and a considerable amount of information as to the general features of the zoulony of the region, is conveyer in the easiest manner.

The tables of genera of Manmalia and Birls, are arranged on a somewhat different plan. Each genus is given under its Family and Order, and they follow in the same succession in all the tables. The number of species of each genus, inhabiting the region, is given as nearly as can be ascertained; but in many cases this can only be a general approximation. The distribution of the genera within the region, is then given with some detail; and, lastly, the range of the genus heyond the region is given in general terms, the words "Oriental," "Ethiopian," \&c., being used for brevity, to indicate that the genus occurs over a considerable part of such regions. Genera which are restricted to the region (or which are very characteristic of it though just transgressing its limits) are given in italics; while those which only just enter the region from another to which they really belong, are enclosed in parentheses - ( . . ) thus. The genera are here numbered consecutively, in order that the number of - genera in each family or each order, in the region, may be readily ascertained (by one process of subtraction), and thus comparisons made with other regions or with any other area. As the tables of birds would be swelled to an inconvenient length by the insertion in each region of all the genera of Waders and Aquatics, most of which have a very wide range and would have to be repeated in several or all the regions, these have been omitted; but a list has been given of such of the genera as are peculiar to, or highly characteristic of each region.

As this is the first time that any such extensive tubles of 
distribution have been constructed for the whole of the Mammalia and Birds, they must necessarily contain many errors of detail; but with all their imperfections it is believed they will prove very useful to naturalists, to teachers, and to all who take. an intelligent interest in the wider problems of geography and natural history. 


\section{CHATTER X.}

THE PAIAEARCTIC REGION.

Tuls region is of immense extent, comprising all the temperate portions of the great eastern continents. It thus extends from the Azores and Canary Islands on the west to Japan on the cast, a distance not far short of half the circumference of the globe. Yet so great is the zoological unity of this vast tract, that the majority of the genera of animals in countries so far removed as Great Britain and Northern Japan are identical. Throughout its northern half the animal productions of the Palearctic region are very uniform, except that the vast elevated desert-regions of Central Asia possess some characteristic forms; but in its southern portion, we find a warm district at each extremity with somewhat contrasted features. On the west we have the rich and luxuriant Mediterranean sub-region, possessing many peculiar forms of life, as well as a few which are more especially characteristic of the Ethiopian region. On the east we have the fertile plains of Northern China and the rich and varied islands of Japan, possessing a very distinct set of peculiar forms, with others belonging to the Oriental region, into which this part of the Palæarctic region merges gradually as we approach the Tropic of Cancer. Thus, the countries roughly indicated by the names-Northern Europe, the Mediterranean district, Central and Northern Asia, and China with Japan-have each wellmarked minor characteristics which entitle them to the rauk of sub-regions. Their boundaries are often indefinable; and those here adopted have becn fixed upon to some extent by considera- 
I'A I.A:ARC

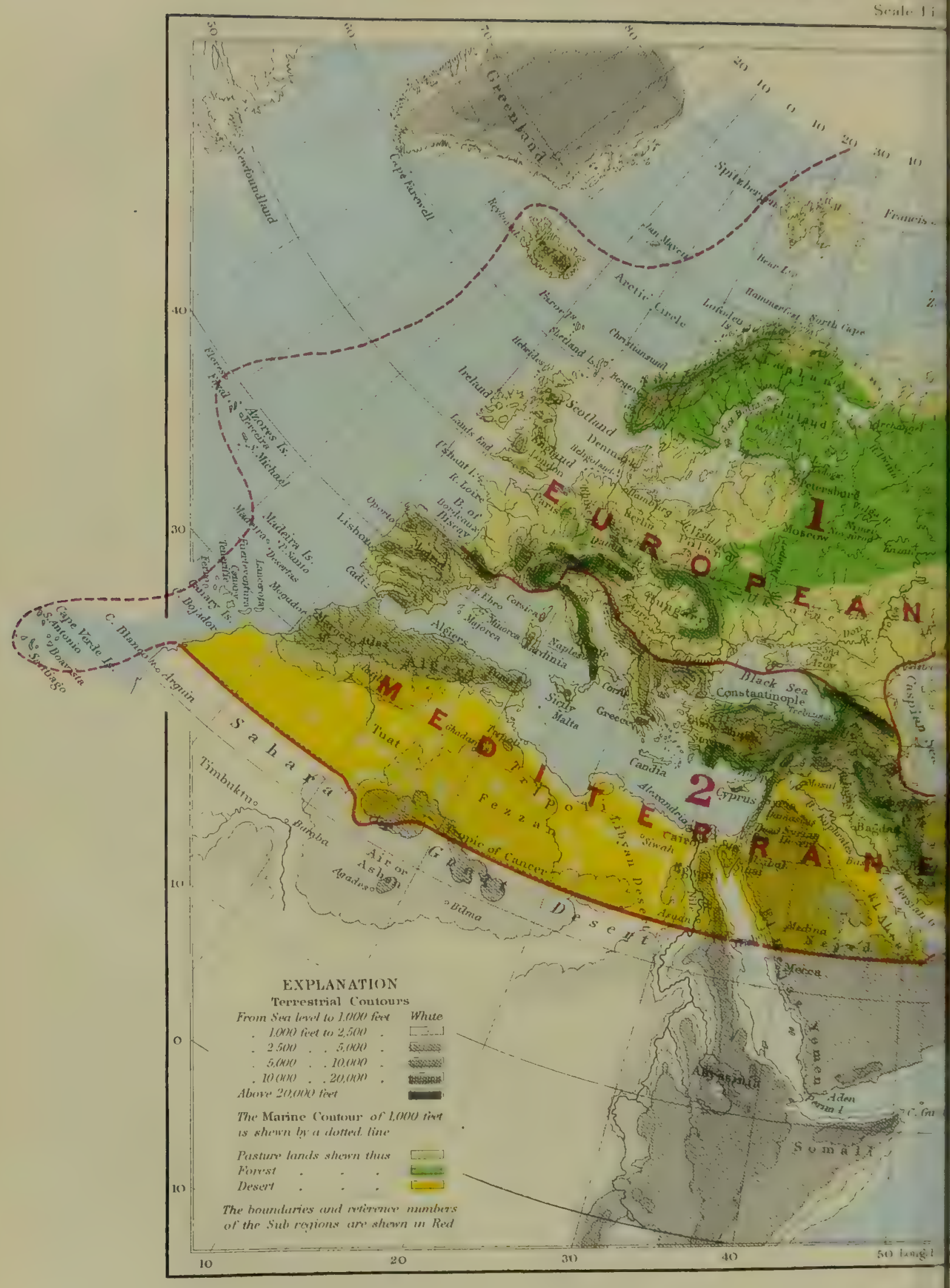

London : 

tions of convenience, dependent on custom and ou the more or less perfect knowledge we possess of some of the intervening countries.

Zoological Characteristics of the Palacarctic Region.-The Paliearctic region has representatives of thirty-five families of mammalia, fifty-five of birds, trenty-five of reptiles, nine of amphibia, and thirteen of freshwater fishes. Comparing it with the only other wholly temperate region, the Nearctic, we find a much greater variety of types of mammalia and birds. This may be due in part to its greater area, but more, probably, to its southern boundary being conterminous for an enormous distance with two tropical regions, the Ethiopean and Oriental; whereas the Nearctic has a comparatively short southern boundary conterminous with the Neotropical region only. This is so very important a difference, that it is rather a matter of surprise that the two north temperate regions should not be more unequal in the number of their higher vertebrate forms, than they actually are.

It is also to the interblending of the Palearctic with the two adjacent tropical regions, that we must attribute its possession of so few peculiar family groups. These are only three; two of reptiles, Trogonophidce and Ophiomoridie, and one of fishes, Comephoridce. The number of peculiar genera is, however, considerable, as the following enumeration will show.

Mammalia.-The monkey of Gibraltar and North Africa, and an allied species found in Japan, are now considered to belong to the extensive eastern genus Macacus. The former, however, is peculiar in the entire absence of the tail, and has by many naturalists, been held to form a distinct genus, Imuus, confined to the Palæarctic region.

Of bats there are one or two genera (Barbastellus, Plecotus) which seem to be mainly or wholly Palrarctic, but the classification of these animals is in such an unsettled state that the distribution of the genera is of little importance.

In the next order, Insectivora, we have almost the entire family of the Moles confined to the region. Talpa just enters Northern India; and Unotrifues is common to Tapan and North- 
Western America, but the remaining genera, six in number, are all exclusively Palæarctic.

Among Carnivora we have $N$ yctereules, the curious racoon-dog of Japan and North-Eastern Asia; Lutronectes, an otter peculiar to Japan; and the badger (Meles), which ranges over the whole region, and just enters the Oriental region as far as Hongkong; Aluropus, a curious form of the Himalayan panda, inhabiting the high mountains of Eastern Thibet; and Pelugins, a genus of seals, ranging from the shores of Madeira to the Black Sea.

The Ungulata, or hoofed animals, are still more productive of forms peculiar to this region. First we have the Camels, whose native home is the desert region of Central and Western Asia and Northern Africa, and which, even in their domesticated condition, are confined almost wholly within the limits of the Palæarctic region. Of Deer we have six peculiar genera, Dama and Capreolus found in Europe, with Elcephodus, Lophotragus, Hydropotes, and Moschus, confined to Northern China and Mongolia. The great family Bovidæ-comprising the oxen, sheep, goats and antelopes -furnishes no less than seven peculiar Palæarctic genera. These are Poephagus, the yak of Thibet; $A$ ddax, a well-known antelope of Northern Africa and Syria; Procapra, Pantholops and Budorcas, antelopine genera peculiar to Thibet and Mongolia; with Rupicapra (the chamois), and the extraordinary large-nosed antelope Saiga, confined to Europe and Western Asia. Besides these we have Capro (the wild sheep and goats), all the numerous species of which, except two, are exclusively Palaarctic.

Coming to the Rodents, we have again many peculiar forms. Of Muridx (the mouse and rat tribe), we have six peculiar genera, the more important being Cricetus, Rhombomys Sminthus, and Myospalax. Of Spalacidie (mole-rats) both the Palæarctic genera, Ellobius and Spalax, are peculiar. Ctenodactylus, a genus of the South American family Octodontidæ, is found only in North Africa. To these we may add Myoxus (the (lormice) and Layomys (the pikas or tail-less hares) as essentially Palrarctic, since but one species of each genus is found beyond the limits of the region.

Birds.-It appears to have been the opinion of many natural- 
ists that the Paliearctic region could not be well characterised by its peculiar genera of birds. In Mr. Sclater's celebrated paper' already referred to, he remarks, "It carnot be denied that the ornithology of the Paliearctic region is more easily characterised by what it has not than by what it has," and this has been quite recently quoted by Mr. Allen, in his essay on the distribution of North American birds, as if it represented our present know. ledge of the subject. But, thanks to the labours of Dr. Jerdon, Mr. Swinhoe, Père David and others, we have now learnt that a large number of birds included in the Indian list, are either mere winter emigrants from Central Asia, or only inhabit the higher ranges of the Himalayas, and thus really belong to the Palæarctic region. The result is, that a host of genera are now seen to be either exclusively or characteristically Palæarctic, and we have no further difficulty in giving positive ornithological characters to the region. In the talules appended to this chapter, all these truly Palaarctic genera will be found printed in italics, with an indication of their distribution, which will sometimes be found more fully given under the respective families in the third part of this work. Referring to this table for details we shall here summarise the results.

Of the Sylviidæ or warblers, no less than fourteen genera are either exclusively or characteristically Palæaretic, of which Locustella, Sylvia, Curruca and Erithacus are good examples. Of the oriental family Timaliidæ, the genus Pterortinus is Palæaretic. Of Panurida, or reedlings, there are four peculiar genera (comprising almost the whole family); of (Yerthiidæ, or creepers, one-Tichodroma - which extends southward to the Abyssinian highlands. Of Paridæ, or tits, one-Acredula ; of Corvidæ, or crows, four-Pica (containing our magpie) being a good example; of Fringillidæ, or finches and buntings, twelve, among which Acanthis, Pyrrhula and Emberiza are good illustrations; of Alaudidæ, or larks, there are two peculiar genera. Leaving the Passeres we next come to peculiar forms among the gallinaceous birds: Syprhaptes amongr the Pteroclidæ or sand grouse; four genera of Tetraonidæ or" grouse and partridges, and five of Phasianidæ or pheasants, comprising some of the most magnificent birds in the world. Iastly 
among the fur-windering aquatic binds we have no less than five genera which are more especially Palicarctic,-Oriygometre, the corn-crake, and Otis, the great bustard, being typical exam] les. We may akl to these, several genera almost confined to this region, such as Gurrulus (jays), Fringilla (true finches), Yuns? (wrynecks) and some others; so that in proportion to its total generic forms a very large number are found to be peculiar or characteristic.

This view, of the high degree of speciality of the Palicarctic region, will no doubt be objected to by some naturalists, on the ground that many of the genera reckoned as exclusively l'alrearctic are not so, but extend more or less into other regions. It is well, therefore, to consider what principles should guide us in a matter of this kind, especially as we shall have to apply the same rules to each of the other regions. We may remark first, that the limits of the regions themselves are, when not formed by the ocean, somewhat arbitrary, depending on the average distribution of a number of characteristic forms; ant that slight local peculiarities of soil, elevation, or climate, may cause the species of one region to penetrate more or less deeply into another. The land boundary between two regious will be, not a defined line but a neutral territory of greater or less width, within which the forms of both regions will intermingle; and this neutral territory itself will merge imperceptibly into both recrions. So long therefore as a species or genus does not permanently reside considerably beyonid the possible limits of this neutral territory, we should not claim it as an inhabitant of the adjacent region. A consideration of perhaps more importance arises, from the varying extent of the range of a grenus, over the area occupied by the region. Some genera are represented by single species existing only in a very limited area; others by numerous species which occupy, entirely or very nearly, the whole extent of the region; and there is every intermediate grade between these extremes. Now, the small localised genera, are always reckoned as among the best cxamples of types peculiar to a region; while the more wide-spread groulss are often denied that character if they extend a little beyourl 
the supposed regional limits, or send one or two, out of a large number of species, into adjacent regions; yet there is some reason to believe that the latter are really more important as characterising a zoological region than the former. In the case of a single isolated species or genus we have a dying-out group; and we have so many cases of discontinuous species of such groups (of which Urotrichus in Japan and British Columbia, Eupctes in Sumatra and New Guinea are examples), that it is quite as probable as not, that any such isolated species has only become peculiar to the region by the recent extinction of an allied form or forms in some other region. On the other hand, a genus consisting of numerous species ranging over an entire region or the greater part of one, is a dominant group, which has most likely been for some time extending its range, and whose origin dates back to a remote period. The slight extension of such a group beyond the limits of the region to which it mainly belongs, is probally a recent phenomenon, and in that case cannot be held in any degree to detract from its value as one of the peculiar forms of that region.

The most numerous examples of this class, are those birds of the temperate regions which in winter migrate, either wholly or partially, into adjacent warmer countries. This migration most likely began subsequent to the Miocene period, during that gradual refrigeration of the temperate zones which culminated in the glacial epoch, and which still continues in a mitigated form. Most of the genera, and many even of the species of birds which migrate southwards in winter, have therefore, most likely, always been inhabitants of our present Palæarctic and Nearctic regions; permanent residents during warm epochs, but only able now to maintain their existence by migration in winter. Such groups belong truly to the temperate zones, and the test of this is the fact of their not having any, or very few, representatives, which are permanent residents in the adjacent tropical regions. When there are such representative species, we do not claim them as peculiar to the Northern regions. Bearing in mind these various considerations, it will be found that we have been very moderate in our estimate of the number of genera 
that may fairly be considered as exclusively or characteristically Palæarctic.

Reptiles and Amphitica-The Palararctic resion possesses, in proportion to its limited reptilian fauna, a full proportion of peculiar types. We have for instance two genera of snakes, Rhinechis and Halys; seven of lizards, Trigonophis, Psanmodromus, Hyalosaurus, Scincus, Ophiomorus, Megalochilus, and Phrynocephalus; eight of tailed batrachians, Proteus, Sulamandra, Seiranota, Chioglossa, Hynobius, Onychodactylus, Geotriton, and Sieboldic; and eight of tail-less batrachians, Bombinator, Pelobates, Didocus, Alytes, Pelodytes, Discoylossus, Laprissa, and Latonia. The distribution of these and other Palrarctic genera will be found in our second vol. chap. xix.

Freshwater Fish.-About twenty genera of freshwater fishes are wholly confined to this region, and constitute a feature which ought not to be overlooked in estimating its claim to the rank of a separate primary division of the earth. They belong to the following families:--Percidx (three genera), Acerina, Percarina, Aspro; Comephoridæ (one genus), Comephorus, found only in Lake Baikal; Salmonidre (three genera), Brachymystax, Luciotrutta, and Plecoglossus; Cyprinodontidæ (one genus), Tellia, found only in Alpine pools on the Atlas Mountains; Cyprinidx (thirteen genera), Cyprinus, Carassus, Paraphoxinus, Tinca, Achilognathus, Rhodeus, Chondrostoma, Pseudoperilampus, Ochetebius, Aspius, Alburnus, Misgurnus, and Nemachilus.

Summary of Paloerctic Vertebrata.-Summarising these details, we find that the Palæarctic region possesses thirty-five peculiar genera of marnmalia, fifty-seven of birds, nine of reptiles, sixteen of amphibia, and twenty-one of freshwater fishes; or a total of 138 peculiar generic types of vertebrata. Of these, 87 are mammalia and land-birds out of a total of 274 genera of these groups; or rather less than one-third peculiar, a number which will serve usefully to compare with the results obtained in other regions.

In our chapter on Zoological liegions we have already pointed out the main features which distinguish the Paliearctic from the Oriental and Ethiopian regions. The details now given will 
strengthen our view of their radical distinctness, by showing to how considerable an extent the former is inhabited by peculiar, and often very remarkable generic types.

Insects : Lepidoptera.-The Diurnal Lepidoptera, or butterflies, are not very abundant in species, their number being probably somewhat over 500 , and these belong to not more than fifty genern. But no less than fifteen of these genera are wholly confined to the region. Nine of the families are represented, as follows:1. Danaidce; having only a single species in South Europe. 2. Satyrido; well represented, there being more than 100 species in Europe, and three peculiar genera. 3. Nymphalido; rather poorly represented, Europe having only about sixty species, but there is one peculiar genus. 4. Libytheidce; a very small family, represented by a single species occurring in South Europe. 5. Nemeobiidce; a rather sinall family, also having only one species in Europe, but which constitutes a peculiar genera. 6. Lycoenidoe; an extensive family, fairly represented, having about eighty European species; there are two peculiar genera in the Palæarctic region. 7. Piericloc; rather poorly represented with thirty-two European species; two of the genera are, however, peculiar. 8. Papilionidoe; very poorly represented in Europe with only twelve species, but there are many more in Siberia and Japan. No less than five of the small number of genera in this family are wholly confined to the region, a fact of much importance, and which to a great extent redeems the character of the Palæarctic region as regard this order of insects. Their names are Mesapia, Hypermnestra, Doritis, Sericinus, and Thais; and besides these we have Parnassiusthe "Apollo" butterflies-highly characteristic, and only found elsewhere in the mountains of the Nearctic region. 9. Hesperida ; poorly represented with about thirty European species, and one peculiar genus.

Four families of Sphingina occur in the Palæarctic region, and there are several peculiar genera.

In the Zygcenidce there are two exclusively European genera, and the extensive genus $Z$ ygana is itself mainly Palaarctic. The small family Stygiidce has two out of its three genera 


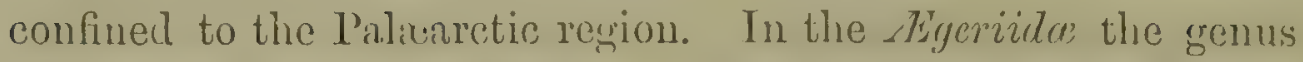
AEgeria is mainly Paladatic. The Sphingide have a wider general range, and none of the larger genera are peculiar to any one region.

Coleopterch,-The Palrearctic region is the richest portion of the globe in the great family of Carabidce, or predacious groundbeetles, about 50 of the genera being confined to it, while many others, including the magnificent genus Carabus, liave here their highest development. While several of the smaller genera are confined to the eastern or western sub-regions, most of the larger ones extend over the whole area, and give it an unmistakable aspect; while in passing from east to west or vice-versî, allied species and genera replace each other with considerable regularity, except in the extreme south-east, where, in China and Japan, some Oriental forms appeax, as do a few Ethiopian types in the south-west.

Cicindelidæ, or tiger-beetles, are but poorly represented by about 70 species of the genus Cicindele, and a single Tetracha in South Europe.

Lucanidæ, or stag-beetles, are also poor, there being representatives of 8 genera. One of these, Assalus (a single species), is peculiar to South Europe, and two others, Cladognathus and Cyclopthalmus, are only represented in Japan, China, and Thibet.

Cetoniidæ, or rose-chafers, are represented by 13 genera, two of which are peculiar to South Europe (Tropinota and Heterocnemis), while Stalagmosoma, ranging from Persia to Nubia, and the fine Dicranocephalus inhabiting North China, Corea, and Nipal, may also be considered to belong to it. The genera Trichins, Gnorimus, and Osmoderma are confined to the two north temperate regions.

Buprestidæ, or metallic beetles, are rather abundant in the warmer parts of the region, 27 genera being represented, nine of which are peculiar. By far the larger portion of these are confined to the Mediterranean sub-region. A considerable number also inhabit Japan and China.

The Longicorns, or long-horned beetles, are represented by no less than 196 genera, 51 of which are peculiar. They are 
much more abundant in the southern than the northern lialf of the region. Several Oriental genera extend to Japan and North China, and a few Ethiopian genera to North Africa. Thirteen genera are confined to the two north temperate regions. Several large genera, such as Dorcadion (15t species), Phytacia (85 species), Pogonocharus (22 species), Agapanthice (22 species), and Vesperus (7 species), are altogether peculiar to the Palaaretic region; and with a preponderance of Leptura, Grammopterce, Stenocoms, and several others, strongly characterise it as distinct from the Nearctic and Oriental regions.

The other families which are well developed in the Palrarctic regions, are, the Staphylinidæ or rove-beetles, Silphidæ or burying-beetles, Histeridæ or mimic-beetles, Nitidulidæ, Aphodiidæ, Copridæ (especially in South Europe), Geotrupidæ or dung-beetles, Melolonthidæ or chafers, Elateridæ or clickbeetles, the various families of Malacoderms and Heteromera, especially I'imeliidx in the Mediterranean sub-region, Curculionidæ or weevils, the Phytophaga or Ieaf-eaters, and Cocinellidæ or lady-birds.

The number of species of Coleoptera in the western part of the Yalæarctic region is about 15,000 , and there are probably not more than 2,000 to add to this number from Siberia, Tapan, and North China; but were these countries as well explored as Europe, we may expect that they would add at least 5,000 to the number above given, raising the Palæarctic Coleopterous fauna to 20,000 species. As the total number of species at present known to exist in collections is estimated (and perhaps somewhat over-estimaterl) at 70,000 species, we may be sure that were the whole earth as thoroughly investigated as Europe, the number would be at least doubled, since we cannot suppose that Europe, with the Mediterranean basin, can contain more than one-fifth of the whole of the Coleoptera of the globe.

Of the other orders of insects we here say nothing, because in their case much more than in that of the Coleoptera and Lepidoptera, is the disproportion enormous between our knowledge of the Euroyean fauna and that of almost all the rost of the globe. 
They are, therefore, at present of comparatively little use for purposes of geographical distribution, even were it advisable to enter into the subject in a work which will, perhaps, be too much overburdened with details only of interest to specialists.

Land Shells.-These are very numerous in the warmer parts of the region, but comparatively scarce towards the North. South Europe alone possesses over 600 species, whereas there are only 200 in all Northern Europe and Asia. The total number of species in the whole region is probably about 1,250 , of which the great majority are Helicidic; the Operculated families being very poorly represented. Several small genera or sub-genera are peculiar to the region, as Testacella (West Europe and Cunaries); Lencochroa (Mediterranean district); Acicula (Lurope); Craspedopoma (Atlantic Islands); Lconia (Algeria and Spain); Pomatias (Europe and Canaries); Cecince (Mongolia). The largest genera are Helix and Clausitic, which together comprise more than half the species; Pupa, very numerous; Bulimus and Achatina in moderate numbers, and all the rest small. Helix is the only genus which contains large and handsome species; Bulimus and Achatina, so magnificent in tropical countries, being here represented by small and obscure forms only. Daudebardic is confined to Central and South Europe and New Zealaud; Glandina is chiefly South American; Hyalina is only American and European; Buliminus ranges over all the world except America; and the other European genera of Helicidæ are widely distributed. Of the Operculata, Cyclotus, Cyclophorns, and Pupina extend from the Oriental region into Japan and North China; Tudoria is found in Algeria and the West Indies; Hydrocena is widely scattered, and occurs in South Europe and Japan. The genera of freshwater shells are all wirlely distributed.

\section{The Paldilictic SUb-RegioN's.}

The fuur sub-regions which arc here adopted, have becn fixed upon as those which are, in the present state of our knowledge, at once the most natural and the only practicable ones. 
No doubt all of them could be advantageously again subdivided, in a detailed study of the geographical distribution of species. But in a general work, which aims at treating all parts of the world with equal fulness, and which therefore is confined alniost wholly to the distribution of fimilies and genera, such further subdivision would be out of place. It is even difficult, in some of the classes of animals, to find peculiar or even characteristic genera for the present sub-regions; but they all have well marked climatic and physical differences, and this leads to an assemblage of species and of groups which are sufficiently distinctive.

\section{Central and Northern Europe.}

This sub-region, which may perhaps be termed the "European," is zoologically and botanically the best known on the globe. It can be pretty accurately defined, as bounded on the south by the Pyrenees, the Alps, the Balkans, the Black Sea, and the Caucasus range; and by the Ural Mountains, or perhaps more correctly the valley of the Irtish and Caspian Sea, on the east; while Ireland and Iceland are its furthest ontliers in the west. To the north, it merges so gradually into the Arctic zone that no denarcation is possible. The great extent to which this sub-region is interpenetrated by the sea, and the prevalence of westerly winds bringing warmth and moisture from an ocean influenced by the gulf-stream, give it a climate for the most part genial, and free from extremes of heat and cold. It is thus broadly distinguished from Siberia and Northern Asia generally, where a more extreme and rigorous climate prevails.

The whole of this sub-region is well watered, being penetrated by rivers in every direction; and it consists mainly of plains and undulating country of moderate elevation, the chief mountain ranges being those of Scandinavia in the north-west, arid the extensive alpine system of Central Europe. But these are both of moderate height, and a very small portion of their surface is occupied either by permanent snow-fields, or by barren uplands inimical to vegetable and animal life. It is, in 
fict, to these, and the numerous lesser mountains and hills which everywhere diversify the surface of Europe, that the variety and abundance of its animal life is greatly due. They afford the perennial supplies to rivers, and furnish in their valleys and ever varying slopes, stations suited to every form of existence. A considerable area of Central Europe is occupied by uplands of moderate elevation, a comparatively small portion being flat and marshy plains.

Most of the northern and mush of the central portions of Europe are covered with vast forests of coniferous trees; and these, occupying as they do those tracts where the winter is most severe, supply food and shelter to many animals who could not otherwise maintain their existence. It is probable that the original condition of the greater part, if not the whole, of temperate Europe, except the flat marshes of the river valleys and the sandy downs of the coast, was that of woodland and forest, mostly of deciduous trees, but with a plentiful admixture of such hardy evergreens as holly, ivy, privet, and yew. A sufficient proportion of these primeval woods, and of artificial plantations which have replaced them, fortunately remain, to preserve for us most of the interesting forms of life, which were developed before man had so greatly modified the surface of the earth, and so nearly exterminated many of its original tenants. Almost exactly in proportion to the amount of woodland that still remains in any part of Europe, do we find (other things being equal) the abundance and variety of wild animals; a pretty clear indication that the original condition of the country was essentially that of a forest, a condition which only now exists in the thinly inhabited regions of the north.

Although the sub-region we are considering is, for its extent and latitude, richly peopled with animal life, the number of genera altogether peculiar to it is not great. There are, however, several which are very characteristic, and many species, both of the smaller mammalia and of birds, are wholly restricted to it.

Mammalic.-The genera wholly confined to this sub-region are 
only two. Myogale, the desman, is a curious long-snouted Insectivorous animal somewhat resembling the water-rat in its habits. There are two species, one found only on the banks of streams in the French Pyrenees, the other on the great rivers of Sunthern Russia. The other peculiar genus, Rupicapra (the chamois of the Alps), is found on all the high mountains of Central Europe. Almost peculiar are Spalax (the mole-rat) found only in Eastern Europe and Western Siberia; and Saiga, an extraordinary large-nosed antelope which has a nearly similar distribution. Highly characteristic forms, which inhabit nearly every part of the sub-region, are, Talpa (the mole), Erinaceus, (the hedgehog), Sorex (the shrew), Meles (the badger), Ursus (the bear), Canis (the wolf and fox), Mustela (the weasel), Lutra (the otter), Arvicola (the vole), Myoxus (the dormouse), and Lepus (the hare and rabbit); while Bos (the wild bull) was, until exterminated by man, no doubt equally characteristic. Other genera inhabiting the sub-region will be found in the list given at the end of this chapter.

Birds.-It is difficult to name the birds that are most characteristic of this sub-region, because so many of the most familiar and abundant are emigrants from the south, and belong to groups that have a different range. There is perhaps not a single genus wholly confined to it, and very few that have not equal claims to be placed elsewhere. Among the more characteristic we may name Turdus (the thrushes), Sylvia (the warblers), Panurus (the reedling) Parus (the tits), Anthus (the pipits), Motacilla (the wagtails), which are perhaps more abundant here than in any other part of the world, Emberiza (the buntings), Plectrophanes (the snow buntings), Passer (the house sparrows), Loxia (the crossbills), Linota (the linnets), Pica (the magpies), Tetrao (grouse), Lagopus (ptarmigan) and many others.

I am indebted to Mr. H. E. Dresser, who is personally acquainted with the ornithology of much of the North of Europe, for some valuable notes on the northern range of many European birds. Those which are characteristic of the extreme Arctic zone, extending beyond $70^{\circ}$ north latitude, and tolerably abundant, are two falcons (Falco gyrfalco and $F$. peregrinus); 
the rough-legged buzzard (Areluibuteo lagopus); the snowy owl ( $N$ ycten scruliace); the raven (Corvus corax); three buntings (Emberiza schceniculus, Plectrophanes nivalis and $P$. calcarata); a lark (Otocoryss alpestris); several pipits, the most northern being Anthus cervinus; a wagtail (Budytes cinereoccipilla); a dipper (Cinclus melanogaster); a warbler (Cyanecula suecica); the wheatear (Saxicola cenanthe); and two ptarmigans (Lagopus albus and $L$. salicetus). Most of these birds are, of course, only summer visitors to the Aretic regions, the only species noted as a permanent resident in East Finmark (north of latitude $70^{\circ}$ ) being the snow-bunting (Plectrophanes nivalis).

The birds that are characteristic of the zone of pine forests, or from about $61^{\circ}$ to $70^{\circ}$ north latitude, are very numerons, and it will be sufficient to note the genera and the number of species (where more than one) to give an idea of the ornithology of this part of Europe. The birds of prey are, Falco (three species), Astur (two species), Buten, Pandion, Surnia, Buho, Syrnium, Asio, Nyctala. The chief Passerine birds are, Corvus (two species), Pica, Garrulus (two species), Nucifraga, Bombycilla, Hirundo (two species), Muscicapa (two species), Lanius, Sturnus, Passer (two species), Pyrrhula, Carpodacus, Loxia (two species), Pinicola, Fringilla (eight species), Emberiza (five species), Alauda, Anthus, Turdus (five species), Ruticilla, Pratincola, Accentor, Sylvia (four species), Hypolais, Regulus, Phylloscopus (two species), Acrocephalus, Troglodytes, and Parus (six species). Woodpeckers are abundant, Picus (four species), Gecinus, and Yunx. The kingfisher (Alcedo), goatsucker (Caprimulgus), and swift (Cypselus) are also common. The wood-pigeon (Columba) is plentiful. The gallinaceous birds are three grouse, Tetrao (two species) and Bonasa, and the common quail (Coturnix).

The remaining genera and species of temperate or northEuropean birds, do not usually range beyond the region of deciduous trees, roughly indicated by the parallel of $60^{\circ}$ north latitude.

Plate I.-Illustrating the Zoology of Central EuropeBefore considering the distribution of the other classes of vertebrata, it will be convenient to introduce our first illustra- 
$\vdots$ 


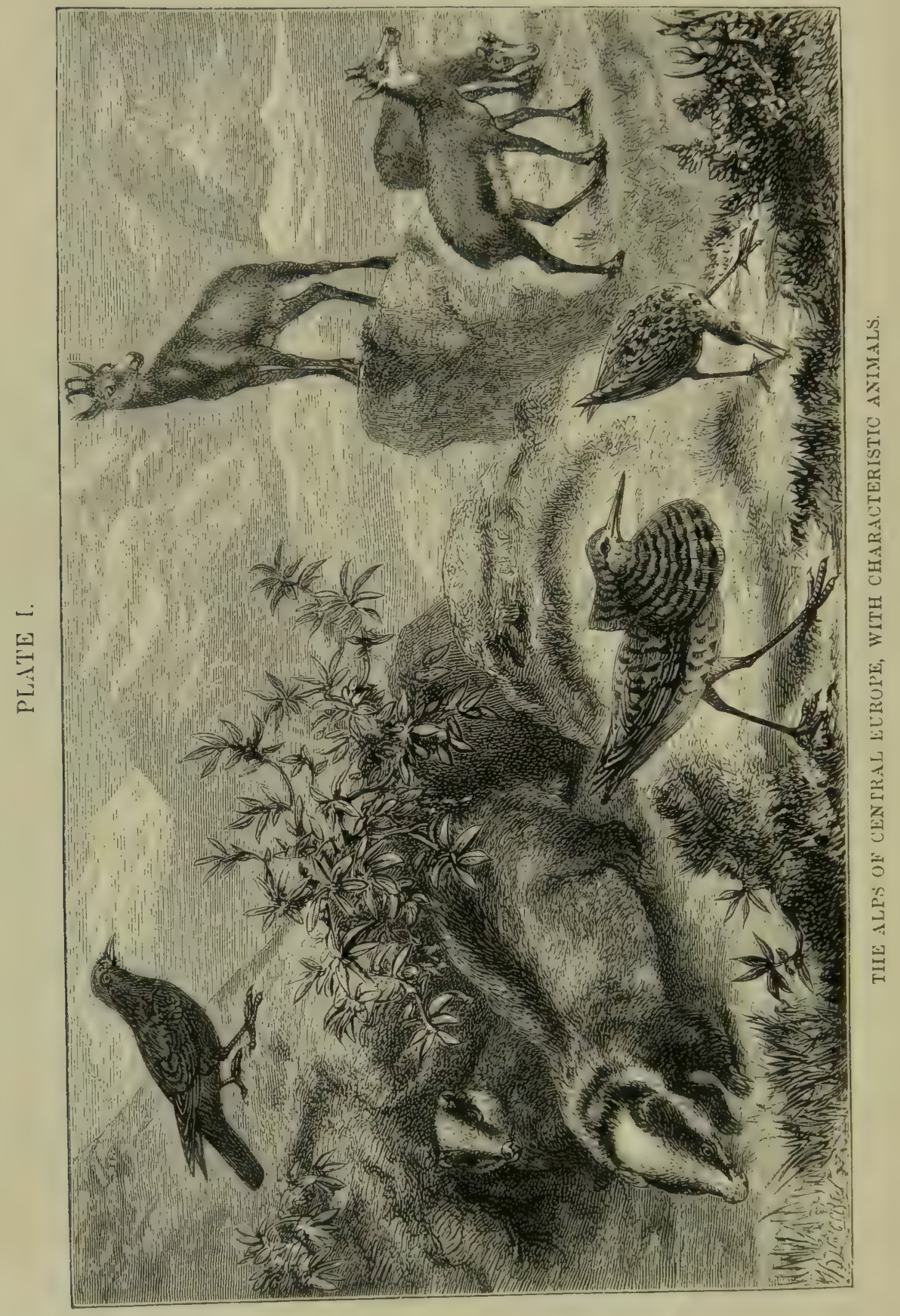


tion, which represents a scene in the Alps of Central Europe, with figures of some of the most characteristic Mammalia and Birds of this sub-region. On the left is the badger (Meles Taxus) one of the weasel family, and belonging to a genus which is strictly Palrarctic. It abounds in Central and Northern Europe and also extends into North Asia, but is represented by another species in Thibet and by a third in Japan. The elegantly-formed creatures on the right are chamois (Rupicapra tragus), almost the only European antelopes, and wholly confined to the higher mountains, from the Pyrenees to the Carpathians and the Caucasus. The chamois is the only species of the genus, and is thus perhaps the most characteristic European mammal. The bird on the left, above the badgers, is the Alpine chough, (Fregilus pyrrhocorax). It is found in the high mountains from the Alps to the Himalayas, and is allied to the Cornish chough, which is still found on our southwestern coasts, and which ranges to Abyssinia and North China. The Alpine chough differs in having a shorter bill of an orange colour, and vermilion red feet as in the other species. In the foreground are a pair of ruffs (Machetes pugnax) belonging to the Scolopacidæ or snipe family, and most nearly allied to the genus Tringa or sandpiper. This bird is remarkable for the fine collar of plumes which adorns the males in the breeding season, when they are excessively pugnacious. It is the only species of its genus, and ranges over all Europe and much of Northern Asia, migrating in the winter to the plains of India, and even down the east coast of Africa as far as the Cape of Good Hope; but it only breeds in the Palæarctic region, over the greater part of which it ranges.

Reptiles and Amphibia-There are no genera of reptiles peculiar to this sub-region. Both snakes and lizards are comparatively scarce, there being about fourteen species of the former and twelve of the latter. Our common snake (Tropidonotus natrix) extends into Sweden and North Russia, but the viper (Viperus berus) goes further north, as far as Archangel ( $64^{\circ} \mathrm{N}$.), and in Scandinavia $\left(67^{\circ} \mathrm{N}\right.$.), and is the most Arctic of all known 
snakes. Of the lizards, Lacolu stirpium (the sand lizard) has the most northerly rangre, extending into Poland and Northern Russia; and Anguis fragilis (the blind or slow-worm) has almost an equal range.

Amphibia, being more adapted to a northern climate, have acquired a more special development, and thus several forms are peculiar to the North European sub-region. Most remarkable is Proteus, a singular eel-like aquatic creature with small legs, found only in the subterranean lakes in Carniola and Carinthia; Alytes, a curious toad, the male of which carries about the eggs till they are hatched, found only in Central Europe from France to the east of Hungary; and Pelodytes, a frog found only in France. Frogs and toads are very abundant all over Europe, the common frog (Rana temporaria) extending to the extreme north. The newts (Triton) are also very abundant and widely spread, though not ranging so far north as the frogs. The genera Bombinator (a toad-like frog), and Hyla (the tree frog) are also common in Central Europe.

Freshwater Fish.-Two genera of the perch family (Percidæ) are peculiar to this sub-region,-Percarina, a fish found only in the river Dniester, and Aspro, confined to the rivers of Central Europe. Of the very characteristic forms are, Gasterostens (stickle-back), which alone forms a peculiar family-Gasterosteidæ; Perca, Acerina and Lucioperca, genera of the perch family; Silurus, a large fish found in the rivers of Cenrtal Europe, of the family Siluridx; Esox (the pike), of the family Esocidx; Cyprinus (carp), Gobio (gudgeon), Leuciscus (roach, chub, dace, \&c.), Tinca (tench), Abramus (bream), Alburnus (bleak), Cobitis (loach), all genera of the family Cyprinidæ.

Insects - Lepidoptera.- No genera of butterflies are actually confined to this sub-region, but many are characteristic of it. Parnassius, Aporia, Leucophasia, Colias, Melitoca, Argynnis, Vanessa, Limenitis, and Chionobas, are all very abundant and widespread, and give a feature to the entomology of most of the countries included in it.

Coleoptera.-This sub-region is very rich in Carabidæ; the genera Elaphrus, Nebria, Carabus, Cychrus, Pterostichus, Amara, 
Trechus and Peryphus being especially characteristic. Staphylinidæ abound. Among Lamellicorns the genus Aphodius is most characteristic. Buprestidæ are scarce; Elateridæ more abundant. Among Malacoderms Telephorus and Málachives are characteristic. Curculionidæ abound: Otiorhyuchus, Omias, Erirhinus, Bagous, Rhynchites and Ceutorhynchus being very characteristic genera. Of Longicorns Callidium, Dorcadion, Pogonochoerus, Pachyta and Leptura are perhaps the best representatives. Donacia, Crioceris, Chrysomela, and Altica, are typical Phytophaga; while Coccinella is the best representative of the Securipalpes.

North European Islands.-The British Islands are known to have been recently conrected with the Continent, and their animal productions are so uniformly identical with continental species as to require no special note. The only general fact of importance is, that the number of species in all groups is much less than in continental districts of equal extent, and that this number is still farther diminishea in Ireland. This may be accounted for by the smaller area and less varied surface of the latter island; and it may also be partly due to the great extent of low land, so that a very small depression would reduce it to the condition of a cluster of small islands capable of supporting a very limited amount of animal life. Yet further, if after such a submergence had destroyed much of the higher forms of life in Great Britain and Ireland, both were elevated so as to again form part of the Continent, a migration would commence by which they would be stocked afresh; but this migration would be a work of time, and it is to be expected that many species would never reach Ireland or would find its excessively moist climate unsuited to them.

Some few British species differ slightly from their continental allies, and are considered by many naturalists to be distinct. This is the case with the red grouse (Lagopus scoticus) among birds; and a few of the smaller Passeres have also been found to vary somewhat from the allied forms on the Continent, showing that the comparatively short interval since the glacial period, and the slightly different physical conditions dependent on 
insularity, have sufficed to commence the work of specific modification. There are also a few small land-shells and several insects not yet found elsewhere than in Britain; and even one of the smaller Mammalia-a shrew (Sorex rusticus). These facts are all readily explained by the former union of these islands with the Continent, and the alternate depressions and elevations which are proved by geological evidence to have occurred, by which they have been more than once separated and united again in recent times. For the evidence of this elevation and depression, the reader may consult Sir Charles Lyell's Antiquity of Man.

Iceland is the ouly other island of importance belonging to this sub-region, and it contrasts strongly with Great Britain, both in its Arctic climate and oceanic position. It is situated just south of the Arctic circle and considerably nearer Greenland than Europe, yet its productions are almust wholly European. The only indigenous land mammalia are the Arctic fox (Canis lagopus), and the polar bear as an occasional visitant, with a mouse (Mus islandicus), said to be of a peculiar species. Four species of seals visit its shores. The birds are more interesting. According to Professor Newton, uinety-five species have been observed; but many of these are mere stragglers. There are twenty-three land, and seventy-two aquatic birds and waders. Four or five are peculiar species, though very closely related to others inhabiting Scandinavia or Greenland. Only two or three species are more nearly related to Greenland birds than to those of Northern Europe, so that the Palæarctic character of the fauna is unmistakable. The foliowing lists, compiled from a paper by Professor Newton, may be interesting as showing more exactly the character of Icelandic ornithology.

1. Peculiar species. - Troglodytes borealis (closely allied to the common wren, found also in the Faroe Islands); Falco islandicus (closely allied to $F$. gyrfalco); Lagopus islandorum (closely allied to $L$. rupestris of Greenland).

2. European species resident in Iceland.-Emberiza nivalis, Corvus corax, Haliccetus albicilla, Rallus aquaticus, Homatopus ostralegus, Cygnus ferus, Mergus (two species), Phalacocorax (two 
species), Sula bassana, Larus (two species), Stercorarius catarractes, Puffnus anglorum, Mergulus alle, Uria (three species), Alca torda.

3. American species resident in Iceland.-Clangula islandica, Histrionicus torquatus.

4. Anuual visitants from Europe-Turdus iliacus, Ruticilla tithys, Saxicola cenanthe, Motacilla alba, Anthus pratensis, Linota linaria, Chelidon urbica, Hirundo rustica, Falco oesalon, Surnia nyctea, Otus brachyotus, Charadrius pluvialis, Egialites hiaticula, Strepsilas interpres, Phalaropus fulicarius, Totanus calidris, Limosa (species), Tringa (three species), Calidris arenaria, Gallinago media, Numetius phoopus, Ardea cinerea, Anser (two species), Bernicla (two species), Anas (four species), Fuligula marila, Harelda glacialis, Somateria mollissima, Eidemia nigra, Sterna macrura, Rissa tridactyla, Larus luecopterus, Stercorarius (two species), Fratercula artica, Colymbus (two species), Podiceps comutus.

5. Annual visitant from Greenland.-Falco candicans.

6.-Former resident, now extinct.-Alca impennis (the great auk).

\section{II.-Mediterranean Sub-region.}

This is by far the richest portion of the Palæarctic region, for although of moderate extent much of it enjoys a climate in which the rigours of winter are almost unknown. It includes all the countries south of the Pyrenees, Alps, Balkans, and Caucasus mountains; all the southern shores of the Mediterranean to the Atlas range, and even beyond it to include the extra-tropical portion of the Sahara; and in the Nile valley as far as the second cataract. Further east it includes the northern half of Arabia and the whole of Persia, as well as Beluchistan, and perhaps Affghanistan up to the banks of the Indus. This extensive district is almost wholly a region of mountains and elevated plateaus. On the west, Spain is mainly a table-land of more than 2000 feet elevation, deeply penetrated by extensive valleys and rising into lofty mountain chains. Italy, Corsica, Sardinia, and Sicily, are all very 
mountainous, and much of their surface considerably elevated. Further east we have all European Turkey and Greece, a mountain region with a comparatively small extent of level plain. In Asia the whole country, from Smyrna through Armenia and Persia to the further borders of Affohanistan, is a vast mountainous plateau, almost all above 2000, and extensive districts above 5000 feet in elevation. The only large tract of low-land is the valley of the Euphrates. There is also some low-land south of the Caucasus, and in Syria the valley of the Jordan. In North Africa the valley of the Nile and the coast plains of Tripoli and Algiers are almost the only exceptions to the more or less mountainous and platean-like character of the country. Much of this extensive area is now bare and arid, and often even of a desert character; a fact no doubt due, in great part, to the destruction of aboriginal forests. This loss is rendered permanent by the absence of irrigation, and, it is also thought, by the abundance of camels and goats, animals which are exceedingly injurious to woody vegetation, and are able to keep down the natural growth of forests. Mr. Marsh (whose valuable work Man and Nature gives much information on this subject) believes that even large portions of the African and Asiatic deserts would become covered with woods, and the climate thereby greatly improved, were they protected from these destructive domestic animals, which are probably not indigenous to the country. Spain, in proportion to its extent, is very barren; Italy and European Turkey are more woody and luxuriant; but it is perhaps in Asia Minor, on the range of the Taurus, along the shores of the Black Sea, and to the south of the Caucasus range, that this sub-region attains its maximum of Iuxuriance in vegetation and in animal life. From the Caspian eastward extends a region of arid plains and barren deserts, diversified by a few more fertile valleys, in which the characteristic flora and fauna of this portion of the Palæarctic region abounds. Further east we come to the forests of the Hindoo Koosh, which probably form the limit of the sub-region. Beyond these we enter on the Siberian sub-region to the north, and on the outlying portion of the Oriental region on the south. 
In addition to the territuries now indicated as forming part of the Mediterranean sub-region, we must add the group of Canary Islands off the west coast of Africa which seem to be an extension of the Atlas mountains, and the oceanic groups of Madeira and the Azores; the latter about 1,000 miles from the continent of Europe, yet still unmistakably allied to it both in their vegetable and animal productions. The peculiarities of the faunas of these islands will be subsequently referred to.

It seems at first sight very extraordinary, that so large and wide a sea as the Mediterranean should not separate distinct faunas, and this is the more remarkable when we find how very deep the Mediterranean is, and therefore how ancient we may well suppose it to be. Its eastern portion reaches a depth of 2,100 fathoms or 12,600 feet, while its western basin is about 1,600 fathoms or 9,600 feet in greatest depth, and a considerable area of both basins is more than 1,000 fathoms deep. But a further examiuation shows, that a comparatively shallow sea or submerged bank incloses Malta and Sicily, and that on the opposite coast a similar bank stretches out from the coast of Tripoli leaving a narrow channel the greatest depth of which is 240 fathoms. Here therefore is a broad plateau, which an elevation of about 1,500 feet would convert into a wide extent of land connecting Italy with Africa; while the same elevation would also connect Morocco with Spain, leaving two extensive lakes to represent what is now the Mediterranean Sea, and affording free communication for land animals between Europe and North Africa. That such a state of things existed at a comparatively recent period, is almost certain; not only because a considerable number of identical species of mammalia inhabit the opposite shores of the Mediterranean, but also because numerous remains of three species of elephants have been found in caves in Mialta,-now a small rocky island in which it would be impossille for such animals to live even if they could reach it. Remains of hippopotami are also found at Gibraltar, and many other animals of African types in Greece; all indicating means of communication between South Europe and North Africa which no longer exist. (See Chapter VI. pp. 113-115.) 
Mammalia.-There are a few groups of Palæarctic Mammalia that are peculiar to this sub-region. Such are, Dama, the fallow deer, which is now found only in South Europe and North Africa; Psammomys, a peculiar genus of Muridæ, found only in Egypt and Palestiue; while Ctenodactylus, a rat-like animal classed in the South American family Octodontidse, inhabits Tripoli. Among characteristic genera not found in other subregions, are, Dysopes, a bat of the family Noctilionidr; Macroscelides, the elephant shrew, in North Africa; Genetta, the civet, in South Europe; Herpestes, the ichneumon, in North Africa and (?) Spain; Hyana, in South Europe; Gazella, Oryx, Alcephalus, and Addax, genera of antelopes in North Africa and Palestiue; Hyrax, in Syria: and Hystrix, the porcupine, in South Europe. Besides these, the camel and the horse were perhaps once indigenous in the eastern parts of the subregion; and a wild sheep (Ovis musmon) still inhabits Sardinia, Corsica, and the mountains of the south-east of Spain. The presence of the large feline animais-such as the lion, the leopard, the serval, and the hunting leopard-in North Africa, together with several other quadrupeds not found in Europe, have been thought by some naturalists to prove, that this district should not form part of the Palæarctic region. No doubt several Ethiopian groups and species have entered it from the south, but the bulk of its Mammalia still remains Paliearctic, although several of the species have Asiatic rather than European affinities. The Macacus innurs is allied to an Asiatic rather than an African group of monkeys, and thus denotes an Oriental affinity. Ethiopian affinity is apparently shown by the three genera of antelopes, by Herpestes, and by Macroscelides; but our examination of the Miocene fauna has shown that these were probably derived from Europe originally, and do not form any part of the truly indigenous or ancient Ethiopian fauna. Against these, however, we have the occurrence in North Africa of such purely Palæarctic and non-Ethiopian genera as Ursus, Meles, Putorius, Sus, Cervus, Dama, Capra, Alactaga; together with actual European or West Asiatic species of Canis, Genetta, Felis, Putorius, Lutra, many bats, Sorex, Crocidure, Crossopus, Hystrix, 
Dipus, Lepus, and Mus. It is admitted that, as regards every other group of animals, North Africa is Palicarctic, and the above enumeration shows that even in Mammalia, the intermixture of what are now true Ethiopian types is altogether insignificant. It must be remembered, also, that the lion inhabited Greece even in historic times, while large carnivora were contemporary with man all over Central Europe.

Birds.-So many of the European birds migrate over large portions of the region, and so many others have a wide permanent range, that we cannot expect to find more than a few genera, consisting of one or two species, each, confined to a subregion; and such appear to be, Lusciniola and Pyrophthalma, genera of Sylviidæ. But many are characteristic of this, as compared with other Palæarctic sub-regions; such as, Bradyptetus, Aedon, Dromoloea, and Cercomela, among Sylviidæ; Crateropus and Malacocercus, among Timaliidæ; Telophonus among Laniidæ; Certhilauda and Mirafra among larks; Pastor among starlings; Upupa, the hoopoe; Halycon and Ceryle among kingfishers; Turnix and Caccabis among Gallinæ, and the pheasant as an indigenous bird; together with Gyps, Vultur and $A^{r}$ eophron, genera of vultures. In addition to these, almost all our summer migrants spend their winter in some part of this favoured land, mostly in North Africa, together with many species of Central Europe that rarely or never visit us. It follows, that a large proportion of all the birds of Europe and Western Asia are to be found in this sub-region, as will be seen by referring to the list of the genera of the region. Palestine is one of the remote portions of this region which has been well explored by Canon Tristram, and it may be interesting to give his summary of the range of the birds. We must bear in mind that the great depression of the Dead Sea has a tropical climate, which accounts for the presence here only, of such a tropical form as the sun-bird (Nectarinea osea).

The total number of the birds of Palestine is 322, and of these no less than 260 are European, at once scttling the question of the general affinities of the fauna. Of the remainder eleven belong to North and East Asia, four to the Red Sea, and thirty- 
one to East Africa, while twenty-seven are peculiar to Palestine. It is evident therefore that an unusual number of East African birds have extended their range to this congenial district, but most of these are desert species and hardly true Ethiopians, and do not much interfere with the general Palæarctic character of the whole assemblage. As an illustration of how wide-spread are many of the Palrearctic forms, we may add, that seventynine species of land birds and fifty-five of water birds, are common to Palestine and Britain. The Oriental and Ethiopian genera Pycnonotus and Nectarinca are found here, while Bessornis and Dromolcea are characteristically Ethiopian. Almost all the other genera are Palæarctic.

Persia is another remote region generally associated with the idea of Oriental and almost tropical forms, but which yet undoubtedly belongs to the Palæarctic region. Mr. Blanford's recent collections in this country, with other interesting information, is summarised in Mr. Elwes's paper on the "Geographical Distribution of Asiatic Birds" (Proc. Zool. Soc. 1873, p. 647). No less than 127 species are found also jn Europe, and thirty-seven others belong to European genera; seven are allied to birds of Central Asia or Siberia, and fifteen to those of North-East Africa, while only three are purely of Indian affinities. This shows a preponderance of nearly nine-tenths of Palæarctic forms, which is fully as much as can be expected in any country near the limits of a great region.

Reptiles and Amphibia.-The climatal conditions being here more favourable to these groups, and the genera being often of limited range, we find some peculiar, and several very interesting forms. Rhinechis, a genus of Colubrine snakes, is found only in South Europe; Trogonophis, one of the Amphisbænianscurious snake-like lizards-is known only from North Africa; Psammosaurus, belonging to the water lizards (Varanidx) is found in North Africa and North-West India; Psummodromus, a genus of Lacertidæ, is peculiar to South Europe; Hyalosaurus, belonging to the family Zonuridæ, is a lizard of especial interest, as it inhabits North Africa while its nearest ally is the Ophisaurus or "glass snake" of North America; the family of 
the scinks is represented by Scincus found in North Africa and Arabia. Besides these Seps, a genus of sand lizards (Sepidæ) and Agama, a genus of Agramidæ, are abundant and characteristic.

Of Amplibia we have Seiranota, a genus of salamanders found only in Italy and Dalmatia; Chioglossa, in Portugal, and Geotriton, in Italy, belonging to the same family, are equally peculiar to the sub-region.

Freshwater Fish-One of the most interesting is Tellia, a genus of Cyprinodontidæ found only in alpine pools in the Atlas mountains. Paraphoxinius, found in South-East Europe, and Chondrostoma, in Europe and Western Asia, genera of Cyprimidæ, seen almost peculiar to this sub-region.

Insects-Lepidoptera.-Two genera of butterflies, Thais and Doritis, are wholly confined to this sub-region, the former ranging over all Southern Europe, the latter confined to Eastern Europe and Asia Minor. Anthocharis and Zegris are very characteristic of it, the latter only extending into South Russia, while Danais, Charaxes, and Libythea are tropical genera unknown in other parts of Europe.

Coleoptera. - This sub-region is very rich in many groups of Coleoptera, of which a few only can be noticed here. Among Carabidæ it possesses Procerus and Procrustes, almost exclusively, while Brachinus, Cymindis, Lebia, Graphipterus, Scarites, Chloenius, Calathus, and many others, are abundant and characteristic. Among Lamellicorns-Copridæ, Glaphyridæ, Melolonthidæ, and Cetoniidæ abound. Buprestidæ are plentiful, the genera Julodis, Acmoodera, Buprestis, and Sphenoptera being characteristic. Among Malacoderms-Cebrionidæ, Lampyridæ, and Malachiidæ abound. The Tenebrioid Heteromera are very varied and abundant, and give a character to the sub-region. The Mylabridæ, Cantharidæ, and Edemeridæ are also characteristic. Of the immense number of Curculionidæ-Thylacites, Brachycerus, Lixus, and Acalles may be mentioned as among the most prominent. Of Longicorns there are fer genera especially characteristic, but perhaps Prinobins, Purpuricenus, Hesperophanes, and Parmena are most so. Of the remaining families, we may mention Clythridæ, Hispidæ, and Cassididæ as being abundant. 
The Mediterranean and Atlantic Islands.-The various islands of the Mediterranean are interesting to the student of geographical clistribution as affording a few examples of local species of very restricted range, but as a rule they present us with exactly the same forms as those of the arljacent mainland. ${ }^{1}$ Their peculiarities do not, therefore, properly come within the scope of this work. The islands of the Atlantic Ocean belonging to this sub-region are, from their isolated position and the various problems they suggest, of much more interest, and their natural history has been carefully studied. We shall therefore give a short account of their peculiar features.

Of the three groups of Atlantic islands belonging to this subregion, the Canaries are nearest to the Continent, some of the islands being only about fifty miles from the coast of Africa. They are, however, separated from the mainland by a very deep channel (more than 5,000 feet), as shown on our general map. The islands extend over a length of 300 miles; they are very mountainous and wholly volcanic, and the celebrated peak of Teneriffe rises to a height of more than 12,000 feet. The small Madeira group is about 400 miles from the coast of Morocco and 600 from the southern extremity of Portugal; and there is a depth of more than 12,000 feet between it and the continent. The Azores are nearly 1,000 miles west of Lisbon. They are quite alone in mid-Atlantic, the most westerly islands being nearer Newfoundland than Europe, and are surrounded by ocean depths of from 12,000 to 18,000 feet. It will be convenient to take these islands first in order.

Azores.-Considering the remoteness of this group from every other land, it is surprising to find as many as fifty-three species of birds inhabiting or visiting the Azores; and still more to

1 Malta is interesting as forming a resting-place for migratory birds, while crossing the Mediterranean. It has only eight land and three aquatic birds which are permanent residents; yet no less than 278 species have been recorded by Mr. E. A. Wright as visiting or passing over it, comprising a large proportion of the European migratory birds. The following are the permanent residents : Cerchneis tinnunculus, Strix flammen, Passer salicicola, Emberiza miliaria, Corvus monedula, Monticola cyanea, Sylvia conspicillata, Oolumba livia, Puffinus cinereus, $P$. anglorum, Thalassidroma pelagica. 
find that they are of Palrarctic genera and, with one exception, all of species found either in Europe, North Africa, Madeira, or the Canaries. The exception is a bullfinch peculiar to the islands, but closely allied to a European species. Of land birds there are twenty-two, belonging to twenty-one genera, all European. These genera are Cerchneis, Buteo, Asio, Strix, Turdus, Oriolus, Erithacus, Sylvia, Regulus, Saxicola, Motacilla, Plectrophanes, Fringilla, Pyprhula, Serinus, Sturnus, Picus, Upupa, Columba, Caccabis, and Coturnix. Besides the bullfinch (Pyrrhula) other species show slight differences from their European allies, but not such as to render them more than varieties. The only truly indigenous mammal is a bat of a European species. Nine butterflies inhabit the Azores; eight of them are European species, one North American. Of beetles 212 have been collected, of which no less than 175 are Europran species; of the remainder, nineteen are found in the Canaries or Madeira, three in South America, while fourteen are peculiar to the islands.

Now these facts (for which we are indebted to Mr. Godman's Natural, History of the Azores) are both unexpected and exceedingly instructive. In most other cases of remote Oceanic islands, a much larger proportion of the fauna is endemic, or consists of peculiar species and often of peculiar genera; as is well shown by the case of the Galapagos and Juan Fernandez, both much nearer to a continent and both containing peculiar genera and species of birds. Now we know that the cause and meaning of this difference is, that in the one case the original immigration is very remote and has never or very rarely been repeated, so that under the unchecked influence of new conditions of life the species have become modified; in the other case, either the original immigration has been recent, or if remote has been so frequently repeated that the new comers have kept up the purity of the stock, and have not allowed time for the new conditions to produce the effect we are sure they would in time produce if not counteracted. For Mr. Godman tells us that many of the birds are modified-instancing the gold-crested wren, blackcap, and rock dove-and he adds, that the modifica- 
tion all tends in one direction - to produce a more sombre plumage, a greater strength of feet and legs, and a more robust bill. We further find, that four of the land-birds, including the oriole, snow-bunting, and hoopoe, are not resident birds, but straggle accidentally to the islands by stress of weather; and we are told that every year some fresh birds are seen after violent storms. Add to this the fact, that the number of species diminishes in the group as we go from east, to west, and that the islands are subject to fierce and frequent storins blowing from every point of the compass,-and we have all the facts requisite to enable us to understand how this remote archipelago has become stocked with animal life without ever probably being much nearer to Europe than it is now. For the islands are all volcanic, the only stratified rock that occurs being believed to be of Miocene date.

Madeira and the Canaries.-Coming next to Madeira, we find the number of genera of land birds has increased to twenty-eight, of which seventeen are identical with those of the Azores. Some of the commonest European birds-swallows, larks, sparrows, linnets, goldfinches, ravens, and partridges, are among the additions. A gold-crested warbler, Regulus Maderensis, and a pigeon, Columba Trocaz, are peculiar to Madeira.

In the Canaries we find that the birds have again very much increased, there being more than fifty genera of land birds; but the additions are wholly European in character, and almost all conmon European species. We find a few more peculiar species (five), while some others, including the wild canary, are common to all the Atlantic Islands or to the Canaries and Madeira. Here, too, the only indigenous mammalia are two European species of bats.

Land Shells. - The land shells of Madeira offer us an instructive contrast to the birds of the Atlantic Islands. About fiftysix species have been found in Madeira, and forty-two in the small adjacent island of Porto Santo, but only twelve are common to both, and all or almost all are distinct from their nearest allies in Europe and North Africa. Great numbers of fossil shells are also found in deposits of the Newer Pliocene period; and 
although these comprise many fresh species, the two faunas and that of the continent still remain almost as distinct from each other as before. It has been already. stated (p. 31) that the means by which land mollusca have been carried across arms of the sea are unknown, although several modes may be suggested; but it is evidently a rare erent, requiring some concurrence of favourable conditions not always present. The diversity and specialization of the forms of these animals is, therefore, easily explained by the fact, that, once introduced they have been left to multiply under the influence of a variety of local conditions, which inevitably lead, in the course of nges, to the formation of new varieties and new species.

Coleopterc. - The beetles of Madeira and the Canaries have been so carefully collected and examined by Mr. T. V. Wollaston, and those of the Azores described and compared loy Mr. Crotch, and they illustrate so many curious points in geographical distribution, that it is necessary to give some account of them. No less than 1,480 species of beetles have been obtained from the Canaries and Madeira, only 360 of which are Eurnpean, the remainder being peculiar to the islands. The Canaries are inhabited by a little over 1,000 species, Madeira by ahout 700 , while 240 are common to both ; but it is believed that many of these have been introduced by man. In the Azores, 212 species have been obtained, of which 175 are European; showing, as in the birds, a closer resemblance to the European fauna than in the other islands which, although nearer to the continent, offer more shelter and are situated in a less tempestuous zone. Of the non-European species in the Azores, 19 are found also in the other groups of islands, 14 are peculiar, while 3 are American. Of the European species, 132 are found also in the othor Atlantic islands, while 43 have reached the Azores only. This is interesting as showing to how great an extent the same insects reach all the islands, notwithstanding the difference of latitude and position; and it becomes of great theoretical importance, when we find how many extensive families and genera are altogether absent.

The Madeira group has been more thoronglily explored than 
my of her', and its comparatively remote situation, combined with it.s luxuriant vegetation, have been farourable to the development and increase of the peculiar forms which characterize all the Atlantic islands in a more or less marked derree. A consilleration of some of its peculiarities will, therefore, best serve to show the bearing of the facts presented by the insect fauna of the $A$ tlantic islands, on the general laws of distribution. The 711 species of bectles now known from the Madeira group, helong to 236 genera; and no less than 44 of these genera are not European but are peculiar to the Atlantic islands. Most of them are, however, closely allied to European genera, of which they are evidently modifications. A most curious general feature mesented by the Madeiran beetles, is the total absence of many whole families and large genera abundant in South Europe. Such are the Cicindelidie, or tiger beetles; the Melolonthidæ, or chafers; the Cetoniidx, or rose-chafers; the Eumolpidx and Galerncidie, large families of Phytophagous, or leaf-eating beetles; and also the extensive groups of Elateridx and Buprestidie, which are each represented by but one minute species. Of extensive genera abundant in South Europe, but wholly absent in Madeira, are Carchus, Rhizotrogus, Lampyris, and other genera of Malacoderms; Otiorhynchus, Brachycerus, and 20 other genern of Cureulionidse, comprising more than 300 South Furvenean and North African species; Pimelia, Tentyra, Blaps, ind 18 other genera of Heteromera, comprising about 550 species in South Europe and North Africa; and Timarcha, containing 44 South European and North African species.

Another most remarkable feature of the Madeiran Coleoptera is the unusual prevalence of apterous or wingless insects. This is especially the case with groups which are confined to the Atlantic islands, many of which consist wholly of wingless species; but it also affects the others, no less than twenty-two genera which are usually or sometimes winged in Europe, having only wingless species in Madeira; and even the same species which is winged in Europe becomes, in at least three cases, wingless in Macleira, without any other perceptible change having taken place. But there is another most curious fact noticed by 
Mr. Wollaston; that those species which possess wings in Madeira, often have them rather larger than their allies in Europe. These two facts were connected by Mr. Darwin, who suggested that flying insects are much more exposed to be blown out to sea and lost, than those which do not fly (and Mr. Wollaston had bimself supposed that the "storny atmosplere" of Madeira had something to do with the matter); so that the most frequent fliers would be continually weeded out, while the more sluggish individuals, who either could not or would not Hy, remained to continue the race; and this process going on from generation to generation, would, on the well-ascertained principles of selection and abortion by disuse, in time lead to the entire loss of wings by those insects to whom wings were not $u$ necessity. But those whose wings were essential to their existence would be acted upon in another way. All these must fly to obtain their food or provide for their offspring, and those that flew best would be best able to battle with the storms, and keep themselves safe, and thus those with the longest and most powerful wings would be preserved. If however all the individuals of the species were too weak on the wing to resist the storms, they would soon become extinct. ${ }^{1}$

Now this explanation of the facts is not only simple and probable in itself, but it also serves to explain in a remarkable manner some of the peculiarities and deficiencies of the Madeiran insect fauna, in harmony with the view (supported by the distribution of the birds and land shells, and in particular by the immigrant birds and insects of the Azores) that all the insects have been derived from the continent or from other islands, by

1 A remarkable confirmation of this theory, is furnished in the Report to the Royal Society of the naturalist to the Kerguelen Island, "Transit Expedition"-the Rev. A. E. Eaton. Insects were assiduously collected, and it was found that almost all were either completely apterous, or had greatly "Lbbreviated wings. The only moth found, several flies, and numerous beetles, were alike incapatble of flight. As this island is subject to violent, and almost perpetual gales, even in the finest season, the weaning of the extriordinary loss of wings in almost all the insects, can, in this case, hardly be nisunderstood. 
immigration across the occan, in various ways and during a long period. These deficiencies are, on the other hand, quite inconsistent with the theory (still held by some entomologists) that a land communication is absolutely necessary to account for the origin of the Madeiran fauna.

First, then, we can understand how the tiger-beetles (Cicindelide) are alsent; since they are insects which have a short weak flight, but yet to whom flight is necessary. If a few had been blown over to Madeira, they would soon have become exterminated. The same thing applies to the Melolonthidæ, Cetoniidx, Eumolpidæ, and Galerucidæ,-all flower and foliagelaunting insects, yet bulky and of comparatively feeble powers of flight. Again, all the large genera abundant in South Europe, which have been mentioned above as absent from Madeira, are wholly apterous (or without wings), and thus their absence is a most significant fact; for it proves that in the case of all insects of moderate size, flight was essential to their reaching the island, which could not have been the case had there been a land connection. There are, however, one or two curious exceptions to the absence of these wholly apterous European genera in Madeira, and as in each case the reason of their being exceptions can be pointed out, they are eminently exceptions that prove the ruie. Two of the apterous species common to Europe and Madeira are found always in ants' nests; and as ants, when winged, fly in great swarms and are carried by the wind to great distances, they may have conveyed the minute eggss of these very small beetles. Two European species of Blaps occur in Madeira, but these are house beetles, and are admittecl to have been introduced by man. There are also three species of Meloe, of which two are European and one peculiar. These are large, sluggish, wingless insects, but they have a most extraordinary and exceptional metamorphosis, the larvie in the first state being minute active insects parasitic on bees, and thus easily conveyed across the ocean. This case is most suggestive, as it accounts for what would be otherwise a difficult anomaly. Another case, not quite so easily explained, is that of the genus Acalles, which is very ahundant in all the Atlantic 
islands and also occurs in South Europe, but is always apterous. It is however closely allied to another genus, Cryptorhynchus, which is apterous in some species, winged in others. We may therefore well suppose that the ancestors of Acalles were once in the same condition, and that some of the winged forms reached Madeira, the genus having since become wholly apterous.

We may look at this curious subject in another way. The Coleoptera of Madeira may be divided into those which are found also in Furope or the other islands, and those which are peculiar to it. On the theory of introduction by accidental immigration across the sea, the latter must be the more ancient, since they have had time to become modified; while the former are comparatively recent, and their introduction may be supposed to be now going on. The peculiar influence of Madeira in aborting the wings should, therefore, have acted on the ancient and changed forms much more powerfully than on the recent and unchanged forms. On carefully comparing the two sets of insects (omitting those which have almost certainly been introduced by man) we find, that out of 263 species which lave a wide range, only 14 are apterous; while the other class, consisting of 393 species, has no less than 178 apterous; or about 5 per cent in the one case, and 45 per cent in the other. ${ }^{1}$ On the theory of a land connection as the main agent in introclucing the fauna, both groups must have been introduced at or about the same time, and why one set should have lost their wings and the other not, is quite inexplicable.

Taking all these singular facts, in connection with the total absence of all truly indigenous terrestrial mammalia and reptiles from these islands-even from the extensive group of the Canaries so comparatively near to the continent, we are forced to reject the theory of a lind connection as quite untenable; and this view becomes almost demonstrated by the case of the Azores, which being so much further off, and surrounded by such a vast expanse of deep ocean, could only hare been con-

1 The ficts on which these slatements rest, will be found more fully detailer in the Authur's Presidential Address to the Entomological Society
of London for the year 1871 . 
nected with Europe at a fin remoter epoeh, and onglit therefores to exhibit to us a fuma composed almost entirely of peculiar forms both of birls and insects. Yet, so far from this being thes cuse, the facts are exactly the reverse. Far more of the birds and inscets are identical with those of Furope than in the other islands, and this difference is clearly traced to the more tempestuous atmosphere, which is shown to be even now annually bringing fresh inmigrants (both birls and insects) to its shores. We here see nature actually at work; and if the case of Madeira rendered her mode of action probable, that of the Azores may be said to demonstrate it.

Mr. Wollaston has objected to this view that "storms and hurricanes" are somewhat rare in the latitude of Madeira and the Canaries; but this little affects the question, since the time allowed for such operations is so ample. If but one very violent storm happened in a century, and ten such storms recurred before a single species of insect was introrluced into Madeira, that would be more than sufficient to people it, as we now find it, with a varied fauna. But he also adds the important information that the ordinary winds blow almost uninterruptedly from the north-east, so that there would be always a chance of a little stronger wind than usual bringing insect, or larva, or egg, attached to leaves or twigs. Neither Mr. Wollaston, Mr. Crotch, Mr. A: Murray, nor any other naturalist who upholds the land-connection theory, has attempted to account for the fact of the absence of so many extensive groups of insects that ought to be present, as well as of all small mammalia and reptiles.

Cape Verd Islends. - There is yet another group of Atlantic islands which is very little known, and which is usually considered to be altogether African-the Cape Verd Islands, situated between 300 and 400 miles west of Senegal, and a little to the sonth of the termination of the Sahara. The evilence that we possess as to the procluctions of these islands, shows that, like the precerling groups, they are truly oceanic, and have probably derived their fama from the desert and the Canaries to the north-east of them rather than from the fertile and more truly 
Lthiopian districts of Senegal and Gambia to the east. There is a mingling of the two faunas, but the preponderance seems to be undoubtedly with the Palæarctic rather. than with the Ethiopian. I owe to Mr. R. B. Sharpe of the British Museum, a MS. list of the birds of these islands, twenty-three species in all. Of these eight are of wide distribution and may be neglected. Seven are unloulsted Paliearetic species, viz.:- Hitur.-s ictimus, Sylvia atricapilla, S'. conspicillata, Corvus corone, Passcr salicarius, Certhilauda desertorum, Columba livia. Three are peculiar species, but of Palrarctic genera and affinities, viz:Calamoherpe brevipennis, Ammomanes cinctura, and P(tsser jayoensis. Against this we have to set two West African species, Estrilda cinerea and Numida meleagris, both of which were probably introduced by man; and three which are of Ethiopian genera and affinities, viz.:-Halcyon erythrorhyncha, closely allied to $H$. semiccerulece of Arabia and North-east Africa, and therefore almost Palrarctic; Accipiter mclunolcucus; and Pymluulanda niypiceps, an Ethiupian form; but the same species occurs in the Canaries.

The Coleoptera of these islands have been also collected by Mr. Wollaston, and he finds that they have generally the same European character as those of the Canaries and Madeira, several of the peculiar Atlantic genera, such as Acalles and Hegetcr, vccurring, while others are represented by new but closely allicd genera. Out of 275 species 91 were found also in the Canaries and 81 in the Madeirau group; a wonderful amount of similarity when we consider the distance and isolation of these isliuds and their great diversity of climate and vegetation.

This connection of the four groups of Atlantic islands now referrer to, receives further support from the occurence of landshells of the subgenus Leptaxis in all the groups, as well as in Majorca; and by another subgenus, Hemicycle, being common to the Canaries and Cape Verd islands. Cumbining these sererial classes of ficts, we seem justified in extending the Mediterrmean sub-regicn to include the Cape Veril Islands. 


\section{III.-The S'Siberiun Sub-retgion, or Northern Asia.}

This large and comparatively little-known subdivision of the T'aliearetic region, extends from the Caspian Sea to Kanschatka and Behring's Straits, a distance of alout 4,000 miles; and from the shores of the Arctic Ocean to the high Himalayas of Sikhim in North Latitude $29^{\circ}$, on the same parallel as Delhi. 'T'o the east of the Caspian Sea and the Ural Mountains is a great extent of lowlind which is continued round the northern coast, becoming narrower as it approaches the East Cape. Beyond this, in a general E.N.E. direction, rise hills and uplands, soon becoming lolty mountains, which extend in an uubroken line from the Hindu Koosh, through the Thian Shan, Altai and Yablonoi Mountains, to the Stanovoi range in the north-easteru extremity of Asia. South of this region is a great central basin, which is almost wholly desert; beyond which again is the vast plateau of Thibet, with the Kuenlun, Karakorum, and Himalayan snow-capped ranges, forming the most extensive elevated district on the globe.

The superficial aspects of this vast territory, as determined by its vegetable coveriug, are very striking and well contrasted. A broad tract on the northem coast, varying from 150 to 300 and even 500 miles wide, is occupied by the Tumdras or barrens, where nothing grows but nosses and the lwarfest Arctic plants, and where the ground is permanently frozen to a great depth. 'This tract has its greatest southern extension between the rivers Obi and Yenesi, where it reaches the parallel of $60^{\circ}$ north latitude. Next to this comes a vast extent of northern forests, mostly of conifers in the more northern and lofty situations, while deciduous trees freponderate in the southern portions and in the more sheltered valleys. The greatest extension of this forest region is north of Lake Baikal, where it is more than 1,200 miles wide. These forests extend along the nountain ranges to join those of the Hindu Koosh. South of the forest.s the remainder of the sub-region consists of open pasture-lands and vast intervening deserts, of which the Gobi, and those of Turkestan between the Aral and Balkitsh likes, are the most 
extensive. The forner is nearly 1,000 miles long, with a width of from 200 to 350 miles, and is almost as complete a desert as the Sahara.

With very few exceptions, this vast territory is exposed to an extreme climate, inimical to animal life. All the lower parts being situated to the north, have an excessively cold winter, so that the limit of constantly frozen ground descends below the parallel of $60^{\circ}$ north latitucle. To the south, the land is greatly clevated, and the climate extremely dry. In summer the heat is excessive, while the winter is almost as severe as further north. The whole country, too, is subject to violent storms, both in summer and winter; and the rich vegetation that clothes the steppes in spring, is soon parched up and replaced by dusty plains. Under these adverse influences we cannot expect animal life to be so abundant as in those sub-regions subject to more favourable physical conditions; yet the country is so extensive and so varied, that it does actually, as we shall see, possess a very considerable and interesting fauna.

Mammalia.-Four genera seem to be absolutely confined to this sub-region, $\Lambda^{r}$ ectogule, a peculiar form of the mole family (Talpidr); Pocphayns, the yals, or hairy bison of Thibet; with Procupra and I'untholops, Thibetan antelopes. Some others more especially belong here, although they just enter Europe, as Saiga, the Tartarian antelope; Sminthus, a desert rat; and Eillotius, a burrowing mole-ret; while Myospalax, a curious rodent allied to the voles, is found only in the Altai mountains and North China ; and Moschus, the musk-deer, is almost confined to this sub-region. Among the characteristic animals of the extreme north, are Mustele, and ILurtes, including the ermine and sable; Gulo, the glutton; Tarandus, the reindeer; Myodes, the lemming; with the lynx, arctic fox, and polar bear; and here, in the I'ost-pliocene epoch, ranged the hairy rhinoceros and Siberian mammoth, whose entire bodies still remain preserved in the ice-cliffs near the mouths of the great rivers. Farther surth, species of wild cat, bear, wolf, deer, and pika (Layomys) ahound; while in the mountains we find wild goats and shcep of several species, and in the plains and deserts wild horses 
and asses, gilzelles, two species of antelopes, flying spuirrels (Ptromys), ground squirrels (T'temius), marmots, of the genus Stermophilus, with camels and dromedaries, probably natives of the south-wester'n part of this sub-region. The most abundant and conspienous of the mammalia are the great herils of reindeer in the north, the wolves of the steppes, with the wild horses, goats, sheep, and antelopes of the plateaus and mountains.

Among the curiosities of this sub-region we must notice the seal, found in the inland and freshwater lake Baikal, at an elevation of about 2,000 feet above the sea. It is a species of Callocephalus, closely allied to, if not identical with, one inhabiting northern seas as well as the Caspian and Lake Aral. This would indicate that almost all northern Asia was depressed beneath the sea very recently; and Mr. Belt's view, of the ice during the glacial epoch having dammed up the rivers and converted much of Siberia into a vast freshwater or brackish lake, perhaps offers the best solution of the difficulty. ${ }^{1}$

Plate II.-Characteristic Mammatia of Western Tartary.Several of the most remarkable animals of the Palrearctic region inhabit Western Tartary, and are common to the European and Siberian sub-regions. We therefore choose this district for one of our illustrative plates. The large animals in the centre are the remarkable saiga antelopes (Saiga Tartarica), distinguished from all others by a large and fleshy proboscis-like nose, which gives them a singular appearance. They differ so much from all other antelopes that they have been formed into a distinct fanily by some naturalists, but are here referred to the great family Bovidie. 'They inhabit the open plains from Poland to the Irtish River' On the left is the mole-rat, or sand-rat (spaler.murinus). 'This animal hurrows under ground like a mole, feeding ou bulbous roots. It inhabits the same country as the saiga, but extentis farther south in Europe. On the right is a still more curious animal, the desman (IFyogale Mruscovitica), a long-snouter water-mole. This creature is fifteen inches long, including the tail ; it burrow's in the banks of streams, leeding on insects,

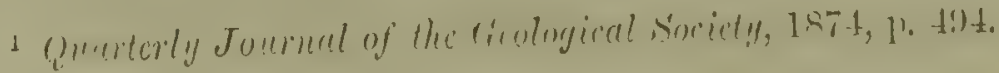




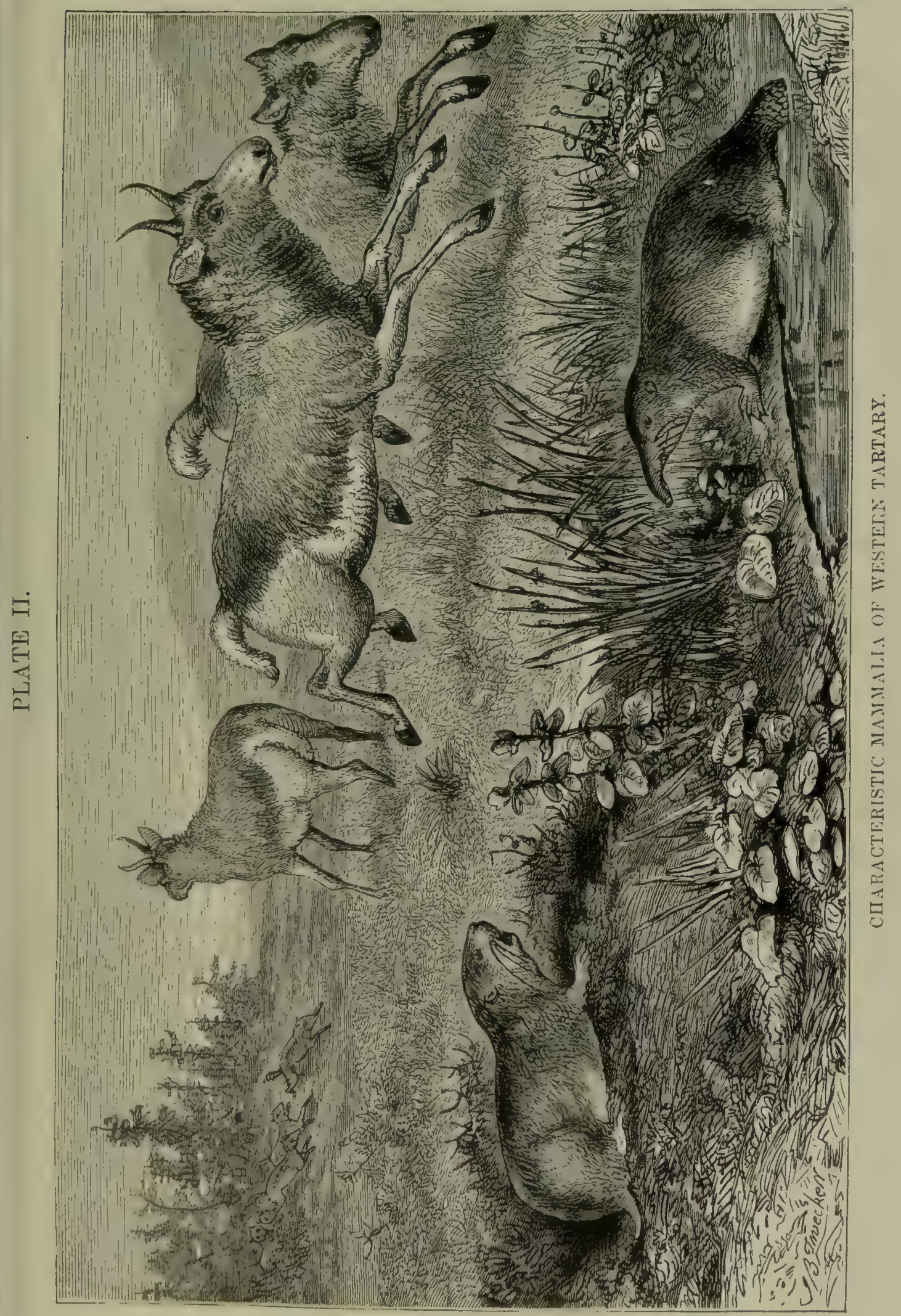



worms, and leeches; it swims well, and remains long under water, raising the tip of the snout, where the nostrils are situated, to the surface when it wants to breathe. It is thus well concenled; and this may be one use of the development of the long snout, as well as serving to follow worms into their holes in the soft earth. This species is confined to the rivers Volga and Don in Southern Russia, and the only other species known inhabits some of the valleys on the north side of the Pyrenees. In the distance are wolves, a characteristic feature of these wastes.

Birds.-But few genera of birds are absolutely restricted to this sub-region. Podoces, a curious form of starling, is the most decidedly so; Mycerobas and Pyrrhospiza are genera of finches confined to Thibet and the snowy Himalayas; Leucosticte, another' genus of finches, is confined to the eastern half of the subregion and North America; Tetraogallus, a large kind of partridge, ranges west to the Caucasus; Syrrhaptes, a form of sand-grouse, and Lerwa (snow-partridge), are almost confined here, only extending into the next sub-region; as do Grandald, and Calliope, genera of warblers, Uragus, a finch allied to the North American cardinals, and Crossoptilon, a remarkable group of pheasants.

Almost all the genera of central and northern Europe are found here, and give quite a European character to the ornithology, though a considerable number of the species are different. There are a few Oriental forms, such as Abrornis and Larvirorce (warblers); with Ceriornis and Ithaginis, genera of pheasants, which reach the snow-line in the Himalayas and thus just enter this sub-region, but as they do not penetrate farther nortl, they hardly serve to modify the exclusively Palaarctic character of its ornithology.

According to Middendorf, the extreme northern Asiatic birds are the Alpine ptarmigan (Lagopus mutus); the snow-bunting (Plectrophanes nivalis); the raven, the gyvfalcon and the snowyowl. Those which are characteristic of the barren "tundras," lut which do not range so far north as the preceding are,-the

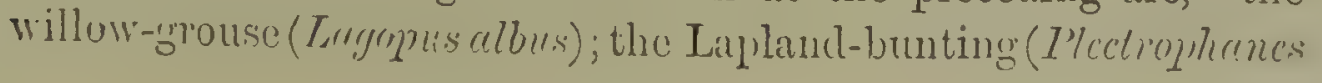


lapponica); the shore-link (Ctocorys alpestris); the sand-nuartin (Cotyle riparia), and the sea-eagle (Hrulicedus albicilla).

Those which are more characteristic of the northern forests, and which do not pass beyond them, are-the linnet; two cross-

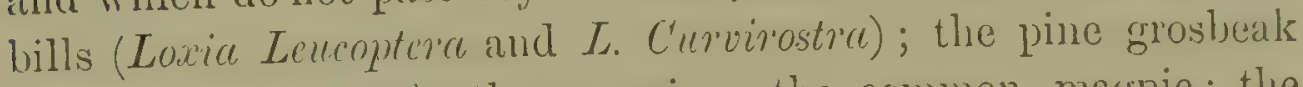
(Pinicolc enuclector); the waxwing; the common maspie; the common swallow; the peregrine falcon; the rough-legred buzard; and three species of owls.

Fully one-half of the land-birds of Siberia are identical with those of Europe, the remainder being mostly representative species peculiar to Northern Asia, with a few straggler's and immigrants from China and Japan or the Himalayas. A much larger proportion of the wading and aquatic families are European or Aretic, these groups having always a wider range than land birds.

Reptiles and Amphibia,--From the nature of the country and climate these are comparatively few, but in the more temperate districts snakes and lizards seem to be not uncommon. Halys, a genus of Crotaline snakes, and Phrynocephalus, lizards of the family Agamida, are characteristic of these parts. Simotes, a snake of the family Oligodontick, reaches an elevation of 16,000 feet in the Himalayas, and therefore enters this sub-region.

Insects.-Mescipia and Hypermnestra, genera of Papilionidie, are butterflics peculiar to this sub-region; and Parnassius is as characteristic as it is of our Europenn mountains. Carabidie are also abundant, as will be seen by referring to the Chapter on the Distribution of Insects in the succeeding part of this work. The insects, on the whole, have a strictly European character, although a large proportion of the species are peculiar, and several new genera appear.

IV.-Japan and North China, or the Manchurian Sub-region.

This is an interesting and very productive district, corresponding in the east to the Mediterranean sub-region in the west, ol rather perhaps to all western temperate Europe. Its limits are not very well defined, but it probably includes all Japan; the Corea and Manchuria to the Amour river and to the lower 
slopes of the Khingan and Peling mountains; and China to the Namlin mountains south of the Yang-tse-kiang. On the coast of China the dividing line between it and the Oriental region seems to be somewhere about Foo-chow, but as there is here no natural barrier, a great intermingling of northern and southern forms takes place.

Japan is volcanic and mountainous, with a fine climate and a most luxuriant and varied vegetation. Manchuria is billy, with a high range of mountains on the coast, and some descrt tracts in the interior, but fairly wooded in many parts. Much of northern China is a vast alluvial plain, backed by hills and mountains with belts of forest, above which are the dry and barren uplands of Mongolia. We have a tolerable knowledge of China, of Japan, and of the Amoor valley, but very little of Corea and Manchuria. The recent researches of Père David in Moupin, in east Thibet, said to be between $31^{\circ}$ and $32^{\circ}$ north latitude, show, that the fauna of the Oriental region here advances northward along the flanks of the Yun-ling mountains (a continuation of the Himalnyas); since he found at different altitudes representatives of the Indo-Chinese, Manchurian, and Siberian faunas. On the higher slopes of the Himalayas, there must be a narrow strip from about 8,000 to 11,000 feet elevation intervening between the tropical faun of the Indo-Chinese subregion and the almost arctic fauna of Thibet; and the animals of this zone will for the most part belong to the fauna of temperate China and Manchuria, except in the extreme west towards Cashmere, where the Mediterranean fauna will in like manner intervene. On a map of sufficiently large scale, therefore, it would be necessary to extend our present sub-region westward along the Himalayas, in a narrow strip just below the upper limits of forests. It is evident that the large number of Fringillidæ, Corvidæ, Troglodytidæ, and Paridæ, often of south Palæarctic forms, that abound in the higher Himalayas, are somewhat out of place as members of the Oriental fauna, and are equally so in that of Thibet and Siberia; but they form a natural portion of that of North China on the one side, or of South Europe on the other. 
Mummalia.-This sub-region contains a number of jeculiar and very interesting forms, most of which lave been recently discovered by Pire David in North and West China and East Thibet. The following are the peculiar gencra:-Rhinopithecus, a sub-genus of monkeys, here classed under Semnopithecus; Anurosorex, Scaptochirus, Uropsilus and Scaptonyx, new forms of I'ilpilice or moles; Liluropus (Aluridx); Nyclerentes (Canidx); Iutroncetes (Mustelidx); Cricetulus (Muridæ); Hydropotes, Moschus, and Elcuphodus (Cervidx). The Rlinopithecus appears to be a permanent inhabitant of the highest forests of Moupin, in a cold climate. It has a very thick fur, as has also a new species of Macacus found in the same district. North China and East Thibet seem to be very rich in Insectivora. Scaptochirns is like a mole; Uropsilus between the Japanese Urotrichus and Sorex; Scaptonyx between Urotrichus and Talpa. AEluropus seems to be the most remarkable manmal discovered by Pire David. It is allied to the singular panda (AElurus fulgens) of Nepal, but is as lingre as a bear, the body wholly white, with the feet, ears, and tip of the tail black. It inhabits the highest forests, and is therefore a true Palæarctic animal, as most likely is the Allurus. Nyctereutes, a curious racoon-like dog, ranges from Canton to North China, the Amoor and Japan, and therefore seems to come best in this sub-region; Hydropotes and Lophotiagus are small hornless deer confined to North China; Elaphodus, from East Thibet, is another peculiar form of deer; while the musk deer (Moschus) is confined to this sub-region and the last. Besides the above, the following Palæarctic senera were found by Pire David in this sub-region: Macacus; five genera or sub-genera of bats (Vespertilio, Vesperus, Vesperugo, Iilinolophus, and IFurina); Erinaceus, N'ectoyale, Talpa, Crocicurce and Sorex, among Insectivora; Mustela, Putorius, Martes, Lutra, Viverra, Meles, Alurus, Ursus, Felis, and Canis, among Carnivora; Hystrix, Arctomys, Myospalax, Spermoplitus, Gertrillus, Dipus, Lagomys, Lepus, Sciurus, Ptcromys, Arvicole, and Mres, among Rollentia; Budoreas, Nemorhedus, Antilope, Oris, Moschus, Cervulus and Cervus among Timinants; and the wide. spread Sus or wild boar. The following Oriental genera are also 
included in Père David's list, but no doubt occur only in the lowlands and warm valleys, and can hardly be considered to helong to the Palrarctic region: Paguma, Hclictis, Arctonyx, Rhizomys, Manis. The Rhizomys from Moupin is a peculiar species of this tropical genus, but all the others inhabit Southern China.

A few additional forms occur in Japan: Urotrichus, a peculiar Mole, which is found also in north-west America; Enhydra, the sea otter of California; and the dormouse (Myoxus). Japan also jossesses peculiar species of Macacus, Talpa, Mcles, Canis, and Scincropterus.

It will be seen that this sub-region is remarkably rich in Insectivora, of which it possesses ten genera; and that it has also several peculiar forms of Carnivora, Rodentia, and Ruminants.

Bircls.-To give an accurate idea of the ornithology of this sub-region is very difficult, both on account of its extreme richness and the impossibility of defining the limits between it and the Oriental region. A considerable number of genera which are well developed in the high Himalayas, and some which are peculiar to that district, have hitherto always been classed as Indian, and therefore Oriental groups; but they more properly belong to this sub-region. Many of them frequent the highest forests, or descend into the Himalayan temperate zone only in winter; and others are so intimately connected with Palcearctic species, that they can only be considered as stragglers into the border land of the Oriental region. On these priuciples we consider the following genera to be confined to this sub-region :-

Grandala, Nemura (Sylviidæ); Pterortinus (Timaliidx); Cholornis, Conostoma, Heteromorpha (Panurida); Cyanoptila (Muscicapidæ); Eophona (Fringillidx); Dendrotreron (Columbidæ); Lophophorus, Tetraophasis, Crossoptilon, Pucrasia, Thaumalea, and Ithrginis (Phasianidr). This may be called the sub-region of Pheasants; for the above six genera, comprising sixteen species of the most magnificent birds in the world, are all confined to the temperate or cold mountainous regions of the Hinalayas, Thibet, and China; and in adlition we have 
most of the species of tragopan (Ceriornis), and some of the true pheasants (Phasianus).

The most abundant and characteristic of the smaller birds are warblers, tits, and finches, of Palæarctic types; but there are also a considerable number of Oriental forms which penetrate far into the country, and mingling with the northern birds give a character to the Ornithology of this sub-region very different from that of the Mediterranean district at the western end of the region. Leaving out a large number of wide-ranging groups, this mixture of types may be best exhibited by giving lists of the more striking Palrearctic and Oriental genera which are here found intermingled.

\section{Palearctic Gexera.}

\begin{tabular}{|c|}
\hline 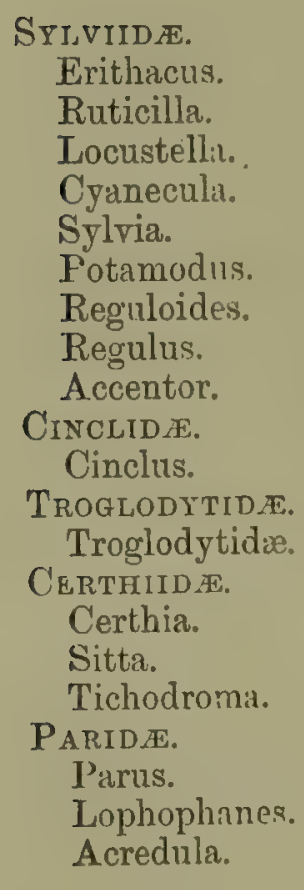 \\
\hline
\end{tabular}

CORVID AE.

Fregilus.

Nucifragiı.

Pica.

Cyanopica.

Garrulus.

AMPELID王.

Ampelis.

FringILLID E.

Fringilla.

Chrysomitris.

Chlorospiza.

Passer.

Coccothraustes.

Pyrrhula.

Carpodacis.

Uragus.

Loxia.

Linota.

Emberiza.

Sturnide.

Sturuus.
Alaudid.e.

Otocorys.

Picide.

Picoides.

Picus.

Hyopicus.

Dryocopus.

YUNGIDE.

Yunx.

Pteroclide.

Syrrhaptes.

Tetraonid .

Tetrao.

Tetra.ogallus.

Lerwa.

Lagopus.

VULTURIDA.

Gypaëtus.

Vultur.

FALCONIDA.

Archibuteo.

Oriental Genera.

SrLvidde.
Suya.
Calliope.
Larvivora.
Tribura.
Horites.

SyLVIIDA-(continued).

Abrornis.

Copsychus,

TURDIDE.

Oreocincli.

Timalid.F.

Alcippe.

Timalia.

Pterocychus.

Garrulax.

'Trochalopternn. 


\section{Oriental Genera-continued.}

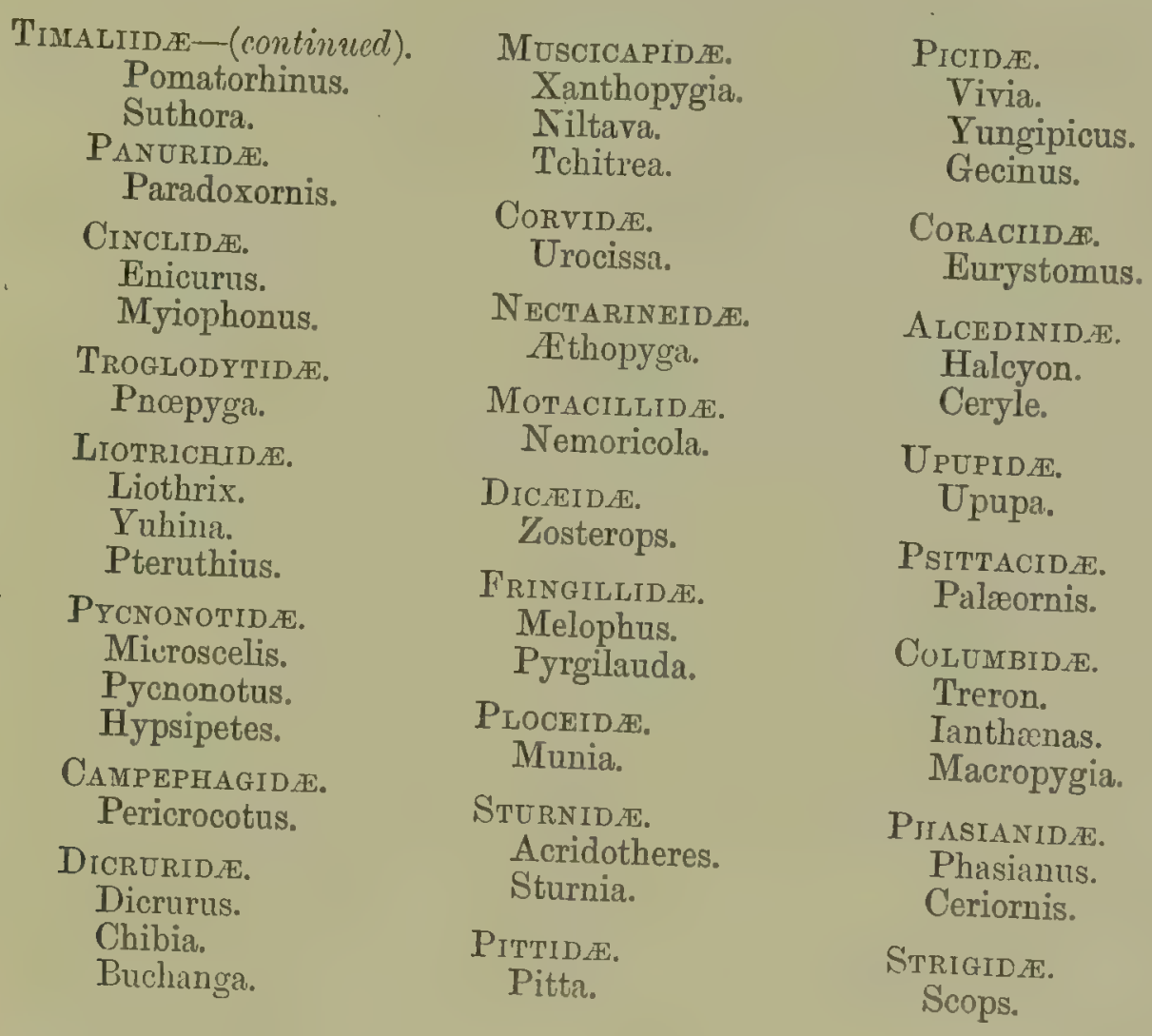

In the above lists there are rather more Oriental than Palæarctic genera; but it must be remembered that most of the former are summer migrants only, or stragglers just entering the sub-region; whereas the great majority of the latter are permanent residents, and a large proportion of them range over the greater part of the Manchurian district. Many of those in the Oriental column should perhaps be omitted, as we have no exact determination of their range, and the limits of the regions are very uncertain. It must be remembered, too, that the Palæarctic genera of Sylviidæ, I'aridx, and Fringillidæ, are often represented by numerous species, whereas the corresponding Oriental genera have for the most part only single species; and we shall then find that, except towards the borders of the Oriental region the Ialcearctic element is strongly predominant. Four of the more especially Oriental groups are confined to Jnyan, the southern 
extremity of which should perhaps come in the Oriental region. The great richness of this sub-region compared with that of Siberia is well shown by the fact, that a list of all the known land-birds of East Siberia, including Dahuria and the comparatively fertile Amoor Valley, contains only 190 species; whereas Père David's catalogue of the birds of Northern China with adjacent parts of East Thibet and Mongolia (a very much smaller area) contains for the same families 366 species. Of the Siberian birds more than 50 per cent. are European species, while those of the Manchurian sub-region comprise about half that proportion of land-birds which are identical with those of Europe.

Japan is no doubt very imperfectly known, as only 134 landbirds are recorded from it. Of these twenty-two are peculiar species, a number that would probably be diminished were the Corea to be explored. Of the genera, only nine are IndoMalayan, while forty-three are Palæarctic.

Plate III.-Scene on the Borders of North-West China and Mongolia with Characteristic Mermmalic and Birds. - The mountainous districts of Northern China, with the adjacent portions of Thibet and Mongolia, are the head-quarters of the pheasant tribe, many of the most beautiful and remarkable species being found there only. In the north-western provinces of China and the southern parts of Mongolia may be found the species figured. That in the foreground is the superb golden pheasant (Thaumalea picta), a bird that can liardly be surpassed for splendour of plumage by any denizen of the tropics. The large bird perched above is the eared pheasant (Crossoptilon auritum), a species of comparatively sober plumage but of remarkable and elegant form. In the middle distance is Pallas's sand grouse (Syrrhaptes paradoxus), a curious bird, whose native country seems to be the high plains of Northern Asia, but which often abounds near Pekin, and in 1863 astonished European ornithologists by appearing in considerable numbers in Central and Western Europe, in every part of Great Britain, and even in Ireland.

The quadruped figured is the curions racoon dog (Nycterentes 
PLA'E III.

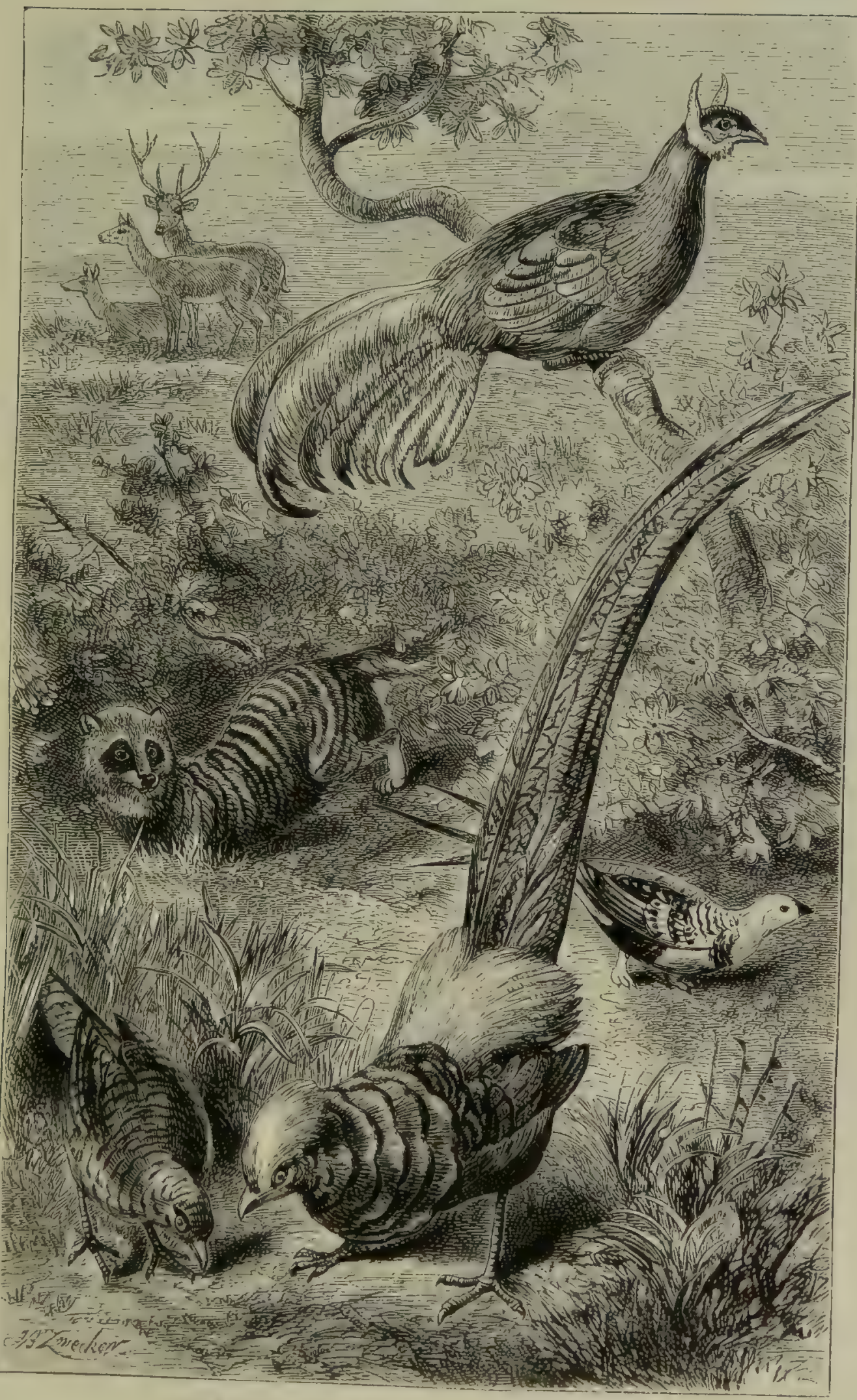

CIIARACTEISTIC ANIMALS OF NORTH CIINA. 

procyonoides), an animal confined to North China, Japan, and the Amoor Valley, and having no close allies in any other part of the globe. In the distance are some deer, a group of animals very abundant and varied in this part of the Palæarctic region.

Reptiles and Amphibia.-Reptiles are scarce in North China, only four or five species of snakes, a lizard and one of the Geckotidæ occurring in the country round Pekin. The genus Halys is the most characteristic form of snake, while Callophis, an oriental genus, extends to Japan. Among lizards, Plestiodon, Maybouya, Tachydromus, and Gecko reach Japan, the two latter being very characteristic of the Oriental region.

Amphibia are more abundant and interesting; Hynobius, Onychodactylus, and Sicboldtia (Salamandridæ) being peculiar to it, while most of the European genera are also represented.

Fresh-water Fish-Of these there are a few peculiar genera; as Plecoglossus (Salmonidæ) from Japan; Achilognathus, Pseudoperilampus, Ochetobius, and Opsariichthys (Cyprinidæ); and there are many other Chinese Cyprinidæe belonging to the border land of the Palæarctic and Oriental regions.

Insects-The butterflies of this sub-region exhibit the same mixture of tropical and temperate forms as the birds. Most of the common European genera are represented, and there are species of Parnassius in Japan and the Amoor. Isodema, a peculiar genus of Nymphalidæ is found near Ningpo, just within our limits; and Sericinus, one of the most beautiful genera of Papilionidæ is peculiar to North China, where four species occur, thus balancing the Thais and Doritis of Europe. The genus Zephyrus (Lycænidx) is well represented by six species in Japan and the Amoor, against two in Europe. Papilio paris and $P$. bianor, magnificent insects of wholly tropical appearance, abound near Pekin, and allied forms inhabit Japan and the Amoor, as well as $P$. demetrius and $P$. alcinous belonging to the "Protenor" group of the Himalayas. Other tropical genera occurring in Japan, the Amoor, or North China are, Debis, Neope, Mycalesis, Ypthimia (Satyridx); Thaumantis (Morphidx), at Shanghae; Euripus, Neptis, Athyma (Nymphalidx); I'crias (Pieridæ); and the above-mentioned Papilionidæ. 
Coleoptera. - The beetles of Japan decidedly exhibit a mixture of tropical forms with others truly Palæarctic, and it has been with some naturalists a matter of doubt whether the southern and best known portion of the islands should not be joined to the Oriental region. An important addition to our knowledge of the insects of this country has recently been made by Mr. George Lewis, and a portion of his collections have been described by various entomologists in the Transactions of the Entomological Society of London. As the question is one of considerable interest we shall give a summary of the results fairly deducible from what is now known of the entomology of Japan; and it must be remembered that almost all our collections come from the southern districts, in what is almost a sub-tropical climate; so that if we find a considerable proportion of Palæarctic forms, we may be pretty sure that the preponderance will be much greater a little further north.

Of Carabidæ Mr. Bates enumerates 244 species belonging to 84 genera, and by comparing these with the Coleoptera of a tract of about equal extent in western Europe, he concludes that there is little similarity, and that the cases of affinity to the forms of eastern tropical Asia preponderate. By comparing his genera with the distributions as given in Gemminger and Harold's Catalogue, a somewhat different result is arrived at. Leaving out the generic types altogether peculiar to Japan, and also those genera of such world-wide distribution that they afford no clear indications for our purpose, it appears that no less than twentytwo genera, containing seventy-four of the Japanese species, are either exclusively Palæarctic, Palæarctic and Nearctic, or highly characteristic of the Palæarctic region; then come thirteen genera containing eighty-seven of the species which have a very wide distribution, but are also Palrarctic: we next have seventeen genera containing twenty-four of the Japanese species which are decidedly Oriental and tropical. Here then the fair comparison is between the twenty-two genera and seventy-four species whose affinities are clearly Palæarctic or at least north temperate, and seventeen genera with twenty-four species which are Asiatic and tropical; and this scems to prove that, although South 
Japan (like North China) has a considerable infusion of tropical forms, there is a preponderating substratum of Palæarctic forms, which clearly indicate the true position of the islands in zoolngical geography. There are also a few cases of what may be called eccentric distribution; which show that Japan, like many other island-groups, has served as a kind of refuge in which dying-out forms continue to maintain themselves. These, which are worthy of notice, are as follows: Orthotrichus (1 sp.) has the only other species in Egypt; Trechichus (1 sp.) has two other species, of which one inlabits Madeira, the other the Southern United States; Perileptus (1 sp.) has two other species, of which one inhabits Bourbon, the other West Europe; and lastly, Crepidogaster (1 sp.) has the other known species in South Africa. These cases diminish the value of the indications afforded by some of the Japanese forns, whose only allies are single species in various remote parts of the Oriental region.

The Staphylinidæ have been described by Dr. Sharp, and his list exhibits a great preponderance of north temperate, or cosmopolitan forms, with a few which are decidedly tropical. The Pselaphidæ and Scydmenidæ, also described by Dr. Sharp, exhibit, according to that gentleman, "even a greater resemblance to those of North America than to those of Europe," but he says nothing of any tropical affinities. The water-beetles are all either Palæarctic or of wide distribution.

The Lucanide (Gcmm. and Har. Cat., 1868) exhibit an intermingling of Palæarctic and Oriental genera.

The Cetoniidre (Gemm. and Har. Cat. 1869) show, for North China and Japan, three Oriental to two Palparctic genera.

The Buprestidæe collected by Mr. Lewis have been described by Mr. Edward Saunders in the Journal of the Linnoean Socicty, vol. xi. p. 509. The collection consisted of thirty-six species belonging to fourteen genera. No less than thirteen of these are known also from India and the Malay Islands; nine from Europe; seven from Africa; six from America, and four from China. In six of the genera the Japanese species are said to be allied to those of the Oriental region; while in three they are allied to European forms, and in two to American. Consideriug 
the southern latitude and warm climate in which these insects were mostly collected, and the proximity to Formosa and the Malay Islands compared with the enormous distance from Europe, this shows as much Palæarctic affinity as can be expected. In the Palrarctic region the group is only plentiful in the southern parts of Europe, which is cut off by the cold plateau of Thibet from all direct communication with Japan; while in the Oriental region it everywhere abounds and is, in fact, one of the most conspicuous and dominant families of Coleoptera.

The Longicorns collected by Mr. Lewis have been described by Mr. Bates in the Annals of Natural History for 1873. The number of species now known from Japan is 107 , belonging to sixty-four genera. The most important genera are Leptura, Clytanthus, Monohammus, Praonetha, Exocentrus, Glenea, and Oberea. There are twenty-one tropical genera, and seven peculiar to Japan, leaving thirty-six either Palæarctic or of very wide range. A number of the genera are Oriental and Malayan, and many characteristic European genera seem to be ahsent; but it is certain that not half the Japanese Longicoms are yet known, and many of these gaps will doubtless be filled up when the more northern islands are explored.

The Phytophaga, described by Mr. Baly, appear to have a considerable preponderance of tropical Oriental forms.

A considerable collection of Hymenoptera formed by $\mathrm{Nr}$. Lewis have been described by Mr. Frederick Smith ; and exhibit the interesting result, that while the bees and wasps are decidedly of tropical and Oriental forms, the Tenthredinidre and Iclneumonidx are as decidedly Palæarctic, "the general aspect of the collection being that of a European one, only a single exotic furm being found among them."

Remarks on the General Character of the Fauna of JapanFrom a general view of the phenomena of distribution we feel justified in placing Japan in the Palcarctic region; although some tropical groups, especially of reptiles and insects, liave largely occupied its southern portions; and these same groups have in many cases spread into Northern Clrina, beyond the 
usual dividing line of the Palæarctic and Oriental regions. The causes of such a phenomenon are not difficult to conceive. Even now, that portion of the Palrarctic region between Western Asia and Japan is, for the most part, a bleak and inhospitable region, abounding in desert plateaus, and with a rigorous climate even in its most favoured districts, and can, therefore, support but a scanty population of snakes, and of such groups of insects as require flowers, forests, or a considerable period of warm summer weather; and it is precisely these which are represented in Japan and North China by tropical forms. We must also consider, that during the Glacial epoch this whole region would have become still less productive, and that, as the southern limit of the ice retired northward, it would be followed up by many tropical forms along with such as had been driven south by its advance, and had survived to return to their northern homes.

It is also evident that Japan has a more equable and probably moister climate than the opposite shores of China, and has also a very different geological character, being rocky and broken, often volcanic, and supporting a rich, varied, and peculiar vegetation. It would thus be well adapted to support all the more hardy denizens of the tropics which might at various times reach it, while it might not he so well adapted for the more boreal forms from Mongolia or Siberia. The fact that a mixture of such forms occurs there, is then, little to be wondered at, but we may rather marvel that they are not more predominant, and that even in the extreme south, the most abundant forms of mammal, bird, and insect, are modifications of familiar Palæarctic types. The fact clearly indicates that the former land connections of Japan with the continent have been in a northerly rather than in a southerly direction, and that the tropical immigrants have had difficulties to contend with, and have found the land already fairly stocked with northern aborigines in almost every class and order of animals.

General Conclusions as to the Fauna of the Palocarctic Region.-From the account that has now been given of the faumi 
of the Palwaretic region, it is evident that it owes many of its deficiencies and some of its peculiarities to the influence of the Glacial epoch, combined with those important changes of pliysical geography which accompanied or preceded it. The elevation of the old Sarahan sea and the complete formation of the Nediterranean, are the most important of these changes in the western portion of the region. In the centre, a wicle arm of the Arctic Ocean extender southward from the Gulf of Obi to the Aral and the Caspian, dividing northern Europe and Asia. At this time our European and Siberian sub-regions were probably more distinct than they are now, their complete fusion haring been effected since the Glacial epoch. As we know that the Himalayas have greatly increased in altitude during the Tertiary period, it is not impossible that during the Miocene and Pliocene epochs the vast plateau of Central Asia was much less elevated and less completely cut off from the influence of rain-bearing winds. It might then have been far more fertile, and have supported a rich and varied animal population, a few relics of which we see in the Thibetan antelopes, yaks, and wild horses. The influence of yet earlier changes of physical geography, and the relations of the Palæarctic to the tropical regions immediately south of it, will be better understood when we have examined and discussed the faunas of the Ethiopian and Oriental regions. 


\section{TABLES OF DISTRIBUTION.}

IN constructing these tables showing the distribution of various classes of animals in the Palæarctic region, the following sources of information have been chiefly relied on, in addition to the gereral treatises, monographs, and catalogues used in compiling the fourth part of this work.

Mammalic.-Lord Clement's Mammalia and Reptiles of Europe; Siebold's Fauna Japonica; Père David's List of Mammalia of North China and Thibet; Swinhoe's Chinese Mammalia; Radde's List of Mammalia of South-Eastern Siberia; Canon Tristram's, Lists for Salıara and Palestine; Papers by Professor Milne-Edwards, Mr. Blanford, Mr. Sclater, and the local lists given by Mr. A. Murray in the Appendix to his Geographical Distribution of Mammalia.

Birds.-Blasius' List of Birds of Europe; Godman, On Birds of Azores, Madeira, and Canaries; Middendorf, for Siberia; Père David and Mr. Swinhoe, for China and Mongolia; Homeyer, for East Siberia; Mr. Blanford, for Persia and the high Himalayas; Mr. Elwes's paper on the Distribution of Asiatic Birds; Canon Tristram, for the Sahara and Palestine; Professor Newton, for Iceland and Greenland; Mr. Dresser, for Scandinavia; and numerous papers and notes in the Ibis; Journal furr Crnithologie; Aunals and Mag. of Nat. History; and Proceedings of the Zoological Society.

Reptites und Amphibia.-Schreiber's European Herpetology. 


\section{'LABI,E I.}

\section{FA.ULIES OF ANIIALS INHABITING THE PALAEARCTIC REGION.}

\section{Expianation.}

Names in itatics show families peculiar to the region.

Names inclosed thus (......) barely enter the region, and are not considered properly to belong to it.

Numbers are not consecutive, but correspond to those in Part IV.

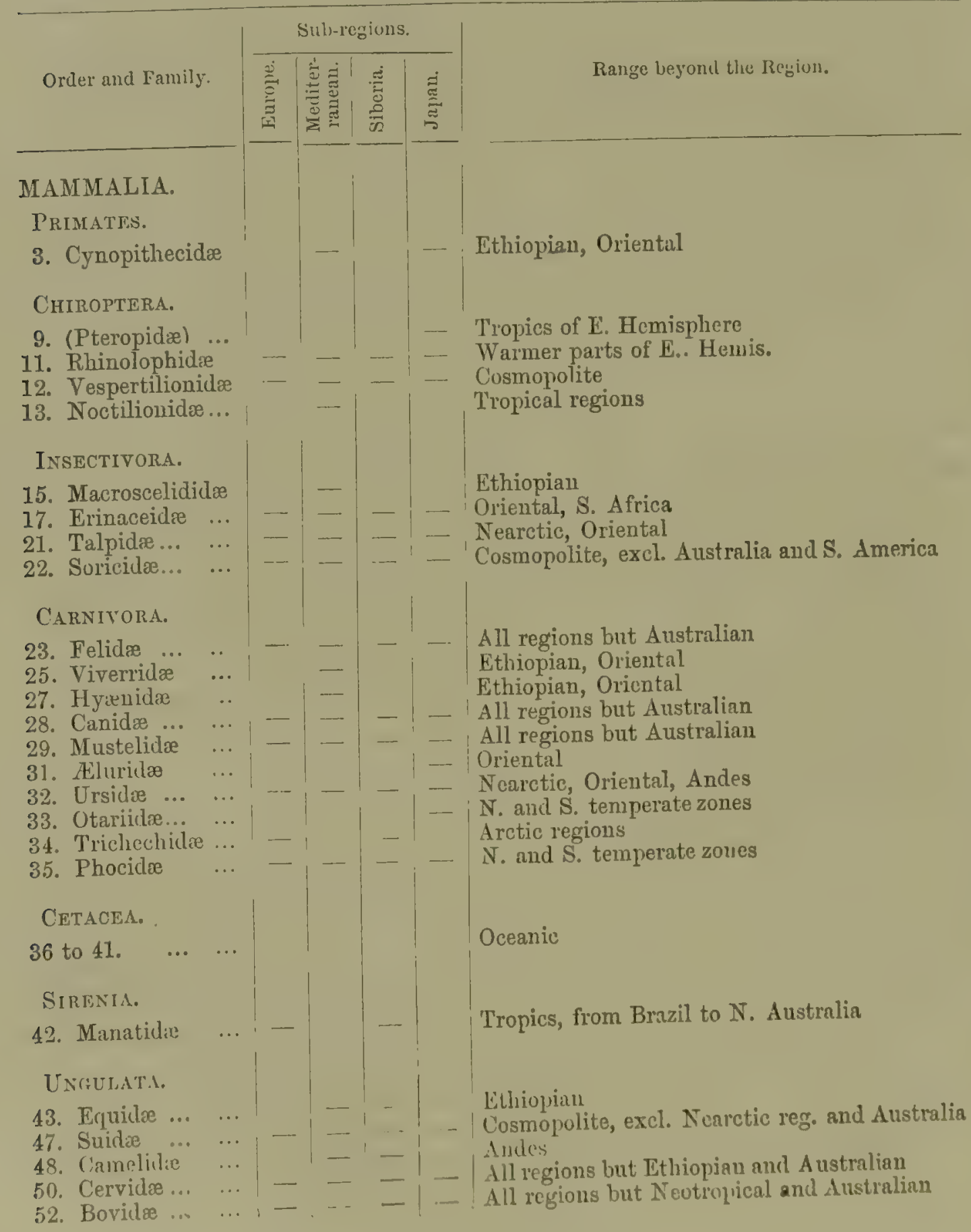




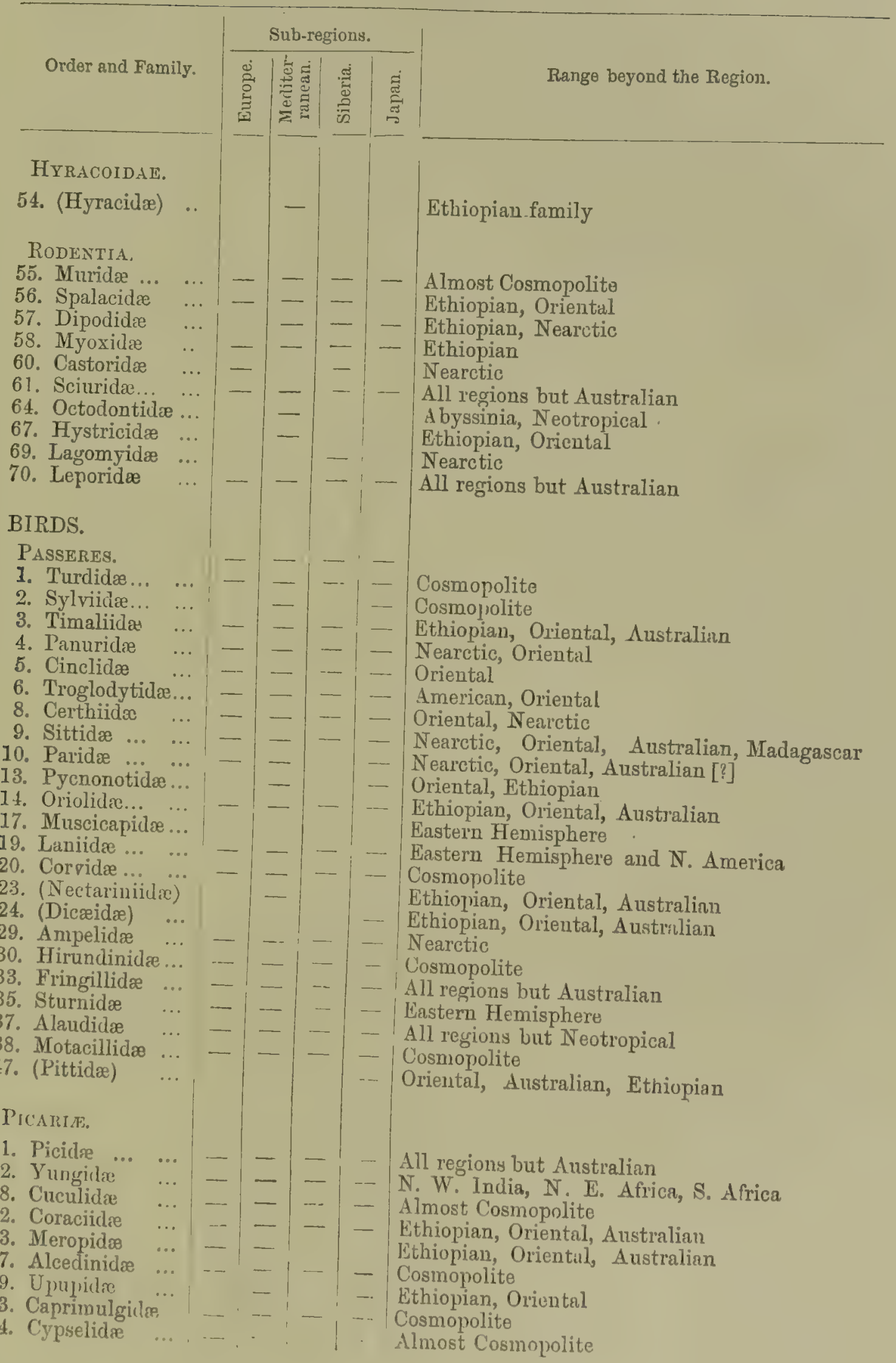




\begin{tabular}{|c|c|c|c|c|c|}
\hline \multirow[b]{2}{*}{ Order and Family. } & \multicolumn{4}{|c|}{ Sub-regions. } & \multirow[b]{2}{*}{ Range beyond the Region. } \\
\hline & 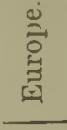 & 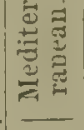 & 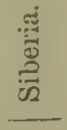 & 苛 & \\
\hline $\begin{array}{l}\text { CoLUмв.玉. } \\
\text { 84. Columbidæ ... }\end{array}$ & - & - & - & - & Cosmopolite \\
\hline $\begin{array}{l}\text { Galdin.e. } \\
\text { 86. Pteroclidæe ... } \\
\text { 87. Tetraonidæ ... } \\
\text { 88. Phasianidæ ... } \\
\text { 89. Turnicidæ .. }\end{array}$ & & - & 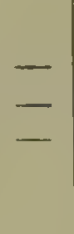 & $\begin{array}{c}- \\
-\end{array}$ & $\begin{array}{l}\text { Ethioplan, Indian } \\
\text { Nearctic, Ethiopian, Oriental } \\
\text { Oriental, Ethiopian, Nearctic } \\
\text { Ethiopian, Oriental, Australian }\end{array}$ \\
\hline $\begin{array}{l}\text { Accipitues. } \\
\text { 94. Vulturidæ ... } \\
\text { 96. Falconidæ } \\
\text { 97. Pandionidæ... } \\
\text { 98. Strigidæ ... }\end{array}$ & $\begin{array}{c}- \\
- \\
-\end{array}$ & 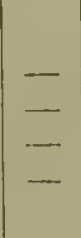 & $\begin{array}{l}- \\
- \\
-\end{array}$ & $\overline{-}$ & $\begin{array}{l}\text { All regions but Australian } \\
\text { Cosmopolite } \\
\text { Cosmopolite } \\
\text { Cosmopolite }\end{array}$ \\
\hline 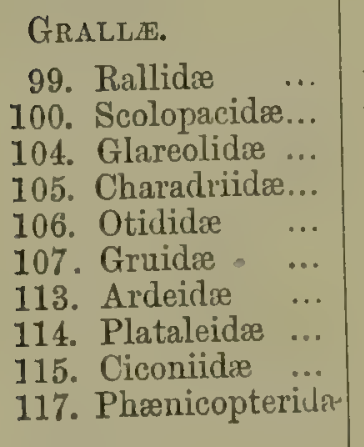 & $\begin{array}{l}- \\
z \\
z \\
z \\
-\end{array}$ & $\begin{array}{l}- \\
- \\
- \\
- \\
- \\
- \\
-\end{array}$ & $\begin{array}{l}- \\
- \\
- \\
- \\
- \\
-\end{array}$ & $\begin{array}{l} \pm \\
- \\
- \\
- \\
- \\
-\end{array}$ & $\begin{array}{l}\text { Cosmopolite } \\
\text { Cosmopolite } \\
\text { Ethiopian, Oriental, Australian } \\
\text { Cosmopolite } \\
\text { Ethiopian, Oriental, Australian } \\
\text { Eastern Hemisphere, and N. America } \\
\text { Cosmopolite } \\
\text { Almost Cosmopolite } \\
\text { Nearly Cosmopolite } \\
\text { Neotropical, Ethiopian, Indian }\end{array}$ \\
\hline $\begin{array}{l}\text { ANSEREs. } \\
\text { 118. Anatidæ } \\
\text { 119. Laridæ.... ... } \\
\text { 120. Procellaridie } \\
\text { 121. Pelecanidæ ... } \\
\text { 123. Colymbidæ ... } \\
\text { 124. Podicipidæe ... } \\
\text { 125. Alcidæ ... ... }\end{array}$ & $\begin{array}{l}- \\
\overline{-} \\
\overline{-} \\
-\end{array}$ & $\begin{array}{l}- \\
- \\
-\end{array}$ & $\begin{array}{l}- \\
- \\
- \\
- \\
-\end{array}$ & $\begin{array}{l}- \\
\overline{-} \\
- \\
- \\
-\end{array}$ & $\begin{array}{l}\text { Cosmopolite } \\
\text { Cosmopolite } \\
\text { Cosmopolite } \\
\text { Cosmopolite } \\
\text { Arctic and N. Temperate } \\
\text { Cosmopolite } \\
\text { N. Temperate zone }\end{array}$ \\
\hline 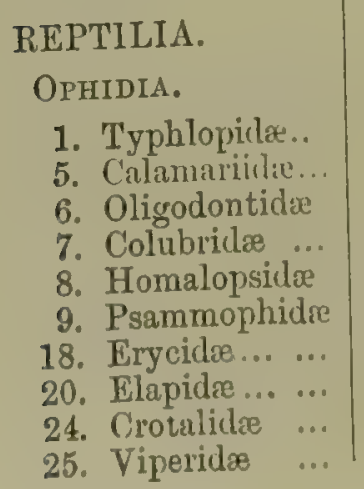 & - & $\begin{array}{l}- \\
- \\
-\end{array}$ & $\begin{array}{l}- \\
- \\
-\end{array}$ & $\begin{array}{l}- \\
- \\
- \\
- \\
- \\
- \\
-\end{array}$ & $\begin{array}{l}\text { All regions but Nearctic } \\
\text { All other regions } \\
\text { Oriental and Neotropical } \\
\text { Almost Cosmopolite } \\
\text { Oriental, and all other regions } \\
\text { Ethiopian anil Oriental } \\
\text { Oriental and Ethiopian } \\
\text { Australian and all otlier regions } \\
\text { Nearctic, Neotropical, Orientul } \\
\text { Lithiopian, Oriental }\end{array}$ \\
\hline
\end{tabular}




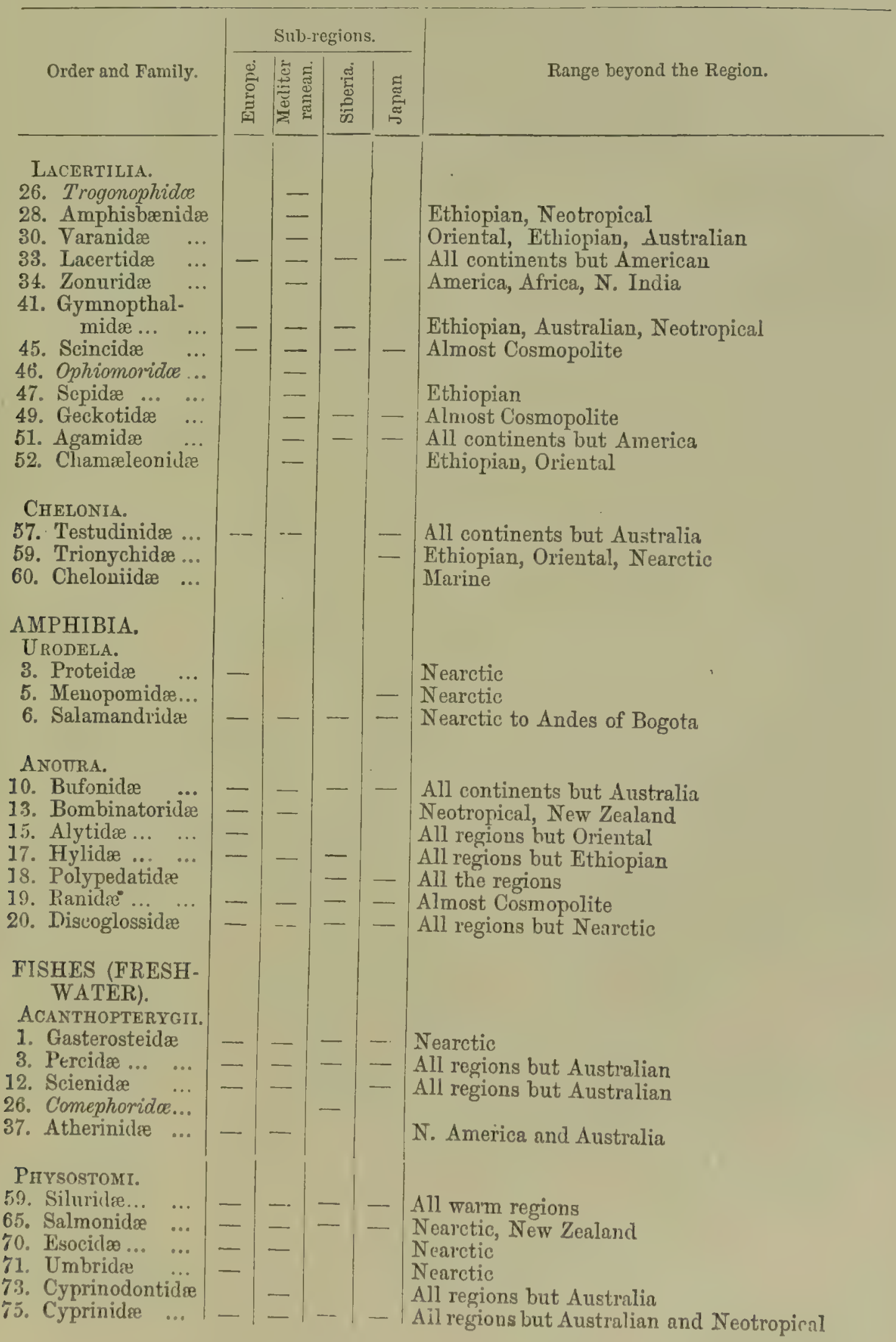




\begin{tabular}{|c|c|c|c|c|c|}
\hline \multirow[b]{2}{*}{ Order and Family. } & \multicolumn{4}{|c|}{ Stub-regions. } & \multirow[b]{2}{*}{ Range beyond the Region. } \\
\hline & 离 & 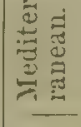 & . & 营 & \\
\hline $\begin{array}{l}\text { GANOIDEI. } \\
\text { 96. Accipenseridx } \\
\text { 97. Polydontidæ ... }\end{array}$ & - & - & - & - & $\begin{array}{l}\text { Nearctic } \\
\text { Nearctic }\end{array}$ \\
\hline $\begin{array}{l}\text { INSECTS } \\
\text { DOPTERA (PART) }\end{array}$ & & & & & \\
\hline $\begin{array}{l}\text { DURINI (BUTTER- } \\
\text { FLIES). }\end{array}$ & & & & & \\
\hline 1. Danaidæ & 一 & - & & - & All tropical regions \\
\hline 2. Satyridæ $\ldots$ & - & - & - & - & Cosmopolite \\
\hline $\begin{array}{l}\text { 8. Nymphalidr ... } \\
\text { 9. Libytheidæ ... }\end{array}$ & - & - & - & - & $\begin{array}{l}\text { Cosmopolite } \\
\text { All continents but Australia }\end{array}$ \\
\hline 10. Nemeobeidx.. & - & & & & Absent from Nearctic region and Australia \\
\hline 13. Lycænidæ & - & - & - & - & Cosmopolite \\
\hline 14. Pieridæ $: \ldots \quad \ldots$ & - & - & - & - & Cosmopolite \\
\hline 15. Papilionidæ ... & - & - & 一 & - & Cosmopolite \\
\hline 16. Hesperidæ & - & - & - & - & Cosmopolite. \\
\hline SPHIRIGIDEA. & & & & & \\
\hline $\begin{array}{l}\text { 17. Zygænidæe } \\
\text { Stvgiidæ }\end{array}$ & - & - & - & - & $\begin{array}{l}\text { Cosmopolite } \\
\text { Neotropical }\end{array}$ \\
\hline 22. Eg Egriidx & - & - & - & - & Absent only from Australia \\
\hline 23. Sphingidæ $\quad \ldots$ & - & - & - & - & Cosmopolite \\
\hline
\end{tabular}

Coleoptera. - Of about 80 families into which the Coleoptera are dividel, all the inore important are cosmopolite, or nearly so. It would therefore unnecessarily occupy space to give tables of the whole for each region.

LAND SHELLS. - The more important families being cosmopolite, and the smaller ones being somewhat uncertain in their limits, the reader is referred to the account of the families and genera under each region, and to the chapter on Mollusca in the concluding part of this work, for such information as can be given of their distribution. 
TABLE II.

\section{LIST OF THE GENERA OF TERRESTIAL MAMMALIA AND BIRDS INHABITING THE PALAEARUTIC REGION.}

Explanation.

Names in italics show genera peculiar to the region.

Names inclosed thus (...) show genera which just enter the region, but are not considered. properly to belong to it.

Genera which undoubtedly belong to the region are numbered consecutively.

MAMMALIA.

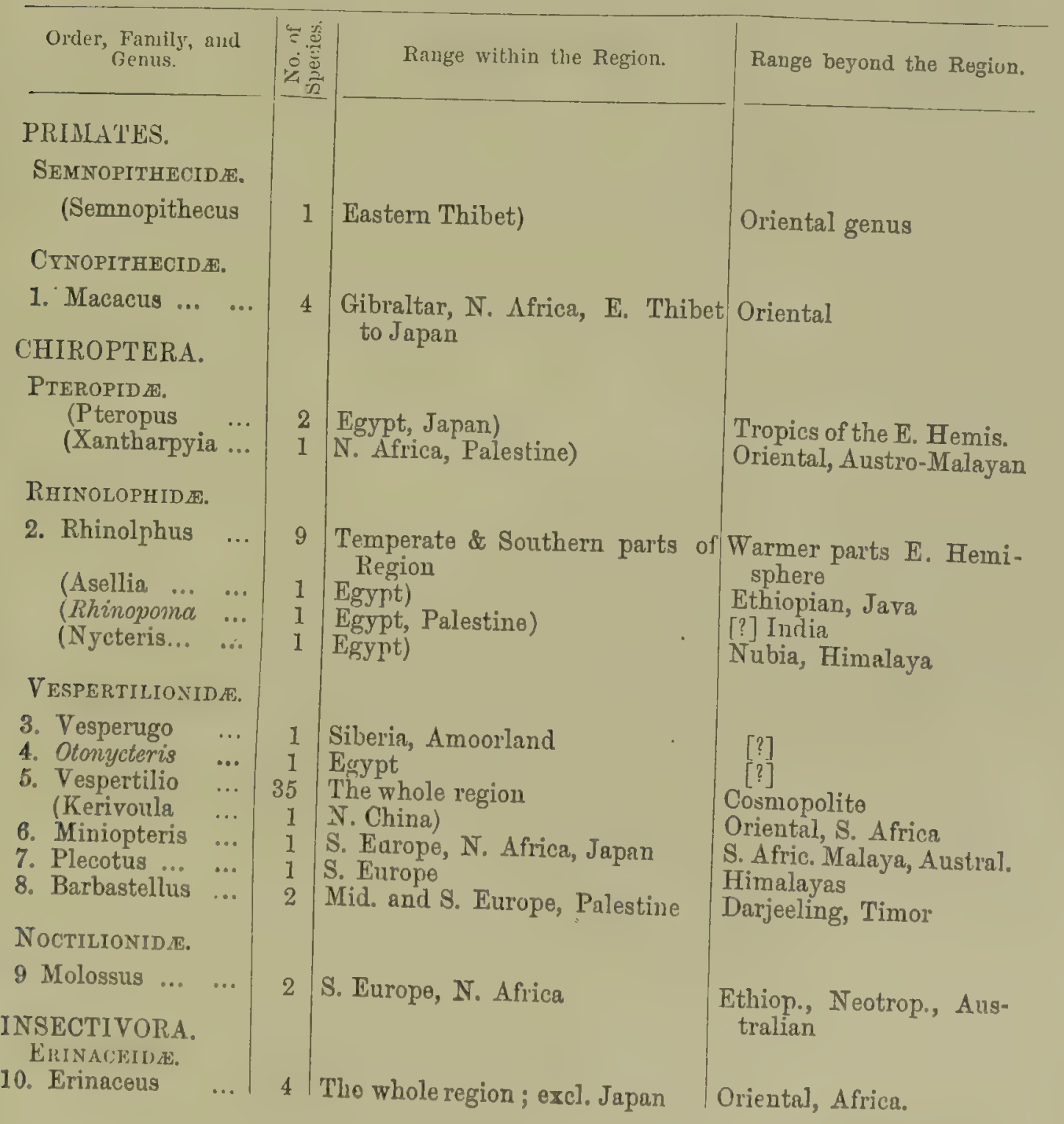




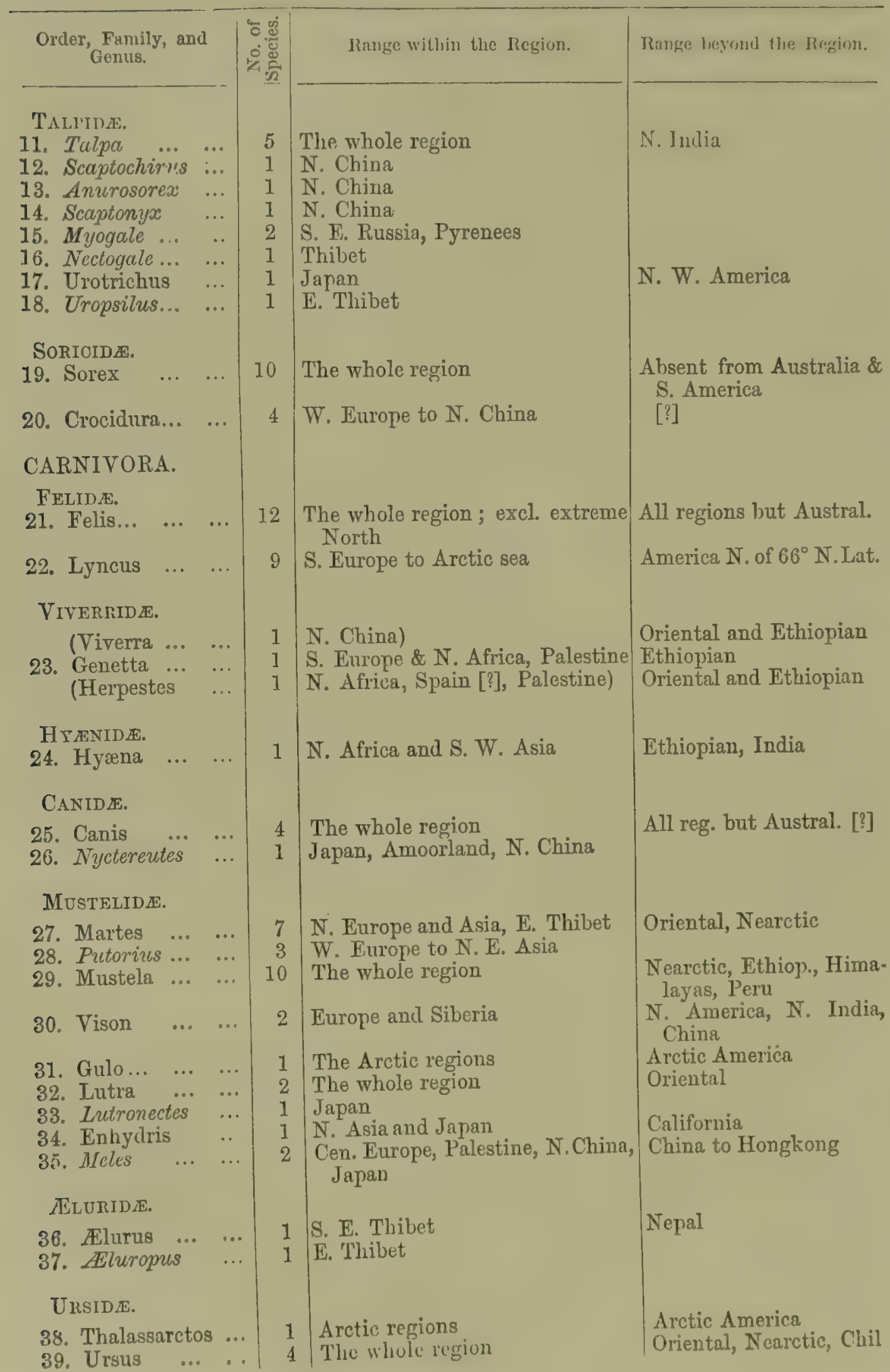




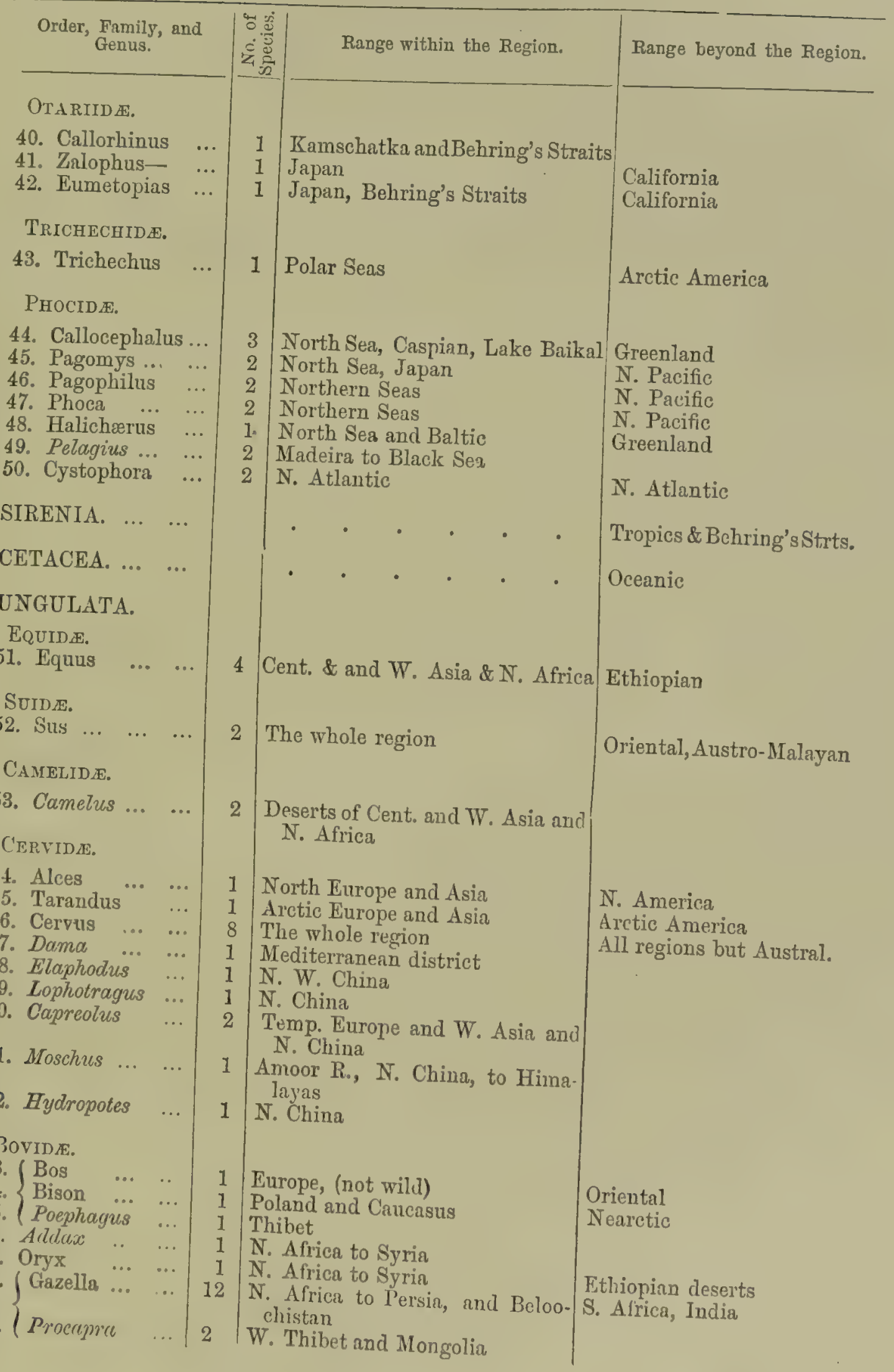




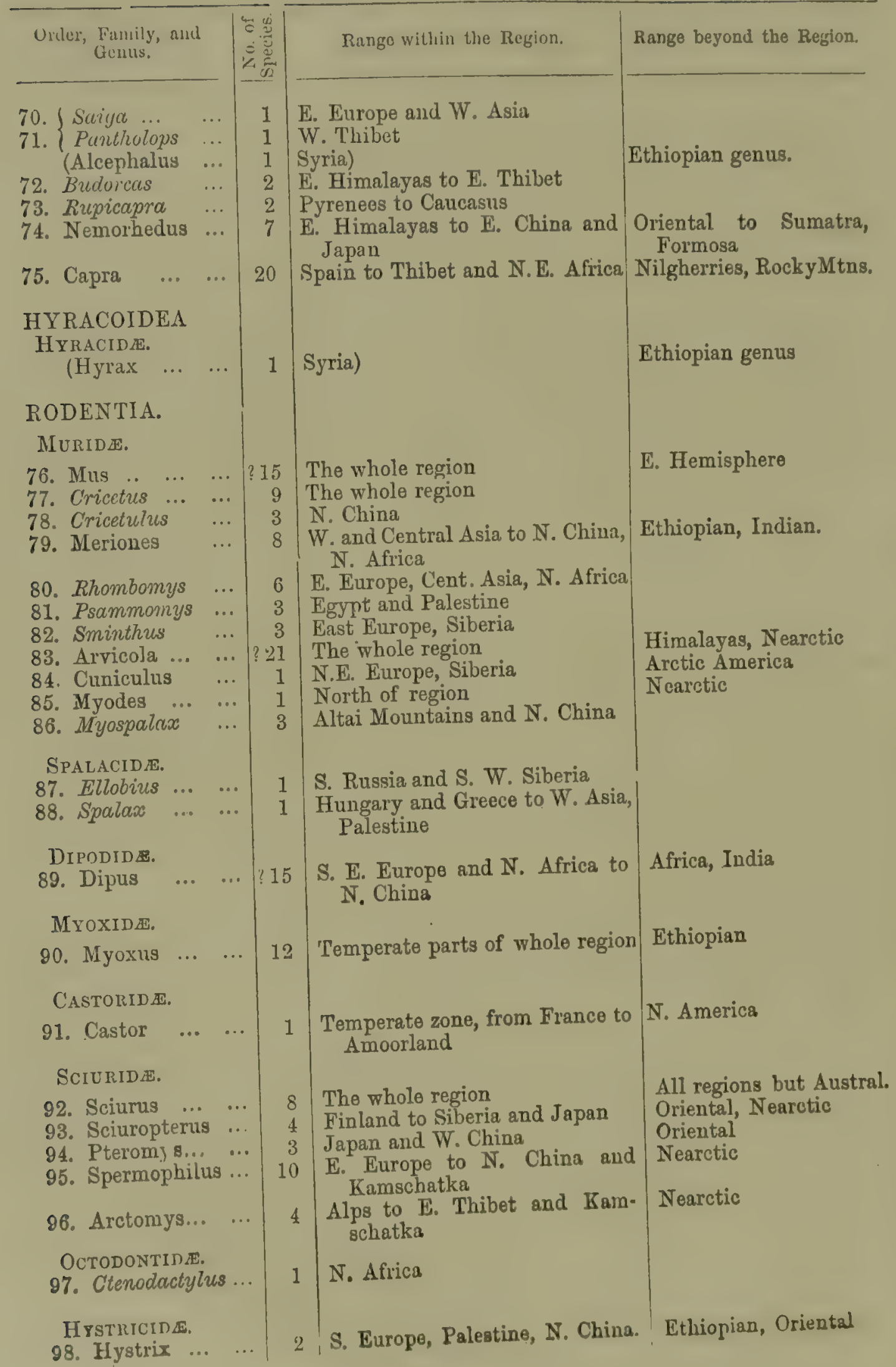




\begin{tabular}{|c|c|c|c|}
\hline $\begin{array}{l}\text { Order, Fanily, and } \\
\text { Geuus. }\end{array}$ & 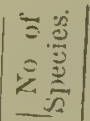 & Range within the Region. & Range beyoud the Region. \\
\hline 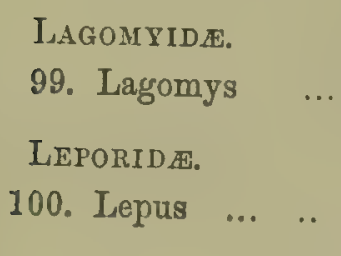 & $\begin{array}{l}10 \\
12\end{array}$ & $\begin{array}{l}\text { Volga to E. Thibet and Kam- } \\
\text { schatka } \\
\text { The whole region }\end{array}$ & $\begin{array}{l}\text { Nearctic } \\
\text { All regions but Austral. }\end{array}$ \\
\hline
\end{tabular}

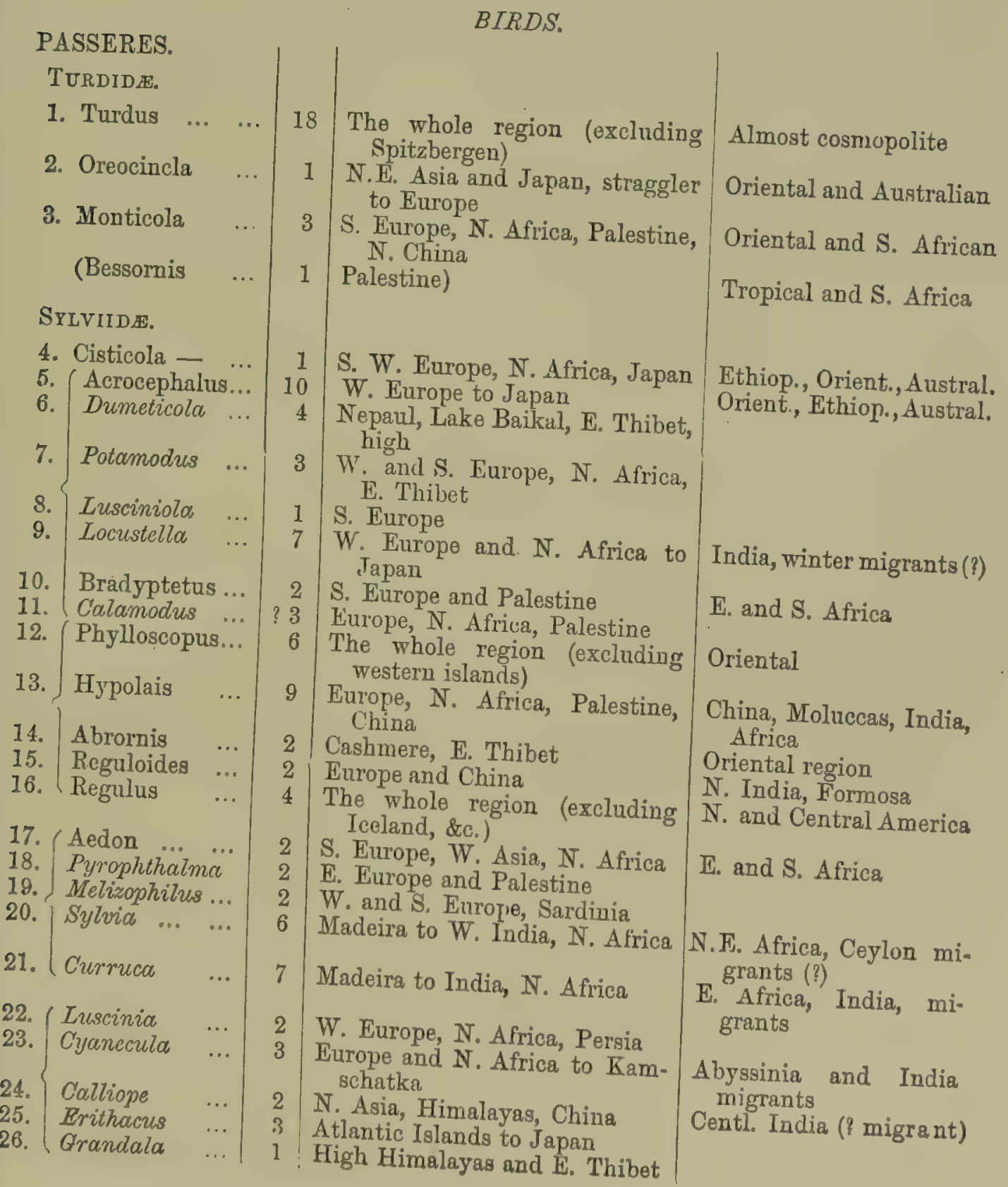




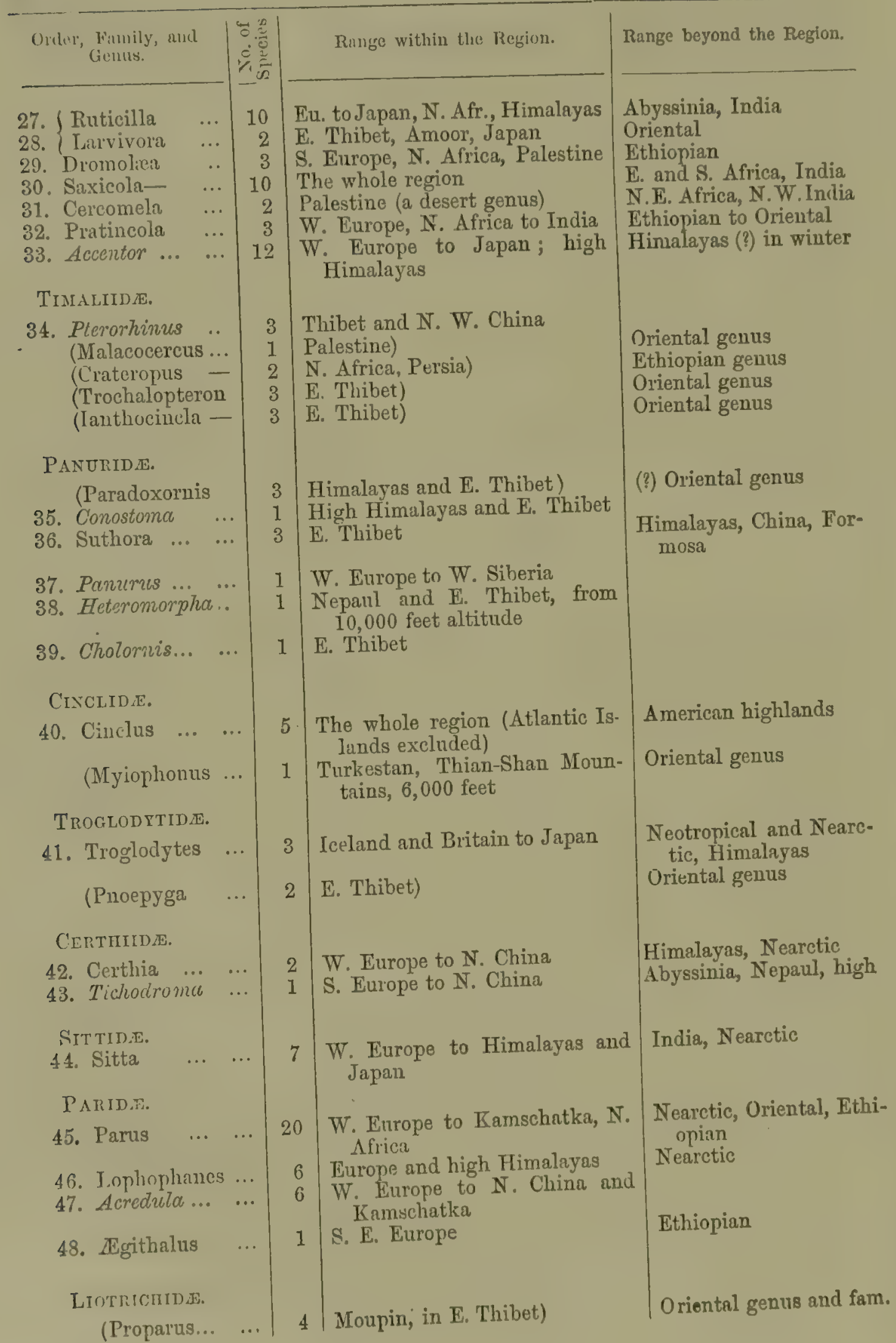




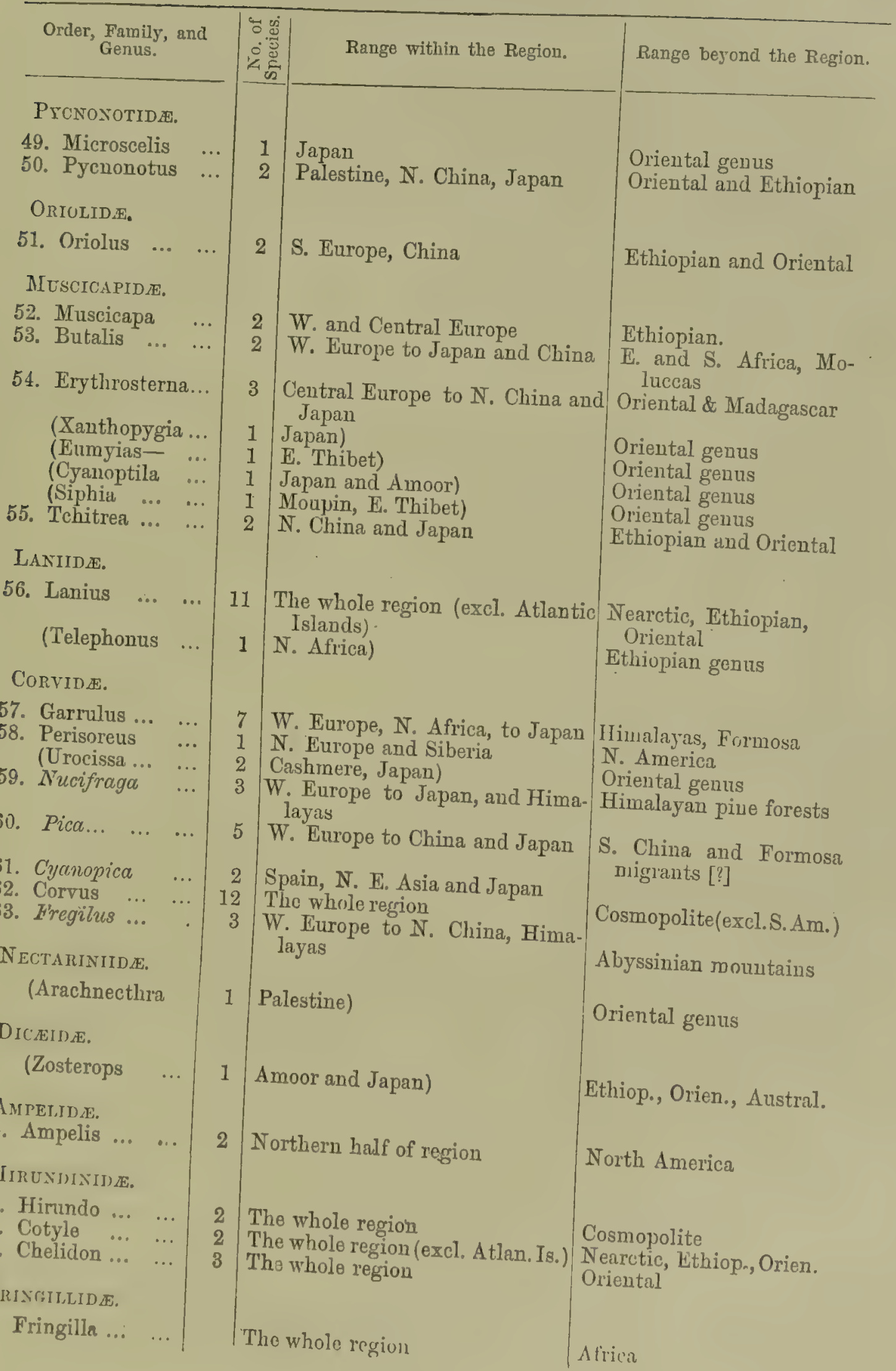


Order, Farnily, and Ginus.

69. Acanthis

70. Procarduetis ...

71. Chrysomitris...

72. Dryospiza

73. Metoponia

74. Chlorospiza ...

75. Passer … …

76. Montifringilla

77. Fringillauda..

78. Coccothraustes

79. Mycerobas ...

80 Eophona ... ...

81. Pyrrhula … (Crithagra ...

82. Carpodacus ...

83. Erythrospiza...

84. Uragus ... ...

85. Loxia ... ...

86. Pinicola ... ...

87. Propyrrhula...

88. Pyrrhospiza ...

89. Linota ... ...

90. Leucosticte ... Emberizinæ

91. (Euspiza

92. Emberiza …

93. Fringillaria...

94. Plectroplianes

\section{STURNIDR.}

95. Pastor ... ...

96. Stumia ... ...

97. Sturuus ... ...

(Amydrus $\quad \ldots$...

98. Podoces ... ...

ALAUDIDE.

99. Otocorys

100. Alauda .. ..

101. Galerita ... ...

102. Calandrella ...

103. Melanocorypha

104. Pallasia... .. (Certhilauda ... (Alaemon "...

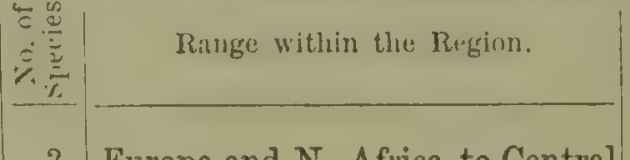 \\ Europe and N. Africa to Central Asia \\ 1 High Himalayas and E. Thibet \\ W. Europe to Japan \\ Atlantic Islands to Palestine, $\mathrm{N}$. Africa \\ N. E. Europe to W. Himalayas}

W. Europe, N. Africa to Japan

The whole region

Europe to Cashmere and Siberia

$\mathrm{N}$. W. Himalayas to E. Thibet, high

W. Europe, High Himalayas to Japan

Central Asia \& High Himalayas

E. Thibet, China, and Japan

Azores to Japan, High Himalayas

Palestine)

12 Cent. Eu. to Japan, High Himalayas

4 N. Africa to Afghanistan and Turkestan

Turkestan \& E. Thibet to Japan

Europe, High Himalayas to Japan

N. Europe, Siberia

High Himalayas

Snowy Himalayas

The whole region

Turkestan to Kamschatka

E. Europe to Japan

Europe to Japan

S. Europe, N. Africa

Northern half of region

China, E. Africa

Ethiopian, Oriental

\section{N. America}

China

Ethiopian genus

India \& China, N. Amer.

East Europe, Central Asia

Amoor, Japan, N. China

The whole region (excl. Atlantic Islands)

Palestine)

Cen. Asia, Turkestan, Yarkand

N. America

N. America

Darjeeling in winter

N. America

N. W. America

N. America

N. India, China

African genus

N. America

India

Oriental

India, China

N. E. African genus

N. Europe to Japan, N. Africa, India, N.Anerica, Andes Arabia

7 The whole region (excl. Iceland) India, Africa

2 Central Europe to N. China, N. Africa

4 Central Europe to N. China, N Africa

5 S. Eu. N. Africa, N. \& Cen. Asia

India, Central Africa

ndia

N. W. India

Mongolia

N. Africa)

1 N. Africa, Arabia)
S. African genus

Ethiopian geutus 


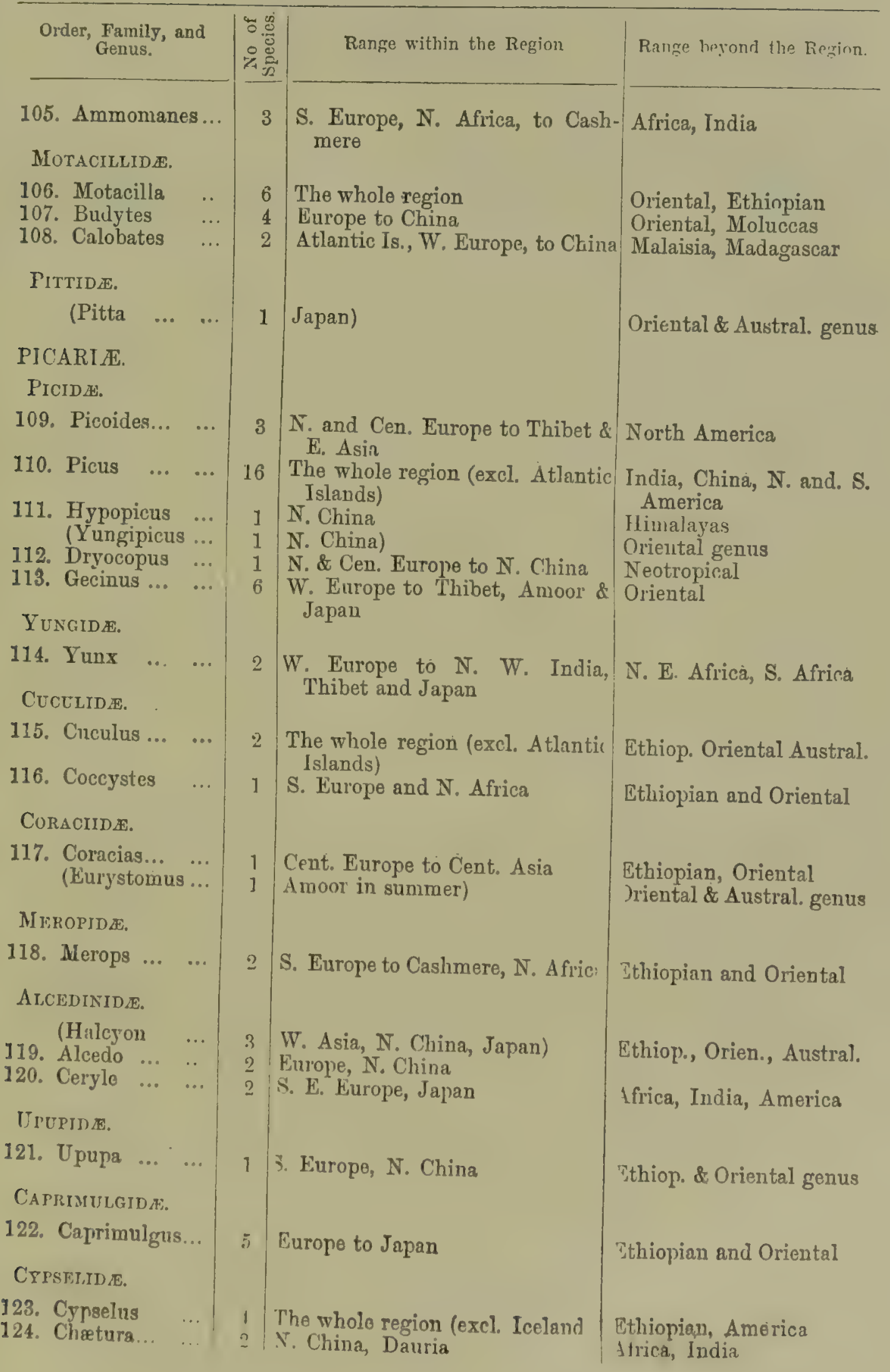




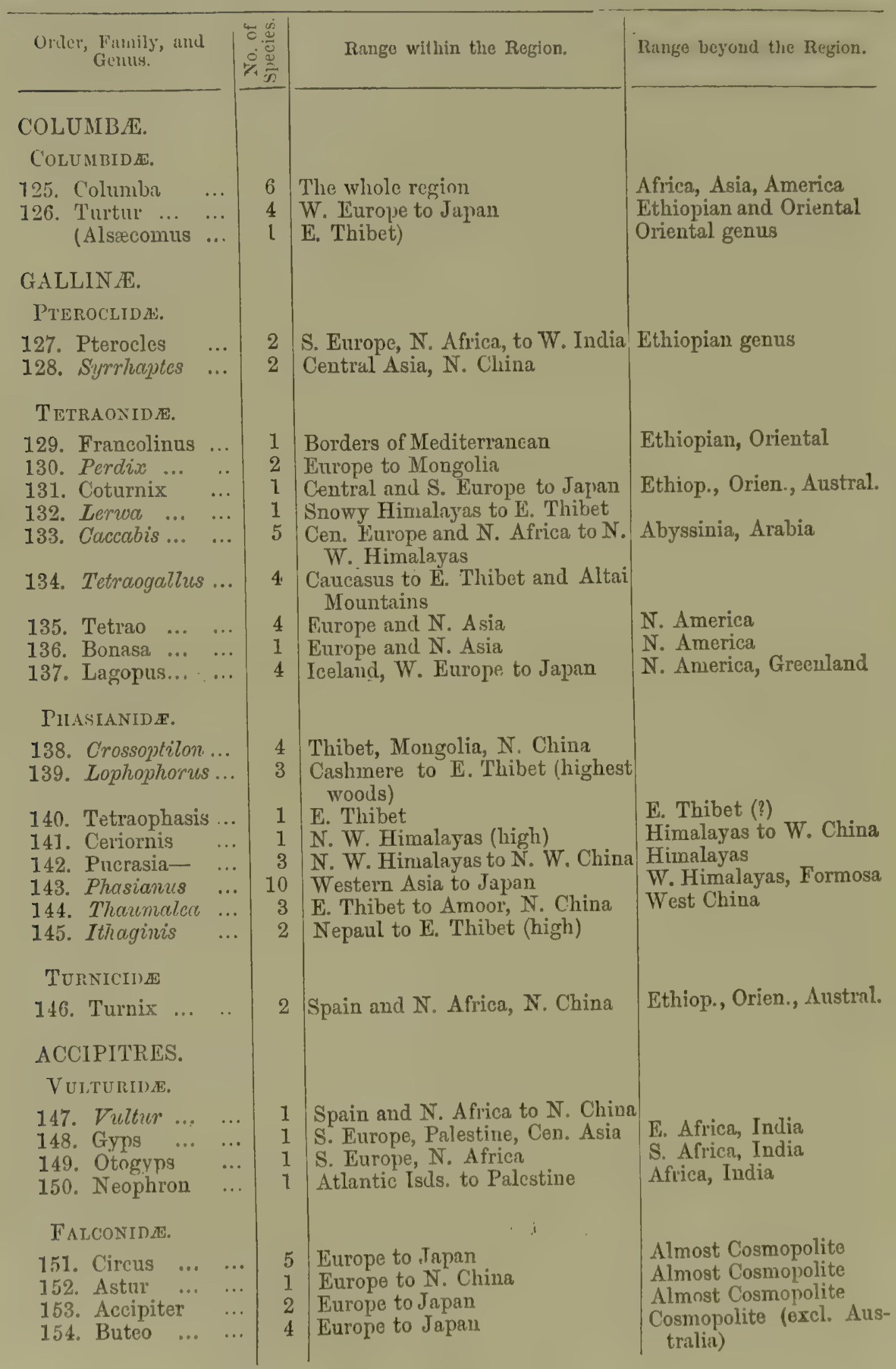




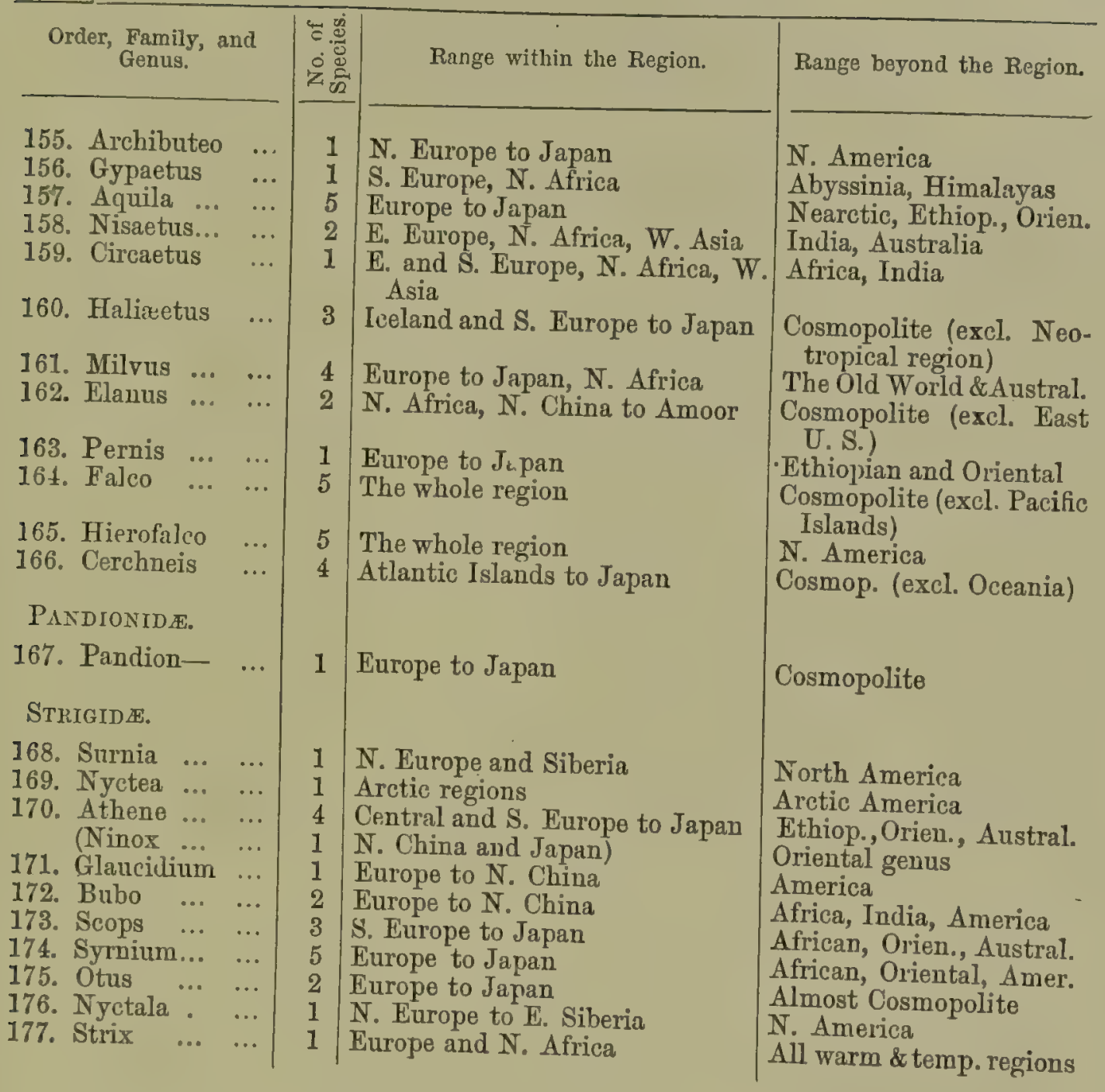

Peculior or very characteristic Genera of Wading and Swimming Birds.

\section{GRALLA.}

RALLIDE.

Ortygometra

SCOLOPACIDE.

Ibidorhyncha

Terekia...

Helodromas

Machetes...

Entrinorhynchus

Glareolide.

Pluvianus

Cimamantidas.

Vanellus
Europe, N. E. Africa

Cashmere \& Cen. Asia, N. China Himalayan Valleys

1 N. E. Europe and Siberia

1 E. and N. Europe, N. India

1 N. and Cen. Europe, Cén. Asia

1 N.E. Asia

1 N. Africa, Spain

8 Europe to the Punjaub
India, Australia(migrant)

India in winter

Bengal

S. America 


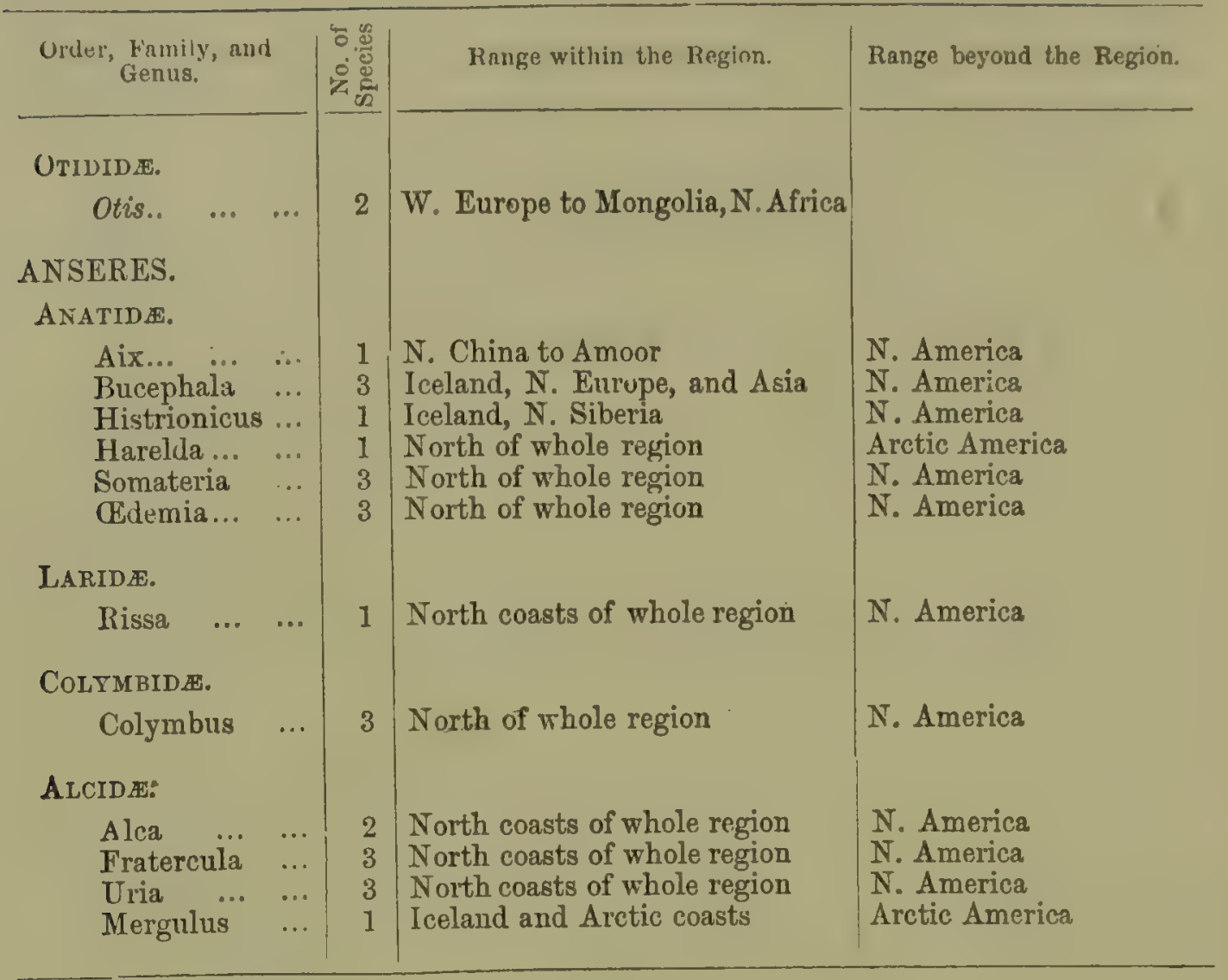





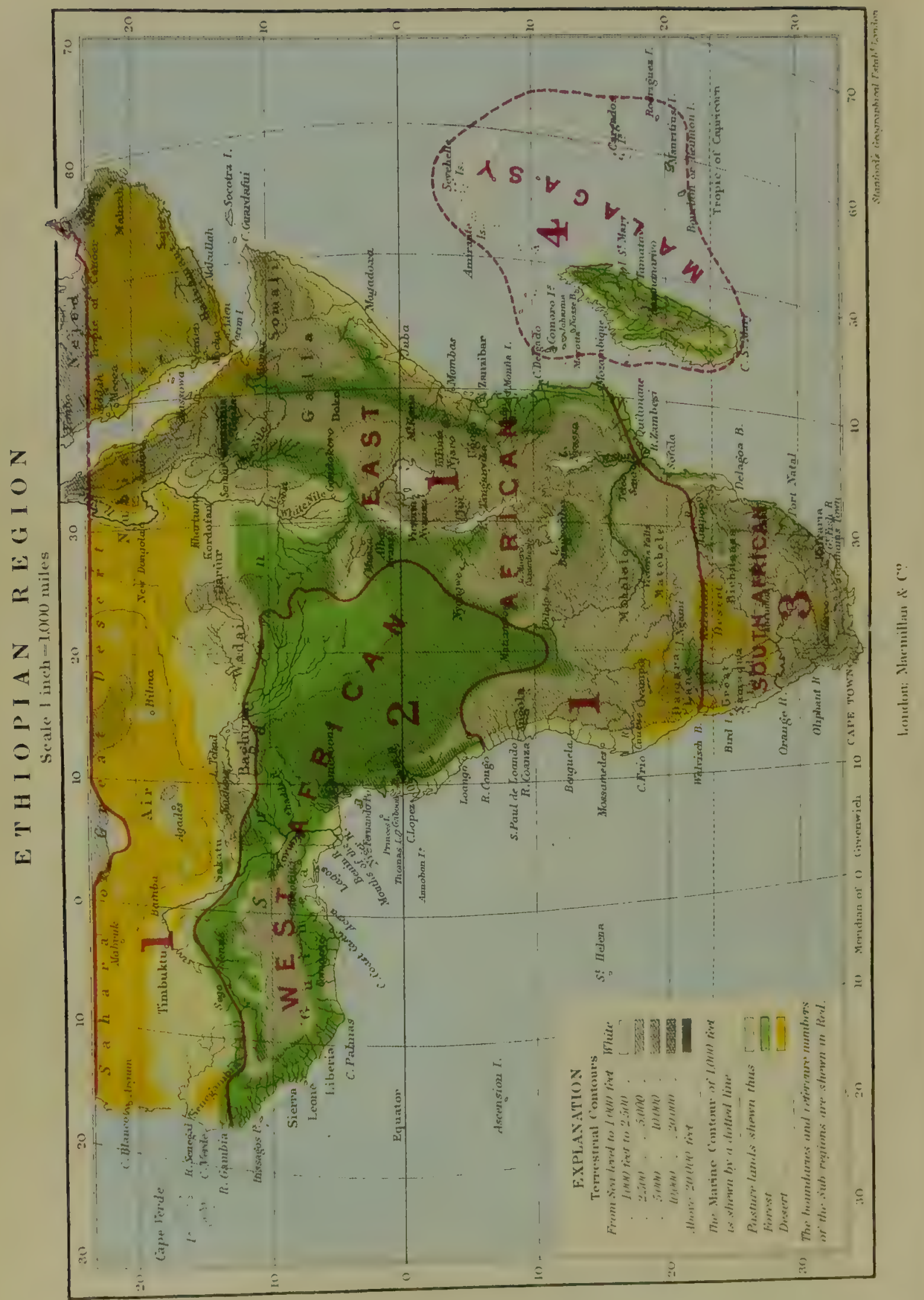




\section{CHAPTER XI.}

THE ETHIOPIAN REGION.

Turs is one of the best defined of the great zoological regions, consisting of tropical and South Africa, to which must be added tropical Arabia, Madagascar, and a few other islands, all popularly known as African. Some naturalists would extend the region northwards to the Atlas Mountains and include the whole of the Sahara; but the animal life of the northern part of that great desert seems more akin to the Palæarctic fauna of North Africa. The Sahara is really a debatable land which has been peopled from both regions; and until we know more of the natural history of the great plateaus which rise like islands in the waste of sand, it will be safer to make the provisional boundary line at or near the tropic, thus giving the northern half to the Palæarctic, the southern to the Ethiopian region. The same line may be continued across Arabia.

With our present imperfect knowledge of the interior of Africa, only three great continental sub-regions can be well defined. The open pasture lands of interior tropical Africa are wonderfully uniform in their productions; a great number of species ranging from Senegal to Abyssinia and thence to the Zambesi, while almost all the commoner African genera extend over the whole of this area. Almost all this extensive tract of country is a moderately elevated plateau, with a hot and dry climate, and characterised by a grassy vegetation interspersed with patches of forest. This forms our first or East African sub-region. The whole of the west coast from the south side of the Gambia River to about $10^{\circ}$ or $12^{\circ}$ south latitude, is a very 
different kind of country; being almost wholly dense forests where not cleared by man, and having the hot moist uniform climate, and perennial luxuriance of vegetation, which claracterise the great equatorial belt of forest all round the globe. This forest country extends to an unknown distance inland, but it was found, with its features well marked, by Dr. Schweinfurth directly he crossed the south-western watershed of the Nile; and far to the south we find it again unmistakably indicated, in the excessively moist forest country about the head waters of the Congo, where the heroic Livingstone met his death. In this forest district many of the more remarkable African types are alone found, and its productions occasionally present us with curious similarities to those of the far removed South American or Malayan forests. This is our second or West African subregion.

Extra-tropical South Africa possesses features of its own, quite distinct from those of both the preceding regions (although it has also much in common with the first). Its vegetation is known to be one of the richest, most peculiar, and most remarkaljle on the globe; and in its zoology it has a speciality, similar in kind but less in degree, which renders it both natural and convenient to separate it as our third, or South African sub-region. Its limits are not very clearly ascertained, but it is probably bounded by the Kalahari desert on the north-west, and by the Limpopo Valley, or the mountain range beyond, on the north-east, although some of its peculiar forms extend to Mozambique. There remains the great Island of Madagascar, one of the most isolated and most interesting on the globe, as regards its animal productions; and to this must be added, the smaller islands of Bourbon, Mauritius and Rodriguez, the Seychelles and the Comoro Islands, forming together the Mascarene Islands, - the whole constituting our fourth sub-region.

Zoological Characteristics of the Ethiopian Regrion.-We have now to consider briefly, what are the peculiarities and cliaracteristics of the Ethiopian Region as a whole,--those which give it its distinctive features and broadly separate it from the other primary zoological regions. 
Mammalia.-This region has 9 peculiar families of mammalia. Chiromyidæe (containing the aye-aye); Potamogalidæ and Chrysochloridæe (Insectivora); Cryptoproctidæ and Protelidæ (Carnivora); Hippopotamidæ and Camelopardalidæ (Ungulata); and Orycteropodidæ (Edentata). Besides these it possesses 7 peculiar genera of apes, Troglodytes, Colobus, Myiopithecus Cercopithecus, Cercocebus, Theropithecus, and Cynocephalus; 2 subfamilies of lemurs containing 6 genera, confined to Madagascar, with 3 genera of two other sub-families confined to the continent; of Insectivora a family, Centetidæ, with 5 genera, peculiar to Madagascar, and the genera Petrodromus and Rhynchocyon belonging to the Macroscelididæ, or elephant-shrews, restricted to the continent; numerous peculiar genera or subgenera of civets; Lyccon and Megalotis, remarkable genera of Canidx; Ictonyx, the zorilla, a genus allied to the weasels; 13 peculiar genera of Muridæ; Pectinator, a genus of the Soutl American family Octodontidæ; and 2 genera of the South American Eshimyidæ or spiny rats. Of abundant and characteristic groups it possesses Macroscelides, Felis, Hycena, Hyrax, Rhinoceros, and Elephas, as well as several species of zebra and a great variety of antelopes.

The great speciality indicated by these numerous peculiar families and genera, is still farther increased by the absence of certain groups dominant in the Old-World continent, an absence which we can only account for by the persistence, through long epochs, of barriers isolating the greater part of Africa from the rest of the world. These groups are, Ursidx, the bears; Talpidæe the moles; Camelidæ, the camels; Cervidæ, the deer; Caprinæ, the goats and sheep; and the genera Bos (wild ox); and Sus (wild boar). Combining these striking deficiencies, with the no less striking peculiarities above enumerated, it seems hardly possible to have a region more sharply divided from the rest of the globe than this is, by its whole assemblage of mammalia.

Birds.-In birds the Ethiopian region is by no means so strikingly peculiar, many of these having been able to pass the ancient barriers which so long limited the range of manmalia. 
It is, however, sufficiently rich, possessing 54 families of land birds, besides a few genera whoze position is not well ascertained, and which may constitute distinct families. Of these 6 are peculiar, Musophagidæ (the plantain eaters); Coliidæ (the colies) ; Leptosomidx, allied to the cuckoos; Irrisoridx, allied to the hoopnes; and Serpentaridæ, allied to the hawks. Only one Passerine family is peculiar-Paictidx, while most of the other tropical regions possess several; but Euryceros and Buphaga, here classed with the Sturnidæ, ought, perhaps, to form two more. It has, however, many peculiar genera, especially among the fruit-thrushes, Pycnonotidæ; flycatchers, Muscicapidæ; shrikes, Lanidæ ; crows, Corvidæ ; starlings, Sturnidæ ; and weaver-birds, Ploceidr; the latter family being very characteristic of the region. It is also rich in barbets, Megalæmidæ (7 peculiar genera); cuckoos, Cuculidæ; rollers, Coraciidæ; bee-eaters, Meropidæ; hornbills, Bucerotidæ; an goat-suckers, Caprimulgidæ. It is poor in parrots and rather so in pigeons; but it abounds in Pterocles and Francolinus, genera of Gallinæ, and possesses 4 genera of the peculiar group of the guinea-fowls, forming part of the pheasant family. It abounds in vultures, eagles, and other birds of prey, among which is the anomalous genus Serpentarius, the secretary-bird, constituting a distinct family. Many of the most remarkable forms are confined to Madagascar and the adjacent islands, and will be noticed in our account of that subregion.

Reptiles.-Of the reptiles there are 4 peculiar Ethiopian families ; -3 of snakes, Rachiodontidæ, Dendraspidæ, and Atractaspidæ and 1 of lizards, Chamæsauridæ.

Psammophidæ (desert snakes) are abundant, as are Lycodontidæ (fanged ground-snakes), and Viperidæ (vipers). The following genera of snakes are peculiar or highly characteristic:-Leptorhynchus, Rhamnophis, Herpetethiops and Grayia (Colubridx); Hopsidrophis and Bucephalus (Dendrophidæ); Langalia (Dryophidæ); Pythonodipsas (Dipsadidæ); Boedon, Lycophidion, Holuropholis, Simocephalus and Lamprophis (Lycodontida); Hortulia and Sanzinia (Pythonidæ); Cyrptophis, Elapsoidea and Pacilophis (Elapidæ); and Atheris (Viperidæ). The following genera 
of lizards are the most characteristic:-Monotrophis (Lepidosternidæ); Cordylus, Pseudocordylus, Platysaurus, Cordylosaurus, Pleurostichus, Saurophis and Zonurus (Zonuridæ); Sphoenops, Scelotes, Sphcenocephalus and Sepsina (Sepidæ); Pachydactylus (Geckotidæ); Agama (Agamidæ); and Chameleon (Chameleonidæ). Of tortoises, Cynyxis, Pyxis and Chersina (Testudinidæ), and Cycloderma (Trionychidæ) are the most characteristic.

Amphibia.-Of the 9 families of amphibia there is only 1 peculiar, the Dactylethridx, a group of toads; but the Alytidæ, a family of frog's, are abundant.

Fresh-water Fish.-Of the 14 families of fresh-water fishes 3 are peculiar: Mormyridæ and Gymnarchidæ, small groups not far removed from the pikes; and Polypteridæ, a small group of ganoid fishes allied to the gar-pikes (Lepidosteidæ) of North America.

Summary of Ethiopian Vertebrates.-Combining the results here indicated and set forth in greater detail in the tables of distribution, we find that the Ethiopian region possesses examples of 44 families of mammalia, 72 of birds, 35 of reptiles, 9 of amphibia, and 15 of fresh-water fishes. It has 23 (or perhaps 25) families of Vertebrata altogether peculiar to it out of a total of 175 families, or almost exactly one-eighth of the whole. Out of 142 genera of mammalia found within the region, 90 are peculiar to it; a proportion not much short of two-thirds. Of land birds there are 294 genera, of which 179 are peculiar; giving a proportion of a little less than three-fifths.

Compared with the Oriental region this shows a considerably larger amount of speciality under all the heads; but the superiority is mainly due to the wonderful and isolated fauna of Madagascar, to which the Oriental region has nothing comparable. Without this the regions would be nearly equal.

Insects: Lepidoptera. -11 out of the 16 families of butterflies have representatives in Africa, but none are peculiar. Acræidæ is one of the most characteristic families, and there 
are many interesting forms of Nymphalidx, Lycæuidæ, and Papilionidæ. The peculiar or characteristic forms are Amauris (Danaidæ); Gnophodes, Leptoneura, Bicyclus, Heteropsis and Ccenyra (Satyridæ); Acroea (Acræidæ); Lachnoptera, Precis, Salamis, Crenis, Godartia, Amphidema, Pseudacrca, Catunu, Euryphene, Romalocosoma, Hamanumida, Aterica, Harma, Meneris, Charaxes, and Philognoma (Nymphalià); Pentila, Liptena, Durbania, Zeritis, Capys, Phytala, Epitola, Hewitsonia and Deloneura (Lycænidæ); Pseudopontia, Idmais, Teracolus, Callosune (Pieridæ); Abantis, Ceratrichic and Caprona (Hesperidæ). The total number of species known is about 750 ; which is very poor for an extensive tropical region, but this is not to be wondered at when the nature of much of the country is considered. It is also, no doubt, partly due to our comparative ignorance of the great equatorial forest district, which is the only part likely to be very productive in this order of insects.

Colcoptera.-In our first representative family, Cicindelidæ or tiger-beetles, the Ethiopian region is rather rich, having 13 genera, 11 of which are peculiar to it; and among these are such remarkable forms as Manticora, Myrmecoptera and Dromica; with Megacephala, a genus only found elsewhere in Australia and South America.

In Carabidæ or carnivorous ground beetles, there are about 75 peculiar genera. Among the most characteristic are Anthia, Polyrhina, Graphipterus and Piezia, which are almost all peculiar; while Orthogonius, Hexagonia, Macrochilus, Thyreopterus, Eudema, and Abacetus are common to this and the Oriental region; and Hypolithus to the Neotropical.

Out of 27 genera of Buprestidæ, or metallic beetles, only 6 are peculiar to the region, one of the most remarkable being Polybothrus, confined to Madagascar. Sternocera and Chrysochroa are characteristic of this region and the Oriental; it has Julodis in common with the Mediterranean sub-region, ana Belionota with the Malayan.

The region is not rich in Lucanidæ, or stag-beetles, possessing only 10 genera, 7 of which are peculiar, but most of them con- 
sist of single species. The other three genera, Cladognathus, Nigidius, and Figulus, are the most characteristic, though all have a tolerably wide range in the Old World.

In the elegant Cetoniidæ, or rose-chafers, this region stands preeminent, possessing 76 genera, 64 of which are peculiar to it. The others are chiefly Oriental, except Oxythroea which is European, and Stethodesma which is Neotropical. Preeminent in size and beauty is Goliathus, comprising perhaps the most bulky of all highly-coloured beetles. Other large and characteristic genera are Ceratorhina, Ischnostoma, Anochilia, Diplognatha, Agenius, and many others of less extent.

In the enormous tribe of Longicorns, or long-horned beetles, the Ethiopian is not so rich as the other three tropical regions; but this may be, in great part, owing to its more productive districts having never been explored by any competent entomologists. It nevertheless possesses 262 genera, 216 of which are peculiar, the others being mostly groups of very wide range. Out of such a large number it is difficult to select a few as most characteristic, but some of the peculiarities of distribution as regards other regions may be named. Among Prionidæ, Tithoes is a characteristic Ethiopian genus. A few species of the American genera Parandra and Mallodon occur here, while the North Temperate genus Prionus is only found in Madagascar. Among Cerambycilæ, Promeces is the most characteristic. The American genera Oeme and Cyrtomerus occur; while Homalachnus and Philagathes are Malayan, and Leplocera occurs only in Madagascar, Ceylon, Austro-Malaya, and Australia. The Lamiidæ are very fine; Sternotomis, Tragocephala, Ceroplesis, Phryneta, Volumnia, and Nitocris, being very abundant and characteristic: Most of the non-peculiar genera of this family are Oriental, but Spalacopsis and Acanthoderes are American, while Tetraglenes and Schoeniontc have been found only in East and South Africa and in Malaya.

Terrestrial Mollusca-In the extensive family of the Helicidie or snails, 13 genera are represented, only one of which, Columna, is peculiar. This region is however the metropolis of Achatina, some of the species being the largest land-shells 
known. Bulinimus, Stenogyra, and Pupa are characteristic genern. Bulimus is absent, though one species inhabits St. Helena. The operculated shells are not very well represented, the great family of Cyclostomida having here only nine genera, with but one peculisu, Lithidion, found in Madagascar, Socotra, and Arabia. None of the genera appear to be well represented throughout the region, and they are almost or quite absent from IVest Africa.

According to Woodward's Manual (1868) West Africa has about 200 species of Jand-shells, South Africa about 100, Madagascar nearly 100, Mauritius about 50. All the islands have their peculiar species; and are, in proportion to their extent, much richer than the continent; as is usually the case.

\section{The Ethiorian Sub-Regions.}

It has been already explained that these are to some extent provisional; yet it is believed that they represent generally the primary natural divisions of the region, however they may be subdivided when our knowledge of their productions becomes more accurate.

\section{The Eust African Sub-region, or Central and East Africa.}

This division includes all the open country of tropical Africa south of the Sahara, as well as an undefined southern margin of that great desert. With the exception of a narrow strip along the east coast and the valleys of the Niger and Nile, it is a vast elevated plateau from 1,000 to 4,000 feet high, hilly rather than mountainous, except the Iofty table land of Abyssinia, with mountains rising to 16,000 feet and extending south to the equator, where it terminates in the peaks of Kenia and Kilimandjaro, 18,000 and 20,000 feet high. The northern portion of this sub-region is a belt about 300 miles wide between the Sahara on the north and the great equatorial forest on the south, extending from Cape Verd, the extreme western point of Africa, across the northern bend of the Niger and Lake Tchad to the mountains of Abyssinia. The grenter part of this tract has $a$ 
moderate elevation. The eastern portion reaches from about the sccond cataract of the Nile, or perhaps from about the parallel of $20^{\circ} \mathrm{N}$. Latitude, down to about $20^{\circ} \mathrm{S}$. Latitude, and from the east coast to where the great forest region commences, or to Lake Tanganyika and about the meridian of $28^{\circ}$ to $30^{\circ} \mathrm{E}$. Longitude. The greater part of this tract is a lofty plateau.

The surface of all this sub-region is generally open, covered with a vegetation of high grasses or thorny shrubs, with scattered trees and isolated patches of forest in favourable situations. The only parts where extensive continuous forests occur, are on the eastern and western slopes of the great Abyssinian plateau, and on the Mozambique cnast from Zanzibar to Sofala. The whole of this great district has one general zoological character. Many species range from Senegal to Abyssinia, others from Abyssinia to the Zambesi, and a few, as Mungos fasciatus and Phacocherus cethiopicus, range over the entire sub-region. Fennecus, Ictonyx, and several genera of antelopes, characterise every part of it, as do many genera of birds. Coracias nevvia, Corythornis cyanostigma, Tockus nasutus, T. erythrorhynchus, Pans lencopterus, Buphorgx africana, Viduce paradisea, are examples of species, which are found in the Gambia, Abyssinia and South East Africa, but not in the West African sub-region; and considering how very little is known of the natural history of the country immediately south of the Sahara, it may well be supposed that these are only a small portion of the species really common to the whole area in question, and which prove its fundamental unity.

Although this sub-region is so extensive and so generally uniform in plysical features, it is by far the least peculiar part of Africa. It possesses, of course, all those wide-spread Ethiopian types which inhabit every part of the region, but it has hardly any special features of its own. The few genera which are peculiar to it have generally a limited range, and for the most part belong, either to the isolated mountain-platean of Abyssinia which is almost as much Palaarctic as Ethiopian, or to the woody districts of Mozambique where the fauna has more of a West or South African character. 
Mammalia.-The only forms of Mammalia peculiar to this sub-region are Theropithecus, one of the Cynopithecidx confined to Abyssinia; Petrodromus and Rhynchocyon, belonging to the insectivorous Macroscelididæ, have only been found in Mozambique; the Antelopine genus Neotragus, from Abyssinia southward ; Scccostomus and Pelomys genera of Muridæ inhabiting Mozambique; Heterocephalus from Abyssinia, and Heliophobius from Mozambique, belonging to the Spalacidæ; and Pectinator from Abyssinia, belonging to the Octodontidx. Cynocephalus, Rhinoceros, Camelopardalis, and antelopes of the genera Oryx, Cervicapra, Kobus, Nanotragus, Cephalophus, Hippotragus, Alcephalus, and Catoblepas, are characteristic; as well as Felis, Hyoena, and numerous civets and ichneumons.

Birds.-Peculiar forms of birds are hardly to be found here; we only meet with two-Hypocolius, a genus of shrikes in Abyssinia; and Balceniceps, the great boat-billed heron of the Upper Nile. Yet throughout the country birds are abundant, and most of the typical Ethiopian forms are well represented.

Reptiles.-Of reptiles, the only peculiar forms recorded are Xenocalamus, a genus of snakes, belonging to the Calamariidæ; and Pythonodipsas, one of the Dipsadidre, both from the Zambesi ; and among lizards, Pisturus, one of the Geckotidæ, from Abyssinin.

Amphibia and Fishes.-There are no peculiar forms of amphibia or of fresh-water fishes.

Insecis.--Iusects are almost equally unproductive of peculiar forms. Among butterflies we have Abantis, one of the Hesperidæ, from Mozambique; and in Coleoptera, 2 genera of Cicindelidæe, 8 of Carabide, 1 or 2 of Cetoniidre, and about half-a-dozen of Longicorns: a mere nothing, as we shall see, compared with the hosts of peculiar genera that characterise each of the other subregions. Neither do land-shells appear to present any peculiar forms.

The fact that so very few special types characterise the extensive area now under consideration is very noteworthy. It justifies us in uniting this linge and widespread tract of country as forming essentially but one sub-rivision of the great Ethiopian 


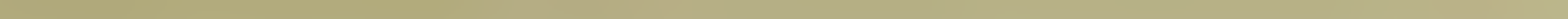


PLATIE IV.

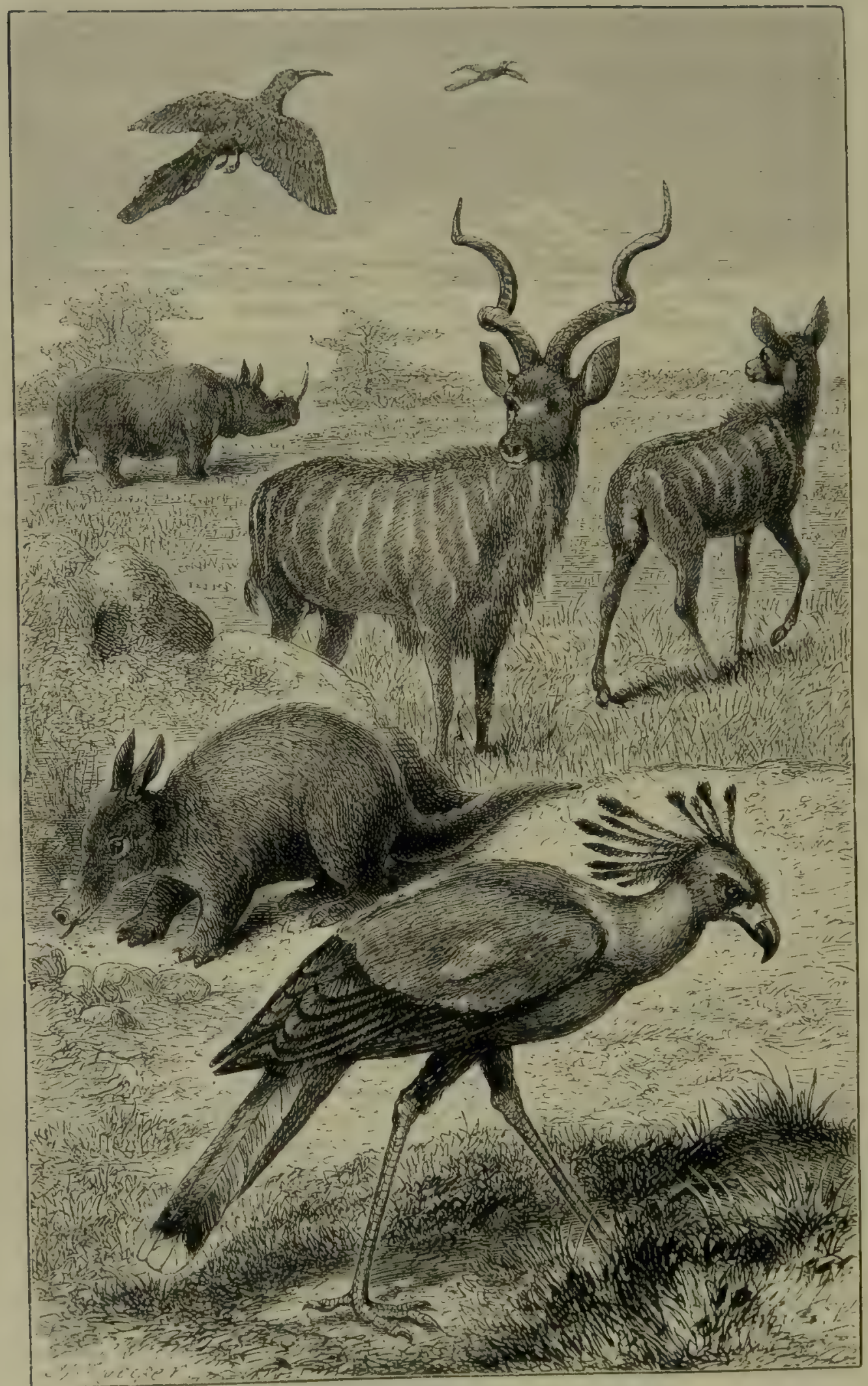

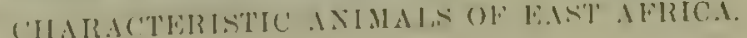


region, and it suggests some curious speculations as to the former history of that region, a subject which must be deferred to the latter part of this chapter. In none of the other great tropical regions does it occur, that the largest portion of their area, although swarming with life, yet possesses hardly any distinctive features except the absence of numerous types characteristic of the other sub-regions.

Plate IV.-Illustrating the Zoology of East Africa.-Although this sub-region has so little speciality, it is that which abounds most in large animals, and is, perhaps, the best representative of Africa as regards zoology. Some of the most distinctive of African animals range over the whole of it, and as, from recent explorations, many parts of this wide area have been made known to the reading public, we devote one of our plates to illustrate the especially African forms of life that here abound. The antelopes represented are the koodoo (Tragelaphus strepsiceros) one of the handsomest of the family, which ranges over all the highlands of Africa from Abyssinia to the southern districts. To the left is the aardvark, or earth pig, of North Eastern Africa (Orycteropus cethiopicus) whicb, to the north of the equator in East Africa, represents the allied species of the Cape of Good Hope. These Edentata are probably remnants of the ancient fauna of Africa, when it was completely isolated from the northern continents and few of the higher types had been introduced. The large bird in the foreground is the secretary-bird, or serpent-killer (Serpentarius reptilivorus), which has affinities both for the birdsof-prey and the waders. It is common over almost all the open country of Africa, destroying and feeding on the most venomous serpents. The bird on the wing is the red-billed promerops (Irrisor erythrorhynchus), a handsome bird with glossy plumage and coral-red bill. It is allied to the hoopoes, and feeds on insects which it hunts for among the branches of trees. This species also ranges over a large part of east and central Africa to near the Cape of Good Hope. Other species are foumd in the west; and the genus, which forms a distinct family, Irrisoridce, is one of the best marked Ethiopian types of birds. In the distance is a rhinoceros, now one of the characteristic features of African 
zoology, though there is reason to believe that it is a comparatively recent intruder into the country.

\section{The West-African Sub-region.}

This may be defined as the equatorial-forest sub-region, since it comprises all that portion of Africa, frcm the west coast inland, over which the great equatorial forests prevail more or less uninterruptedly. These commence to the south of the Gambia River, and extend eastwards in a line roughly parallel to the southern margin of the great desert, as far as the sources of the upper Nile and the mountains forming the western boundary of the basin of the great lakes; and southward to that high but marshy forest-country in which Livingstone was travelling at the time of his death. Its southern limits are undetermined, but are probably somewhere about the parallel of $11^{\circ} \mathrm{S}$. Latitude. ${ }^{1}$

This extensive and luxuriant district has only been explored zoologically in the neighbourhood of the West coast. Much, no doubt, remains to be done in the interior, yet its main features are sufficiently well known, and most of its characteristic types of animal life have, no doubt, been discovered,

Mammatia.-Several very important groups of mammals are peculiar to this sub-region. Most prominent are the great anthropoid apes-the gorilla and the chimpanzee-forming the genus Troglodytes; and monkeys of the genera Myiopithecus and Cercocebus. Two remarkable forms of lemurs, Pcrodicticus and Arctocebus, are also peculiar to West Africa. Among the Insectivora is Potemogule, a semi-aquatic animal, forming a distinct family; and three peculiar genera of civets (Viverridie) have been described. Hyomoschus, a small, deer-like animal, belongs to the Tragulidx, or chevrotains, a family otherwise

1 Dr. Schweinfurth has accurntely determined the limits of the sub-region at the point where he crossed the watershed between the Nile tributaries and those of the Shari, in $41^{\circ} \mathrm{N}$. Lat. and $28 \frac{1}{2}^{\circ} \mathrm{E}$. Long. He describes a sudden change in the character of the vegetation, which to the southward of this point assumes a West-Africin chiracter. Here also the chimpanzee and grey parrot first appear, and certain species of plants only known elsewhere iil Western Africa. 
confined to the Oriental region; and in the squirrel family is a curious genus, Anomalumus, which resembles the flying squirrels of other parts of the world, without being directly allied to them.

Birds.-In this class we find a larger proportionate number of peculiar forms. Hypcrgerus and Alethe, belonging to the Timaliidæ, or babblers, are perhaps allied to Malayau groups; Parinia, a peculiar form of tit, is found only in Prince's Island; Ixonotus is an abundant and characteristic form of Pycnonotida; Fraseria, Hypodes, Cuphopterus, and Chaunonutus, are peculiar genera of shrikes; Picathartes is one of the many strange forms of the crow family; Cinnyricinclus is a peculiar genus of sunbirds ; Pholidomis is supposed to belong to the Oriental Dicæidæe, or flower-peckers; Waldenia is a recently-described new form of swallow; Ligurnus, a finch, Spermospiga, a weaver bird, and Onychognathus a starling, are also peculiar West African genera. Coming to the Picariæe we have Verreauxia, a peculiar woodpecker; three peculiar genera of barbets (Megalæmidæ); the typical plantain-eaters (Musophaga); Myioceyx, a peculiar. genus of kingfishers; while Berenicornis is a genus of crested hornbills, only found elsewhere in Malaya. The grey parrots, of the genus Psittacus, are confined to this sub-region, as are two peculiar genera of partridges, and three of guineafowl. We have also here a species of Pitta, one of the Oriental family of ground-thrushes; and the Oriental paroquets, Palcoornis, are found here as well as in Abyssinia and the Mascarene Islands.

We thus find, both in the Mammalia and birds of West Africa, a special Oriental or even Malayan element not present in the. other parts of tropical Africa, although appearing again in Madagascar. In the Mammalia it is represented by the anthropoid apes; by Colobus allied to Semnopithecus, and by Cercocebus allied to Macacus; and especially by a form of the Malayan family of chevrotains (Tragulidæ). The Malayan genus of otters, Aonyx, is also said to occur in West and South Africa. In birds we have special Oriental and Malayan affinities in Alcthe, Pholidornis, Berenicornis, P'tta, and Pulcornis; while the Oriental genus Treron has a wide range in Africa. We shall 
endearour to ascertain the meaning of this special relation at a subsequent stage of our inquiries.

Plate V.-River Scene in West Africa, with Characteristic Animals.-Our artist has here well represented the luxuriance and beauty of a tropical forest; and the whole scene is such as might be witnessed on the banks of one of the rivers of equatorial West Africa. On the right we see a red river-hog (Potamochoerus penicillatus), one of the handsomest of the swine family, and highly characteristic of the West African sub-region. In a tree overhead is the polto (Perodicticus potto), one of the curious forms of lemur confined to West Africa. On the left is the remarkable Potamogale velox, first discovered by $\mathrm{Du}$ Chaillu,-an Insectivorous animal, with the form and habits of an otter. On the other side of the river are seen a pair of gorillas (Troglodytes gorilla), the largest of the anthropoid apes.

The bird on the wing is the Whydah finch (Vidua paradisea), remarkable for the enormous plumes with which the tail of the male bird is decorated during the breeding season. The crested bird overhead is one of the beautiful green touracos (Turacus macrorhynchus), belonging to the Musophagida, or plantain-eaters, a family wholly African, and most abundant in the western sub-region.

Reptiles.-In this class we find a large number of peculiar forms ; 13 genera of snakes, 3 of lizards, and 2 of tortoises being confined to the sub-region. The snakes are Pariaspis, Elapops, and Prosymna (Calamariidx), Rhamnoptis, Herpetethiops, and Grayia (Colubridx), Neusterophis and Limnophis (Homalopsidæ), Simocephalus and Holurophis (Lycodontidæ); Pelophilus (Pythonidæ); Elapsoidea (Elapidæ); and Atheris (Viperidæ). The lizards are Dalophia (Lepidostemidæ); Otosaurus (Scincidæ); Psilodactylus (Geckotidæ). The tortoises, Cinyxis (Testudinidæ) and Tetrathyra (Trionichidæ).

Amphibia.-Of Amphibia, there are 2 peculiar genera of treefrogs, Hylambatis and Hemimantis, belonging to the Polypeditidx. 


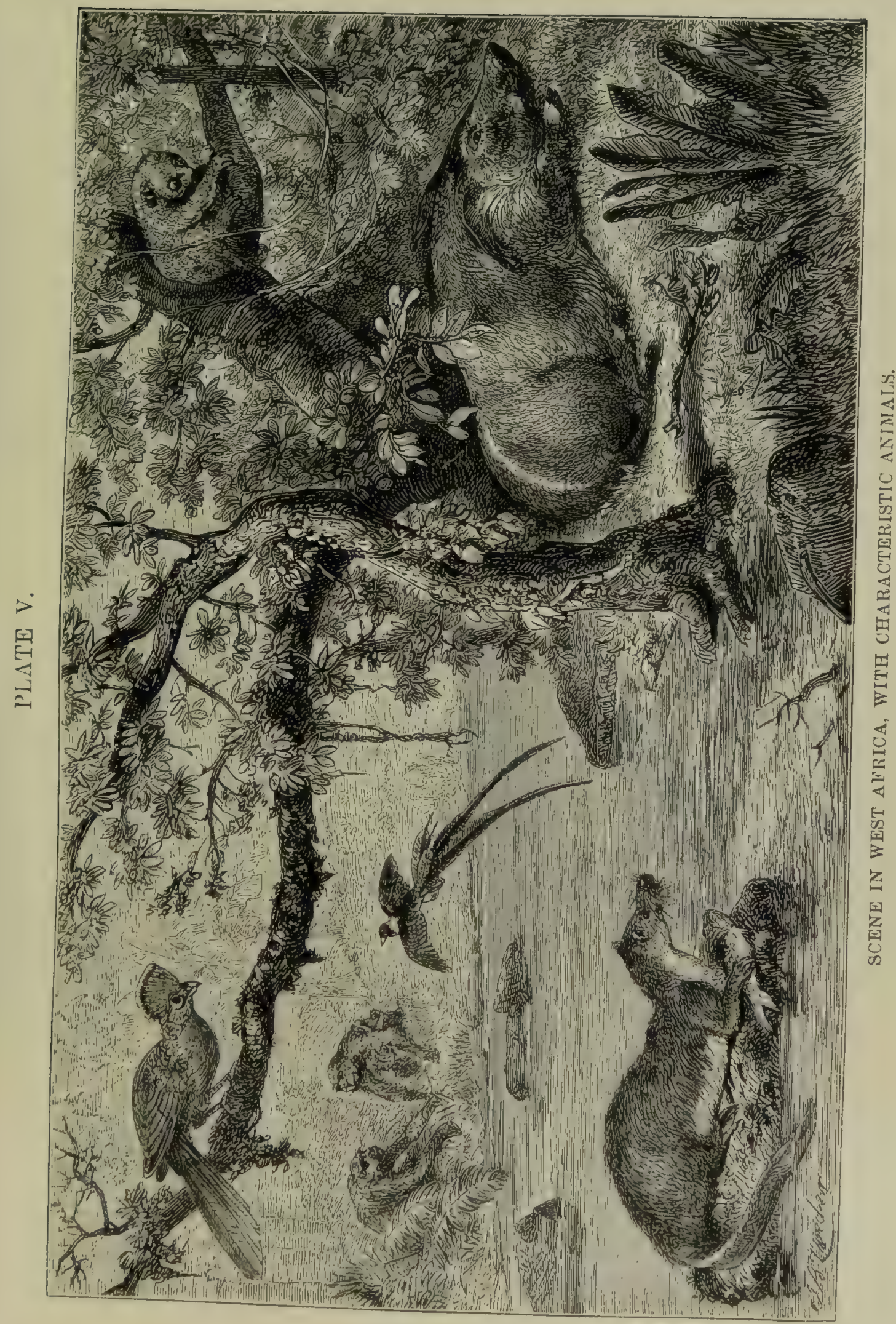



Here, too, we find some interesting relations with the Oriental region on the one side, and the Neotropical on the other. The snakes of the family Homalopsidæ have a wide range, in America, Europe, and all over the Oriental region, but are confined to West Africa in the Ethiopian region. Dryiophis (Dryinphidæ) and Dipsadoboa (Dipsadidæ) on the other hand, are genera of tropical America which occur also in West Africa. The family of lizards, Acontiadæ, are found in West and South Africa, Ceylon, and the Moluccas. The family of toads, Engystomidæ, in West and South Africa and the whole Oriental region; while the Phryniscidæ inhabit tropical Africa and Java.

Insects.-We have here a large number of peculiar genera. There are 10 of butterflies, Lachnoptera, Amphidema, and Catuna belonging to the Nymphalidæ, while four others are Lycænidæ. The genus Euxanthe is common to West Africa and Madagascar.

Of Coleoptera there are 53 peculiar genera ; 20 are Carabidæ, 2 Lucanidæ, 12 Cetoniidæ, 3 Prionidæ, 16 Cerambycidæ, and 34 Lamiidæ. Besides these there are 4 or 5 genera confined to West Africa and Madagascar.

Land Shells.-West Africa is very rich in land shells, but it does not appear to possess any well-marked genera, although several of the smaller groups or sub-genera are confined to it. Helicidæ of the genera Nanina, Buliminus and Achatina are abundant and characteristic.

Islands of the West African Sub-region.-The islands in the Gulf of Guinea are, Fernando Po, very near the main land, with Prince's Island and St. Thomas, considerably further away to the south-west. Fernando Po was once thought to be a remarkable instance of an island possessing a very peculiar fauna, although close to the main land and not divided from it by a deep sea. This, however, was due to our having obtained considerable collections from Feruando Po, while the opposite coast was almost unknown. One after another the species supposed to be peculiar have been found on the continent, till it becornes probable, that, as in the case of other islands similarly situated, it contains no peculiar species whatever. The presence of numerous mammalia, anong which are baboons, lemurs, Hyrax, and 
Anomalurus, shows that this island has probably once been united to the continent.

I'rince's Islund, situated about 100 miles from the coast, lias no manmals, but between 30 and 40 species of birds. Of these 7 are peculiar species,viz., Zosterops ficedulina, Cuphopter'us dohrni (a peculiar genus of Sylviidæ), Symplectes princeps, C'rithagra viffiluta, Colunba chlorophece, Peristera principalis, and Strix thomensis.

In the Isiand of St. Thomas, situated on the equator about 150 miles from the coast, there are 6 peculiar species out of 30 known birds, viz., Scops leucopsis, Zosterops lumpuris, Turdus olivaceofuscus, Oriol:s crassirostris, Symplectes sancti-thomce and Aplopelia simplex; also Strix thomensis in common with Prince's Island. The remainder are all found on the adjacent coasts. It is remarkable that in I'rince's Island there are no birds of prey, auy that appear being driven off by the parrots (Psittacus erithacus) that abound there; whereas in St. Thomas and Fernando Po they are plentiful.

\section{South-African Sub-region.}

This is the most peculiar and interesting part of Africa, but owing to the absence of existing barriers its limits cannot be well defined. The typical portion of it hardly contains more than the narrow strip of territory limited by the mountain range which forms the boundary of the Cape Colony and Natal, while in a wider sense it may be extended to include Mozambique. It may perhaps be best characterised as bounded by the Kalahari desert and the Limpopo river. It is in the more limited district of the extreme south, that the wonderful Cape flora alone exists. IIere are more genera and species, and more peculiar types of plants congregated together, than in any other part of the globe of equal extent. There are indications of a somewhat similar richness and specialization in the zoology of this country; but animals are so much less closely dependent on soil and climate, that much of the original peculiarity has been obliterated, by jong continued interchange of species with su vast an area as 
that of Africa south of the equator. The extreme peculiarity and isolation of the flora must not, however, be lost sight of, if we would correctly interpret the phenomena afforded by the distribution of animal life on the African continent.

Mammalia.-A much larger number of peculiar forms of mammals are found here than in any of the other sub-regions, although it is far less in extent than either of the three divisions of the continent. Among Insectivora we have the Chrysochloridre, or golden moles, consisting of two genera confined to South Africa; while the Macroscelididre, or elephant shrews, are also characteristically South African, although ranging as far as Mozambique and the Zambezi, with one outlying species in North Africa. The Viverridæ are represented by three peculiar genera, Aricla, Cynictis, and Suricata. The Carnivora present some remarkable forms: Proteles, forming a distinct family allied to the hyænas and weasels; and two curious forms of CanidxMegalotis (the long-eared fox) and Lyccon (the hyæna-dog), the latter found also in parts of East Africa. Hydrorgule is a peculiar form of Mustelidx; Pelec one of the antelopes; Dendromys, Malacothrix, and Mystromys are peculiar genera of the mouse family (Muridæ); Bathyerges one of the mole-rats (Spalacidæ); Pedetes, the Cape-hare, a remarkable form of jerboa; and Petromys, one of the spiny-rats (Echimyida). The remarkable Orycteropus, or earth-pig, has one species in South and one in North East Africa. We have thus eighteen genera of mammalia almost or quite peculiar to South Africa.

Birds.-These do not present so many peculiar forms, yet some are very remarkable. Chotops is an isolated genus of thrushes (Turdide). Lioptilus, one of the fruit-thrushes (Pycnonotide). Pogonocichla, one of the fly-catchers; Urolcstes, a shrike; Promerops, a sun-bird; Philetarns and Chcru, wearerbirds; and three peculiar genera of larks-Spizocorys, Hetcrocorys, and Tephrocorys, complete the list of peculiar types of Insseres. A wood-pecker, Geocolaptes, is nearly allied to a Sorth American genus. The Cape-dove, Uina, is confined to South and Eist Africa and Madagascar; and I'lualassomis is a peculiar form of duck. Several genera are also confined to West and sunth Africil;-- 
as Phyllastrephus (Pycnonotidx), Smithomis (Muscicapidx), Corvinella (Laniidæ); Barbatula and Xylobucco (Megalæmidæ); C'euthmochares, also in Madagascar, (Cuculidx); Typanistria (Columbidx). Other remarkable forms, though widely spread over Africa, appear to have their metropolis here, as Colius and Indicator. Others seem to be confined to South Africa and Abyssinia, as the curious Buphaga (Sturnidæ); and Apaloderma (Trogonidæ). Machoerhamphus (Falconidæ) is found only in South-West Africa, Madagascar, and the Malay Peninsula.

Reptiles.-There are 4 peculiar genera of snakes,-Typhline, belonging to the blind burrowing snakes, Typhlopidæ; Lamprophis (Lycodontidæ); Cyrtophis and Pcecilophis (Elapidæ), a family which is chiefly Oriental and Australian. Of Lizards there are 10 peculiar genera; Monotrophis (Lepidosternidæ), but with an allied form in Angola; Cordylus, Pseudocordylus, Platysaurus, Cordylosaurus, Pleurostichus, and Saurophis, all peculiar genera of Zonuridæ; Chamoesaura, furming the peculiar family Chamæsauridæ; Colopus and Rhopitropus (Geckotidæ).

Amphibia.-Of Amphibia there are 4 peculiar genera: Schismaderma (Bufonidæ); Brachymerus (Engystomidæ); Phrynobatrachus and Stenorhynchus (Ranidx). These last are allied to Oriental genera, and the only other Engystomidæ are Oriental and Neotropical.

Fresh-water Fish.-Of fresh-water fishes there is 1 genus-Abrostomus-belonging to the carp family, peculiar to South Africa.

Insects.-South Africa is excessively rich in insects, and the number of peculiar types surpasses that of any other part of the region. We can only here summarize the results.

Lepidopterc.-Of butterflies there are 7 peculiar genera; 2 belonging to the Satyridæ, 1 to Acræidæ, 3 to Lycænidæ, and 1 to Hesperidx. Zeritis (Lycænidæ) is also characteristic of this sub-region, although 1 species occurs in West Africa.

Colcoptera.-These are very remarkable. In the family of Cicindelidæ, or tiger-beetles, we have the extraordinary Manticora and Platychile, forming a sub-family, whose nearest allies are in North America; as well as Ophryodera and Dromica, the latter an extensive genus, which ranges as far north as Mozamlique 
and Lake Ngami. Another genus of this family, Jansenia, is common to South Africa and South India.

In the large family of Carabidæ, or ground-beetles, there are 17 peculiar South African genera, the most important being Crepiclogaster, Hytrichopnus, Arsinoe, and Piezia. Three othersEunostus, Glyphodactyla, and Megalonychus-are common to South Africa and Madagascar only. There is also a genus in common with Java, and one with Australia.

Of Lucanidæ, or stag-beetles, there are 3 peculiar genera; of Cetoniidæ, or rose-chafers, 14; and of Buprestidæ, 2.

In the great family of Longicorns there are no less than 67 peculiar genera-an immense number when we consider that the generally open character of the country, is such as is not usually well suited to this group of insects. They consist of 5 peculiar genera of Prionidæ, 25 of Cerambycidæ, and 37 of Lamiidæ.

Summary of South-African Zoology.-Summarizing these results, we find that South Africa possesses 18 peculiar genera of Mammalia, 12 of Birds, 18 of Reptiles, 1 of Fishes, 7 of Butterflies, and 107 of the six typical families of Coleoptera. Besides this large amount of speciality it contains many other groups, which extend either to West Africa, to Abyssinia, or to Madagascar only, a number of which are no doubt to be referred as originating here. We also find many cases of direct affinity with the Oriental region, and especially with the Malay districts, and others with Australia; and there are also less marked indications of a relation to America.

\section{Atlantic Islands of the Ettiopian Region. St. Helena.-The} position of St. Helena, about 1,000 miles west of Africa and $16^{\circ}$ south of the equator, renders it difficult to place it in either of the sub-regions; and its scanty fauna has a general rather than any special resemblance to that of Africa. The entire destruction of its luxuriant native forests by the introduction of goats which killed all the young trees (a destruction which was nearly completed two centuries ago) must have led to the extermination of most of the indigenous birds and insects. At present there is no land bird that is believed to be really indigenous, and but one 
water, a small plover (Atyintitis sencta-thelene) which is peculiar to the island, but closely allied to African species. Numerous inported birls, such as canaries, Java sparrows, some African finches, guinen-fowls, and partridges, are now wild. There are no native kutterflics, but a few introduced species of almost world-wide range. The only important remnant of the original fauna consists of beetles and land shells. The beetles are the more numerous and have been critically examined and describerl by Mr. T. V. Wollaston, whose researches in the other Atlantic islands are so well known.

Colcoptera of St. Helena.-Omitting tiose beetles which get introduced everywhere through man's agency, there are 59 species of Coleoptera known from St. Helena; and even of these there are a few widely distributed species that may have been introduced by man. It will be well, therefore, to confine ourselves almost wholly to the species peculiar to the island, and, therefore, almost certainly forming part of the endennic or original fauna. Of these we find that 10 belong to genera which have a very wide range, and thus afford no indication of geograplical affinity; 2 belong to genera which are characteristic of the Palaarctic fauna (Bembidium, Longitursus); 3 to African genera (Adoretus, Sciobius, Aspidomorpha); and two species of Calosoma are most allied to African species. There are also 4 African species, which may be indigenous in St. Helena. The peculiar genera, 7 in number, are, however, the most interesting. We have first Haplothorax, a large bectle allied to Carabus and Calosoma, though of a peculiar type. This may be held to inclicate a remote Palcarctic affinity. Melissins, one of the Dynasticie, is allied to South African forms. Microxylubius, one of the Cossonides (a sub-family of Curculionila) is the most important genus, comprising as it does 13 species. It is, according to Mr. Wollaston, an altogether peculiar type, most allied to Pentarthrum, a genus found in St. IIelena, Ascension, and the south of England, and itself very isolated. A'esiotes, another genus of Curculinnidie, belongs to a small group, the allied genera forming which inhatit Europe, Madeira, and Australia. A third peculiar and isolater genus is Trechinphleresome. The Anthribidir are represented by 
2 genera, Notioxcnus aud Homcodere, which are altogether peculiar and isolated, and contain 9 species. Thus no less than 27 species, or more than half of the undoubtedly indigenous beetles, belong to 5 peculiar and very remarkable genera of Rhyncophora.

It appears from this enumeration, that the peculiar species as a whole, exhibit most affinity to the Ethiopian fauna; next to the South European fauna; and lastly to that of the islands of the North Atlantic; while there is such a large amount of peculiarity in the most characteristic forms, that no special geographical affinity can be pointed out.

Land Shells.-These consist of about a dozen living species, and about as many extinct found in the surface soil, and probably exterminated by the destruction of the forests. The genera are Succinea, Zonites, Helix, Bulimus, Pupa, and Achatina. The Rulimi (all now extinct but one) comprise one large, and several small species, of a peculiar type, most resembling forms now inhabiting South America and the islands of the Pacific. Zonites is chiefly South European, but the other genera are of wide range, and none are peculiar to the island.

The marine shells are mostly Mediterranean, or West Indian species, with some found in the Indian Ocean; only 4 or 5 species being peculiar to the island.

Tristan d'Acunha.-This small island is situated nearly miclway between the Cape of Good Hope and the mouth of the La Plata, but it is rather nearer Africa than America, and a little nearer still to St. Helena. An island so truly oceanic and of whose productions so little is known, cannot be placed in any region, and is only noticed here heeause it comes naturally after St. Helena. It is known to possess three peculiar land birds. One is a thrush (Nesocichla eremita) whose exact affinities are not determined; the other a small water-hen (Gullinula nesiotis) allied to our native species, but with shorter and softer wings, which the bird does not use for flight. A finch of the genus Crithagre shows African affinities; while another recently described as Nesospizu acunha (Journ. für Orn. 1873, p. 154) forms a new genus said to resemble more nearly some American forms. 
The only known land-shells are 2 peculiar species of Balea, a genus only found elsewhere in Europe and Brazil.

\section{Madagascar and the Mascarene Islands, or the Malagasy Sub-region.}

This insular sub-region is one of the most remarkable zoological districts on the globe, bearing a similar relation to Africa as the Antilles to tropical America, or New Zealand to Australia, but possessing a much richer fauna than either of these, and in some respects a more remarkable one even than New Zealand. It comprises, besides Madagascar, the islands of Mauritius, Bourbon, and Rodriguez, the Seychelles and Comoro islands. Madagascar itself is an island of the first class, being a thousand miles long and about 250 miles in average width. It lies parallel to the coast of Africa, near the southern tropic, and is separated by 230 miles of sea from the nearest part of the continent, although a bank of soundings projecting from its western coast reduces this distance to about 160 miles. Madagascar is a mountainous island, and the greater part of the interior consists of open elevated plateaus; but between these and the coast there intervene broad belts of Iuxuriant tropical forests. It is this forest-district which has yielded most of those remarkable types of animal life which we shall have to enumerate; and it is probable that many more remain to be discovered. As all the main features of this sub-region are developed in Madagascar, we shall first endeavour to give a complete outline of the fauna of that country, and afterwards show how far the surrounding islands partake of its peculiarities.

Maminalia.-The fauna of Madagascar is tolerably rich in genera and species of mammalia, although these belong to a very limited number of families and orders. It is especially characterized by its abundance of Lemuridx and Insectivora; it also possesses a fow peculiar Carnivora of small size; but most of the other groups in which Africa is especially rich-apes and monkeys, lions, leopards and hyænas, zebras, giraffes, antelopes, elephants and rhinoceroses, and even porcupines and squirrels, are wholly wanting. No less than 40 distinct families of land 
mammals are represented on the continent of Africa, only 11 of which occur in Madagascar, which also possesses 3 families peculiar to itself. The following is a list of all the genera of Mammalia as yet known to inhabit the island :-

\section{PRIMATES.}

LeMURIDAs.

INSECTIVORA.

\section{Indrisinæ.}

Indris :

Lemurinx.

Lemur...

Hapalemur

Microcebus

Chirogaleus

Lepilemur

CHIRomyide.

Chiromys

$$
\begin{array}{crr} 
& \multicolumn{2}{r}{\text { species. }} \\
\ldots & \ldots & 6 \\
\ldots & \ldots & 15 \\
\ldots & \ldots & 2 \\
\ldots & \ldots & 4 \\
\ldots & \ldots & 5 \\
\ldots & \ldots & 2
\end{array}
$$

CenteTid.e.

\begin{tabular}{lcccr}
\multicolumn{5}{c}{ CENTETID.E. } \\
Centetes & $\ldots$ & $\ldots$ & \multicolumn{2}{c}{ speries. } \\
Hemicentetes & $\ldots$ & $\ldots$ & $\ldots$ & 2 \\
Ericulus & $\ldots$ & $\ldots$ & $\ldots$ & 2 \\
Oryzorictes & $\ldots$ & $\ldots$ & $\ldots$ & 2 \\
Echinops & $\ldots$ & $\ldots$ & $\ldots$ & 1 \\
& & $\ldots$ & 3 \\
Sorex & $\ldots$ & Soricide. & & \\
& $\ldots$ & $\ldots$ & $\ldots$ & 1
\end{tabular}

CARNIVORA.

CRYptoproctid.

BATS-(Chiroptera).

Pteropide.

Pteropus

Rhinolophus

Rhinolophide

Vespertilionidiz.

$\begin{array}{lllll}\text { Vespertilio } & \ldots & \ldots & \ldots & 1 \\ \text { Taphozous } & \cdots & & & \\ & & & \end{array}$

Cryptoprocta ... ...

VIVERRID.E.

Fossa $\ldots \quad \ldots \quad \ldots \quad \ldots \quad \ldots \quad 2$

$\begin{array}{lllll}\text { Galidia } & \cdots & \cdots & \cdots & 2 \\ \text { Gallictis } & \cdots & \cdots & \cdots & 3\end{array}$

Eupleres $\quad \ldots \quad \cdots \quad \cdots \quad \cdots \quad 2$

UNGULATA.

SUID.玉.

Potamochœrus

RODENTIA.

Nesomys MURID正.

Nyctinomus

Noctilionides

We have here a total of 12 families, 27 genera, and 65 species of Mammals; 3 of the families and 20 of the genera (indicated by italics) being peculiar. All the species are peculiar, except perhaps one or two of the wandering bats. Remains of a Hippopotamus have been found in a sub-fossil condition, showing that this animal probably inhabited the island at a not very remote epoch.

The assemblage of animals above noted is remarkable, and seerns to indicate a very ancient connection with the southern portion of Africa, before the apes, ungulates, and felines had entered it. The lemurs, whicb are here so largely developed, are repre- 
sented hy a single group in Africa, with two peculiar forms on the West const. They also re-appear under peculiar and isolated forms in Southern India and Malaya, and are evidently but the remains of a once wide-spread group, since in Eocene times they inhabited North America and Europe, and very probably the whole northern hemisphere. The Insectivora are another group of high antiquity, widely scattered over the globe under a number of peculiar forms; but in no equally limited area represented by so many peculiar types as in Madagascar. South and West Africa are also rich in this order.

The Carnivora of Madagascar are mostly peculiar forms of Viverridæ, or civets, a family now almost confined to the Ethiopian and Oriental regions, but which was abundant in Europe during the Miocene period.

The Potumochcens is a peculiar species only, which may be perhaps explained by the unustial swimming powers of swine, and the semi-aquatic habits of this genus, leading to an immigration at a later period than in the case of the other Mammalia. The same remark will apply to the small Hippopotamus, which was coeval with the great Strulhious bird Apiornis.

Rodents are only represented by three peculiar forms of Muride, but it is probable that others remain to be discovered.

Eirds.-Madagascar is excecdingly rich in lirds, and especially in remarkable forms of Passeres. No less than 88 genera and 111 species of land-birds have been discovered, and every year some additions are being made to the list. The African families of Passeres are almost all represented, only two being absent-Paride and Fringillidæ, both very poorly represented iu Africa itself. Among the Picarice, however, the case is very different, no less than 7 families being absent, viz.-Picidre, or woodpeckers; Indicatoridie, or honey-guides; Megalæmida, or barbets; Musophagilie, or plantain-eaters; Coliidæe, or colies; Bucerotidie, or hombills; and Irrisoride, or mockers. Three of these are peculiar to Africa, and all are well represented there, so that their absence from Madagiscar is a very remarkable fact. The number of peculiar genera in Maliugitscar constitutes one of the main features of its omithology, and many of these are so 
isolated that it is very difficult to classify them, and they remain to this day a puzzle to ornithologists. In order to exhibit clearly the striking characteristics of the bird-fauna of this island, we shall first give a list of all the peculiar genera; another, of the genera of which the species only are peculiar; and, lastly, a list of the species which Madagascar possesses in common with the African continent.

Genera of Birds peculiar to Madagascar, or Found elsewhere only in the Mascarene IsLands.

SYIVIID E.

\begin{tabular}{llllr} 
VIID无. & & \multicolumn{2}{c}{ species. } \\
1. Bernieria & $\ldots$ & $\ldots$ & 2 \\
2. Ellisia & $\ldots$ & $\ldots$ & 1 \\
3. Mystacornis & $\ldots$ & $\ldots$ & 1 \\
4. Eroessa & $\ldots$ & $\ldots$ & 1 \\
5. Gervasia & $\ldots$ & $\ldots$ & 1
\end{tabular}

Trmalitide.

6. Oxylabes

Cinclidie (?).

7. Mesites

SitTides.

8. Hypherpes

PrCnONOTID.e (?)

9. Tylas ..

ORIOLIDA.

10. Artamia

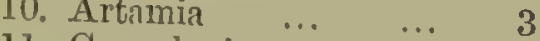

Musctcapide.

12. Newtonia

13. Psendobias

LANIIDA.

14. Calicalicus (?)

15. Vanga

NeCtarinilde.

16. Neodrepanis

Hirundinida.

17. Phedina

Ploceid

18. Nelicurvius ...
STURNide.

19. Euryceros (?)

21. Falculia $\quad \ldots \quad$...

Paictidas.

22. Philepitta ... ... 1

Cuculide.

23. Coua ... ... ... 9

24. Cochlothraustes $\quad \ldots \quad 1$

LEPTOSOMID无.

25. Leptosomus

Coraciide.

26. Atelornis $\quad \ldots \quad$... 2

27. Brachypteraci $i s \quad \ldots \quad 1$

28. Geobiastes ... ... 1

.. 1 Psittacide.

29. Coracopsis. .. $\quad \ldots \quad 2$

Columbide.

30. Alectronas

Tetraonidie.

31. Margaroperdix $\quad \ldots \quad 1$

FALCONIDE.

32. Nisoides

33. Eutriorchis … $\ldots, \quad 1$

Total species of peculiar genera $\overline{50}$

Apyorithid (extinct).

34. Apyornis ... ... 1 
Ethlopian or Oriental Genera which are represeyted iN MADAGASCAR BY PECULIAR BPECIES.

TURDIDE.

1. Bessonornis ... ... i

Alcedivide.

Siperias.

21. Corythornis ... $\quad \ldots \quad 1$

22. Ispidina $\quad \ldots \quad \ldots \quad 1$

SYLVIIDE.

2. Acrocephalus ... ... 1 UPUPIDE.

$\begin{array}{lllllll}\text { 3. Copsychus (Or.) } & \ldots & 1 & \text { 23. Upupa (3) } & \ldots & \ldots & 1\end{array}$

Caprimulaide.

PrCnonotide.

$\begin{array}{lll}\text { 5. Hypsipetes }(\mathrm{Or} .) & \ldots & 1 \\ \text { 6. Audropadus ... } & \ldots & 1\end{array}$

24. Caprimulgus $\quad$... 1

Cypselide.

CAMPEPHAGINA.

7. Campephaga ... … 1

25. Cypselus $\quad \ldots \quad \ldots \quad 2$

26. Chieturia $\ldots \quad \ldots \quad 1$

DicruRIDA.

8. Dicrurus $\quad \ldots \quad \ldots \quad 1$

Psittacide.

MUscicapId E.

27. Poliopsittr ... .. 1

Columbide.

9. Tchitren $\quad \ldots \quad \ldots, \quad 1$

LANID Rx.

28. Treron

29. Columba $\quad \ldots \quad \ldots . \quad 1$

30. Turtur $\quad \ldots \quad \ldots \quad 1$

10. Laniarius $\quad \ldots \quad \ldots \quad 1 \quad$ PTEROCLID

Nectarininde.

11. Nectarinir ... ... 1

31. Pterocles ‥ … 1

Ploceind 不.

12. Foudia $\quad \ldots \quad \ldots \quad 2$

13. Hypargos $\quad \ldots \quad$...

TETRAONIDX.

32. Francolinus ... .. 1

ALAUDID舟。

15. Mirafra $\ldots \quad$... 1

TURAICIDA.

31. Turnix

FaLCONIDAE.

16. Motacilla ... ... 1

Cuevlidar.

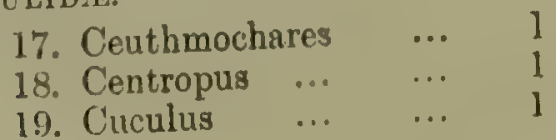

35. Polyboroides

36. Circus $\quad \ldots \quad \ldots . \quad 1$

37. Astur... $\quad \ldots \quad \ldots \quad$... 3

38. Aocipiter $\ldots$... 1

39. Buteo... ‥ …

CORACIIDE.

20. Eurystomus ... $\quad \ldots \quad 1$

40. Halimetus $\ldots \quad$... 1

41. Pernis $\ldots$... 1

$\begin{array}{llll}\text { 42. Buza ... } & \ldots & \ldots & 1 \\ \text { 43. Cerchneis } & \ldots & \ldots & 1\end{array}$ 


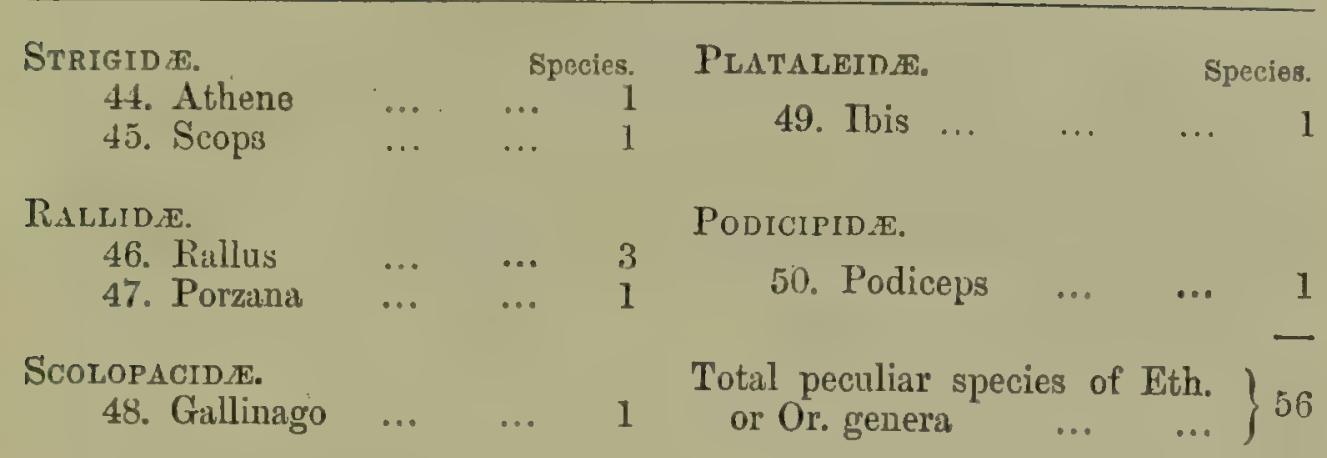

Species of Birds common to Madagascar and Africa or Asia.
1. Cisticola cursitans.
2. Corvus scapulatus.
7. Aplopelia tympanistria.
3. Crithagra canicollis.
4. Merops superciliosus.
5. Collocalia fuciphaga.
6. Ena capensis.
8. Falco ninor.
9. Falco conculor.
10. Milvus ægyptius.
11. Milvus migrans.
12. Strix flammeir.

These three tables show us an amount of speciality hardly to be found in the birds of any other part of the globe. Out of 111 land-birds in Madagascar, only 12 are identical with species inhabiting the adjacent continents, and most of these belong to powerful-winged, or wide-ranging forms, which probably now often pass from one country to the other. The peculiar species -49 land-birds and 7 waders, or aquatics-are mostly wellmarked forns of African genera. There are, however, several genera (marked by italics) which have Oriental or Palrearctic, affinities, but not African, viz.-Copsychus, Hypsipetes, Hypherpes, Alectranas, and Margaroperdix. These indicate a closer approximation to the Malay countries than now exists.

The table of 33 peculiar genera is of great interest. Most of these are well-marked forms, belonging to families which are fully developed in Africa; though it is singular that not one of the exclusively African families is represented in any way in Madagascar. Others, however, are of remote or altogether doubtful aftinities. Sittide is Oriental and Palearctic, but not Ethiopian. Oxylabes and Mystacomis are of doultful affinities. Artamia and Cyanolanius still more so, and it is quite undecided what family they belong to. Calicalicus is almost equally obscure. Neodrepanis, one of the most recent discoverics, secms to comect the Nectariniidie with the Pacific 
Depanidide. Euryceros is a complete puzzle, having been placed with the hornbills, the starlings, or as a distinct family. Falculia is an exceedingly aberrant form of starling, long thought to be allied to Irrisor. Philepitta, forming a distinct family, (Paictidx), is most remarkable and isolated, perhaps with remote South American affinities. Leptosoma is another extraordinary form, connecting the cuckoos with the rollers. Atelornis, Brachypteracias, and Geobiastes, are terrestrial roller's, with the form and colouring of Pittu. So many perfectly isolated and remarkable groups are certainly nowhere else to be found; and they fitly associate with the wonderful aye-aye (Chiromys), the insectivorous Centetidæ, and carnivorous Cryptoprocte among the Mammalia. They speak to us plainly of enormous antiquity, of long-continued isolatiou; and not less plainly of a lost continent or continental island, in which so many, and various, and peculiarly organized creatures, could have been gradually developed in a connected fauna, of which we have here but the fragmentary remains.

Plate VI.-Illustrating the characteristic features of the Zoology of Madagascar.-The lemurs, which form the most prominent feature in the zoology of Madagascar, being comparatively well-known from the sumerous specimens in our zoolcgical gardens; and good figures of the Insectivorous genera not being available, we have represented the nocturnal and extraordinary aye-aye (Chiromys madagascariensis) to illustrate its peculiar and probably very ancient mammalian fauma; while the river-hogs in the distance (Potamochoorus edwardsii) allied to African species, indicate a later immigration from the mainland than in the case of most of the other Mammalia. The peculiar birds being far less generally known, we have figured three of them. The largest is the Euryceros provosti, here classed with the starlings, although its remarkable bill and other peculiarities render it probable that it should form a distinct family. Its colours are velvety black and rich brown with the bill of a pearly grey. The bird bencath (Vanga curvirostris) is one of the peculiar Madagascar shrikes whose plumage, variegated with green-black and pure white is very conspicuous; while that in 
PLA'L'V VI.

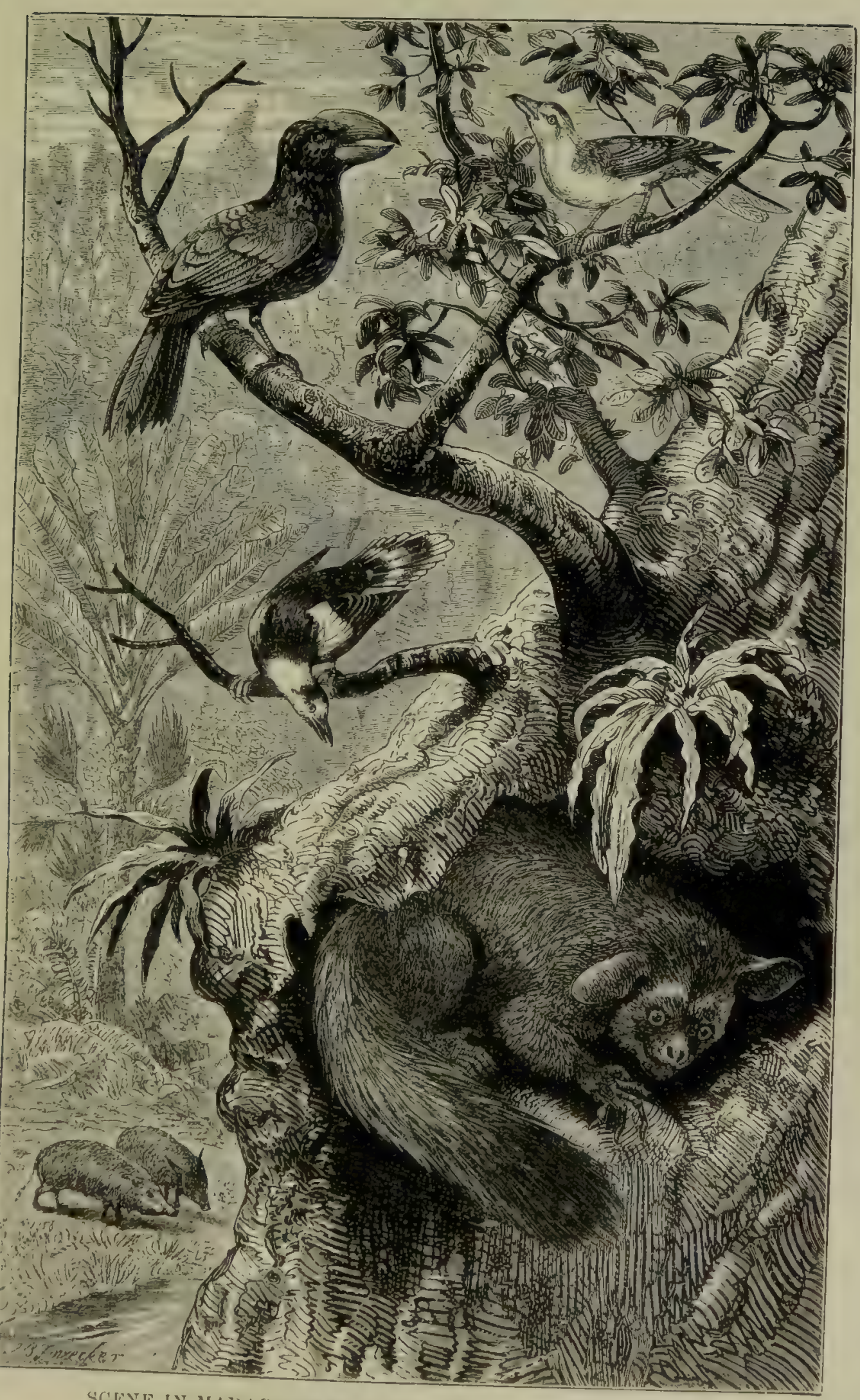

SCE.VE IN MAIAGASOAR, WITI CHIRACTERISTIC ANIMAS 

the right hand corner is the Leptosoma disculer, a bird which appears to be intermediate between such very distinct families as the cuckoos and the rollers, and is therefore considered to form a family by itself. It is a coppery-green above and nearly white leneath, with a black bill and red feet. The fan-shaped plant on the left is the traveller's tree (Urania speciosa), one of the peculiar forms of vegefation in this marvellous island.

Reptiles:- These present some very curious features, comparatively few of the African groups bcing represented, while there are a considerable number of Eastern and even of American forms. Beginning with the snakes, we find, in the enormous family of Colubridx, none of the African types; but instead of them three genera-Herpetodryas, Phitodryess, and Heterodononly found elsewhere in South and North America. The Psammophidæ, which are both African and Indian, are represented by a peculiar genus, Nimoplis. The Dendropliclie are represented by Ahotulla, a genus which is both African and American. The Dryiophidæ, which inhabit all the tropics but are most developed in the Oriental region, are represented by a peculiar genus, Langahr. The tropical Pythonidie are represented by another peculiar genus, Sanzinia. The Lycodontida and Viperidie, so well developed in Africa, are entirely absent.

The lizards are no less remarkable. The Zonurida, alundantly developed in Africa, are represented by one peculiar genus, Cicignce. The wide-spread Scincida by another peculiar genus, Pyyomcles. The African Sepsidxe, are represented by three gthera, two of which are African, and one, Amphiglossus, peculiar. The Acontiadic are represented by a species of the African crenus Aconticus. Of scincilic there is the wide-spread Euprepes. The Sepida are represented by the $\Lambda$ frican genera Seps and Scelutes. The Geckotidio are not represented by any purely African senerd, lut by I'hyllodactylus, which is American and Australian; Iremidactylus, which is spread over all the tropics; by two peculiar gencra; and by L'roplatis, Geckolepis, and Pholsuma, confined to Marlagascar, Bourbon, and the Andaman Islinds. The Agnmidie, which are mostly Oriental and are represented in 
Africa by the single gemus Agama, have here three peculiar genera, Tracheloptychus, Chularodon, and Hoplums. Iastly, the American Iguanidac are said to be represented by a species of the South American genus Oplurus. The classification of Reptiles is in such an unsettled state that some of these deterninations of alfinities are probably exroneous; but it is not likely that any corrections which may be required will materially affect the general bearing of the evidence, as indicating a remarkable amount of Oriental and American relationship.

The other groups are of less interest. Tortoises are represented by two African or wide-spread genera of Testudinidx, Testudo and Cheisinc, and by one peculiar genus, $P_{y} x i s$; and there are also two African genera of Chelydidie.

The Amphibia are not very well known. They appear to be confined to species of the wide-spread Ethiopian and Oriental genera-Hylarana, Polypedutes, and Rappia (Polypedatidæ); and Pyxicephalus (Ranidæ).

Fresh-water Fishes.-These appear to be at present almost unknown. Wlien carefully collected they will no doubt furnish some important facts.

\section{The Mascarene Islands.}

The various islands which surround Madagascar-Bourbon, Mauritius, Rodriguez, the Seyclielles, and the Comoro Islands -all partake in a considerable degree of its peculiar fauna, while having some special features of their own.

Indigenous Mammalia (except bats) are probably absent from all these islands (except the Comoros), although Lemur and Centetes are given as natives of Bourbon and Mauritius. They have, however, perhaps been introduced from Madagascar. Lcmur mayottensis, a peculiar species, is found in the Comoro Islands, where a Madagascar species of Viverra also occurs.

Bourbon and Mauritius may be taken together, as they much resemble each other. They each possess species of a peculiar genus of Campephagidre, or caterpillar shrikes, Oxynotus; while the remarkable Fregilumus, belonging to the starling family, inhalits Bourhon, if it is not now extinct. They also have 
peculiar species of Pratincola, Irypsipctes, Phedina, Tchitrea, Zosterops, Foudice, Collocalia, and Coracopsis; while Mauritius has a very peculiar form of dove of the sub-genus Trocaza ; an Alectricnas, extinct within the last thirty years; and a species of the Oriental genus of parroquets, Palcornis. The small and remote island of Rodriguez has another Palcoornis, as well as a peculiar Foudia, and a Drymoeca of apparently Indian affinity.

Coming to the Seychelle Islands, far to the north, we find the only mammal an Indian species of bat (Pteropus edwardsii). Of the twelve land-birds all but one are peculiar species, but all belong to genera found also in Madagascar, except one-a peculiar species of Palcoornis. This is an Oriental genus, but found also in several Mascarene Islands and on the African continent. A species of black parrot (Corccopsis barkiayi) and a weaver bird of peculiar. type (Foudia seychellarum) show, however, a decided connection with Madagascar. There are also two peculiar pigeons-a shortwinged Turtur and an Alectrcencs.

Most of the birds of the Comoro Islands are Madagascar species, only two being African. Five are peculiar, belonging to the genera Nectarinic, Zosterops, Dicrurus, Foudia, and Alcctroenas.

Reptiles are scarce. There appear to be no snakes in Mauritius and Bourbon, though some African species are said to be found in the Seychelle Islands. Lizards are fairly represented. Mauritius has Cryptoblepharus, an Australian genus of Gymnopthalmidie; Hemidactylus (a wide-spread genus); Percpus (Oriental and Australian)-both belonging to the Geckotidæ. Bourbon has Heteropus, a Moluccan and Australian genus of Scincidæ; Phelsuma (Geckotidæ), and Chameleo, both found also in Madagascar; as well as Pyais, one of the tortoises. The Seychelles have Theconyx, a peculiar genus of Geckotidx, and Chameleo. Gigantic land-tortoises, which formerly inhabited most of the Mascarene Islands, now only survive in Aldabra, a small island north of the Seychelles. These will be noticed again further on. Amphibia seem only to be recorded from the Seychelles, where two genera of tree-frogs of the family Polypedatida are found; one (Mcyalixaluss) peculiar, the other (Rappia) found also in Madagascar and Africa. 
The few insect groups peculiar to these islands will be noted when we deal with the entomology of Madagascar.

Extinct fauna of the Mascarene Islands and Madagascar.-Tefore quitting the vertebrate groups, we must notice the remarkahle birls which have become extinct in these islands little more than a century ago. The most celebrated is the dudo of the Mauritius (Didus ineptus), but an allied genus, Przophaps, inhabited Rodriguez, and of both of these almost perfect skeletons have been recovered. Other species probably existed in Bourbon. Remains of two genera of flightless rails have also been found, Aphanapteryx and Erythromachus; and even a heron (Ardea megacephala) which was short-winged and seldom flew; while in Madagascar there lived a gigantic Struthious bird, the Epyornis. Some further details as to these extinct forms will be found under the respective families, Dididr, Ralliclie, and Epyornithidæ, in the fourth part of this work; and their bearing on the past history of the region will be adverted to in the latter part of this chapter. Dr. Guinther has recently distinguished five species of fossil tortoises from Mauritius and Rodriguez,-all of them quite different from the living species of Aldabra.

Insects.-The butterflies of Madagascar are not so remarkaljle as some other orders of insects. There seems to be only one peculiar genus, Hetcropsis (Satyridæ). The other generia are African, Leptoneura being confined to Madagascar and South Africa. There are some fine Papitios of uncommon forms. The most interesting lepidopterous insect, however, is the fine diumal moth (Urania), as all the other species of the genus inhalit tropical America and the West Indian Islands.

The Coleoptera have been better collected, and exhilit some very remarkable aftinities. There is but one peculiar genus of Cicindelidx, Pogonostoma, which is allied to the South American genus, Ctenostome. Another genus, Peritexia, is common to Madagascar and South America. None of the important Africnn genera are represented, except Eurymorphtice; while Megleomma is common to Madagascar and the Oriental region.

In the Carabidx we have somewhat similar plienomena on it 
wider scale. Such large and important African genera as Polyhirma and Anthic, are absent; but there are four genera in common with South Africa, and two with West Africa; while three others are as much Oriental as African. One genus, Distrigus, is wholly Oriental; and another, Homalosoma, Australian. Colpodes, well developed in Bourbon and Mauritius, is Oriental and South American. Of the peculiar genera, Sphocrostylis has South American affinities; Microchila, Oriental; the others being related to widely distributed genera.

The Lucanidie are few in number, and all have African affinities. Madagascar is very rich in Cetoniidæ, and possesses 20 peculiar genera. Bothrorkina, and three other genera belonging to the Ichnostoma group, have wholly African relations. Doryscelis and Chromoptila are no less clearly allied to Oriental genera. A series of eight peculiar genera belong to the Schizorhinida, a family the bulk of which are Australian, while there are only a few African forms. The remaining genera appear to have African affinities, but few of the peculiarly African genera are represented. Glyciphana is characteristic of the Oriental region.

The Buprestidx of Madagascar consist mainly of one large and peculiar genus, Polybothris, allied to the almost cosmopolite Psilopterc. Most of the other genera are both Ethiopian and Oriental; but Polycesta is mainly South American, and the remarkable and isolated genus Sponsor is confined to the Mauritius with a species in Celebes and New Guinea.

The Longicorns are numerous and interesting, there being no less than 24 peculiar genera. Two of the genera of Prionida are very isolated, while a third, Closterus, belongs to a group which is Malayan and American.

Of the Cerambycide, Philematium ranges to Africa and the West Indies; Leptocerc is only found eastward in Ceylon and the New Hebrides; while Euporus is African. Of the peculiar genera, 2 are of African type; 3 belong to the Leptura group, which are mostly Palrarctic and Oriental, with a few in South Africa; while Philocalocera is allied to a South American genus.

Among the Lamiidx there are several wide-ranging and 7 
African genera; but Coptops is Oriental, and the Oriental Praonctha occurs in the Comoro Islands. Among the peculiar genera several have African affinities, but Tropidema belongs to a group which is Oriental and Australian; Oopsis is found also in the Pacific Islands; Nythergatcs, Sulemus, and Coclomoca, are allied to Malayan and American genera.

General Remarks on the Insect-fauna of Madagascar.-Taking the insects as a whole, we find the remarkable result that their affinities are largely Oriental, Australian, and South American: while the African element is represented chiefly by special South African or West African forms, rather than by such as are widely spread over the Ethiopian region. ${ }^{1}$ In some families-as Cetoniidre and Lamiidx-the African element appears to preponderate; in others-as Cicindelidre-the South American affinity seems strongest; in Carabidx, perhaps the Oriental; while in Buprestidæ and Cerambycidie the African and foreign elements seem nearly balanced. We must not impute too much importance to these foreign alliances among insects, because we find examples of them in every country on the globe. The reason they are so much more pronounced in Madagascar may be, that during long periods of time this island has served as a refuge for groups that have been dying out on the great continents; and that, owing to the numerous deficiencies of a somewhat similar kind in the series of vertebratia in Australia and South America, the same groups have often been able to maintain themselves in all these comtries as well as in Madagascar. It must be remembered ton, that these peculiarities in the Malagasy and Mascarene insect-fauna are but exaggerations of a like phenomenon on the mainland. Africa also has numerous affinities with South America, with the Malay countries, and with Australia; but they do not bear anything like so large a proportion to the whole fauna, and do not, therefore, attract so much attention. The special conditions of existence and the long-continued isolation of Madagascar, will account for much of this difference; and it will evidently not be necessary

1 There are also some special resemblances between the plants of Madagascar and South Africa, according to Dr. Kirk. 
to introduce, as some writers are disposed to do, a special land comnection or near approach between Madagascar and all these countries, independently of Africa; except perhaps in the case of the Malay Islands, as will be discussed further on.

Land-shells.-Madagascar and the adjacent islands are all ricb in land-shells. The genera of Helicidæ are Vitrina, Helix, Achatina, Columna (peculiar to Madagascar and West Africa), Buliminus, Cionella (chiefly Oriental and South American, but not African), Pupa, Streptaxis, and Succinea. Among the Operculata we have Truncatella (widely scattered, but not African); Cyclotus (South American, Oriental, and South African); Cyclophorus (mostly Oriental, with a few South African); Leptopoma (Oriental); Megalomastoma (Malayan and South American); Lithidion (peculiar to Madagascar, Socotra, and South-West Arabia); Otopoma (with the same range, but extending to West India and New Ireland); Cyclostomus (widely spread but not African); and Omphalotropis (wholly Oriental and Australian). We thus find the same general features reproduced in the landshells as in the insects, and the same remarks will to a great extent apply to both. The classification of the former is, however, by no means so satisfactory, and we have no extensive and accurate general catalogues of shells, like those of Lepidoptera and Coleoptera, which have furnished us with such valuable materials for the comparison of the several faunas.

On the probable Pust History of the Ethiopian Region.

Perhaps none of the great zoological regions of the earth present IIS with problems of greater difficulty or higher interest than the Ethiopian. We find in it the evidence of several distinct and successive faunas, now intermingled; and it is very difficult, with our present imperfect knowledge, to form an adequate conception of how and when the several changes occurred. There are, however, a few points which seem sufficiently clear, and these afford us a secure foundation in our endeavour to comprehend the rest.

Let us then consider what are the main facts we have to account for.-1. In Continental Africa, more especially in the south 
and west, we find, along with much that is peculiar, a number of genera showing a decided Oriental, and others with an equally strong South American affinity; this latter more particularly showing itself among reptiles and insects. 2. All over Africa, but more especially in the east, we have abundance of large ungulates and felines-antelopes, giraffes, buffaloes, elephants, and rhinoceroses, with lions, leopards, and hyænas, all of types now or recently found in India and Western Asia. 3. But we also have to note the absence of a number of groups which abound in the abovenamed countries, such as deer, bears, moles, and true pigs; while camels and goats-characteristic of the desert regions just to the north of the Ethiopian-are equally wanting. 4. There is a wonderful unity of type and want of speciality in the vast area of our first sub-region extending from Senegal across to the east coast, and southward to the Zambezi; while West Africa and South Africa each abound in peculiar types. 5. We have the extraordinary fauna of Madagascar to account for, with its evident main derivation from Africa, yet wanting all the larger and higher African forms; its resemblances to Malaya and to South America; and its wonderful assemblage of altogether peculiar types.

Here we find a secure starting-point, for we are sure that Madagascar must have been separated from Africa before the assemblage of large animals enumerated above, had entered it. Now, it is a suggestive fact, that all these belong to types which abounded in Europe and India about the Miocene period. It is also known, from the prevalence of Tertiary deposits over the Sahara and much of Arabia, Persia, and Northern India, that during early Tertiary times a continuous sea from the Bay of Bengal to the British Isles completely cut off all land communication between Central and Southern Africa on the one side, and the great continent of the Eastern hemisphere on the other. When Africa was thus isolated, its fauna probably had a character somewhat analogous to that of South America at the same period. Most of the higher types of mammalian life were absent, while lemurs, Edentates, and Insectivora took their place. At this period Madagascar was no doubt united with Africa, 
and helped to form a great southern continent which must at one time have extended eastward as far as Southern India and Ceylon; and over the whole of this the lemurine type no doubt prevailed.

During some portion of this period, South Temperate Africa must have had a much greater extension, perhaps indicated by the numerous shoals and rocks to the south and east of the Cape of Good Hope, and by the Crozets and Kerguelen Islands further to the south-east. This would have afforded means for that intercommunion with Western Australia which is so clearly marked in the flora, and to some extent also in the insects of the two countries; and some such extension is absolutely required for the development of that wouderfully rich and peculiar temperate flora and fauna, which, now crowded into a narrow. territory, is one of the greatest marvels of the organic world.

During this early period, when the great southern continents - South America, Africa, and Australia-were equally free from the incursions of the destructive felines of the north, the Struthious or ostrich type of birds was probably developed into its existing forms. It is not at all necessary to suppose that these three continents were at any time united, in order to account for the distribution of these great terrestrial birds; as this may have arisen by at least two other easily conceivable modes. The ancestral Struthious type may, like the Marsupial, have once spread over the larger portion of the globe ; but as higher forms, especially of Carnivora, became developed, it would be exterminated everywhere but in those regions where it was free from their attacks. In each of these it would develope into special forms adlapted to surrounding conditions; and the large size, great strength, and excessive speed of the ostrich, may have been a comparatively late development caused by its exposure to the attacks of enemies which rendered such modification necessary. This secms the most probable explanation of the distribution of Struthious birds, and it is rendered almost certain by the discovery of remains of this order in Europe in Eocene deposits, and by the occurrence of an ostrich among the fossils of the Siwalik hills; but it is just possible, also, that the 
ancestral type may have been a bird capable of flight, and that it spread from one of the three southern continents to the others at the period of their near approach, and more or less completely lost the power of flight owing to the long continued alssence of enemies.

During the period we have been considering, the ancestors of existing apes and monkeys flourished (as we have seen in Chapter VI.) along the whole southern shores of the old Palxarctic continent; and it seems likely that they first entered Africa by means of a land connection indicated by the extensive and lofty plateaus of the Sahara, situated to the south-east of Tunis and reaching to a little north-west of Lake Tchad; and at the same time the elephant and rhinoceros type may have entered. This will account for the curious similarity between the higher faunas of West Africa and the Indo-Malay sub-region, for owing to the present distribution of land and sea and the narrowing of the tropical zone sinee Miocene times, these are now the only lowland, equatorial, forest-clad countries, which were in connection with the southern shores of the old Palæarctic continent at the time of its greatest luxuriance and development. This western connection did not probably last long, the junction that led to the greatest incursion of new forms, and the complete change in the character of the African fauna, having apparently been effected by way of Syria and the shores of the Red Sea at a somewhat later date. By this route the old South-Palæarctic fauma, indicated by the fossils of Pikermi and the Siwalik Hills, poured into Africa; and finding there a new and favourable country, almost wholly unoccupied by large Mammalia, increased to an enormous extent, developed into new forms, and finally overran the whole continent.

Before this occurred, however, a great change had taken place in the geography of Africa. It had gradually diminished on the south and east; Madagascar had been left isolated; while a number of small islands, banks, and coral reefs in the Indian Ocean alone remained to indicate the position of a once extensive equatorial land. The Mascarene Islands appear to represent the portion which separated earliest, before any carnivora had 
reached the country; and it was in consequence of this total exemption from danger, that several groups of birds altogether incapable of flight became developed here, culminating in the huge and unwieldy Dodo, and the more active Aphanapteryx. To the same cause may be attributed the development, in these islands, of gigantic land-tortoises, far surpassing any others now living on the globe. They appear to have formerly inhabited Mauritius, Bourbon, and Rodriguez, and perhaps all the other Mascarene islands, hut having been recklessly destroyed, now only survive in the small uninhabited Aldabra islands north of the Seychelle group. The largest living specimen ( $5 \frac{1}{2}$ feet long) is now in our Zoological Crardens. The only other place where equally large tortoises (of an allied species) are found, is the Galapagos islands, where they were equally free from enemies till civilized man came upon the scene; who, partly by using them for food, partly by the introduction of pigs, which destroy the eggs, has greatly diminished their numbers and size, and will probably soon wholly exterminate them. It is a curious fact, ascertained by Dr. Giinther, that the tortoises of the Galaparos are more nearly related to the extinct tortoises of Mauritius than is the living tortoise of Aldabra. This would imply that several distinct groups or sub-genera of Testudo have had a wide range over the globe, and that some of each have survived in very distant localities. This is rendered quite conceivable by the known antiquity of the genus Testudo, which dates back to at lenst the Eocene formation (in North America) with very little change of form. These sluggish reptiles, so long-lived and so tenacions of life, may have remained unchanged, while every higher animal type around them has become extinct and been replaced by very different forms; as in the case of the living Emys tectum, which is the sole survivor of the strange Siwalik fauna of the Miocene epoch. The ascertained history of the genus and the group, thus affords a satisfactory explanation of the close affinity of the gigantic tortoises of Mauritius and the Galapagos.

The great island of Madagascar seems to have remained longer united with Africa, till some of the smaller and more active 
carnivora had reached it; and we consequently find there, no wholly terrestrial form of bird but the gigantic and powerful Alyornis, well able to defend itself against such enemies. As already intimated, we refer the South American element in Madagascar, not to any special connection of the two countries inclependently of Africa, but to the preservation there of a number of forms, some derived from America through Africa, others of once almost cosmopolitan range, but which, owing to the severer competition, have become extinct on the African continent, while they have continued to exist under modified forms in the two other countries.

The deptlis of all the great oceans are now known to be so profound, that we cannot conceive the elevation of their beds above the surface without some corresponding depression elsewhere. And if, as is probable, these opposite motions of the earth's crust usually take place in parallel bands, and are to some extent dependent on each other, an elevation of the sea bed could hardly fiil to lead to the submergence of large tracts of existing continents; and this is the more likely to occur ou account of the great disproportion that we have seen exists between the mean height of the land and the mean depth of the ocean. Keeping this principle in view, we may, with some probability, suggest the successive stages by which the Ethiopian region assumed its present form, and acquired the striking peculiarities that characterise its several sub-regions. During the early period, when the rich and varied temperate flora of the Cape, and its hardly less peculiar forms of insects and of low type mammalia, were in process of development in an extensive south temperate land, we may be pretty sure that the whole of the east and much of the north of Africa was deep sea. At a later period, when this continent sank towards the south and east, the elevation may have occurred which connected Madagascar with Ceylon; and only at a still later epoch, when the Indian Ocean had again been formed, did central, eastern, and northern Africa graclually rise above the ocean, and effect a comnection with the great northern continent by way of Abyssinia and Arabia. And if this last change took place with 
tolerable rapidity, or if the elevatory force acted from the north towards the south, there would be a new and unoccupied territory to be taken possession of by immigrants from the north, together with a few from the south and west. The more highly-organised types from the great northern continent, however, would inevitably prevail; and we should thus have explained the curious uniformity in the fauna of so large an area, together with the absence from it of those peculiar Ethiopian types which so abundantly characterise the other three sub-regions.

We may now perhaps see the reason of the singular absence from tropical Africa of deer and bears; for these are both groups which live in fertile or well-wooded countries, whereas the line of immigration from Europe to Africa was probably always, as now, to a great extent a dry and desert tract, suited to antelopes and large felines, but almost impassable to deer and bears. We find, too, that whereas remains of antelopes and giraffes abound in the Miocene deposits of Greece, there were no deer (which are perhaps a somewhat later development); neither were there any bears, but numerous forms of Felidæ, Viverridæ, Mustelidæ, and ancestral forms of Hyona, exactly suited to be the progenitors of the most prevalent types of modern African Zoology.

There appears to have been one other change in the geography of Africa and the Atlantic Ocean that requires notice. The rather numerous cases of close similarity in the insect forms of tropical Africa and America, seem to indicate some better means of transmission, at a not very remote epoch, than now exists. The vast depth of the Atlantic, and the absence of any corresponding likeness in the vertebrate fauna, entirely negative the idea of any union between the two countries; but a moderate extension of their shores towards each other is not improbable, and this, with large islands in the place of the Cape Verd group, St. Paul's Rocks, and Fernando Noronha, to afford resting places in the Atlantic, would probably suffice to explain the amount of similarity that actually exists.

Our knowlerge of the geology and palienntology of Africa. 
being so scanty, it would be imprudent to attempt any more detailed explanation of the peculiarities of its existing fauna. The sketch now given is, it is believed, founded on a sufficient basis of facts to render it not only a possible but a probable account of what took place; and it is something gained to be able to show, that a large portion of the peculiarities and anomalies of so remarkable a fauna as that of the Ethiopian region, can be accounted for by a series of changes of physical geography during the tertiary epoch, which can hardly be considered extreme, or in any way unlikely to have occurred. 


\section{TABLES OF DISTRIBUTION.}

IN drawing up these tables showing the distribution of various classes of animals in the Ethiopian Region, the following sources of information have been chiefly relied on, in addition to the general treatises, monographs, and catalogues, used for the Fourth Part of this work :-

Mammalia.-Blanford's Abyssinia; Peters's Mozambique; Heuglin and Schweinfurth for North East Africa; Grandidier Schlegel, \&c., for Madagascar; the local lists given by Mr. Andrew Murray; numerous papers by Fraser, Gray, Kirk, Mivart, Peters, Sclater, and Spelie; and a MS. list of Bovidie from Sir Victor Brooke.

Bircls.-Finsch and Hartlaub for East Africa; Heuglin for North-East Africa; Blanford for Abyssiuia; Layard for South Africa; Hartlaub for West Africa; Dohrn for Princes Island; Audersson for Damaralaud; and papers by Gurney, Hartlaub, Kirk, Newton, Peters, Sharpe, Sclater, Schlegel, and Pollen and a MS. list of Madagascar Birds from Mr. Sharpe. 


\section{'IABIL I.}

\section{FAMILIES OF ANIMALS INUABITING T'HE ETIIOPIAN LEGION.}

Explanation.

Names in ilatics show families peculiar to the region.

Names inclosed thus (.....) barely enter the region, and are not considered properly to belong to it.

Numbers are not consecutive, but correspond to those in Part IV.

\begin{tabular}{|c|c|c|c|c|c|}
\hline \multirow[b]{2}{*}{ Order and Family. } & \multicolumn{4}{|c|}{ Sub-regions. } & \multirow[b]{2}{*}{ Range beyond the Region. } \\
\hline & 莡莺 & $\mid \begin{array}{ll}1 \\
0\end{array}$ & 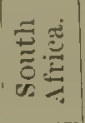 & $\mid$ & \\
\hline $\begin{array}{l}\text { MLAMMALIA. } \\
\text { Plimitis. } \\
\text { 1. Simiida } \\
\text { 2. Semuopithecida } \\
\text { 3. Cynopithecidæe } \\
\text { 6. Lemuridæ ... } \\
\text { 8. Chiromyidce ... }\end{array}$ & - & $\begin{array}{l}- \\
- \\
-\end{array}$ & - & - & $\begin{array}{l}\text { Oriental } \\
\text { Oriental } \\
\text { Oriental, Palæaretic } \\
\text { Oriental }\end{array}$ \\
\hline $\begin{array}{l}\text { CIIEIIOPTERA. } \\
\text { 9. Pteropidæ ... } \\
\text { 11. Rhinolophidæ } \\
\text { 12. Vespertilionidæ } \\
\text { 13. Noctilionidæ... }\end{array}$ & $\begin{array}{l}- \\
- \\
-\end{array}$ & $\begin{array}{l}- \\
- \\
-\end{array}$ & $\begin{array}{l}- \\
- \\
-\end{array}$ & $\begin{array}{l}- \\
- \\
-\end{array}$ & $\begin{array}{l}\text { Oriental, Australian } \\
\text { The Eastern Hemisphere } \\
\text { Cosmopolite } \\
\text { All Tropical regions }\end{array}$ \\
\hline $\begin{array}{l}\text { INsectivora. } \\
\text { 15. Macroscelididæ } \\
\text { 17. Erinnceidæe ... } \\
\text { 18. Centetida } \\
\text { 19. Potcmogalide } \\
\text { 20. Chrysochlorida } \\
\text { 22. Sulicide... ... }\end{array}$ & - & - & 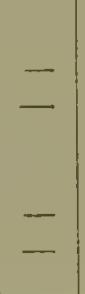 & - & $\begin{array}{l}\text { South Palæarctic } \\
\text { Palæarctic, Oriental } \\
\text { Greater Antilles } \\
\text { All regions but Australian and Neotropical }\end{array}$ \\
\hline 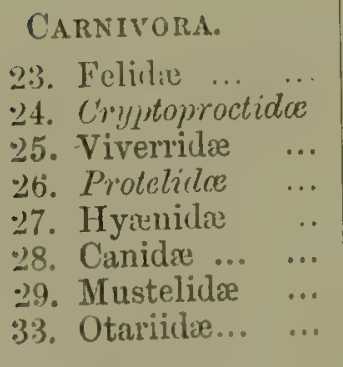 & $\begin{array}{l}- \\
- \\
-\end{array}$ & $\begin{array}{l}- \\
- \\
-\end{array}$ & $\begin{array}{l}- \\
- \\
- \\
- \\
-\end{array}$ & - & $\begin{array}{l}\text { All regions but Australian } \\
\text { Oriental, S. Palaarctic } \\
\text { S. Palrearctic, India } \\
\text { Almost cosmopolite } \\
\text { All regions but Australian } \\
\text { All temperate regions }\end{array}$ \\
\hline $\begin{array}{l}\text { I'WTACEA. } \\
31 \text { to } 41 . \quad \ldots \quad \ldots\end{array}$ & & & & & Oceanic \\
\hline $\begin{array}{l}\text { Sirkinia. } \\
\text { t2. Manitidit: }\end{array}$ & - & - & & & Neotroplical, Oricutal, Australinn \\
\hline $\begin{array}{l}\text { livgutata. } \\
\text { 43. Equidic ... ... }\end{array}$ & - & - & - & & Palicaretic \\
\hline
\end{tabular}




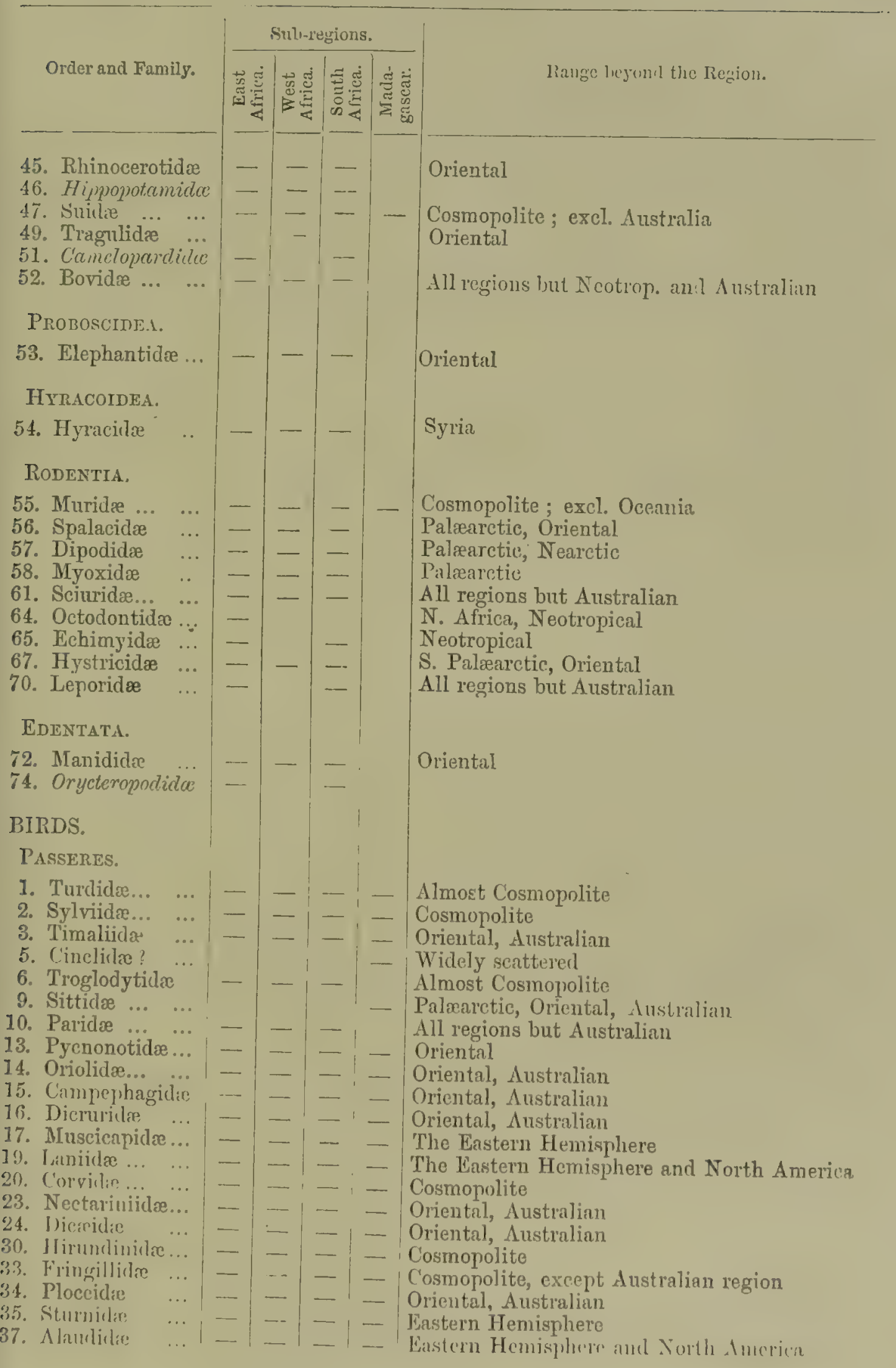




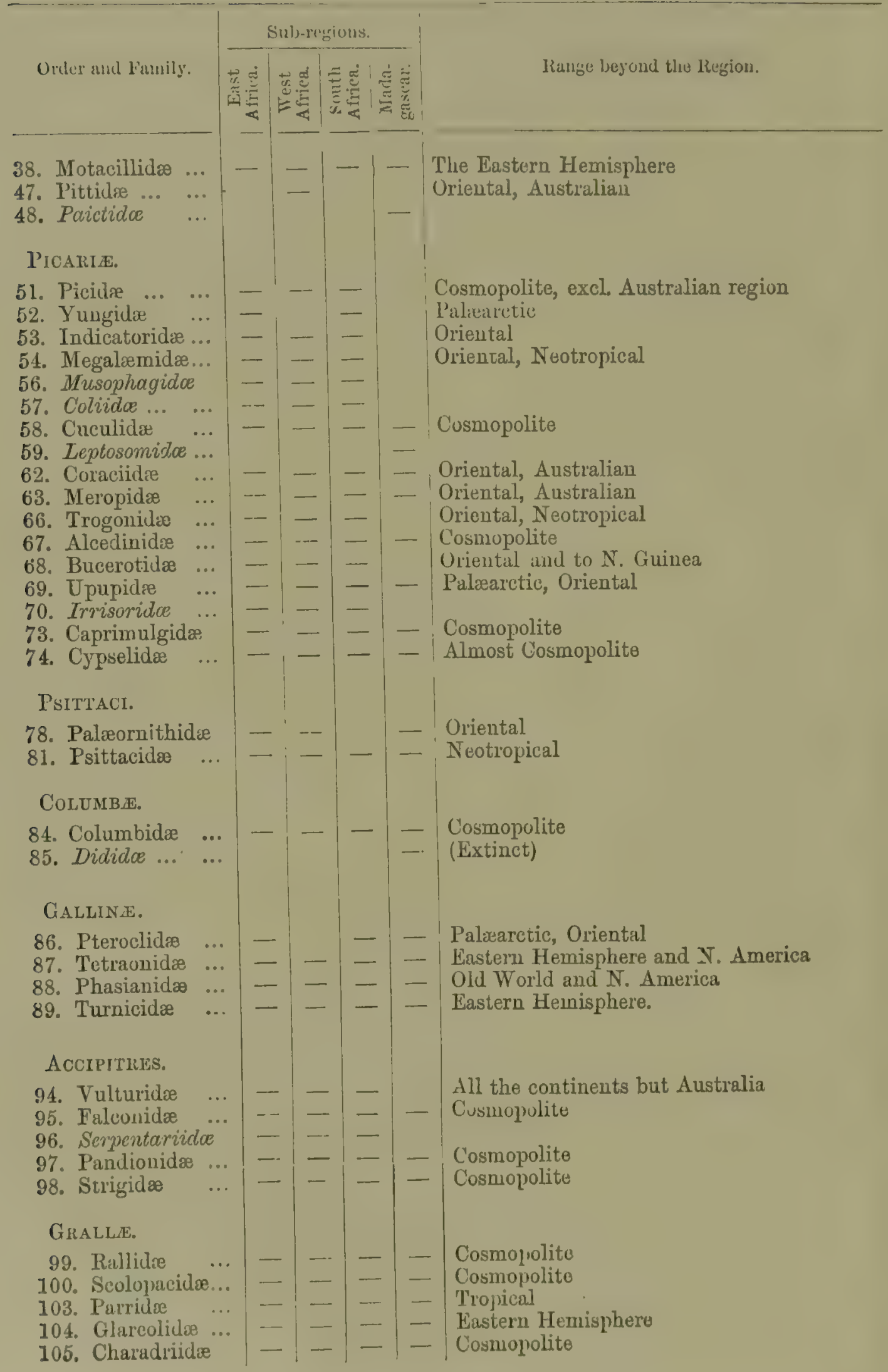




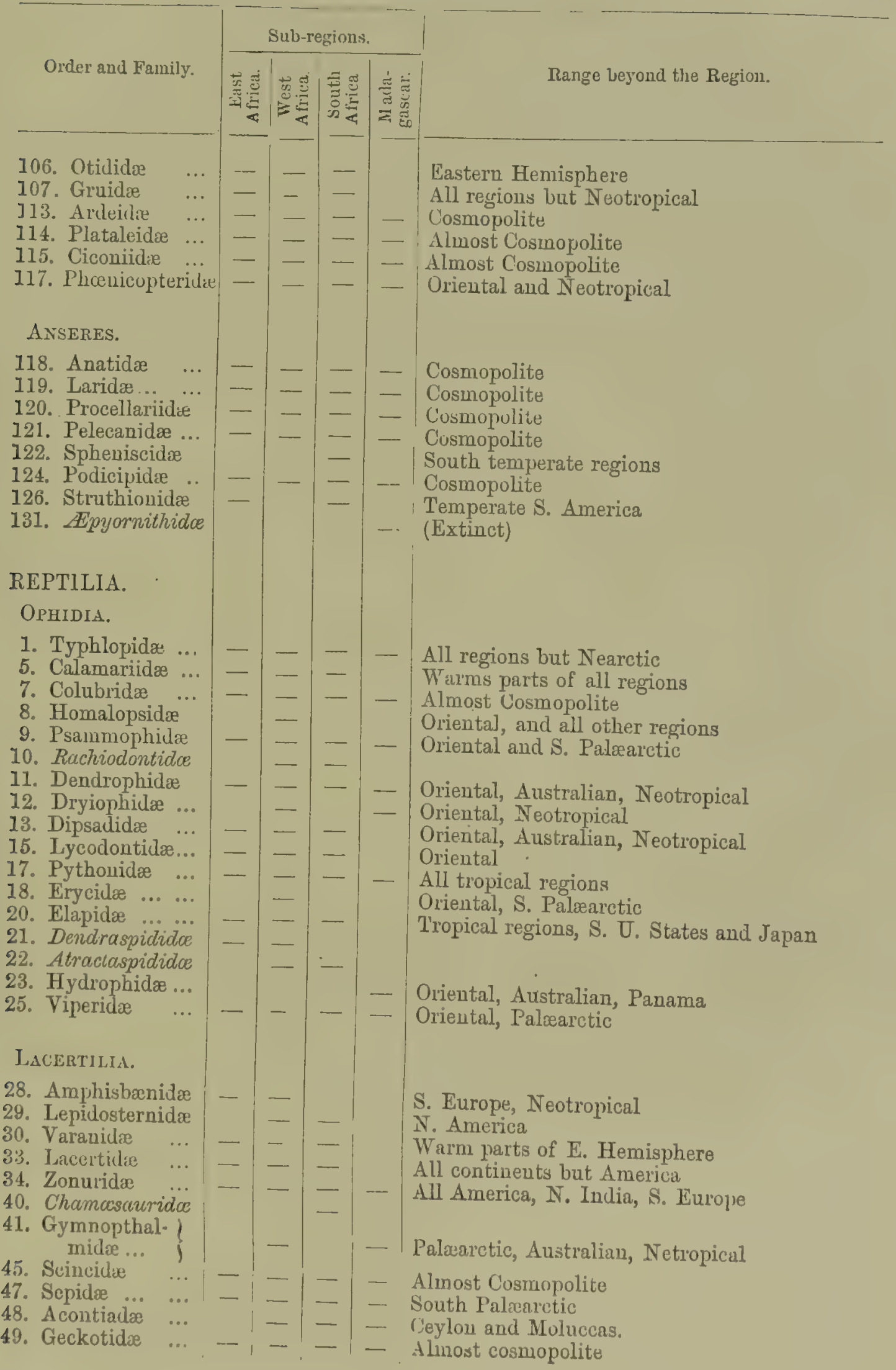




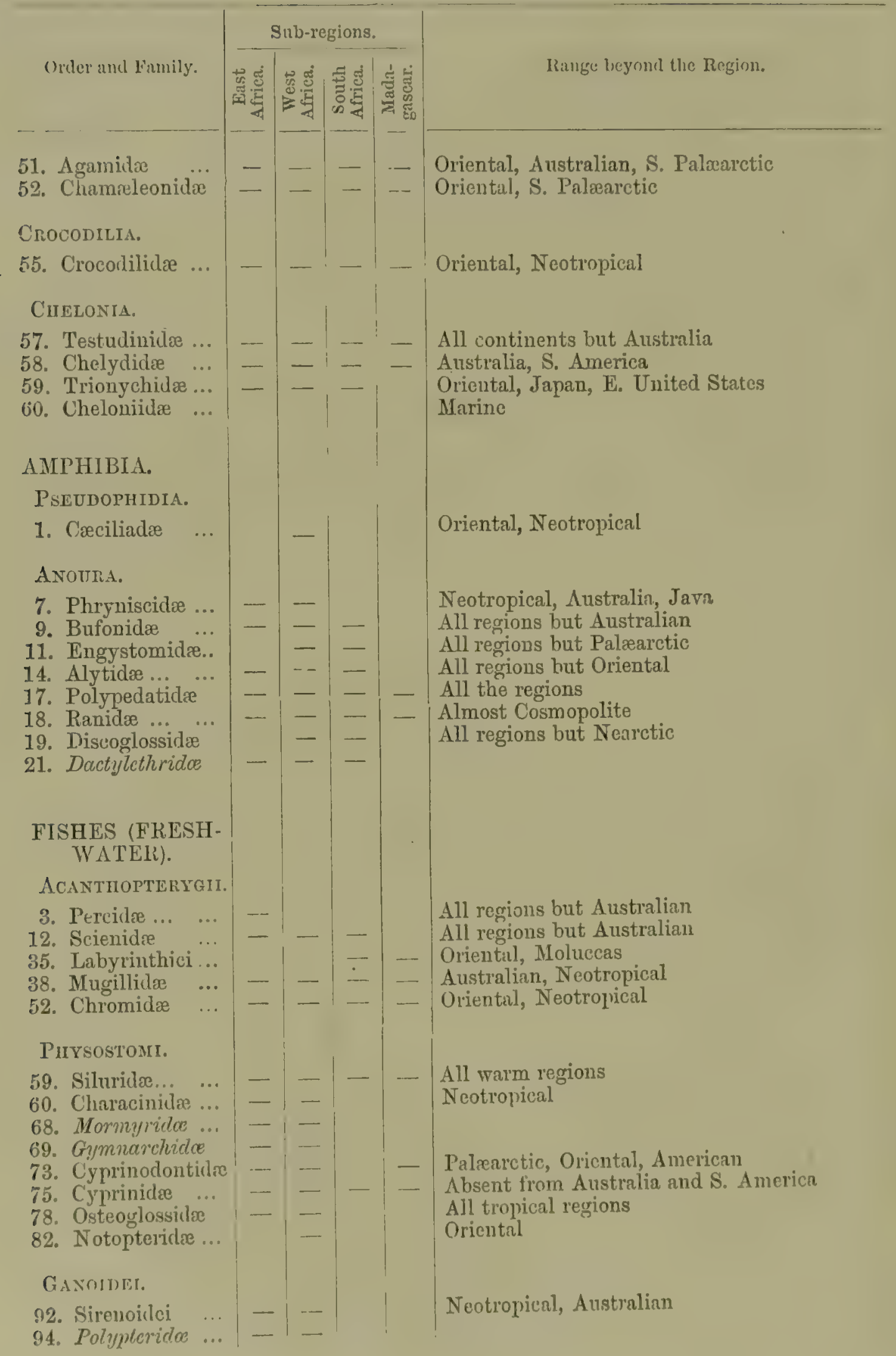




\begin{tabular}{|c|c|c|c|c|c|}
\hline \multirow[b]{2}{*}{ Order and Family. } & \multicolumn{4}{|c|}{ Sub-regions. } & \multirow[b]{2}{*}{ Range boyond the Recrirul. } \\
\hline & $\mid$ & 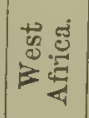 & 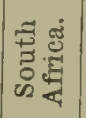 & 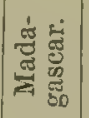 & \\
\hline $\begin{array}{l}\text { INSECTS, LEPI- } \\
\text { DOPTERA (PART). } \\
\text { DIURNI (BUTTER- } \\
\text { FLIES). }\end{array}$ & & & & & \\
\hline 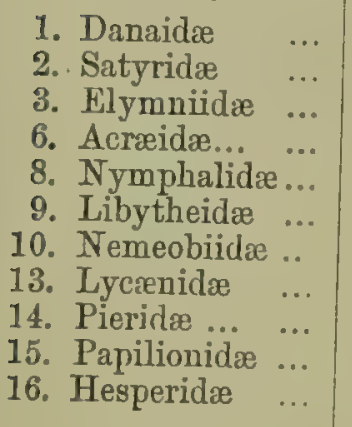 & $\begin{array}{l}- \\
- \\
-\end{array}$ & $\begin{array}{l}- \\
- \\
- \\
- \\
- \\
- \\
- \\
- \\
-\end{array}$ & $\begin{array}{l}- \\
- \\
-\end{array}$ & $\begin{array}{l}- \\
- \\
= \\
= \\
= \\
=\end{array}$ & $\begin{array}{l}\text { All warm countries and Canada } \\
\text { Cosmopolite } \\
\text { Oricntal, Moluccas } \\
\text { All tropical regions } \\
\text { Cosmopolite } \\
\text { Absent from Australia only" } \\
\text { Absent from Australia and Nearctic region } \\
\text { Cosmopolite } \\
\text { Cosmopolite } \\
\text { Cosmopolite } \\
\text { Cosmopolite }\end{array}$ \\
\hline $\begin{array}{l}\text { SPHINGIDEA. } \\
\text { 17. Zygænidæ } \\
\text { 19. Agaristidæ } \\
\text { 20. Uraniidæ } \\
\text { 22. Ageriidæ } \\
\text { 23. Sphingidæ } \\
\text { 2... }\end{array}$ & $\begin{array}{l}- \\
- \\
-\end{array}$ & $\begin{array}{l}- \\
- \\
-\end{array}$ & $\begin{array}{l}- \\
- \\
-\end{array}$ & $\begin{array}{l}E \\
\overline{-} \\
-\end{array}$ & $\begin{array}{l}\text { Cosmopolite } \\
\text { Australian, Oricntal } \\
\text { All tropical regions } \\
\text { Cosmopolite, excl. Austrulia } \\
\text { Cosmopolite }\end{array}$ \\
\hline
\end{tabular}


TALLE 11.

\section{LIST OF GENERA UF TERRESTRLAL MIA.YIIALIA AND BIRDS INHABITING 'T'HE E'THIOPIAN REGION.}

\section{EXPLANATION.}

Names in ikutics show genera peculiar to the region.

Names inclused thus (...) show genera which just enter the region, but are not cousidered properly to belong to it.

Genera which undoubtedly belong to the region are numbered consecutively.

IIA MIMALIA.

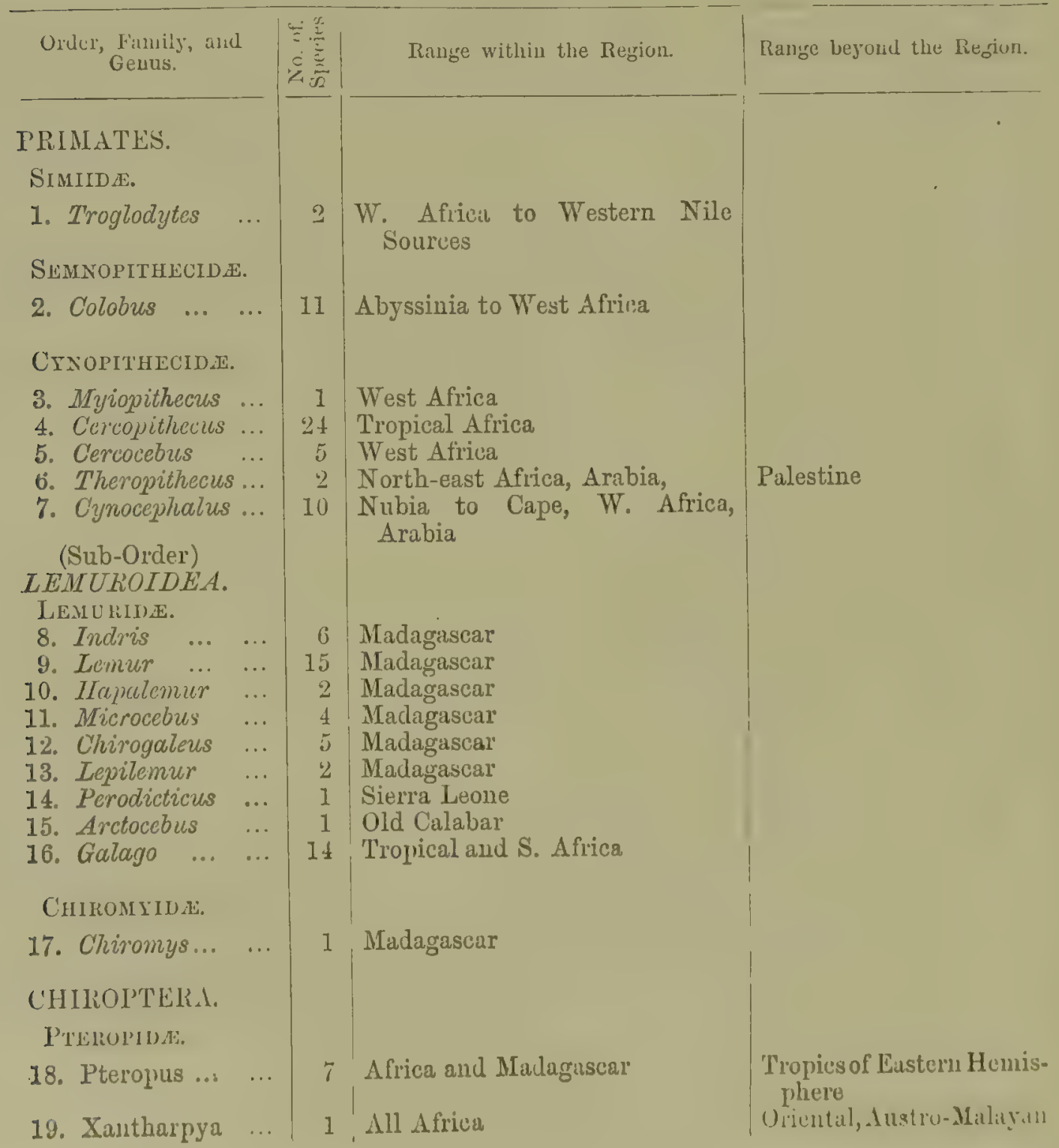




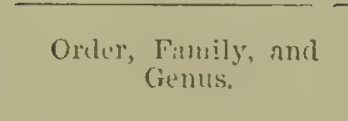

20. Cynopterus

21. Epomophores ...

22. Hy/psignathus ..

Rhtyolophine.

23. Rhinolophus

24. Macronycterys...

25. Phyllorhina ..

26. Asellia ... ...

27. Megaderma ...

28. Nycteris ... ...

TESPERTILIONIDAF.

29. Vespurtilio ...

30. Kerivoula

31. Minionteris

32. Nycticejus

33. Taphozous

Noctilinginds.

34. Nyetinomus

35. Molossus ...

INSECTIVORA.

MArTRSCELADIDE.

36. Mfacroscelides ...

37. Petrodromus ..

38. Rihynchocyon ...

Finivaceine.

39. Erinaceus... ...

CENTETHA.

10. Cientertes ... ...

41. Hemicentetes ...

42. Ericulus...

43. Oryzonictes

44. Erhinops...

Potamogatidat.

45. Polamograle

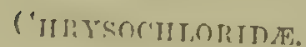

16. Chrysochloris

Sotistion.

47. Sinrex
Range within the Reyion.

Tropical Africa

Tropical Africa and Abyssinia

W. Africa

Africa and Marlagansear

WV. Afriea

Tropical Africa

Nubia

Senegnl, Trper Nile

All Africa

Africa and Madagascar

S. Afriea

S. Africa

7 Tropical Africa

2 Africa and Madagascar

1 Malagascar

3 Africa, Bombon

2 Sonth and Fast Africa

1 Mozamilique

1 Mozambique

2 Cen. anil South Africa

2. Mallasassar"and Mamritius

2 Madlagasear

2. Madagascar

Mudacisear

:Madagascar

1 Old calahar

:3 Cape to Morambique

('ape to Monambique

15 A!l Africa amk Mndacrascar
Range heyond the Regrion.

Oriental

Warmer parts of Eastern Hemisphere

Indo-Malaya, AustroMalaya

Indo-Malaya, Austro-

Malaya

(Jiental, Moluceas

lava

C'osmopolite

Oriental

Indo-Malaya

India

Oriental, Austro-Malayan, Neotropical

Oriental, American, S. Palæarctic

Neotropical, S. Palæarctic

N. Africa.

Pularetic, N. Inclia

Pulanre, Neare, Ori 


\begin{tabular}{|c|c|c|c|}
\hline $\begin{array}{l}\text { Order, Family, and } \\
\text { Genus. }\end{array}$ & 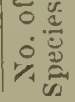 & Range within the Region. & Range beyond the Region. \\
\hline 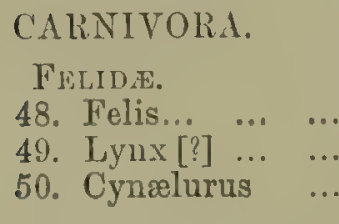 & $\begin{array}{l}8 \\
1 \\
1\end{array}$ & $\begin{array}{l}\text { All Africa } \\
\text { N. and S. Africa } \\
\text { Cape of Good Hope }\end{array}$ & $\begin{array}{l}\text { All reg. but Australian } \\
\text { Palæarctic and Nearcti } \\
\text { Persia, India }\end{array}$ \\
\hline $\begin{array}{l}\text { CRYPTOPROCTIDA. } \\
\text { 51. Cryptoprocta }\end{array}$ & 1 & Madagascar & \\
\hline 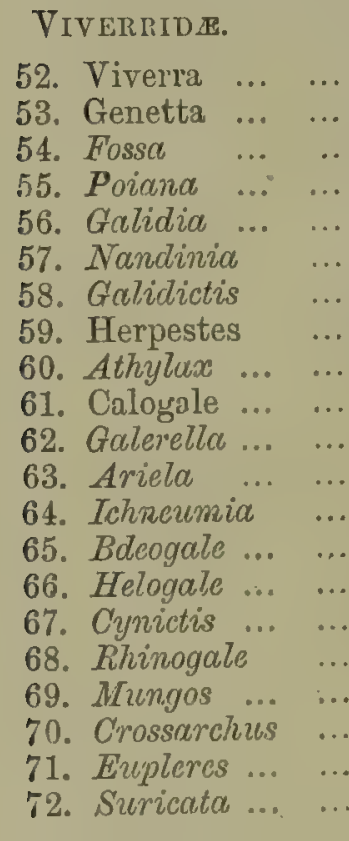 & \begin{tabular}{r|}
1 \\
4 \\
2 \\
1 \\
3 \\
1 \\
2 \\
13 \\
3 \\
9 \\
1 \\
1 \\
4 \\
3 \\
2 \\
3 \\
1 \\
3 \\
1 \\
1 \\
1
\end{tabular} & $\begin{array}{l}\text { Tropical Africa } \\
\text { Tropical and S. Africa } \\
\text { Madagascar } \\
\text { W. Africa } \\
\text { Madagascar } \\
\text { W. Africa } \\
\text { Madagascar } \\
\text { All dfrica } \\
\text { S. and E. Africa (?) Madagascar } \\
\text { Tropical and S. Africa } \\
\text { E. Africa } \\
\text { S. Africa } \\
\text { E. Africa, Senegal, S. Africa } \\
\text { Tropical Africa } \\
\text { E. and S. Africa } \\
\text { S. Africa } \\
\text { E. Africa } \\
\text { Tropical and S. Africa } \\
\text { Tropical Africa } \\
\text { Madngiscar } \\
\text { S. Africa }\end{array}$ & $\begin{array}{l}\text { S. Europe, Oriental } \\
\text { Oriental }\end{array}$ \\
\hline $\begin{array}{l}\text { Protrilid } . \\
\text { 73. Proteles }\end{array}$ & 1 & S. Africa & \\
\hline 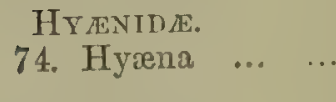 & 3 & All Africa & S. Palæartic, India \\
\hline 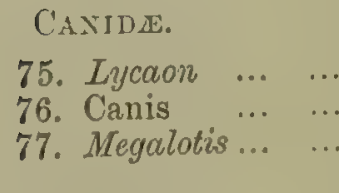 & $\begin{array}{l}1 \\
5 \\
1\end{array}$ & $\begin{array}{l}\text { S., Central, and E. Africa } \\
\text { All Africa } \\
\text { S. Africa }\end{array}$ & Almost Cosmopolitan \\
\hline 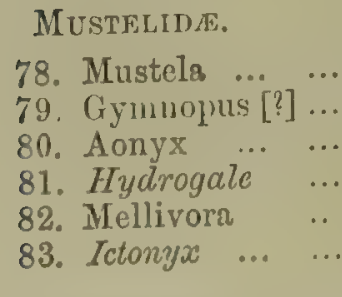 & $\begin{array}{l}1 \\
1 \\
1 \\
1 \\
2 \\
2\end{array}$ & $\begin{array}{l}\text { Angola } \\
\text { S. Africa } \\
\text { S. and W. Africa } \\
\text { S. Africa } \\
\text { South and Tropical Africa. } \\
\text { Tropical and S. Africa }\end{array}$ & $\begin{array}{l}\text { Palæarctic, Nearctic } \\
\text { Oriental } \\
\text { Oriental } \\
\text { India }\end{array}$ \\
\hline $\begin{array}{l}\text { OTanitis. } \\
\text { 84. Arctocephalus }\end{array}$ & 1 & Cape of Good Hope & South Temperate Zone \\
\hline
\end{tabular}




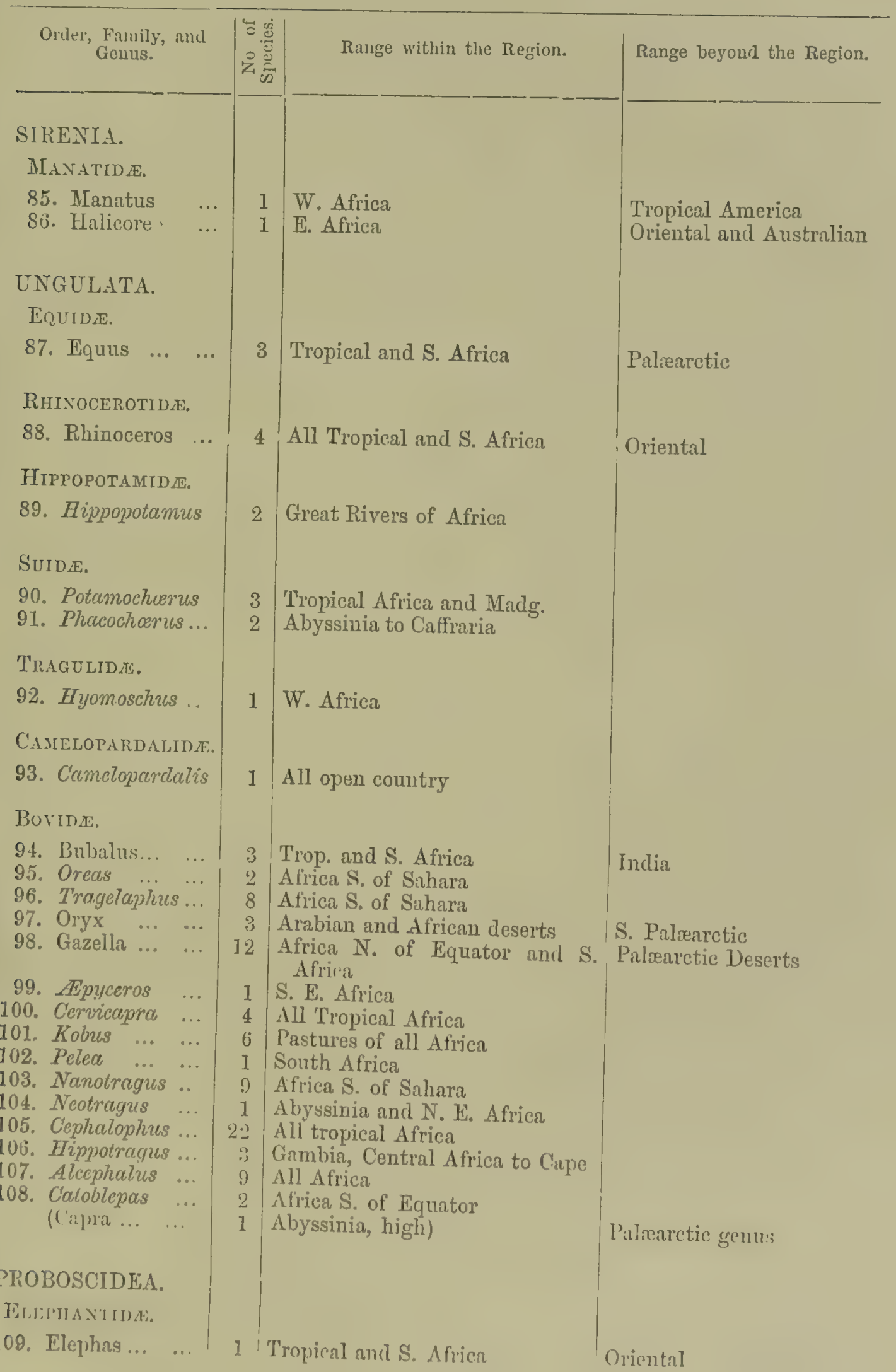




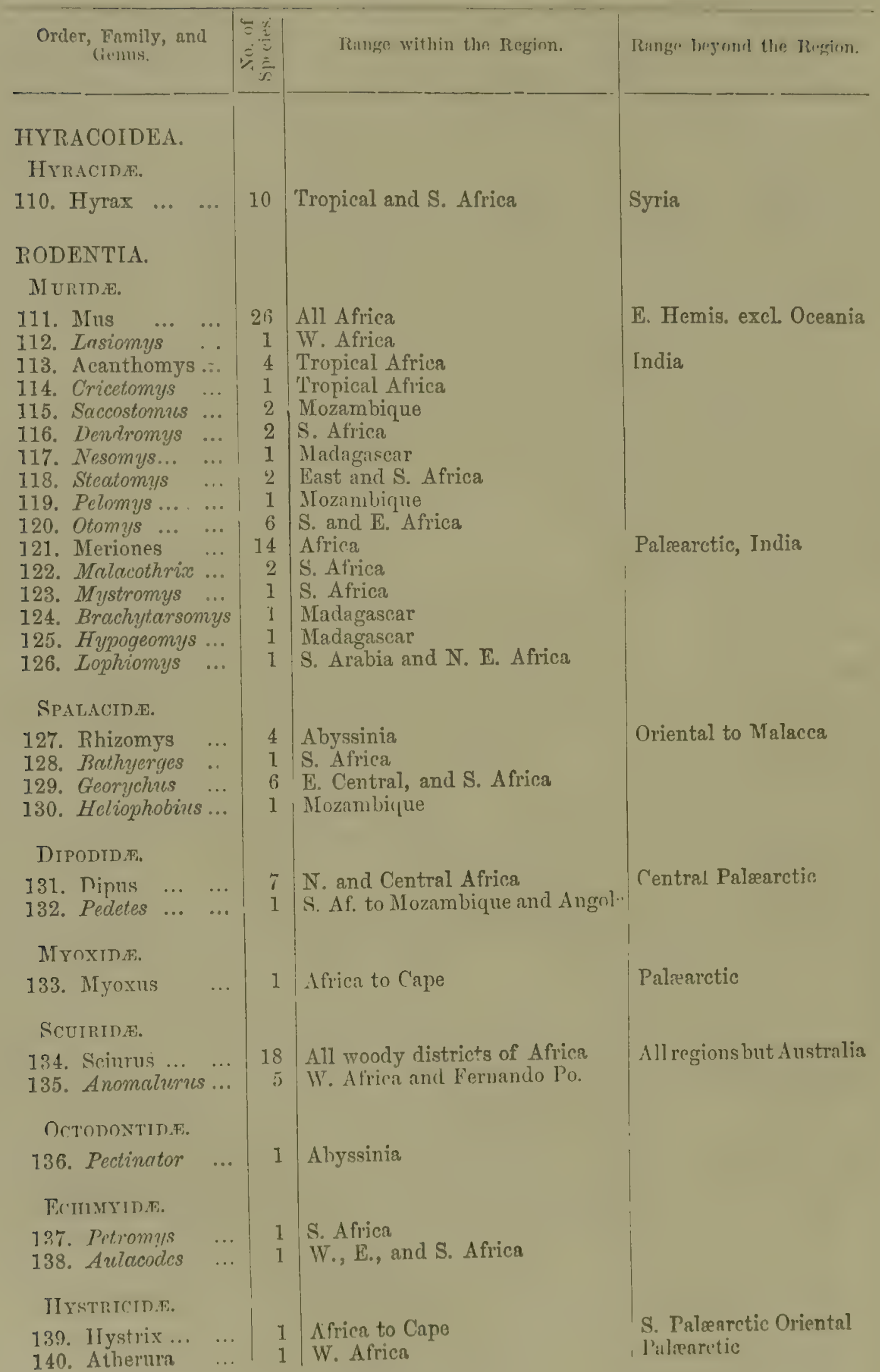




\begin{tabular}{|c|c|c|c|}
\hline $\begin{array}{l}\text { Order, Family, and } \\
\text { Genus. }\end{array}$ & 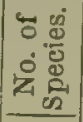 & Range within the Region. & Range beyond the Region. \\
\hline $\begin{array}{l}\text { LEPORIDE. } \\
\text { 141. Lepus ... ... } \\
\text { EDENTATA. } \\
\text { MANIDIDE. }\end{array}$ & 5 & East and South Africa & Allregions but Australian \\
\hline $\begin{array}{l}\text { 142. Manis ... ... } \\
\text { ORYCTEROPODIDE. } \\
\text { 143. Orycteropus ... }\end{array}$ & 4 & $\begin{array}{l}\text { Sennaar to W. Africa and Cape } \\
\text { N. E. Africa to Nile Sources, and } \\
\text { S. Africa }\end{array}$ & Oriental \\
\hline
\end{tabular}

BIRDS.

\section{PASSERES。}

TURDIDE.

1. Turdu

2. Monticol

3. Choetops ... …

4. Bessonornis $\ldots$

SYLVIID

5. (Drymeca... ...

6. Cisticola .... ...

7. Sphenceacus

8. Camaroptera ...

9. (Acrocephalus ...

10. Bradyptetus ...

11. Catriscus ... ...

12. Bernicria... ...

13. Eltisia $\ldots$... $^{2}$

14. Mystacornis ...

15. Phylloscopus ...

16. Eremomela ...

17. Eroessa

18. Hypolais ... $\ldots$

19. Aerion ... ...

20. Sylvia $\ldots . .$.

21. Curruca ... ...

22. $\{$ Ruticilla ... $\ldots$

23. Cyrnecula $\ldots$

24. (Copsychus

25. Thamnobia

26. Cercotrichas

27. Pcooptera. .

28. Gervasia

29. Dromolin ... ...

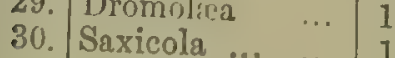

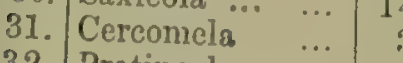

32. Pratincola
13

S. Africa

S. Africa

5 The whole region

70 The whole region

13 The whole region

S. Africa

Ifrica

8 The whole region

8 Abyssinia and S. Africa

All Africa

Madagascar

Marlagasear

Madagascar

S. Africa

All Africa

Marlagascar

S. Africa

E. and S. Africa N. E. Africa, Gambia, Cape
Verd Ids.

2 S. Africa

Abyssinia and Senegal

N E. Africa

Madagnscar and Seychelle Ids.

All Airica

W. and $N$

W. Africa

Madagascar and Seychelle Ids.

All Africa

Central, E. and S. A frica

N. E. Africa

7 Africa and Madngascar
Almost Cosmopnlite

Palæarctic and Oriental

Palestine

Palestine

Palæarc, , Oricn., Austral. Australian

Palæarc, Orien., A ustral.

S. Lurope, Palestine

Palæarctic, Oriental

Palæarctic, Oriental

Palrarctic

Palæurctic, Orientrl

Palæarctic

Palæarctic, Oriental

Palæarctic

Oriental

Oriental

S. Palæretic, India

Palæarctic, India

Palestine, N. W. India

Palrarctic, Oriental 


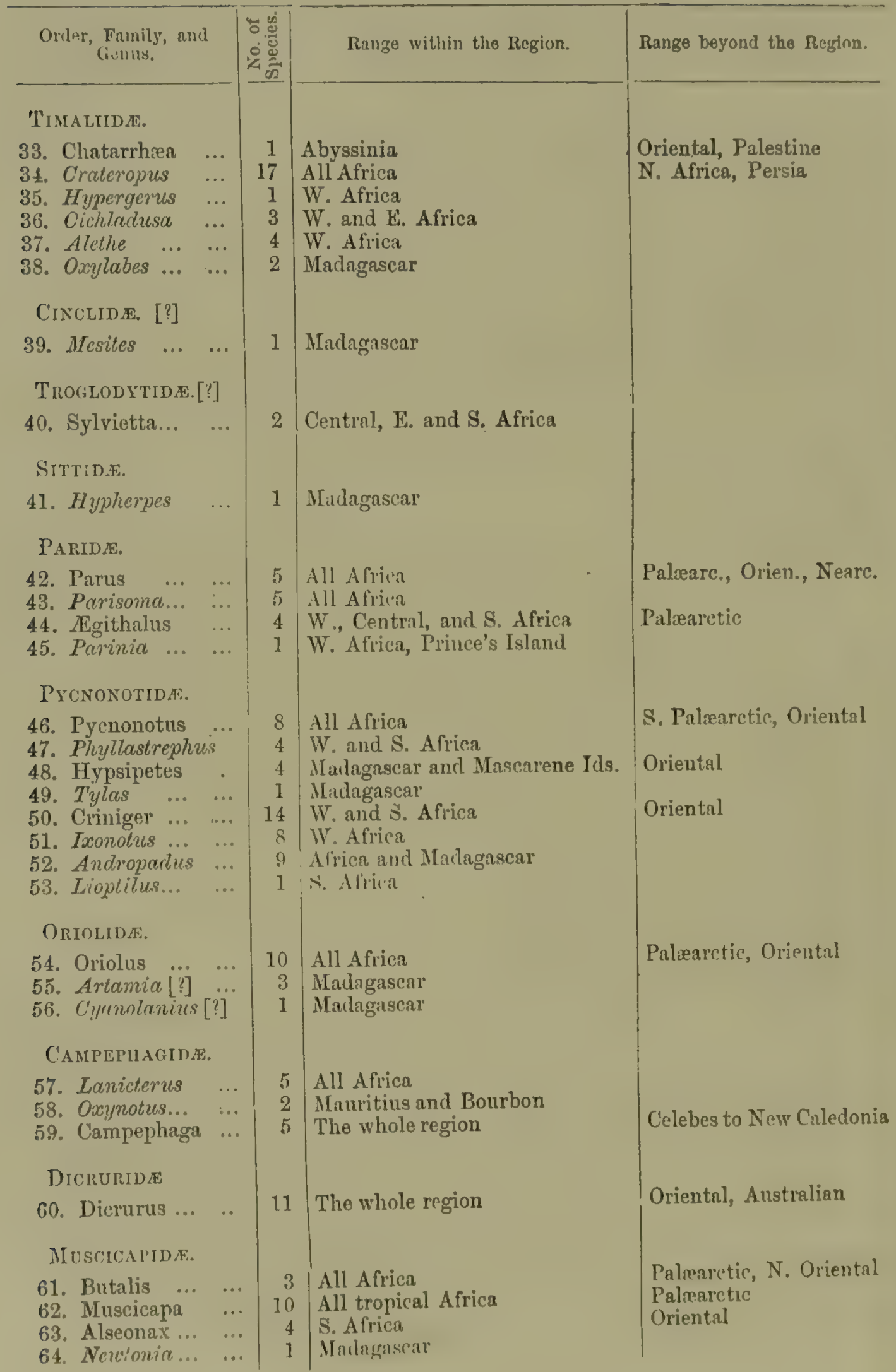




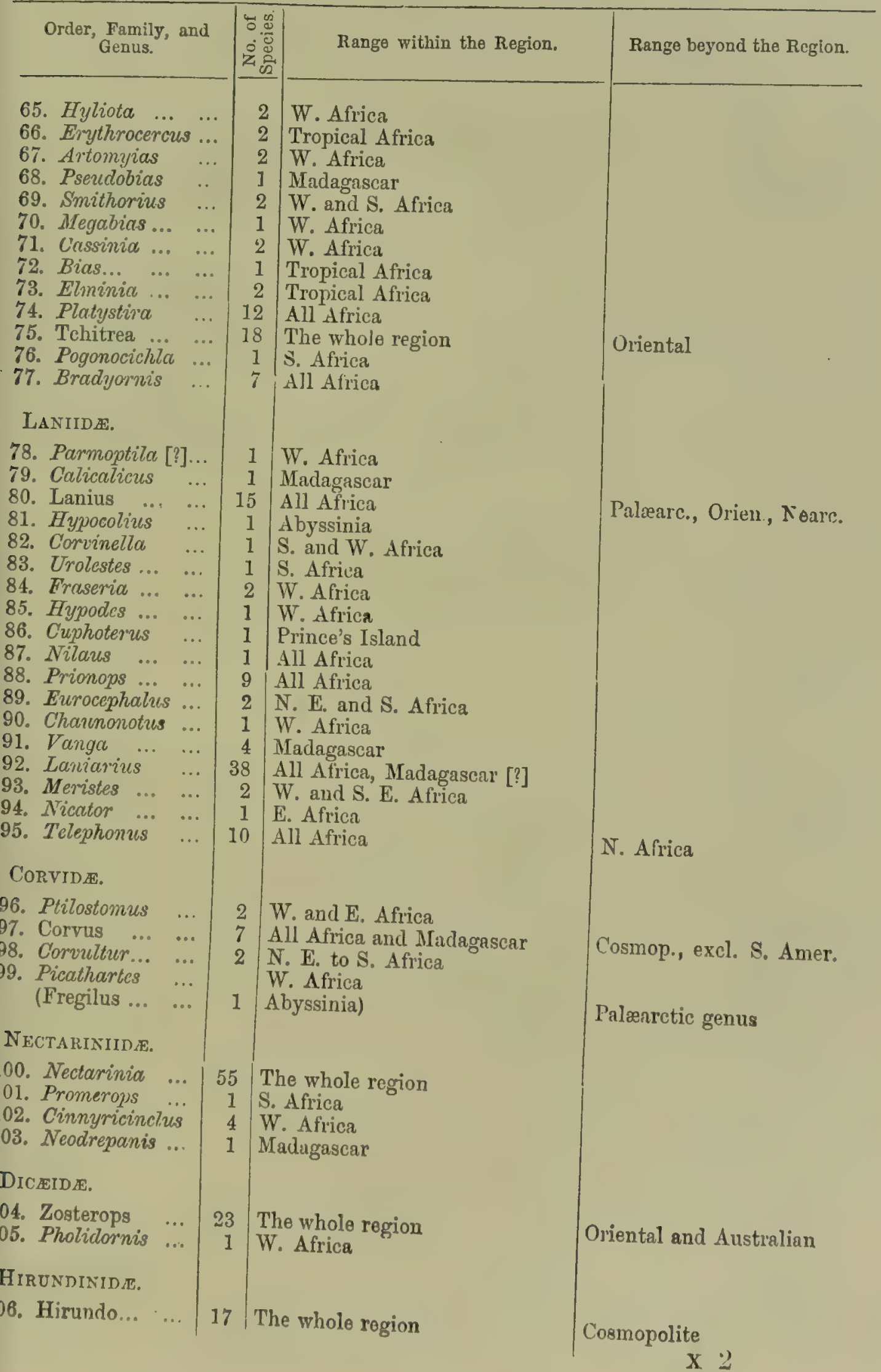




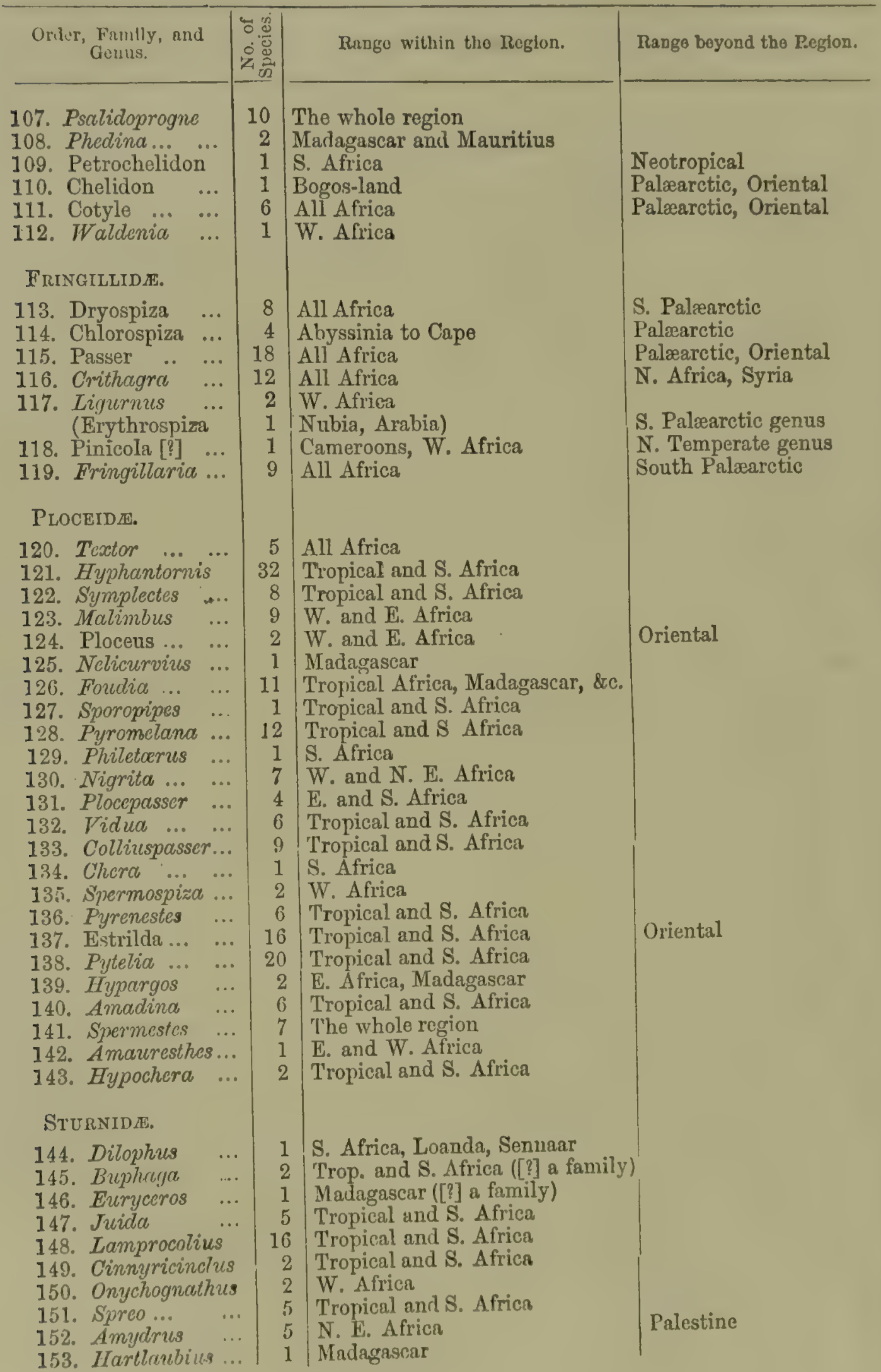




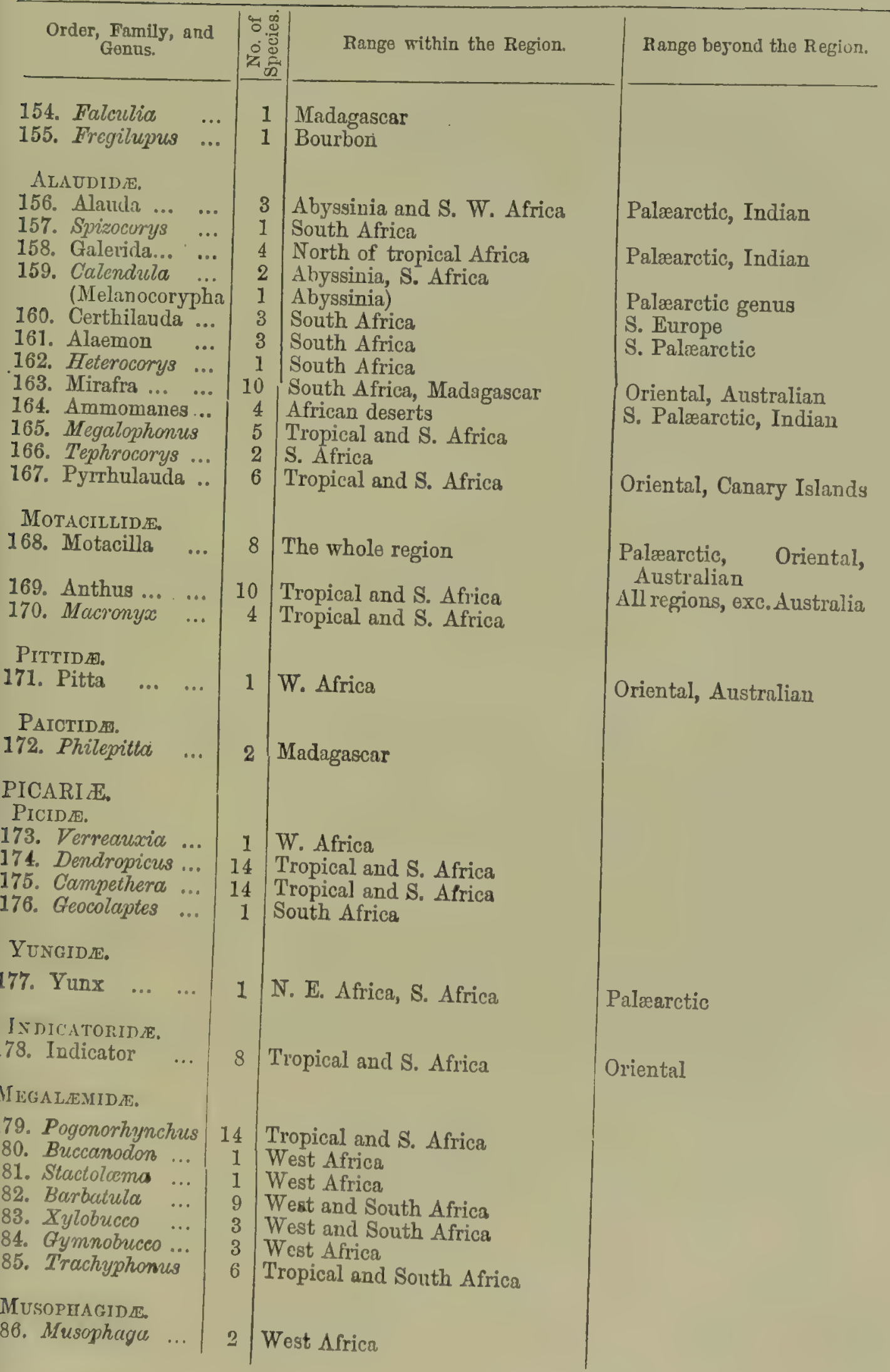




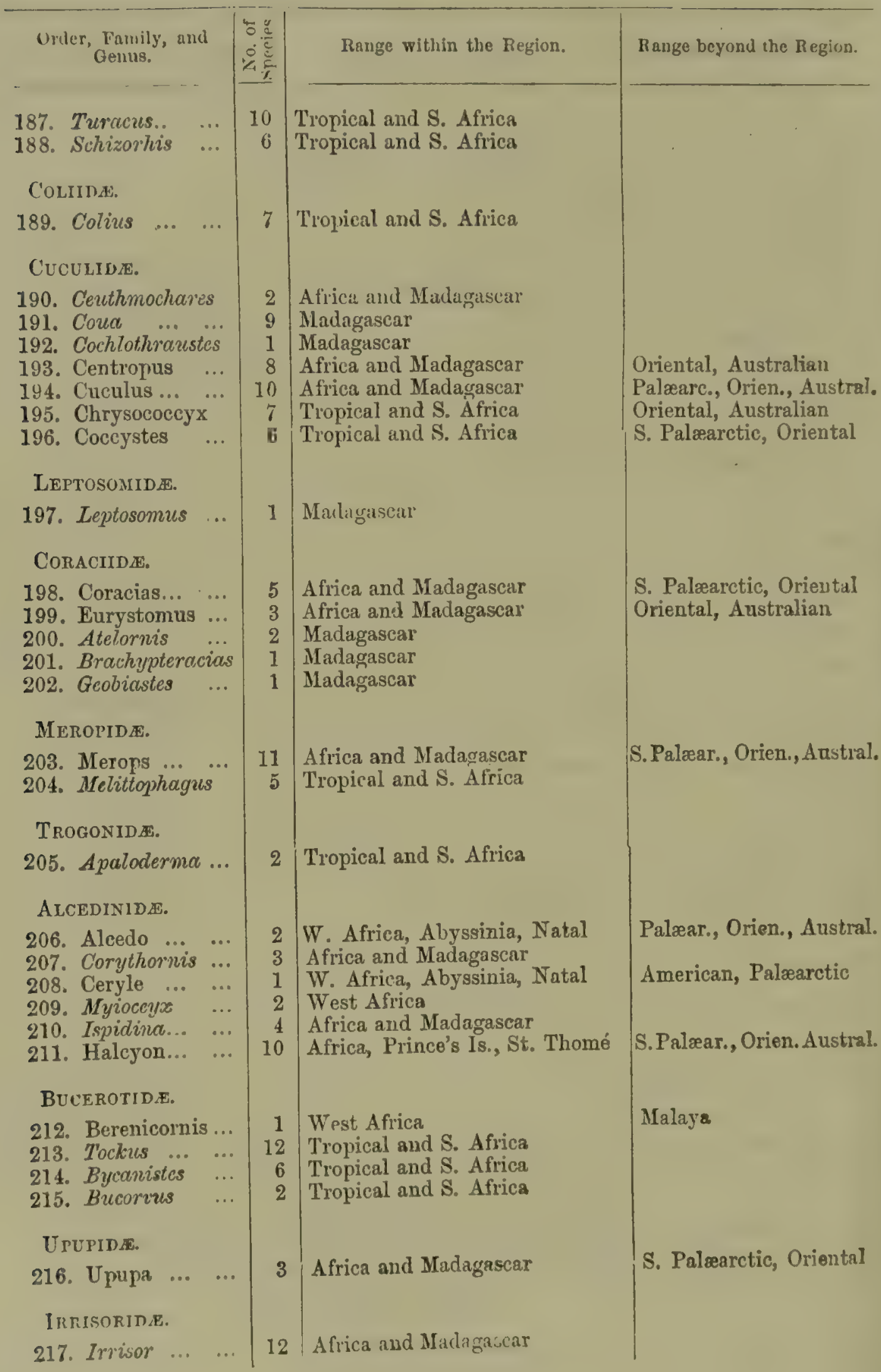




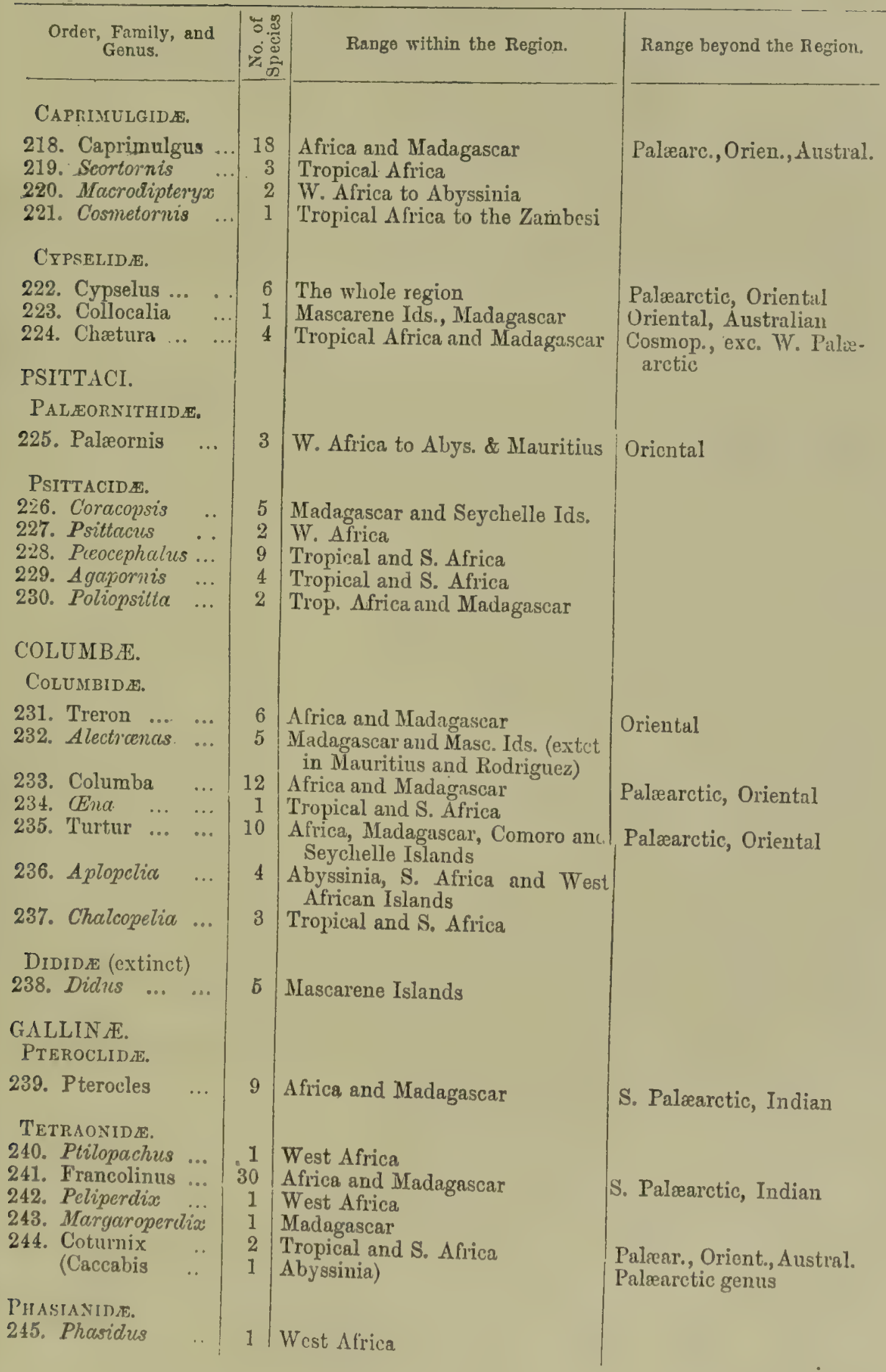




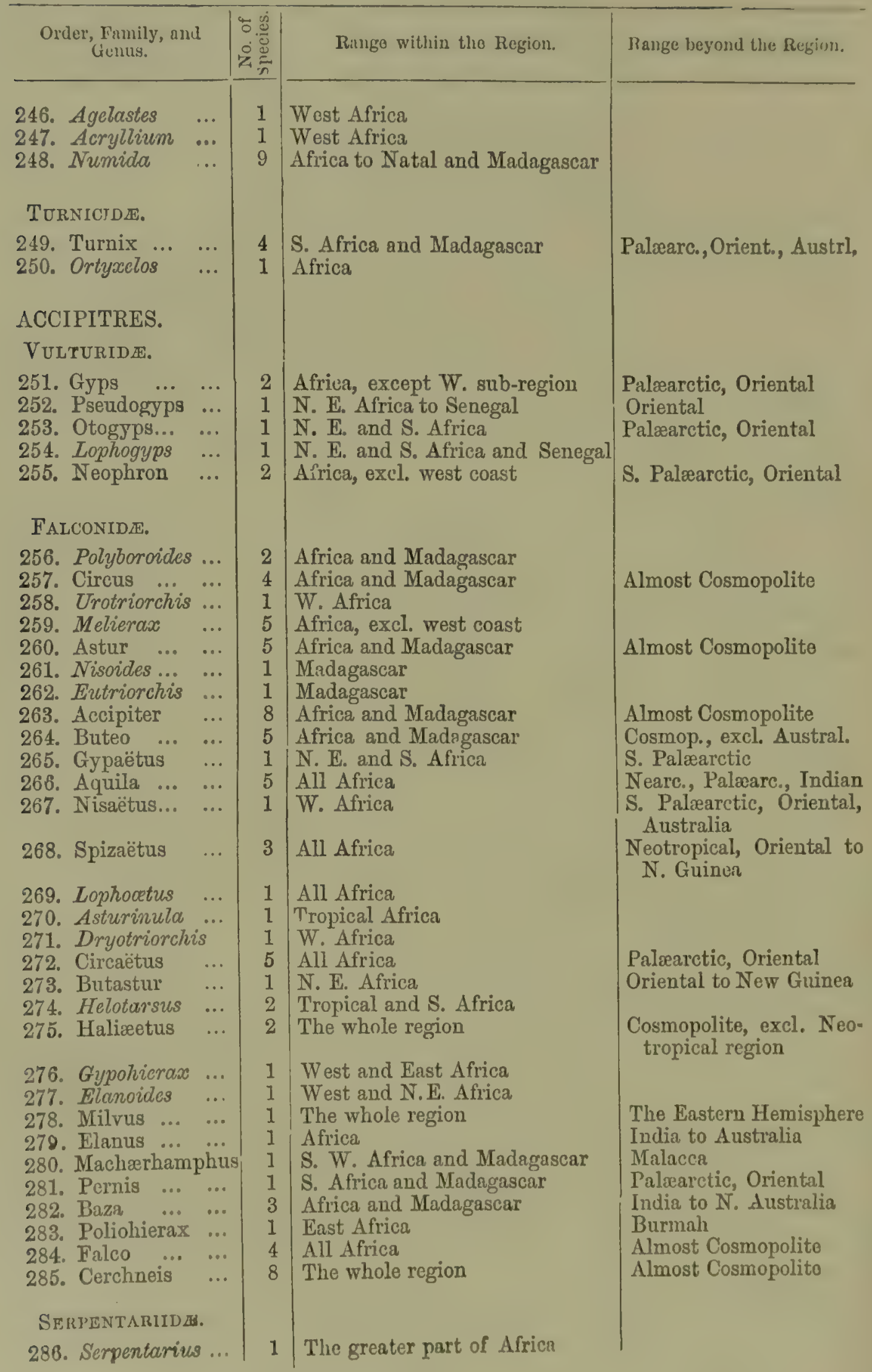




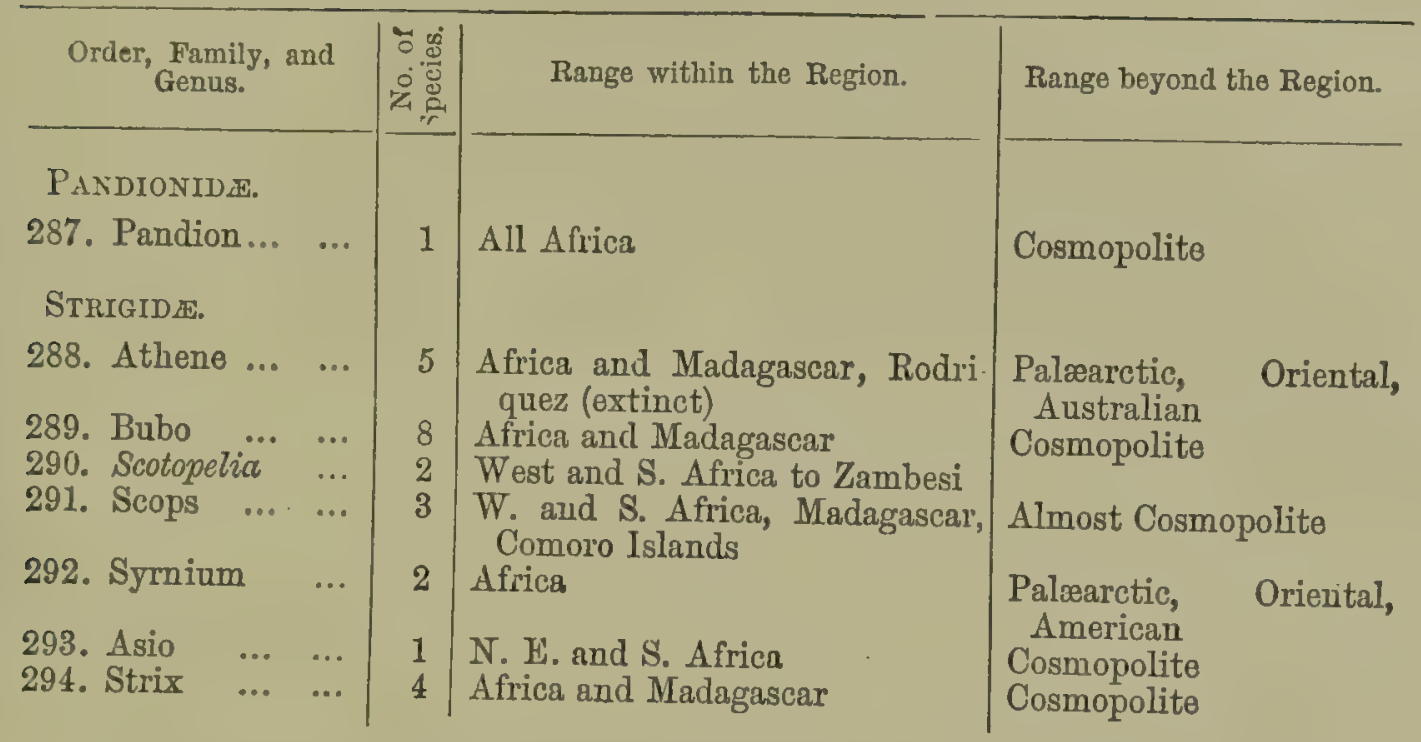

Peculiar or very Characteristic Genera of Wading or Swimming Birds.

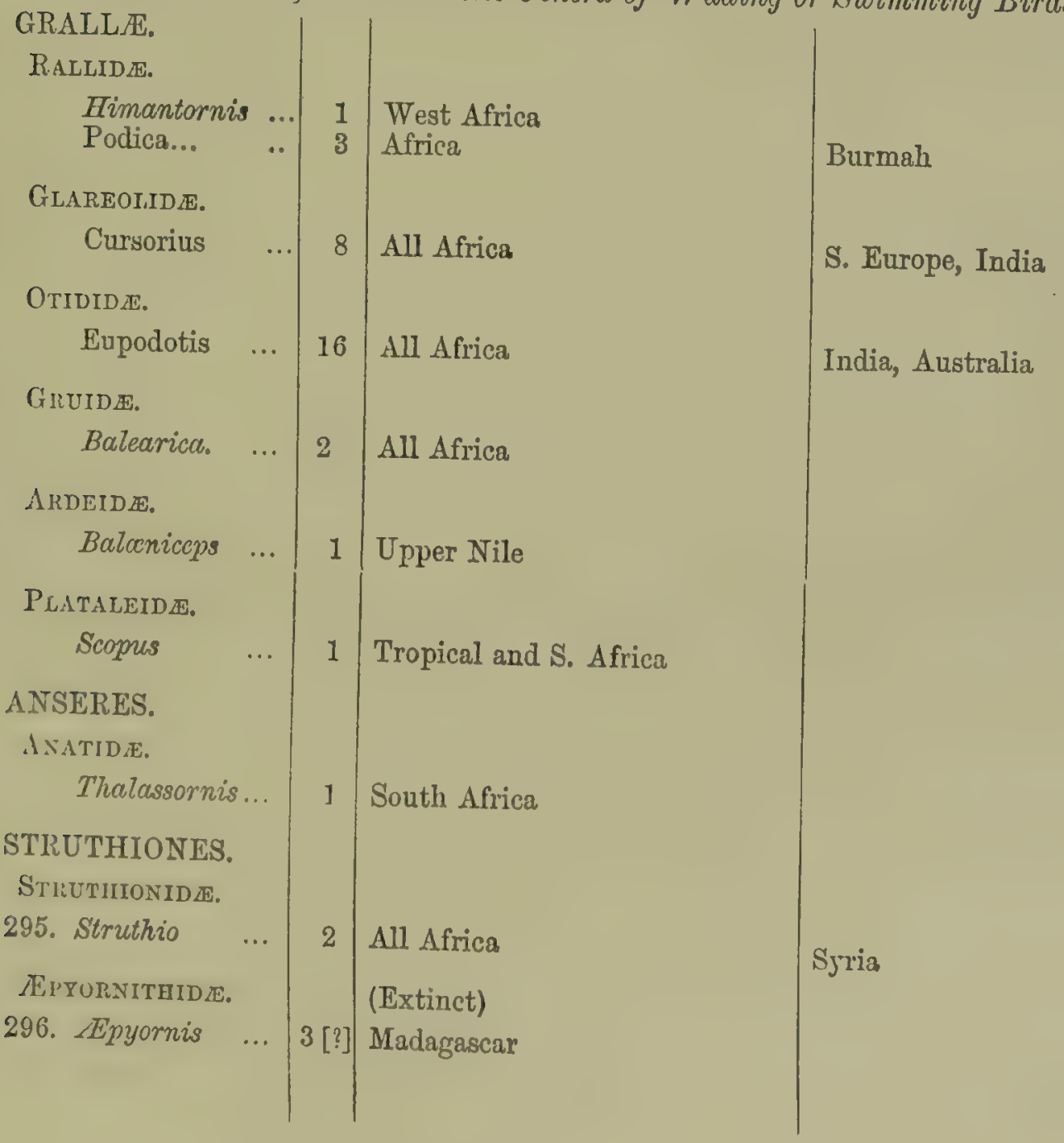




\section{CHAPTER XII.}

THE ORIENTAL REGION.

THIS region is of comparatively small extent, but it has a very diversified surface, and is proportionately very rich. The deserts on the north-west of India are the debatable land that separates it from the Palæarctic and Ethiopian regions. The great triangular plateau which forms the peninsula of India is the poorest portion of the region, owing in part to its arid climate and in part to its isolated position; for there can be little doult that in the later Tertiary period it was an island, separated by an arm of the sea (now forming the valleys of the Ganges and Indus) from the luxuriant Himalayan and Burmese countries. Its southern extremity, with Ceylon, has a moister climate and more luxuriant vegetation, and exhibits indications of a former extension southwards, with a richer and more peculiar fauna, partly Malayan and partly Mascarene in its character. The whole southern slopes of the Himalayas, with Burmah, Siam and Western China, as well as the Malay peninsula and the IndoMalay islands, are almost everywhere covered with tropical forests of the most luxuriant character, which abound in varied and peculiar forms of vegetable and animal life. The flora and fauna of this extensive district are essentially of one type throughout; yet it may be usefully divided into the IndoChinese and the Malayan sub-regions, as each possesses a number of peculiar or characteristic animals. The former subregion, besides having many tropical and sub-tropical types of its own, also possesses a large number of peculiarly modified tempurate forms on the mountain ranges of its northern 



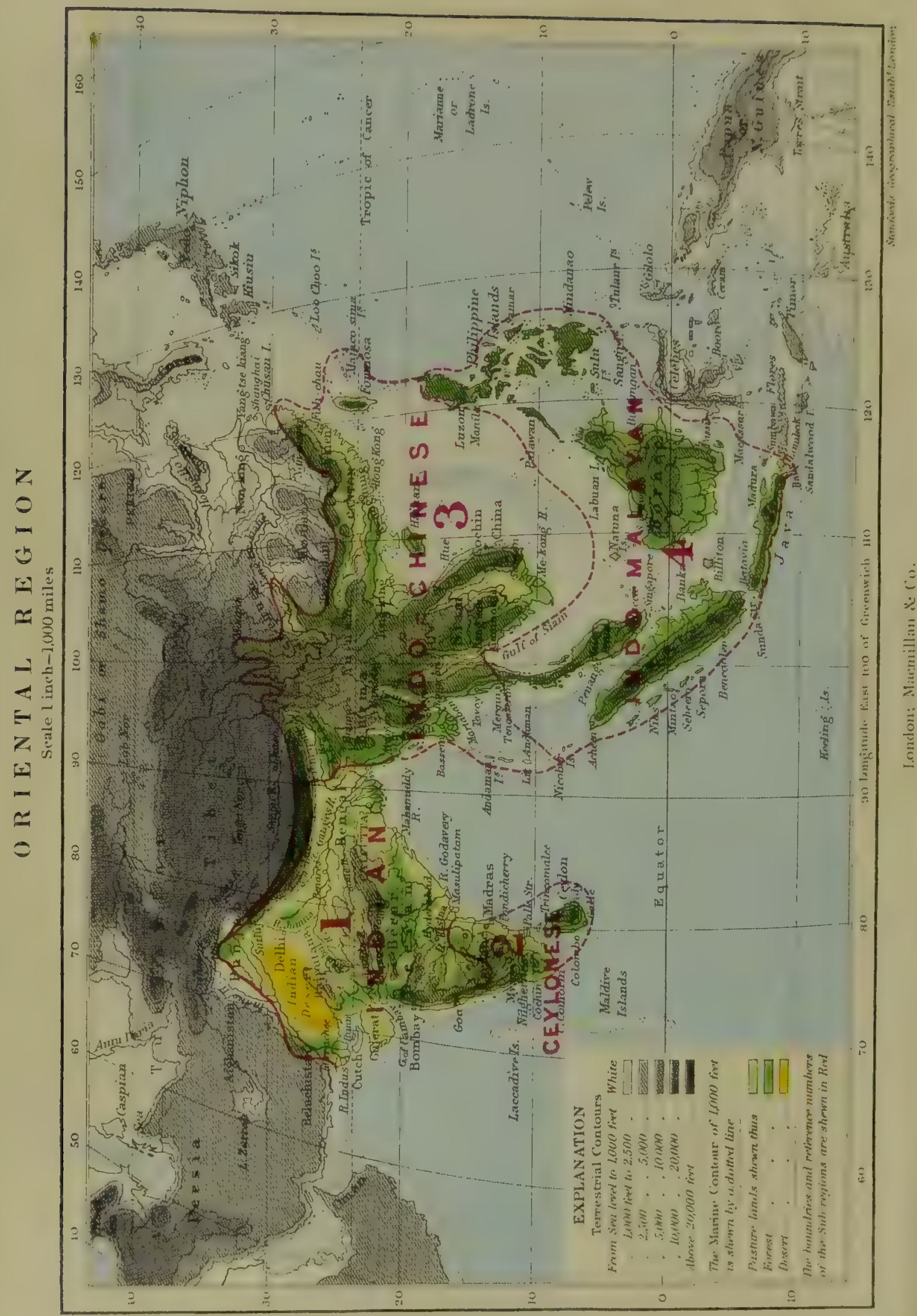


boundary, which are wholly wanting in the Malayan subregion. The Philippine islands are best classed with the IndoMalay group, although they are strikingly deficient in many Malayan types, and exhibit an approach to the Celebesian division of the Austro-Malay sub-region.

Zoological Characteristics of the Oriental Region.-The Oriental Region possesses examples of 35 families of Mammalia, 71 of Birds, 35 of Reptiles, 9 of Amphibia, and 13 of Fresh-water Fishes. Of these 163 families, 12 are peculiar to the region; namely, Tarsiidæ, Galeopithecidæ, and Tupaiidæ among Mammalia, while Eluridæ, though confined to the higher Himalayas, may perhaps with more justice be claimed by the Palæarctic region; Liotrichidæ, Phyllornithidæ, and Eurylæmidæ among birds; Xenopeltidæ (extending, however, to Celebes), Uropeltidæ, and Acrochordidæ among reptiles; Luciocephalidæ, Ophiocephalidæ and Mastacembelidæ among fresh-water fishes. A number of other families are abundant, and characteristic of the region; and it possesses many peculiar and characteristic genera, which must be referred to somewhat more in detail.

Mammalia.-The Oriental region is rich in quadrumana, and is especially remarkable for its orang-utans and long-armed apes (Simia, Hylobutes, and Siamanga); its abundance of monkeys of the genera Presbytes and Macacus; its extraordinary long-nosed monkey (Presbytes nasalis); its Lemuridæ (Nycticebus and Loris); and its curious genus Tarsius, forming a distinct family of lemurs. All these quadrumanous genera are confined to it, except Tarsius which extends as far as Celebes. It possesses more than 30 genera of bats, which are enumerated in the lists given at the end of this chapter. In Insectivora it is very rich, and possesses several remarkable forms, such as the flying lemur (Galeopithecus); the squirrel-like Tupaiidæ consisting of three genera; and the curious Gymnura allied to the hedgehogs. In Carnivora, it is especially rich in many forms of civets (Viverridæ), possessing 10 peculiar genera, among which Frionodon and Cynogale are remarkable; numerous Mustelidx, of which Gymnopus, Mydaus, Aonyx and Helictis are the most conspicuous; ALlurus, a curious animal, cat-like in appearance but 
more allied to the bears, forming a distinct family of Carnivora, and confined to the high forest-districts of the Eastern Himalayas and East Thibet; Melursus and Helarctos, peculiar forms of bears; Platanista, a dolphin peculiar to the Ganges and Indus. Among Ruminants it has the beautiful chevrotain, forming the genus Tragulus in the family Tragulidæ; with one peculiar genus and three peculiar sub-genera of true deer. The Antilopinæ and Caprinæ are few, confined to limited districts and not characteristic of the region; but there are everywhere wild cattle of the genera Bibos and Bubalus, which, with species of Rhinoceros and Elephas, form a prominent feature in the fauna. The Rodents are less developed than in the Ethiopian region, but several forms of squirrels everywhere abound, together with some species of porcupine; and the Edentata are represented by the scaly manis.

Birds. - The families and genera of birds which give a character to Oriental lands, are so numerous and varied, that we can here only notice the more prominent and more remarkable. The Timaliidæ, represented by the babblers (Garrulax, Pomatorhinus, Timalia, \&c.), are almost everywhere to be met with, and no less than 21 genera are peculiar to the region; the elegant fork-tailed Enicurus and rich blue Myiophonus, though comparatively scarce, are characteristic of the Malayan and IndoChinese faunas; the elegant little "hill-tits" (Liotrichidæ) abound in the same part of the region; the green bulbuls (Phyllornis) are found everywhere ; as are various forms of Pycnonotidæ, the black and crimson "minivets" (Pericrocotus), and the glossy "king-crows" (Dicrurus); Urocissa, Platylophus and Dendrocitta are some of the interesting and characteristic forms of the crow family; sun-birds (Netariniidx) of at least three genera are found throughout the region, as are the beautiful little Hower-peckers (Dicæidæ), and some peculiar forms of weaverbirds (Ploceus and Mrnia). Of the starling family, the most conspicuous are the glossy mynahs (Eulabcs). The swallowshrikes (Artamus) are very peculiar, as are the exquisitely coloured pittas (Pittidx), and the gaudy broad-bills (Eurylæmidæ). Leaving the true Passeres, we find woodpeckers, barbets, and cuckoos everywhere, often of peculiar and re- 
markable forms; among the bee-eaters we have the exquisite Nyctiornis with its pendent neck-plumes of blue or scarlet; brilliant kingfishers and strangely formed hornbills abound everywhere; while brown-backed trogons with red and orange breasts, though far less frequent, are equally a feature of the Ornithology. Next we have the frog-mouthed goatsuckers (Battrachostomus), and the whiskered swifts (Dendrochelidon), both wide-spread, remarkable, and characteristic groups of the Oriental region. Coming to the parrot tribe, we have only the long-tailed Palcoornis and the exquisite little Loriculus, as characteristic genera. We now come to the pigeons, among which the fruiteating genera Treron and Carpophaga are the most conspicuous. The gallinaceous birds offer us some grand forms, such as the peacocks (Pavo); the argus pheasants (Argusianus); the firebacked pheasants (Euplocamus); and the jungle-fowl (Gallus), all strikingly characteristic; and with these we may close our sketch, since the birds of prey and the two Orders comprising the waders and swimmers offer nothing sufficiently remarkable to be worthy of enumeration here.

Reptiles.-Only the more abundant and characteristic groups will here be noticed. In the serpent tribe, the Oligodontidx, a small family of ground-snakes; the Homalopsidæ, or freshwater snakes; the Dendrophidæ, or tree-snakes; the Dryiophidæ, or whip-snakes; the Dipsadidæ, or nocturnal tree-snakes; the Lycodontidæ or fanged ground-snakes; the Pythonidæ, or rocksnakes; the Elapidix, or venomous colubrine snakes (including the "cobras"); and the Crotalidæ, or pit-vipers, are all abundant and characteristic, ranging over nearly the whole region, and presenting a great variety of genera and species. Among lizards, the Varanidæ or water-lizards; the Scincidæ or " scinks;" the Geckotidæ, or geckoes; and the Agamidæ, or eastern iguanas; are the most universal and characteristic groups. Among crocodiles the genus Crocodilus is widely spread, Gavialis being characteristic of the Ganges. Among Chelonia, or shiclded reptiles, forms of fresh-water Testudinidæ and Trionychidæ (soft tortoises) are tolerably abundant.

Amphitia.-The only abundant and charncteristic groups of 
this class are toads of the family Engystomidæ; tree-frogs of the family Polypedatidx; and several genera of true frogs, Ranidæ.

Fresh-water Fishes.-The more remarkable and characteristic fishes inhabiting the fresh waters of the Oriental region belong to the following families: Nandidæ, Labyrinthici, Ophiocephalidæ, Siluridæ, and Cyprinidæ; the last being specially abundant.

The sketch here very briefly given, must be supplemented by an examination of the tables of distribution of the genera of all the Mammalia and Birds inhabiting the region. We will now briefly summarize the results.

Summary of the Oriental Vertebrata.-The Oriental region possesses examples of 163 families of Vertebrata of which 12 are peculiar, a proportion of a little more than one-fourteenth of the whole.

Out of 118 genera of Mammalia 54 seem to be peculiar to the region, equal to a proportion of $\frac{9}{20}$ or a little less than half. Of Land-Birds there are 342 genera of which 165 are peculiar, bringing the proportion very close to a half.

In the Ethiopian region the proportion of peculiar forms both of Mammalia and Birds is greater; a fact which is not surprising when we consider the long continued isolation of the latter region-an isolation which is even now very complete, owing to the vast extent of deserts intervening between it and the Palæarctic region; while the Oriental and Palæarctic were, during much of the Tertiary epoch, hardly separable.

\section{Insects.}

Lepidoptera.-We can only glance hastily at the more prominent features of the wonderfully rich and varied butterflyfauna of the Oriental region. In the first family Danaidæ, the genera Danais and Euplaca are everywhere abundant, and the latter especially forms a conspicuous feature in the entomological aspect of the country; the large "spectre-butterflies" (Hestia) are equally characteristic of the Malayan sub-region. Satyridæ, though abundant are not very remarkable, Debis, Melanitis, Mycalesis, and Ypthima being the most characteristic 
genera. Morphidæ are well represented by the genera Amathusia, Zeuxidia, Discophora, and Thaumantis, some of the species of which almost equal the grand South American Morphos. The Nymphalidæ furnish us with a host of characteristic genera, among the most remarkable of which are; Terinos, Adolias, Cethosia, Cyrestis, Limenitis, and Nymphalis, all abounding in beautiful species. Among the Lycænidæ are a number of fine groups, among which we may mention Ilerda, Myrina, Deudoryx, Aphneus, Iolaus, and Amblypodia, as characteristic examples. The Pieridæ furnish many fine forms, such as Thyca, Iptias, Thestias, Eronia, Prioneris, and Dercas, the last two being peculiar. The Papilionidæ are unsurpassed in the world, presenting such grand genera as Teinopalpus and Bhutanitis; the yellow-marked Ornithopterce; the superb "Brookiana;". the elegant Leptocercus; and Papilios of the "Coon," "Philoxenus," "Memnon," "Protenor," and especially the 'green-andgold-dusted" "Paris" groups.

The Moths call for no special observations, except to notice the existence in Northern India of a number of forms which resemble in a striking manner some of the most remarkable of the above mentioned groups of the genus Papitio, especially the "Protenor" group, which there is reason to believe is protected by a peculiar smell or taste like the Heliconias and Danaidæ.

Coleoptera.-The most characteristic Oriental form of the Cicindelidæ or tiger beetles, is undoubtedly the elegant genus Collyris, which is found over the whole region and is almost confined to it. Less abundant, but equally characteristic, is the wingless ant-like Tricondyla. Two small genera Apteroessa and Dromicidia are confined to the Indian Peninsula, while Therates only occurs in the Malayan sub-region.

The Carabidæ, or ground carnivorous beetles, are so numerous that we can only notice a few of the more remarkable and characteristic forms. The wonderful Mormolyce of the IndoMalay sub-region, stands pre-eminent for singularity in the entire family. Thyreopterus, Orthogonius, Catascopus, and Pericallus are very characteristic forms, as well as Planetes and 
Distrigus, the latter having a single species in Madagascar. There are 80 genera of this family peculiar to the region, 10 of which have only been found in Ceylon.

Among the Lucanidæ, or stag-beetles, Lucanus, Odontolabris, and Cladognathus are the most characteristic forms. Sixteen genera inhabit the region, of which 7 are altogether peculiar, while three others only extend eastward to the Austro-Malayan sub-region.

The beautiful Cetoniidæ, or rose-chafers, are well represented by Rhomborhina, Heterorhina, Clinteria, Macronota, Agestrata, Chalcothea and many fine species of Cetonia. There are 17 peculiar genera, of which Mycteristes, Phoedimus, Plectrone, and Rhagopteryx, are Malayan; while Narycius, Clerota, Bombodes, and Chiloloba are Indian.

In Buprestidæ-those elongate metallic-coloured beetles whose elytra are used as ornaments in many parts of the world - this region stands pre-eminent, in its gigantic Catoxantha, its fine Chrysochroa, its Indian Sternocera, its Malayan Chalcophora, and Belionota, as well as many other beautiful forms. It possesses 41 genera, of which 14 are peculiar to it, the rest being generally of wide range or common to the Ethiopian and Australian regions.

In the extensive and elegant group of Longicorns, the Oriental region is only inferior to the Neotropical. It possesses 360 genera, 25 of which are Prionidæ, 117 Cerambicidæ, and 218 Lamiidx;-about 70 per cent. of the whole being peculiar. The most characteristic genera are Rhaphidopodus and AEgosoma among Prionidæ; Neocerambyx, Euryarthrum, Pachyteria, Acrocyrta, Tetraommatus, Chloridolum, and Polyzonus among Cerambycidæ; and Colosterna, Rhytidophora, Batocera, Agelasta, and Astathes among Lamiidæ.

Of remarkable forms in other families, we may mention the gigantic horned Chalcosoma among Scarabridæ; the metallic Campsosternus among Elateridæ; the handsome but anomalous Trictenotoma forming a distinct family; the gorgeous Pachyrhynchi of the Philippine Islands among Curculionidx; Diurus 
among Brenthidie; with an immense number and variety of Anthotribida, Heteromera, Malacoderma, and Phytophaga.

\section{The ORIental SUb-REgIONS.}

The four sub-regions into which we have divided the Oriental region, are very unequal in extent, and perhaps more so in productiveness, but they each have well-marked special features, and serve well to exhibit the main zoological characteristics of the region. As they are all tolerably well defined and their faunas comparatively well-known, their characteristics will be given with rather more than usual detail.

\section{Hindostan, or Indian Sub-region.}

This includes the whole peninsula of India from the foot of the Himalayas on the north to somewhere near Seringapatam on the south, the boundary of the Ceylonese sub-region being unsettled. The deltas of the Ganges and Brahmaputra mark its easteru limits, and it probably reaches to about Cashmere in the northwest, and perhaps to the valley of the Indus further south; but the great desert tract to the east of the Indus forms a transition to the south Palæarctic sub-region. Perhaps on the whole the Indus may be taken as a convenient boundary. Many Indian naturalists, especially Mr. Blyth and Mr. Blanford, are impresserl with the relations of the greater part of this sub-region to the Ethiopian region, and have proposed to divide it into several. zoological districts dependent on differences of climate and vegetation, and characterized by possessing faunas more or less allied either to the Himalayan or the Ethiopian type. But these subdivisions appear far too complex to be useful to the general student, and even were they proved to be natural, would be beyond the scope of this work. I agree, however, with Mr. Elwes in thinking that they really belong to local rather than to geographical distribution, and confound "station" with "habitat." Wherever there is a marked diversity of surface and vegetation the Iroductions of a country will correspondingly differ; the groups peculiar to forests, for example, will be absent from opeu 
plitins or arid deserts. It happens that the three great Old World regions are separated from each otler by a debatalse land which is chiefty of a desert character; hence we must expect to find a resemblance between the inhabitants of such districts in each region. We also find a great resemblance between the aquat ic birds of the three regions; and as we generally give little weight to these in our estimate of the degree of affinity of the faunas of different countries, so we should not count the desert fauna as of equal weight with the more restricted and peculiar types which are found in the fertile tracts, - in the mountains and valleys, and especially in the primeval forests. The supposed preponderance of exclusively Ethiopian groups of Mammalia and Birds in this sub-region, deserves however a close examination, in order to ascertain how far the facts really warrant such an opinion.

IIammalia.-The following list of the more important genera of Mammalia which range over the larger part of this sub-region will enable naturalists to form an independent judgment as to the preponderance of Ethiopian, or of Oriental and Palæarctic types, in this, the most important of all the classes of animals for geographical distribution.

\section{Range of the Genera of Mammalia which Inhabit the Sub-Region} of Hindostan.
1. Presbytes
2. Macacus
Oriental only.
3. Erinaceus
4. Sorex ...
5. Felis ...
6. Cynæliurus
7. Viverra
... Oriental only.
... Palæaretic genus.
... Widely distributed.
... Almost Cosmopolitan.
... Ethiopian and S. Palrearctic.
8. Viverricula ... Oriental only.
... Ethiopian and Oriental to China and Malaya.
9. Paradoxurus ... Oriental only.
10. Herpestes
11. Cilogale.
12. Tæuiogale
13. Hyænฉ
14. Canis ...
15. Cuon ...
16. Vulpes
17. Lutra ...
18. Mellivori
19. Melursus
20. Sus $\ldots$
21. Tragulus
... Ethiopian, S. Palrearctic, and Oriental to Mulaya.
... Ethiopian, Oriental to Cambodja.
... Oriental.
... Palæarctic and Ethiopian (a Palæurctic sfecies.)
... Palrearctic and Oriental to Maliyy.
... Oriental to Malaya.
... Very wide ringe.
... Oriental and Palourctic.
... Ethiopian.
... Oriental only; family not Ethiopian.
... Palæarctic and Oriental, not Ethiopian.
... Oriental. 


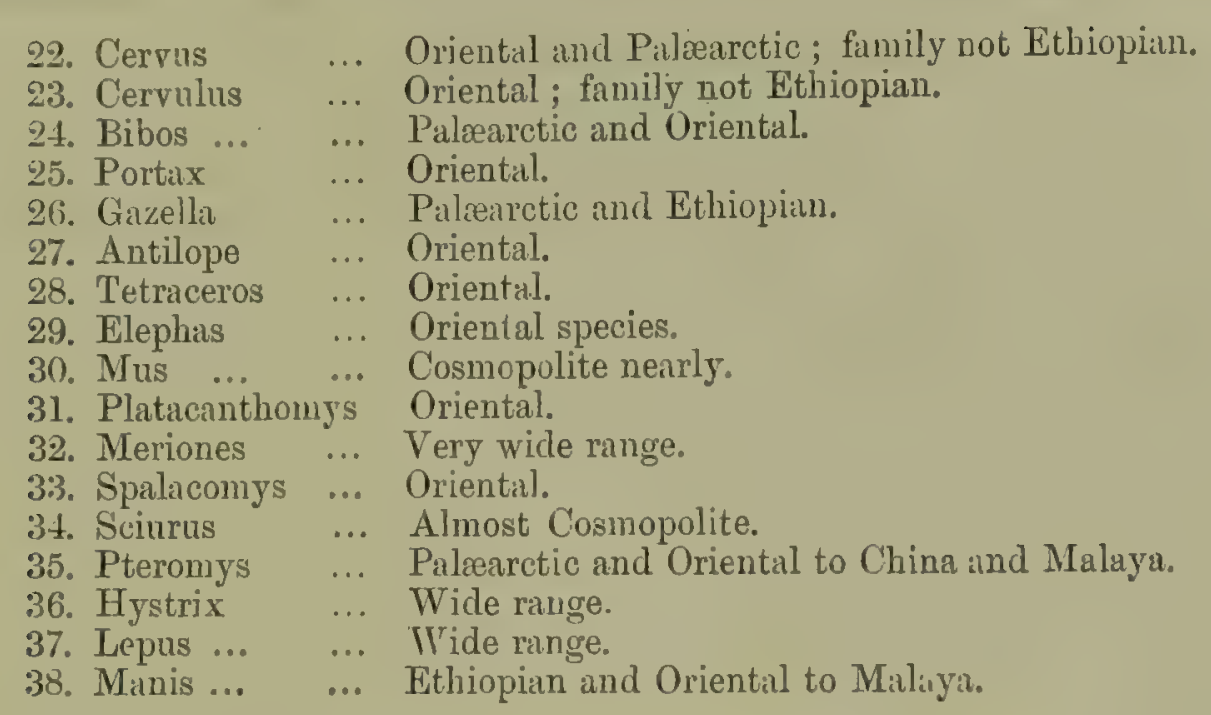

Out of the above 38 genera, 8 have so wide a distribution as to give no special geographical indicatious. Of the remaining 30 , whose geographical position we have noted, 14 are Oriental only; 5 have as much right to be considered Oriental as Ethiopian, extending as they do over the greater part of the Oriental region; 2 (the hyæna and gazelle) show Paliearctic rather than Ethiopian affinity; 7 are Paliearctic and Oriental but not Ethiopian; and only'2 (Cyncelurus and Mellivora) can be considered as especially Fthiopian. We must also give due weight to the fact that we have here Uridie and Cervidæ, two families entirely absent from the Ethiopian region, and we shall then be forced to conclude that the affinities of the Indian peninsula are not only clearly Oriental, but that the Ethiopian element is really present in a far less degree than the Palæarctic.

Bircls.-The naturalists who have adopted the "Ethiopian theory" of the faun of Hindostan, have always supported their views by an appeal to the class of birds; maintaining, that not cnly are alnost all the characteristic Hinalayan and Malayan genera absent, but that their place is to a great extent supplied by others which are characteristic of the Ethiopian region. After a careful exanination of the subject, Mr. Elwes, in a paper real vefore the Zoulogical Society (June 1873) cime to the conclnsion, that this view was an erroneous one, fonnded on the finct that the birds of the plains are the more abundant and more 
open to observition; and that these are often of wide-sprearl types, and some few almost exclusively African. The facts lie adduced do not, however, seem to have satisfied the oljectors; and as the subject is an important one, I will here give lists of all the genera of Passeres, Picarix, Psittaci, Columba, and Gallinæ, which inhabit the sub-region, leaving out those which only just enter within its boundaries from adjacent sub-regions. These are arrauged under four heads:- -1 . Oriental genera; which are either wholly confined to, or strikingly prevalent in, the Oriental region beyond the limits of the Indian peninsula. 2. Genera of Wide Range; which are fully as much entitled to be considered Oriental or Palæarctic as Ethiopian, and cannot be held to prove any Ethiopian affinity. 3. Palæarctic genera; which are altogether or almost absent from the Ethiopian region. 4. Ethiopian genera; which are confined to, or very prevalent in, the Ethiopian region, whence they extend into the Indian peninsula but not over the whole Oriental region. The last are the only ones which can be fairly balanced against those of the first list, in order to determine the character of the fauna.

\section{Oriental Genera in Central India.}

Geocichla, Orthotomus, Prinia, Mcgalumes, Abromis, Larvivora, Copsychus, Kittncincla, Pometorhinus, Malacocercus, Chaterrhace, Layardia, Gammlax, Trochalopteron, Pellorneum, Dumetia, Pyctoris, Alcippe, Myiophonus, Sitta, Dendrophila, Phyllornis, Iora, Hypsipetes, Pericrocotus, Graucalus, Volvocivora, Chibiu, Chaptia, Irena, Erythrosterna, Hemipus, Hemichelidon, Niltava, Cyornis, Eumyias, Hypothymis, Myialestes, Tephrodornis, Dendrocitta, Arachnechthre, Nectarophila, Arachnothera, Dicaum, Piprisoma, Munia, Eulabes, Pastor, Acridotheres, Sturnia, Sturnopastor, Aitamus, Nemorrcola, Pitta, Iungipicus, Chrysosolaptes, Hemicircus, Gecinus, Mulleripicus, Brachyptemus, Tigu, Micropternus, Megalama, Xantholema, Rhopodytes, I'accocona, Surniculus, Hierococcyx, Eudynamnis, Nyctionnis, Harpactes, Pclurgopsis, Ceyx, Hydrocissa, Meniceros, Batrachostomus, Dendrochelidon, C'ollocatia, Palcomis, Treron, Carpophayge, Chalcophaps, Oity-

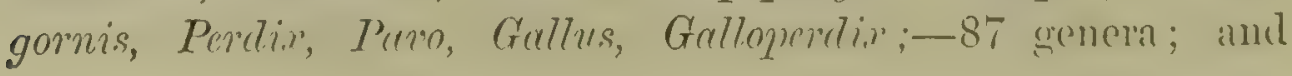


(ne peculiar genus, Salpornis, whose affinities are I'alxarctic $\mathrm{cr}$ Oriental.

\section{Genjelia of Wide Range occurring in Central India.}

Tardus, Monticola, Drymaca, Cisticola, Acrocepplalus, Phylloscopus, Pratincola, Parus, Pycnonotus, Criniger, Oriolus, Dicrurus, I'chitrea, Lanius, Corvus, Zosterops, Hirundo, Cotyle, Passer, Ploceus, Eistrilda, Alauda, Calana'rella, Mirafra, Ammomanes, Motacilla, Anthus, Picus, Yunx, Centropus, Cuculus, Chrysoccocyx, Coccystes, Coracias, Lurystomus, Merops, Alcedo, Ceryle, Halcyon, I'pupa, Caprimulgne, Cypselus, Choctura, Columba, Turtur, Pterocles, Coturnix, Turnix;-48 genera.

\section{Palmarctic Genera occurring in Central India.}

Hypolais, Sylvia, Curruca, Cyanceula, Calliope, Chetidon, Euspiza, Emberiza, Galerita, Calobates, Corydalla;-11 genera.

\section{Ethiopian Genera occurring in Central India.}

Thamnobic, Pyrrthulauda, Pterocles, Francolinus;-4 genera.

A consideration of the above lists shows us, that the Hindostan sub-region is by no means so poor in forms of bird-life as is gencrally supposed (and as I had myself anticipated, it would prove to be), possessing, as it does, 151 genera of land-birds, without counting the Accipitres. It must also set at rest the question of the zoological affinities of the district, since a preponderance of 88 genera, against 4 , cannot be held to be insufficient, and camnot be materially altered by any corrections in details that may be proposed or substantiated. Even of these four, only the first two are exclusively Ethiopian, Pterocles and Francolinus both being Palicarctic also. It is a question, indeed, whether anywhere in the world an outlying sub-region can he found, exhibiting less zoological affinity for the adjacent regions; and we have here a striking illustration of the necessity of deciding all such cases, not by cxcmples, which may be so chosen as to support any view, but hy earefully weighing and contrasting the whole of the facts on which the solution of the 
problem admittedly depends. It will, perhajs, be said that a freat many of the 88 genera above given are very scarce and very Jocal ; but this is certainly not the case with the majority of them; and even where it is so, that does not in any degree affect their value as indicating zoo-geographical affinities. It is the picscnce of a type in a region, not its abundance or scarcity, that is the important fact; and when we have to do, as we have here, with many groups whose habits and mode of life necessarily seciule them from olservation, their supposed scarcity may not even be a fact.

Reptiles and Amphitia.-Reptiles entirely agree with Mammalia and Birds in the main features of their distribution. Out of 17 families of snakes inhabiting Hindostan, 16 range over the greater part of the entire region, and only two can he supposed to show any Ethiopian affinity. These are the Psammophidre and Erycidie, both desert-haunting groups, and almost as much South Palrearctic as African. The genus Tromidococcyx is peculiar to the sub-region, and Aspidura, Passerita and Cynophis to the peninsula and Ceylon; while a large number of the most characteristic genera, as Dipsas, Simotes, Bungarus, Ncoje, Trimercsurvs, Lycodon and Python, are characteristically Oriental.

Of the six families of lizards all have a wide.range The gencra Eumeces, Pentadactylus, Gecko, Enblepharis, and Draco, are characteristically or wholly Oriental; Ophiops and Uromastix are Palearctic; while Chamclcon is the solitary case of deciled Ethiopian affinity.

()f the Amplibia not a single family exlihits special Ethiopian affinities.

\section{Sub-region of Ceylon and South-India.}

The Island of Ceylon is characterised by such striking peculiarities in its animal productions, as to render necessary its separation from the peninsula of India as a sub-region; but it is found that most of these special features extend to the Neilgherries and the whole southern nountainous portion of India, and that the two must be united in any zoo-gengrajhical pro- 
vince. Tise main features of this division are,- the appearance of numerous animals allied to forms only found again in the Himalayas or in the Malayan sub-regiou, the possession of several peculiar generic types, and an unusual number of peculiar species.

Manmalia-Among MIammalia the most remarkable form is Loris, a genus of Lemurs altogether peculiar to the subregion; several peculiar monkeys of the genus Presbytes; the Malayan genus Tupaia; and Platacanthomys, a peculiar genus of Muridæ.

Birds,-Among birds it has Ochromeln, a peculiar genus of flycatchers; Phonicophaës (Cuculide) and Drymocataphus (Timaliidæe), both Malayan forms; a species of Myiophonus whose nearest ally is in Java; Trochalopteron, Brachypteryx, Buceros and Loriculus, which are only found elsewhere in the Himalayas and Malayana. It also possesses albout 80 peculiar species of birls, including a large jungle fowl, one owl and two hornbills.

Reptiles.-It is however by its Reptiles, even more than by its ligher vertebrates, that this sub-region is clearly characterised. Among snakes it possesses an entire family, Uropeltidre, consisting of 5 genera and 18 species altogether confined to it,-Rhinophis and Uropeltis in Ceylon, Silybura, Plecturus and Mclanophitium. in Southern India. Four other genera of snakes, Haplocercus, C'crcaspis, Peltopelor, and Hipnocle are also peculiar; Chersydrus is only found elsewhere in Malaya; while Aspidura, Passcrita, and Cynophis, only extend to Hindostan; species of Eryx, Echis, and I'sammoptlis show an affinity with Ethiopian and Paliearctio forms. Among lizards several genera of Agamida are peculiar, such as Otocryptis, Lyricocphalus, Ceratophora, Cophotis, Salea, Sitana and Charasia. In the family Acontiadæ, Nessia is peculiar to C'eylon, while a species of the African grenus Acontias shows an affinity for the Ethiopian region.

Amplibia.-The genera of Amphibians that occur here are gencrally of wide range, but Nannophrys, Haplobatrachus, and Cacopus are confined to the sub-region; while Megalophrys is Malayan, amb the species found in Ceylon also inhah Java. 
Inscets.-The insects of Ceylon also furnish some curious examples of its distinctness from Hindostan, and its affinity with Malaya. Among its buttertlies we find Papilio jophon, closely allied to P. untiphtus of Malaya. The remarkable genus Hestia, so characteristic of the Malay archipelago, only occurs elsewhere on the mountains of Ceylon; while its Cynthia and Parthenos are closely allied to, if not identical with, Malayan species. $\Lambda$ nong Coleoptera we have yet more striking examples. The highly characteristic Malayan genus T'ricondyla is represented in Ceylon by no less than 10 species; and among Longicorns we find the genera Tetraommatus, Thranius, Cacia, Praonetha, Ropica, and Serixia, all exclusively Malayan or only just entering the Indo-Chinese peninsula, yet all represented in Ceylon, while not a single species occurs in any part of India or the Himalayas.

The Past History of Ceylon and South-India as indicated by its Fauna.-In our account of the Ethiopian region we have already had occasion to refer to an ancient connection between this subregion and Madagascar, in order to explain the distribution of the Lemurine type, and some other curious affinities between the two countries. This view is supported by the geolugy of India, which shows us Ceylon and South India consisting mainly of granitic and old metamorphic rocks, while the greater part of the peninsula, forming our first sub-region, is of tertiary formation, with a few isolated patches of secondary rocks. It is evident therefore, that during much of the tertiary period, Ceylon and South India were bounded on the north by a considerable extent of sea, and probably formed part of an extensive southern continent or great island. The very numerous and remarkable cases of affinity with Malaya, require however some closer approximation to these islands, which probably occurred at a later period. When, still later, the great plains and table-lands of Hindostan were formed, and a permanent land communication effected with the rich and highly developed Himalo-Chinese fauna, a rapid immigration of new types took place, and many of the less specinlised forms of mammalia and birds (particularly those of ancient Ethiopian type) became extinct. Among reptiles and insects the competition was less severe, or the older forms were too well 
adapted to local conditions to be expelled; so that it is among these groups alone that we find any considerable number, of what are probably the remains of the ancient fauna of a now submerged southern continent.

\section{Himalayan or Indo-Chinese Sub-region.}

This, which is probably the richest of all the sub-regions, and perhaps one of the richest of all tracts of equal extent on the face of the globe, is essentially a forest-covered, mountainous country, mostly within the tropics, but on its northern margin extending some degrees beyond it, and rising in a continuous mountain range till it meets and intercalates with the Manchurian sub-division of the Palæarctic region. The peculiar mammalia, birds and insects of this sub-region begin to appear at the very foot of the Himalayas, but I). Gunther has shown that many of the reptiles characteristic of the plains of India are found to a height of from 2,000 to 4,000 feet.

In Sikhim, which may be taken as a typical example of the Himalayan portion of the sub-region, it seems to extend to an altitude of little less than 10,000 feet, that being the limit of the characteristic Timaliidæ or babbling thrushes; while the equally characteristic Pycnonotidie, or bulbuls, and Treronidæ, or thickbilled fruit-pigeons, do not, according to Mr. Blanford, reach quite so high. We may perliaps take 9,000 feet as a good approximation over a large part of the Himalayar range; but it is evidently not possible to define the line with any great precision. Westward, the sub-region extends in diminishing breadth, till it terminates in or near Cashmere, where the fauna of the plains of India almost meets that of the Palrarctic region, at a moderate elevation. Eastward, it reaches into East Thibet and North-west China, where Père David has found a large number of the peculiar types of the Eastern Himalayas. A fuuna, in general features identical, extends over Burmah and Siam to South China; mingling with the Palrarctic fauna in the mountains south of the Yang-tse-kiang river, and with that of Indo-Malaya in Tenasserim, and to a lesser extent in Southern Siam and Cochin China. 
Zoologicul Characteristics of the Himulayun Sub-region.Taking this sub-region as a whole, we find it to he characterised by 3 genera of mammalia (without counting hats), and 44 genera of land-birds, which are altogether peculiar to it; and by 13 genera of mammalia and 36 of hirds, which it possesses in common with the Malayan sub-region; and besides these it has almost all the genera before enumerated as "Oriental," and several others of wide range, more especially a number of Palæarctic genera which appear in the higher Himalayas. The names of the more characteristic genera are as follows:-

\section{Pecultar Himalo-Cininese Gexera.}

Mammalia.-Urva, Arctonyx, Ailurus.

Birds. - Suya, Horites, Chamarrhornis, Tarsiger, Oreicola, Acanthoptila, Grammatoptila, Trochalopteron, Actinodura, Sibia, Suthora, Paradoxornis, Chlenasicus, Tesia, Rimator, Aigithaliscus, Cephalopyrus, Liothrix, Siva, Minla, Proparus, Cutia, Yuhinu, Ixulus, Myzornis, Erpornis, Hemixus, Chitia, Niitava, Anthipes, Chclidorhynx, Urocissa, Pachyglossa, Heterura, Hamatospiza, Ampeticeps, Saroglossa, Psarisomus, Serilophus, Vivia, Hyopicus, Gecinulus, Aceros, Ceriornis.

\section{Genera comanon to the Himalo-Ciminese and Malayan SUB-REGIONS.}

Mammalia.-Hylobates, Nycticcbus, Vircricula, Prionodon, Arctitis, Paguma, Arctogale, Cuon, Gymnomes, Aonyx, Helictis, Rhinoceros, Nemorhedus, Rhizomys.

Birds.-Oreocincla, Notodcla, Janthocincla, Timalia, Stachypis, Mixomis, Trichastoma, Enicums, Pnepyga, Melanochlora, Allotrius, Microscclis, Iole, Analcimus, Cochoce, Bhringe, Aunthopygia, Hylocharis, Cissa, Temnurus, Crypsirhina, Chalcostctha, Anthreptes, Chalcoparia, Cymbirhynchus, Hydromis, Sasia, Tenitia, Indicator, Carcineutes, Lyncornis, Macropyygire, Argusianus Polyplectron, Euplocamus, Phodilus.

Plete VII. Scene in Nepal, with Characteristic ITimalaygn Animals.-Our illustretion contains figures of two mammals 



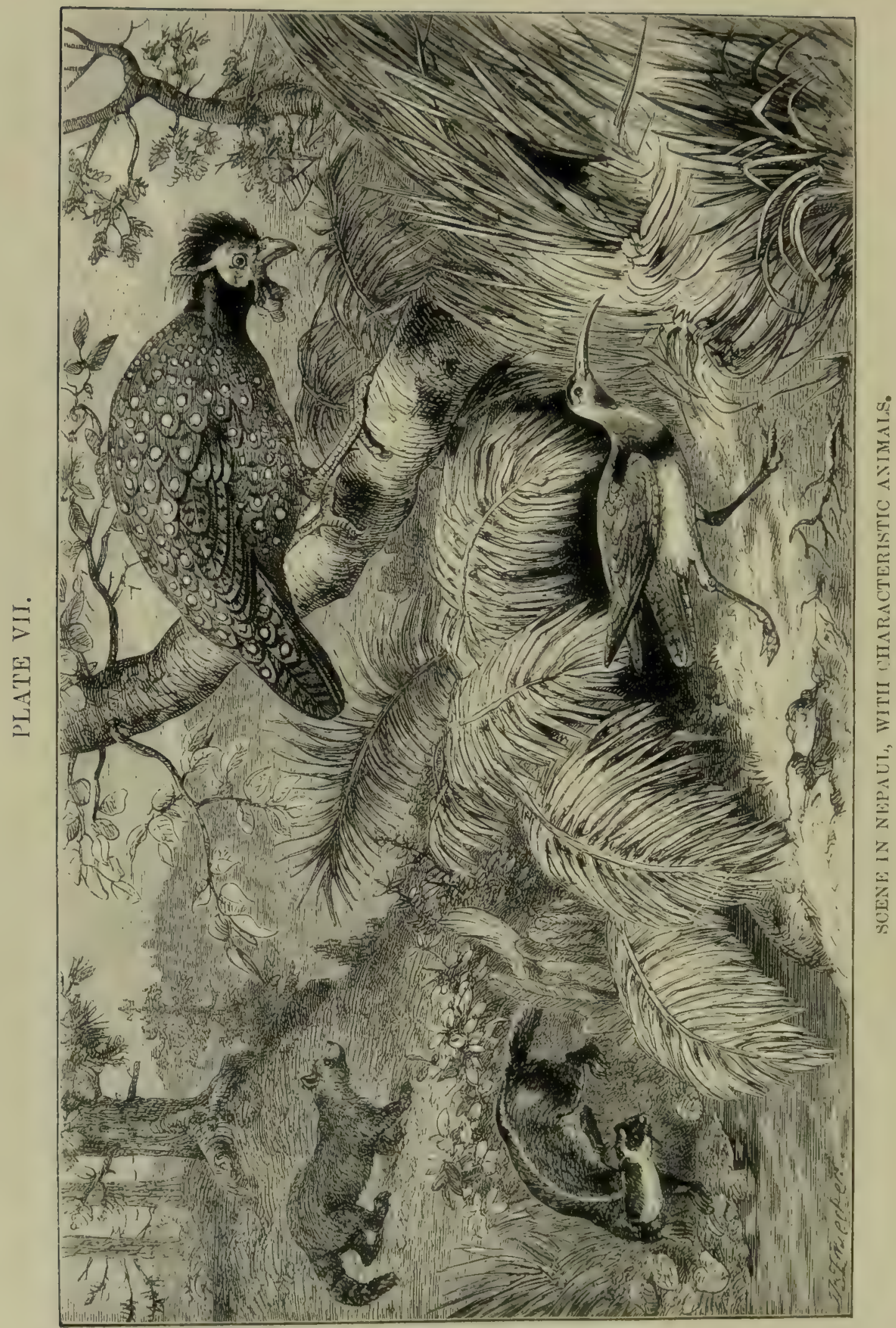


and two birds, characteristic of the higher woody region of the Himalayas. The lower figure on the left is the Helictis nepalensis, confined to the Eastern Himalayas, and belonging to a genus of the weasel family which is exclusively Oriental. It is marked with white on a grey-brown ground. Above it is the remarkable Panda (Alurus fulgens), a beautiful animal with a glossy fur of a reddish colour, darker feet, and a white somewhat cat-like face. It is distantly allied to the bears, and more nearly to the American racoons, yet with sufficient differences to constitute it a distinct family. The large bird on the tree, is the horned Tragopan (Ceriomis satyra), one of the fine Himalayan pheasants, magnificently spotted with red and white, and ornamented with fleshy erectile vattles and horns, of vivid blue and red colours. The bird in the foreground is the Ibidorhynchus struthersii, a rare and curious wader, allied to the curlews and sandpipers but having the bill and fect red. It frequents the river-beds in the higher Himalayns, but has also been found in. Thibet.

Reptilcs-Very few genera of reptiles are peculiar to this sub-region, all the more important ranging into the Malay islands. Of snakes the following are the more characteristic genera:-Typhline, Cylindrophis, Xenopeltis, Calamaria, Xenelaphis, Hypsirhina, Fordonia, several small genera of Homalopsidæ (Herpeton and Hipistes being characteristic of Burmah and Siam) Psammodynastes, Gonyosoma, Chrysopelea, Tragops, Dipsas, I'areas, Python, Bungarus, Naja, Callopthis, and Trimeresurus. Arija reaches 8,000 fect elevation in the Himalayas, Tropidonotus 9,000 feet, Ablabes 10,000 feet, and Simotes 15,000 feet.

Of lizards, Pseudopus has one species in the Khasya hills while the other inhabits South-east Europe; and there are two small genera of Agamidæ peculiar to the Himalayas, while Draco and Culotes have a wide, range and Accuthosenre, Dilophyrus, Physignathus, and Liolepis are found chicfly in the Indo-Chinese peninsula. There are several genera of Scincide; and the extensive genus of wall-lizards, Geclio, ranges over the whole region.

() Amphibia, the peculiar forms are not numerous. Iethynpsis 
a genus of Ceciliatie, is peculiar to the Khasya Hills; I'ylotritron (Salamandridx) to Yunan in Wester'ı C'hina, and yerhaps belongs to the Palæarctic region.

Of the tail-less Batrachians, Glyphoglossus is found in P'egu; Xenophys in the Eastern Himalayas; while Collula, Ixculus, Rhacophorus, Hylurana, Oxyglossus, and Phrynoglossus, are common to the Himalo-Chinese and Malayan sub-regions.

Of the lizards, Colotes, Barycephalus, and Hinulic,-and of the Batrachia, Bufo,-are found at above 11,000 feet elevation in the Himalayas.

Insects.--So little has been done in working out the insect faunas of the separate sub-regions, that they cannot be treated in detail, and the reader is referred to the chapter on the distribution of insects in the part of this work devoted to Geographical Zoology. A few particulars may, however, be given as to the butterflies, which have been more systematically collected in tropical countries than any other order of insects. The Himalayan butterflies, especially in the eastern portions of the rangein Assam and the Khasya Hills-are remarkably fine and very abundant; yet all the larger groups extend into the Malayan sub-region, many to Ceylon, and a considerable proportion even to Africa and Austro-Malaya. There are a large number of peculiar types, but most of them consist of few or single species. Such are Neope, Orenoma, and Rhaphicera, genera of Satyrida; Enispe (Morphidie); Hestina, Penthema, and Abrota (Nymphalidæ); Dodona (Erycinidæ); Ilerda (Lycænidx); Calinaga, T'einopalpus, and Bhutanitis (Papilionidre). Its more prominent features are, however, derived from what may be termed Malayan, or even Old World types, such as Euplece, among Danaidæ; Amathusia, Clerome, and Thaumantis, among Morphidr ; Euripus, Diadema, Athyma, Limenitis, and Adolias, among Nymphalidæ, Zemeros and Taxila among Erycinidio; Amblypodia, Mriletus, Ilerda, and Myrina, among Lycænidx; Thyca, Irioneris, Dercas, Iphias, and Thestias among l'ieridx; and Papilios of the "Amphrisins," "Coon," "Philoxenus," "Protenor," "Paris," and "Sarpedon" groups. In the IIimalayas there is an unusual abundance of large and gorgeous species of the gemus l'apilio, 
and of large and showy Nymphalidx, Morphidæ, and Danaidæe, which render it, in favoured localities, only second to South America for a display of this form of beauty and variety in insect life.

Among the other orders of insects in which the Himalayas are remarkably rich, we may mention large and brilliant Cetoniidæ, chiefly of the genus Rhomborhima; a magnificent Lamellicorn, Euchirus macleayii, allied to the gigantic long-armed beetle (E. longimanus) of Amboyna; superb moths of the families Agaristidie and Sesiidr; elegant and remarkable Fulgoridx, and strange forms of the gigantic Phasmidx; most of which appear to be of larger size or of more brilliant colours than their Malayan allies.

Islands of the Indo-Chinese Sub-region.-A few important islands belong to this sub-region, the Andamans, Formosa, and Hainan being the most interesting.

Andamans.-The only mammalia are a few rats and mice, a Paradoxurus, and a pig supposed to be a hybrid race,-all of which may have been introduced by man's agency. The birds of the Andaman Islands have been largely collected, no less than 155 species having been obtained; and of these 17 , (all land-birds) are peculiar. The genera are all found on the continent, and are mostly characteristic of the Indo-Chinese fauna, to which most of the species belong. Reptiles are also tolerably abundant; about 20 species are known, the majority being found also on the continent, while a few are peculiar. There are also a few Batrachia, and some fresh-water fishes, closely resembling those of Burmah. The alsence of such mammalia as monkeys and squirrels, which abound on the mainland, and which are easily carrierl over straits or narrow seas by floating trees, is sufficient proof that these islands have not recently formed part of the continent. The birds are mostly such as may have reached the islands while in their present geographical position; and the occurrence of reptiles and fresh-water fishes, said to be identical in species with those of Bumah, must be due to the facilities, which some of these animals undoubtedly 
possess, for passing over a considerable willth of sea. WVe must conclude, therefore, that these islinds do not owe their existing fauna to an actual union with the mainland; but it is probable that they may have been formerly more extensive, and have then been less distint from the continent than at the present time.

The Nicobar Islands, usually associated with the Andamans, are less known, but present somewhat similar phenomena. They are, however, more Malayan in their fauna, and seem properly to belong to the Indo-Malay sub-region.

Formosa.-This island lias been carefully examined liy Mr. Swinhoe, who found $14 t$ species of birds, of which 34 are peculiar. There is one peculiar genus, but the rest are all Indo-Chinese, though some of the species are more allied to Malayan than to Chinese or Himalayan forms. About 30 species of mammalia were found in Formosa, of which 11 are peculiar species, the rest being either Chinese or Ifimalayan. The peculiar species belong to the genera Talpa, Helictis, Sciuropterus, Pteromys, Mus, Sus, Cervus, and Capricornis. A few lizards and snakes of continental species have also been found. These facts clearly indicate the former connection of Formosa with China and Malaya, a connection which is rendered the nore probable by the shallow sea which still connects all these countries.

Hainan.-The island of Hainan, on the south const of China, is not so well known in proportion, though Mr. Swinhoe collected 172 species of birds, of which 130 were land-birds. Of these about 20 were peculiar species; the remainder being either Chinese, Himalayan, or Indo-Malayan. Mr. Swinlioe also obtained 24 species of mammalia, all being Chinese, Himalayan, or Indo-Malayan species except a hare, which is peculiar. This assemblage of animals would imply that Hainan, as might be anticipated from its yosition, has been more recently scpirated from the continent than the more distant island of Formosa.

\section{Indo-Malaya, ir the Malayan Sub-region.}

This sub-region, which is almost wholly insular (including only the Malityan penimsula on the continent of Astil), is equal, if 
not superior, in the variety and beanty of its productions, to that which we have just been considering. Like Indo-China, it is a region of forests, but it is more exclusively tropical; and it is therefore deficient in many of those curious forms of the temperate zone of the Himalayas, which seem to have been developed from Palæarctic rather than from Oriental types. Here alone, in the Oriental region, are found the most typical equatorial forms of life-organisms adapted to a climate characterised by uniform but not excessive heat, abundant moisture, and no marked departure from the average meteorological state, throughout the year. These favourable conditions of life only occur in three widely separated districts of the globe-the Malay archipelago, Western Africa, and equatorial South America. Hence perhaps it is, that the tapir and the trogons of Malacca should so closely resemble those of South America; and that the great anthropoid apes aud crested hornbills of Western Africa, should find their nearest allies in Borneo and Sumatra.

Although the islands which go to form this sub-region are often separated from each other by a considerable expanse of sea, yet their productions in general offer no greater differences than those of portions of the Indo-Chinese subregion separated by an equal extent of dry land. The explanation is easy, however, when we find that the sea which separates them is a very shallow one, so shallow that an elevation of ouly 300 feet would unite Sumatra, Java, and Borneo into one great South-eastern prolongation of the Asiatic continent. As we know that our own country has been elevated and depressed to a greater amount than this, at least twice in recent geological times, we can have no difficulty in admitting similar changes of level in the Malay archipelago, where the subterranean forces which bring about such changes are still at work, as manifested by the great chain of active volcanoes in Sumatra and Java. Proofs of somewhat earlier changes of level are to be scen in the Tertiary coal formations of Borneo, which demonstrate a succession of elevations and subsiclences, with as much certainty as if we had historical record of them.

It is not necessiny to sulpmse, nor is it problalle, that all these 
great islands were recently united to the continent, and that their separation took place by one general subsidence of the whole. It is more consonant with what we know of such matters, that the elevations and depressions were partial, varying in their points of action and often recurring; sometimes extending one part of an island, sometimes another; now joining an island to the main land, now bringing two islands into closer proximity. There is reason to believe that sometimes an intervening island has sunk or receded and allowed others which it before separated to effect a partial union independently of it. If we recognise the probability that such varied and often-renewed changes of level have occurred, we shall be better able to understand how certain anomalies of distribution in these islands may have been brought about. We will now endeavour to sketch the general features of the zoology of this interesting district, anil then proceed to discuss some of the relations of the islands to each other.

Mammalia.-We have seen that the Indo-Chinese sub-region possesses 13 species of mammalia in common with the IndoMalay sub-region, and 4 others peculiar to itself, besides one Ethiopian and several Oriental and Palæarctic forms of wide range. Of this latter class the Malay islands have comparatively few, but they possess no less than 14 peculiar genera, viz. Simia, Siamanga, Tarsius, Galeopithecus, Hylomys, Ptilocerus, Gymnura, Cynogale, Hemigalea, Arctogale, Barangia, Mydans, Helarctos, and Tapirus. The islands also possess tigers, deer, wild pigs, wild cattle, elephants, the scaly ant-cater, and most of the usual Oriental genera; so that they are on the whole fully as rich as, if not richer than, any part of Asia; a fact very unusual in island faunas, and very suggestive of their really continental nature.

Plate VIII. Scene in Borneo with Characteristic Maluyan Quadrupeds.-The Malayan fauna is so rich and peculiar that we devote two plates to illustrate it. The have lere a group of manmalia, such as might be seen together in the vast forests of Borneo. In the foreground we have the beantiful deer-like Chevrotain (Tragulus jurmicus). These are delicate littls 

I'Al'L VIII.

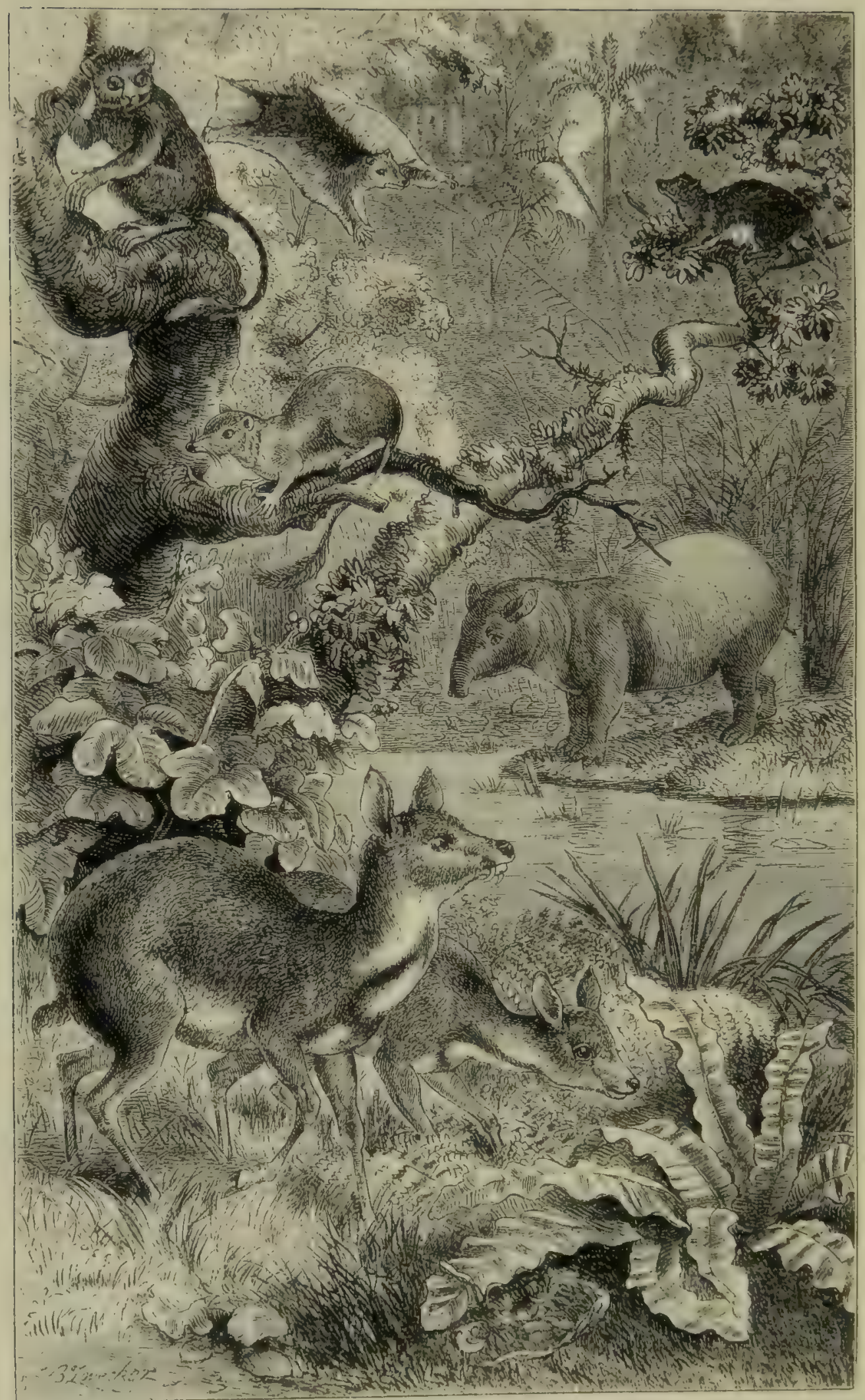

A FOREST IN BORNEO, WITII CIIRACTERISTIC MAMMALA 
animals whose body is not larger than a rablit's, thence often called "mouse-deer." They were formerly classed with the "musk-deer," owing to their similar tusk-like upper canines; but their anatomy shows them to form quite" a distinct fanily, having more resemblance to the camels. On the branch above is the curious feather-tailed Tree-Shrew (Ptilocerus lowii), a small insectivorous animal altogether peculiar to Borneo. Above this is the strange little Tarsier (Tarsins spectrum), one of the lemurs confined to the Malay islands, but so distinct from all others as to constitute a separate family. The other small animals are the Flying Lemurs (Galcopithecus volans) formerly classed with the lemurs, but now considered to belong to the Insectivora. They have a very large expansion of the skin comnecting the fore and hind limbs and tail, and are able to take long flights from one tree to another, and even to rise over obstacles in their course by the elevatory power of the tail-membrane. They feed chiefly on leaves, and have a very soft and beautifully marbled fur.

In the distance is the Malayan tapir (Topirus indicus), a representative of a group of animals now confined to the larger Malay islands and tropical America, but which once ranged over the greater part of temperate Europe.

Bircls.-Owing to several of the families consisting of very obscure and closely allied species, which have never been critically examined and compared by a competent ornithologist, the number of birds inhabiting this sub-region is uncertain. From the best available materials there appear to be somewhat less than 650 species of land-birds actually known, or excluding the Philippine Islands somewhat less than 600. The larger part of these are peculiar species, but mostly allied to those of Indo-China; 36 of the genera, as alrearly stated, being common to these two sub-regions. There are, however, no less than 46 genera which are peculiarly or wholly Indo Malayan and, in many cases, have no close affinity with other Oriental groups. These peculiar genera are as follows:-T'imalia, Malccopteron, Macronus, Napotherc, Turdinus, and Trichixos-generi 
of Timaliida ; Eupetes, a most remarkable form, perhaps allied to Enicurus, and Cinclus; Rhabclornis (Certhiidæ) found only in the Philippines; Psaltria, a diminutive bird of doubtful affinities, provisionally classed among the tits (Paridæ); Setornis (Pycnonotidæ); Lalage (Campephagidæ) extending eastward to the Pacific Islands; Pycnosphrys, Philentoma (Muscicapidæ) ; Laniellus, a beautiful bird doubtfully classed with the shrikes (Laniidae); Platylophus and Pityriasis, the latter a most anomalous formperhaps a distinct family, at present classed with the jays, in Corvide; Prionochilus, a curious form classed with Dicæidæ; Erylhrura (Ploceidæ), extending eastwards to the Fiji Islands; Gymnops, Calornis, (Sturnidæ); Eurylcemus, Corydon, and Calyptomena (Eurylæmidæ); Eucichla, the longest tailed and most elegantly marked of the Pittidæ; Reinwardtipicus and Miglyptes (Pjcidæ); Psilopogon and Calorhamphus, (Megalæmidæ); Rhinococcyx, Dasylophus, Lepidogrammus, Carpococcyx, Zanclostomus, Poliococcyx, Rhinortha, (Cuculidx); Berenicornis, Caldo, Cranorhinus, Penclopides, Rhinoplax, (Bucerotidx); Psittinus, (Psittacidæ); Ptilopus, Phapitreron, (Columbidx); Rollulus, (Treronidæ); Machcerhamphus, (Falconidæ). Many of these genera are abundant and wide-spread, while some of the most characteristic Himalayan genera, such as Larvivora, Garrulax, Hypsipetes, Pomatorhinus, and Dendrocitta, are here represented by only a few species.

Among the groups that are characteristic of the Malayan sub-region, the Timaliidre and Pycnonotidæe stand pre-eminent; the former represented chiefly by the genera Timalia, Malacopteron, Macronus, and Trichastoma, the latter by Criniger, Microscelis, and many forms of Pycnonotus. The Muscicapidx, Dicruridx, Campephagide, Ploceidæ, and Nectariniidæ are also well developed; as well as the Pittidæ, and the Eurylæmidæ, the limited number of species of the latter being compensated by a tolerable abundance of individuals. Among the Picaria are many conspicuous groups; as, woodpcckers (Picidx); barbets (Megalæmidx); trogons (Trogonidx); kingfishers (Alcedinidix); and hornbills (Bucerotidis); five families which are perhaps the most conspicuous in the whole fauna. Lastly come the pigeons 
(Columbidæ), and the pheasants (Phasianidæ), which are fairly represented by such fine genera as Treron, Ptilnpus, Euplocamus, and Argusianus. A few forms whose affinities are Australian rather than Oriental, help to give a character to the ornithology, though none of them are numerous. The swallow-shrikes (Artamus); the wag-tail fly-catchers (Rhipidura); the green fruitdoves (Ptilopus); and the mound-makers (Megapodius), are the chief of these.

There are a few eurious examples of remote geographical alliances that may be noted. First, we have a direct African connection in Machoerhamphus, a genus of hawks, and Berenicornis, a genus of hornbills; the only close allies being, in the former case in South, and in the latter in West Africa. Then we have a curious Neotropical affinity, indicated by Carpococcyx, a large Bornean ground-cuckoo, whos a nearest ally is the genus Neomorphus of South America; and by the lovely green-coloured Calyptomena which seems unmistakably allied to the orangecoloured Rupicola, or "Cock of the rock," in general structure and in the remarkable form of crest, a resemblauce which has been noticed by many writers.

In the preceding enumeration of Malayan genera several are included which extend into the Austro-Malay Islands, our object, at present, being to show the differences and relations of the two chief Oriental sub-regions.

Plate IX. A Malayan Forest with some of its peculiar Birds.Our second illustration of the Malayan fauna is devoted to its bird-life; and for this purpose we place our scene in the Malay peninsula, where birds are perhaps more abundant and more interesting, than in any other part of the sub-region. Conspicuous in the foreground is the huge Rhinoceros Hornbill (Buceros rhinoceros), one of the most eharacteristic birds of the Malayan forests, the flapping of whose wings, as it violently beats the air to support its heavy body, may be heard a mile off. On the ground behind, is the Argus pheasant (Argusianus giganteus) whose beautifully ocellated wings have been the subject of a most interesting description in Mr. Darwin's Descent of Man. The wing-feathers are here so enormously 
developed for display (as shown in our figure) that they become almost, if not quite, useless for their original purpose of flight; yet the colours are so sober, harmonizing completely with the surrounding vegetation, and the bird is so wary, that in the forests where it abounds an old hunter assured me he had never been able to see a specimen till it was caught in his snares. It is interesting to note, that during the display of the plumage the bird's head is concealed by the wings from a spectator in frout, and, contrary to what usually obtains among pheasants, the head is entirely unadorned, having neither crest nor a particle of vivid colour, - a remarkable confirmation of Mr. Darwin's views, that gayly coloured plumes are developed in the male bird for the purpose of attractive display in the breeding season. The long-tailed bird on the right is one of the Drongo-shrikes (Edolius remifer), whose long bare tail-feathers, with an oar-like web at the end, and blueblack glossy plumage, render it a very attractive object as it flies after its insect prey. On the left is another singular birul the great Broad-bill (Coryclon sumatramus), with dull and sombre plumage, but with a beak more like that of a boat-bill than of a fruit-eating passerine bird. Over all, the white-handed Gibbon (Hylobatcs lar) swings and gambols among the topmost branches of the forest.

Reptiles and Amphibia.-These are not sufficiently known to be of much use for our present purpose. Most of the genera belong to the continental parts of the Oriental region, or have a wide range. Of suakes Rhablosoma, Typhlocalamus, Tetragonosoma, Acrochordus, and Atropos, are the most peculiar, and there are several peculiar genera of Homalopsidx. Of Oriental genera, Cylinclrophis, Xenopeltes, Calamaria, Hypsirhina, Pscmmodynastes, Gonyosoma, Tragops, Dipsas, Parcas, Python, Bungarus, Naja, and Callophis are abundant; as well as Simotes, Ablabes, Tropidonotus, and Dcndroptis, which are widely distributed. Among lizards Hydrosaurus and Gccko are common; there are many isolated groups of Scincidie; while Draco, Calotes, and many forms of Agamidre, some of which are peculinr, abound.

Am ong the Amphibia, toarls and frogs of the genera Micrhyla, 
PLATE IX.

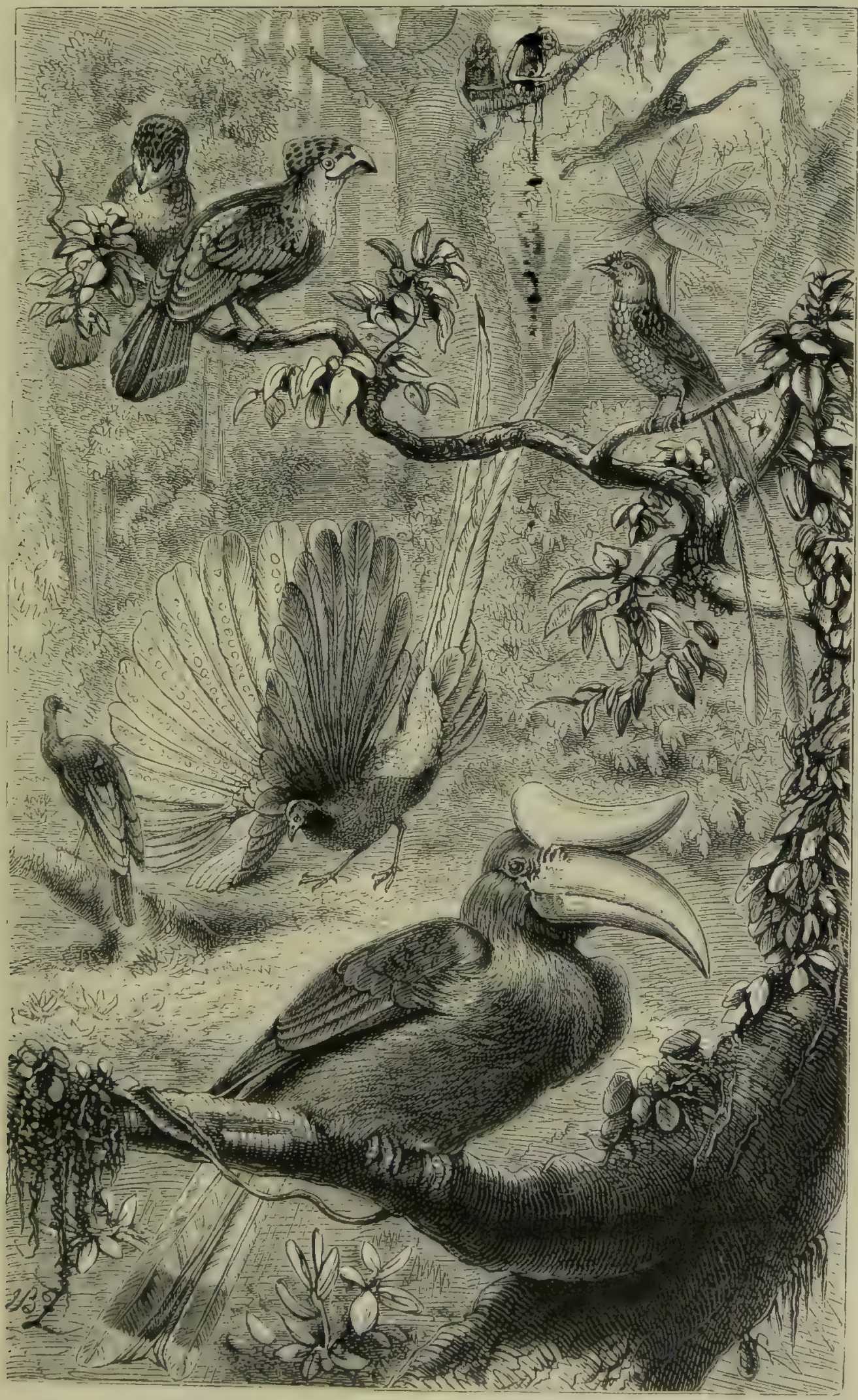

A MALAYAN FOREST, WITH ITS CHARACTERISTIC BIRDS. 

Kalophrynus, Ansonia, and Pscudabufo, are peculiar: while the Oriental Mfcgalophrys, Ixalus, Rlacophorus, and Hylorana are abundant and characteristic.

Fishes.-The fresh-water fishes of the Malay archipelago have been so well collected and examined by the Dutch naturalists, that they ofler valuable indications of zoo-geographical affinity; and they particularly well exhibit the sharply defined limits of the region, a large number of Oriental and even Ethiopian genera extending eastward as far as Java and Borneo, but very rarely indeed sending a single species further east, to Celebes or the Moluccas. Thirteen families of fresh-water fishes are found in the Indo-Malay sub-region. Of these the Scienidæe and Symbranchidi have mostly a wide range in the tropics. Ophiocephalida are exclusively Oriental, reaching Borneo and the Philippine islands. The Mastacemhelidæ are also Oriental, but one species is found as far as Ceram. Of the Nandicle, 3 genera range orer the whole region. The Iabyrinthici extend from Africa through the Oriental region to Amboyna. The single species constituting the family Luciocephalidre is confined to Borneo and the small islands of Biliton and Banca. Of the extensive family Siluridæe 17 genera are Oriental and Malayan, and 11 are Malayan exclusively; and not one of these appears to pass beyond the limits of the subregion. The Cyprinide offer an equally striking example, 23 genera ranging eastward to Java and Borneo and not one beyond; 14 of these being exclusively Malayan. It must be remembered that this is not from any want of knowledge of the countries farther east, as extensive collections have also been made in Celebes, the Moluccas, and Timor; so that 1he facts of distribution of fresh-water fishes come, most mexpectedly, to fortify that division of the archipelago into two primary regions, which was founded on a consideration of mammalia and birds only.

Insects.-Few countries in the world can present a richer and more varied series of insects than the Indo-Malay islands, and we can only here notice a few of their more striling peculiarities and more salient features. 
The butterflies of this sub-region, according to the luest estimate that can be formed, amount to about 650 described species, a number that will yet, no doubt, be very considerably increased. The genera which appear to be peculiar to it are Erites (Satyridæ); Zeuxidia (Morphidæ); Amnosia, Xanthotonia, and Tanocix (Nymphalidæ). The groups which are most characterisic of the region, either from their abundance in individuals or species, or from their size and beauty, are-the rich darkcoloured Euploca; the large semi-transparent Hestia; the plaincoloured Mycalesis, which replace our meadow-brown butterflies (Hipparchia); the curious Elymnias, which often closely resemble Euplæas; the large and handsome Thamantis and Zeuxidia, which take the place of the giant Morphos of South America; the Cethosict, of the brightest red, and marked with a curious zigzag pattern; the velvety and blue-glossed Terinos; the pale and delicately-streaked Cyrestis; the thick-bodied and boldly coloured Adolias; the small wine-coloured Taxila; the fine blue Amblypodia; the beautiful Thyca, elegantly marked underneath with red and yellow, which represent our common white butterflies and are almost equally abundant; the pale blue Eronia, and the large red-tipped Iphias. The genus Papilio is represented by a variety of fine groups; the large Ornithoptera, with satiny yellow under wings; the superb green-marked "broukeana;" the "paradoxa" group, often closely resembling the Euplæas that abound in the same district; the "paris" group richly dusted with golden-green specks; the "hclenus" group with wide-spreading black and white wings; the black and crimson "polydorus" group; the "memnon" group, of the largest size and richly-varied colours ; and the "eurypilus" group, elegantly banded or spotted with blue or green : all these are so abundant that some of them are met with in every walk, and are a constant delight to the naturalist who has the privilege of observing them in their native haunts.

The Coleoptera are far less prominent and require to be carefully sought after; but they then well repay the collector. As affording some measure of the productiveness of the tropics in insect life it will not be out of place to give a few notes of the 
number of species collected by myself in some of the best localities. At Singapore 300 species of Coleoptera were collected in 15 days, and in a month the number had increased to 520 ; of which 100 were Longicorns and 140 Rhyncophora. At Sarawak in Borneo I obtained 400 species in 15 days, and 600 in a month. In two montlis this number had increased to about 850 , and in three months to 1,000 species. This was the most prolific spot I ever collected in, especially for Longicorns which formed about one-fifth of all the species of beetles. In the Aru Islands in one month, I obtained only 235 species of Coleoptera, and about 600 species of insects of all orders; and this may be taken as a fair average, in localities where no specially favourable conditions existed. On the average 40 to 60 species of Coleoptera would be a good day's collecting; 70 exceptionally good; while the largest number ever obtained in one day was 95 , and the majority of these would be very minute insects. It must be remembered, however, that many very common species were passed over, yet had every species nuet with been collected, not much more than 100 species would ever have been obtained in one day's collecting of four or five hours. These details may afford an interesting standard of comparison for collectors in other parts of the world.

Of Cicindelidæ the most peculiarly Malayan form is Therates, found always on leaves in the forests in the same localities as the more widely spread Collyris. Five genera of this family are Indo-Malayan.

The Carabidæ, though sufficiently plentiful, are mostly of smali size, and not conspicuous in any way. But there is one striking exception in the purely Malayan genus Mormolyce, the largest and most remarkable of the whole family. It is nocturnal, resting during the days on the under side of large boleti in the virgin forest. Pericallus and Catrescopus are among the few genera which are at all brillantly coloured.

Buprestirle are abundant, and very gay; the genus Belionotre being perhaps one of the most conspicuous and characteristic. The giant Calorantha is, however, the most peculiar, though comparatively scarce. Chrysochroe and Chaleophore are also 
ahmolant and characteristic. Ont of the 41 Oriental gencra 21 are Malayan, and 10 of these are not found in the other sulbregions.

In Lucanidre the Malay islands are rich, 14 out of the 16 Oriental genera occurring there, and 3 being peculiar. There are many fine species of Odontolatris, which may be considered the characteristic genus of the sub-region.

The Cetoniidie are well represented by 16 genera and about 120 species. The genera Mycteristes, Phodimus, Plectrone, Euremina, Rhagopteryx and Centroynathus are peculiar, while Agestrata, Chalcothea, and Macronota are abundant and characteristic.

The Longicorns, as in all contimental forest regions near the equator, are very abundant and in endlessly varied forms. No less than 55 genera containing about 200 species are peculiar to this sub-regiou, the Cerambycidie being much the most numerous. Euryarthrum, Ceelosterna, Agclasta, and Astethes may be considered as most characteristic; but to name the curious and interesting forms would be to give a list of half the genera. For the relations of the Longicorns of the Indo-Malay, and those of the Austro-Malay region, the reader is referred to the chapter on the distribution of insects in the succeeding part of this work.

Terrestrial Mollusca.-The Philippine islands are celebrated as being one of the richest parts of the world for land shells, about 400 species being known. The other islands of the subregion are far less rich, not more than ahout 100 species having yet been described from the whole of them. Helix and Bulimus both abound in species in the Philippines, whereas the latter genus is very scarce in Boneo and Java. Ten genera of Helicidre inhabit the sub-region; Pfeifferia is found in the Philippines and Moluccas, while the large genus Cochlostyla is almost peculiar to the Philippines. Of the Operculata there are representatives of 20 genera, of which Dermatoma and Prpinelle are peculiar, while Registoma and Callia extend to the Australian region. Cyclophorus, Leptopoma, and Pupina are perhaps the most characteristic genera. 
The Zoological Relations of the Several Islands of the Indo-Malay Sub-region.

Althongh we have grouped the Philippine islands with the Indo-Malay sub-region, to which, as we shall see, they undoubtedly belong, yet most of the zoological characteristics we have just sketched out, apply more especially to the other groups of islands and the Malay peninsula. The Philippine islands stand, to Malaya proper, in the same relation that Madagascar does to Africa or the Antilles to South America; that is, they are remarkable for the absence of whole families and genera which everywhere characterise the remainder of the district. They are, in fact, truly insular, while the other islands are really continental in all the essential features of their natural history. Before, therefore, we can conveniently compare the separate islands of Malaya ${ }^{1}$ with each other, we must first deal with the Philippine group, showing in what its speciality consists, and why it must be considered apart from the sub-region to which it belongs.

Mammals of the Philippine Islands.-The only mammalia recorded as inhabiting the Philippine Islands are the following :- .

Quadrumana, 1. Macacus cynomolgus.

2. Cynopithecus niger. Dr. Semper doubts this being

LEMUROIDEA. 3. Tarsius spectrum.

a Philippine species.

Insectrvora, 4. Galeopithecus philippinensis.

Carnivora. 6. Viverra tangalunga.

On Dr. Semper's authority.

7. Paradoxurus philippensis.

Ungulata.

8. Sus (species).

9. Cervus mariannus.

On Dr. Semper's authority.

10. Cervus philippensis.

11. Cervus alfiedi。

12. Bos (species).

Rodretis, 13. Phlromys cummingii.

Wild cattle ; perhaps introduced.

14. Scuirus philippinensis.

Also 24 species, belonging to 17 genera, of bats.

1 As so many typical Malay groups are absent only from the Philippines, I have adopted the term "Malaya," to show the distribution of these, using the term "Indo-Malaya" when the range of the group includes the Thilippines. This must be remembered when consulting the tables of distribution at the end of this chapter. 
The foregoing list, although small, contains an assemblage of species which are wholly Oriental in character, and several of which (Tarsius, Galeopitherus, Tupaia) are characteristic and highly peculiar Malayan forms. At the same time these islands are completely separated from the rest of Malaya by the total absence of Semnopithecus, Hylobates, Felis, Helarctos, Rhinoceros, Manis, and other groups constantly found in the great IndoMalay islands and peninsula of Malacca. We find apparently two sets of animals : a more ancient series, represented by the deer, Graleopithecus, and squirrel, in which the species are distinct from any others; and a more recent series, represented by Macacus cynomolgus, and Viverra tangalunga, identical with common Malayan animals. The former indicate the earliest period when these volcanic islands were connected with some part of the Malayan sub-region, and they show that this was not geologically remote, since no peculiar generic types have been preserved or differentiated. The latter may indicate either the termination of the period of union, or merely the effects of introduction by man. The reason why a larger number of mammalian forms were not introduced and established, was probably because the union was effected only with some small islands, and from these communicated to other parts of the archipelago; or it may well be that later subsidences extinguished some of the forms that had established themselves.

Birds of the Philippine Islands. - These have been carefully investigated by Viscount Walden, in a paper read before the Zoological Society of London in 1873, and we are thus furnished with ample information on the relations of this important portion of the fauna.

The total number of birls known to inhabit the Philippines is 219, of which 106 are peculiar. If, however, following our usual plan, we take only the land-birds, we find the numbers to be 159 species, of which 100 are peculiar; an unusually large proportion for a group of islands so compraratively near to various parts of the Oriental and Australian regions. The families of birls which are more especially characteristic of the Indo-Maliy sul-region are about 28 in number, and examples 
of all these are found in the Philippines except four, viz., Cinclidæ, Phyllornithidæ, Eurylæmidæ, and Podargidæ. The only Philippine families which are, otherwise, exclusively AustroMalayan are, Cacatuidæ and Megapodiidæ. Yet although the birds are unmistakably Malayan, as a whole, there are, as in the mammalia (though in a less degree), marked deficiencies of most characteristic Malayan forms. Lord Walden gives a list of no less than 69 genera thus absent; but it will be sufficient here to mention such wide-spread and specially Indo-Malay groups as,-Eurylcomus, Nyctiornis, Arcichnothera, Geocichla, Malacopteron, Timalia, Pomatorhinus, Phyllornis, Iora, Criniger, Enicurus, Chaptia, Tchitrea, Dendrocitta, Eulabes, Palocornis, Miglyptes, Tiga, and Euplocamus. These deficiencies plainly show the isolated character of the Philippine group, and imply that it has never formed a part of that Indo-Malayan extension of the continent which almost certainly existed when the peculiar Malayan fauna was developed; or that, if it has been so united, it has been subsequently sulumerged and broken up to such an extent, as to cause the extinction of many of the absent types.

It appears from Lord Walder's careful analysis, that 31 of the Philippine species occur in the Papuan sub-region, and 47 in Celebes; 69 occur also in India, and 75 in Tava. This last fact is curious, since Java is the most remote of the Malayan islands, but it is found to arise almost wholly from the birds of that island being better known, since only one species, Xantholama rosea, is confined to the Philippine Islands and Java.

The wading and swimming birds are mostly of wide-spread forms, only 6 out of the 60 species being peculiar to the Philippine archipelago. Contining ourselves to the land-birds, and combining several of the minutely subdivided genera of Lord Walden's paper so as to agree with the arrangement adopted in this work, we find that there are 112 genera of land-birds represented in the islands. Of these, 50 are eithər cosmopolitan, of wide range, or common to the Oriental and Australian regions, and may be put aside as affording few indications of geographical alfinity. Of the remaining 62 no less than 40 are exclusively 
or mainly Oriental, and most of them are genera which range widely over the region, only two (P7itentomu and Rollulus) being exclusively Malayan, and two others (MCgrelurus and Mrelucocircus) more especially Indian or continental. Five other genera, though having a wide range, are typically I'alwarctic, and have reached the islands through Nortl China. They are, Monticola, Acrocephalus, Phylloscopus, Calliope, and Passer ; the two first having extended their range southward into the Moluccas. The peculiarly Australian genera are only 12, the majority being characteristic Papuan and Moluccan forms; such as-C'ampephaga, Alcyone, Cacatua, Tanygnathus, Ptilopus, Janthcenas, Phloganas, and Megupoctius. One is peculiar to Celebes (Prioniturus); one to the Papuan group (Cyclopsittc ) and one is chiefly Australian (Gerygone). The beautiful little parroquets forming the genus Loriculus, are characteristic of the Philippines, which possess 5 species, a larger number than occurs in any other group of islands, though they range from India to Flores. There remain six peculiar genera--Rhabdornis, an isolated form of creepers (Certhiidæ): Gymnops, a remarkable bareheaded bird belonging to the starlings (Sturnidæ); Desylophus, and Lepidogrammus, remarkable genera of cuckoos (Cuculidx); Penelopides, a peculiar hornbill, and Phapitreron, a genus of pigeons. Besides these there are four other types (here classed as sub-genera, but considered to be distinct by Lord Walden) which are peculiar to the I'hilippines. These are Pseudoptynx, an owl of the genus Athene; Pseudolalage, a sub-genus of Lalage; Zioccplues, a sub-genus of I'chitrea; and Ptilocolpa, included under Carpophaga.

When we look at the position of the Philippine group, connected by the Bashee islands with Formosa, by Palawan and the Sooloo archipelago with Borneo, and by the Tulour and other islets with the Moluccas and Celebes, we have little difficulty in accounting for the peculiarities of its bird fauna. The absence of a large number of Malayan groups would indicate that the actual connection with Borneo, which seems necessary for the introduction of the Malay types of manmalia, was mot of long duration; while the large proportion of wide-spread continental genera of birds would scem to imply that greater facilities had 
once existed for immigration from Southern China, perhaps by a land connection through Formosa, at which time the ancestors of the peculiar forms of deer entered the country. It may indeed be objected that our knowledge of these islands is far too imperfect to arrive at any satisfactory conclusions as to their former history; but although many more species no doubt remain to be discovered, experience shows that the broad characters of a fauna are always determined by a series of collections made by different persons, at various localities, and at different times, even when more imperfect than those of the Philippine birds really are. The isolated position, and the volcanic structure of the group, would lead us to expect them to be somewhat less productive than the Moluccas, close to the rich and varied Papuan district,-- or than Celebes, with its numerous indications of an extensive area and great antiquity; and taking iuto account the excessive poverty of its mammalian fauna, which is certain to be pretty well known, I am inclined to believe that no future discoveries will materially alter the character of Philippine ornithology, as determined from the materials already at our cornmand.

Jara.-Following the same plan as we have adopted in first discussing the Philippine islands, and separating them from the body of the sub-regrion on account of special peculiarities, we must next take Java, as possessing marked individuality, and as being to soine extent more isolated in its productions than the remaining great islands.

Java is well supplied with indigenous mammalia, possessing as nearly as can be ascertained 55 genera and 90 species. None of these genera are peculiar, and only about 5 of the species, -3 quadrumana, a deer and a wile pig. So far then there is nothing remarkable in its fauna, but on comparing it with that of the other great islanls, viz., Borneo and Sumatra, and the Malay peninsula, we find an unmistakable deficiency of characteristic forms, the same in kind as that we have just commented on in the case of the Philipuines, though much less in degree. First, taking gonera which are found in all three of the above-named 
localities and which must therefore be held to be typical Malayan groups, the following are absent from Java: Viverra, Gymnopus, Lutra, Helarctos, T'apirus, Elephas, and Gymnura; while of those known to occur in two, and which, owing to our imperfect knowledge, may very probably one day be discovered in the third, the following are equally wanting: Simia, Siamanga, Hemigalea, Paguma, Rhinosciumus, and Rhizomys. It may be said this is only negative evidence, but in the case of Java it is much more, because this island is not only the best known of any in the archipelago, but there is perhaps no portion of British India of equal extent so well known. It is one of the oldest of the Dutch possessions and the seat of their colonial government; good roads traverse it in every direction, and experienced naturalists have been resident in various parts of it for years together, and have visited every mountain and every forest, aided by bands of diligent native collectors. We should be almost as likely to find new species of mammalia in Central Europe as in Java; and therefore the absence of such animals as the Malay bear, the elephant, tapir, gymnura, and even less conspicuous forms, must be accepted as a positive fact.

In the other islands there are still vast tracts of forest in the hands of natives and utterly unexplored, and any similar absence in their case will prove little; yet on making the same comparison in the case of Borneo, the most peculiar and the least known of the other portions of the sub-region, we find only 2 genera absent which are found in the three other divisions, and only 3 which are found in two others. A fact to be noted also is, that the only genus found in Java but not in other parts of the sub-region (Helictis) occurs again in North India; and that some Javan species, as Rhinoceros javanicus, and Lepus kurgosa occur again in the Indo-Chinese sub-region, but not in the Malayan.

Among the birds we meet with facts of a similar import; and though the absence of certain types from Java is not quite so certain as among the mammalia, this is more than balanced by the increased number of such deficiencies, so that if a few 
should be proved to be erroneous, the main result will remain unaltered.

Java possesses about 270 species of land birds, of which about 40 are peculiar to it. There are, however, very few peculiar genera, Laniellus, a beautiful spotted shrike, being the most distinct, while Cochoa and Psaltria are perhaps not different from their Indian allies. The island has however a marked individuality in two ways-in the absence of characteristic Malayan types, and in the presence of a number of forms not yet found in any of the other Malay islands, but having their nearest allies in various parts of the Indo-Chinese sub-region. The following 16 genera are all found in Malacca, Sumatra, and Borneo, but are absent from Java: Setornis, Temnurus, Dendrocitta, Corydon, Calyptomena, Venilia, Reinwardtipicus, Caloramphus, Rhinortha, Nyctiornis, Cranorhinus, Psittinus, Polyplectron, Argusianus, Euplocamus, and Rollulus. The following 9 are known from two of the above localities, and will very probably be found in the third, but are absent from, and not likely to occur in, Java: Trichixos, Eupetes, Melanochlora, Chaptia, Pityriasis, Lyncornis, Carpococcyx, Poliococcyx, and Rhinoplax. We have thus 25 typically Malayan genera which are not known to occur in Java.

The following genera, on the other hand, do not occur in any of the Malayan sub-divisions except Java, and they all occur again, or under closely allied forms, in the Indo-Chinese subregion: Brachypteryx (allied species in Himalayas); Zoothera allied species in Aracan); Notodela (allied species in Pegu); Pnoёpyga (allied species in Himalayas); Allotrinos (allied species in the Himalayas); Cochoc (allied species in the Himalayas); Crypsirhina (allied species in Burmah); Estrilda (allied species in India); Psaltria (allied genus-Egithaliscus-in Himalayas); Pavo muticus and Harpactes oreskios (same species in Siam and Burmah); Cecropis striolata (same species in Java and Formosa, and allied species in India).

Here we have 12 instances of very remarkable distribution, and considering that there are nearly as many birds known from Sumatra and Borneo as from Java, and considerably more from 
the Malay peninsula, it is not likely that many of these well marked forms will be discovered in these countries.

There are also a considerable number of species of birds common to Malacca, Sumatra, and Borneo, but represented in Java by distinct though closely allied species. Such are,-

$\begin{array}{lccl}\text { Venilia malaccensis } & \text { (represented in Java by) } & \text { D. miniata. } \\ \text { Drymocataphus nigrocapitalus } & " & " & \text { D. capistralus. } \\ \text { Malacopteron coronatum } & " & " & \text { M. ruffrons. } \\ \text { Irena cyanea } & " & " & \text { I. turcosa. } \\ \text { Ploceus baya } & " & " & P . \text { hypoxantha. } \\ \text { Loriculus galgulus } & " & " & \text { L. pusillus. } \\ \text { Ptilopus jambu } & " & " & P . \text { porphyreus. }\end{array}$

Now if we look at our map of the region, and consider the position of Java with regard to Borneo, Sumatra, and the IndoChinese peninsula, the facts just pointed out appear most anomalous and perplexing. First, we have Java and Sumatra forming one continuous line of volcanoes, separated by a very narrow strait, and with all the appearance of having formed one continuous land; yet their productions differ considerably, and those of Sumatra show the closest resemblance to those of Porneo, an island ten times further off than Java and differing widely in the absence of volcanoes or any continuous range of lofty mountains. Then again, not only does Java differ from these two, but it agrees with a country beyond them botha country from which they seem to have a much better chance to have been supplied by immigration than Java has, and to have (almost necessarily) participated, even more largely, in the benefits of any means of transmission capable of reaching the latter island. Yet more; whatever changes have occurred to bring about the anomalous state of things that exists must liave been, zoologically and geologically, recent; for the strange crossaffnities between Java and the Indo-Chinese continent (in which Sumatra and Borneo have not participated), as well as that between Malacca, Sumatra, and Borneo (in which Java has not participated) are exhibited, in many cases by community of species, in others by the presence of very closely allied forms of the same generd, of mammalia and birds. Now we know that 
these higher animals become replaced by allied species much more rapidly than the mollusca; and it is also pretty certain that the modification by which this replacement is effected takes place more rapidly when the two sets of individuals are isolated from each other, and especially when they are restricted to islands, where they are necessarily subject to distinct and pretty constant conditions, both physical and organic. It becomes therefore almost a certainty, that Siam and Java on the one hand, and Sumatra, Borneo, and Malacca on the other must have been brought into some close connexion, not earlier than the newer Pliocene period; but while the one set of countries were having their meeting, the other must have been by some means got out of the way. Before attempting to indicate the mode by which this might have been effected in accordance with what we know of the physical geography, geology, and vegetation of the several islands, it will be as well to complete our sketch of their zoological relations to each other, so as ascertain with some precision, what are the facts of distribution which we have to explain.

Malacca, Sumatra, and Borneo--After having set apart the Philippine Islands and Java, we have remaining two great islands and a peninsula, which, though separated by considerable arms of the sea, possess a fauna of wonderful uniformity having all the typical Malayan features in their full development. Their unity is indeed so complete, that we can find hardly any groups of sufficient importance by which to differentiate them from each other; and we feel no confidence that future discoveries may not take away what speciality they possess. One after another, species or genera once peculiar to Borneo or Sumatra have bcen found elsewhere; and this has gone to such an extent in birds, that hardly a peculiar genus and very few peculiar species are left in either island. Bornco however is undoubtedly the most peculiar. It possesses thrce senera of Mammalia not found elsewhere: C'ynogale, a cuilous carnivore allied to the otters; with Dendrogale and Ptilocerus, small insectivora allied to Tupeice. It has Simic, the Orang- 
utan, and Petyeme, one of the Viverride, in common with Sumatra ; as well as Rhinosciurus, a peculiar form of squirrel, and Hemigalea, one of the Viverridx, in common with Malacca. Sumatra has only one genus not found in any other Malayan district-Nemorhedus, a form of antelope which occurs again in North India. It also has Siamanga in common with Malacea, Mydaus with Java, and Rhizomys with India. The Malay Peninsula seems to have no peculiar forms of Mammalia, though it is rich in all the characteristic Malay types.

The bats of the various islands have been very unequally collected, 36 species being recorded from Java, 23 from Sumatra, but only 16 each from Borneo and Malacca. Leaving these out of consideration, and taking into account the terrestrial mammals only, we find that Java is the poorest in species, while Borneo, Sumatra, and Malacca are tolerably equal; the numbers being $55,62,66$, and 65 respectively. Of these we find that the species confined to each island or district are (in the same order). 6, 16, 5, and 6 . It thus appears that Borneo is, in its mammalia, the most isolated and peculiar; next comes Sumatra, and then Malacca and Java, as shown by the following table.

\begin{tabular}{lccccccc} 
& \multicolumn{9}{c}{$\begin{array}{c}\text { Peculiar } \\
\text { Genera. }\end{array}$} & & & & Peculiar \\
Species. & \\
Borneo ... & $\ldots$ & $\ldots$ & 4 & $\ldots$ & $\ldots$ & $\ldots$ & 16 \\
Sumatra & $\ldots$ & $\ldots$ & 1 & $\ldots$ & $\ldots$ & $\ldots$ & 5 \\
Malacca & $\ldots$ & $\ldots$ & 0 & $\ldots$ & $\ldots$ & $\ldots$ & 6 \\
Java $\ldots$ & $\ldots$ & $\ldots$ & 0 & $\ldots$ & $\ldots$ & $\ldots$ & 6
\end{tabular}

This result differs from that which we have arrived at by the more detailed consideration of the fauna of Java; and it serves to show that the estimate of a country by the number of its peculiar genera and species alone, may not always represent its true zoological importance or its most marked features. Java, as we have seen, is differentiated from the other three districts by the absence of numerous types common to them all, and by its independent continental relations. Borneo is also well distinguished by its peculiar genera and specific types, yet it is at the same time more closely related to Sumatra and Malacca than is Java. The two islands have evidently had a very different history, which a detailed knowledge of their geology 
would alone enable us to trace. Should we ever arrive at a fair knowledge of the physical changes that have resulted in the present condition, we shall almost certainly find that many of the differences and anomalies of their existing fauna and flora will be accounted for.

In Birds we hardly find anything to differentiate Borneo and Sumatra in any clear manner. Pityriasis and Carpococcyx, once thought peculiar to the former, are now found also in the latter; and we have not a single genus left to characterize Borneo except Schwaneria a peculiar fly-catcher, and Indicator, an African and Indian group not known to occur elsewhere in the Malay sub-region. Sumatra as yet alone possesses Psilopogon, a remarkable form of barbet, but we may well expect that it will be soon found in the interior of Borneo or Malacca; it also has Berenicornis, an African form of hornbill. The Malay Peninsula appears to have no genus peculiar to it, but it possesses some Chinese and Indian forms which do not pass into the islands. As to the species, our knowledge of them is at present very imperfect. The Malay Peninsula is perhaps the best known, but it is probable that both Sumatra and Borneo are quite as rich in species. With the exception of the genera noted above, and two or three others as yet found in two islands only, the three districts we are now considering may be said to have an almost identical bird-fauma, consisting largely of the sime species and almost wholly of these together with closely allied species of the same genera. There are no well-marked groups which especially characterise one of these islands rather than the other, so that even the amount of speciality which Porneo undoubtedly exhibits as regards mammalia, is only faintly shown by its birds. The Pittidre may perhaps be named as the most characteristic Bornean group, that island possessing six species, three of which are peculiar to it and are among the most beautiful birds of an unusually beautiful family. Yet Sumatra possesses two peculiar, and hardly less remarkable species.

In other classes of vertebrates, in insects, and in land-shells, our knowledge is far too imperfect to allow of our making any useful comparison between the faunas. 
Banca.-We must, however note the fact of peculiar species occurring in Banca, a small island close to Sumatra, and thus offering another problem in distribution. A squirrel (Sciurus bangkanus) is allied to three species found in Malacca, Sumatra, and Borneo respectively, but quite as distinct from them all as they are from each other. More curious are the two species of Pitta peculiar to Banca; one, Pitta megarhynchus, is allied to the $P$. brachyurus, which inbabits the whole sub-region and extends to Siam and China, but differs from it in its very large bill and differently coloured head; the other, $P$. bangkanus, is allied to P. cucullatus, which extends from Nepal to Malacca, and to $P$. sordidus, which inhabits both Borneo and Sumatra as well as the Philippines.

We have here, on a small scale, a somewhat similar problem to that of Java, and as this is comparatively easy of solution we will consider it first. Although, on the map, Banca is so very close to Sumatra, the observer on the spot at once sees that the proximity has been recently brought about. The whole southeast coast of Sumatra is a great alluvial plain, hardly yet raised above the sea level, and half flooded in the wet season. It is plainly a recent formation, caused by the washing down into a shallow sea of the débris from the grand range of volcanic mountains 150 miles distant. Banca, on the other hand is, though low, a rugged and hilly island, formed almost wholly of ancient rucks of apparently volcanio origin, and closely resembling parts of the Malay Peninsula and the intervening chain of small islands. There is every appearance that Banca once formed the extremity of the Peninsula, at which time it would probably have been separated from Sumatra by 50 or 100 miles of sea. Its productions should, therefore, most resemble those of Singapore and Malacca, and the few peculiar species it possesses will be due to their isolation in a small tract of country, surrounded by a limited number of animal and vegetable forms, and Eubject to the influence of a peculiar soil and climate. The parent species existing in such large tracts as Borneo or Sumatra, subjected to more varied conditions of soil, climate, vegetation, food, and enemies, would preserve, almost or quite 
unchanged, the characteristics which had been developed under nearly identical conditions when the great island formed part of the continent. Geology teaches us that similar changes in the forms of the higher vertebrates have taken place during the Post-Tertiary epoch; and there are other reasons for believing that, under such conditions of isolation as in Banca, the change may have required but a very moderate period, even reckoned in years. We will now return to the more difficult problem presented by the peculiar continental relations of Java, as already detailed.

\section{Probable Recent Geographical Changes in the Indo-Malay} Islands.-Although Borneo is by far the largest of the IndoMalay islands, yet its physical conformation is such that, were a depression to occur of one or two thousand feet, it would be reduced to a smaller continuous area than either Sumatra or Java. Except in its northern portion it possesses no lofty inountains, while alluvial valleys of great extent penetrate far into its interior. A very moderate depression, of perhaps 500 feet, would convert it into an island shaped something like Celebes; and its mountains are of so small an average elevation, and consist so much of isolated hills and detached ranges, that a depression of 2,000 feet would almost certainly break it up into a group of small islands, with a somewhat larger one to the north. Sumatra (and to a less extent Java) consists of an almost continuous range of lofty mountains, connected by plateaus from 3,000 to 4,000 feet high ; so that although a depression of 2,000 feet would greatly diminish their size, it would probably leave the former a single island, while the latter would be separated into two principal islands of still considerable extent. The enormous amount of volcanic action in these two islands, and the great number of conical mountains which must have been slowly raised, chiefly by ejected matter, to the height of 10,000 and 12,000 feet, and whose shape indicates that they have been formed above water, renders it almost certain that for long periods they have not undergone submersion to any considerable extent. In liornen, however, wo have no such evilences. No volcano, 
active or extinct, is known in its entire area; while extensive beels of coal of tertiary age, in every part of it, prove that it has been subject to repeated submersions, at no distant date geologically. An indication, if not a proof, of still more recent sulsmersion is to be found in the great alluvial valleys which on the south and south-west extend fully 200 miles inland, while they are to a less degree a characteristic feature all round the island. These swampy plains have been formed by the combined action of rivers and tides; and they point clearly to an immediately preceding state of things, when that which is even now barely raised above the ocean, was more or less sunk below it.

These various indications enable us to claim, as an admissible and even probable supposition, that at some epoch during the Pliocene perind of geology, Borneo, as we now know it, did not exist; but was represented by a mountainous island at its present northern extremity, with perhaps a few smaller islets to the south. We thus have a clear opening from Java to the Siamese Peninsula; and as the whole of that sea is less than 100 fathoms deep, there is no difficulty in supposing an elevation of land connecting the two together, quite independent of Borneo on the one hand and Sumatra on the other. This union did not probably last long; but it was sufticient to allow of the introduction into Java of the Rhinoceros jaranicus, and that group of IndoChinese and Himalayan species of mammalia and birds which it alone possesses. When this ridge had disappeared by subsillence, the next elevation occurred a little more to the east, and produced the union of many islets which, aided by subaerial denudation, formed the present island of Bomeo. It is frobable that this elevation was sufficiently extensive to unite Borneo for a time with the Malay P'eninsula and Sumatra, thus helping to produce that close resemblance of genera and even of species, which these countries exhibit, and obliterating much of their former speciality, of which, however, we have still some traces in the long-nosed monkey and Ptilocerus of Jorneo, and the considerable number of genera both of mammalia and hirds confined to two only out of the three divisions of typiral Malayil. The subsidence which ngain divided these 
countries by arms of the sea rather wider than at present, might have left Banca isolated, as already referred to, with its proportion of the common fauna to be, in a few instances, subsequently modified.

Thus we are enabled to understand how the special relations of the species of these islands to each other may have been brought about. To account for their more deep-seated and general zoological features, we must go farther back.

Probable Origin of the Malayan Fauna.-The typical Malayan fauna is essentially an equatorial one, and must have been elaborated in an extensive equatorial area. This ancient land almost certainly extended northward over the shallow sea as far as the island of Palawan, the Paracels shoals and even Hainan. To the east, it may at one time have included the Philippines and Celebes, but not the Moluccas. To the south it was limited by the deep sea beyond Java. It included all Sumatra and the Nicobar islands, and there is every reason to believe that it stretched out also to the west so as to include the central peak of Ceylon, the Maldive isles, and the Cocos islands west of Sumatra. We should then have an area as extensive as South America to $15^{\circ}$ south latitude, and well calculated to develop that luxuriant fauna and flora which has since spread to the Himalayas. The submergence of the western half of this area (leaving only a fragment in Ceylon) would greatly diminish the number of animals and perhaps extinguish some peculiar types; but the remaining portion would still form a compact and extensive district, twice as large as the peninsula of India, over the whole of which a uniform Malayan fauna would prevail. The first important change would be the separation of Celebes; and this was probably effected by a great subsidence, forming the deep strait that now divides that island from Borneo. During the process Celebes itself was no doubt greatly submerged, leaving only a few islands in which were preserved that remnant of the ancient Malayan fauna that now constitutes one of its most striking and anomalous features. The Philippine area would next be separated, and perhaps be alnost wholly submerged; or 
broken up into many small volcanic islets in which a liniterl number of Mialayan types alone survived. Such a condition of things will account for the very small variety of mammalia conpared with the tolerably numerous grenera of birds, that now chirracterise its fauna; while both here and in Celebes we fincl some of the old Malayan types preserved, which, in the extended area of the Sunda Isles liave been replaced by more dominant forms.

The next importaut change would be the separation of Java; and here also no doubt a considerable submergence occurrerl, rendering the island an unsuitable habitation for the varions Malay types whose absence forms one of its conspicuous features. It has since remained permanently separated from the other islands, and lias no doubt developed some peculiar species, while it may have preserved some ancient forms which in the larger area have become clianged. From the fact that a number of its species are confined either to the western or the eastern half of the island, it is probable that it long continued as two islands, which have become united at a comparatively recent perioul. It has also been subjected to the immigration of Indo-Chinese forms, as already referred to in the earlier part of this sketcli.

We have thus shown how the main zoological features of the several sub-divisions of the Malayan sub-region may be accounted for, by means of a series of suppositions as to past changes which, though for the most part purely hypothetical, are always in accordance with what we know both of the physical geography and the zoology of the districts in question and those which surround them. It may also be remarked, that we know, with a degree of certainty which may be called absolute, that alternate elevation and subsidence is the normal state of things all over the globe; that it was the rule in the earliest geological epochs, and that it has continued down to the historical era. We know too, that the amonnt of clevation and subsidence that can be proved to have occurred again and again in the same area, is often much greater than is required for the changes here speculated on, - while the time required for such changes is certainly less than that necessitated by the changes 
of specific and generic forms which have coincided with, and been to a large extent dependent on them. We have, therefore, true causes at work, and our only suppositions have been as to how those causes could have brought about the results which we see; and however complex and unlikely some of the supposed changes may seem to the reader, the geologist who has made a study of such changes, as recorded in the crust of the earth, will not only admit them to be probable, but will be inclined to believe that they have really been far more complex and more unexpected than any supposition we can make about them.

There is one other external relation of the Malayan fauna about which it may be necessary to say a few words. I have supposed the greatest westward extension of the Malayan area to be indicated by the Maldive islands, but some naturalists would extend it to include Madagascar in order to account for the range of the Lemuridie. Such an extension would, however, render it difficult to explain the very small amount of correspondence with a pervading diversity, between the Malayan and Malagasy faunas. It seems more reasonable to suppose an approximation of the two areas, without actual union having ever occurred. This approximation would have allowed the interchange of certain genera of birds, which are common to the Oriental Region and the Mascarene islands, but it would have been too recent to account for the diffusion of the lemurs: which belong to distinct genera and even distinct families. This probably dates lack to a much earlier period, when the lemurine type had a wide range over the northern hemisphere. Subjected to the competition of higher forms, these imperfectly developed groups have mostly died out, except a few isolated examples, chiefly found in islands, and a few groups in Africa.

In our discussion of the origin of the Ethiopian fauna, we have supposed that a close connection once existed between Madagascar and Ceylon. This was duriug a very early tertiary epoch; and if, long after it had ceased and the fauna of Ceylon and South India had assumed somewhat more of their present chararter, we suppose the approximation or union of Ceylon 
and Malaya to have taken place, we shall perhaps be able to account for most of the special affinities they present, with the least amount of simultaneous elevation of the ocean bed; which it must always be remembered, requires a corresponding depression elsewhere to balance it.

Concluding Remarks on the Oriental Region.-We have already so fully discussed the internal and external relations of the several sub-regions, that little more need be said. The rich and varied fauna which inhabited Europe at the dawn of the tertiary period,-as shown by the abundant remains of mammalia wherever suitable deposits of Eocene age have been discovered,proves, that an extensive Palæarctic continent then existed; and the character of the flora and fauna of the Eocene deposits is so completely tropical, that we may be sure there was then no barrier of climate between it and the Oriental region. At that early period the northern plains of Asia were probaily under water, while the great Thibetan plateau and the Himalayan range, had not risen to more than a moderate height, and would have supported a luxuriant sub-tropical flora and fauna. The Upper Miocene deposits of northern and central India, and Burmah, agree in their mammalian remains with those of central and southern Europe, while closely allied forms of elephant, hyæna, tapir, rhinoceros, and Chalicotheriun have occurred in North China; leading us to conclude that one great fauna then extended over much of the Oriental and Palæarctic regions. Perim island at the mouth of the Red Sea, where similar remains are found, probably shows the southern boundary of this part of the old Palæarctic region in the Miocene period. Towards the equator there would, of course, be some peculiar groups; but we can hardly doubt, that, in that wonderful time when even the lands that stretched out furthest towards the pole, supported a luxuriant forest vegetation, substantially one fauna ranged over the whole of the great eastern continent of the northern hemisphere. I) uring the Pliocene period, however, a progressive change went on which resulted in the complete differentiation of the Oriental and Palcarctic fanmas. The 
causes of this change were of two kinds. There was a great geographical and physical revolution effected by the elevation of the Himalayas and the Thibetan plateau, and, probably at the same time, the northward extension of the great Siberian plains. This aloue would produce an enormous change of climate in all the extra-tropical part of Asia, and inevitably lead to a segregation of the old fauna into tropical and temperate, and a modification of the latter so as to enable it to support a climate far more severe than it had previously known. But it is almost certain that, concurrently with this, there was a change going on of a cosmical nature, leading to an alteration of the climate of the northern hemisphere from equable to extreme, and culminating in that period of excessive cold which drove the last remnants of the old sub-tropical fauna beyond the limits of the Palæarctic region. From that time, the Oriental and the Ethiopian regions alone contained the descendants of many of the most remarkable types which had previously flourished over all Europe and Asia; but the early history of these two regions, and the peculiar equatorial types developed in each, sufficiently separate them, as we have already shown. The Malayan sub-region is that in which characteristic Oriental types are now best developed, and where the fundamental contrast of the Oriental, as compared with the Ethiopian and Palæarctic regions, is most distinctly visible. 


\section{TABLES OF DISTRIBUTION.}

In constructing these tables, showing the distribution of various classes of animals in the Oriental region, the following sources of information have been chiefly relied on, in addition to the general treatises, monographs, catalogues, \&c., used for the compilation of the Fourth Part of this work.

Mammalia.--Jerdon's Indian Mammalia; Kelaart's Fauna of Ceylon; Horsfield and Moore's Catalogue of the East India Museum; Swinhoe's Catalogue of Chinese Mammalia; S. Muiller's Zoology of the Indian Archipelago; Dr. J. E. Gray's list of Mammalia of the Malay Archipelago (Voyage of Samarang); and papers by Anderson, Blyth, Cantor, Gray, Peters, Swinhoe, \&c.

Birds.-Jerdon's Birds of India; Horsfield and Moore's Catalogue; Holdsworth's list of Ceylon Birds; Schlegel's Catalogue of the Leyden Museum; Swinhoe on the Birds of China, Formosa, and Hainan; Salvadori on the Birds of Borneo; Lord Walden on the Pirds of the Philippine Islands; and papers by Blyth, Blanford, Elwes, Elliot, Stoliczka, Sclater, Sharpe, Swinhoe, Verreaux, and Lord Walden.

Reptiles.-Guinther's Reptiles of British India; papers by same author, and by Dr. Stoliczka. 


\section{TABLE I.}

\section{FAMILIES OF ANIMALS INHABITING THE ORIENTAL REGION.}

Explanation.

Names in itatics show families peculiar to the region.

Numbers correspond with those in Part IV.

Names enclosed thus (.....) barely enter the region, and are not considered really to belong to it.

\begin{tabular}{|c|c|c|c|c|c|}
\hline \multirow[b]{2}{*}{ Order and Fanily. } & \multicolumn{4}{|c|}{ Sub-regions. } & \multirow[b]{2}{*}{ Range beyond the Region. } \\
\hline & 密苟 & 离 & 递总 & 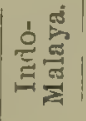 & \\
\hline $\begin{array}{l}\text { MAMMALIA. } \\
\text { PPIMATES. } \\
\text { 1. Siniidæ ... ... } \\
\text { 2. Semnopithecidæ } \\
\text { 3. Cynopithecidæ } \\
\text { 6. Lenuridæ } \\
\text { 7. Tarsiidœ... }\end{array}$ & - & - & E & $\begin{array}{l}- \\
- \\
- \\
-\end{array}$ & $\begin{array}{l}\text { W. Africa } \\
\text { Tropical Africa } \\
\text { All Africa, S. Palæarctic } \\
\text { Ethiopian } \\
\text { Celebes }\end{array}$ \\
\hline $\begin{array}{l}\text { Chiroptera. } \\
\text { 9. Pteropidæ .. } \\
\text { 11. Rhinolophidæ } \\
\text { 12. Vespertilionidæ } \\
\text { 13. Noctilionidæ ... }\end{array}$ & $\begin{array}{l}- \\
- \\
-\end{array}$ & E & $\begin{array}{l}- \\
\text { - }\end{array}$ & \begin{tabular}{c|}
- \\
-- \\
-
\end{tabular} & $\begin{array}{l}\text { Ethiopian, Australian } \\
\text { The Eastern Hemisphere } \\
\text { Cosmopolite } \\
\text { Tropical regions }\end{array}$ \\
\hline $\begin{array}{l}\text { INSECTIVoRA. } \\
\text { 14. Galeopithecidae } \\
\text { 16. Tupaiidoe } \\
\text { 17. Erinaceidæ } \\
\text { 21. . Talpidæ } \\
\text { 22. }\end{array}$ & - & - & $\begin{array}{l}- \\
- \\
-\end{array}$ & \begin{tabular}{l|l}
- & - \\
- & \\
- &
\end{tabular} & $\begin{array}{l}\text { Palæarctic, S. Africa } \\
\text { Palæarctic, Nearctic } \\
\text { Palæarctic, Ethiopian, N. America }\end{array}$ \\
\hline 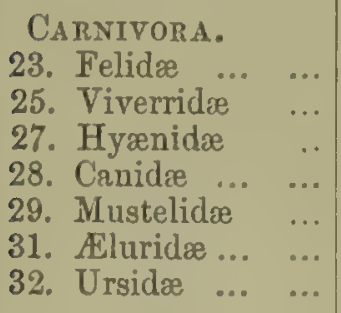 & $\begin{array}{l}- \\
- \\
-\end{array}$ & $\begin{array}{l}- \\
- \\
-\end{array}$ & $\begin{array}{l}- \\
- \\
-\end{array}$ & $\begin{array}{l}- \\
- \\
- \\
-\end{array}$ & $\begin{array}{l}\text { All regions but Australian } \\
\text { Ethiopian, S. Palæarctic } \\
\text { Ethiopian, S. Palæarctic } \\
\text { All regions but Australian [?] } \\
\text { All regions but Australian } \\
\text { Paloarctic } \\
\text { Palæarctic, Nearctic, Chili }\end{array}$ \\
\hline Cetacea. & & & & & Oceanic \\
\hline $\begin{array}{l}\text { Sirenia. } \\
\text { 42. Manatidæ }\end{array}$ & - & - & -- & -- & Ethiopian, N. Pacific \\
\hline $\begin{array}{l}\text { UNGULATA. } \\
\text { 3. (Hquidir). }\end{array}$ & & & & & Palæarctic, Ethiopian \\
\hline
\end{tabular}




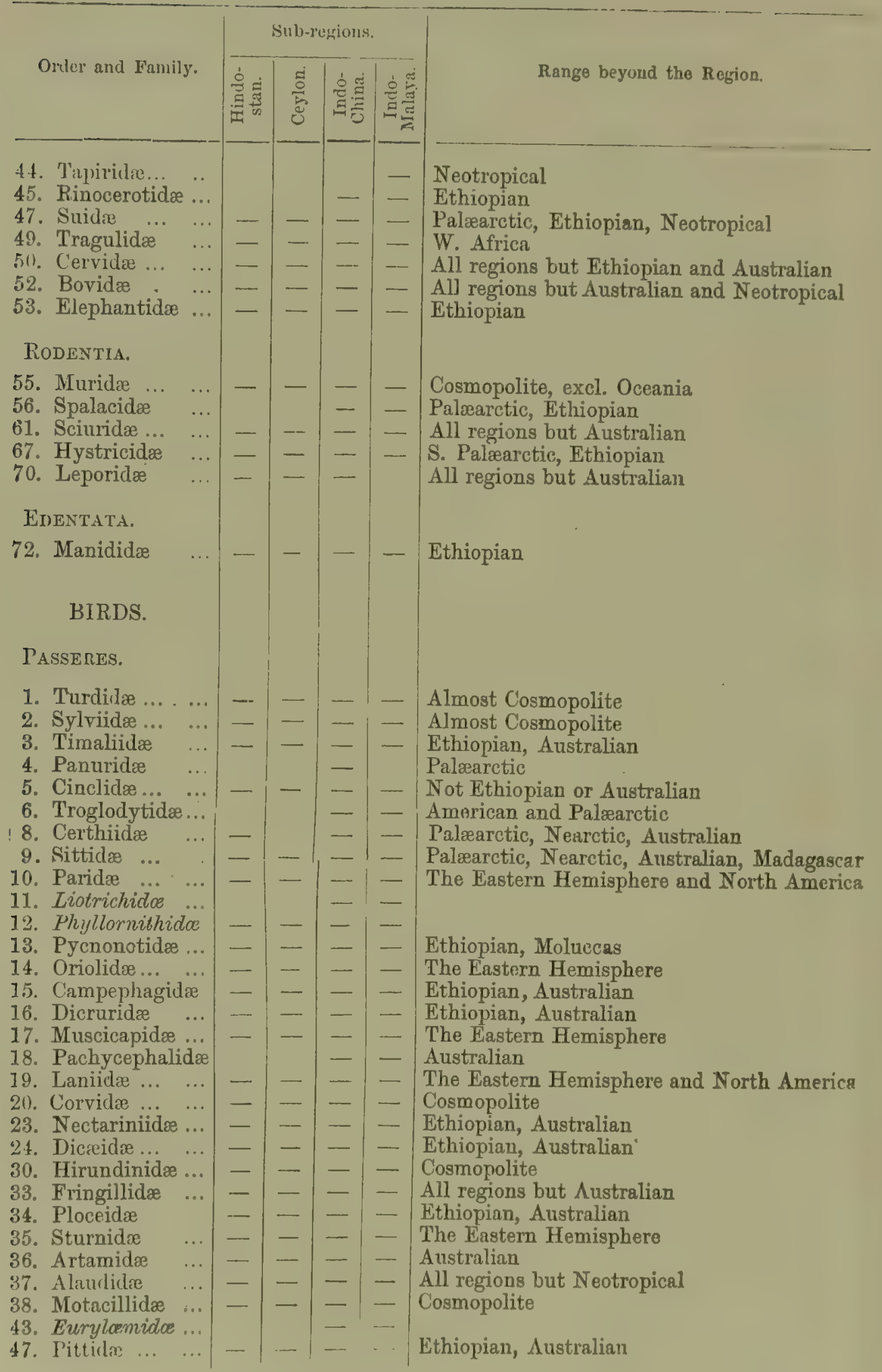




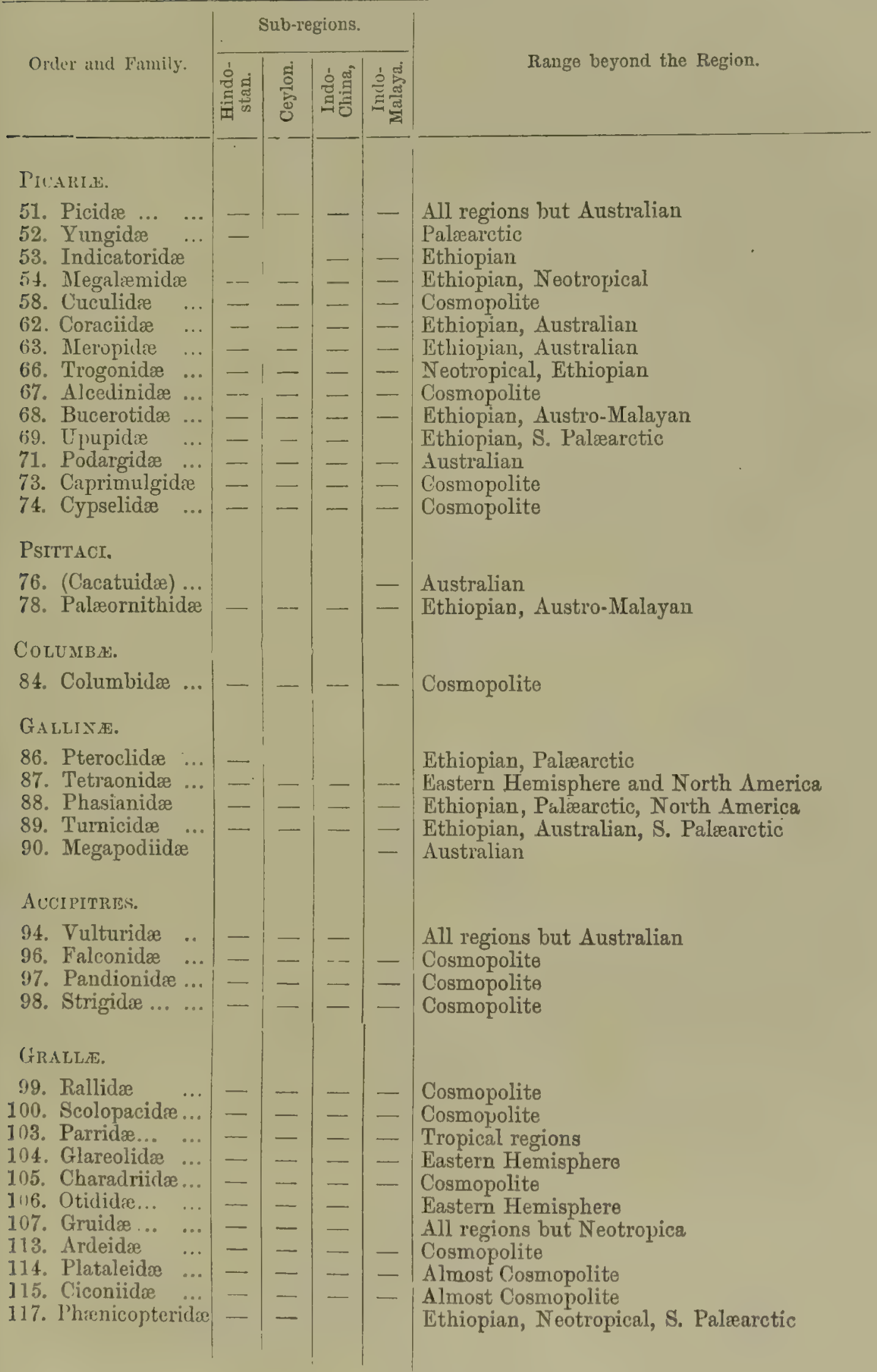




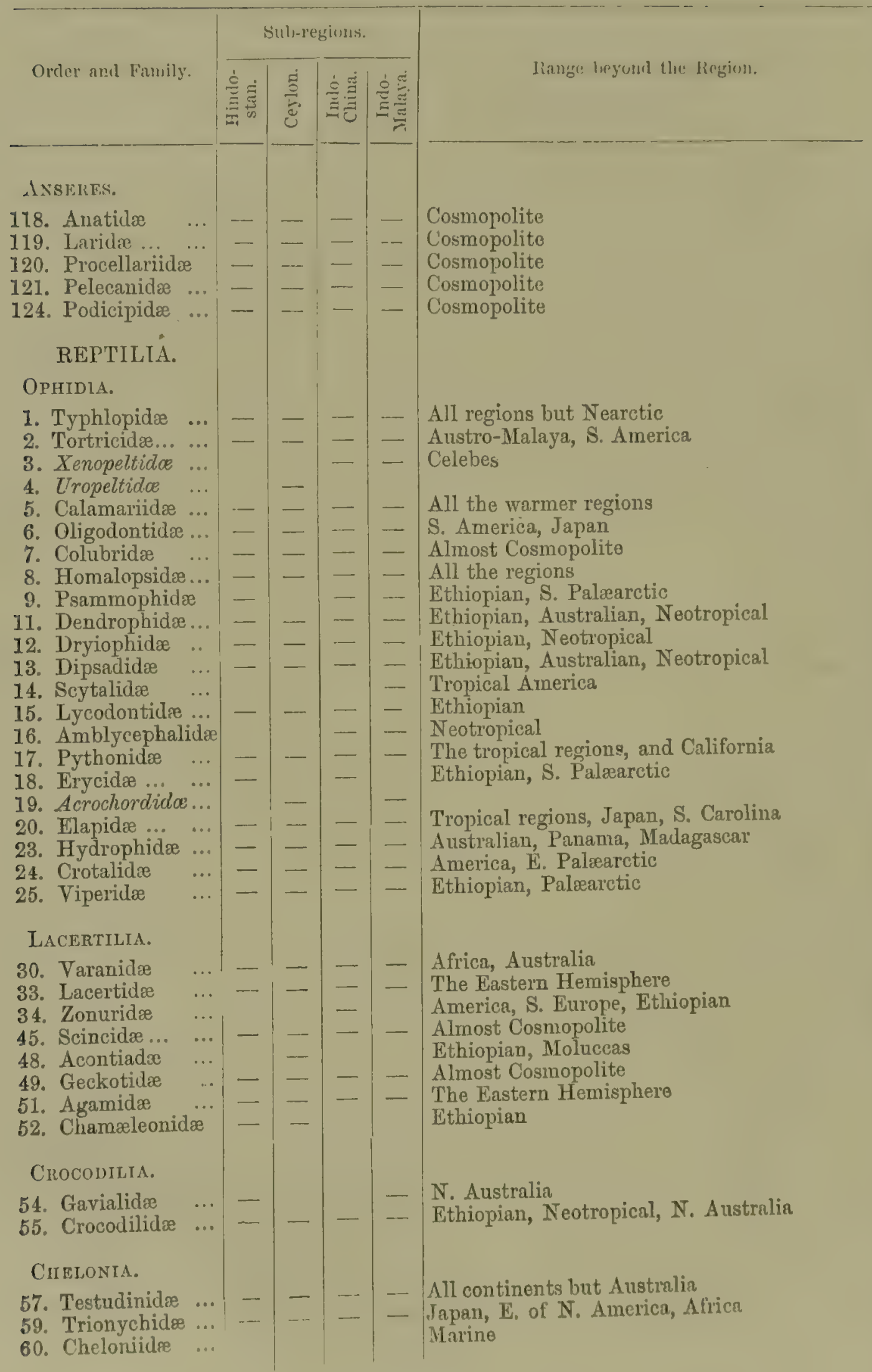




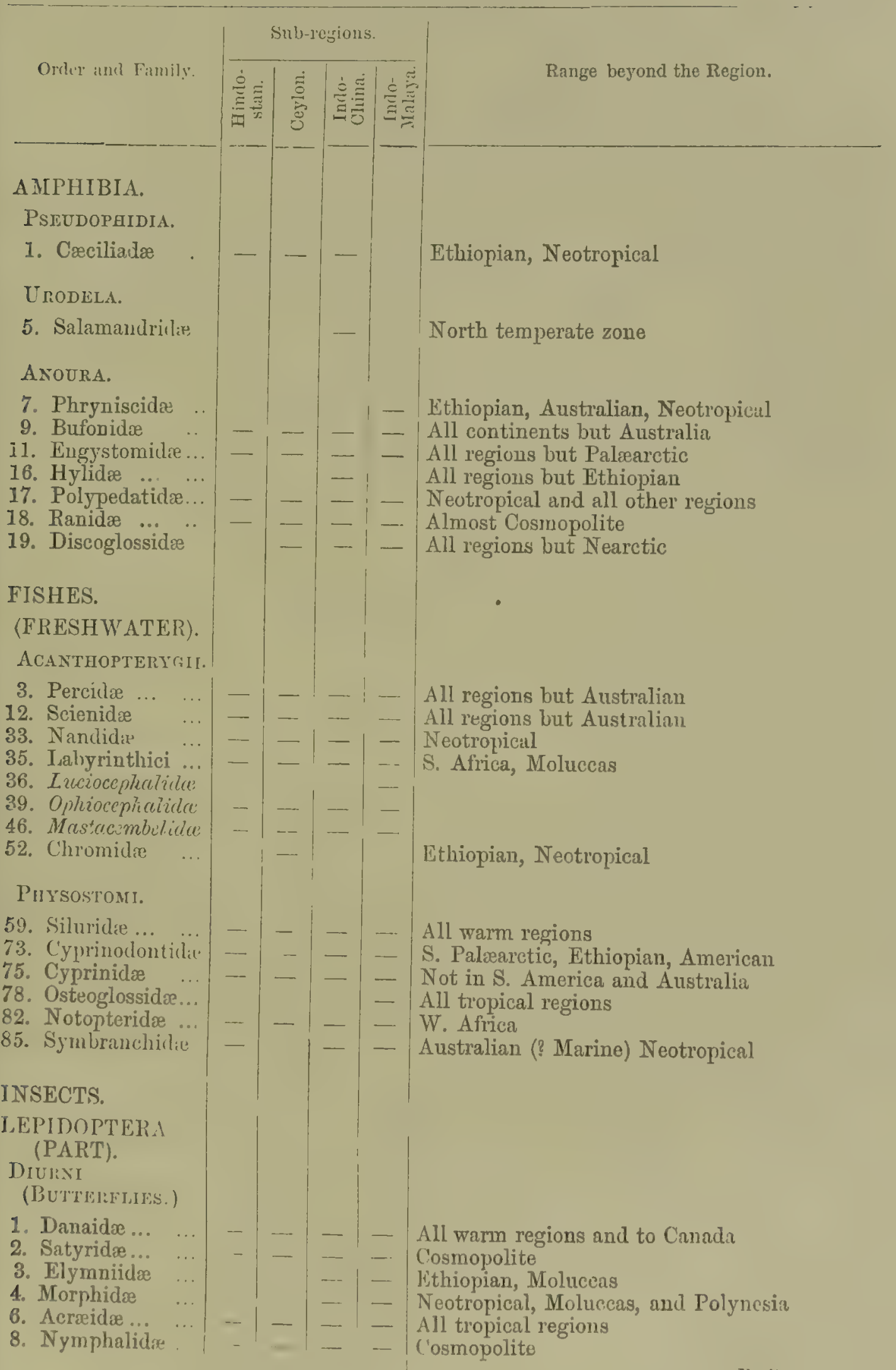




\begin{tabular}{|c|c|c|c|c|c|}
\hline \multirow[b]{2}{*}{ Oreler and Fanily. } & \multicolumn{4}{|c|}{ sull ragions. } & \multirow[b]{2}{*}{ liange: beyond the Regiom. } \\
\hline & 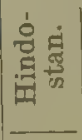 & $\begin{array}{l}5 \\
\text { 悹 } \\
0 \\
\end{array}$ & 总氙 & 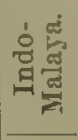 & \\
\hline 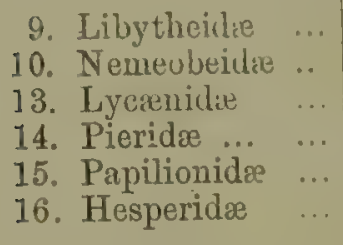 & $\overline{-}$ & $\begin{array}{l}- \\
- \\
- \\
-\end{array}$ & $\begin{array}{l}- \\
- \\
- \\
- \\
-\end{array}$ & $\begin{array}{l}- \\
- \\
- \\
-\end{array}$ & $\begin{array}{l}\text { Absent from Australia } \\
\text { Not in Australia or Nearctic regions } \\
\text { Cosmopolite } \\
\text { Cosmopolite } \\
\text { Cosmopolite } \\
\text { Cosmopolite }\end{array}$ \\
\hline 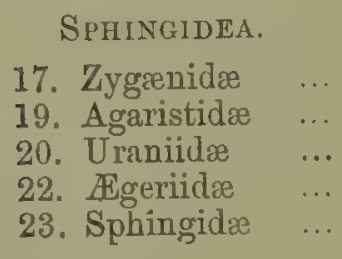 & $\begin{array}{l}E \\
\text { E } \\
-\end{array}$ & $\begin{array}{l}E \\
E \\
-\end{array}$ & $\begin{array}{l}E \\
E \\
-\end{array}$ & $\begin{array}{l}E \\
\text { - } \\
-\end{array}$ & $\begin{array}{l}\text { Cosmopolite } \\
\text { Australian, Ethiopian } \\
\text { All tropical regions } \\
\text { Absent from Australia } \\
\text { Cosmopolite }\end{array}$ \\
\hline
\end{tabular}


TABLE 11.

\section{GENERA OF TERRESTRIAL MIAIIIALIA AND BIRDS INHABITING THE ORIENTAL REGION.}

\section{ExPLANATION.}

Names in italics show genera peculiar to the region.

Names imclosed thus (...) show genera which just enter the region, but are not considerel properly to belong to it.

Genera truly belonging to the region are numbered consecutively.

MA MMALIA.

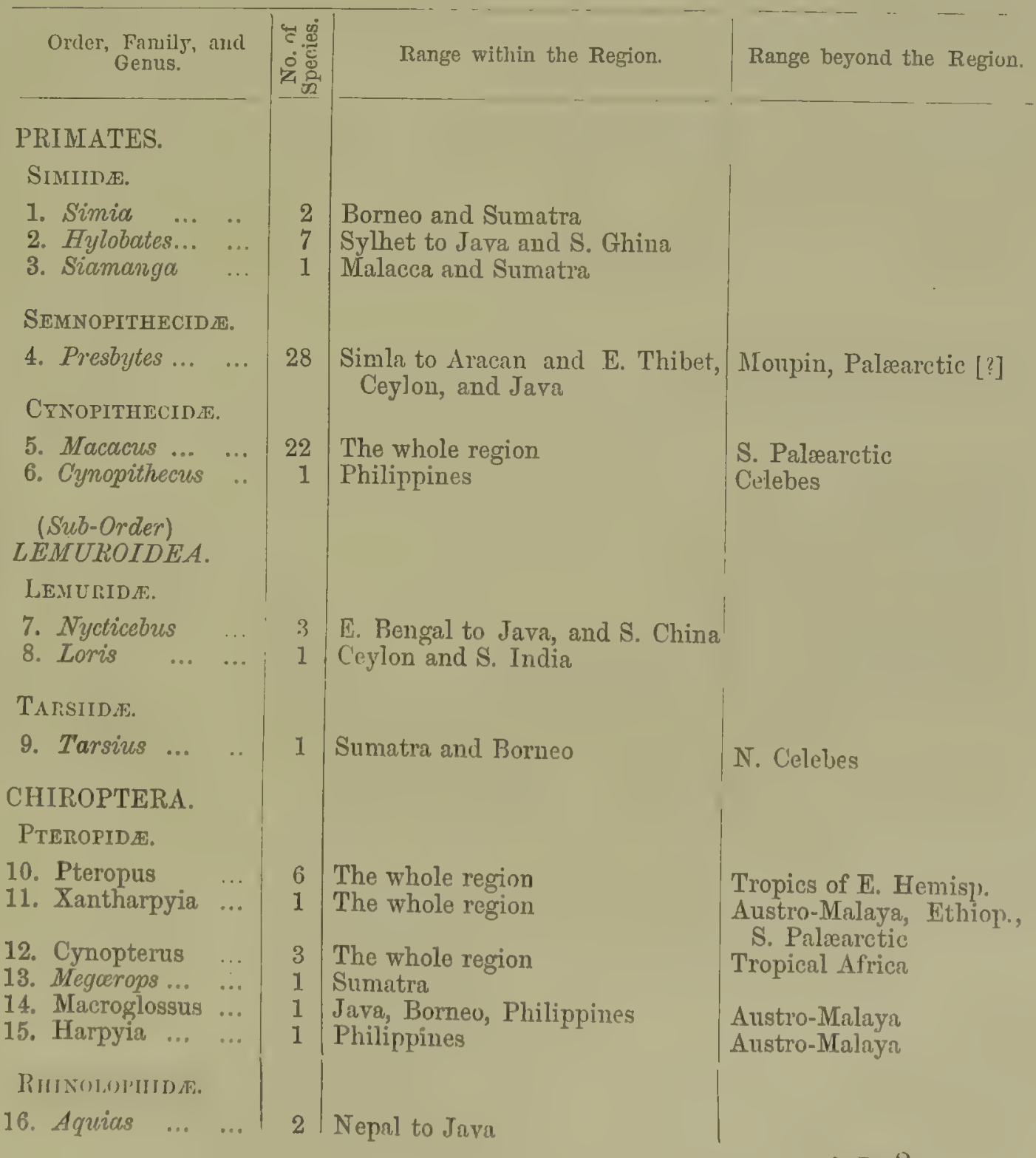




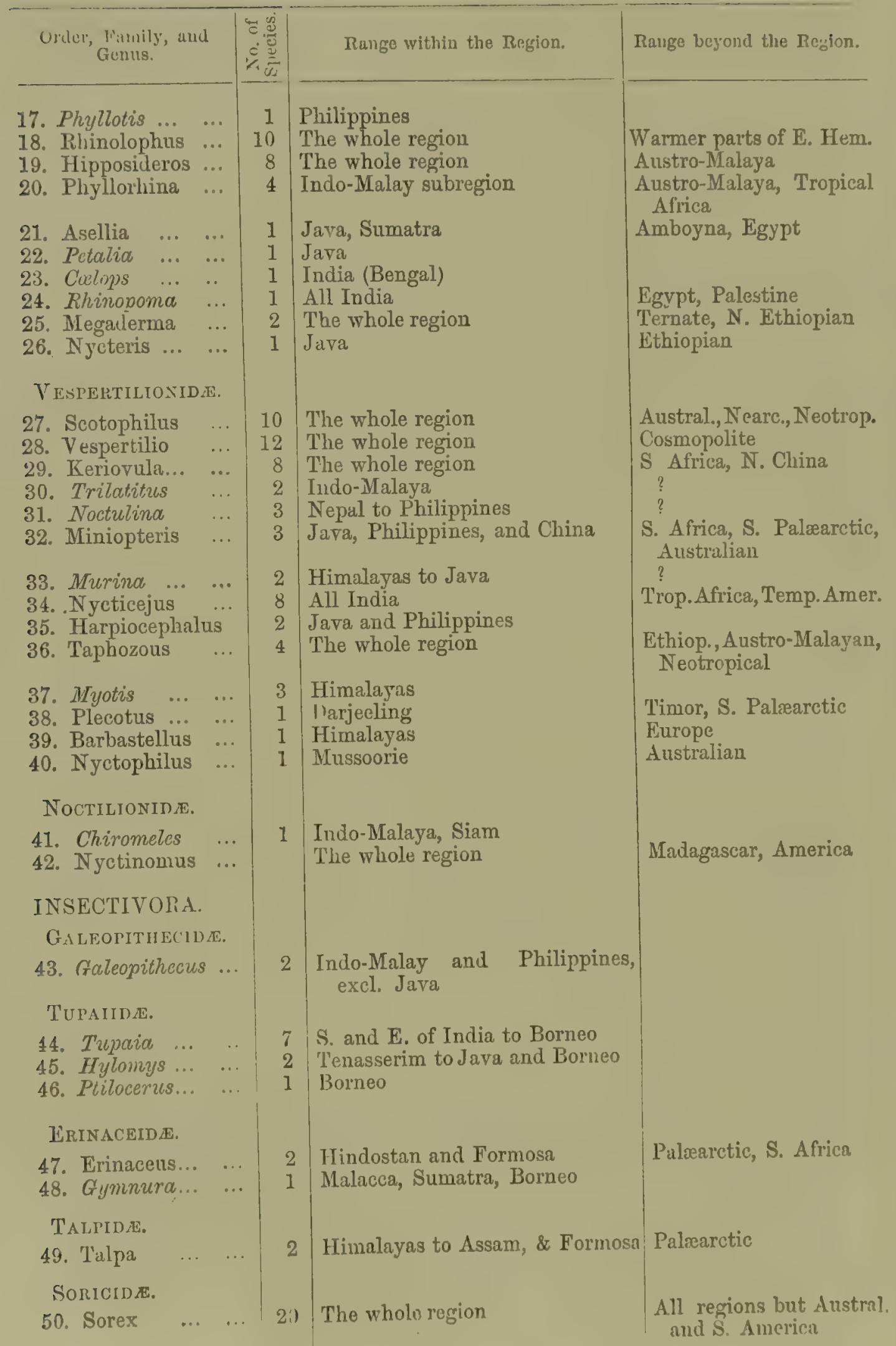




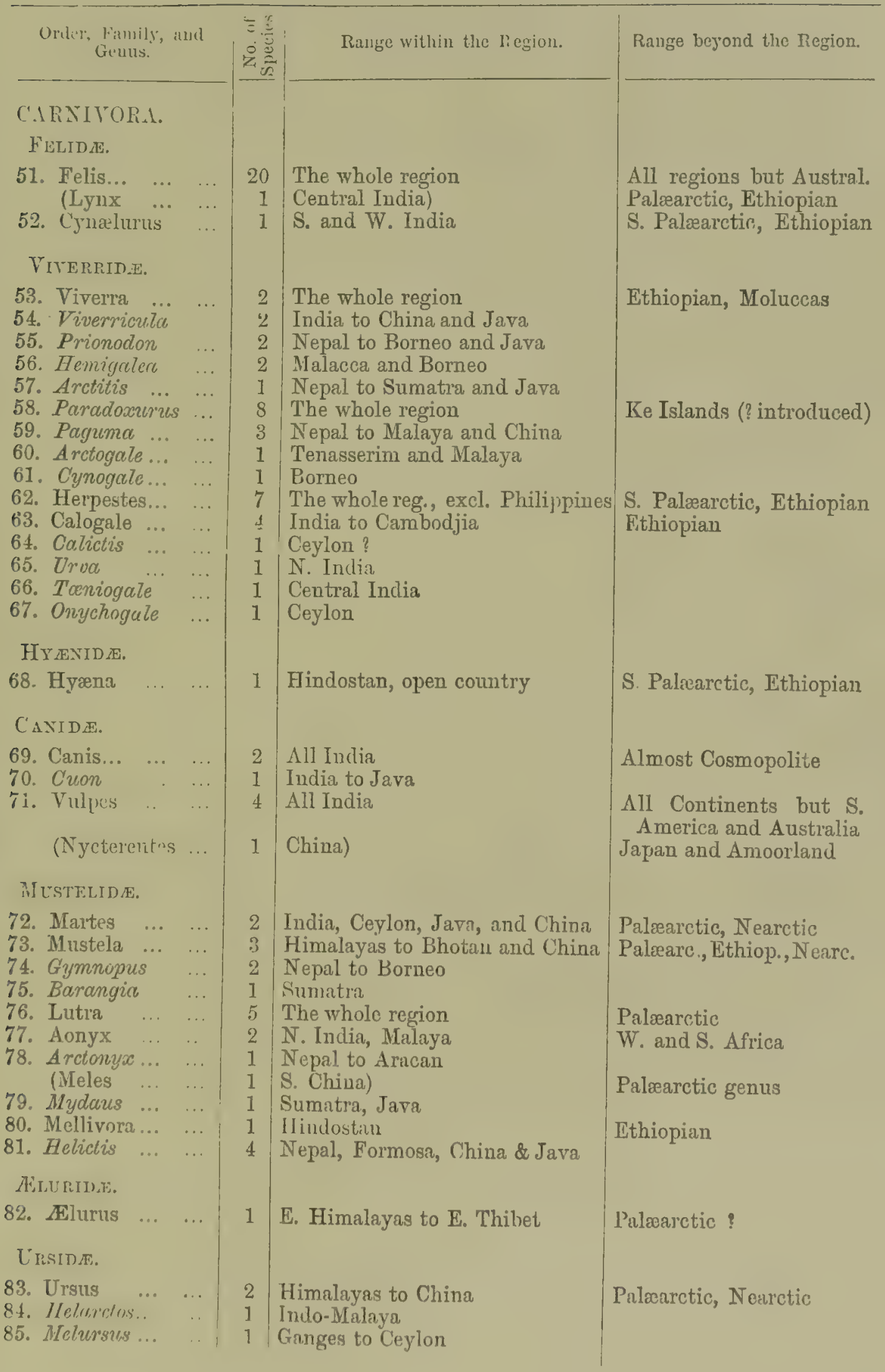




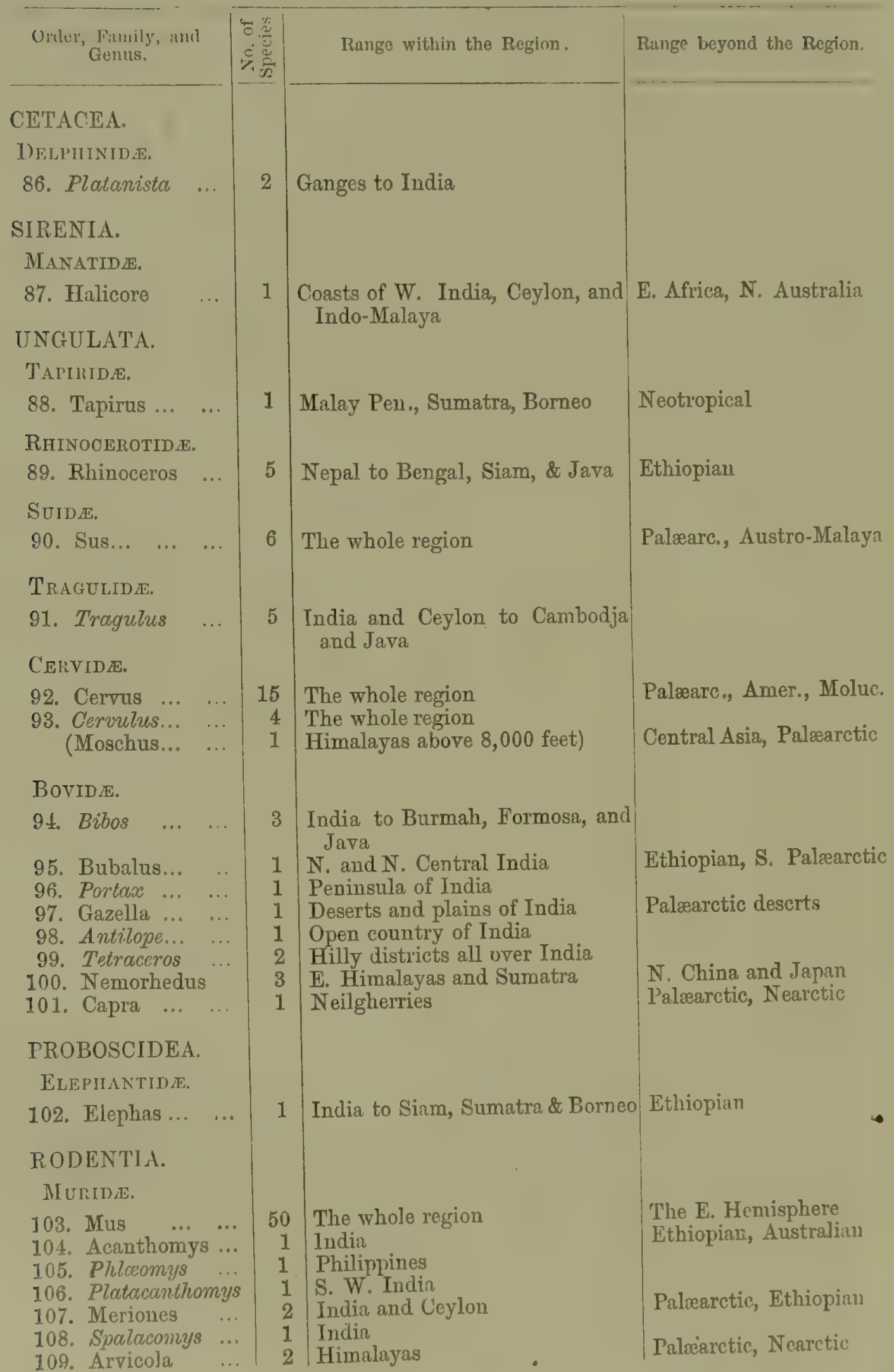




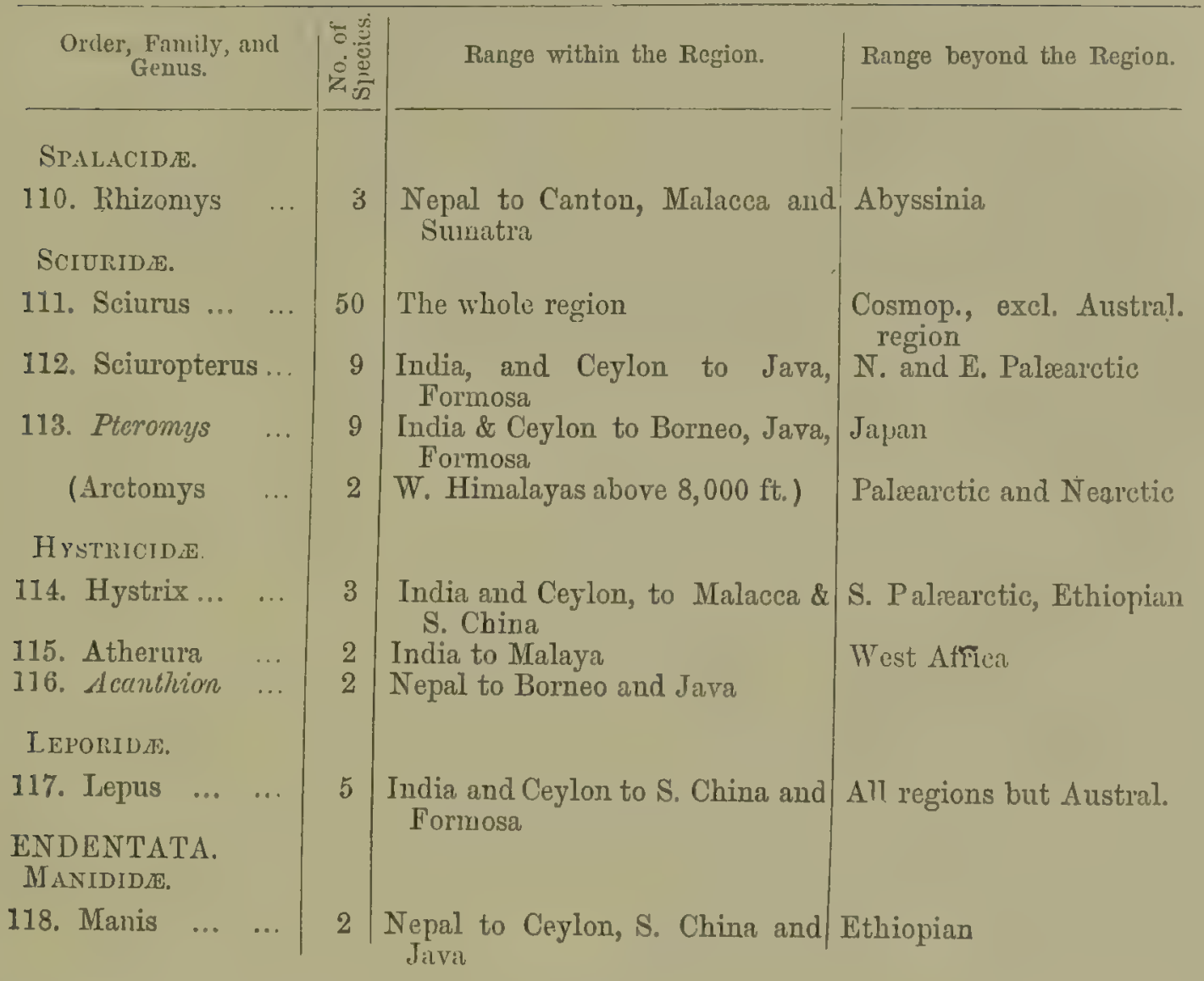

BIRDS.

\section{PASSERES.}

TURDIDE.

1. Brachypteryx ...

2. Oreocincla ...

3. Turdus

4. Geocichla... …

5. Monticola

6. Oroccetes ... ...

7. Zoothera ...

SYLVIIDE.

8. Orthotmmus

9. Prinia ... $\quad$... 13 Tho whole region

10. Drymanc ... 11

11. Cisticola ... ... 13

12. Suya

13. Megalumis

14. Acrocephalus

(Dumeticola

The whole reg., excl. Philippines

The whole reg., excl. Philippines

The whole region

Nepal to S. China and Formosa

3 Central India, Java, Philippines

India to Ceylon, S. China, and Palaarc, Ethiop., Austrnl.

Philippines

2 Nepal and E. Thibet)
$\Delta$ Imost Cosmopolite

Celebes, Lombock, to N. Australia

Palrarctic, Ethiopian, Molucens

Lombock, Timor ?

Ethiopian

Ethiopian Anstralian

A Palrearctic genus 


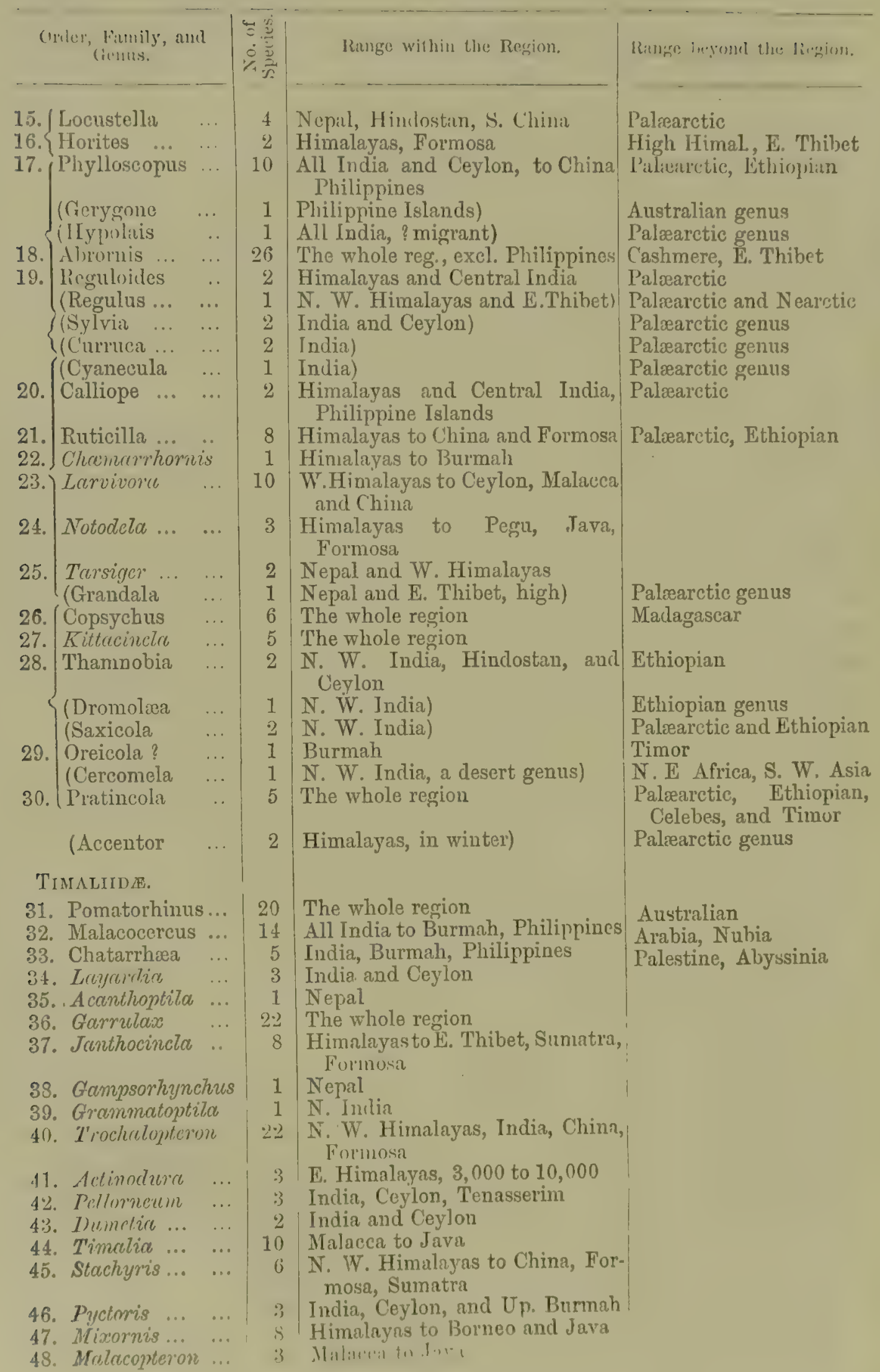




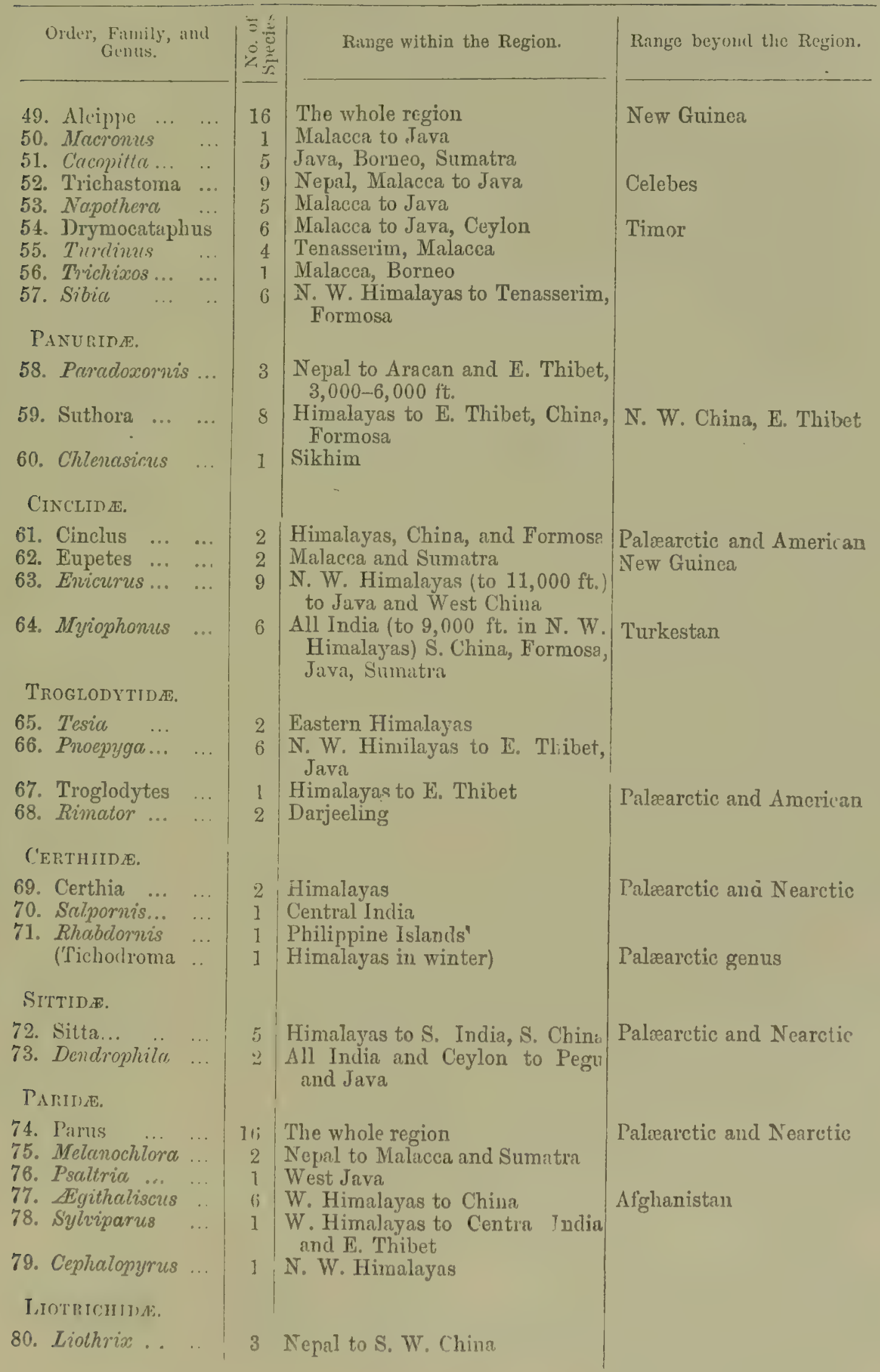




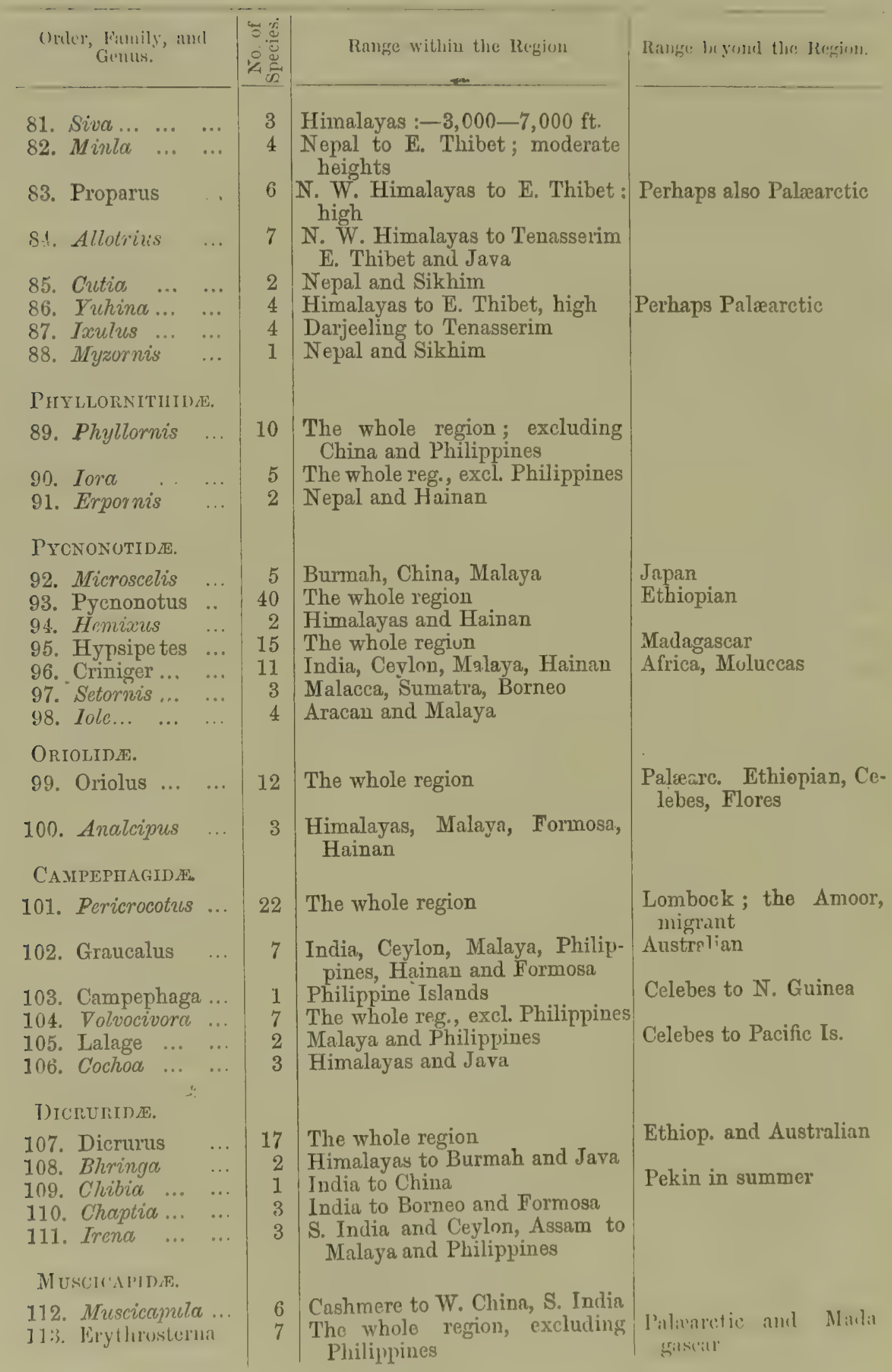




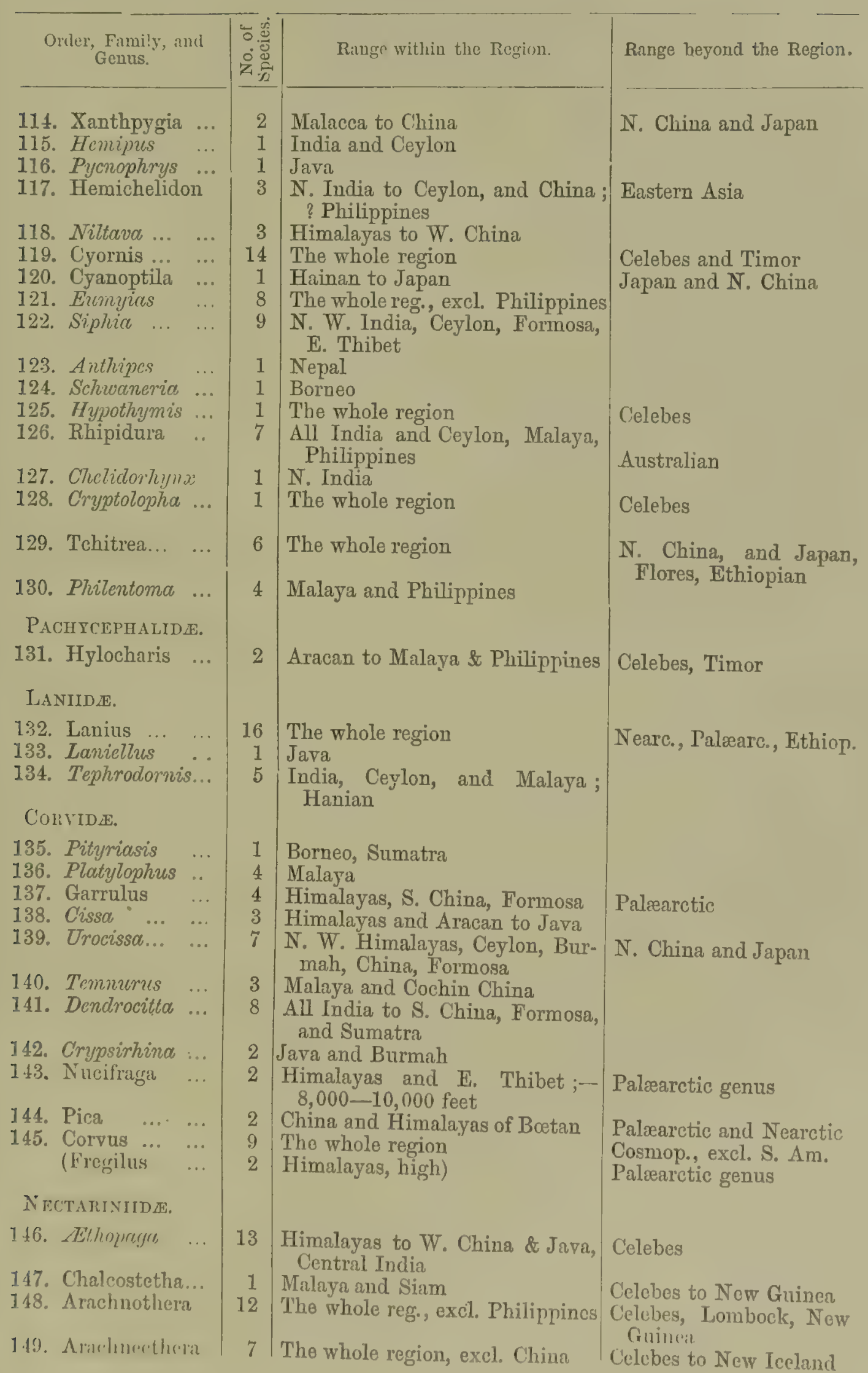




\begin{tabular}{|c|c|c|c|}
\hline $\begin{array}{l}\text { Order, Fanily, and } \\
\text { Genus. }\end{array}$ & 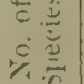 & Range within the Remgon. & 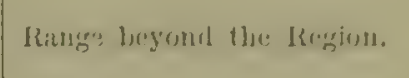 \\
\hline $\begin{array}{l}\text { 150. Nectrorophila ... } \\
\text { 151. Anthreptes } \ldots\end{array}$ & $\begin{array}{l}4 \\
1\end{array}$ & $\begin{array}{l}\text { India, Ceylon, Malaya, Philipp. } \\
\text { Malaya and Indo-China }\end{array}$ & $\begin{array}{l}\text { Celebes } \\
\text { Celebes }\end{array}$ \\
\hline $\begin{array}{l}\text { Drc.EIDAs. } \\
\text { 152. Dicretum ... } \\
\text { 153. Pachyglossa ... } \\
\text { 154. Piprisoma ... } \\
\text { 155. Prionochilus ... } \\
\text { 156. Zosterops ... } \\
\text { 157. Chalcoparia ... }\end{array}$ & $\begin{array}{r}10 \\
1 \\
1 \\
4 \\
8 \\
1\end{array}$ & $\begin{array}{l}\text { The whole region } \\
\text { Nepal } \\
\text { India and Ceylon } \\
\text { Malaya } \\
\text { The whole region } \\
\text { Aracan to Malaya }\end{array}$ & $\begin{array}{l}\text { Australian } \\
\text { Celebes . } \\
\text { Ethiopian, Australian }\end{array}$ \\
\hline 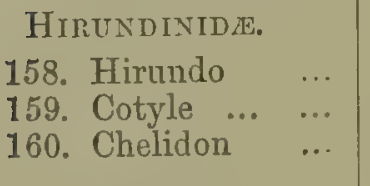 & $\begin{array}{r}10 \\
5 \\
3\end{array}$ & $\begin{array}{l}\text { The whole region } \\
\text { India to China } \\
\text { India, Borneo }\end{array}$ & $\begin{array}{l}\text { Cosmopolite } \\
\text { Palæarc, Ethion., Amer. } \\
\text { Palæarctic }\end{array}$ \\
\hline 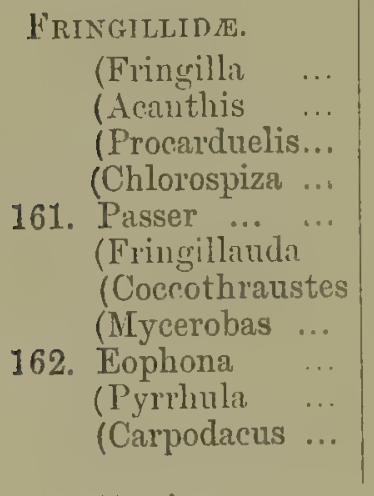 & $\begin{array}{l}1 \\
1 \\
1 \\
1 \\
6 \\
1 \\
2 \\
1 \\
1 \\
4 \\
4\end{array}$ & $\begin{array}{l}\text { Himalayas, in winter) } \\
\text { N. W. Himalayas, in winter) } \\
\text { High Himalayas) } \\
\text { ('hima) } \\
\text { The whole region } \\
\text { High Himalayas) } \\
\text { High Himalayas) } \\
\text { High Himalayas) } \\
\text { China } \\
\text { Himalayas, winter) } \\
\text { Himalayas and Central India, in } \\
\text { winter). }\end{array}$ & $\begin{array}{l}\text { Palæarctic genus } \\
\text { Palæarctic genus } \\
\text { Palæarctic genus } \\
\text { Palæarctic and Ethiopian } \\
\text { Palæarctic and Ethiopian } \\
\text { Palæarctic genus } \\
\text { Palæarctic and Nearctic } \\
\text { Palæarctic genus } \\
\text { Palæarctic } \\
\text { Palæarctic } \\
\text { Palæarctic and Nearctic }\end{array}$ \\
\hline 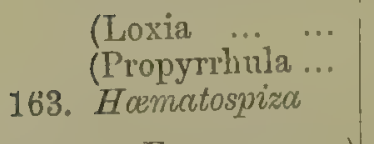 & $\begin{array}{l}1 \\
1 \\
1\end{array}$ & $\begin{array}{l}\text { Snowy Himalasas) } \\
\text { Darjeeling, in winter) } \\
\text { S. E. Hinal., } 5,000 \text { to } 10,000 \mathrm{ft} \text {. }\end{array}$ & $\begin{array}{l}\text { Palæarctic and Nearctic } \\
\text { [?] Palæarctic }\end{array}$ \\
\hline $\begin{array}{l}\text { (S. Fam. EMberizIN E) } \\
\text { 164. Euspiza ... . . } \\
\text { 165. Emberiza }\end{array}$ & $\begin{array}{l}4 \\
7\end{array}$ & $\begin{array}{l}\text { N. W. India to Burmah, \& China } \\
\text { All India and China, in winter }\end{array}$ & $\begin{array}{l}\text { Palæarctic and Nearctic } \\
\text { Palæarctic genus }\end{array}$ \\
\hline $\begin{array}{l}\text { PLOCEIDE. } \\
\text { 166. Ploceus ... . .. } \\
\text { 167. Minia ... . .. } \\
\text { 168. Estrilda } \\
\text { 169. Erythrura ... }\end{array}$ & $\begin{array}{r}4 \\
20 \\
2 \\
1\end{array}$ & $\begin{array}{l}\text { India \& Ceylon, Burmah, Malaya } \\
\text { The whole region } \\
\text { India and Ceylon, Burmah, Java } \\
\text { Java, Sumatra }\end{array}$ & $\begin{array}{l}\text { Ethiopian } \\
\text { Austro-Malnyan } \\
\text { Ethiopian, Australian } \\
\text { Moluccas to Fiji Islands }\end{array}$ \\
\hline 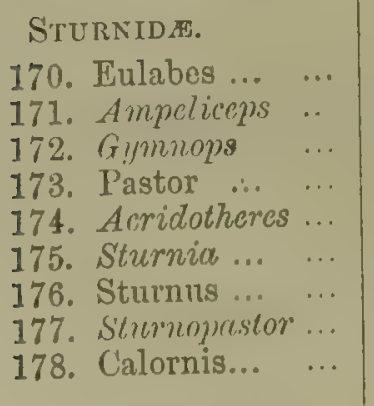 & $\begin{array}{r}7 \\
1 \\
1 \\
1 \\
6 \\
12 \\
3 \\
3 \\
2\end{array}$ & $\begin{array}{l}\text { The whole reg., excl. Thilippines } \\
\text { Tenasserim to Cochin-China } \\
\text { Philippine 1slands } \\
\text { All India to Burmah } \\
\text { The whole region } \\
\text { The whole region } \\
\text { India and China } \\
\text { Cen. India to Burmah \& Malaya } \\
\text { Malaya and Philippines }\end{array}$ & $\begin{array}{l}\text { Flores, Papua } \\
\text { S. Palixarctic } \\
\text { Celebes } \\
\text { N. China\&Japan, Celebes } \\
\text { Palmarctic } \\
\text { [?] Celebes, Moluccas to } \\
\text { Samoan Islands }\end{array}$ \\
\hline 179. Saroglosse & 1 & W. and Central Himalayas & \\
\hline
\end{tabular}




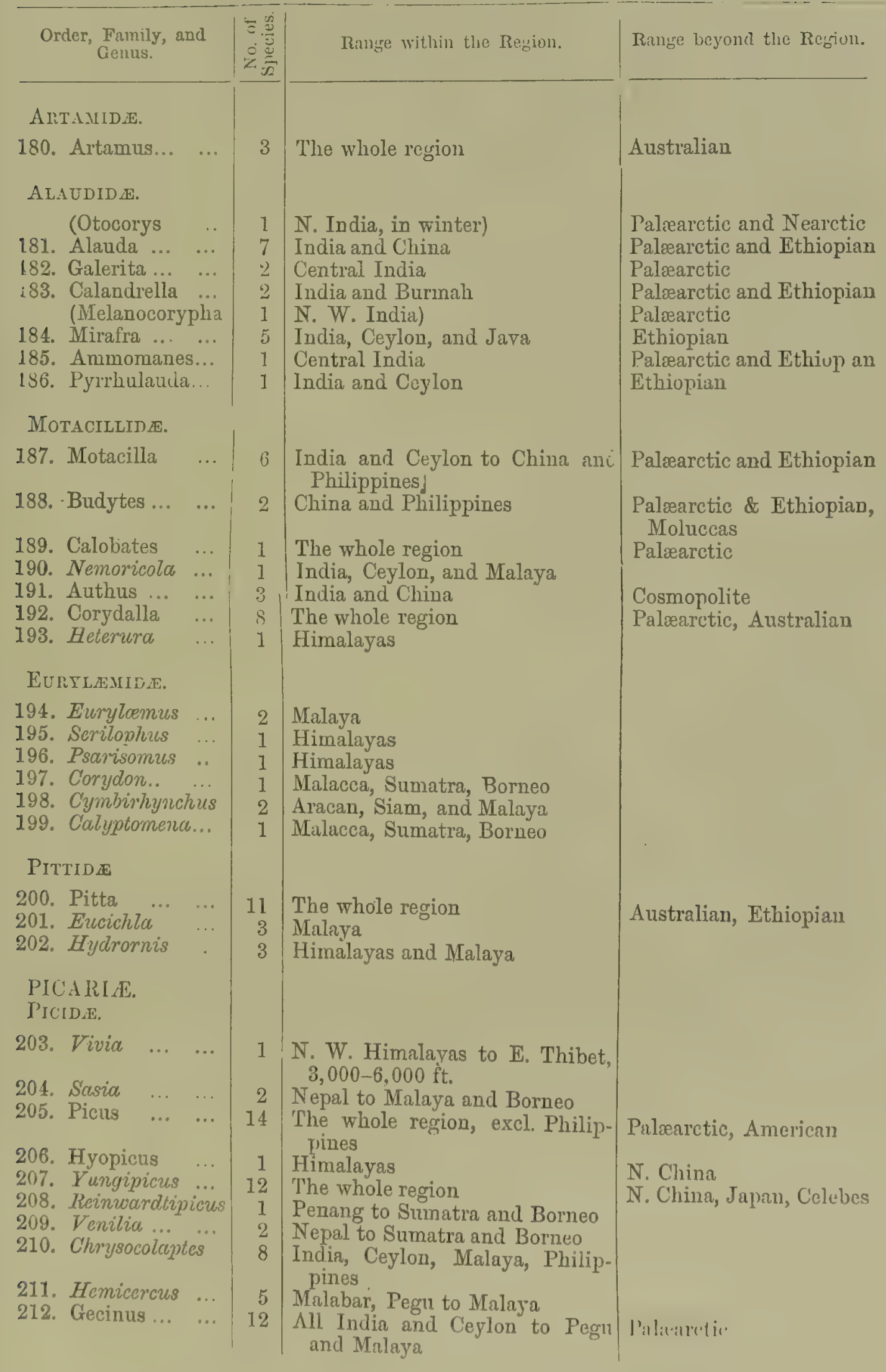




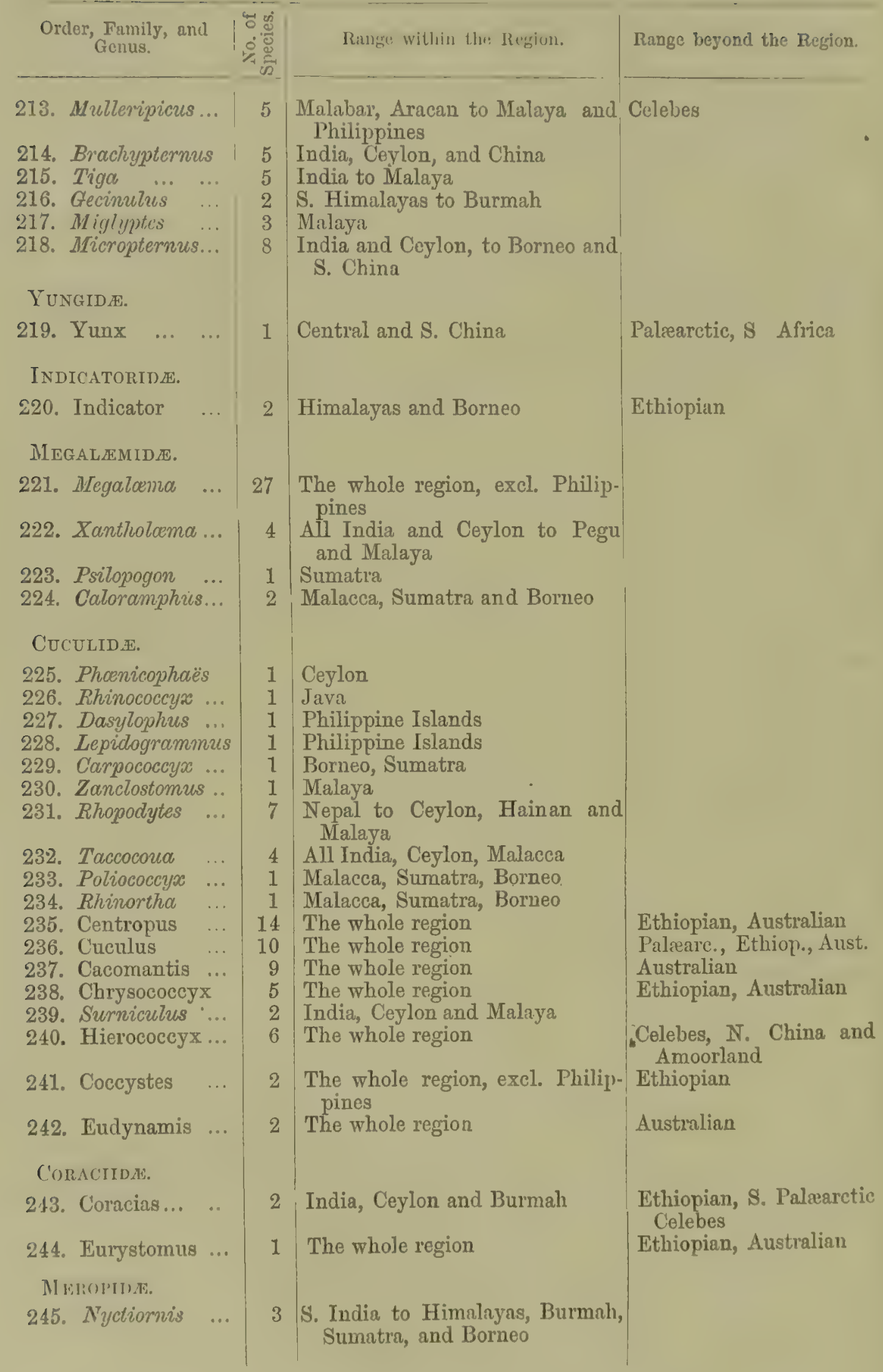


Order, Fanily, and Genus.

246. Merops ... ...

TrOgONIDE.

247. Harpactes

Alcedinide.

248. Halcyon... ...

249. Pelargopsis

250. Carcineutes ...

251. Ceyx ... ...

252. Alcedo ... ...

253. Alcyone... ...

254. Ceryle .. ...

Bucerotide.

255. Buceros..

256. Hydrocissa

257. Berenicornis ...

258. Calao ... ...

259. Aceros ... ...

260. Cranorrininus

261. Penelopides ...

262. Rhinoplax ...

263. Meniceros

UPUPID E.

264. Upupa

Podargide.

265. Batrachostomus

Caprinulaidz.

266. Caprimulgus ...

267. Lyncornis

Ctpselide.

268. Cypselus

269. Dendrochelidon

270. Collocalia

271. Chæturn... ...

PSITTACI.

CACATUIDER.

(Cacatua

PA T, NollNithide.

272. Palromis

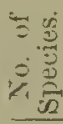

5 The whole region

10 The whole region, excl. China

The whole region

The whole region, excl. China

Burmah, Siam, and Malaya

India and Ceylon, Malaya and Moluccas \& New Guin. Philippines

The whole region

Philippines

India to S. China

Nepal to Malaya, S. India, Philippines

India, Ceylcn and Malaya

Sumatra

Tenasserim, Malaya

S. E. Himalayas

Malacca to Borneo and Philippirues

Philippines

Sumatra, Borneo

India and Ceylon to Tenasserim

India, Ceylon and Burmah

India, Ceylon and Malaya

13 The whole region

4 Burmah, Malaya, \& Philippines

The region, excl. Philippines

Ceylon, India, Malaya, Philipp.

The whole region

3

Ceylon, India, Malaya, Hainan

S. Palæarctic, Ethopian, Australian

Celebes and Timor

Palæarctic, Ethiopian,

Austro-Malayau

Australian genus

Ethiopian, S. Palæarctic, American

W. Africa

Austro-Malaya

Celebes

Ethiopian, S. Palæarctic

Moluccas

The Eastern Hemisphere

Celebes

The OldWorld \& S.Amer.

Austro-Malaya

Madagascar, Moluccas,

Pacific Islands

America, Africa

Australian genus

14 N. W. India to Ceylon, Siam \& Ethiopian 


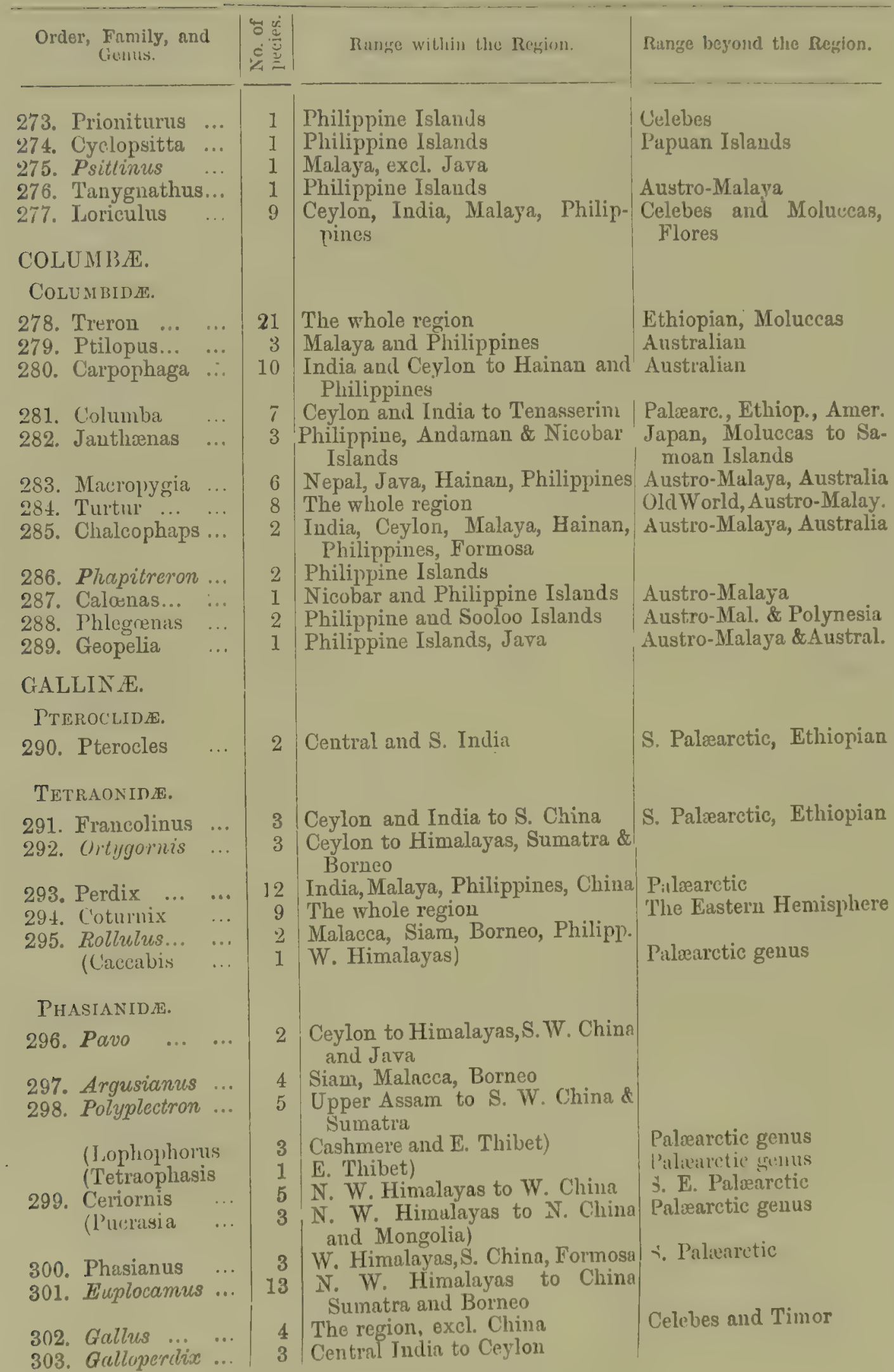




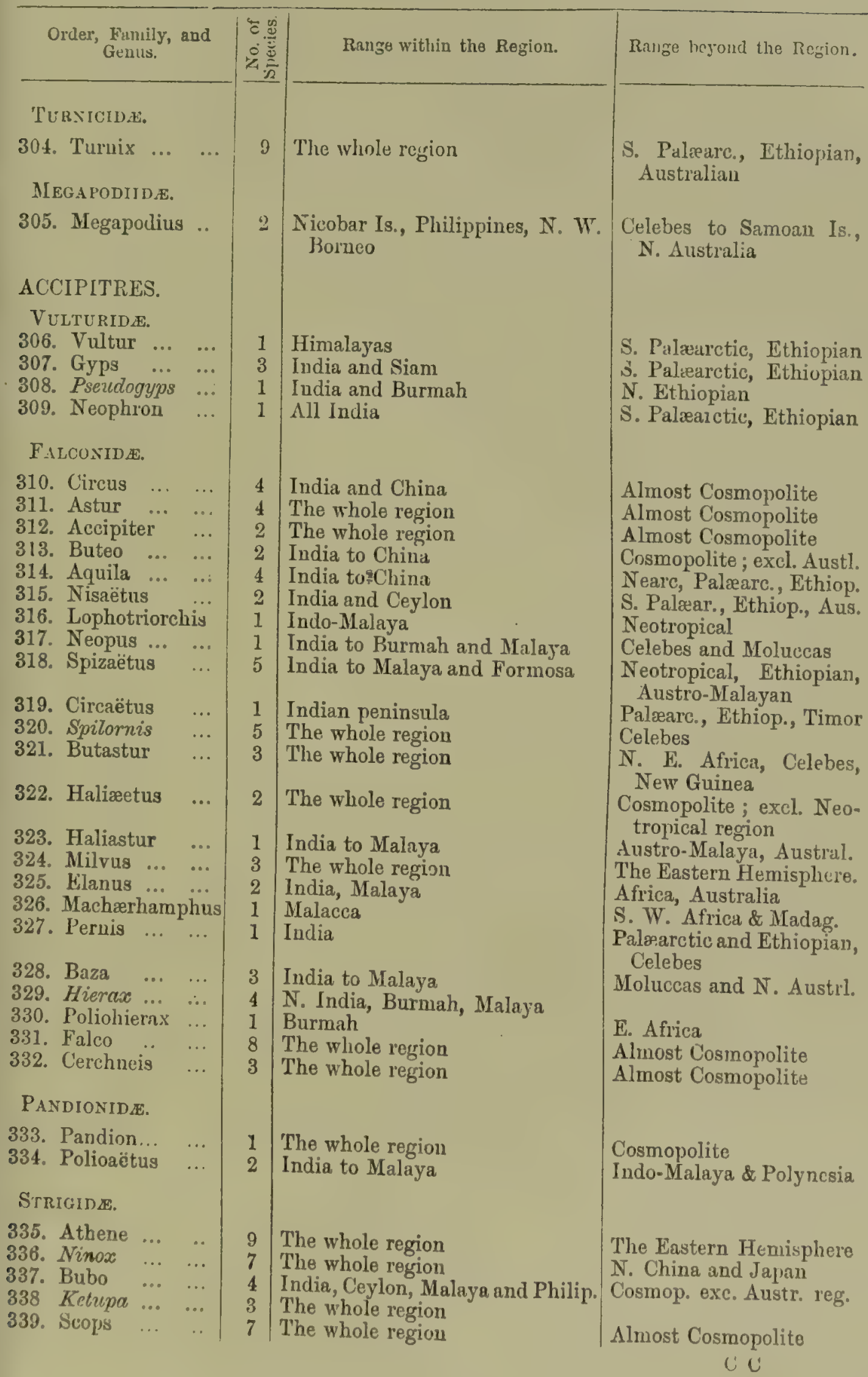




\begin{tabular}{|c|c|c|c|}
\hline $\begin{array}{l}\text { Order, Fanily. and } \\
\text { Genus. }\end{array}$ & $\begin{array}{ll}0 \\
0\end{array}$ & Range within the Reginn. & Range beyond the Reginn. \\
\hline $\begin{array}{llll}\text { 340. Syrnium } & \ldots \\
& \text { (Asio ... } & \ldots \\
\text { 341. Strix ... } & \ldots \\
\text { 342. Phodilus } & \ldots\end{array}$ & $\begin{array}{l}6 \\
2 \\
4 \\
2\end{array}$ & $\begin{array}{l}\text { The whole region } \\
\text { India) } \\
\text { The whole region } \\
\text { Nepal, Malaya }\end{array}$ & $\begin{array}{l}\text { Cosmop. exc. Austr. reg. } \\
\text { Palæarc, Ethiop. Amer. } \\
\text { Cnsmopolite }\end{array}$ \\
\hline
\end{tabular}

Peculiar or very Characteristic Gencre of Wading or Swimming Birds.
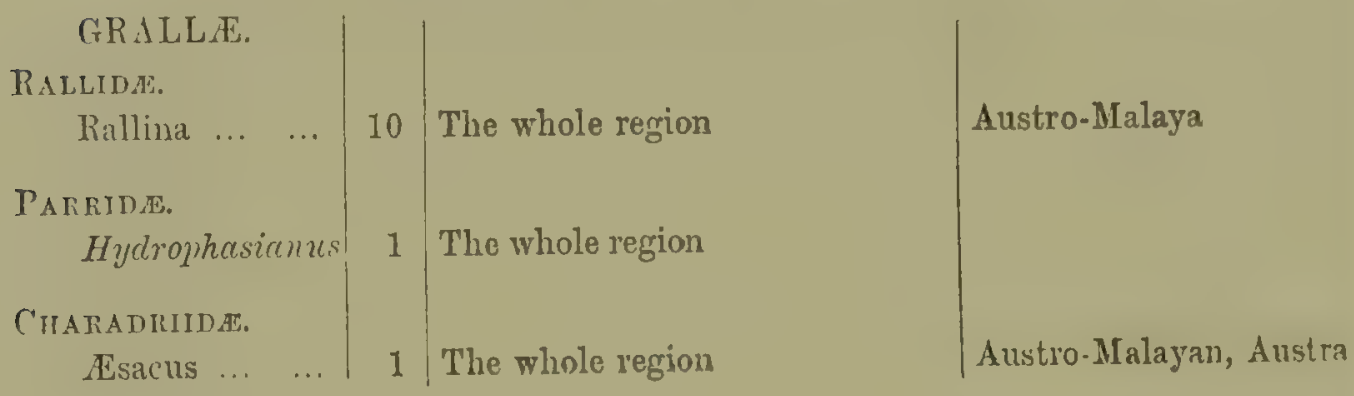
. 
A I'S TA

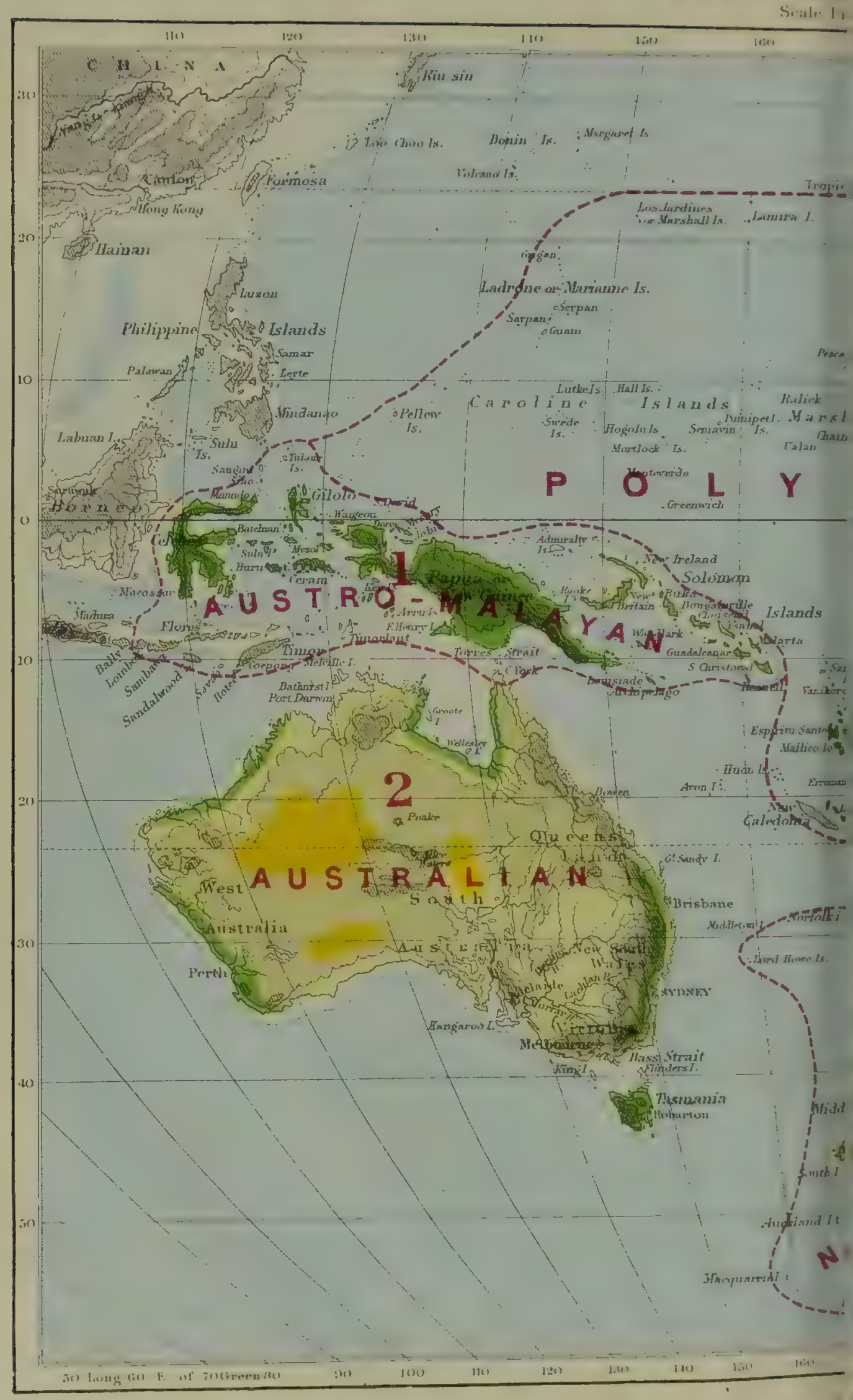


RE E ( I I O N

oon miles

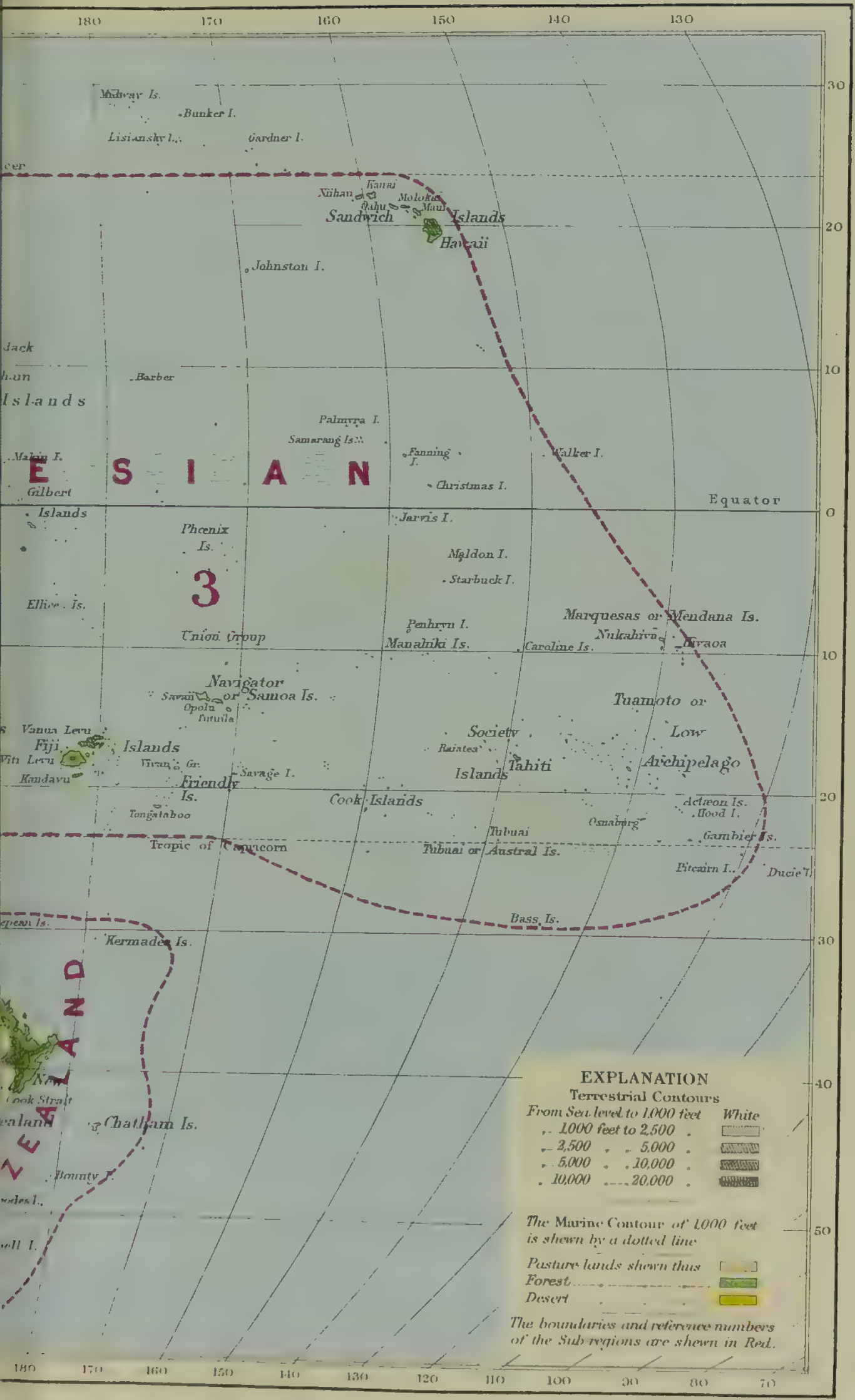

$2 x \cdot r, r$

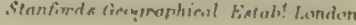





\section{CHAPTER XIII.}

\section{THE AUSTRALIAN REGION.}

ThE Australian is the great insular region of the earth. As a whole it is one of the best marked, and has even been considered to be equal in zoological value to all the rest of the globe; but its separate portions are very heterogeneous, and their limits sometimes ill-defined. Its central and most important masses consist of Australia and New Guinea, in which the main features of the region are fully developed. To the north-west it extends to Celebes, in which a large proportion of the Australian characters have disappeared, while Oriental types are mingled with them to such an extent that it is rather difficult to determine where to locate it. To the south-east it includes New Zealand, which is in some respects so peculiar, that it has even been proposed 10 constitute it a distinct region. On the east it embraces the whole of Oceania to the Marquesas and Sandwich Islands, whose very scanty and often peculiar fauna, must be affiliated to the general Australian type.

Australia is the largest tract of land in the region, being several times more extensive than all the other islends combined, and it is here that the greatest variety of peculiar types have been developed. This island-continent, being situated in the track of the southern desert zone, and having no central mountains to condense the vapours from the surrounding ocean, has a large portion of its interior so parched up and barren as to be almost destitute of animal life. The most extensive tract of fertile and well-watered country is on the east and south east,

C $\mathrm{C} 2$ 
where a fine range of mountains reaches, in the Culuny of Victoria, the limits of perpetual suow. The west coast also posisesses mountains of moderate height, but the climate is very dry and hot. The northern portion is entirely tropical, yet it nowhere presents the luxuriance of vegetation characteristic of the great island of New Guinea immediately to the north of it. Taken as a whole, Australia is characterized by an arid climate and a deficiency of water; conditions which have probably long prevailed, ant under which its very peeuliar fauna and flora have been developed. This fact will account for some of the marked differences between it and the adjacent sub-regions of New Guinea and the Moluccas, where the climate is moist, and the vegetation luxuriant; and these divergent features must never be lost sight of, in comparing the different portions of the Australian reginn. In Tasmania alone, which is however, essentially a detached portion of Australia, a more uniform and moister climate prevails; but it is too small a tract of land, and has been tou recently severed from its parent mass to have developed a special fauna.

The Austro-Malay sub-region (of which New Guinea is the central and typical mass) is strikingly contrasted with Australia, being subjected to purely equatorial conditions, - - a high, but miform temperature, excessive moisture, and a luxuriant forest vegetation, exactly similar in general features to that which clothes the Indo-Malay Islands, and the other portions of the great equatorial forest zone. Such a climate and vegetation, being the necessary result of its geographical position, must have existed from remote geological epochs with but little change, and must therefore have profoundly affected all the forms of life which have been developed under their influence. Around New Guinea as a centre are grouped a number of important islands, more or less closely agreeing with it in physical features, climate, vegetation, and forms of life. In most immediate connection we place the Aru Islands, Mysol and Waigiou, with Jobie and the other Islands in Geelvinck Bay, all of which are connected with it by shallow seas ; they possess one of its most characteristic groups, the Birds of Paradise, and have no doubt only recently (in 
a geological sense) been separated from it. In the next rank come the large islands of the Moluccas on the west, and the range terminating in the Solomon Islands on the east, both of which groups possess a clearly Papuan fauna, although deficient in many of the most remarkable Papuan types.

All these islands agree closely with New Guinea itself in heing very mountainous, and covered with a luxuriant forest vegetation; but to the south-west we find a set of islands extending from Timor to Lombock, which agree more nearly with Australia, both in climate and vegetation; being arid and abounding in eucalypti, acacias, and thickets of thorny shrubs. These, like the Moluccas, are surrounded by deep sea, and it is doubtful whether they have either of them been actually connected with New Guinea or Australia in recent geological times; but the general features of their zoology oblige us to unite all these islands with New Guinea as forming the Austro-Malay sub-division of the Australian region. Still further west however, we have the large island of Celebes, whose position is very difficult to determine. It is mountainous, but has also extensive plains and low lands. Its climate is somewhat arid in the south, where the woods are often scattered and thorny, while in the north it is moister, and the forests are luxuriant. It is surrounded by deep seas, but also by coralline and volcanic islets, indicating former elevations and subsidences. Its fauna presents the most puzzling relations, showing affinities to Java, to the Philippines, to the Moluccas, to New Guinea, to continental India, and even to Africa; so that it is almost impossible to decide whether to place it in the Oriental or the Australian region. On the whole the preponderance of its relations appears to be with the latter, though it is undoubtedly very anomalous, and may, with almost as much propriety, be classed with the former. This will be better understood when we come to discuss its zoological peculiarities.

The next sub-region consists of the extensive series of islands scattered over the Pacific, the principal groups being the Sandwich Islands, the Marquesas and Society Islands, the Navigators', Friendly, and Fiji Islands. New Caledonia and the New 
Hebrides have rather an uncertain position, and it is difficult to decide whether to class them with the Austro-Malay Islands, the Pacific Islands, or Australia. 'The islands of the west Pacific, north of the equator, also probably come into this region, although the Ladrone Islands may belong to the Philippines; liut as the fauna of all these small islets is very scanty, and very little known, they are not at present of much importance.

There remains the islands of New Zealand, with the surrounding small islands, as far as the Auckland, Chatham, and Norfolk Islands. These are situated in the south temperate forest-zone. They are mountainous, and have a moist, equable, and temperate clinute. They are true oceanic islands, and the total ausence of mammalia intimates that they have not been connected with Australia or any other continent in recent geological times. The general character of their zoology, no less than their lotany, affiliates them however, to Australia as portions of the same zoological region.

General Zoological Characteristics of the Australian Region.For the purpose of giving an ilea of the rery peculiar and striking features which characterise the Australian region, it will be as well at first to confine ourselves to the great central land masses of Australia and New Guinea, where those features are manifested in their greatest force and purity, leaving the various peculiarities and anomalies of the outlying islands to be dealt with subsequently.

Mammalia.-The Australian region is broadly distinguished from all the rest of the globe by the entire absence of all the orders of non-aquatic mammalia that abound in the old Worll, except two-the winged bats (Chiroptera), and the equally cosmopulite rodents (Rodentia). Of these latter however, only one family is represented-the Muridx-(comprising the rats and mice), and the Australian representatives of these are all of small or moderate size - a suggestive fact in appreciating the true character of the Australian famn. In place of the Quadrunana, Carnivora, and Ungulates, which abound in endless variety in all the other regions under equally favourable conditions, Australia possesses two new orders (or perhaps sub-classes) - 
Marsupialia and Monotremata, found nowhere else on the globe except a single family of the former in America. The Marsupials are wonderfully developed in Australia, where they exist in the most diversified forms, adapted to different modes of life. Some are carnivorous, some herbivorous; some arboreal, others terrestrial. There are insect-eater's, root-gnawers, fruit-eaters, honey-eaters, leaf or grass-feeders. Some resemble wolves, others marmots, weasels, squirrels, flying squirrels, dormice or' jerboas. They are classed in six distinct families, comprising about thirty genera, and subserve most of the purposes in the economy of nature, fulfilled in other parts of the world by very different groups; yet they all possess common peculiarities of structure and habits which show that they are members of one stock, and have no real affinity with the Old-World forms which they often outwardly resemble.

The other order, Monotremata, is only represented by two rare and very remarkable forms, Ornithorhynchus and Echidna, probably the descendants of some of those earlier developments of mammalian life which in every other part of the globe have long been extinct.

The bats of Australia all belong to Old-World genera and possess no features of special interest, a result of the wandering halits of these aerial mammals. The Rodents are more interesting. They are all more or less modified forms of mice or rats. Some belong to the widely distributed genus MIus, others to four allied genera, which may be all modifications of some common Old-World form. They spread all over Australia, and allied species occur in Celebes, so that although not yet known from New Guinea or the Moluccas, there can be little doubt that some of them exist there.

Birds.-The typical Australian region, as above defined, is almost as well characterized by its birds, as by its mammalia; but in this case the deficiencies are less conspicuous, while the peculiar and characteristic families are numerous and important. 'The most marked deficiency as regards wide-spread families, is the total absence of Fringillide (true finches), I'icille (woodpeckers), Tulturide (vultures), and I'hasianidie (phensmits). 
and among prevalent Oriental groups, Pycnonotidx (bulbuls), Phyllornithidæ (green bulbuls), and Megalæmidæ (barbets) are families whose absence is significant. Nine families are peculiar to the region, or only just pass its limit 3 in the case of single species. These are laridiseidxe (paradise-birds), Meliphagidx (honey-suckers), Menuridæ (lyre-birds), Atrichidæ (scrub-birds), Cacatuidæ (cockatoos), Platycercidæ (broad-tailed and grassparoquets), Trichoglossidæ (brush-tongued paroquets, Megapodiidæ (mound-makers), and Casuariidæ (cassowaries). There are also eight very characteristic families, of which four,--Pachycephalidæ (thick-headed shrikes), Campephagidæe (caterpillar shrikes), Dicæidæ (llower-peckers), and Artamidæ (swallowshrikes) - are feebly represented elsewhere, while the other four -Ploceidie (weaver-finches), Alcædinidæ (kingfishers), Podargidæ (frog-mouths), and Columbidæ (pigeons) - although widely distributed, are here unusually abundant and varied, and (except in the case of the Ploceidæ) better represented in the Australian than in any other region. Of all these the Meliphagidæ (honeysuckers) are the most peculiarly and characteristically Australian. This family abounds in genera and species; it extends into every part of the region from Celebes and Lombock on the west, to the Sandwich Islands, Marquesas, and New Zealand on the east, while not a single species overpasses its limits, with the exception of one (Ptilotis limbata) which abounds in all the islands of the Timorese group, and has crossed the narrow strait from Lombock to Baly; but this can hardly be considered to inpugn the otherwise striking fact of wide diffusion combined with strict limitation, which characterizes it. This family is the more important, because, like the Trichoglossidæe or brush-tongued paroquets, it seems to have been developed in co-ordination with that wealth of nectariferous flowering shrubs and trees which is one of the marked features of Australian vegetation. It probably originated in the extensive land-area of Australia itself, and thence spread into all the tributary islands, where it has become variously modified, yet always in such close adaptation to the other great features of the Australian fiuna, that it seems unable to maintain itself when subject to the competition of the more 
varied forms of life in the Oriental region; to which, possessing great powers of flight, some species must occasionally have emigrated. Its presence or absence serves therefore to define and limit the Australian region with a precision hardly to be equalled in the case of any other region or any other family of birds.

The Trichoglossidæ, as already intimated, are another of these peculiarly organized Australian families,--parrots with an extensile brush-tipped tongue, adapted to extract the nectar and pollen from flowers. These are also rigidly confined to this region, but they do not range so completely over the whole of it, being absent from New Zealand (where however they are represented by a closely allied form $N$ estor), and from the Sandwich Islands. The Paradiseidæ (birds of paradise and allies) are another remarkable family, confined to the Papuan group of Islands, and the tropical parts of Australia. The Megapodiidæ (or mound-builders) are another most remarkable and anomalous group of birds, no doubt specially adapted to Australian conditions of existence. Their peculiarity consists in their laying enormous eggs (at considerable jntervals of time) and burying them either in the loose hot sand of the beach above high-water mark, or in enormous mounds of leaves, sticks, earth, and refuse of all kinds, gathered together by the birds, whose feet and claws are enlarged and strengthened for the work. The warmth of this slightly fermenting mass hatches the eggs; when the young birds work their way out, and thenceforth take care of themselves, as they are able to run quickly, and even to fly short distances, as soon as they are hatched. This may perhaps be an adaptation to the peculiar condition of so large a portion of Australia, in respect to prolonged droughts and scanty watersupply, entailing a periodical scarcity of all kinds of food. In such a country the confinement of the parents to one spot during the lung period of incubation would often lead to starvation, and the consequent death of the offspring. But the same birds with free power to roam about, might readily mainta in themselves. This peculiar constitution and habit, which enabled the Megapodii to maintain an existence under the unfavourable conditions of their 
original habitat gives them a great advantage in the luxuriant islinds of the Moluccas, to which they have spread. There they abound to a remarkable extent, and their eggs furnish a luxurious repast to the natives. They have also reached many of the smallest islets, and have spread beyond the limits of the region to the I'hilippines, and North-Western Borneo, as well as to the remote Nicobar Islands.

The I'latycercidx, or broad-tailed paroquets, are another wide-spread Australian group, of weak structure but gorgeously coloured, ranging from the Moluccas to New Zealand and the Society Islands, and very characteristic of the region, to which they are strictly confined. The Cockatoos have not quite so wide a range, being confined to the Austro-Malayan and Australian sub-regions, while one species extends into the Philippine Islands. The otlier two peculiar families are more restricted in their range, aud will be noticed under the sub-regions to which they respectively belong.

Of the characteristic families, the Pachycephalidæ, or thichlieaded shrikes, are especially Australian, ranging over all the region, except New Zealand; while only a single species has spread into the Oriental, and one of doubtful affinity to the Ethiopian region. The Artamidre, or swallow-shrikes, are also almost wholly confined to the region, one species only extendirg to India. They range to the Fiji Islands on the east, but only to Tasmania on the south. These two families must be considered as really peculiar to Australia. The Podargidæ, or frogmouths-large, thick-billed goat-suckers-are strange birds very characteristic of the Australian region, although they have representatives in the Oriental and Neotropical regions. Campephargida (caterpillar-shrikes) also abound, but they are fairly represented both in India and Africa. The Ploceida, or weaverhirds, are the finches of Australia, and present a variety of interesting and beautiful forms.

We now come to the kingfishers, a cosmopolitan family of birds, yet so largely developed in the Australian region as to deserve special notice. Two-thirds of all the genera are found here, and no less than 10 out of the 19 genera in the family are 
peculiar to the Australian region. Another of the universally distributed families which have their metropolis here, is that of the Columbidæ or pigeons. Three-fourths of the genera have representatives in the Australian region, while two-fifths of the whole are confined to it; and it possesses as many species of pigeons as any other two regions combined. It also possesses the most remarkable forms, as exemplified in the great crowned pigeons (Goura) and the hook-billed Didunculus, while the green fruit-pigeons (Ptilopus) are sometimes adorned with colours vying with those of the gayest parrots or chatterers. This enormous development of a family of birds so defenceless as the pigeons, whose rude nests expose their eggs and helpless young to continual danger, may perhaps be correlated, as I have suggested elsewhere (Ibis, 1865 , p. 366), with the entire absence of monkeys, cats, lemurs, weasels, civets and other arboreal mammals, which prey on eggs and young birds. The very prevalent green colour of the upper part of their plumage, may be due to the need of concealment from their only enemies,-birds of prey; and this is rendered more probable by the fact that it is among the pigeons of the sinall islands of the Pacific (where hawlis and their allies are exceedingly scarce) that we alone meet with species whose entire plumage is a rich and conspicuous yellow. Where the need of concealment is least, the brilliancy of colour has attained its maximum. We may therefore look upon the genus Plilopus, with its fifty species whose typical coloration is green, with jatches of bright blue, red, or yellow on the head and breast, as a special development suited to the tropical portion of the Australian region, to which it is almost wholly confined.

It will be seen from the sketch just given, that the ornithological features of the Australian region are almost as remarkable as those presented by its Miummalian fauna; and from the fuller development attained by the aërial class of birds, much more varied and interesting. None of the other regions of the carth can offer us so many families, with special points of interest in structure, or habits, or general relations. The paradise-birds, the honeysuckers, the brush-tongued paroquets, the mound-huilders, and the cassowaries-all strictly feculial' 
to the region-with such remarkable developments as we lave indicated in the kingfishers and pigeons, place the Australian region in the first rank for the variety, singularity, and interest of its birds, and only second to South America as regards numbers and beauty.

Reptiles.-In Reptiles the peculiarity of the main Australian region is less marked, although the fauna is sufficiently distinct. There is no family of snakes confined to the region, but many peculiar genera of the families Pythonidæ and Elapidæ. About two-thirds of the Australian snakes belong to the latter family, and are poisonous; so that although the Crotalidæ and Viperidæ are absent, there are perhaps a larger proportion of poisonous to harmless snakes than in any other part of the world. According to Mr. Gerard Krefft the proportion varies considerably in the different colonies. In Victoria, New South Wales, and Queensland the proportion is about two to one; in West Australia three to one; and in South Australia six to one. In Tasmania there are only 3 species and all are poisonous. The number of species, as in other parts of the world, seems to increase with temperature. The 3 in Tasmania have increased to 12 in Victoria, 15 in South Australia and the same in West Australia; 31 in New South Wales, and 42 in sub-tropical Queensland.

The lizards of Australia have lately been catalogued by Dr. Günther in the concluding part of the "Voyage of the Erebus and Terror," issued in 1875. They belong to 8 families, 3 of which are peculiar; 57 genera of which 36 are peculiar; and about 140 species, all but 2 or 3 of which are peculiar. The scinks and geckoes form the great bulk of the Australian lizards, with a few Agamidæ, Gymnopthalmidæ, and Varanidæ. The three peculiar families are the Pygopodidx, Aprasiidx and Lialidx; comprising only $t$ genera and 7 species. The above all belong to Australia proper. Those of the other sub-regions are few in number and will be noticed under their respective localities. They will perhaps bring up the number of genera to 70. West and South Australia seem to offer much peculiarity in their lizards; these districts possessing 12 peculiar genera, 
while a much smaller number are confined to the East and South-East, or to the North.

Annong the fresh-water turtles of the family Chelydider there are three peculiar genera-Chelodina, Chelemys, and Elseya, all from Australia.

Amphibia. - No tailed amphibians are known from the whole region, but no less than eleven of the families of tail-less Batrachians (toads and frogs) are known to inhabit some part or other of it. A peculiar family (Xenorhinidæ), consisting of a single species, is found in New Guinea; the true toads (Bufonidx) are only represented by a single species of a peculiar genus in Australia, and by a Bufo in Celebes. Nine of the families are represented in Australia itself, and the following genera are peculiar to it:-Psendophryne (Phryniscidæ), Pachybatrachus, and Chelydobatrachus (Engystomydx); Helioporus (Alytidx); Pelodyras and Chirodyras (Pelodryadx); Notaden (Bufonidæ).

Fresh-water Fish.-There is only one peculiar family of freshwater fishes in this region-the Gadopsidæ-represented by a single genus and species. The other species of Australia belong to the families Trachinidæ, Atherinidæ, Mugillidæ, Siluridæe, Homalopteræ, Haplochitonidæ, Galaxidæ, Osteoglossidæ, Symbranchidæ, and Sirenoidei; most of the genera being peculiar. The large and widely-distributed families, Cyprinodontidæ and Cyprinidx, are absent. The most remarkable fish is the recently discovered Ceratodus, allied to the Lepidosiren of Tropical America, and Protopterus of Tropical Africa, the three species constituting the Sub-class Dipnoi, remains of which have been found fossil in the Triassic formation.

Summary of Australian Vertebrata. - In order to complete our general sketch of Australian zoology, and to afford materials for comparison with other regions, we will here summarize the distribution of Vertebrata in the entire Australian region, as given in detail in the tables at the end of this chapter. When an undoubted Oriental family or genus extends to Celebes ouly we do not count it as belonging to the Australian region, that island beingr so very anomalous and intermediate in character. 
The Australian region, then, possesses examples of 18 families of Mammalia, 8 of which are peculiar; 71 of Birds, 16 beingr peculiar; 31 of Reptiles, 4 being peculiar; 11 of Amphibia, with 1 peculiar'; and 11 of Fresh-water fish, with 1 peculiar. In all, 142 families of Vertebrates, 30 of which are almost or quite confined to it, or between one-fourth and one-fifth of the whole number.

The genera of Mammalia occurring within the linits of this region are 70 , of which 45 are almost, or quite, confined to it.

Of Land-Birds there are 296 genera, 196 of which are equally limited. The proportion is in both cases very nearly fiveeighths.

This shows a considerable deficiency both in families of Vertebrates and genera of Mammalia, as compared with the Oriental and Ethiopian regions; while in genera of Birds it is a little superior to the latter in total numbers, and considerably so in the proportion of peculiar types.

Supposed Land Connection between Australia and South America.

We may now consider how far the different classes and orders of vertebrates afford indications that during past ages there has been some closer connection between Australia and South America than that which now exists.

Among Mammalia we have the remarkable fact of a group of marsupials inhabiting South America, and extending even into the temperate regions of North America, while they are found in no other part of the globe beyond the limits of the Australian region; and this has often been held to be evidence of a former connection between the two countries. A preliminary objection to this view is, that the opossums seem to be rather a tropical group, only one species reaching as far as $42^{\circ}$ south latitude on the west coast of South America; but whatever evidence we have which seems to require a former union of these countries shows that it took place, if at all, towards their cold southern limits, the tropical faunas on the whole showing no similarity. This is nut a very strong objection, since climates may have changed in the south to as great an extent as we 
know they have in the north. Perhaps a more important consideration is, that Didelphys is a family type unknown in Australia; and this implies that the point of common origin is very remote in geological time. But the most conclusive fact is that in the Eocene and Miocene periods this very family, Didelphyidæ, existed in Europe, while it only appeared in America in the Post-pliocene or perhaps the Pliocene period; so that it is really an Old-IVorld group, which, though long since extinct in its birthplace, has survived in America, to which country it is a comparatively recent emigrant. Primeval forms of marsupials we know abounded in Europe during much of the Secondary epoch, and no doubt supplied Australia with the ancestors of the present fauna. It is clear, therefore, that in this case there is not a particle of evidence for any former union between Australia and South America; while it is almost demonstrated that both derived their marsupials from a common source in the northern hemisphere.

Birds ofter us more numerous but less clearly defined cases of this kind. Among Passeres, the wonderful lyre bird (Menura) is believed by some ornithologists to be decidedly allied to the South American Pteroptochidæ, while others maintain that it is altogether peculiar, and has no such affinity. The Australian Pachycephalidx.have also been supposed to find their nearest allies in the American Vireonidæ, but this is, perhaps, equally problematical. That the mound-makers (Megapodiidæ) of the Australian region are more nearly allied to the South American curassows (Cracidæ) than to any other family, is perhaps better established; but if proved, it is probably due, as in the case of the marsupials, to the survival of an ancient and once wide-spread type, and thus lends no support to the theory of a land connection between the two regions. A recent author, Professor Garrod, classes Phaps and other Australian genera of pigeons along with Zenaida and allied South American forms; but here again the affinity, if it exists, is so remote that the explanation already given will suffice to account for it. There remain only the penguins of the genus Eudyptes; and these have almost certainly passed from one region to the other, hut 
no actual land connection is required for birds which can cross considerable arms of the sea.

Reptiles again seem to offer no more support to the view than do manmalia or birds. Among snakes there are no families in common that have not a very wide distribution. Among lizards the Gymnopthalmidx are the only family that favour the notion, since they are found in Australia and South America, but not in the Oriental region. Yet they occur in both the Palaarctic and Ethiopian regions, and their distribution is altogether too erratic to be of any value in a case of this kind; and the same remarks apply to the tortoises of the family Chelydidæ.

The Amphibia, however, furnish us with some more decided facts. We have first the family of tree-frogs, Pelodryade, confined to the two regions; Litoria, a genus of the family Hylidæ peculiar to Australia, but with one species in Paraguay; and in the family Discoglossidæ, the Australian genus Chiroleptes has its nearest ally in the Chilian genus Calyptocephalus.

Fresh-water fishes give yet clearer evidence. Three groups are exclusively found in these two regions; Aphritis, a fresh-water genus of Trachinidæ, has one species in Tasmania and two others in Patagonia; the Haplochitonidæ inhabit only Terra del Fuego, the Falkland Islands and South Australia; while the genus Galaxias (forming the family Galaxidæ) is confined to South Temperate America, Australia, and New Zealand. We have also the genus Osteoglossum confined to the tropical rivers of Eastern South America, the Indo-Malay Islands and Australia.

It is important here to notice that the heat-loving Reptilia afford hardly any indications of close affinity between the two regions, while the cold-enduring amphibia and fresh-water fish, offer them in abundance. Taking this fact in connection with the absence of all indications of close affinity among the mammalia and terrestrial birds, the conclusion seems inevitable that there has been no land-connection between the two regions within the period of existing species, genera, or families. Yet some interchange of amphibia and fresh-water 
fishes, as of plants and insects, has undoubtedly occurred, but this has been effected by other means. If we look at a globe we see at once how this interchange may have taken place. Immediately south of Cape Horn we have the South Shetland Islands and Graham's land, which is not improbably continuous, or nearly so, with South Victoria land immediately to the south of New Zealand. The intervening space is partly occupied by the Auckland, Campbeil, and Macquarics' Islands, which, there is reason to believe are the relics of a great southern extension of New Zealand. At all events they form points which would aid the transmission of many organisms; and the farthest of the Macquaries' group, Emerald Island, is only 600 miles from the outlying islets of Victoria land. The ova of fish will survive a considerable time in the air, and the successful transmission of salmon ova to New Zealand packed in ice, shows how far they might travel on icebergs. Now there is evidently some means by which ova or young fishes are carried moderate distances, from the fact that remote alpine lakes and distinct river systems often have the same species. Glaciers and icebergs generally have pools of fresh water on their surfaces ; and whatever cause transmits fish to an isolated pond might occasionally stock these pools, and by this means introduce the fishes of one southern island into another. Batrachians, which are equally patient of cold, might be transported by similar means; while, as Mr. Darwin has so well sliown, (Origin of Species, 6th Ed. p. 345) there are various known modes by which plants might be transmitted, and we need not therefore be surprised that botanists find a much greater similarity between the production of the several Southern lands and islands, than do zoologists. It is important to notice that, however this intercommunication was effected, it has continued down to the epoch of existing species; for Dr. Guinther finds the same species of fresh-water fish (Galaxias attenuatus) inhabiting Tasmania, New Zealand, the Falkland Islands, and Temperate South America; while another species is common to New Zealand and the Auckland Islands. We cannot believe that a land connection has existed between all these remote lands within the period of existence of this one species of fish, 
not only on account of what we know of the permanence of continents and deep oceans, but because such a comnection must have led to much more numerons and important cases of similarity of natural productions than we actually find. And if within the life of species such interchange may have taken place across seas of greater or less extent, still more easy is it to understand, how, within the life of genera and families, a number of such interchanges may have occurred; yet always limited to those groups whose conditions of life render transmission possible. Had an actual land connection existed within the temperate zone, or during a period of warmth in the Antarctic regions, there would have been no such strict limitations to the inter-migration of animals. It may be held to support the view that floating ice las had some share in the transmission of fish and amphibia, when we find that in the case of the narrow tropical sea dividing Borneo from Celebes and the Moluccas, no proportionate amount of transmission has taken place, but numerous species, genera, and whole families, terminate abruptly at what we have other rensons for believing to be the furthest limits of an ancient continent. We can hardly suppose, however, that this mode of transmission would have sufficed for such groups as tree-frogs, which are inhabitants of the more, temperate or even warm portions of the two southern lands. Some of these cases may perhaps be explained by the supposition of a considerable extent of land in the South-Temperate and Antarctic regions now submerged, and by a warni or tempcrate climate analogous to that which prevailed in the Arctic regions during some part of the Miocene epoch; while others may he due to cases of survival in the two areas of once wide-spread groups, a view supported in the case of the Amphibia by the erratic manner in which many of the groups are spread over the globe.

From an examination of the facts presented by the various classes of vertebrates, we are, then, led to the conclusion, that there is no evidence of a former land-comnection between the Australian and Neotropical regions; but that the varions scattered resemblances in their natural productions 
that undoubtedly occur, are probably due to three distinct callses.

First, we have the American Didelphyidæ, among Mammals, and the Cracidre, among birds, allied respectively to the Marsupials and the Megapodiilse of Australia. This is probably more a coincidence than an affinity, due to the preservation of ancient wide-spread types in two remote areas, each cut off from the great northern continental masses, in which higher forms were evolved leading to the extinction of the lower types. In each of these southern isolated lands the original type would undergo a special development; in the one case suited to an arboreal existence, in the other to a life among arid plains.

The second case is that of the tree-frogs, and the genus Ostroglossum among fishes; and is most likely due to the extension and approximation of the two southern continents, and the existence of some intermediate lands, during a warm period when facilities would be afforded for the transmission of a few organisms by the causes which have led to the exceptional diffusion of fresh-water productions in all parts of the world. As however Ostenglossum occurs also in the Sunda Islands, this may be a case of survival of a once wide-spread group.

The third case is that of the same genera and even species of fish, and perhaps of frogs, in the two countries; which may be due to transmission from island to island by the aid of floating ice, with or without the assistance of more intervening lands than now exist.

Having arrived at these conclusions from a consideration of the vertebrata, we shall be in a position to examine how far the same causes will explain, or agree with, the distribution of the invertebrate groups, or elucidate any special difficulties we may meet with in the relations of the sub-regions.

\section{Insects.}

The insects of the Australian region are as varied, and in some respects as peculiar as its higher forms of life. As we have already indicated in our sketch of the Oriental region, a vast number of forms inhabit the Austro-Malay sub-region 
Which are absent from Australia proper. Such of these as are common to the Malay archipelago as a whole, have been already noted; we shall liere confine ourselves more especially to the groups peculiar to the region, which are almost all either Australian or Austro-Malayan, the Pacific Islands and New Zealand being very poor in insect life.

Lepidopterca.-Australia itself is poor in butterflies, except in its northern and more tropical parts, where green Ornithopterce and several other Malayan forms occur. In South Australia there are less than thirty-five species, whereas in Queensland there are probably over a hundred. The peculiar Australian forms are few. In the family Satyricle, Tenica and Heteronymplan, with Hypocista extending to New Guinea; among the Lycxnidx, Ogyris and Utica are confined to Australia proper, and Hypochrysops to the region; and in Papilionidx, the remarkable Eurycus is confined to Australia, but is allied to Euryades, a genus found in Temperate South America (La Plata), and to the Parnassius of the North-Temperate zone.

The Austro-Malay sub-region has more peculiar forms. Hamadryas, a genus of Danaidx, approximates to some South American forms; Hyades and Hyantis are remarkable groups of Morphidæ; Myncs and Prothoë are fine Nymphalidx, the former extending to Queensland; Dicallanerura, a genus of Erycinidæ, and Eludina, of Pieridie, are also peculiar forms. The fine AEgcus group of Papitio, and Primnus group of Onithoptera, also belong exclusively to this region.

Xois is confincil to the Fiji Islands, Bletogonce to Celebes, and Acropthalmia to New Zealand, all genera of Satyridx. Serenteen genera in all are confined to the Australian region.

Among the Sphingina, Pollanisus, a genus of Zygrenidx, is Australian; also four genera of Castniidr-Synemon, Euschemon, Damixs, and Cocylia, the latter being confined to the Papuan islands. The occurrence of this otherwise purely South American family in the Australian region, as well as the affinity of Eurycus and Euryades noticed above, is interesting; but as we have secu that the genera and families of insects are more permanent than those of the liigher animals, and as the groups in question are 
confined to the warmer parts of both.countries, they may be best explained as cases of survival of a once wide-spread type, and may probably date back to the period when the ancestors of the Marsupials and Megapodii were cut off from the rest of the world.

Coleoptera.-The same remark applies here as in the Lepidoptera, respecting the affinity of the Austro-Malay fauna to that of Indo-Malay Islands; but Australia proper is much richer in beetles than in butterflies, and exhibits much more speciality. Although the other two parts of the Australian region (Polynesia and New Zealand) are very poor in beetles, it will, nevertheless, on the whole compare farourably with any of the regions except the very richest.

Cicindelidie are not very abundant. Therates and Tricondyla are the characteristic genera in Austro-Malaya, but are absent from Australia, where we have Tetracha as the most characteristic genus, with one species of Megacephala and two of Distypsidera, a genus which is found also in New Zealand and some of the Pacific Islands. The occurrence of the South American genus, Tetracha, may perhaps be due to a direct transfer by means of intervening lands during the warm southern period; but considering the permanence of coleopterous forms (as shown by the Miocene species belonging almost wholly to existing genera), it seems more probable that it is a case of the survival of a once wide-spread group.

Carabidie are well represented, there being no less than 94 peculiar genera, of which 19 are confined to New Zealand. The Australian genera of most importance are Carcnum (68 species), Promecoderus (27 species), Silphomorpha (32 species), Adelotopus (27 species), Scaraphites (25 species), Notonomus (18 species), Gnathoxys (12 species), Eutoma (9 species), Enigma (15 species), Iacordairea (8 species), Pamborns (8 species), Catadromus (4 species),- - the latter found in Australia and Celebes. Common to Australia and New Zealand are Mecodema (14 species), Homalosoma (32 species), Dicrochile (12 species), and Scopodes (5 species). The larger genera, confined to New Zealand only, are Metaglymma (8 species), and Demetrida (3 species). The curious genus Pscudomorpha (10 species), is divided between California, Brazil, 
and Australia; and the Australian genera, Adelotopus, Silpilomorpha, and $S_{1}$ hallomorpha, form with it a distinct tribe of Coleoptera. These being all confined to the warmer regions, and having so scattered a distribution, are no doubt the relics of a widespread group. The Australian genus, Promecoderus, has, however, closely allied genera (Cascelius and its allies), in Chili and Iatagonia; while two small genera confined to the Auckland Islands (Hetcrodactylus and Pristancyclus) are allied to a group found only in Terra-del-Fuego and the Falkland Islands, (Migadops); and in these cases we may well believe that a direct transmission has taken place by some of the various means already indicated.

In Lucanidæ, Australia is only moderately rich, having 7 peculiar genera. The most important are Cercitognathus and Rilys sonotus, confined to Australia; Lissotes to Australia and New Zealand; Lamprima to Australia and Papua. Mitophyllus and Dendroblax inhabit New Zealaud only; while Syndesus is found in Australia, New Caledonia, and tropical South America.

The beautiful Cetoniidæe are poorly represented, there being only 3 peculiar genera;-Schizorhina, mainly Australian, but extending to Papua and the Moluccas; Anacamptortina, confined to New Guinea, and Sternoplus to Celebes. Lomaptera is very characteristic of the Austro-Malay Islands. This almost tropical family shows no approximations between the Australian and Neotropical faunas.

In Buprestidæ, the Australian region is the richest, possessing no less than 47 genera, of which 20 are peculiar to it. Of these, 15 are peculiar to Australia itself, the most inmportant being Stiymodera (212 species), Ethon (13 species), and Nascio (3 species); Cisseis (17 species), and the magnificent Calodema (3 species), are common to Australia and Austro-Malaya; while Sambus (10 species) and Anthaxomorpha (4 species), with some smaller groups, are peculiarly Austro-Malayan. In this family occur several points of contact with the Neotropical region. Stigmodera is said to have a species in Chili, while there are undoubtedly several allied genera in Chili and South Temperate America. The genus Curis has 5 Australian and 3 Chilian species, and 
Acherusia has 2 species in Brazil, 1 in Australia. These rescmblances may probably have arisen from intercommunication during the warm southern period, when floating timber would occasionally transmit a few larva of this family from island to island across the antarctic seas. When the cold period returned, they would spread northward, and become more or less modified under the new physical conditions and organic competition, to which they were subjected.

We now come to the very important group of Longicorns, in which the Australian region as a whole, is very rich, possessing 360 genera, of which 263 are peculiar to it. Of these about 50 are confined to the Austro-Malay Islands, 12 to New Zealand, and the remainder to Australia proper with Tasmania. Of the genera confined to, or highly characteristic of Australia, the following are the most important :-Cnemoplites, belonging to the Prionidæ; Phoracantha, to the Cerambycidæ; Zygocera, Hebecerus, Symphyletes, and Rhytidophorce, to the Lamiidx. Confined to the Austro- Malay Islands are Tethionea (Cerambycidæ): Tmesisternus, Amrhenotus, Micracantha, and Sybra (Lamiidæ); but there are also such Malayan gevera as Batocerca Gnoma, Praonetha, and Sphenura, which are very abundant in the Austro-Malay sub-region. A species of each of the Australian genera, Zygocera, Syllitus, and Pseudoccphalus, is said to occur in Chili, and one of the tropical American genus, Hammatocharus, in tropical Australia; an amount of resemblance which, as in the case of the Buprestidx, may be imputed to trans-oceanic migration during the Southern warm period. This concludes our illustrations of the distribution of some of the more important groups of Australian insects; and it will be admitted that we have not met with any such an amount of identity with the fauna of Temperate South America, as to require us to modify the conclusions we arrived at from a consideration of the vertebrate groups.

Lancl-Shells. - The distribution of many of the larger genera of land-shells is very erratic, while others are exceedingly restricted, so that it requires an experienced conchologist to investigate the affinitics of the several groups, and thus work 
out the important facts of distribution. All that can be done here is to note the claracteristic and peculiar generi, and any others presenting features of special interest.

In the great family of the snails (Helicilre), the only genera strictly confined to the region are, Purtula, now containing alove 100 species, and ranging over the Pacific from the Solomon Isles on the west, to the Sandwich Islands and Tahiti on the east; and Achatinella, now contrining nearly 300 species, and wholly confined to the Sandwich Islands. Pfeifferia is confined to the Philippine Islands and Molucras; Cochlostyla to the Indo-Malay Islands and Australia; Bulimus occurs in most of the insular groups, including New Zealand, but is absent from Australia.

Among the Aciculidee, the widely-scattered Truncatclla is the only genus represented. Among Diplommatinidie, Diplommatina is the characteristic genus, ranging over the whole region, and found elsewhere as far as India; with one species in Trinidad. The extensive family Cyclostomidx, is not well represented. Seven genera reach the Austro-Malay Islands, one of which, Registoma, is confined to the Philippines, Molnccas, New Caledonia, and the Marshall Islands. Omphalotropis is the most characteristic genus, ranging over the whole region; Callia is confined to the Philippines, Ceram, and Australia; Realia to New Zealand and the Marquesas. The genus Hclicina alone represents the Helicinidæ, and is found in the whole region cxcept New Zealand. The number of species known from Australia is perhaps about 300; while the Polynesian sub-region, nccording to Mr. Harper Pease, contains over 600 ; the AustroMalay Islands will furnish probably 200; and New Zealand about 100 ; making a total of about 1,200 species for the whole region.

\section{Australian Sub-Regions.}

Few of the great zoological regions comprise four divisions so strongly contrasted as these, or which present so many interesting jublems. Tre have first the Austro-Malay Islands, an equatorial forest-region teeming with varied and beautiful forms of life; next we have Australia itself, an jsland-continent with its satellite 
Tasmania, both tropical and temperate, but for the most part arid, yet abounding in peculiar forms in all the classes of animals; then come the Polynesian Islands, another luxuriant region of tropical vegetation, yet excessively poor in most of the higher groups of animals as well as in some of the lower; and lastly, we have New Zealand, a pair of temperate forest-clad islands far in the southern occan, with a very limited yet strange and almost wholly peculiar fauna. We have now to consider the general features and internal relations of the faunas of each of these sub-regions, together with any external relations which have not been discussed while treating the region as a whole.

\section{Austro-Malayan Sub-region.}

The central mass on which almost every part of this subregion is cleasly dependent, is the great island of New Guinea, inhabited by the Papuan race of mankind; and this, with the surrounding islands, which are separated from it by shallow seas and possess its most marked zoological features, are termed Papua. A little further away lie the important groups of the Moluccas on one side and the Eastern Papuan Islands on the other, which possess a fauna mainly derivative from New Guinea, yet wanting many of its distinctive types; and, in the case of the Moluccas possessing many groups which are not Australian, but derived from the adjacent Oriental region. To the south of these we lave the Timor group, whose fauna is clearly derivative, from Australia, from Java, and from the Moluccas. Lastly comes Celebes, whose fauna is most complex and puzzling, and, so far as we can judge, not fundamentally derivative from any of the surrounding islands.

Papuc, or the New Guinea Group.-New Guinea is very deficient in Mammalia as compared with Australia, though this apparent poverty may, in part, depend on our very scanty knowlerlge. As yet only four of the Australian families of Marsupials are known to inlahit it, with nine genera, several of which are peculiar. It also possesses a peculiar form of wild pig; but as yet no other non-marsupial terrestrial mammal has been discovered, except a rat, described by Dr. Gray as Uromys 
aruensis, but about the locality of which there seems some doubt. ${ }^{1}$ Omitting bats, of which our knowledge is very imperfect, the Papuan Mammals are as follows:-

\begin{tabular}{|c|c|c|}
\hline \multirow{4}{*}{$\begin{array}{l}\text { Family. } \\
\text { Suidic ... } \\
\text { Muridæ ... } \\
\text { Dasyuridæ }\end{array}$} & \multirow{2}{*}{\multicolumn{2}{|c|}{$\begin{array}{l}\text { Genus. } \\
\text { Sus }\end{array}$}} \\
\hline & & \\
\hline & ... & \\
\hline & & Phascogale \\
\hline " & $\cdots$ & Antechinus \\
\hline$"$ & 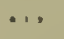 & Dactylopsila \\
\hline & & Myoictis \\
\hline Peramelidæ & $\cdots$ & Perameles \\
\hline 100 & & Dendrolagus \\
\hline Phalangisti & & $\begin{array}{l}\text { Dorcopsis } \\
\text { Cuscus }\end{array}$ \\
\hline , & & Belideus \\
\hline
\end{tabular}

Species.

1 Eistern limit of the genus.

1 Aru Islands (?)

1 Australian genus.

1 To N"orth Australia only.

1 Aru islands only.

1 New Guinea only.

2 New Guinea only.

2 Papua only.

7 Celebes to New Guinea.

1 Australia and Moluceas.

We have here no sign of any approach to the Mammalian fauna of the Oriental region, for though Sus has appeared, the Muridæ (rats and mice) seem to be wanting.

In Birds the case is very different, since we at once meet with important groups, either wholly, or almost peculiar to the Papuan fauna. According to a careful estimate, embodying the recent discoveries of Meyer and D'Albertis, there are 350 species of Papuan land-birds comprised in 136 genera. About 300 of the species are absolutely peculiar to the district, while 39 of the genera are exclusively Papuan or just extend into the Moluccas, or into North Australia where it closely approaches New Guinea. In analysing the genera we may set aside 31 as having a wide range, and being of no significance in distribution; such are most of the birds of prey, with the genera Hirundo, Caprimulgus, Zosterops; and others widely spread in both the Oriental and Australian regions, as Dicaum, Munia, Eudynamis, \&c. Of the remainder, as above stated, about 39 are peculiar to the Papuan fauna, 50 are characteristic Australian genera ; 9 are more especially Malayan, and as much Australian as Oriental; while 7 only, appear to be typically Oriental with a discontinuous distribution, none of them occurring in the Moluccas.

1 Sce Ann. Nat. Hist., 1873, p. 418, where the species is said to inlaibit the Aru Islands and Celeles, which renders it not improbable that it may have been curried to the former islands from the latter. 
This Papuan fauma is so interesting and remarkable, that it seems advisable to give lists of these several classes of generic types.

I. Genera occurring in the Papuan Islands which are characteristic of the Australian region (89). Those marked with an asterisk are exclusively Papuan.

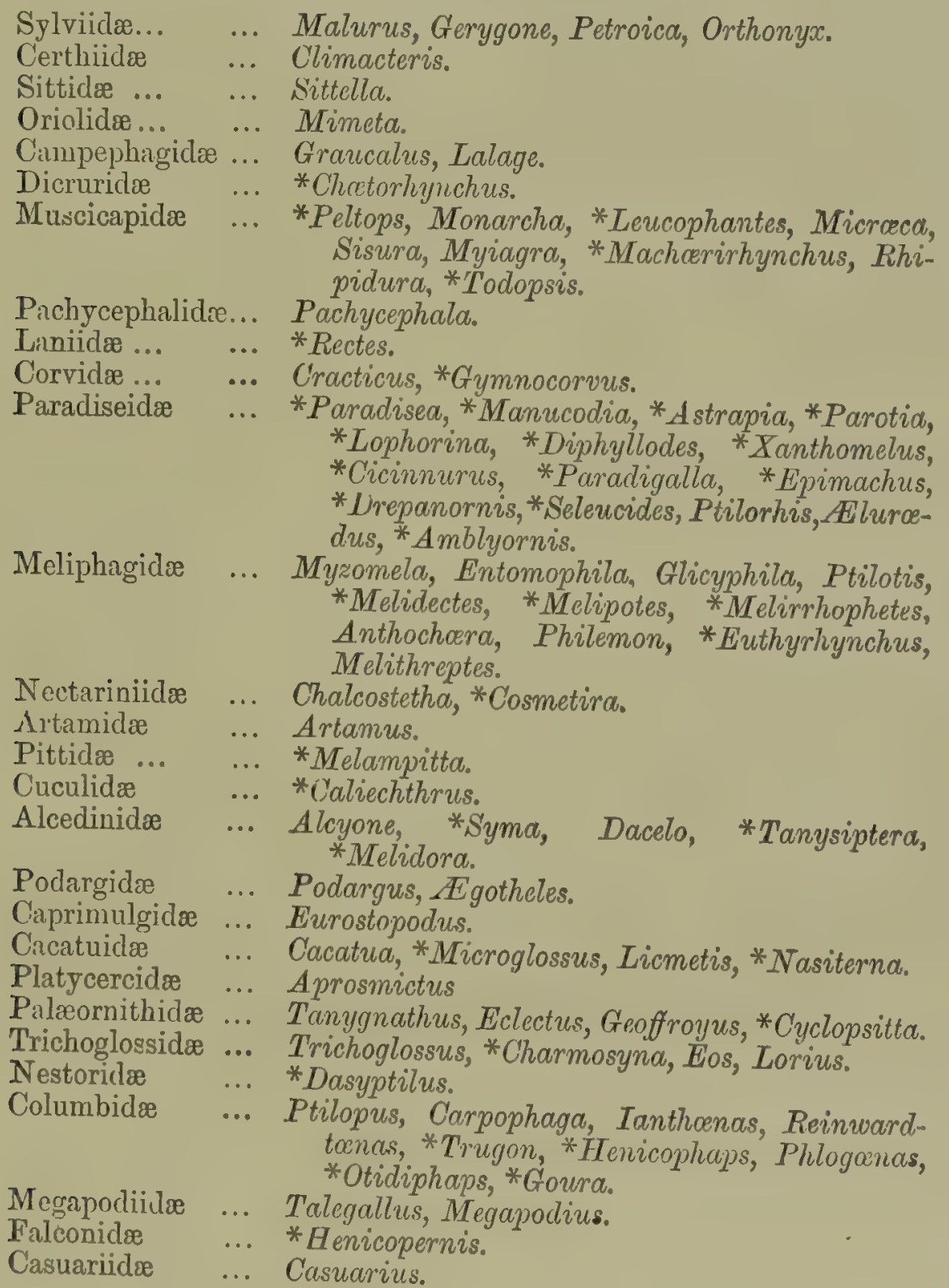

The chief points of interest here are the richness and specialization of the parrots, pigeons, and kingfishers; the wonderful paradise-birds; the honeysuckers; and some remarkable flycatchers. 
The most prominent deficiencics, as compared with $\Lambda$ ustralia, are in Sylviidæ, Timaliidæ, Ploceidæ, Platycercidæe, and Falconider.

II. The genera which are characteristic of the whole Malay Archipelago are the following (10) :-
1. Erythrurce $\ldots$ (Ploccidæ)
2. Pitta... ... (Pittidæ)
3. Сeyx ... … (Alcedinidæ)
4. Calao … (Bucerotidæ)
5. Dendrochelidon (Cypselidæ)
6. Loriculus ... (Psittacidæ)
7. Macropygia ... (Columbidæ)
8. Chalcophaps ... ,
9. Calsenas
10. Baza ... … (Falconidx)

III. The curious set of genera apparently of Indo-Malayan origin, but unknown in the Moluccas, are as follows:-
1. Eupetes … (Cinclidæ)
2. Alcippe $\ldots$ (Timaliidæ)
3. Pomatorhinus
"
4. Arachnothera (Nectariniidæ)
5. Prionochilus... (Dicæidæ)
6. Eulabes … (Sturnidæ)

The above six birds are very important as indicating past changes in the Austro-Malay Islands, and we must say a few words about each. (1) Eupetes is very remarkable, since the New Guinea birds resemble in all important characters that which is confined to Malacca and Sumatra. They are probably the survivors of a once wide-spread Malayan group. (2) Alcippe or Drymacataphus (for in which genus the birds should be placed is doubtful) seems another clear case of a typical Indo-Malayan form occurring in New Guinea and Java, but in no intervening island. (3) Pomatorhinus is a most characteristic Himalayan and Indo-Malayan genus, occurring again in New Guinea and also in Australia, but in no intermediate island. The New Guinea bird seems as nearly related to Oriental as Australian species. (4) Arachnothera is exactly parallel to Alcippe, occurring nowhere east of Borneo except in New Guinea. (5) Prionochilus, a small black bird, sometimes classed as a distinct genus, but evidently allied to the Prionochiti of the Indo-Malay Islands. (6) Eulctes, the genus which contains the well known Mynahs of India, extends east of Java as far as Flores, but is not found in Celebes or the Moluccas. The two New Guinea species are sometimes classed in different genera, but they are undoubtedly allied to the Mynahs of India and Malaya.

We find then, that while the ornithology of New Guinea is 
preeminently Australian in character and possesses many peculiar developments of Australian types, it has also-as might be expected from its geographical position, its climate, and its vegetation-received an infusion of Malayan forms. But while one group of these is spread over the whole Archipelago, and occasionally beyond it, there is another group which presents the unusual and interesting feature of discontinuous distribution, jumping over a thousand miles of island-studded sea from Java and Borneo to New Guinea itself. It is a parallel case to that of Java in the Oriental region, which we have already discussed, but the suggested explanation in that case is more difficult to apply here. The recent soundings by the Challenger show us, that although the several islands of the Moluccas are surrounded by water from 1,200 to 2,800 fathoms deep, yet these seas form inclosed basins with rims not more than from 400 to 900 fathoms deep, suggesting the idea of great lakes or inland seas which have sunk down bodily with the surrounding land, or that enormous local and restricted elevations and subsidences have here occurred. We have also the numerous small islands and coral banlis south of Celebes and eastward towards Timor-Laut and the Aru Islands, indicating great subsidence; and it is possible that there: was an extension of Papua to the west, approaching sufficiently near to Java to receive occasional straggling birds of IndoMalay type, altogether inclependent of the Moluccas to the north. Bright Colours and Ornamental Plumagc of $\Lambda^{\top} \mathrm{c}$ Guinea Birds. -One of the most striking features of Papuan ornithology is the large proportion which the handsome and bright-coloured birds bear to the more obscure species. That this is really the case has been ascertained by going over my own collectious, made at Aru and New Guinea, and comparing them with my collection made at Malacea-a district remarkable for the number of handsome birds it produces. Using, as nearly as possible, the same standard of beanty, about one-third of the Malacea birds may be classed as handsome, ${ }^{1}$ while in Papua the proportion comes out exactly one-half. This is due, in part to the great abundince of

1 I also find about this proportion in my Amazonian collections, cven counting all the humming-birds, parrots, and toucans as handsome birds. 
parrots, cockatoos, and lories, almost all of which are beautiful; and of pigeons, more than half of which are very beautiful; as well as to the numerous kingfishers, most of which are excessively brilliant. Then we have the absence of thrushes, and the very small numbers of the warblers, shrikes, and Timaliidre, which are dull-coloured groups; and, lastly, the presence of numerous gay pittas, flycatchers, and the unequalled family of paradise-birds. A large number of birds adorned with metallic plumage is also a marked feature of this fauna, more than a dozen genera being so distinguished. Among the remarkable forms are Peltops, a flycatcher, long classed as one of the Indo-Malayan Eurylæmidæ, which it resembles both in bill and coloration; Macharirhynchus, curious little boat-billed flycatchers; and Todopsis, a group of terrestrial flycatchers with the brilliant colours of Pitta or Malurus. The paradise-birds present the most wonderful developments of plumage and the most gorgeous varieties of colour, to be fornd arnong passerine birds. The great whiskered-swift, the handsomest bird in the entire family, has its head-quarters here. Ainong kingfishers the elegant long-tailed Tanysiptcrce are preeminent, whether for singularity or beauty. Among parrots, New Guinea possesses the great black cockatoo, one of the largest and most singular birds in the order; Nasiterna, the smallest of known parrots; and Charmosyna, perhaps the most elegant. Lastly, among the pigeons we have the fine crowned-pigeons, the largest and most remarkable group of the order.

Plate X. Illustrating the Ornithology of New Guinea.-The wonderful ornithological fauna we have just sketched, could only be properly represented in a series of elaborate coloured plates. We are obliged here to confine ourselves to representing a few of the more remarkable types of form, as samples of the great number that adorn this tecming bird-land. The large central figure is the fine twelve-wired paradise-bird (Elvimachus albus), one of the most beautiful and remarkable of the family. Its general plumage appears, at first sight, to be velvety black; but on closer examination, and by holding the bird in various lights, it is found that every part of it glows with the most exquisite metallic tints-rich hronze, intense riolet, and, on the 

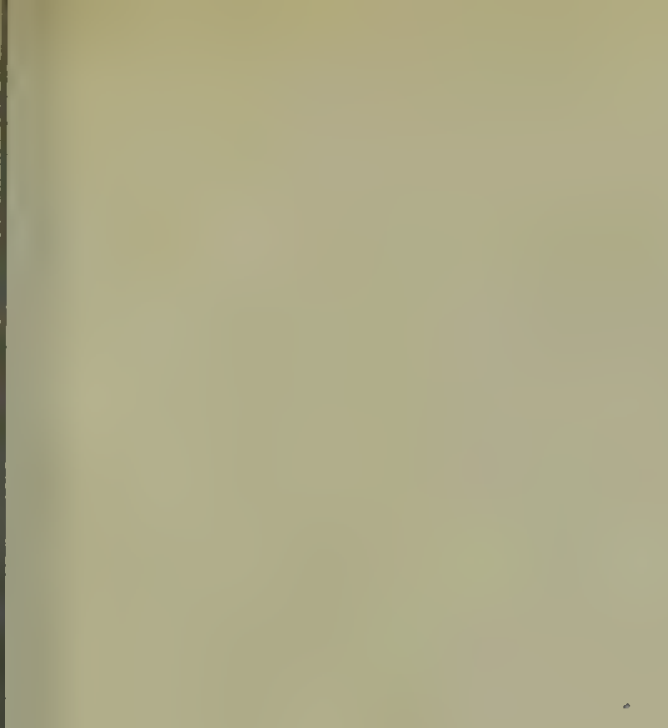

.

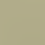


PI.J'P X.

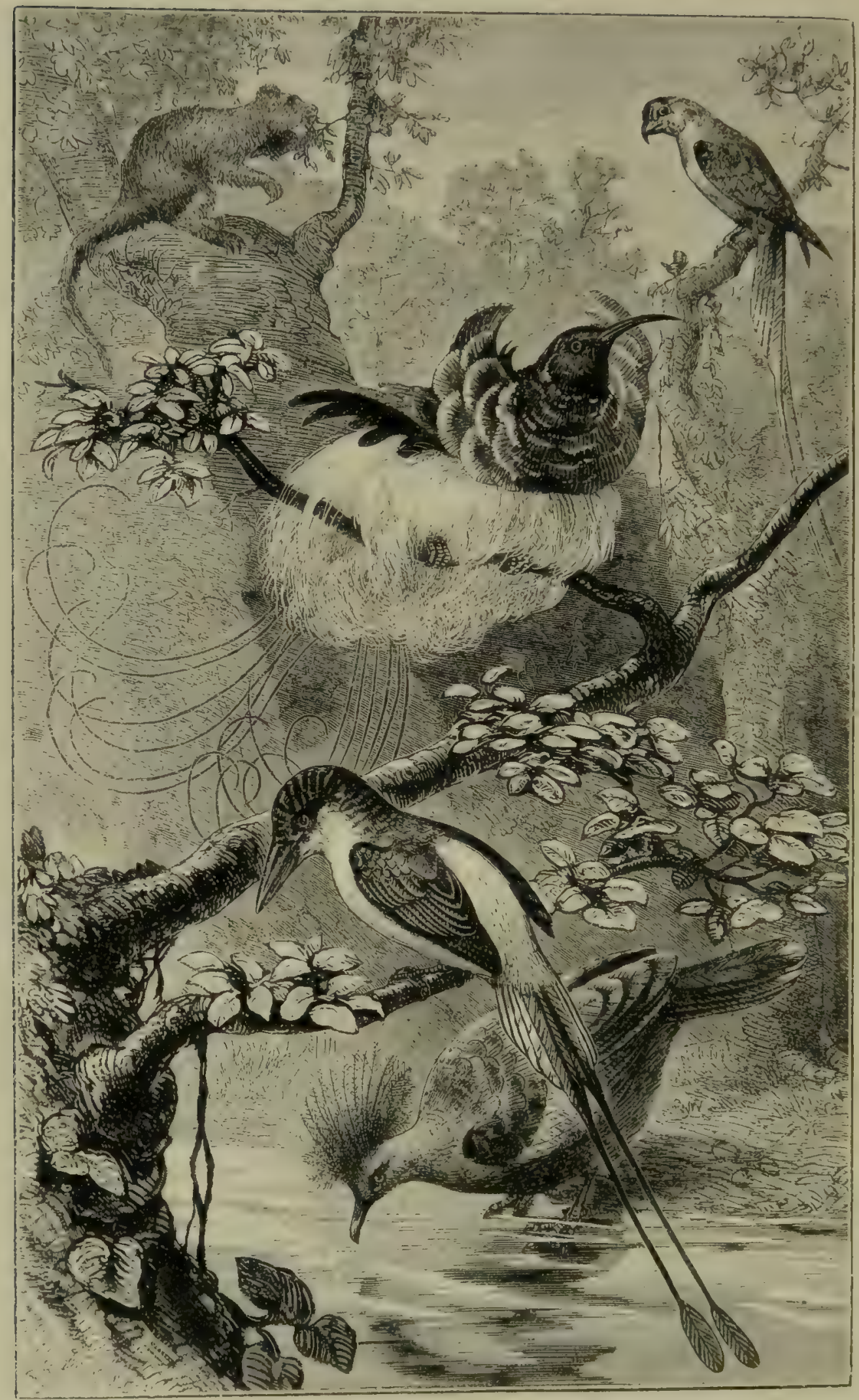

SLENE IN NHW GUINAA, WITI CHARACTHRISTIC ANIMAIS. 
edges of the breast-feathers, brilliant green. An immense tuft of dense plumes of a fine orange-buff colour, springs from each side of the body, and six of these on each side terminate in a black curled rachis or shaft, which form a perfectly unique adornment to this lovely bird. To appreciate this wonderful family (of which no good mounted collection exists) the reader should examine the series of plates in Mr. Elliot's great work on the Paradiseidx, where every species is figured of the size of life, and with a perfection of colouring that leaves little to be desired.

Below the Epimachus is one of the elegant racquet-tailed king-hunters (Tanysiptera galatea) whose plumage of vivid blue and white, and coral-red bill, combined with the long spatulate tail, renders this bird one of the most attractive of the interesting family of kingfishers. On a high branch is scated the little Papuan parroquet (Charmosyna papuensis), one of the Trichoglossidæ, or brush-tongued parrots,-richly adorned in red and yellow plumage, and with an unusually long and slender tail. On the ground is the well-known crowned pigeon (Gour coronata, ) a genus which is wholly confined to New Guinea and a few of the adjacent islands. One of the very few Papuan mammals, a tree-kangaroo (Dendrolagus inustus), is seated on a high branch. It is interesting, as an arboreal modification of a family which in Australia is purely terrestrial; and as showing how very little alteration of form or structure is needed to adapt an animal to such a different mode of life.

Reptiles and Amphitia.-Of these classes comparatively little is at present known, but there is evidence that the same intermixture of Oriental and Australian forms that occurs in birds and insects, is also found here. Dr. A. B. Meyer, the translator of this work into German, and well known for his valuable discoveries in New Guinea, has kindly furnished me with a manuscript list of Papuan reptiles, from which most of the information I am able to give is derived.

Of Snakes, 24 genera are known, belonging to 11 families. Six of the genera are Oriental,-Calamaria, Ccrberus, Chrysopclea, Lycodon, Chersydrus, and Ophimphorgus. Four are Australian, 
-Morelia, Liasis, Diemenia, and Acanthophis; while four others are more especially Papuan,-Dibamus (Typhlopidie), Biocksyorros-a sub-genus of the wide-spread Rhabdosona (Calarnariidie), found also in Timor; Nardoce and Enygrus (Pythonidx), rangring from the Molnceas to the Fiji Islands. The rest are either conmon to the Oriental and Australian regions or of wide range.

Of Lizards also, $2 \pm$ genera are recorded, belonging to 5 families. Three only are peculiarly Oriental,-Eumeces, Ticuris, and Nycteridium; but another, Gonyocephalus, is Malayan, ranging from Java and Borneo to the Pelew Islands. Three are Australian,Cyclodus, Heteropus, and Gchyra; while six are especially Papuan, -Keneuxia (extendings to the Philippines), Elania, Carlia (to North Australia), Lipinia (to the Philippine Islands), and I'ribolonotus, - all belonging to the Scincidr; and Ama belonging to the Agamidre. We must adil C'ryptoblepharus, which is confined to the Australian region, except a species in Mauritius. The other genera have a wider distribution.

The preponderant Oriental element in the suakes as compared with the lizards, is suggestive of the dispersal of the former being depenclent on floating trees, or even on native canoes, which for an unknown period have traversed these seas, and in which various species of snakes often secrete themselves. This seems the more probable, as snakes are usually more restricted in their range than lizaris, and exhibit less numerous examples of widespread genera and species. The other orders of reptiles present no features of interest.

Of Amphibia only 8 genera are known, belonging to 6 families. Rana, Hylarana, and Hyla are wide-spread genera, the former being, however, absent from Australia. Hyperolius, Pelodryas, Litoria, and Asterophrys are Australian; while Platymantis is Polynesian, with a species in the Plilippine Islands. Hence it appears that the amphibia, so far as yet known, exhibit no Oriental affinity; and this is a very suggestive fact. $\mathrm{T}^{\top} \mathrm{e}$ have seen (p. 29) thut salt water is almost a complete barrier to the dispersal of these creatures; so that the wholly Australian character of the I'apuan batrachia is what we might expect, if, as herc alvocated, no actual land comnection between 
the Oriental and'Australian regions, has probably occurred during the entire Tertiary and Post-tertiary periods.

Insects.-The general character of the Papuan insects has been sufficiently indicated in our sketch of the Entomology of the region. We will here only add, that the metallic lustre so prevalent among the birds, is also apparent in such insects as Sphingnotus mirabilis, a most brilliant metallic Longicorn; Lomaptera wallacei and Anacamptorlina fulyida, Cetonii of intense lustre; Calodema wallacei among the Buprestidæ; and the elegant blue Eupholi among the weevils. Even among moths we have Cocytia durvillii, remarkable for its brilliant metallic colours.

The Moluccas.-The islands of Gilolo, Bouru, and Ceram, with several smaller islands adjacent, together with Sanguir, and perhaps Tulour or Salibaboo to the north-west, and the islands from Ke to Timor-Laut to the sonth-east, form the group of the Moluccas or Spice-Islands, remarkable for the luxuriance of their vegetation and the extreme beauty of their birds and insects. Their Mammalia are of Papuan character, with some foreign intermixture. Two genera of the New Guinea marsupials, Belideus and Cuscus, abound; and we have also the widespread Sus. But besides these, we find no less than five genera of placental Mammals quite foreign to the Papuan or Australian. faunas. These are 1. Cynopithecus nigrescens, found only in the small island of Batchian, and probably introduced from Celebes, where the same ape occurs. 2. Viverra tangalunga, a common Indo-Malayan species of civet, probably introduced. 3. Cervus hippelaphus, var. Moluccensis, a deer abundant in all the islands, very close to a Javan species and almost certainly introduced by man, perhaps very long ago. 4. Babirusa alfurus, the babirusa, found only in the island of Bouru, and perhaps originally introduced from Celebes. 5. Sorex sp., small shrews. With the exception of the last, all these species are animals habitually domesticated and kept in confinement by the Malays ; and when we consider that none of the smaller Mammalia of Java and Borneo, numbering at least fifty different species, are fount 
in any of the Moluccas, we can hardly suppose that such large animals as the deer and ape, could have reached them by natural means. There is every reason to believe, therefore, that the indigenous Mammalia of the Moluccas are wholly of Papuan stock, and very limited in number.

The birds are much more varied and interesting. About 200 species of land-birds are now known, belonging to 85 genera. Of the species about 15 are Indo-Malayan, 32 Papuan, and about 140 peculiar. Of the genera only two are peculiar,--Semioptera, a paradise bird, and Lycocorax, a singular form of Corvidæ; but there is also a peculiar rail-like wader, Habroptila. One genus, Basilornis, is found only in Ceram and Celebes; another, Scythrops, is Australian, and perhaps a migrant. About 30 genera are characteristic Papuan types, and 37 others, of more or less wide range, are found in New Guinea and were therefore probably derived thence. There remains a group of birds which are not found in New Guinea, and are either Palæarctic or Oriental. These are 13 in number as follows :-
1. Monticola.
8. Corydalla.
2. Acrocephalus.
9. Hydrornis.
3. Cisticola.
4. Hypolais.
5. Criniger.
6. Butalis.
7. Budytes.
10. Batrachostomus.
11. Loriculus.
12. Treron.
13. Neopus.

Of these the Monticola, found only in Gilolo, appears to be a straggler or migrant from the Philippine islands. Acrocephalus, of which four species occur, is a wide-spread group; one of the Moluccan birds is an Australian and another a North-Asian species, which perhaps indicates that there has long been some migration southward fron island to island, across the Moluccas. Cisticola is a genus of very wide range, extending to Australin. Hypolais is probably a modified form of a Chinese or Javanese species. Criniger is a pure Indo-Malay form, represented here by three fine species. Butalis is a Chinese species, no doubt straggling southward. Budytes and Corydalla are widespread Oriental and Palæarctic species or slight modifications of them. Iyydrornis is a Malinyan form of Pittida. Batrackinstomus is a distinct representative of a purely Indo-Malny genus. Lori- 
culus is Malayan, and especially Philippine, but it reaches as fur as Mysol. Treron is here at its eastern limit, and is represented in Bouru and Ceram by one of the most beautiful species. Neopus, a Malayan eagle, is said to occur in the Moluccas. We find then only three characteristic Indo-Malay types in the Moluccas,-Criniger, Batrachostomus, and Treron. All are represented by distinct and well marked species, indicating a somewhat remote period since their ancestors entered the district but all are birds of considerable powers of flight, so that a very iittle extension of the islands in a south-westerly direction would afford the means of transmission, but this could not well have been by way of Celebes, because the two former grenera are unknown in that island.

It is evident, therefore, that the Moluccas are wholly Papuan in their zoology ; yet they are no less clearly derivative, and must have obtained their original immigrants under conditions that rendered a full representation of the fauna impossible. Such remarkable and dominant types as the eleven genera of Paradiseidæ, with Cracticus, Rectes, Todopsis, Macherirhynchus, Gerygone, Dacelo, Podargus, Cyclopsitta, Microglossum, Nasiterna, Chalcopsitta, and Gource,-all characteristic Papuan groups, found in almost all the islands and most of them very abundant, are yet totally absent from the Moluccas. Taking this, in conjunction with the absence of the two genera of Papuan kangaroos and the other smaller groups of marsupials, and we must be convinced that the Moluccas cannot be mere fragments of the old Papuan land, or they would certainly, in some one or other of their large and fertile islands, have preserved a more complete representation of the parent fauna. Most of the Moluccan birds are very distinct from the allied species of New Guinea; and this would imply that the entrance of the original forms took place at a remote period. The two peculiar genera with clearly Papuan affinities, show the same thing. The cassowary, found only in the large island of Ceran and distinct from any Papuan species, would however serm to have required a lind connection for its introduction, almost as much as any of the larger mammalia. 
Taking all the facts into consideration, I would sugrest as the most probable explanation, that if the Moluccas ever formed part of the main Papuan land, they were separated at an early date, and subsequently so greatly submerged as to destroy a large proportion of their fauna. They have since risen, and have probably been larger than at present, and rather more closely approximated to the parent land, whence they received a considerable immigration of such animals as were adapted to cross narrow seas. This gave them several Papuan forms, but still left them without a number of the types more especially confined to the forest depths, or powerful enough to combat the gales which often blow weaker flyers out to sea. Most of the birds whose absence from the Moluccas is so conspicuous belong to one or other of these classes.

Among the most characteristic birds of the Moluccas are the handsome crimson lories of the genera Lorius and Eos. These are found in every island (but not in Celebes or the Timor group); and a fine species of Eos, peculiar to the small islands of Siau and Sanguir, just north of Celebes, obliges us to place these with the Moluccas instead of with the former island, to which they seem most naturally to belong. The crimson parrots of the genus Eclectus are almost equally characteristic of the Moluccas, and add greatly to the brilliancy of the ornithology of these favoured islands.

Reptiles.-The Reptiles, so far as known, appear to agree in their distribution with the other vertebrates. In some small collections from Ceram there were no less than six of the genera peculiar to the Australian region, and which were before only known from Australia itself. These are, of snakes, Liasis and Enygrus, genera of Pythonidx; with Diemenia and Acanthophis (Flapidx); of lizards, Cyclodus, a genus of Scincidr; and of Amphibia, a tree-frog of the genus Pelodryas.

Insccts-Peculiarities of the Moluccan Fauna.-In insects the Moluccas are hardly, if at all, inferior to New Guinea itself. The islands abound in grand Papiiios of the largest size and extreme beauty; and it is a very remarkable fact, that when the closelyallied species of the Moluccas and New Guinea are comparerl. 
the former are almost always the largest. As examples may be mentioned, Ornithoptera priamus and O. helena of the Moluccas, both larger than the varieties (or species) of Papua; Papiliu ulysses and deiphobus of Amboyna, usually larger than their allies in New Guinea; Hestia idea, the largest species of the genus; Diadema pandarus and Charaxes euryalus, both larger than any other species of the same genera in the whole archipelago. It is to be noted also, that in the Moluccas, the very largest specimens or races seem always to come from the small island of Amboyna; even those of Ceram, the much larger island to which it is a satellite, being almost always of less dimensions. Among Coleoptera, the Moluccas produce Euchirus longimanus, one of the largest and most remarkable of the Lamellicornes; Sphingnotus dunningi, the largest of the Austro-Malayan Tmesisterninæ; a Sphenura, the largest and handsomest of an extensive genus; an unusually large Schizorhina (Cetoniidæ); and some of the most remarkable and longest-horned Anthotribidx. Even in birds the same law may be seen at work,--in the Tanysiptera nais of Ceram, which has a larger tail than any other in the genus; in Centropus goliath of Gilolo, being the largest and longest-tailed species; in Hydrornis maximus of Gilolo, the largest and perhaps the most elegantly and conspicuously coloured of all the Pittidx; in Platycercus amboinensis, being pre-eminent in its ample blue tail ; in the two Moluccan lories and L'os rubra, being more conspicuously red than the allied New Guinea species; and in Megapodius wallacei of Bouru, being the only species of the genus conspicuously marked and banded.

All these examples, of larger size, of longer tails or other appendages, and of more conspicuous colouring, are probably indications of a less severe struggle for existence in these islands than in the larger tract of New Guinea, with a more abundant and more varied fauna; and this may apply even to the smaller islands, as compared with the larger in the immediate vicinity. The limited number of forms in the small islands compared with a similar area in the parent land, implies, perbaps, less competition and less danger; and thus allows, where all other conditions are favourable, an unchecked and continuous de- 
velopment in size, form, and colour, until they become positively injurious. This law may not improbably apply to the New Guinen faunn itself, as compared with that of Iiomen or any other similar country; and some of its peculiaritics (such as its wonderful paradise-birds) may be due to long isolation, and consequent freedom from the influence of any competing forms, The difference between the very sober colours of the Coleoptera, and in a less degree of the birds, of Borneo, as compared with their brillinncy in Nerw Guinea, always struck me most forcibly, and was long without any, even conjectural, explanation. It is not the place here to go further into this most curious and interesting subject. The reader who wishes for additional facts to aid him in forming an opinion, should consult Mr. Darwin's Descent of Man, chapters x. to xv.; and my own Contributions to the Theory of Natural Selection, chapters iii. and iv.

Timor Group.-Mammalia.-In the group of islands between Java and Australia, from Lombok to Timor inclusive, we find a set of mammals similar to those of the Moluccas, but some of them different species. A wide-spread species of Cuscus represents the Papuan element. A Sorex and a peculiar species of wild pig, we may also accept as indigenous. Three others have almost certainly been introduced. These are, (1.) Macacus cynomolgus, the very commonest Malay monkey, which may have crossed the narrow straits from island to island between Java and Timor, though it seems much more probable that it was introduced by Malays, who constantly capture and rear the young of this species. (2.) Cerrus timoriensis, a deer, said to be a distinct species, inhabits Timor, but, it is probably only a variety of the Corrus hippelapturs of Java. 'This animal is, however, much more likely to have crossed the sea than the monkey. (3.) Paracloxurus fasciatus, takes the place of Viverra tangalunga in the Moluccas, both common and wide-spread civets which are often kept in confinement by the Malays. The Felis megalotis, long supposerl to be a native of Timor, has been ascertained by MIr. Elliot to belong to a different country altogether.

Birls.-The birls are much more interesting, since they are 
sufficiently numerous to allow us to determine their relations, and trace their origin, with unusual precision. There are 96 genera and 160 species of land-birds known to inhabit this group of islands; and on a careful analysis, they are found to be almost equally related to the Australian and Oriental regions, 30 geuera being distinctly traceable to the former, and the same number to the latter. Their connection with the Moluccas is shown by the presence of the genera Mimeta, Geoffroyus, Cacatru, Ptilopus, and Ianthcenas, together with Megapodius and Cerchncis represented by Moluccan species. Turacoena shows a connection with Celebes, and Scops is represented by a Celebesian species. The connection with Australia is shown by the genera Sphocotherce, Gerygone, Myiagra, Pardalotus, Gliciphila, Amadina, and Aprosmictus; while Milvus, Hypotriorchis, Eudynamis, and Eurystomus, are represented by Australian species. Other genera confined to or characteristic of the Australian region, are Rhipidura, Monarcha, Artamus, Campephaga, Pachycephala, Philemon, Ptilotis, and Myzomela.

We now come to the Indo-Malay or Javan element represented by the following genera:

1. Turdus (T.)

2. Geocichla (T.)

3. Zoothera.

4. Megalurus (T.)

5. Orthotomus.

6. Pratincola (T.)

7. Oreicola (T.)

8. Drymocataphus (T.)

9. Parus.

10. Pycnonotus.
11. Oriolus.

12. Pericrocotus.

13. Cyornis (T.)

14. Hypothymis.

15. Tchitrea.

16. Lanius ( $\mathrm{T}$.)

17. Anthreptes.

18. Eulabes.

19. Estrilda (T.)

20. Erythrura (T.)
21. Yungipicus.

22. Merops.

23. Pelargopsis.

24. Ceyx.

25. Loriculus.

26. Treron (T.)

27. Iotreron (s.g. of Ptilopus).

28. Chalcophaps (T.)

29. Gallus (T.)

30. Strix.

Such genera as Merops and Strix, which are as much Australian as Oriental, are inserted here because they are represented by Javan species. The list is considerably swelled by genera which have reached Lombok across the narrow strait from Baly, but have passed no further. Such are Zootherc, Orthntomus, Pycnonotus, Pericrocotus and Strix. A much larger number (12) stop short at Flores, leaving only 13 , indicated in the list by $(\mathrm{T})$ after their names, which reach Timor. It is evident, therefore, that these islands have been stocked from three chief sources, - the 
Moluccas (with New Guinea and Celebes,) Australia, and Java. The Moluccan forms may well have arrived as stragglers from island to island, aided by whatever facilities have been afforded by lands now submerged. Most of the rernainder have been derived either from Australia or from Java; and as their relations to these islands are very interesting, they must be discussed with some detail.

Origin of the Timorese Fauna. - We must first note, that 80 species, or exactly one-half of the land-birds of the islands, are peculiar and mostly very distinct, intimating that the immigration commenced long enough back to allow of much specific modification. There is also one peculiar genus of kingfishers, Curidonax, found only in Lombok and Flores, and more allied to Australian than to Oriental types. The fine white-banded pigeons (s. g. Leucotreron) are also almost peculiar; one other less typical species only being known, a native of $\mathrm{N}$. Celebes. In order to compare the species with regard to their origin, we must first take away those of wide distribution from which tio special indications can be obtained. In this case 49 of the landbirds must be deducted, leaving 111 species which afford good materials for comparison. These, when traced to their origin, show that 62 came from some part of the Australian region, 49 from Java or the Oriental region. But if we divide them into two groups, the one containing the species identical with those of the Australian or Oriental regions, the other containing allicd or representative species peculiar to the islands, we have the following result :

Species common to the Timorese Islands and the Oriental Region 30

Peculiar Tinorese species allied to those of the Oriental Region 19

$\begin{array}{lllllllll}\text { Total } & \ldots & \ldots & \ldots & \ldots & \ldots & \ldots & \ldots & 49\end{array}$

Species common to the Timorese Islands and the Australian

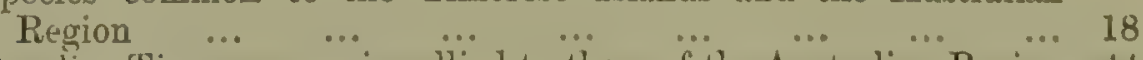
I'eculicr Timorese species allied to those of the Australian Region 44 $\begin{array}{lllllllll}\text { Total } & \ldots & \ldots & \ldots & \ldots & \ldots & \ldots & \ldots & 62\end{array}$

This table is very important, as indicating that the connection 
with Australia was probably earlier than that with Java; since the majority of the Australian species have become modified, while the majority of the Oriental species have remained unchanged. This is due, no doubt, in part to the continued immigration of fresh individuals from Java, after that from Australia, the Moluccas and New Guinea had almost wholly ceased. We must also notice the very small proportion of the genera, either of Australia or Java, that have found their way into these islands, many of the largest and most wide-spread groups in both countries being altogether absent. Taking these facts into consideration, it is pretty clear that there has been no close and longcontinued approximation of these islands to any part of the Australian region; and it is also probable that they were fairly stocked with such Australian groups as they possess before the imnigration from Java commenced, or a larger number of characteristic Oriental forms would have been able to have established themselves.

On looking at our map, we find that a shallow submerged bank extends from Australia to within about twenty miles of the coast of Timor; and this is probably an indication that the two countries were once only so far apart. This would have allowed the purely Australian types to enter, as they are not numerous; there being about 6 Australian species, and 10 or 12 representatives of Australian species, in Timor. All the rest may have been derived from the Moluccas or New Guinea, being mostly widespread genera of the Australian region; and the extension of I'apua in a south-west direction towards Java (which was suggested as a means of providing New Guinea with peculiar IndoMalay types not found in any other part of the region) may have probably served to supply Tinnor and Flores with the mass of their Austro-Malayan genera across a narrow strait or arm of the sea. Lombok, Baly, and Sumbawa were probably not then in existence, or nothing more than small volcanic cones rising out of the sea, thus leaving a distance of 300 miles between Flores and Java. Subsequently they grew into islands, which olfered an easy passage for a number of Indo-Malay genera into such scantily stocked territories as Flores and Wimor. The 
north coast of Australia then sank, cutting off the supply from that country; and this left the Timorese group in the position it now occupies.

The reptiles and fishes of this group are too little known to enable us to make any useful comparison.

Insects.-The insects, though not numerous, present many fine species, some quite unlike any others in the Archipelago. Such are-Papilio liris, Pieris lata, Cirrochroa lamarckii and C. leschenaultii among butterflies. The Coleoptera are comparatively little known, but in the insects generally the Indo-Malay element predominates. This may have arisen from the peculiar vegetation and arid climate not being suitable to the Papuan insects. Why Australian forms did not establish themselves we cannot conjecture; but the field appears to have been open to immigrants from Java, the climate and vegetation of which island at its eastern extremity approximates to that of the Timorese group. The insects are, however, so peculiarly modified as to imply a very great antiquity, and this is also indicated by a group of Sylviine birds here classed under Oreicola, but some of which probably form distinct genera. There may, perhaps, have been an earlier and a later approximation to Java, which, with the other changes indicated, would account for most of the facts presented by the fauna of these islands. One deduction is, at all events, clear: the extreme paucity of indigenous mammals along with the absence of so many groups of birds, renders it certain that the Timorese islands did not derive their animal life by means of an actual union with any of the large islands either of the Australian or the Oriental regions.

Celebes Group. - We now come to the Island of Celebes, in many respects the most remarkable and interesting in the whole region, or perhaps on the globe, since no other island secms to present so many curious problems for solution. We shall therefore give a somewhat full account of its peculiar fama, and cndeavour to elucidate some of the causes to which its zoological isolation may be attributed.

Mammalia.-The following is the list of the mammalia of 
Celebes as far as at present known, though many small species may yet be discovered.

1. Cynopithecus nigrescens.

2. Tarsius spectrum.

3. Viverra tangalunga.

4. Cervus hippelaphus.

5. Anoa depressicornis

6. Sus celebensis.
7. Barbirusa alfums.

8. Sciurus (5 peculiar sp.)

9. Mus (2 peculiar sp.)

10. Cuscus (2 peculiar sp.) Also 7 species of bats, of which 5 are peculiar.

The first-a large black ape-is itself an anomaly, since it is not closely allied to any other form of quadrumana. Its flat projecting muzzle, large superciliary crests and maxillary ridges, with the form and appearance of its teeth, separate it altogether from the genus Macacus, as represented in the Indo-Malay islands, and ally it closely to the baboons of Africa. ${ }^{1}$ We have already seen reason to suppose that it has been carried to Batchian, and there is some doubt about the allied species or variety ( $C$. niger) of the Philippines being really indigenous there; in which case this interesting form will remain absolutely confined to Celebes. (2.) The tarsier is a truly Malayan species, but it is said to occur in a small island at the northern extremity of Celebes. It might possibly have been introduced there. (3) and (4) - a civet and a deer-are, almost certainly, as in the Moluccas, introduced species. (5.) Anoc depressicornis. This is one of the peculiar Celebesian types; a small straighthorned wild-bull, anatomically allied to the buifaloes, and somewhat resembling the bovine antelopes of Africa, but having no near allies in the Oriental region. (6.) Sus Celebensis; a peculiar species of wild-pig. (7.) Babirusa alfurus; another remarkable type, having no near allies. It differs in its dentition from the typical Suidæ, and seems to approach the African Phacochnridæ. The manner in which the canines of the upper tusks are reversed, and grow directly upwards in a spiral curve over the eyes, is unique among mammalia. (8.) Five squirrels inhabit Celebes, and all are peculiar species. (9.) These are forest rats of the sub-genus Aymnomys, allied to Australian species. 10. Cuscus. This typical

1 The general form of the skull agrees best with that of Cynocephalus mormon, the largest and most typical of the African baboons; while tho position of the nostrils brings it nearer the macaques. 
Australian form is represented in Celebes by two peculiar species.

Leaving out the Indo-Malay species, which may probably have been introduced by man, and are at all events comparatively recent immigrants, and the wild pig, a genus which ranges over the whole archipelago and which has therefore little significance, we find two genera which have come from the Australian side, -Cuscus and Mus; and four from the Oriental side,-Cynopithecus, Anoa, Babirusa, and Sciurus. But Sciurus alone corresponds to Cuscus, as a genus still inhabiting the adjacent islands; the other three being not only peculiar to Celebes, but incapable of being atfiliated to any specially Oriental group. We seem, then, to have indications of two distinct periods; one very ancient, when the ancestors of the three peculiar genera roamed over sume unknown continent of which Celebes formed, perhaps, an outlying purtion ; - another more recent, when from one side there entered Sciurus, and from the other Cuscus. But we must remember that the Moluccas to the east, possess scarcely any indigenous nammals except Cuscus; whereas Borneo and Java on the west, have nearly 50 distinct genera. It is evident then, that the facilities for inmigration must have been much less with the Oriental than with the Australian region, and we may be pretty certain that at this later period there was no land connection with the Indo-Malay islands, or some other animals than squirrels would certainly have entered. Lct us now see what light is thrown upon the subject by the birds.

Birds. - The total number of birds known to inhabit Celebes is 205 , belonging to about 150 genera. We may leave out of consideration the wading and aquatic birds, most of which are wide-ranging species. There remain 123 genera and 152 species of land-birds, of which 9 genera and 66 species are absolutely confined to the island, while 20 more are found also in the Sula or Sanguir Islands, so that we may take 86 to be the number of peculiar Celehes species. Lord Walden, from whose excellent paper on the birds of Celebes (Trans. Zool. Soc. vol. viii. p. 23) most of these figures are oltained, estimates, that of the species which are not peculiar to Celebes, 55 are of Oriental and 22 of 
Australian origin, the remainder being common to both regions. This shows a preponderant recent immigration from the West and North, which is not to be wondered at when we look at the long coast line of Java, Borneo, and the Philippine islands, with an abundant and varied bird population, on the one side, and the small scattered islands of the Moluccas, with a comparatively scanty bird-fauna, on the other.

But, adopting the method here usually followed, let us look at the relations of the genera found in Celebes, omitting for the present those which are peculiar to it. I divide these genera into two series:- those which are found in Borneo or Java but not in the Moluccas, and those which inhabit the Moluccas and not Borneo or Java; these being the respective sources from which, prima facie, the species of these genera must have been derived. Genera which range widely into both these districts are rejected, as teaching us nothing of the origin of the Celebesian fauna. In a few cases, sub-genera which show a decided eastern or western origin, are given.

\section{Genera derived from Borneo and Java.}

1. Geocichla.

2. Pratincola (sp.)

3. Trichastoma.

4. Oriolus (sp.)

5. Cyornis

6. Hypothymis,

7. Hylochnris.

8. AEthopyga.
9. Nectarophila.

10. Anthreptes (sp.)

11. Munia (sp.)

12. Acridotheres.

13. Yungipicus.

14. Mulleripicus.

15. Rhamphococcyx.

16. Hierococcyx.
17. Hydrocissa.

18. Cranorrhinus.

19. Lyncornis.

20. Treron (sp.)

21. Gallus (sp.)

22. Spilornis.

23. Butastur.

24. Pernis.

\section{Genera derived from the Molutccas or Trmor.}

1. Graucalus (sp.)

2. Chalcostetha.

3. Myzomela.

4. Munia (sp.)

5. Cacatua (sp.)
6. Tanygnathus.

7. Trichoglossus.

8. Scythrops (sp.)

9. Turacoena.

10. Reinwardtœnas (sp.) 15. Megapodius.
11. Myristicivora (s. g.)

12. Ducula (s. g.)

13. Zonœnas (s. go)

14. Lamproteron (s.g.)'

These tables show a decided preponderance of Oriental orer Australian forms. But we must remember that the immediately adjacent liands from whence the supply was derived, is 
very much richer in the one case than in the other. The 24 genera derived from Borneo and Java are only about one fourth of the characteristic genera of those islands; while the 15 Moluccan and Timorese genera are fully one third of their characteristic types. The proportion derived from the Australian, is greater than that derived from the Oriental side.

We shall exhibit this perhaps more clearly, by giving a list of the important groups of each set of islands which are absent from Celebes.

Important Families of Java and Bomeo absent from Celebos.

1. Eurylæmidio.

2. Timaliidæ.

3. Phyllornithidæ.

4. Pycnonotidæ
5. Laniidæ.

6. Megalæmidr.

7. Trogonidæ.

8. Phasianidx.

\author{
Important Families of the Molucoas \\ absent from Celobes.
}

1. Meliphagidæ.
Additional important genera of Java or Borneo absent from Celebes.
1. Orthotomus.
2. Copsychus.
3. Enicurus.
4. Tchitrea.
5. Pericrocotus.
6. Irena.
7. Platylophus.
8. Dendrocitti.
9. Eulabes.
10. Hemicercus.
11. Chrysocolaptes.
12. Tiga.
13. Micropternus.
14. Batrachostomus.
15. Palæornis.
16. Rollulus.

Important genera of the Moluccas absent from Celebes.

1. Mimeta.

2. Monarcha.

3. Rhipidura.

4. Pachycephala.

5. Lycocorax.

6. Alcyone.

7. Tanysiptera.

8. Geoffroyus.

9. Eclectus.

10. Platycercus.

11. Eos.

12. Lorius.

If we reckon the absent families to be each represented by only two important genera, we shall find the deficiency on the Oriental side much the greatest; yet those on the side of the Moluccas are sufficiently remarkable. The Meliphagidae are not indeed absolutely wanting, since a Myzomela has now been found in Celebes; but all its larger and more porverful forms which range over almost the entire region, are absent. This may be balanced by the absence of the excessively abundant Timaliidx of the Iudo-Malay islands, which are represented by 
only a single species; and by the powerful Phasianidx, represented only by the common Malay jungle fowl, perhaps introduced. The entire absence of Pycnonotidæ is a very anomalous fact, since one of the largest genera, Criniger, is well represented in several islands of the Moluccas, and one has even been found in the Togian islands in the great northern inlet of Celebes; but yet it passes over Celebes itself. Ceyx, a genus of small kingfishers, is a parallel case, since it is found everywhere from India to New Guinea, leaving out only Celebes; but this comes among those curiosities of the Celebesian fauna which we shall notice further on. In the list of genera derived from Borneo or Java, no less than 6 are represented by identical species (indicated by sp. after the name); while in the Moluccan list 5 are thus identical. These must be taken to indicate, either that the genus is a recent introduction, or that stragglers still occasionally enter, crossing the breed, and thus preventing specific modification. In either case they depend on the existing state of things, and throw no light on the different distribution of land and sea which aided or checked migration in former times; and they therefore to some extent diminish the weight of the Indo-Malay affinity, as measured by the relations of the peculiar species of Celebes.

From our examination of the evidence thus far,--that is, taking account firstly, of the species, and, secondly, of the generc, which are common to Celebes and the groups of islands between which it is situated, we must admit that the connexion seems rather with the Oriental than with the Australian region; but when we take into account the proportion of the genera and species present, to those which are absent, and giving some weight to the greater extent of coast line on the Indo-Malay side, we seem justified in stating that the Austro-Malay element is rather the most fully represented. This result applies both to birds and mammals; and it leads us to the belief, that during the epoch of existing specios and genera, Celebes has never been united witl any extensive tract of land either on the Indo-Malay or AustroMalay side, but has received inmigrants from both duriug a very long period, the facilities for inmigration having been rather the 
greatest on the Austro-Malay or Australian side. We have now to consider what further light can be thrown on the subject by the consideration of the pcculiar genera of Celebes, and of those curiosities or anomalies of distribution to which we have referred.

Nine genera of birds are altogether peculiar to Celebes; three more are found only in one other island, and seem to be typically Celebesian; while one is found in the Sula islands (which belongs to the Celebes group) and probably exists in Celebes also. The following is a list of these 13 genera:

1. Artamides... (Cimpephagidx)

2. Streptocitta... (Corvidæ)

3. Charitornis.. ",

4. Gazzola, (s. g.) ,

5. Basilornis .. (Sturnidæ)

6. Enodes … ,

7. Scissirostrum
8. Monachalcyon (Alcediniclx)

9. Cittura ... "

10. Ceycopsis ... ,

11. Meropogon .. (Meropidæ)

12. Prioniturus. (Psittacidæ)

13. Megacephalon (Megapodiidæ)

Of the above, Artamides, Monachalcyon, Cittura, and MFegacephalon, are modifications of types characteristic of the Australian region. All are peculiar to Celebes except Cittura, found also in the Sanguir islands to the northward, but which seems to belong to the Moluccan group. Streptocitta, Charitornis, and Gazzola, are peculiar types of Corvidre; the two former allied to the magpies, the latter to the jackdaws. Charitornis is known only from the Sula islands east of Celebes, and is closely related to Streptocitta. There is nothing comparable to these three groups in any of the Malay islands, and they seem to have relations rather with the Corvidx of the old-world northern continent. Busilornis, Enodes, and Scissirostrum, are remarkable forms of Sturnidæ. Busilornis has a beautiful compressed crest, which in the allied species found in Ceram is elongated behind. Enodes has remarkable red superciliary streaks, but seems allied to Calornis. Scissirostrum seems also allied to Calornis in general structure, but has a very peculinrly formed bill and nostrils. We can hardly say whether these three forms show more affinity to Oriental or to Australian types, but they add to the weight of evidence as to the great antiquity and isolation of the Celebesian fauna. Scissirostrum has becn classed with Euryceros, a Mada- 
gascar bird, and with Buphaga, an African genus; but the peculiar beak and nostrils approximate more to Cracticus and its allies, of the Australian region, which should probably form a distinct family. Ceycopsis is undoubtedly intermediate between the Malayan Ceyx and the African Ispidina, and is therefore especially interesting. Meropogon is a remarkable form of beeeater, allied to the Indo-Malayan Nyctiornis. Prioniturus (the raquet-tailed parrots) of which two species inhabit Celebes, and one the Philippines, appears to be allied to the Austro-Malayan Geoffroyus.

Ve must finally notice a few genera found in Celebes, whose nearest allies are not in the surrounding islands, and which thus afford illustrations of discontinuous distribution. The most remarkable, perhaps, is Coracias, of which a fine species inhabits Celebes; while the genus is quite unknown in the Indo-Malay sub-region, and does not appear again till we reach Burmah and India; and the species has no closer affinity for Indian than for African forms. Myiclestes, a small yellow flycatcher, is another exmple; its nearest ally ( $\boldsymbol{M}$. cinereocapilla) being a common Indiau bird, but unknown in the Malay islands. The Celebesian bird described by me as Prionochilus aurcolimbatus, is probably a third case of discontinuous distribution, if (as a more careful examination seems to show) it is not a Prionochilus, but congeneric with Pactuyglossa, a bird only found in the Himalayas. The fine pigeon, Carpophaga forsteri, belongs to a group found in the Philippines, Australia, and New Zealand; but the Celebes species is very distinct from all the others, and seems, if anything, more allied to that of New Zealand.

The Sula islands (Sula-mangola, Sula-taliabo, and Sula-besi) lie midway between Celebes and the Moluccas, being 80 miles from the nearest part of Celebes, with several intervening islands, and 40 miles from Bouru, all open sea. Their birds show, as might be expected, a blending of the two famas, but with a decirled preponderance of that of Celebes. Out of $4: 3$ land birds which have been collected in these islands, we may deduct 6 as of wide range and no significance. Of the 37 remaining, 21 are Celubesian species, and 4 are new species hut 
allied to those of Celebes; while there are 10 Moluccan species and 2 new species allied to those of the Moluccas. It is curious that no less than 3 Moluccan genera, quite unknown in Celebes itself, occur here,--Monarcha, Pachycephulu, and Criniger; but all these, as well as several other of the Moluccan birls, are rather weak flyers, and such as are likely to have been carrierl across by strong winds. Of the generc, 23 are from Celelses, 10 from the Moluccas. These facts show, that the Sula islands form part of the Celebes group, although they have received an infusion of Moluccan forms, which will perhaps in time spread to the main island, and diminish the remarkable individuality that now cha. racterises its fauna.

Insects.-Of the reptiles and fishes of Celebes we have not sufficient information to draw any satisfactory conclusions. I therefore pass to the insects of which something more is known.

The Butterflies of Celebes are not very numerous, less than 200 species in all having been collected; but a very large proportion of them, probably three-fourths of the whole, are peculiar. There is only one peculiar genus, A mechanic, allied to Zethera (a group confined to the Philippine Islands), with which it should perhaps be united. Most of the genera are of wide distribution in the archipelago, or are especially Malayan, only two truly Australian genera, Elodina and Acropthalmia, reaching Celebes. On the other hand, 7 peculiar Oriental genera are found in Celebes, but not further east, viz., Clerome, Aclolias, Euripus, Apatura, Limenitis, Iolxus, and Leptocircus. There are also several indications of a direct affinity with the continent rather than with Malaya, as in the cases already enumerated among birds. A fine butterfly, yet unnamed, almost exactly resembles Dichorragia nesimachus, a Himalayan species. Euripus robustus is closely allied to E. halitherses of N. India ; there are no less than 5 species of Limenitis, all quite unlike those found in other parts of the archipelago. The butterflies of Celebes are remarkably distingnished from all others in the East, by peculiarities of form, size, and colour, which run through groups of species belonging to different genera. Many Papilionide and Pieridre, and some 
Nymphalidre, have the anterior wings elongated, with the apex often acute, and, what is especially remarkable, an abrupt bend or shoulder near the base of the wing. (See Mulay Archipelayn, 3rd Ed. p. 281, woodcut.) No less than 13 species of Papilio, 10 I'ieridx, and 4 or 5 Nymphalidx, are thus distinguished from their nearest allies in the surrounding islands or in India. In size again, a large number of Celebesian butterflies stand preeminent over their allies. The fine Papilios-aulamantius, blumei, and gigon-are perfect giants by the side of the clusely-allied forms of Java; while $P$. androcles is the largest and longest-tailed, of all the true swallow-tailed group of the Old World. Among Nymphalidæ, the species of Rhinopalpa and Euripus, peculiar to Celebes, are immensely larger than their nearest allies; and several of the Pieridæe are also decidedly larger, though in a less marked degree. In colour, many of the Celebesian butterflies differ from the nearest allied species; so that they acquire a singularity of aspect which marks them off from the rest of the group. The most curious case is that of three buttertlies, belonging to three distinct genera (Cethosia myrina, Messarces mceonides, and Atella celcbensis) all having a delicate violet or lilac gloss in lines or patches, which is wholly wanting in every allied species of the surrounding islands. These numerous peculiarities of Celebesian butterflies are very extraordinary; and imply isolation from surrounding lands, almost as much as do the strange forms of nammals and birds, which more prominently characterise this interesting island.

(of the Coleoptera we know much less, but a few interesting facts may be noted. There are a number of fine species of Cicindela, some of peculiar forms; and one Odontochila, a Soutl. American genus; while Collyris reaches Celebes from the Oriental region. In Carabide it has one peculiar genus, Dicresperle; and a species of the fine Australian genus Catadromus. In Lucanide it has the Oriental genus, Oclonslabris. In Cetoniide it has a peculiar genus, Stcrnoplus, and several fine Cetonice; but the characteristic Malayan genus, Lomrptera, found in every other island of the archipelago from Sumatra to New Guinen, is absent-an aualogous fict to the case of Cryn amoing hirds. 
In Buprestida, the principal Austro-Malay genus, Sumbus, is found here; while Sponsor, a genus 8 species of which inlabit Mauritius, has one species here and one in New Guinea. In Longicorns there are four peculiar genera, Comusia, Pytholice, Bityle, and Ombrosaga; but the most important features are the occurrence of the otherwise purely Indo-Malayan genera Agulasta, Nyctimene, and Asiathes; and of the purely AustroMalayan Arrhenotus, Trysimia, Xenolea, Amblymora, Diallus, and EEgocidnus. The remaining genera range over both portions of the archipelargo. In the extensive family of Curculionicle we can only notice the elegant genus, Celctia, allied to Eupholus, which, owing to its abundance and beauty, is a conspicuous feature in the entomology of the island.

Origin of the founa of Celebes.-We have now to consider, briefly, what past changes of physical geography are indicated hy the curious assemblage of facts here adduced. We have evidently, in Celebes, a remnant of an exceedingly ancient land, which has undergone many and varied revolutions; and the stock of ancient forms which it contains must be taken account of, when we speculate on the causes that have so curiously limiter more recent inmigrations. Going back to the arriral of those genera which are represented in Celebes by peculiar species, and taking first the Austro-Malay genera, we find among them such groups as Zonences (s.g.), Phlagances, Lencotreron (s.g), and Turacona, which are not found in the Moluccas at all; and Myzomela, found in Timor and Banda, but not in Ceram or Bouru, which are nearest to Celebes. This, combined with the curious absence of so many of the commonest Moluccan genera, leads to the conclusion that the Austro-Malay immigration taok place by way of Timor and the southem part of New Guinea. It will be remembered, that to account for the IndoMalayan forms in New Guinea, we suggested an extension of that country in a westerly direction just north of Timor. Nuw this is exactly what we require, to account for the stocking of Celebes with the Australian forms it possesses. At this time Tarneo did not appraach so near, and it was at a somewhat later perind that the last great Indo-Malay migration set in; but 
finding the country already fairly stocked, comparatively few groups were able to establish themselves.

Going back a little farther, we come to the entrance of those few birds and insects which belong to India or Indo-China; and this probably occurred at the same time as that continental cxtension southward, which we found was required to account for a similar phenomenon in Java. Celebes, being more remote, received only a few stragglers. We have now to go much farther back, to the time when the ancestors of the peculiar Celebesian genera entered the country, and here our conjectures must necessarily be less defined.

On the Australian side we have to account for Megacephalon, and the other genera of purely Papuan type. It may perhaps be sufficient to say, that we do not yet know that these genera, or some very close allies, do not still exist in New Guinea; in which case they may well have entered at the same time with the species, already referred to. If, on the other hand, they are really as isolated as they appear to be, they represent an earlier communication, either by an approximation of the two islands over the space now occupied by the Moluccas; or, what is perhaps more probable, through a former extension of the Moluccas, which have since undergone so much subsidence, as to lead to the extinction of a large proportion of their ancient fauna. The wide-spread volcanic action, and especially the prevalence of raised coral-reefs in almost all the islands, render this last supposition very probable.

On the Oriental side the difficulty is greater; for here we find, what seem to be clear indications of a connection with Africa, as well as with Continental Asia, at some immensely remote epoch. Cynopithccus, Babirusa, and Anoc; Ceycopsis, Streptocittc, and Gazwole (s. s.), and perhaps Scissirostrum, may be well explained as descendants of ancestral types in their respective groups, which also gave rise to the special forms of Africa on the one hand, and of Asia on the other. For this immigration we must suppose, that at a period before the formation of the present Indo-Malay Islands, a great tract of land extended in a north-westerly direction, till it met the old Asiatic continent. This may have heen before 
the Ifimalityas had risen to any great height, and when a large part of what are now the cold plateaus of Central $\Lambda$ sia nnay have teemerl with life, some forms of which are preserved in Africa, some in Malaya, and a few in Celebes. Here may have lived the common ancestor of Sus, Babirusc, and Pluacocherus; as well as of Cynopithecus, Cynocephalus, and Mucacus; of Anoc and Bubalus; of Scissirostrum and Euryceros; of C'ey.r, Ceycopsis, and Ispidina. Such an origin accounts, too, for the presence of the North-Indian forms in Celebes; and it offers less difficultics than a direct connection with continental Africa, which once alpeared to be the only solution of the problem. If this south-eastward extension of Asia occurred at the same time as the north-eastward extension of South Africa and Madagascar, the two early continents may have approached each other sufficiently to have allowed of some interchange of forms: Tarsius may be the descendant of some Lemurine animal that then cntered the Malayan area, while the progenitors of Cryploprocta may then have passed from Asia to Madagascar.

It is true that we here reach the extremest limits of speculation; but when we have before us such singular phenomena as are presented by the fauna of the island of Celebes, we can hardly help endeavouring to picture to our imaginations by what past changes of land and sea (in themselves not improbable) the actual condition of things may have been brought about.

\section{Australia and Tasmania, or the Australian Sul-region.}

A general sketch of Australian zoology having been given in the earlier part of this chapter, it will not be necessary to occupy much time on this sub-region, which is as remarkably homogeneous as the one we have just left is heterogeneous. Although much of the northern part of Australia is within the tropics, while Victoria and Tasmania are situated from $36^{\circ}$ to $43^{\circ}$ south latitude, there is no striking change in the character of the fauna throughout the continent; a number of importint genera extending over the whole country, and giving a very uniform charactor to its zoology. The eastern parts, including the colonies of New South Wales and Queensland, are uniloubtedly the richest, several 
.

$\mid$

. .

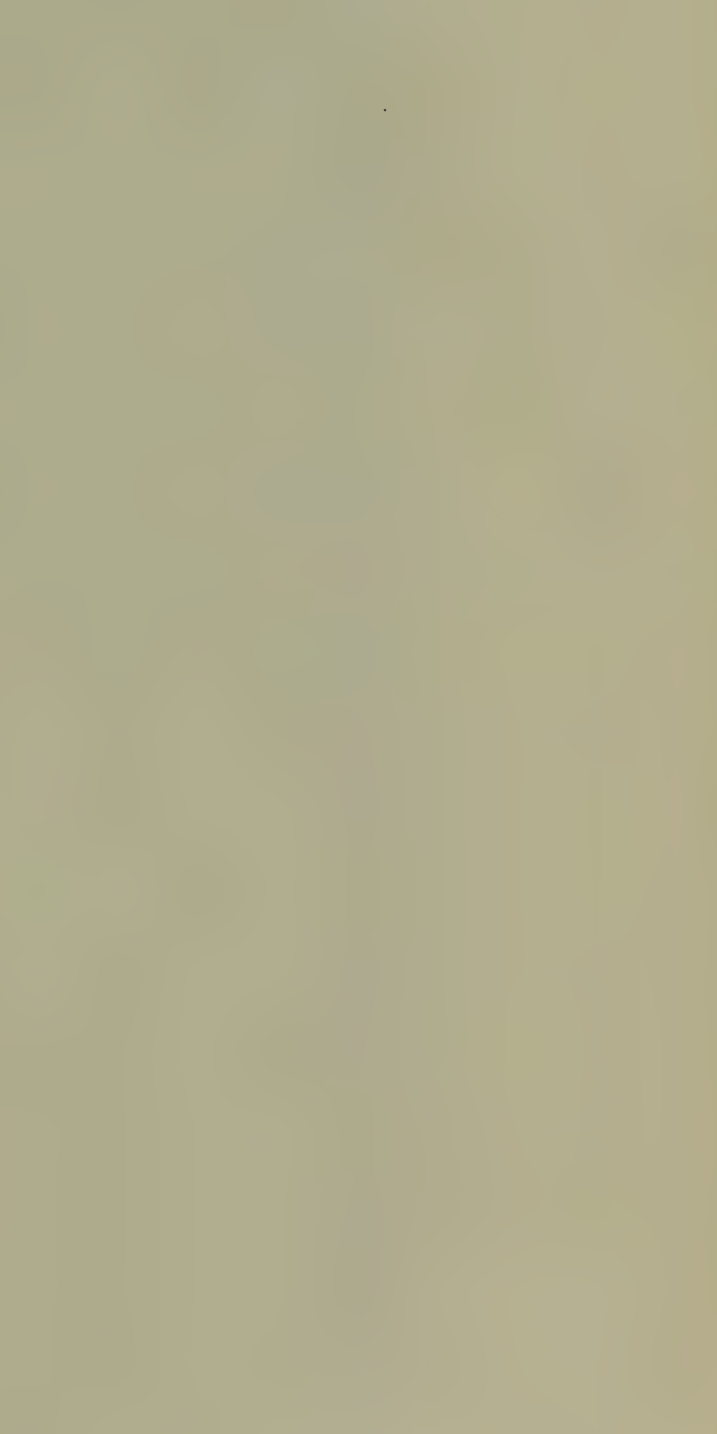




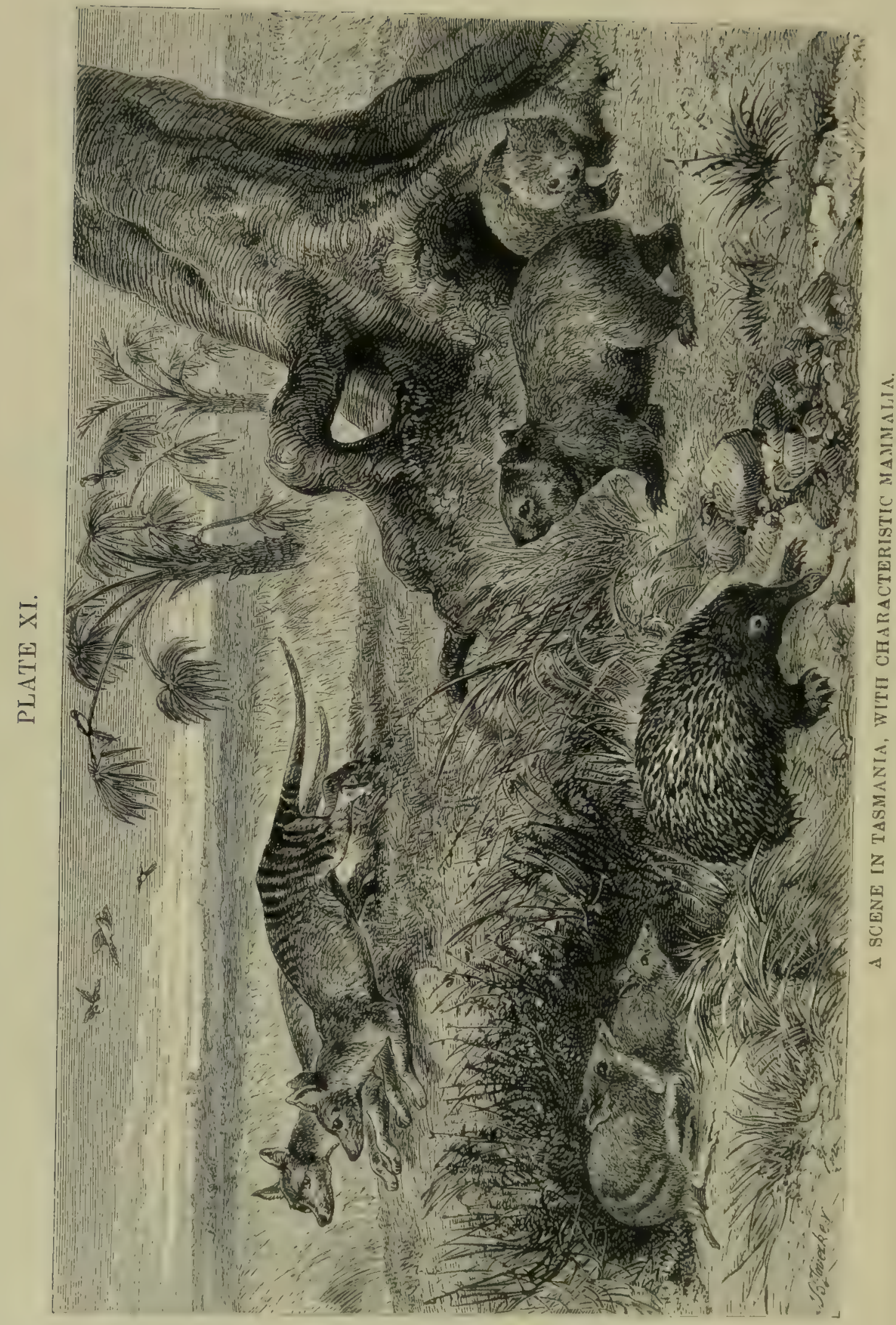


peculiar types being found only here. The southern portion is somewhat poorer, and has very few peculiar forms; and Tasmania being isolated is poorer still, yet its zoology has much resemblance to that of Victoria, from which country it has evidently not been very long separated. The north, as far as yet known, is characterised by hardly any peculiar forms, but by the occurrence of a number of Papuan types, which have evidently been derived from New Guinea.

Mammatia.-The Australian sub-region contains about 160 . species of Mammalia, of which 3 are Monotremata, 102 Marsupials, 23 Chiroptera, 1 Carnivora (the native dog, probably not indigenous), and 31 Muridæ. The north is characterised by a species of the Austro-Malayan genus Cuscus. Phascolarctos (the koala, or native bear) is found only in the eastern districts; Phascolomys (the wombat) in the south-east and Tasmania; Petaurista (a peculiar form of flying opossum) in the east. Thylacinus (the zebra-wolf), and Sarcophitus (the "native devil"), two carnivorous marsupials, are confined to Tasmania. West Australia, the most isolated and peculiar region botanically, alone possesses the curious little honey-eating Tarsipes, and the Peragalea, or native rabbit. The remarkable Myrmecobius, a small ant-eating marsupial, is found in the west and south; and Onychogalea, a genus of kangaroos, in West and Central Australia. All the other genera have a wider distribution, as will be seen by a reference to the list at the end of this chapter.

Plate XI. A Scene in Tasmania, with Characteristic Mammalia. -As some of the most remarkable Mammalia of the Australian region are now found only in Tasmania, we have cliosen this island for the scene of our first illustration of the fauna of the Australian sub-region. The pair of large striped animals are zebra-wolves (Thylacinus cynocephalus), the largest and most destructive of the carnivorous marsupials. These creatures used to be tolerably plentiful in Tasmania, where they are alone found. They are also called "native tigers," or " native hyænas;" and being destructive to sheep, they have been destroyed by the farmers and will doulthess soon he exterminated. In the foreground on 
the left is a bandicoot (Perameles gunnii). These are delicate little animals allied to the kangaroos; and they are found in all parts of Austrinlia, and Tasmania, to which latter country this species is confined. On the right is the wombat (Phascolomys wombat), a root-eating marsupial, with large incisor teeth like those of our rolents. They inhabit south-east Australia and Tasmania. In the foreground is the porcupine ant-eater (Echidna setosa), belonging to a distinct order of mammalia, Monotremata, of which the only other member is the duck-billed Ornithorhynchus. These animals are, however, more nearly allied to the marsupials, than to the insectivora or edentata of the rest of the world, which in some respects they resemble. An allied species (Echidna hystrix) inhabits south-east Australia.

Birds.-Australia (with Tasmania) possesses about 630 species of birds, of which 485 are land-birds. Not more than about onetwentieth of these are found elsewhere, so that it has a larger proportion of endemic species than any other sub-region on the globe. These birls are divided among the scveral orders as follows :

$\begin{array}{lllr}\text { Passeres } & \ldots & \ldots & 306 \\ \text { Picariæ } & \ldots & . . & 41 \\ \text { Psittaci } & \ldots & \ldots & 60 \\ \text { Columbæ } & \ldots . & \ldots & 24 \\ \text { Gallinæ } & \ldots & \ldots & 15\end{array}$

$\begin{array}{lllr}\text { Accipitres } & \ldots & \ldots & 36 \\ \text { Grallæ } & \ldots & \ldots & 77 \\ \text { Anseres } & \ldots & \ldots & 65 \\ \text { Struthiones } & & \ldots & 3\end{array}$

The Psittaci, we see, are very richly represented, while the Picariæe are comparatively few; and the Columbre are scarce as compared with their abundance in the Austro-Malay subregion.

Birds seem to be very evenly distributed over all Australia; comparatively few genera of inportance being locally restricted. In the eastern districts alone, we find Origme, and Orthonyx (Sylviidæ); Sericulus and Ptilorhynchus (Paradiseidr); Lencosarcia (Columbidæ); and Talegalla (Megapodiidr). Nectarinia, Pitta, Ptilorhis, Chlamydoderce, and Sphecotheres, range from the north down the east coasts. Nanodes (Psittacidre), and Lipon (Megapodiidx), are southern forms, the first extending 
to Tasmania; which island appears to possess no peculiar genus of birls except Eudyptes, one of the penguins. West Australia has no wholly peculiar genus except Geopsittacus, a curious form of ground parroquet; the singular Atrichia, first found here, having been discovered in the east. In North Australia, Emblema (Ploceida) is the only peculiar Australian genus, but several Austro-Malayan and Papuan genera enter,as, Syma and Tanysipterc (Alcedinidæ); Machcerihynchus (Muscicapidæ); Calornis (Sturnida); Manucodic, Ptilorhis, and Ailurcedus (Paradiseidr); Megapodius; and Casuarins. The presence of a species of bustard (Eupodotis) in Australia. is very curious, its nearest allies being in the plains of India and Africa. Among waders the genus Tribonyx, a thick-legged bird somewhat resembling the Notomis of New Zealand, though not closely allied to it, is the most remarkable. The district where the typical Australian forms most abound is undoubtedly the eastern side of the island. The north and south are both somewhat poorer, the west much poorer, although it possesses a few very peculiar forms, especially among Mammalia. Tasmania is the poorest of all, a considerable number of genera being here wanting; but, except the two peculiar carnivorous marsupials, it possesses nothing to mark it off zoologically from the adjacent parts of the main land. It is probable that its insular climate, more moist and less variable than that of Australia, may not be suitable to some of the absent forms; while others may require more space and more varied conditions, than are offered by a comparatively small island.

The remaining classes of animals have been already discussed in our sketch of the region as a whole (p. 396).

Plate XII. Illustrating the Faund of Austratia.-In this plate we take New South Wales as our locality, and represent chiefly, the more remarkable Australian types of birds. The most conspicuous figure is the wonderful lyre-bird (Mcnurc superbu), the elegant plumage of whose tail is altogether unique in the whole class of birds. The unadorned bird is the female. In the centre is the cmu (Dromans nove-hollandice), the representative in Anstralia, of the ostrich in Africa and America, but be- 
longing to a different family, the Casurariide. 'To the right are a pair of crested pigeons (Ocyphaps lophotes), one of the many singular forms of the pigeon family to which the Australian region gives birth. In every other part of the globe pigeons are smooth-headed birds, but here they have developed three distinct forms of crest, as seen in this bird, the crowned pigeon figured in Plate X., and the double-erested pigeon (Lopholcemus antarcticus). The large bird on the tree is one of the Australian frog-mouthed goat-suckers (Podargus strigoides), which are called in the colony "More-pork," from their peculiar cry. They do not capture their prey on the wing like true goat-suckers, but hunt about the branches of trees at dusk, for large insects, and also for unfledged birds. A large kangaroo (Macropus gigantcus) is seen in the distance; and passing through the air, a flying opossum (Petcurus sciureus), a beantiful modification of a marsupial, so as to resemble in form and habits the flying squirrels of the northern hemisphere.

\section{The Pacific Islands, or Polynesian Sub-regiun.}

Although the area of this sub-region is so vast, and the number of islands it contains almost innumerable, there is a considerable amount of uniformity in its forms of animal life. From the Ladrone islands on the west, to the Marquesas on the east, a distance of more than 5,000 miles, the same characteristic genera of birds prevail; and this is the only class of animals on which we can depend, nuammalia being quite absent, and reptiles very scarce. The Sandwich Islands, however, form an exception to this uniformity; and, as far as we yet know, they are so peculiar that they ought, perhaps, to form a separate sub-region. They are, however, geographically a part of Polynesia; and a more careful investigation of their natural history may show more poirts of agreement with the other islands. It is therefore a matter of convenience, at present, to keep them in the Polynesian sub-region, which may be divided into Polynesia proper and the Sandwich Islands.

Polynesia proper cousists of a number of groups of islands of some importance, and a host of smaller intermediate islets. 


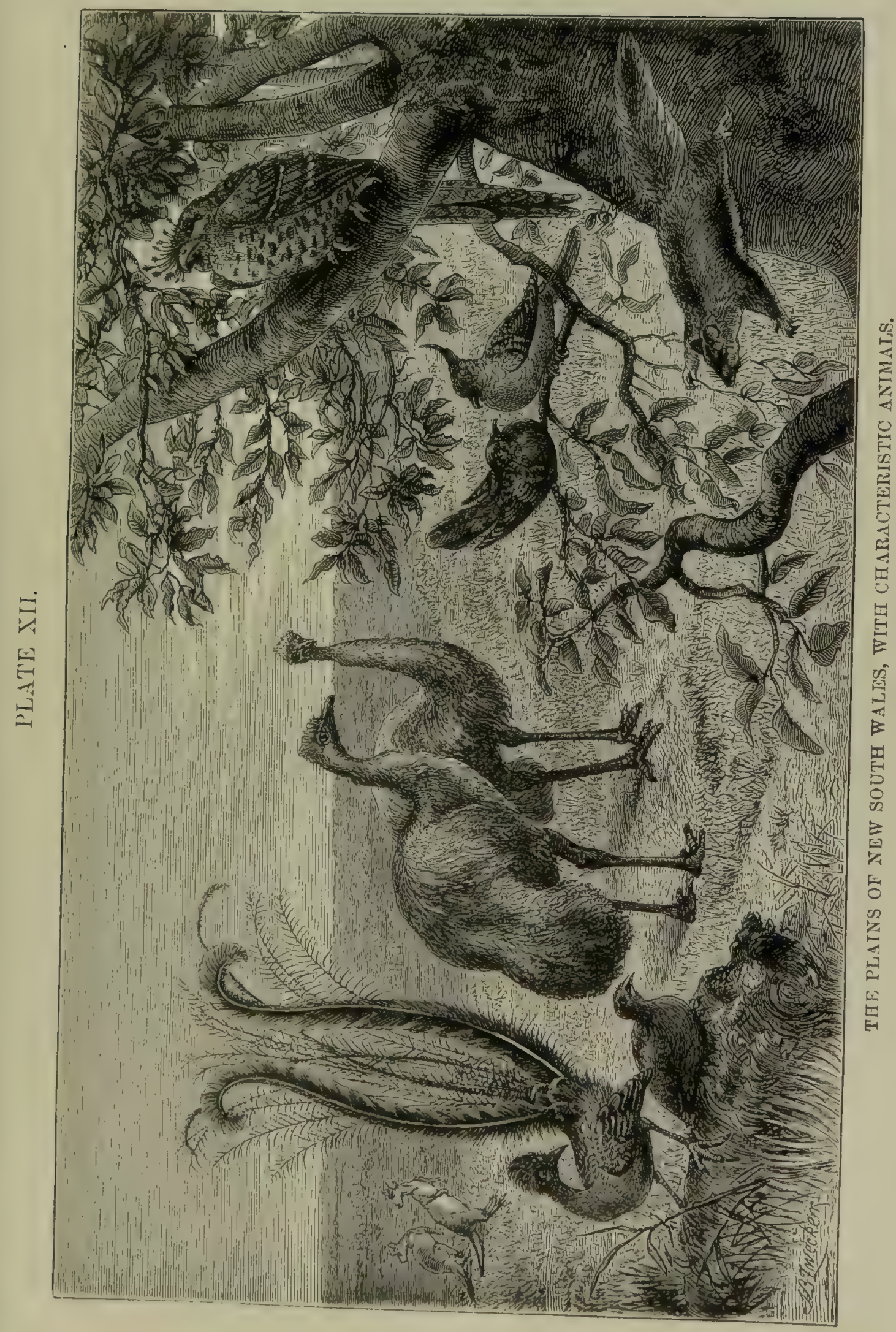



Fur the purpose of zoological comparison, we may class them in four main divisions. 1. The Ladrone and Caroline Islands; 2. New Caledonia and the New Hebrides; 3. The Fiji, Tonga, and Samoa Islands; 4. The Society, and Marquesas Islands. The typical Polynesian fauna is most developed in the third division; and it will be well to describe this first, and then show how the other islands diverge from it, and approximate other sub-regions.

Fiji, Tonga, and Samoa Islands.-The land-birds inhabiting these islands belong to 41 genera, of which 17 are characteristic of the Australian region, and 9 more peculiarly Polynesian. The characteristic Australian genera are the following: Petroica (Sylviidæ); Lalage (Campephagidæ); Monarcha, Myiagra, Rhipidura (Muscicapidæ); Pachycephala (Pachycephalidæ); Rectes (Laniidæ); Myzomela, Ptilotis, Anthochara (Meliphagidx); Amadina, Eythrura, (Ploceidæ); Artamus (Artamidæ); Lorius (Trichoglossidæ); Ptilopus, Phloganas (Columbidæ); Megapodius (Megapodiidæ).

The peculiar Polynesian genera are:-Tature, Lamprolia (Sylviidæ); Aplonis, Sturnodes (Sturnidse); Todiramphus (Alcedinidæ); Pyrhulopsis, Cyanoramphus, (Platycercidæ); Coriphilus (Trichoglossidæ); Didunculus (Didunculidæ).

The wide-spread genera are Turdus, Zosterops, Hirundo, Halcyon, Collocalia, Eudynamis Cuculus, Ianthonas, Carpophaga, Turtur, Halioectus, Astur, Circus, Strix, Asio. The aquatic birds are fifteen in number, all wide-spread species except one-a form of moor-hen (Gallinulidx), which has been constituted a new genus Pareudiastes.

Society, and Marquesas Islands.-Here, the number of genera of land-birds has considerably diminished, amounting only to 16 in all. The characteristic Australian genera are 5;-Monarcha, Anthochara, Trichoglossus, Ptilopts, and Phlogoences. The Polynesian genera are 4 ;-Tatare, Todiramphus, Cyanoramphus, Coriphilus, and one recently described genus, Serresius, an extraordinary form of large fruit pigeon, here classed under Carpophriga. These remote groups have thus all the character of Oceanic islands, even as regards the rest of Polynesia, since they 
possess hardly anything, but what they might have received by immigration over a wide extent of ocean.

Ladrone, and Caroline Islands.-These extensive groups of small islands are very imperfectly known, yet a considerable number of birls have been obtained. They possess two peculiar Polynesian genera, Tatare and Sturnodes; one peculiar sub-genus, Psammathia (here included under Acrocephalus); and ten of the typical Australian genera found in Polynesia,Lalage, Monarcha, Myiagra, Rhipidura, Myzomela, Erythrura, Artamus, Phlogoenas, Ptilopus, and Megapodins, as well as the Papuan genus Rectes, and the Malayan Calornis; - so that they can be certainly placed in the sub-region. Genera which do not occur in the other Polynesian islands are, Acrocephalus, (s.g. Psammathia) originally derived perhaps from the Philippines; and Caprimulgns, a peculiar species, allied to one from Japan.

New Caledonia, and the New Hebrides.-Although these islands seem best placed with Polynesia, yet they form a transition to Australia proper, and to the Papuan group. They possess 30 genera of land-birds, 18 of which are typical of the Australian region; but while 13 are also Polynesian, there are 5 which do not pass further east. These are Acanthiza, Eopsaltria, Gliciphila, Philemon, and Ianthenas. The peculiar Polynesian genus, Aplonis, of which three species inhabit New Caledonia, link it to the other portions of the sub-region. The following are the genera at present known from New Caledonia :-Turdus, Acanthiza, Camprphaya, Lalage, Myiagra, Rhipidure, Pachycephala, Eopsaltria, Corvus, Physocorax (s.g. of Corvus, allied to the jackdaws), Glicphila, Anthochcera, Philemon, Zosterops, Ervythrura, Aplonis, Artamus, Cuculus, Halcyon, Collocalia, Cyaroramphrus, Trichoglossus, F'tilopus, Carpophaga, Macropygia, Inathicenas, Chalcophaps, Heliastur, Accipiter. The curious Rhinochetus jubatus, forming the type of a distinct family of birds (Rhinochetidx), allied to the herons, is only known from New Caledonia.

It thus appears, that not more than about 50 genera and 150 species of land-birds, are known from the vast number of islands that are scattered over the Central Pacific, and it is not prolathle 
that the number will be very largely increased. Some of the species, as the Eudynamis taitensis and Tatare longirostris, range over $40^{\circ}$ of longitude, from the Fiji Islands to the Marquesas. In other genera, as Cyanoramphus and I'tilopus, each important island or group of islands, has its peculiar species. The connection of all these islands with each other, on the one hand, and their close relation to the Australian region, on the other, are equally apparent; but we have no sufficient materials for speculating with any success, on the long series of changes that have brought about their existing condition, as regards their peculiar forms of animal life.

Sundwich Islands.-This somewhat extensive group of large islands, is only known to contain 11 genera and 18 species of indigenous land-birds; and even of this small number, two birds of prey are wide ranging species, which may well have reached the islands during their present isolated condition. These latter are, Strix delicatulet, an owl spread over Australia aud the Pacific; and Asio accipitrinus, a species which has reached the Galapagos from S. America, and thence perhaps the Sandwich Islands. Of the remaining 8 genera, one is a crow (Corvus havaicnsis), and another a fishing eagle (Pandion solitarius), of peculiar species; leaving 7 genera, which are all (according to Mr. Sclater) peculiar. First we have Chasiempis, a genus of Muscicapidx, containing two species (which may however belong to distinct genera); and as the entire family is unknown on the American continent these birds must almost certainly be allied to some of the numerous Muscicapine forms of the Australian region. Next We have the purely Australian family Meliphagida, represented by two genera,-Moho, an isolated form, and Chatoptila, a genus established by Mr. Sclater for a bird before classed in Entomyza, an Australian group. The four remaining genera are believed l,y Mr. Sclater to belong to one group, the I)repanididr, altogether confined to the Sandwich Islands. Two of tlem, Drepanis and Henignathus, with three species each, are undoubtedly allied; the other two, Loxops and 1'sittirustret, liave usually been clissed as finches. The former scem to approach the Dicisidie; and all resemble this group in their coloration. 
The aquatic birds and waders all helong to wide-spread genera, and only one or two are peculiar species.

The Sandwich Islands thus possess a larger proportion of peculiar genera and species of land-birds than any other group of islands, and they are even more strikingly characterised by what seems to be a peculiar family. The only other class of terrestrial animals at all adequately represented on these islands, are the land shells; and here too we find a peculiar family, subfamily, or genus (Achatinella or Achatinellidæ) consisting of a number of genera, or sub-genera,-according to the divergent views of modern conchologists, - and nearly 300 species. The Rev. J. T. Gulick, who has made a special study of these shells on the spot, considers that there are 10 genera, some of which are confined to single islands. The species are so restricted that their average range is not more than five or six square miles, while some are confined to a tract of only two square miles in extent, and very few range over an entire island. Some species are confined to the mountain ridges, others to the valleys; and each ridge or valley possesses its peculiar species. Considerably unore than half the species occur in the island of Oahu, where there is a good deal of forest. Very few shells belonging to other groups occur, and they are all small and obscure; the Achatinellire almost monopolising the entire archipelago.

Remarks on the probable past history of the Sandwich Islunds. -The existence of these peculiar groups of birds and landshells in so remote a group of volcanic islands, clearly indicates that they are but the relies of a more extensive land; and the reefs and islets that stretch for more than 1,000 miles in a westnorth-west direction, may be the remains of a country once sufficiently extensive to develope these and many other, now extinct, forms of life. ${ }^{1}$

Some light may perhaps be thrown on the past history of the

1 A new genus of Beetles (Apterocyclus) of the family Lucanidx, has recently been described from the Sandwich Islands, and it is said to be most nearly related to a group inhabiting Chili,-an indication either of the great antiquity of the fumna, or of the varied accidental migrations from which it has had its origin. 
Sandwich Islands, by the peculiar plants which are found on their mountains. The peak of Teneriffe produces no Alpine plants of European type, and this has been considered to prove that it has been always isolated; whereas the occurrence of North Temperate forms on the mountains of Java, accords with other evidence of this island having once formed part of the Asiatic contiment. Now on the higher summits of the Sandwich Islands, nearly 30 genera of Arctic and North Temperate flowering plants have been found. Many of these occur also in the South Temperate zone, in Australia or New Zealand; but there are others which seem plainly to point to a former connection with some North Temperate land, probably California, as a number of islets are scattered in the ocean between the two countries. The most interesting genera are the following:- Silene, which is wholly North Temperrate, except that it occurs in S. Africa; Vicia, also North Temperate, and in South Temperate America; Fragaria, with a similar distribution; Aster, widely spread in America, otherwise North Temperate only; Vaccinium, wholly confined to the northern hemisphere, in cold and temperate climates. None of these are found in Australia or New Zealand; and their presence in the Sandwich Islands seems clearly to indicate a former approximation to North Temperate America, although the absence of any American forms of vertebrata renders it certain that no actual land connection ever took place.

Recent soundings have shown, that the Sandwich Islands rise from a sea which is 3,000 fathoms or 18,000 feet deep; while there is a depth of at least 2,000 fathoms all across to California on one side, and to Japan on the other. Between the Fiji Islands, New Caledonia, the Solomon Islands, and Australia, the depth is about 1,300 fathoms, and between Sydney and New Zealand 2,600 fathoms; showing, in every case, a general accordance between the depth of sea and the approximation of the several faunas. In a few more years, when it is to he hoped we shall know the contour of the sea-bottom better than that of the continents, we shall be able to arrive at more definite and trustworthy conclusions as to the probable changes 
of land and sea by which the phenomena of animal distribution in the Pacific have been brought about.

Reptiles of the Polynesian Sub-region.-The researches of Mr. Darwin on Coral Islands, proverl, that large areas in the Pacific Ocean have been recently subsiding; but the peculiar forms of life which they present, no less clearly indicate the former existence of some extensive lands. The total absence of Mammalia, however, shows either that these lands never formed part of the Australian or Papuan continents, or if they did, that they have been since subjected to such an amount of subsiden:e as to exterminate most of their higher terrestrial forms of life. It is a remarkable circumstance, that although Mammalia (except bats) are wanting, there are a considerable number of repciles ranging over the whole sub-region. Lizards are the most numerous, five families and fourteen genera being represcnted, as follows:-

1. Cryptoblepharus (Gymnopthalmidæ) Fiji Islands.
2. Ablepharus …(
All the islands.
3. Lygosoma (..) (Scincida)
4. Mabouya
... Pelew Islands, New Caledonia.
5. Euprepes … ",
6. Dactyloperus ... (Geckotidæ)
... Samoa Islands.
... Pacifio Islands.
7. Doryura … (Geckotidø)
... Sandwich Islands.
8. Gehyra ... . "
9. Amydosaurus ... ",
10. Heteronota ... ",
11. Correlophus ... "
12. Brachylophus ... (Iguanidæ)
13. Lophura … (Agamidæ)
14. Chioroscartes ..." "
... Pacific Islands.
... Fiji Islauds.
... Tahiti.
... Fiji Islands.
... New Caledonir.
... Fiji Islands.
... Pelew Islands.
... Fiji Islands.

The first five are wide-spread genera, represented mostly by peculiar species; but sometimes the species themselves have in wide range, as in the case of Ablepharus pecilopleurus, which (according to Dr. Guinther) is found in Timor, Australia, New Caledonia, Savage Island (one of the Samon group), and the Sandwich Islands! Gchyra and Heteronote are Australian genera; while Lophura has reached the l'elew Islands from the Moluccas. The remainder (printed in italics), are peculiar genera ; Bruchylophus being especially interesting as an example of an 
otherwise peculiar American family, occurring so far across the Pacific.

Snakes are much less abundant, only four genera being represented, one of them marine. They are, Anoplodipsas, a peculiar genus of Amblycephalidæ from New Caledonia; Enygrus, a genus of Pythonidie from the Fiji Islands; Ogmodon, a peculiar genus of Elapidæ, also from the Fiji Islands, but ranging to Papua and the Moluccas; and Platurus, a wide-spread genus of sea-snakes (Hydrophilie). In the more remote Sandwich and Society Islands there appear to be no snakes. This accords with our conclusion that lizards have some special means of dispersal over the ocean which detracts from their value as indicating zoo-geographical affinities; which is further proved by the marvellous range of a single species (referred to above) from Australia to the Sandwich Islands.

A species of Hyla is said to inhabit the New Hebrides, and several species of Platymantis (tree-frogs) are found in the Fiji Islands; but otherwise the Amphibians appear to be unrepresented in the sub-region, though they will most likely be found in so large an island as New Caledonia.

From the foregoing sketch, it appears, that although the reptiles present some special features, they arree on the whole with the birds, in showing, that the islands of Polynesia all belong to the Australian region, and that in the Fiji Islands is to be found the fullest development of their peculiar fauna.

\section{New Zealand Sub-region.}

The islands of New Zealand are more completely oceanic than any other extensive tract of land, being about 1,200 miles from Australia and nearly the same distance from New Caledonia and the Friendly Isles. There are, however, several islets scattered around, whose productions show that they belong to the same sub-region;--the principal buing, Norfolk Island, Lord Howe's Island, and the Kermadec Isles, on the north; Chatham Island on the east; the Auckland and Macquarie Isles on the south; - and if these were once joined to 
New Zealand, there would have been formed an island-continent not much inferior in extent to Australia itself.

New Zealand is wholly situated in the warmer portion of the Temperate zone, and enjoys an exceptionally mild and equable climate. It has abundant moisture, and thus comes within the limits of the South-Temperate forest zone; and this leads to its productions often resembling those of the tropical, but moist and wooded, islands of the Pacific, rather than those of the temperate, but arid and scantily wooded plains of Australia. The two islands of New Zealand are about the same extent (approximately) as the British Isles, but the difference in the general features of their natural history is very great. There are, in the former, no mammalia, less than lialf as many birds, very few reptiles and fresh-water fishes, and an excessive and most unintelligible poverty of insects; yet, considering the situation of the islands and their evidently long-continued isolation, the wonder rather is that their fauna is so varied ancl interesting as it is found to be. Our knowledge of this fauna, though no doubt far from complete, is sufficiently ample; and it will be well to give a pretty full account of it, in order to see what conclusions may be drawn as ic its origin.

Mammatia.-The only mammals positively known as indigenous to New Zealand are two bats, both peculiar to it,-Scotophilus tuberculatus and Mystacina tuberculata. The former is allied to Australian forms; the latter is more interesting, as being a peculiar genus of the family Noctilionidæ, which does not exist in Australia; and in having decided resemblances to the Phyllostomidæ of South America, so that it may almost be considered to be a connecting link between the two families. A forest rat is said to have once abounded on the islands, and to have been used for food by the natives; but there is much doulbt as to what it really was, and whether it was not an introduced species. The seals are wide-spread antarctic forms which have no geographical significance.

Birds.-About 145 species of birds are natives of New Zealand, of which 88 are waders or aquatics, leaving 57 land-birds belong- 
ing to 34 genera. Of this latter number, 16 , or nearly half, are peculiar; and there are also 5 peculiar genera of waders and aquatic birds, making 21 in all. Of the remaining genera of land-birds, four are cosmopolite or of very wide range, while the remainder are characteristic of the Australian region. The following is a list of the Australian genera found in New Zealand: Sphenceacus, Gerygone, Orthonyx (Sylviidæ); Graucalus (Campephagidæ); Rhipidura (Muscicapidæ); Anthochoera (Meliphagidæ); Zosterops (Dicæidæ); Cyanoramphus (Platycercidæ); Carpophaga (Columbidx); Hieracidea (Falconidx); Tribonyx (Rallidæ). Besides these there are several genera of wide range, as follows:-Anthus (Motacillidæ); Hirundo (Hirundinidæ); Chrysococcyx, Eudynamis (Cuculidæ); Halcyon (Alcedinidæ); Coturnix (Tetraonidæ); Circus (Falconidæ); Athene (Strigidæ).

Most of the above genera are represented by peculiar New Zealand species, but in several cases the species are identical with those of Australia, as in the following: Anthochcera carunculata, Zosterops lateralis, Hirundo nigricans, and Chrysococcyx lucidus; also one-Eudynamis taitensis-which is Polynesian.

We now come to the genera peculiar to New Zealand, which are of especial interest:

\section{List of Genera of Birds Pectliar to New Zealand,}

SrLtidex.

$$
\begin{array}{r}
\text { Family and Genus. } \quad \text { Species. } \\
\text { Spect }
\end{array}
$$

1. Myiomoira … ,.. 3

2. Miro ...

Timalitd

3. Turnagra $\quad \ldots \quad \ldots \quad 2$ Of doubtful affinities.

SITTIDE.

4. Xenicus $\quad \ldots \quad \ldots \quad 3$ Of doubtful affinities.

5. Acanthisitta $\ldots \quad \ldots \quad 1$ Of doubtful affinities.

PARIDE.

6. Certhiparus $\quad \ldots \quad \ldots \quad 2$ Of doubtful affinities.

Meliphagtide.

7. Prosthemadera $\quad$.. 1 Peculiar genera of honeysuckers, a

8. Pogonomis $\quad \ldots \quad \ldots \quad$ l $\quad$ l family which is confined to the

9. Anthornis $\ldots \quad \ldots \quad 3$
Australian Region.

G G 2 
Sturnida.
Fanily and Genus.
No, of
Remarks.

10. Creadion $\quad \ldots . \quad \ldots \quad 2$ These three genera are probably

11. Heterolocha ... $\ldots . \quad 1 \quad$ allied, and perhaps form a dis-

12. Callæas $\quad \ldots \quad \ldots 2^{2}$ tinct family.

Nestoride.

13. Nestor... ... ... 3 A peculiar family of Parrots.

STringopid.e.
14. Stringops
A peculiar family of Parrots.

STRIGIDE.

15. (Sceloglaux) ... … 1 s.g. of Athene.

RaLtidi.

16. Ocydromus

6 Allied to Eulabeornis, an Australian genus.

17. Notornis _.. ... I Allied to Porphyrio, a genus of wido range.

CHARADRHDE.

18. Thinornis $\quad \ldots \quad \ldots \quad 1$

19. Anarhynchus ... … ।

ANATID.E.

20. Hymenoliemus

1 Allied to Malacorhynchus, an Australian genus.

A PTERYGIDE.

21. Apteryx

4 Forming a peculiar fumily.

We have thus a wonderful amount of speciality; yet the aftinities of the fauna, whenerer they can be traced, are with Australia or Polynesia. Nine genera of New Zealand birds are characteristically Australian, and the eight genera of wide range are Australian also. Of the peculiar genera, 7 or 8 are undoubtedly allied to Australian groups. There are also four Australian and one Polynesian species. Even the peculiar family, Nestoridæe, is allied to the Australian Trichoglossidce. We have therefore every gradation of similarity to the Australian fauna, from identical species, through identical genera, and allied genera, to distinct but allied families; clearly indicating very long continued yet rare immigations from Australia or Polynesia; immigrations which are continued down to our day. For resident oruithologists believe, that the Zosterops lateralis has found its way to New Zealand within the last few years, and that the two cuckoos now migrate annually, the one from Australia, the other from some 
part of Polynesia, distances of more than 1,000 miles! These facts seem, however, to have been accepted on insufficient evidence and to be in themselves extremely improbable. It is observed that the cuckoos appear annually in certain districts and again disappear; but their course does not seem to have been traced, still less have they ever been actually seen arriving or departing across the ocean. In a country which has still such wide tracts of unsettled land, it is very possible that the birds in question may only move from one part of the islands to another.

\section{Islets of the New Zealand Sub-region.}

We will here notice the smaller islands belonging to the sub. region, as it is chiefly their birds that possess any interest.

Norfolk Island. - The land-birds recorded from this island amount to 15 species, of which 8 are Australian, viz. : Climacteris scandens, Symmorphus lencopygius, Zosterops tenuirostris and Z. albogularis, Halcyon sanctus, Platycercus pennanti, Carpophaga spadicea, Phapspicata and $P$. chalcoptera. Of the peculiar species three belong to Australian genera; Petroica, Gerygone, and Rhipidura; one to a cosmopolitan genus, Turdus. So far the affinity seems to be all Australian, and there remain only three birds which ally this island to New Zealaud,-Nestor productus, Cyanoramphus rayneri, and Notornis albo. The former inhabited the small Phillip Island (close to Norfolk Island) but is now extinct. Being a typical New Zealand genus, quite incapable of flying across the sea, its presence necessitates some former connexion between the two islands, and it is therefore perinaps of more weight than all the Australian genera and species, which are birds capable of long flights. The Cyanoramphus is allied to a New Zealand broad-tailed parroquet. The Notornis alba is extinct, but two specimens exist in museums, and it is even a stronger case than the Nestor, as showing a former approximation or union of this island with New Zealand. A beautiful figure of this bird is given in the Tbis for 1873.

Lord Howe's 1sland.-This small island, situated half-way between Australia and Norfolk Island, is interesting, as containing a peculiar species of the New Zealand genus Ocydremus, or 
wood-hen (O. sylvestris). There is also a peculiar thrush, Turdus vinitinctus. Its other birds are wholly of Australian types, and most of them probably Australian species. The following have been observed, and no doubt constitute nearly its whole indigenous bird fauna. Acanthiza sp., Rhipidura sp., Puchycephala gutturalis, Zosterops strennuus and $Z$. tephropleurus, Strepera sp., Irulcyon sp., and Chalcophaga chrysochlora. The two species of Zusterops are peculiar. The Ocydromus is important enough to ally this island to New Zealand rather than to Australia; and if the white bird seen there is, as supposed, the Notornis alba which is extinct in Norfolk Island, the connection will be rendered still more clear.

Chatham Islands.-These small islands, 450 miles east of New Zealand, possess about 40 species of birds, of which 13 are landbirds. All but one belong to New Zealand genera, and all but five are New Zealand species. The following are the genera of the land-birds: Sphenceacus, Gerygone, Myiomoira, Rhipidura, Zosterops, Anthus, Prosthemadera, Anthornis, Chrysococcyx, Cyunoramphus, Carpophaga, Circus. The peculiar species are $A n$ thornis melanocephala, Myiomoira, diffenbachi and $M$. traversi, Rhipidura flabellifera, and a peculiar rail incapable of flight, named by Captain Hutton Cabalus modestus. It is stater that the Zosterops differs from that of $\mathrm{New}$ Zealand, and is also a migrant; and it is therefore believed to come every year from Australia, passing over New Zealand, a distance of nearly 1,700 miles! Further investigation will perhaps discover some other explanation of the facts. It is also stated, that the pigeon and one of the small birds (? Grerygone or Zosterops) have arrived at the islands within the last eight years. The natives further declare, that both the Stringops and Apteryx once inhabited the islands, but were exterminated about the year 1835 .

The Auckland Islands. - These are situated nearly 300 miles south of New Zealand, and possess six land-birds, of which three are peculiar,-Anthus aucklandicus, Cyanoramphus auchlandicus, and C. malherbii, the others being New Zealand species of Myiomoira, Prosthemadera, and Anthornis. It is remarkalule that two peculiar parrots of the same genus should inhabit these 


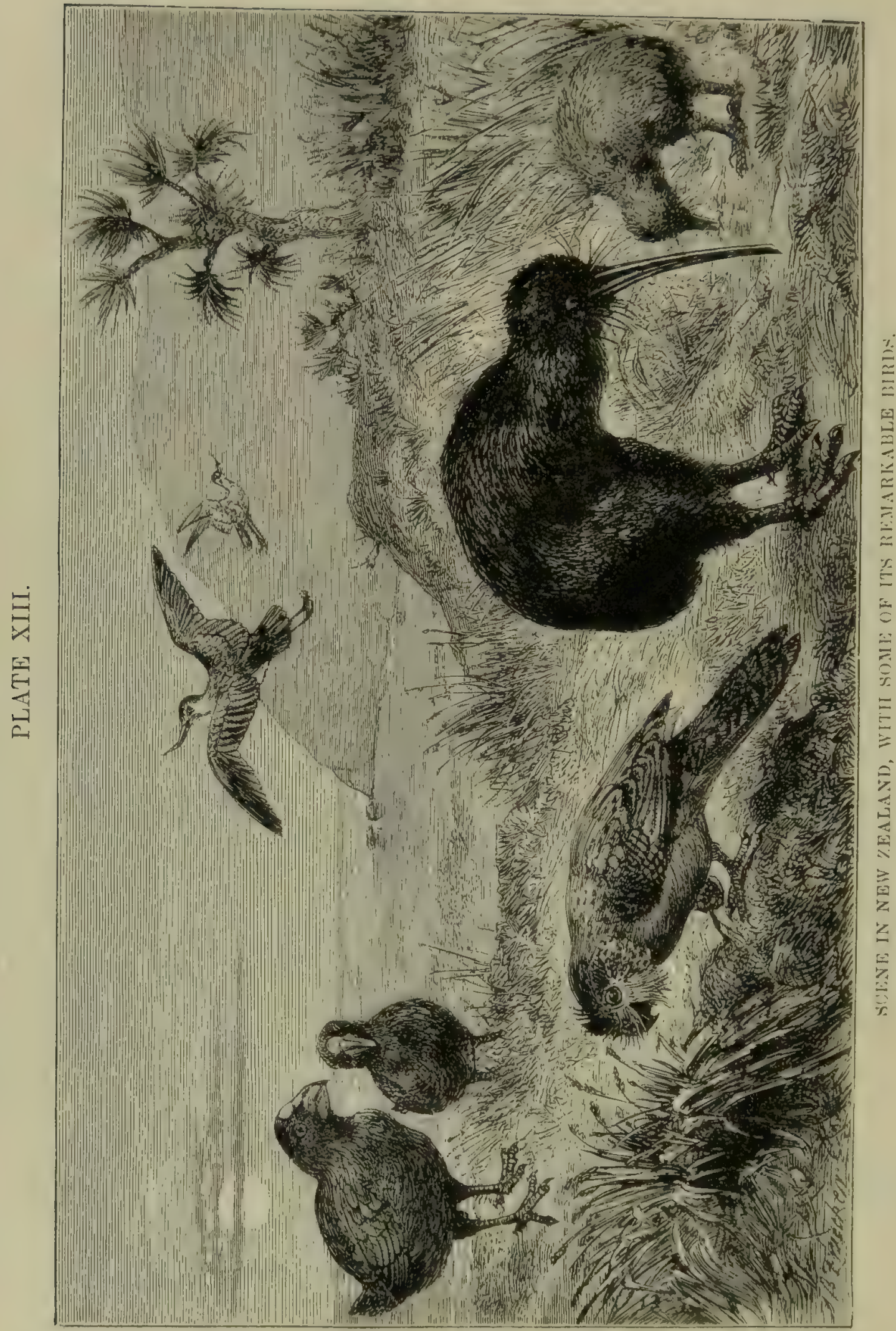


small islands; but such localities seem favourable to the Platycercidie, for another peculiar species is found in the remote Macquarie Islands, more than 400 miles farther south. A peculiar species and genus of ducks, Nesonetta aucklandica, is also found here, and as far as yet known, nowhere else. A species of the northern genus Mergus is also found on these islands, and has been recently obtained by Baron von Hügel.

Plate XIII. Illustrating the peruliar Ornithology of New Zealand.-Our artist has here depicted a group of the most remarkable and characteristic of the New Zealand birds. In the middle foreground is the Owl-parrot or Kakapoe (Stringops habroptilus), a nocturnal burrowing parrot, that feeds on fern-shoots, roots, berries, and occasionally lizards; that climbs but does not fly; and that has an owl-like mottled plumage and facial disc. The wings however are not rudimentary, but fully developed; and it seems to be only the muscles that have become useless for want of exercise. This would imply, that these birds have not long been inhabitants of New Zealand only, but were developed in other countries (perhaps Australia) where their wings were of use to them.

Beyond the Kakapoe are a pair of the large rails, Notornis mantelli; heavy birds with short wings quite useless for flight, and with massive feet and bill of a red colour. On the right is a pair of Kiwis (Apteryx australis), one of the queerest and most unbird-like of living birds. It has very small and rudimentary wings, entirely concealed by the hair-like plumage, and no tail. It is nocturnal, feeding chiefly on worms, which it extracts from soft earth by means of its long bill. The genus Aptery $x$ forms a distinct family of birds, of which four species are now known, besides some which are extinct. They are allied to the Cassowary and to the gigantic extinct Dinornis. On the wing are a pair of Crook-billed Plovers (Anarhynchus frontalis), remarkable for being the only birds known which have the bill bent sideways. This was at first thought to be a malformation; but it is now proved to be a constant character of the species, as it exists even in the young chicks; yet the purpose served hy such an anomalous structure is not yet discovered. 
No country on the globe can offer such an extraordinary set of birds as are here depicted.

Reptiles.-These consist almost wholly of lizards, there being no land-snakes and only one frog. Twelve species of lizards are known, belonging to three genera, one of which is peculiar, as are all the species. Hinulia, with two species, and Mocoa, with four species (one of which extends to the Chatham Islands), belong to the Scincidæ; both are very wide-spread genera and occur in Australia. The peculiar genus Naultinus, with six species, belongs to the Geckotidæ, a family spread over the whole world.

The most extraordinary and interesting reptile of New Zealand is, however, the Hattcria punctata, a lizard-like animal living in holes, and found in small islands on the north-east coast, and more rarely on the main land. It is somewhat intermediate in structure between lizards and crocodiles, and also has bird-like characters in the form of its ribs. It constitutes, not ouly a distinct family, Rhyncocephalidæ, but a separate order of reptiles, Rirvicocephalina. It is quite isolated from all other members of the class; and is probably a slightly modified representative of an ancient and generalised form, which has been superseded in larger areas by the more specialized lizards and saurians.

The only representatives of the Ophidia are two sea-snakes of Australian and Polynesian species, and of no geographical interest.

Amphibic.-The solitary frog indigenous to New Zealand, belongs to a peculiar genus, Liopelma, and to the family Bomburatoridæ, otherwise confined to Europe and temperate South America.

Fresh-voter Fishes.-There are, according to Captain Hutton, 15 species of fresh-water fish in New Zealand, belonging to 7 genera; six species, and one genus (Retropinna), being peculiar. Katropinna vichardsoni belongs to the Salmonidie, and is the only example of that family occurring in the Southern hemisphere, where it is confined to New Zealand and the Chatham Islands. The wide distribution of Goldrias attenuetus-from the 
Chatham Islands to South America-has already been noticed; while another species, $G$. fosciatus, is found in the Chatham and Auckland Isles as well as New Zealand. A second genus peculiar to New Zealand, Neochrnna, allied to Galaxias, has recently been described. Prototroctes oxyrhynchus is allied to an Australian species, but belongs to a family (Haplochitonidæ) which is otherwise South American. An eel, Anguilla latirostris, is found in Europe, China, and the West Indies, as well as in New Zealand! while the genus Agonostoma ranges to Australia, Celebes, Mauritius, and Central America.

Insects.-The great poverty of this class is well shown by the fact, that only eleven species of butterflies are known to inhabit New Zealand. Of these, six are peculiar, and one, Argyrophenga (Satyridæ), is a peculiar genus allied to the Northern genus Erebia. The rest are either of wide range, as Pyrameis cardui and Diadema bolina; or Australian, as Handyaas zoilus ; while one, Danais erippus, is American, but has also occurred in Australia, and is no doubt a recent introduction into both countries. Only one Sphinx is recorded, and no other species of the Sphingina except the British currant-moth, EEgeria tipuliformis, doubtless imported. Coleoptera are better represented, nearly 300 species having been described, all or nearly all being peculiar. These belong to about 150 genera, of which more than 50 are peculiar. No less than 14 peculiar genera belong to the Carabidæ, mostly consisting of one or two species, but Demetrida has 3 , and Metaglymma 8 species. Other important genera are Dicrochile, Homalosoma, Mecodema, and Scopodes, all in common with Australia. Mecodema and Metaglymma are the largest genera. Even the Auckland Islands have two small genera of Carabidæ found nowhere else.

Cicindelidæ are represented in New Zealand by 6 species of Cicindela, and 1 of Dystipsidere, a genus peculiar to the Australian region.

The Lucanidre are represented by two peculiar genera, Dendroblax and Oxyomus; two Australian genera, Lissotes and C'eratognathus; and by the almost cosmopolite Dorcus.

The Scarabeirla consist of ten species only, belonging to four 
genera, two of which are peculiar (Odontria and Stethaspis); and two Australian (Pericoptus and Calonota). There are no Cetoniidæ.

There is only one Buprestid, belonging to the Australian genus Cisseis. The Elateridæ, (about a dozen species,) belong mostly to Australian genera, but two, Metablax and Ochosternus, are peculiar.

There are 30 species of Curculionidæ, belonging to 22 genera. Of the genera, 12 are peculiar; 1 is common to New Zealand and New Caledonia; 5 belong to the Australian region, and the rest are widely distributed.

Longicorns are, next to Carabidix, the most numerous family, there being, according to Mr. Bates (Ann. Nat. Hist., 1874), about 35 genera, of which 26 are peculiar or highly characteristic, and 7 of the others Australian. The largest and most characteristic genera are Amona and Xyloteles, both being peculiar to New Zealand; few of the remainder having more than one or two species. Demonax extends to the Moluccas and S. E. Asia. A dozen of the genera have no near relations with those of any other country.

Phytophaga are remarkably scarce, only two species of Colaspis being recorded; and there is only a single species of Coccinella.

The other orders of Insects appear to be equally deficient. Hymenoptera are very poorly represented, only a score of species being yet known; but two of the genera are peculiar, as are all the species. The Neuroptera and Heteroptera are also very scarce, and several of the species are wide-spread forms of the Australian region. The few species of Homoptera are all peculiar. The Myriapoda afford some interesting facts. There are nine or ten species, all peculiar. One genus, Lithobius, ranges over the northern henisphere as far south as Singapore, and probably through the Malay Archipelagro, but is not found in Australia. Henicops occurs elsewhere only in Tasmania and Chili. Cryptops, only in the north temperate zone; while two others, Cermatia and Cormocepplatus, both occur in Australia. 
Land-Shells._Of these, 114 species are known, 97 being peculiar. Three species of Helix are also found in Australia, and five more in various tropical islands of the Pacific. Nanina, Lymnced, and Assiminea, are found in Polynesia or Malaya, but not in Australia. Amphibolc is an Australian genus, as is Janella. Testacella and Limax belong to the Palæarctic region.

From the Chatham Islands, 82 species of shells are known, all being New Zealand species, except nine, which are peculiar.

The Ancient Fauna of New Zealand.-One of the most remarkable features of the New Zealand fauna, is the existence, till quite recent times, of an extensive group of wingless birds, - called Moas by the natives-many of them of gigantic size, and which evidently occupied the place which, in other countries, is filled by the mammalia. The most recent account of these singular remains, is that by Dr. Haast, who, from a study of the extensive series of specimens in the Canterbury museum, believes, that they belong to two families, distinguished by important differences of structure, and constitute four genera,Dinornis and Miornis, forming the family Dinornithidæ; Palapteryx and Euryapteryx, forming the family Palapterygidæ. These were mostly larger birds than the living Apteryx, and some of them much larger even than the African ostrich, and were more allied to the Casuariidæ and Struthionidæ than to the Apterygidæ. No less than eleven species of these birds have been discovered; all are of recent geological date, and there are indications that some of them may have been in existence less than a century ago, and were really exterminated by man. Remains have been found (of apparently the same recent date) of species of Apteryx, Stringops, Ocydromus, and many other living forms, as well as of Harpagornis, a large bird of prey, and Cnemiornis, a gigantic goose. Bodies of the Hatteria punctata have also been found along with those of the Moa, showing that this remarkable reptile was once more abundant on the main islands than it is now.

The Origin of the New Zealand Fauna.-Having now given 
an outline sketch of the main features of the New Zealand fauna and of its relations with other regions, we may consider what conclusions are fairly deducible from the facts. As the outlying Norfolk, Chatham, and Lord Howe's Islands, are all inhabited (or have recently heen so) by birds of New Zcaland type or even identical species, almost incapable of flight, we may infer that these islands show us the former minimum extent of the land-area in which the peculiar forms which characterise the sub-region were developed. If we include the Auckland and Macquarie Islands to the south, we shall have a territory of not much less extent than Australia, and separated from it by perhaps several hundred miles of ocenn. Some such ancient land must have existed to allow of the development and specialization of so many peculiar forms of birds, and it probably remained with but slight modifications for a considerable geological period. During all this time it would interchange many of its forms of life with Australia, and there would arise that amount of identity of genera between the two countries which we find to exist. Its extension southwards, perhaps considerably beyond the Macquaries, would bring it within the range of floating ice during colder epochs, and within easy reach of the antarctic continent during the warm periods; and thus would arise that interchange of genera and species with South America, which forms one of the characteristic features of the natural history of New Zealand.

Captain F. W. Hutton (to whose interesting paper on the Geographical relations of the New Zealand Fauna we are. indebted for some of our facts) insists upon the necessity of former land-connections in various directions, and especially of an early southern continental period, when New Zealand, Australia, Southern Africa, and South America, rere united. Thus he would account for the existence of Struthious birds in all these countries, and for the various other groups of birds, reptiles, fishes, or insects which have no obvions means of traversing the ocenn, - and this mion must have occurred before manimalia existed in any of these countries. But such a supposition is quite unnecessary, if we consicter that all wingless land-binds and some water-birds (ats the rare-fowl 
and Steamer Duck) are prubably cases of abortion of useless organs, and that the common ancestors of the various forms of Struthiones may have been capable of a moderate degree of flight; or they may have originated in the northern hemisphere, as already explained in Chap. XI. p. 287. The existence of two, if not three, distinct families of these birds in New Zealand, proves that the original type was here isolated at a very early date, and being wholly free from the competition of mammalia, became more differentiated than elsewhere. The Hatteria is probably coeval with these early forms, and is the only relic of a whole order of reptiles, which once perhaps ranged far over the globe.

Still less does any other form of animal inhabiting New Zealand, require a land connection with distant countries to account for its presence. With the example before us of the Bermudas and Azores, to which a great variety of birds fly annually over vast distances, and even of the recent arrival of new birds in New Zealand and Chatham Island, we may be sure that the ancestors of every New Zealand bird could easily have reached its shores during the countless ages which elapsed while the Dinornis and Apteryx were developing. The wonderful range of some of the existing species of lizards and fresh-water fish, as already given, proves that they too possess means of dispersal which have sufficed to spread them, within a comparatively recent period, over countries separated by thousands of miles of ocean; and the fact that, a group like the snakes, so widely distributed and for which the climate of New Zealand is so well adapted, does not exist there, is an additional proof that land connection had nothing to do with the introduction of the existing fauna. We have already (p. 398), discussed in some detail the various modes in which the dispersal of animals in the soutbern hemisphere has been effected; and in accordance with the principles there established, we conclude, that the New Zealand fauna, living and extinct, demonstrates the existence of an extensive tract of land in the vicinity of Australia, Polynesia, and the Antarctic continent, without having been once actually connected with either of these countries, since the period when mammalia had peopled 
all the great continents. That event certainly dates loack to Secondary, if not to Palæozoic, times, because so dominant a group must soon have spread over the whole continuous landarea of the globe. We have no reason for believing that birds were an earlier development; and certainly cannot, with any probability, place the origin of the Struthiones before that of Mammals.

Causes of the Poverty of Insect-life in New Zealand: its Infuence on the Character of the Flora.-The extreme paucity of insects in New Zealand, to which we have already alluded, seems to call for some attempt at explanation. No other country in the world, in which the conditions are equally favourable for insectlife, and which has either been connected with, or is in proximity to, any of the large masses of land, presents a similar phenomenon. The only approach to it is in the Galapagos, and in some of the islands of the Pacific; and in each of these cases the absence of mammals leads us to infer, that no connection with a continent has ever taken place. Yet the fauna of New Zealanủ evidently dates back to a remote geological epoch, and it seems strange that an abundance of indigenous insects have not been developed, especially when we consider the vast antiquity that most of the orders and families, and many of the genera, of insects possess (see p. 156), and that they must always have reached the country in greater numbers and variety than any of the higher animals. The undoubted fact that such an indigenous insectfauna has not arisen, would therefore lead us to conclude, that insects find the conditions requisite for their development only in the great continental masses of land, in strict adaptation to, and dependance on, a varied fauna and flora of ever-increasing richness and complexity. A small number of widely-separated forms, introduced into a country where the fauna and flora are alike scanty and unrelated to them, seem to have little tendency to vary and branch out into that vast network of insect-life which enriches all the great continents and their once connected islands.

It is a striking confirmation on a large scale, of Mr. Darwin's beautiful theory - that the gay colours of flowers have mostly, or 
perhaps, wholly been produced, in order to attract insects which aid in their fertilization-that in New Zealand, where insects are so strikingly deficient in variety, the flora should be almost as strikingly deficient in gaily-coloured blossoms. Of course there are some exceptions, but as a whole, green, inconspicuous, and imperfect flowers prevail, to an extent not to be equalled in any other part of the globe; and affording a marvellous contrast to the general brilliancy of Australian flowers, combined with the abundance and variety of its insect-life. We must remember, too, that the few gay or conspicuous flowering-plants possessed by New Zealand, are almost all of Australian, South American, or European genera; the peculiar New Zealand or Antarctic genera being almost wholly without conspicuous flowers. In the tropical Galapagos the same thing occurs. Mr. Darwin notices the wretched weedy appearance of the vegetation; and states that it was some time before he discovered that most of the plants were in flower at the time of his visit! And the insect-life was correspondingly deficient, consisting mainly of a few terrestrial beetles.

The poverty of insect-life in New Zealand must, therefore, be a very ancient feature of the country ; and it furnishes an additional argument against the theory of land-connection with, or even any near approach to, either Australia, South Africa, or South America. For in that case numbers of winged insects would certainly have entered, and the flowers would then, as in every other part of the world, have been rendered attractive to them by the development of coloured petals; and this character once acquired would long maintain itself, even if the insects had, from some unknown cause, subsequently disappeared.

After the preceding paragraphs were written, it occurred to me, that if this reasoning were correct, New Zealand plants ought to be also deficient in scented flowers; because it is a part of the same theory, that the odours of flowers have, like their colours, been developed to attract the insects required to aid in their fertilization. I therefore at once applied to my friend Dr. Hooker, as the highest authority on New Zealand botany; simply asking whether there was any such observed deficiency. His reply was:-- 
"New Zealand plants are remarkably scentless, botlı in regard to the rarity of scented flowers, of leaves with immersed glands containing essential oils, and of glandular hairs." There are a few exceptional cases, but these seem even more rare than might be expected, so that the confirmation of theory is very complete. The circumstance that aromatic leaves are also very scarce, suggests the idea that these, too, serve as an attraction to insects. Aromatic plants abound most in arid countries, and on Alpine heights; both localities where winged insects are comparatively scarce, and where it may be necessary to attract them in every possible way. Dr. Hooker also informs, me that since his Introduction to the New Zealand Flora was written, many plants with handsome flowers have been discovered, especially among the Ranunculi, shrubby Veronicas, and herbaceous Compositæ. The two former, however, are genera of wide range, which may have originated in New Zealand by the introduction of plants with handsome flowers, which the few indigenous insects would be attracted by, and thus prevent the loss of their gay corollas; so that these discoveries will not much affect the general character of the flora, and its very curious bearing on the past history of the islands through the relations of flovers and insects.

In judging of the relation here supposed to exist, it must be remembered, that if the New Zealand insects have been introduced from the surrounding countries by chance immigrations at distant intervals, then, as we go back into the past the insect fauna will become poorer and poorer, and still more inadequate than at present to lead to the development of attractive flowers and odours. This quite harmonizes with the fact of the ancient indigenous flora being so remarkably scentless and inconspicuous, while a few of the more recently introduced genera of plants have retained their floral attractions.

\section{Concluding Remarks on the Early History of the Australiun liegion.}

We have already discussed in some detail, the various relations of the Australian sub-regions to the surrounding Regions, and the geographical changes that appear to have taken place. A very 
few observations will therefore suffice, on the supposed early history of the Australian region as a whole.

It was probably far back in the Secondary period, that some portion of the Australian region was in actual connection with the northern continent, and becane stocked with ancestral forms of Marsupials; but from that time till now there seems to have been no further land connection, and the Australian lands have thenceforward gone on developing the Marsupial and Monotremate types, into the various living and extinct races we now find there. During some portion of the Tertiary epoch Australia probably comprised much of its existing area, together with Papua and the Solomon Islands, and perhaps extended as far east as the Fiji Islands; while it might also have had a considerable extension to the south and west. Some light has recently been thrown on this subject by Professor McCoy's researches on the Palæontology of Victoria. He finds abundant marine fossils of Eocene and Miocene age, many of which are strikingly similar to those of Europe at the same period. Among these are Cetaceans of the genus Squalodon; European species of Plagiostomous fishes; mollusca and corals closely resembling those of Europe and North America of the same age,--such as numerous Volutes closely allied to those of the Eocene beds of the Isle of Wight, and the genus Dentalium in great abundance, almost or quite identical with European tertiary species. Along with these, are found some living species, but always such as now live farther north in tropical scas. The Cretaceous and Mesuzoic marine fossils are equally close to those of Europe.

The whole of these remains demonstrate that, as in the northern so in the southern hemisphere, a much warmer climate prevailed in the Eocene and Miocene periods than at the present time. This is a most important result, and one which strongly supports MIr. Belt's view, before refered to, that the warmer chinates in past geological epochs, and especially that of the Miocene as compared with our own, was caused by a dimimution of the oblicuity of the eclipitic, leading to a much greater miformity of the scasons for a considerable distance from the equator, and greatly reducing the polar area within which the sun would ever 
disappear during an entire rotation of the carth. During such a period, tropical forms of marine animals would have been able to spread north and south, into what are now cool latitudes; and identical genera, and even species, might then have ranged along the southerm shores of the old Palæarctic continent, from Britain to the Bay of Bengal, and southward along the Malayan coasts to Australia.

Numerous Miocene plant-beds have also been found in Victoria, containing abundance of Dicotyledonous leaves, which are said generally to resemble those of the Asiatic flora, and of the Miocene plant-beds of the Rhine. It is to be hoped these beds will be more closely examined for remains of insects, land-shells, and vertebrates, and that the plants will be carefully preserved and critically studied; for here probably lies hidden the key, that will solve much of the mystery that attaches to the past history of the Australian fauna. 


\section{TABLES OF DISTRIBUTION.}

In drawing up these tables, showing the distribution of the various classes of animals in the Australian region, the following sources of information have been relied on, in addition to the general treatises, monographs, and catalogues used in compiling the 4th Part of this work.

Mammalia.-Gould, Mammals of Australia; Waterhouse on Marsupials; Dr. J. E. Gray's List of Mammalia of New Guinea ; Müller, Temminck and Schlegel on Mammals of the Moluccas; papers by Dr. Gray; and personal observations by the Author.

Birds.-Gould's Birds of Australia; Buller's Birds of New Zealand; G. R. Gray's Lists of Birds of Moluccas, \&c.; Hartlaub and Finsch on Birds of Pacific Islands; Sclater on Birds of Sandwich Islands ; papers by Haast, Hutton, Meyer, Salvin. Schlegel, Sclater, Travers, Lord Walden and the Author.

Reptiles.-Krefft; Catalogue of Snakes; Gunther, List of Lizards in Voyage of Erebus and Terror (1875); and numerous papers. 
TABI,E I.

FAMILIES OF ANIMALS INHABITING THE AUSTRALIAN REGION.

\section{Explanation.}

Names in itaics show families which are peculiar to the region.

Names inclosed thus (.....) show families which only just enter the region, and aro not considered properly to belong to it.

Numbers correspond to the series of numbers to the families in Part IV.

\begin{tabular}{|c|c|c|c|c|c|}
\hline \multirow[b]{2}{*}{ Order and Family. } & \multicolumn{4}{|c|}{ Sub-regions. } & \multirow[b]{2}{*}{ Range beyond the Region. } \\
\hline & 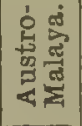 & 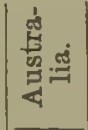 & 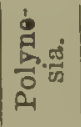 & 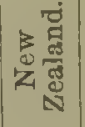 & \\
\hline $\begin{array}{l}\text { MAMMALIA. } \\
\text { Primatrs. } \\
\text { 3. Cynopithecidø }\end{array}$ & - & & & & Oriental and Ethiopian \\
\hline $\begin{array}{l}\text { Crinoptera. } \\
\text { 9. Pteropidø ... } \\
\text { 11. Rhinolophidæ } \\
\text { 12. Vespertilionidæ } \\
\text { 13. Noctilionidæ... }\end{array}$ & $\overline{-}$ & - & - & - & $\begin{array}{l}\text { Oriental and Ethiopian } \\
\text { The Eastern Hemisphere } \\
\text { Cosmopolite } \\
\text { All tropical regions }\end{array}$ \\
\hline $\begin{array}{l}\text { CARnIVoRA. } \\
\text { 25. (Viverridæ) } \\
\text { 33. Otariidæ... } \\
\text { 35. Phocidæ... } \\
\text {... }\end{array}$ & - & - & & - & $\begin{array}{l}\text { Oriental } \\
\text { N. and S. temperate zones } \\
N \text {. and S. temperate zones }\end{array}$ \\
\hline $\begin{array}{l}\text { Cetacta. } \\
\mathbf{3 6} \text { to } 41 . \quad \ldots \quad \ldots\end{array}$ & & & & & Ocennic \\
\hline $\begin{array}{l}\text { Sirkista. } \\
\text { 42. Manatidø }\end{array}$ & - & & & & Ethiopian, Oriental \\
\hline $\begin{array}{l}\text { Ungulata. } \\
\text { 47. Suille } \ldots \\
\text { 50. (Cervidæ) } \\
\text { 52. (Bovidæ) }\end{array}$ & $\begin{array}{l}-1 \\
-\end{array}$ & & & & $\begin{array}{l}\text { All other regions but Nearctic } \\
\text { All other regions but Ethiopian } \\
\text { All other regions but Neotropical }\end{array}$ \\
\hline $\begin{array}{l}\text { Rodentia, } \\
\text { 55. Muridæ } \ldots \quad \ldots \\
\text { 61. (Scuiridæ) } \quad \ldots\end{array}$ & - & - & & & $\begin{array}{l}\text { All other regions } \\
\text { All other regions }\end{array}$ \\
\hline $\begin{array}{l}\text { Marsu Pialia. } \\
\text { 77. Dasyuridoe ... } \\
\text { 78. Myrmecobiidoe } \\
\text { 79. Peramelidoe ... } \\
\text { 80. Maoropodida... }\end{array}$ & - & $\overline{-}$ & & & \\
\hline
\end{tabular}




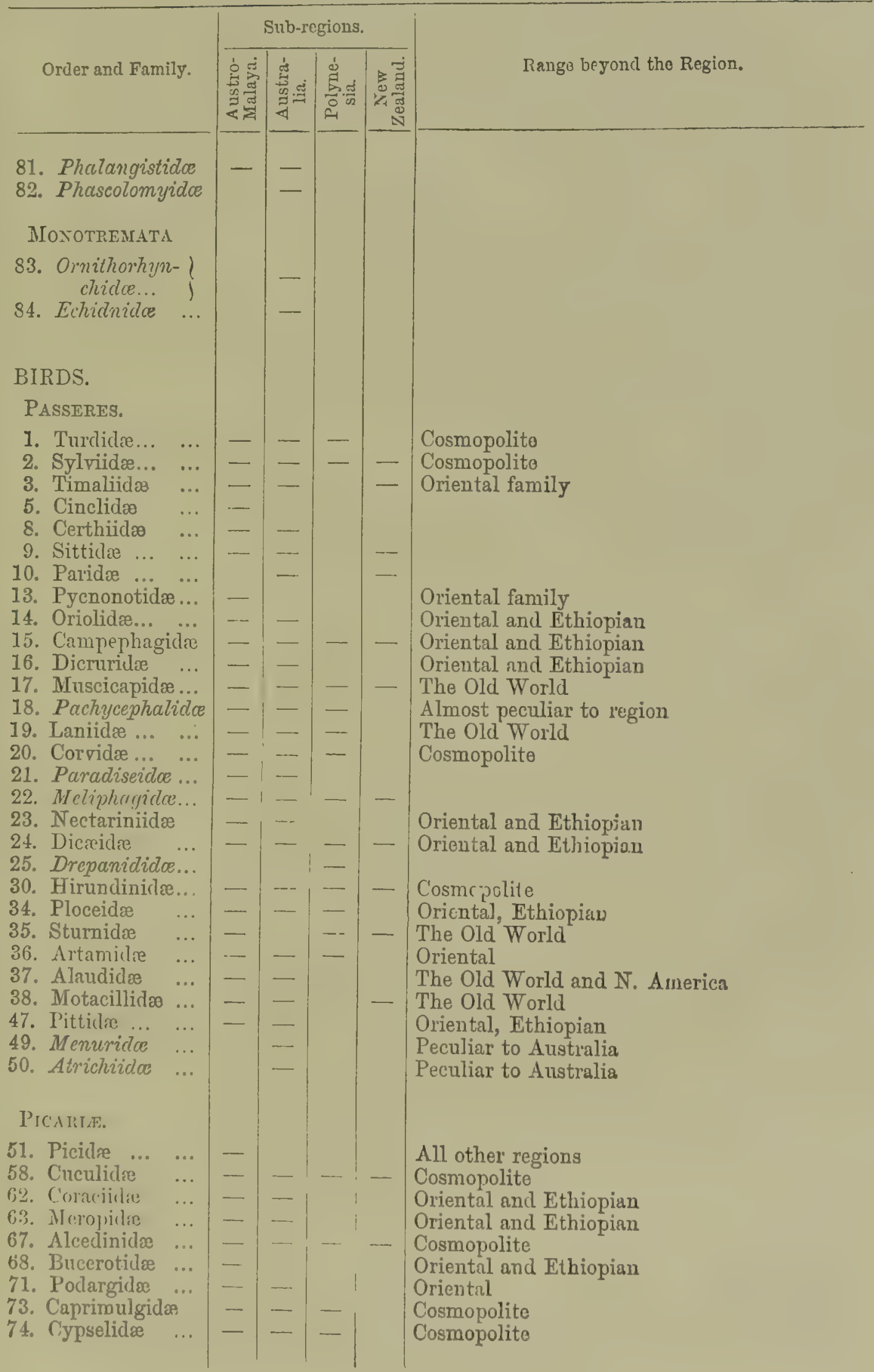




\begin{tabular}{|c|c|c|c|c|c|}
\hline \multirow[b]{2}{*}{ Order and Family. } & \multicolumn{4}{|c|}{ Sub-regions. } & \multirow[b]{2}{*}{ Range bcyond the } \\
\hline & 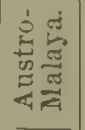 & 密 & 这损 & 竞 & \\
\hline PsITTACI. & & & & & \\
\hline $\begin{array}{l}\text { 76. Cacatuidoe ... } \\
\text { 77. Platycercidoe } \\
\text { 78. Palroornithidx } \\
\text { 79. Trichoglossidoe } \\
\text { 82. Nestoridce ... } \\
\text { 83. Stringopido... }\end{array}$ & $\begin{array}{l}- \\
- \\
- \\
-\end{array}$ & - & - & - & $\begin{array}{l}\text { Philippine Islands } \\
\text { Oriental }\end{array}$ \\
\hline $\begin{array}{l}\text { ContmBs. } \\
\text { 84. Columbidæ ... } \\
\text { 84a. Didunculidoe }\end{array}$ & - & - & - & - & Cosmopolite \\
\hline $\begin{array}{l}\text { Galdina. } \\
\text { 87. Tetraonidæ... } \\
\text { 88. (Phasianidæ) } \\
\text { 89. Turnicidæ .. } \\
\text { 90. Megapodiidae }\end{array}$ & $\begin{array}{l}- \\
- \\
-\end{array}$ & - & - & - & $\begin{array}{l}\text { Old World and N. America } \\
\text { Oriental } \\
\text { The Old World }\end{array}$ \\
\hline $\begin{array}{l}\text { ACCIPITREs. } \\
\text { 96. Falconidæ ... } \\
\text { 97. Pandionidæ .. } \\
\text { 98. Strigidæ ... }\end{array}$ & $\begin{array}{l}- \\
-\end{array}$ & $\begin{array}{l}-1 \\
-\end{array}$ & $\overline{-}$ & E & $\begin{array}{l}\text { Cosmopolite } \\
\text { Cosmopolite } \\
\text { Cosmopolite }\end{array}$ \\
\hline 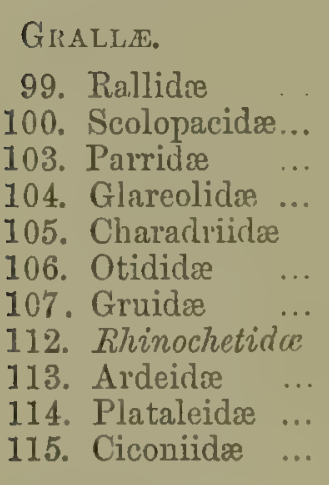 & $\begin{array}{l}- \\
- \\
-\end{array}$ & $\begin{array}{l}- \\
\pm \\
- \\
- \\
- \\
- \\
-\end{array}$ & - & - & $\begin{array}{l}\text { Cosmopolite } \\
\text { Cosmopolite } \\
\text { Tropical } \\
\text { The Eastern Hemisphero } \\
\text { Cosmopolite } \\
\text { The Eastern Hemisphere } \\
\text { The Eastern Hemisphere } \\
\text { Cosmopolite } \\
\text { Almost cosmopolite } \\
\text { Widely distributed }\end{array}$ \\
\hline $\begin{array}{l}\text { Anseres. } \\
\text { 118. Anatidæ ... } \\
\text { 119. Laridæ... .. } \\
\text { 120. Procellariidæe } \\
\text { 121. Pelecanidæ ... } \\
\text { 122. Spheniscidæ } \\
\text { 124. Podicipidæ .. }\end{array}$ & $\begin{array}{l:}- \\
- \\
-\end{array}$ & $\begin{array}{l}- \\
- \\
- \\
-\end{array}$ & \begin{tabular}{l|l}
- & \\
- & \\
- & \\
- & \\
- &
\end{tabular} & $\begin{array}{l}- \\
- \\
- \\
-\end{array}$ & $\begin{array}{l}\text { Cosmopolite } \\
\text { Cosmopolite } \\
\text { Cosmopolite } \\
\text { Cosmopolite } \\
\text { S. temperate regions } \\
\text { Cosmopolite }\end{array}$ \\
\hline 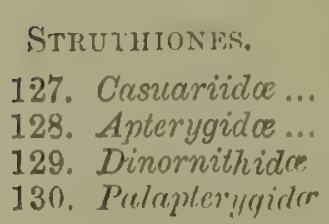 & & - & & - & $\begin{array}{l}\text { Extinct } \\
\text { Extinct }\end{array}$ \\
\hline
\end{tabular}




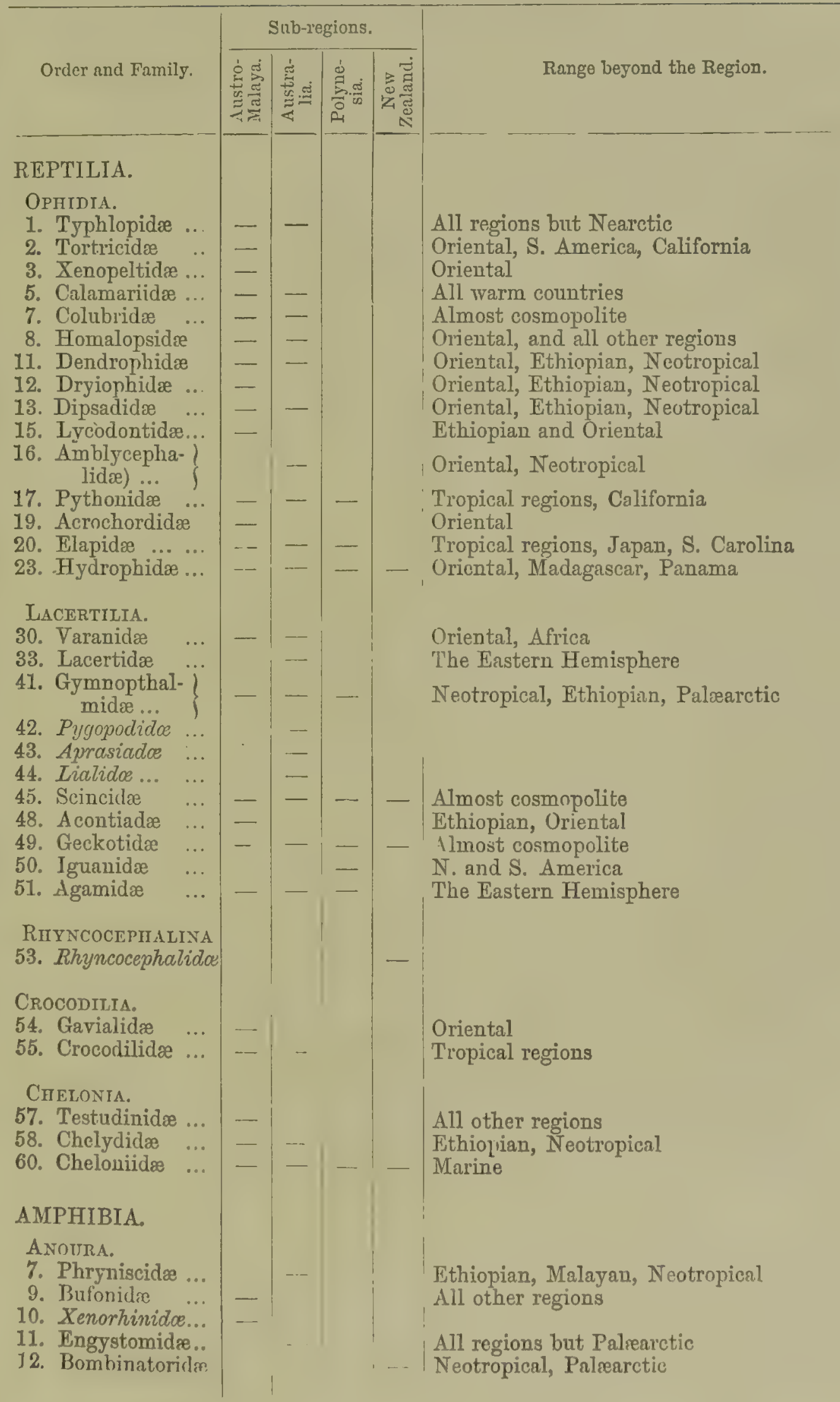




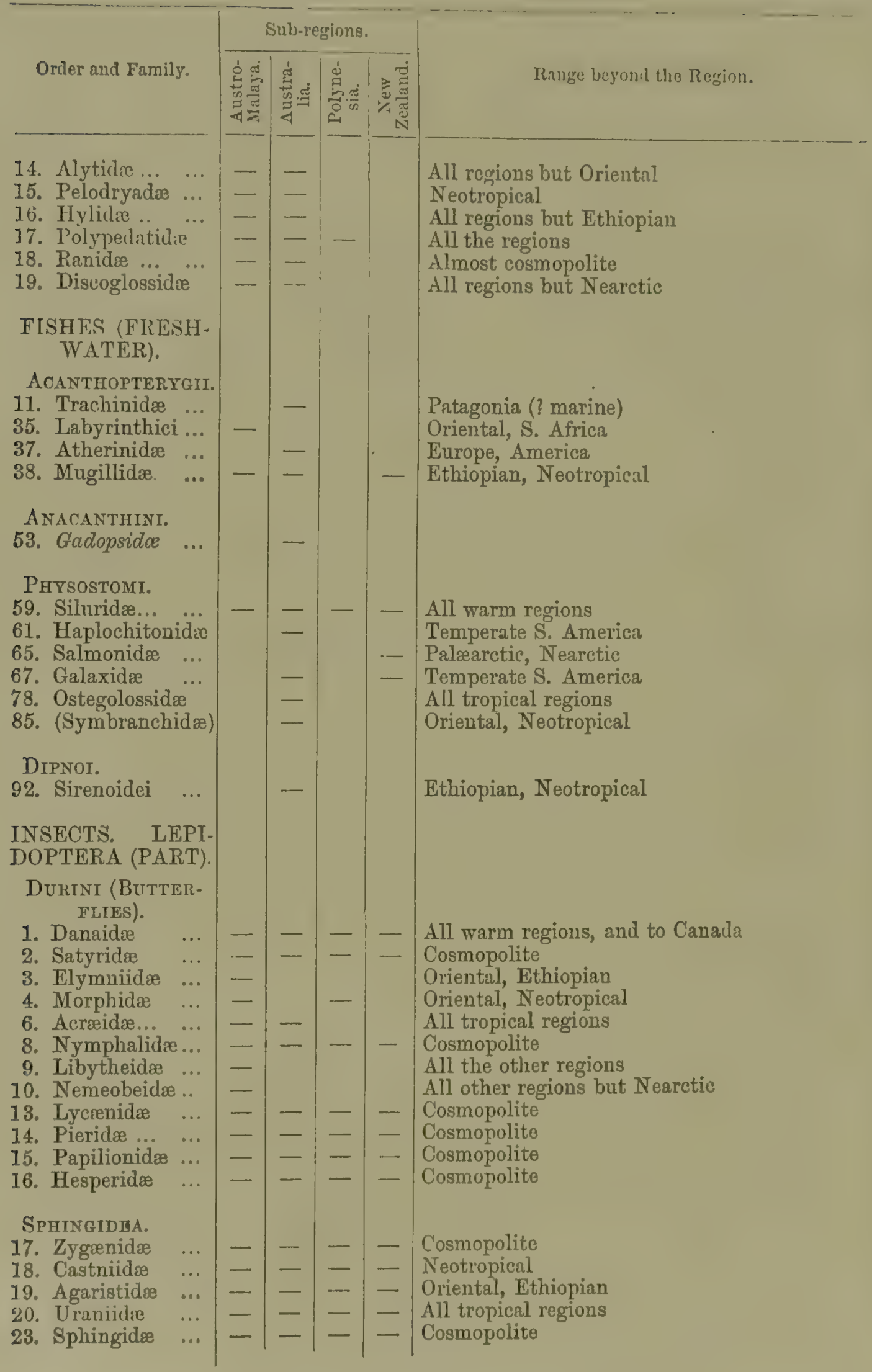




\section{TABLE II.}

GENERA OF TERRESTRIAL MAILILALIA AND BIRDS INHABITING THE AUSTRALIAN REGION.

\section{Explanation.}

Names in italics show genera peculiar to the region .

Names enclosed thus $(\ldots . .$.$) show genera which just enter the region, but are not con-$ sidered properly to belong to it.

Genera truly belonging to the region are numbered consecutively.

MAMMALIA.

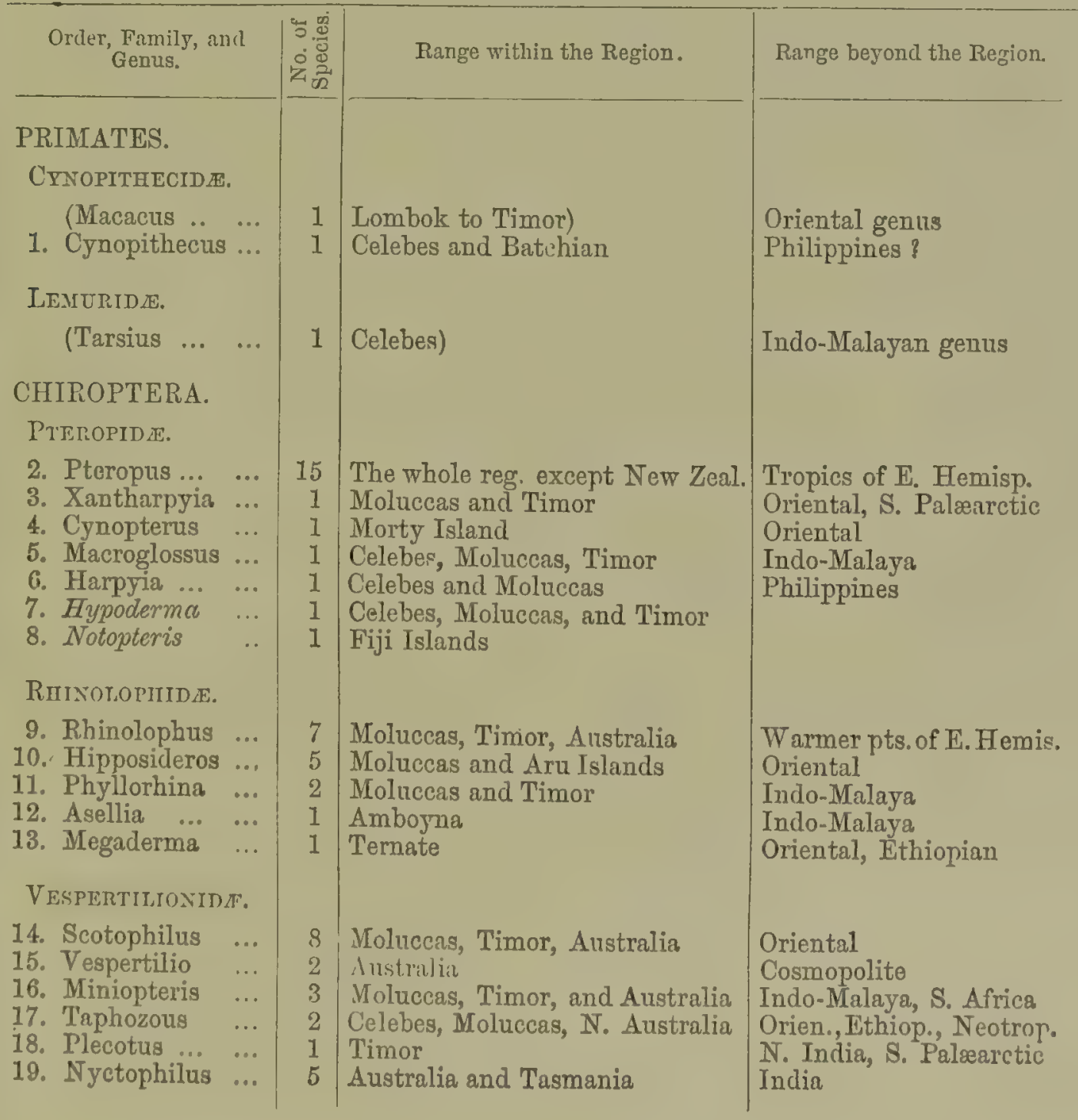




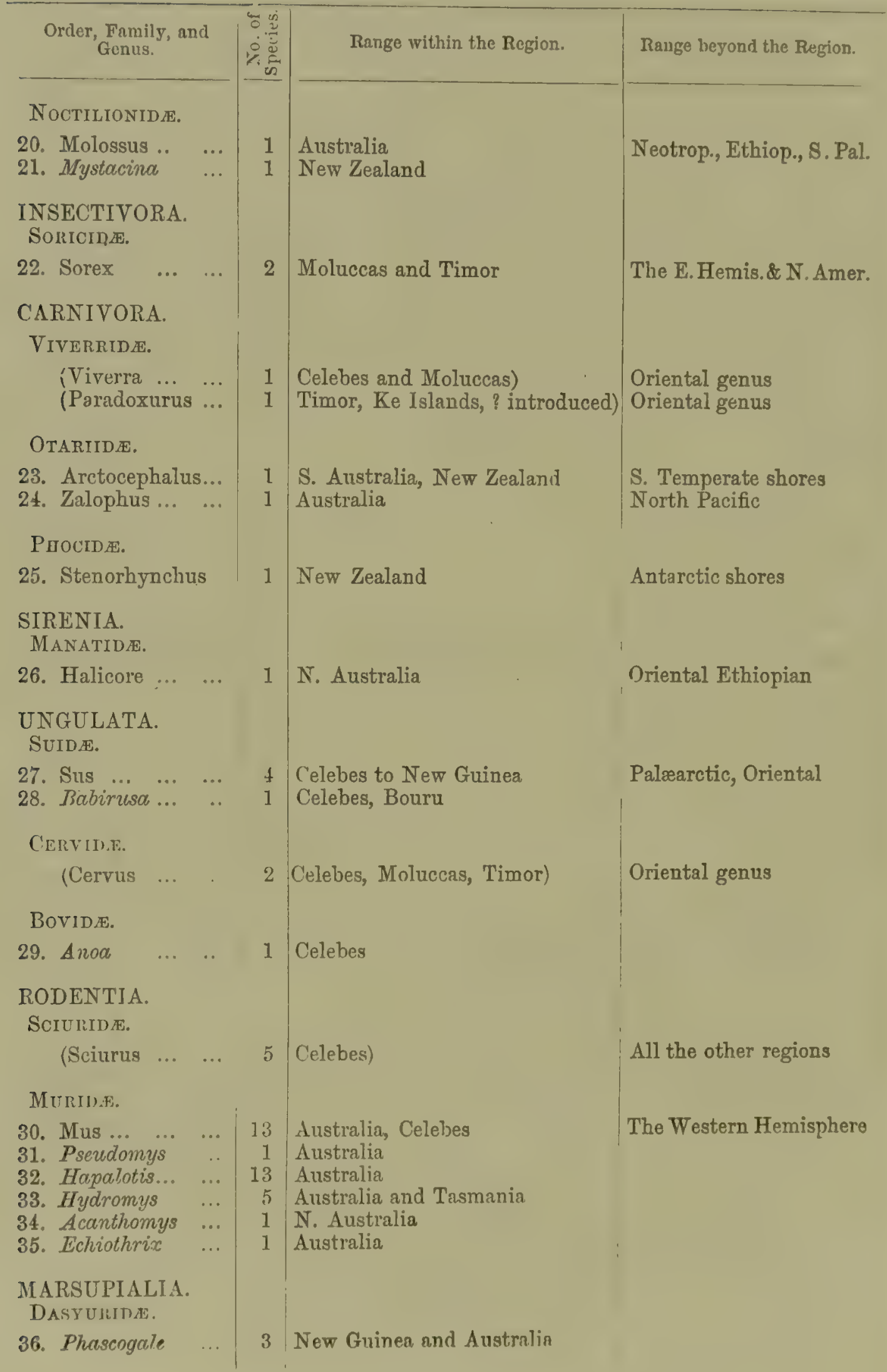




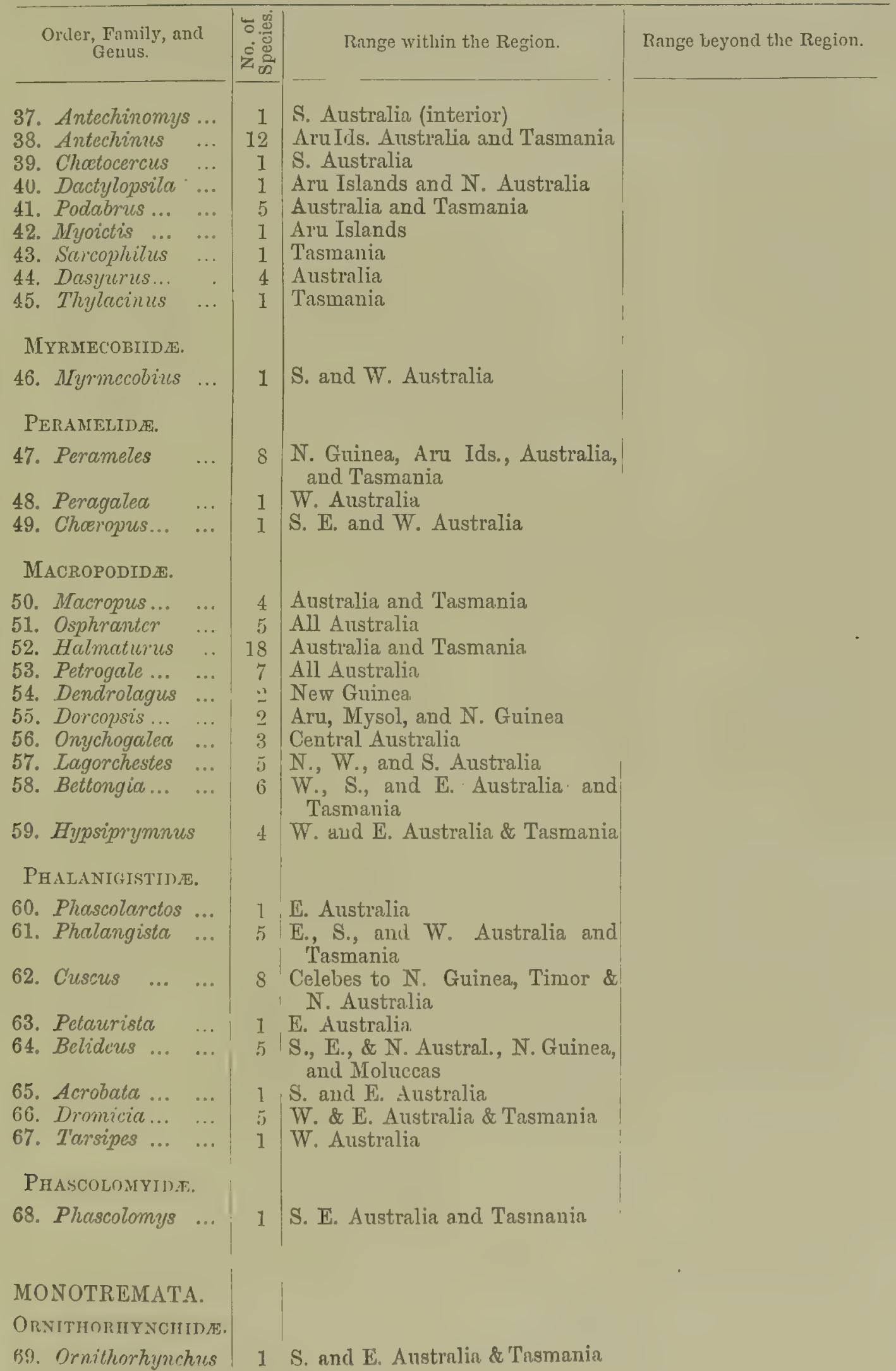




\begin{tabular}{|c|c|c|c|}
\hline $\begin{array}{l}\text { Order, Fanily, and } \\
\text { Genus. }\end{array}$ & 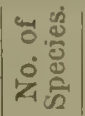 & llange witlin the Reersion. & Range beyond the Region. \\
\hline $\begin{array}{l}\text { EcHInNInd. } \\
\text { 70. Echidna ... ... }\end{array}$ & 2 & S. \& E. Australia, \& Tasmania & \\
\hline
\end{tabular}

PASSERES.

TuRDIDF.

1. Turdus

2. Oreocincla

3. Geocichla … (Monticola ... (Zoothera... ...

SYLVIIDE.

4. Cisticola ...

5. Sphenracus

6. Megalurus

7. Poodytes ... ...

8. Amytis ... ...

9. Sphenura ... ...

10. Stipiturus ...

11. Malumus ... ...

12. Hylacola ... ...

13. Calamanthus ...

14. Acrocephalus ..

15. Tatare

16. Hypolais ...

17. Sericomis

18. Acanthizo

19. Gerygone ... ...

20. Drymodes... ...

21. Oreicola ... ... (Pratincola ...

22. Epthianura ...

23. Petroica ... ...

24. Myiomoira ...

25. Lamprolic ...

26. Miro... ... ...

27. Cinclorhamphus

29. Origma ... ...

29. Orthonyx ... ...

Trmalim N.

30. Pomatorhinus...

31. Cinclosoma

32. Tumargre

33. Psophodes ...

34. Alcippe ... ... (Trichastoma ...
BIRDS.

Timor, Austral., New Caledonia, Cosmopolite Norfolk Island, Lord Howe's and Samoan Islands

S. E. Australia and Tasmania Palæarctic, Oriental Celebes, Lombok, Timor, Austral. Oriental

Gilolo, Celebes)

Lombok)

Palrearctic and Oriental

Oriental genus

Celebes, Boruru, Timor, Australia Palrarctic; Oriental

Australia, N. Zealand, Chatham Ethiopian

\section{Islands}

Timor

Australia

Australia

Australia

Australia, Tasmania

Australia, Tasmania, \& N. Guinea

Australia

Australia and Tasmania

Celebes, Moluccas, Australia, Palæarc., Orien., Ethiop. Caroline Islands

Samoan to Marquesas Islands

Moluccas

Australia and Tasmania

Austral., Tasmania, N. Caledonia

The whole region, excl. Moluccas Philippines

Australia

Lombok to Timor

Celebes to Timor)

Australia

Papua to Samoan Ids., Australia

N. Zealand

Fiji Islands

New Zealand

Australia

Australia

N. Guinea, Austral., New Zeald.

Oriental, Palæarctic

Palæarc., Orien., Ethiop.

N. Guinea and Australia

Australia and Tasmania

New Zealand

S. E. and W. Australia

New Guinea

Celebes)
Burmah ?

Oriental

Oriental

।

Oriontal

Oriental genus 


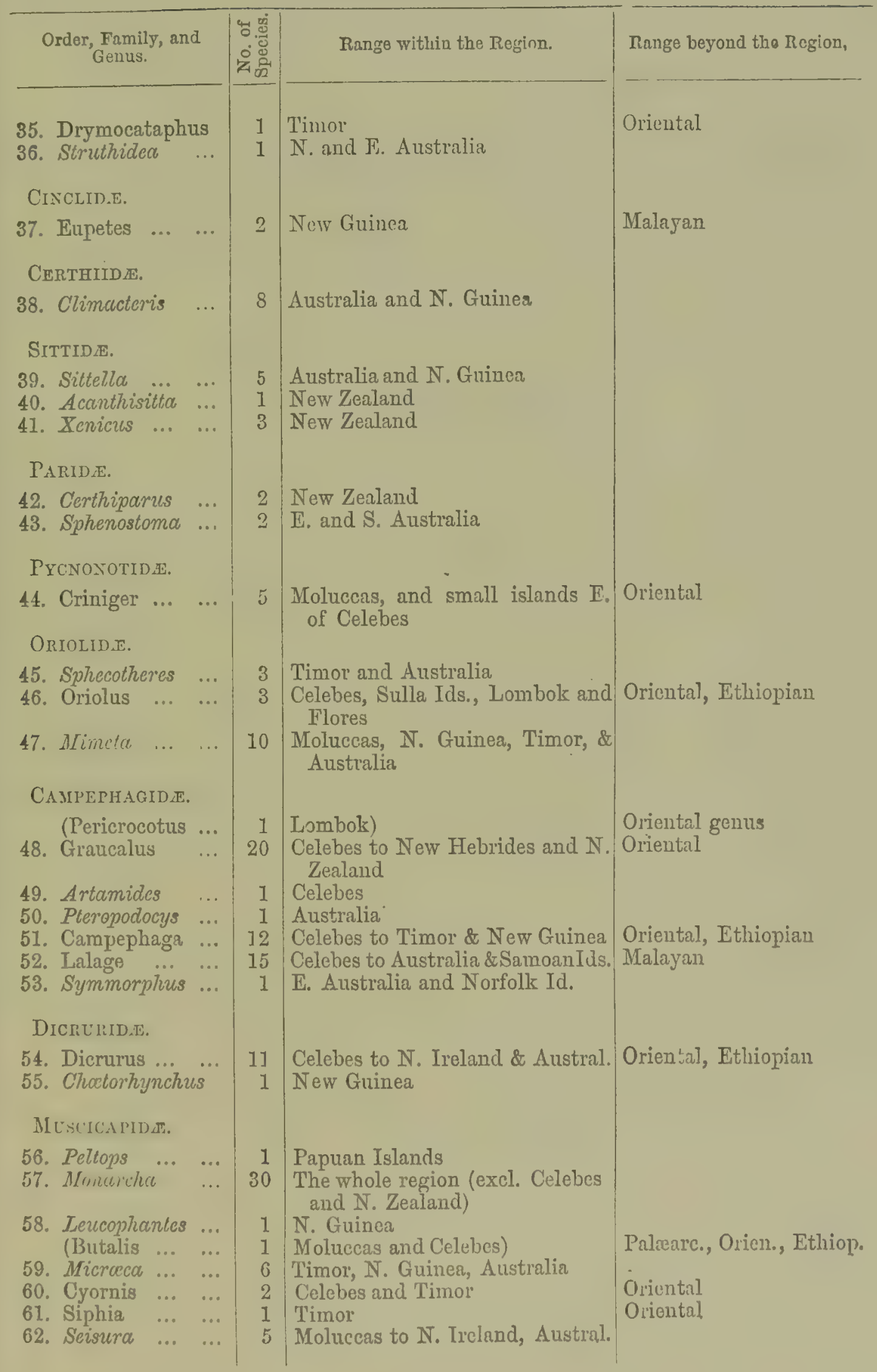




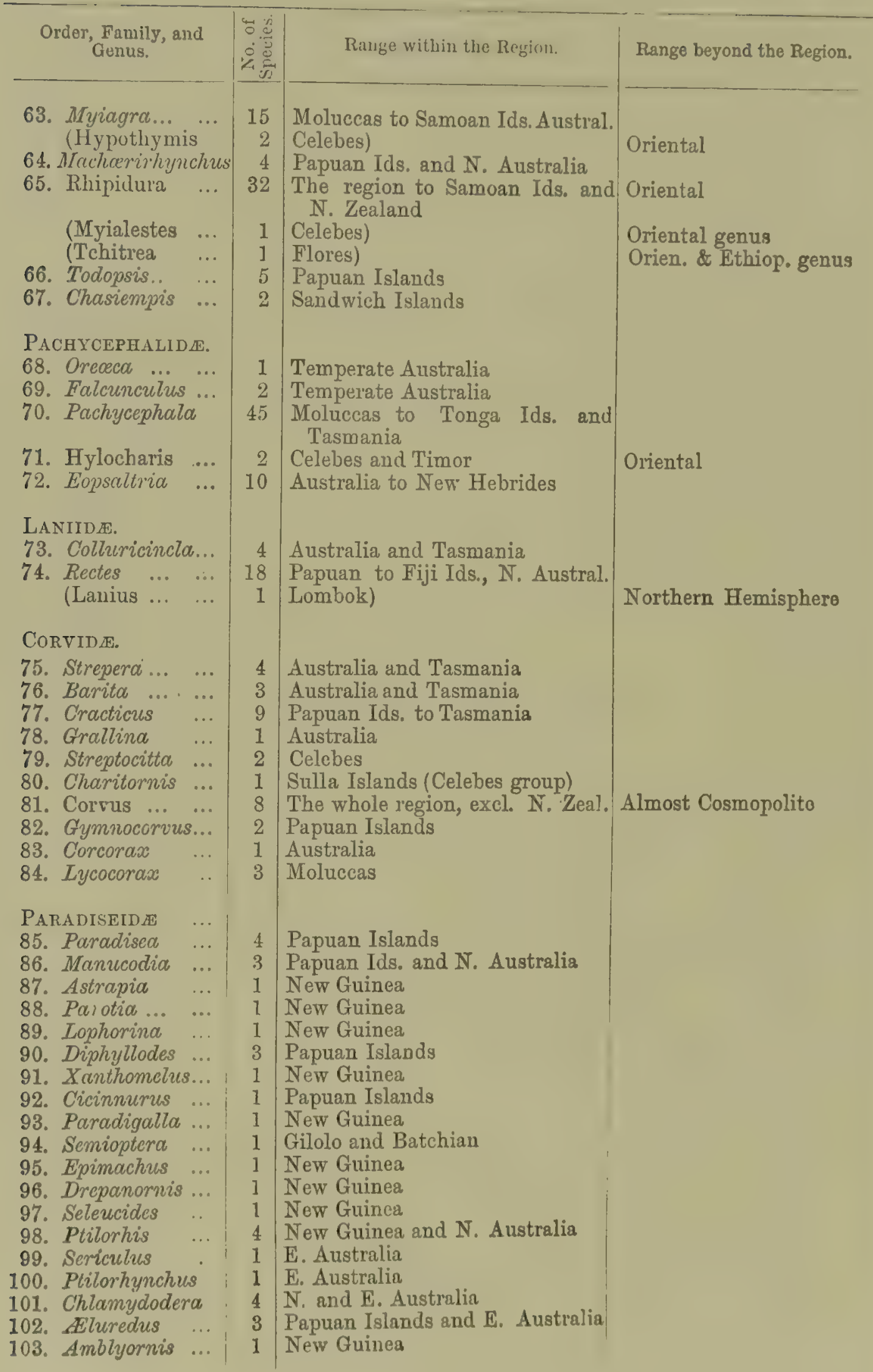




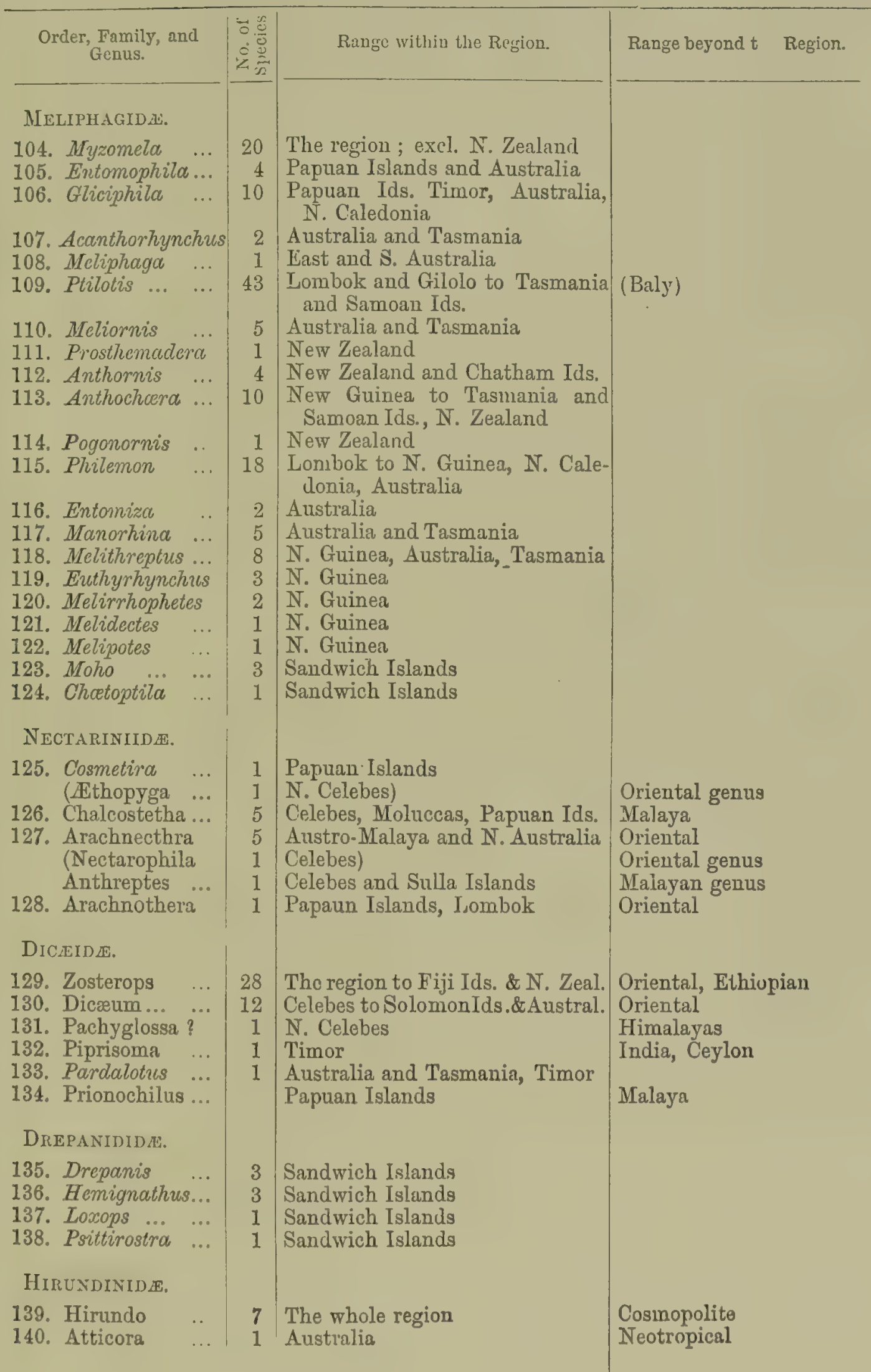




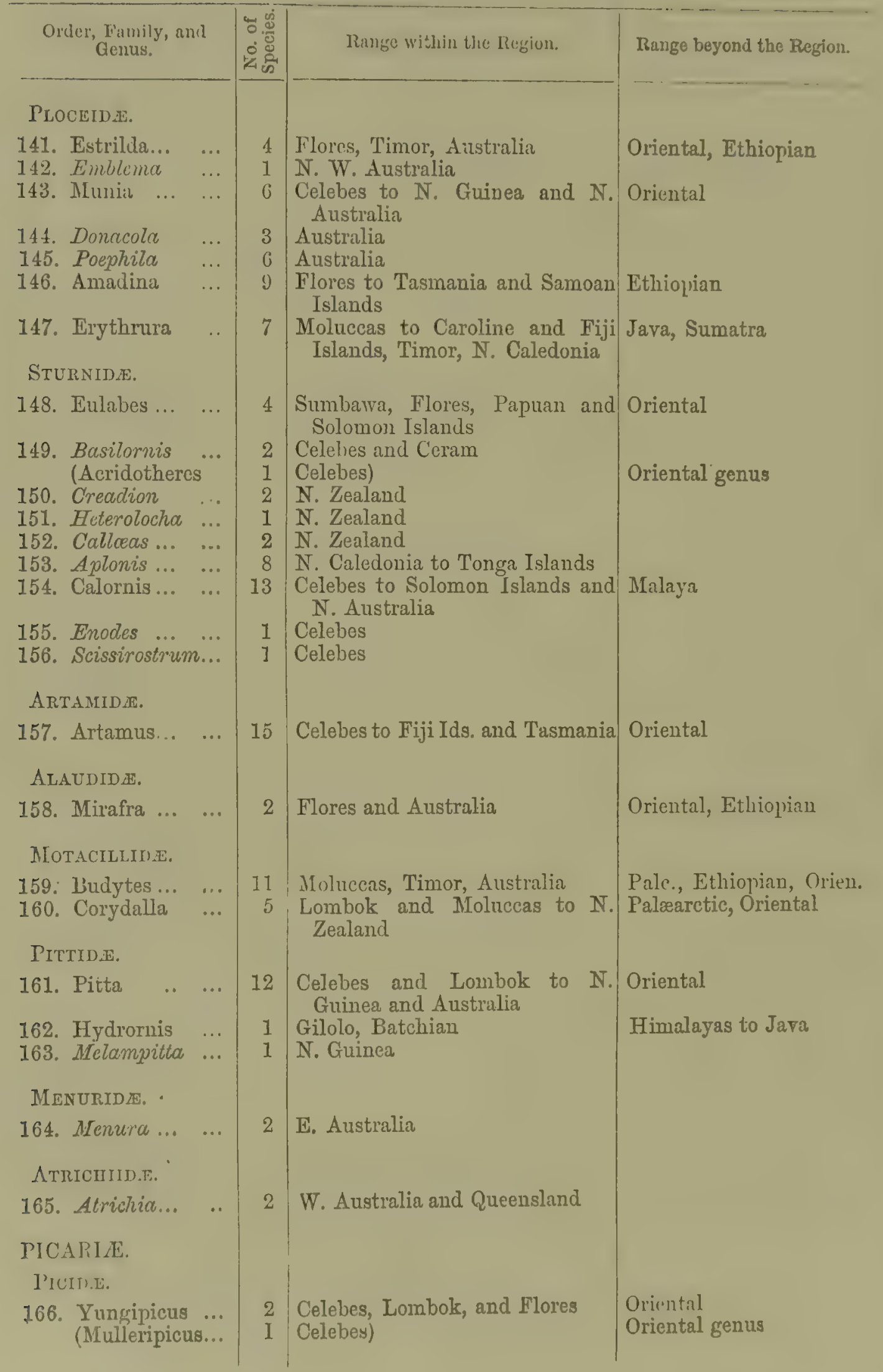




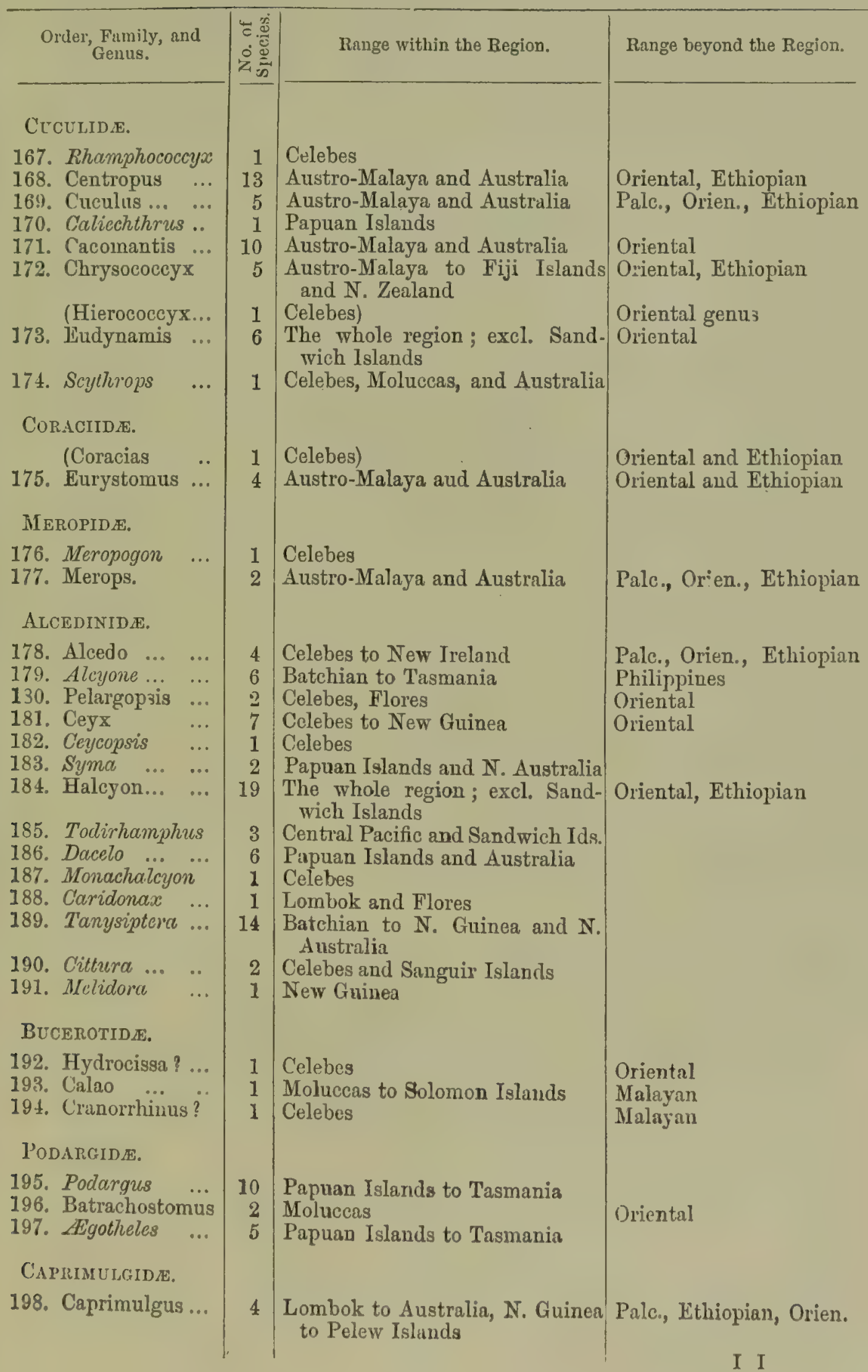




\begin{tabular}{|c|c|c|c|}
\hline $\begin{array}{l}\text { Order, Family, and } \\
\text { Genus. }\end{array}$ & 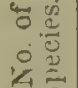 & Range within the Region. & Runge beyond the Regton. \\
\hline $\begin{array}{l}\text { 199. Eurostopontus... } \\
\text { (Lyncomis ... }\end{array}$ & $\begin{array}{l}2 \\
1\end{array}$ & $\begin{array}{l}\text { Aru Islands and Australia } \\
\text { Celebes) }\end{array}$ & Oriental genus \\
\hline Crpselide. & & & \\
\hline 200. Dendrochelidon & 2 & Celebes to N. Cuinea & Oriental \\
\hline 201. Collocalia ... & 4 & Celebes to Pacific Islands & Oriental \\
\hline 202. Cypselus $\quad \ldots$ & 1 & Australia & Palc., Orien., Ethiopian \\
\hline 203. Chrtura... ... & & Celebes, Australia & Ethio., Orien., American \\
\hline $\begin{array}{l}\text { PSITTACI. } \\
\text { CACATUIDE. }\end{array}$ & & & \\
\hline 204. Cocatua... ... & 17 & $\begin{array}{l}\text { Celebes and Lombok, to Solo- } \\
\text { mon Islands and Tasmania }\end{array}$ & Philippinэs \\
\hline 205. Calopsitta ... & 1 & Australia & \\
\hline 206. Calyptorhynchus & 8 & Australia and Tasmania & \\
\hline $\begin{array}{l}\text { 207. Microalossus ... } \\
\text { 208. Iricmetis... ... }\end{array}$ & $\begin{array}{l}2 \\
3\end{array}$ & $\begin{array}{l}\text { Papuan Islands and N. Austral. } \\
\text { Austr., Solmn. Ids., \& N.Guin.? }\end{array}$ & \\
\hline 209. Nasiterna $\quad \ldots$ & 3 & Papuan and Solomon Islands & \\
\hline Platycerctid. & & & \\
\hline 210. Platycercus ... & 14 & Austral., Tasmania, Norfolk Id. & \\
\hline $\begin{array}{ll}\text { 211. Psephotus } & \ldots \\
\text { 212. Polytelis... } & \ldots\end{array}$ & $\begin{array}{l}6 \\
3\end{array}$ & $\begin{array}{l}\text { Australia } \\
\text { Australia }\end{array}$ & \\
\hline 213. Nymphicres ... & 1 & Australia and N. Caledonia & \\
\hline 214. Aprosmictus ... & 6 & $\begin{array}{l}\text { Moluccas, Timor, Papuan Is- } \\
\text { lands, Australia. }\end{array}$ & \\
\hline 215. Pyrrhulopsis... & 3 & Tonga to Fiji Islands & \\
\hline 216. Cyanoramphus & 14 & $\begin{array}{l}\text { N. Zealand, Norfolk Island, N. } \\
\text { Caledonia, Society Islands }\end{array}$ & \\
\hline $\begin{array}{l}\text { 217. Melopsittacus .. } \\
\text { 218. Euphema ... }\end{array}$ & 1 & $\begin{array}{l}\text { Australia } \\
\text { Australia }\end{array}$ & \\
\hline 219. Pezoporus … & $\begin{array}{l}7 \\
1\end{array}$ & $\begin{array}{l}\text { Australia } \\
\text { Australia and Tasmania }\end{array}$ & \\
\hline 220. Geopsittacus ... & 1 & W. Australia & \\
\hline PALEORNITHID无。 & & & \\
\hline $\begin{array}{l}\text { 221. Prioniturus ... } \\
\text { 222. Geoffroyus } \ldots\end{array}$ & $\begin{array}{l}2 \\
5\end{array}$ & $\begin{array}{l}\text { Celebes } \\
\text { Borneo to Timor \& Solomon Ids. }\end{array}$ & Philippines \\
\hline 223. Tanygnathus... & 4 & Celebes to New Guiner & Philippines \\
\hline 224. Eclectus ... ... & 8 & Moluccas and Papuan Islands & \\
\hline $\begin{array}{l}\text { 225. Cyclopsitta } \ldots \\
\text { 226. Loriculus } \ldots\end{array}$ & $\begin{array}{l}7 \\
7\end{array}$ & $\begin{array}{l}\text { Papuan Ids, and N.E. Austral. } \\
\text { Celebes to Mysol, Flores }\end{array}$ & $\begin{array}{l}\text { Philippines } \\
\text { Oriental }\end{array}$ \\
\hline 227. Trichoglossis & 29 & $\begin{array}{l}\text { The whole region, excl. Sandwich } \\
\text { Islands, and N. Zealand }\end{array}$ & \\
\hline $\begin{array}{l}\text { 228. Nanodes... ... } \\
\text { 229. Charmosina ... }\end{array}$ & 1 & $\begin{array}{l}\text { Australia and Tasmania } \\
\text { New Guinea }\end{array}$ & \\
\hline $\begin{array}{l}\text { 229. Charmosyna ... } \\
\text { 230. Eos ... ... ... }\end{array}$ & $\begin{array}{l}1 \\
9\end{array}$ & Sanguir. Ids, and Moluccas to & \\
\hline 231. Lorine \& ... & 23 & Bouru and Gilolo to Solomon Ids. & \\
\hline 232. Coriphilus ... & 4 & Samoen to Marquesas Islands & \\
\hline $\begin{array}{l}\text { NFstorina } \\
\text { 233. Nestor } \\
\text { 234. Desyptilus } \\
\text {.. }\end{array}$ & 5 & $\begin{array}{l}\text { New Zealand and Norfolk Ids. } \\
\text { Now Guinea }\end{array}$ & \\
\hline
\end{tabular}




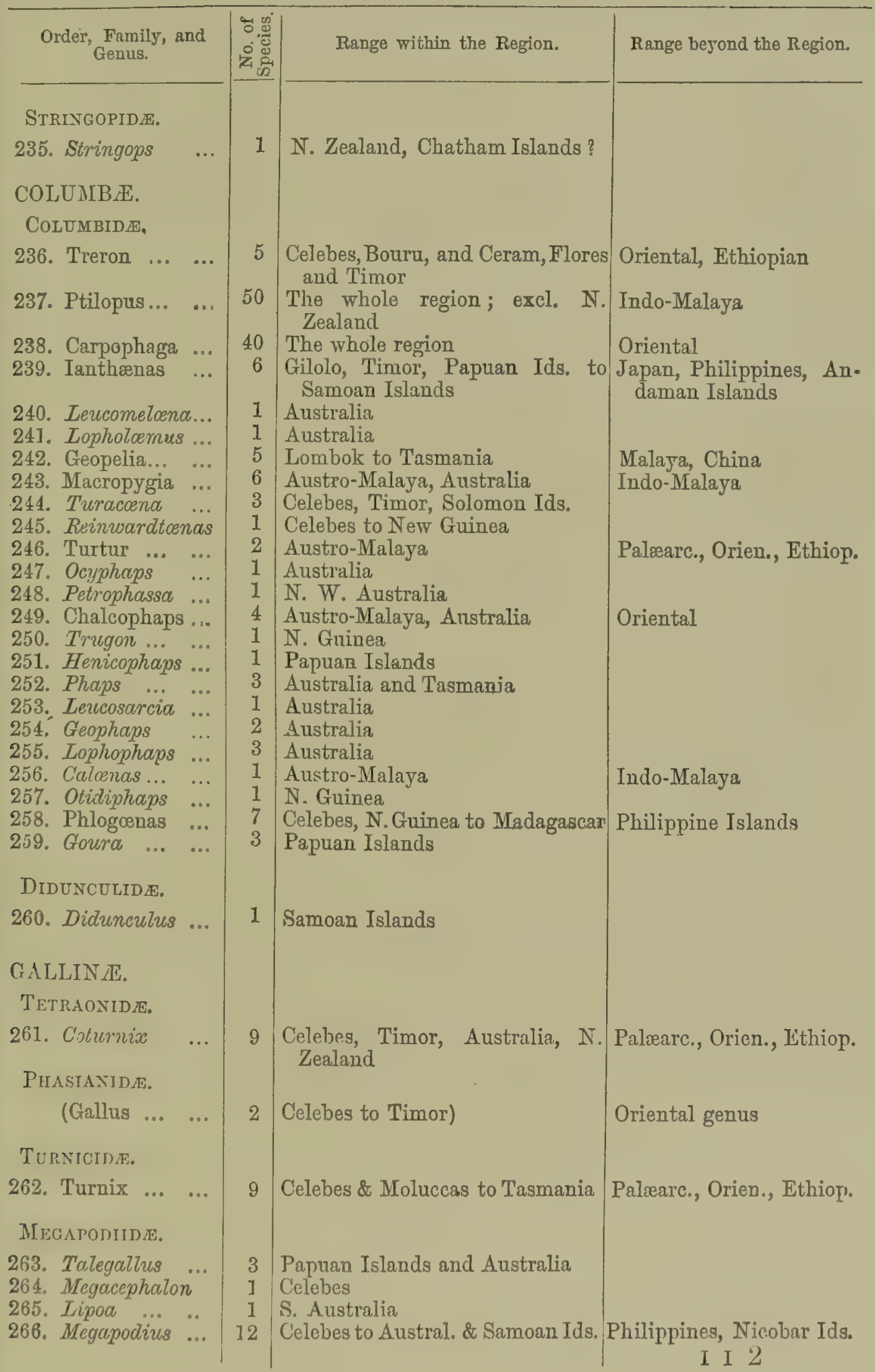




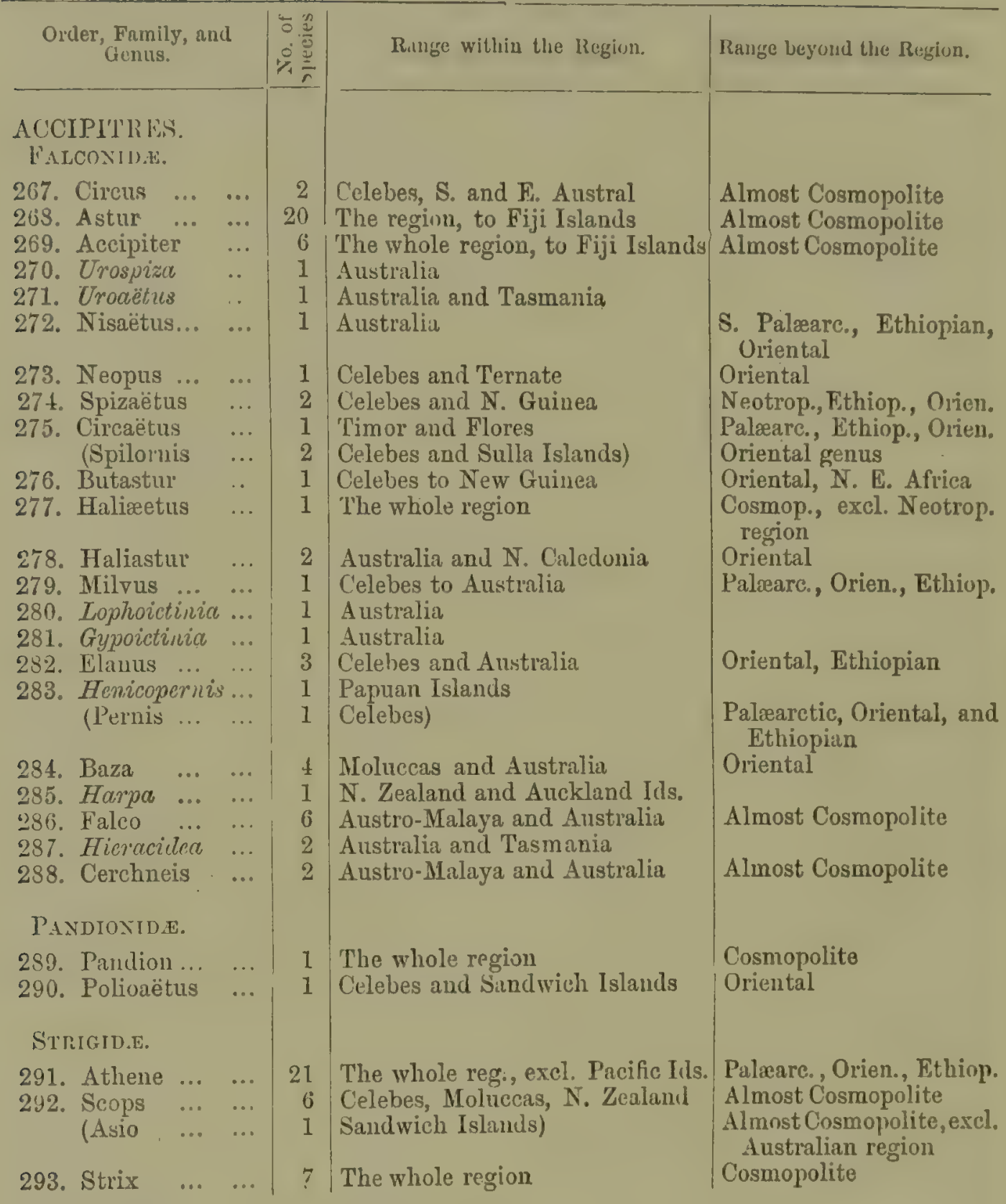

Peculizer or very Cheracteristic Gunera of Wading and Swimming Birds.

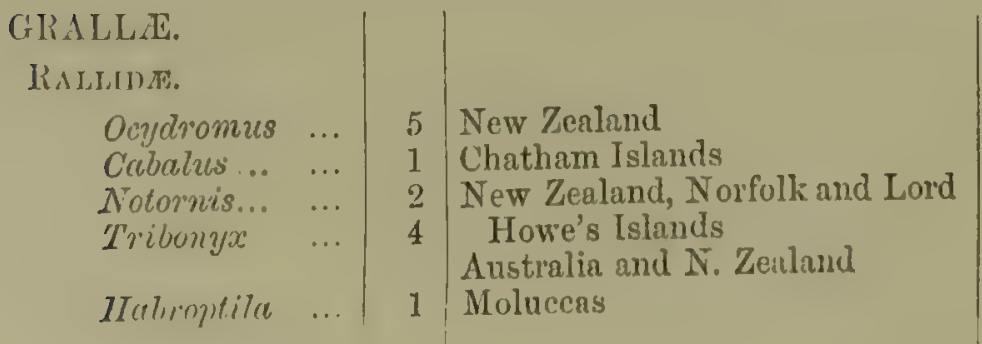




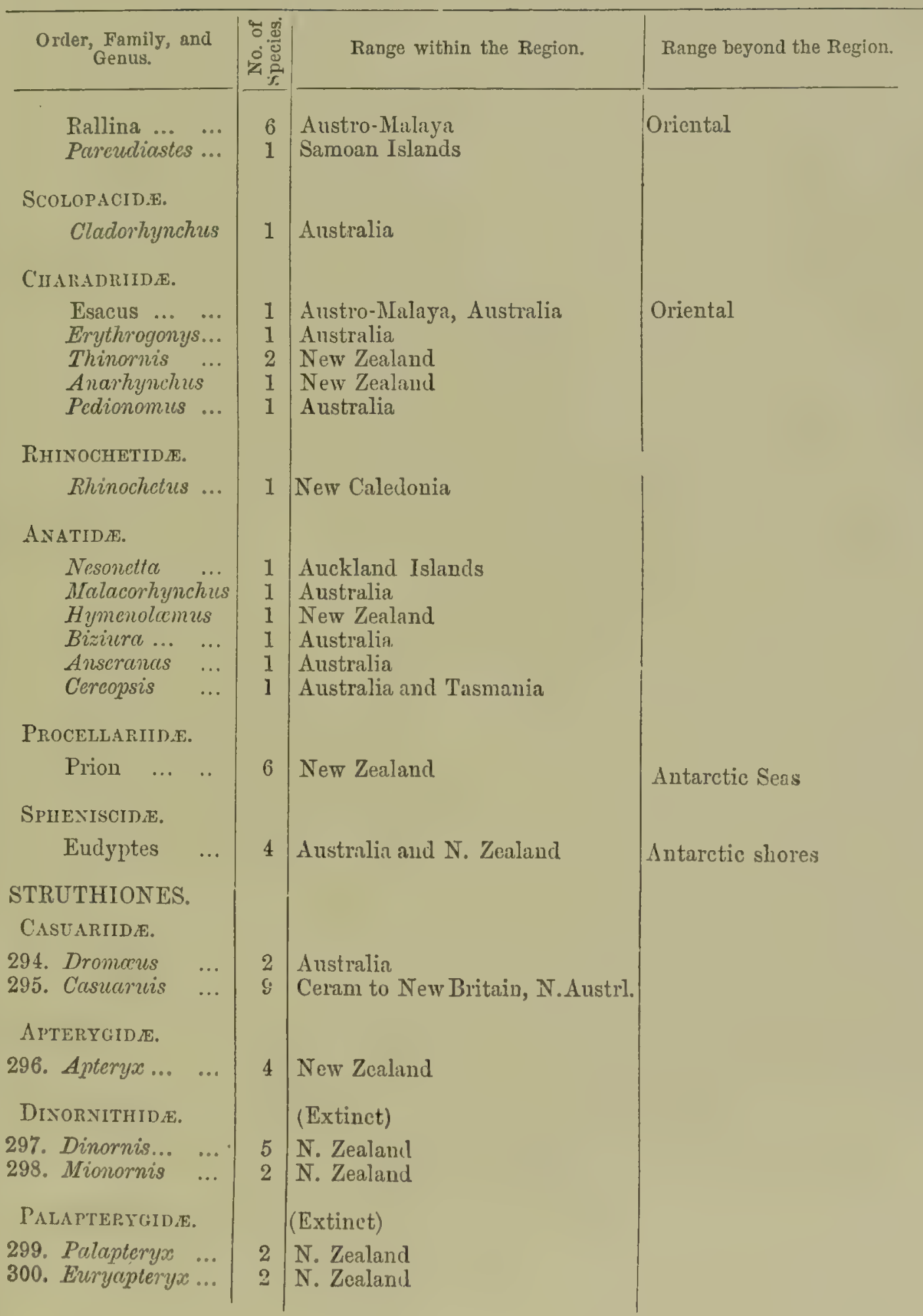



INDEX TO VOL. I. 



\section{INDEX TO VOL. I.}

Note. - In this Index the names in Italics all refer to fossil genera or families mentioned in Part II. The systematic names of genera and families occurring in almost every page of Part III. are not given, as they would unnecessarily swell the Index; but they can be readily referred to by the Class or Order, or by the Geographical Division (Region or Sub-region) under which they occur. They will, however, all be found in the General Index, with a reference to the page (in Vol. II., Part IV.) where a systematic account of their distribution is given.

A.

Aardvark of East Africa, figure of, 261 Accipitres, European Eocene, 163 Accipitres, classification of, 97 range of Palrearctic genera of $24 \mathrm{~S}$ range of Ethiopian genera of, 312 range of Oriental genera of, 385 range of Australian genera of, 486

Acerotherium, European Miocene, 119

N. American Tertiary, $130^{\circ}$

Achcenodon, N. American Tertiary, 138

Acotherium, European Eocene, 126

Adapis, European Eocene, 125

Flurogale, European Encene, 125

Apyornis, of Madagascar, 164

Ashna, from the Lias, 167

Agnopterus, European Eocene, 163

Agriochoerus, N. American Tertiary, 138

Agrion, from the Lias, 167

Alcephalus, Indian Miocene, 122

Aldabra Islands, land-tortoises of, 289

Aletornis, N. American Eocene, 163

Algeria, Post-Pliocene deposits and caves of, 111

en, Mr. J. A., on Zoological regions, 61 objections to his system of circumpolar zones, 67

objections to his zoo-gengraphical nomenclature, 68

Altai mountaina, fossils in caves, 111

Amblyrhiza, Pliocene of Antilles, 148

America, recent separation of North and South, 40

extinct mammalia of, 129

North, Post-Pliocene fauna of, 129

Amomys, $\mathbf{N}$. American Tertiary, 134

Amplechimus, European Mireme, 117

Amphibia, means of dispersal of, 28 classification of, 100

neculiar to Palaerctic region, 180 of Central Europe, 196

of the Mediterranean sub-recion, 205

of Siberian sub-region, 220
Amphibia, of the Manchurian sub-region, 226 table of Palrearctic families of, 237

of the Ethiopian region, 255

of West Africa, 264

South African, 268

of Madagascar, 280

table of Ethiopian families of, 298

of the Oriental region, 317

of the Indian sub-region, 326

of Ceylou, 327

of Indo-Chinese sub-region, 331

of Indo-Malay sub-region, 340

table of Oriental families of, 369

of the Australian region, 397

resemblances of Australian and South-

American, 400

of New Guinea, 416

of New Zealand, 457

A mphibos, Indian Miocene, 122

Amphicyon, European Miocene, 118

Indian Miocene, 121

N. American Tertiary, 134

Amphimericido, European Miocene, 119

Amphimoschus, European Miocene, 120

Amphisorex, European Miocene, 118

Amphitragulus, European Miocene, 120

Anastoma, European Tertiury, 16!)

Anchilophus, European Eocene, 125

Anchippodus, N. Auerican Eocone, 139

Anchippus, N. American Tertiary, 195

Anchitherida, N. American Tertiary, 135

Anchitherium, European Miocene, 119

European Eocene, 125

N. American Tertiary, 135

Ancient fauna of New Zealand, 459

Ancylotherium, Miocene of Greece, 116

European Miocene, 121

Anclaman Islarids, zoology of, 383

probable past history of, 334

Andreas, European Miorene, 165

Animal kingdom, primary divisions of, 85

Animals, development of, afrecting distribution, 7

clispersal and migration of, 10 
Animals, rapid multiplication of, 10 Anisccodon, N. Amerisin 'Tertiary, 137 Anoa of Celebes, neculiarities of, 428 Anoplotheriido, Eurnpean Miocene, 118 Anoplotherium, European Miocenc, 110

European Eocene, 126

8. American Eocene, 148

Anseres, arrangement of, 98

peculiar Palieretic genera, 250

neculiar Ethiopian genera of, 313 peculiar Australian genera of, 487

Antelopes in the Indian Miocene deposits, 122 birthplace and migrations of, $15 \overline{5}$ Palæarctic, 182

Antelotherium, Indian Mincene, 122

Anthracotherido, N. American Tertiary, 137

Anthracotherium, European Miocene, 119

Antiacodon, N. Ámerican Tertiary, 133

Antilles, Pliocene Marnmalia of, 148

Antilope, Post-Pliocene, 112 in Brazilian caves, 144

Antiquity of the genera of insects, 166 of the genera of land and freshwater shells, 168

Aphanapteryx of Mauritius, 164

Aphelotherinm, European Eocene, 125

Aquila, European Miucene, 161

Archoenpteryx, Bavarian Oolite, 163

Arctic zone not a separate region, 68

Arctocyon, European Eocene, 125

Arctodus; N. American Post-Pliocene, 130

Arctomys, European Pliocene, 113

Arctotheriun in Brazilian caves, 144

S. American Pliocene, 146

Argus pheasant, figure of, 339

peculiarity in display of plumage, and confirmation of Mr. Darwin's views, 340

Artioclactyla, European Eocene, 126

N. American Tertiary, 137

S. American Pliocene, 146

Arvicola, European Pliocene, 113

in Brazilian caves, 145

S. American Pliocene, 147

8. Anerican Eocene, 148

Auchena, N. American Post-Pliocene, 130

Auckland Islands, birds of, 455

Australia, physical features of, 387

Australia and S. America, supposed land connection between, 395

Australian region, description of, 387 zoological characteristics of, 390 mammalia of, 390

birds of, 391

reptiles of, 396

amphibia of, 397

fresh-water fish of, 397

summary of vertebrata of, 397

supposed land-connection of with \$. America, 398

insects of, 403

lepidoptera of, 404

coleoptera of 405

land shells of, 407

sub-regions of, 408

early histury of, 465

Anstralian aub-region, manmalia of, 438

illustration of mammalia of, 439

birds of , 440

illustration of fauna of, 44

Austro-Mnlayan sub-region, physical features of, 388 zoology of, 409

A ye-nye, figure of, 278

Azorcs, visited by European birds, 17 birds of, 207
A zores, butterflies of, 207

beetles of, 207, 208

peculiarly modified birds of, 207

stragglers to, 208

how stocked with animal life, 208

B.

Babirusa of Celebes, peculiarities of, 428

Badger, figure of, 195

Baloena, European Pliocente, 112

Bulunodon, European Pliocesie, 112

Baly, Mr., on Phytophaga of Japan, 230

Banca, its peculiar species and solution of \& problem in distribution, 356

Barriers, as affecting distribution, 6 permanence of, as uffecting distribution, 7 to the dispersal of birds, 17

Bates. Mr., on Carabidæ of Japan, 228 on Longicorns of Japun, 230

Bathmodon, N. American Tertiary, 136

Bathrodon, N. American Tertiary, 133

Batrachia, Tertiary, 165

Bats, powers of flight of, I5 classification of, 87 of New Zealand, 450

Bears, probable cause of absence of, from tropical Africa, 291

Beaver, N. American Tertiary, 140

Beetles, families selected for study, 103

from the Lias, 167

of Azores, 207

of Japan, 228

Belemnoziphius, European Pliocene, 112

Belt, Mr., his theory of a great siberian lake during the glacial epoch, 218

on change of climate caused by diminu. tion of obliquity of ecliptic, 466

Birds, means of dispersal of, 15 dispersal of by winds, 16

American, found in Europe, 16

reaching the Azores, 17

barriers to dispersal of, 17

limited by forests, 17

classification of, 93

Miocene of Greece, 116

extinct, 160

fossil of Palæarctic region, 161

European of Miocene period, 161

Eocene of Europe, 162

relations of, 162

extinct of North America, 163

recently extinct in New Zealand, 164

Cretaceous of N. America, 164

remains of in Brazilian caves, 164

recently extinct in Madagasear and the Mascarene Islands, 164

cosmopolitan groups of, 176

numerous genera, Palæarctic, 189

of the European sub-region, 193

northeru range of in Europe, 193

of the zone of pine forests, 194

of Iceland, 198

of the Mediterranean sub-region, 208

of Malta, 206 (note)

of Azores, 207

of the Cape Verd Islands, 215

of Siberian sub-region, 219

Oriental found in Siberia, 219

extrome northern ásiatic, 219

of northern Asiatic forests, 220

of the Manchurian sub-region, 223

Palaretic genera of, in the Manchurian sul)-regiuli, 22:'t 
Birds, Oriental genera of, in the Manchurian sub-region, 224

characteristic of N.W. China and Mongolia, 226

table of Palæarctic families of, 235

of West Africa, 243

list of Palearctic genera of, 243

of the Ethiopian region, 253

of the East African sulu-region, 260

S. African, 267

genera of, peculiar to Madagascar, 275

common to Madagascar and Oriental or

Ethiopian regtons, '276

species common to Madagascar and Africa or Asia, 277

table of Ethiopian fanilies of, 295

table of Ethiopian genera of, 306

of the Oriental region, 316

of the Indian sub-region, 323

Oriental genera of in Central India, 324

Palæarctic and Ethiopian genera in Central India, 325

of Ceylon, 327

of Indo-Chinese subr egion, 330

of Indo-Malayan sub-region, 337

illustration of peculiar Malayan, 339

of the Philippine Islands, 346

table of Oriental families of, 366

table of Oriental genera of, 375

of Australian region, 391

specially organized Australian families of, 392

of the Papuan Islands, 410

peculiarities of, 413

brilliant colour's of, 413

remarkable forms of, 414

of the Moluccas, 418

peculiarities of, 421

of Timor group, 423

of Celebes, 428

of Australia, 440

of New Zealand, 451

peculiar to New Zealand, 452

of Norfolk Island, 453

of Lord Howe's Island, 453

of the Chatham Islands, 454

of the Auckland Islands, 455

table of families of Australian, 471

table of genera of Austra]ian, 478

Black ape of Celebes, 427

Blanford, Mr. W. T., on the "Indian" region, 60

on relations of Indian sub-region with Africa, 321

Blapsinium, Oolitic insect, 167

Blyth, Mr, on zoological regions, 60

on the relations of Indian sub-region with Africa, 321

Borneo, probable recent changes in, 857

Bos, Post-Pliocene, 112

Indian Miocene, 122

Bourbon, zoology of, 280 reptiles of, 281

Bovidce, European Miocene, 120

Brachymys, European Miocene, 120

Brumatherium, Miocene of Perini Island, 122

Brazilian cave-fauna, 143 remarks on, 145

Breyeria borinensis, carboniferous insect, 168

Britain, peculiar species in, 197

British Isles, zoology of, 197

Broad-bill, Malayan, flgure of, 340

Brontotheridce, N. American Tertiary, 137

Brontotherium, N. American Tortiury, 137

Bubo, Turopean Miocene, 162

Bulimus, Eocene, 168
Buncelurus, N. American Tertiary, 134

Buprestidium, Oolitic insect, 167

Butterflies, arrangement of, 103

Palæaretic, 187

of Central Europe, 196

of the Mediterranenn sub-region, 205

of Azores, 207

peculiar to Siberian sub-region, 220

of Japan and North China, 227

of the Ethiopian region, 255 .

number of Ethiopian species, 256

of Indo-Malay sub-region, 342

of the Australian region, 404

of the Austro-Malay sub-region, 404

of the Moluccas, 419

of Celebes, peculiarities of, 434

of New Zealand, 457

\section{C.}

Cadurcotherium, European Eocene, 125

Calndon, in Brazilian caves, 145

Coelogenys, in Brazilian caves, 14

Conopithecus, European Eocene, 124

Cainotherium, European Miocene, 120

European Eocene, 126

Calamodon, N. American Eocene, 139

Callithrix in Brazilian caves, 184

Canaries, birds of, 208

beetles of, 209

Canido, European Miocene, 118

European Eocene, 125

N. American Tertiary, 134

remarkable S. African, 267

Canis, European Pliocene, 112

Post-Pliocene, 112

European Miocene, 118

Indian Miocene, 121

European Eocene, 125

N. American Post-Pliocene, 129

N. American Tertiary, 134, 135

in Brazilian caves, 144

S. Araerican Pliocene, 146

Camel, fossil in Indian Miocene, 122

birth-place and migrations of, 155 Palæarctic, 182

Camelido, essentially extra-tropical, 112

$\mathrm{N}$. American Tertiary, 138

Cumelopardatis, Miocene of Greece, 116 Indian Miocene, 122

Camelotherium, S. American Pliocene, 147

Cape of Good Hope, peculiar flora and fauna of, 266

Cape Verd Islands, zoology of, 214

Cape-hare, S. African, 267

Cardiodus, S. American Pliocene, 147

Cariama, Brazilian caves, 164

Carnivora of Enropean Pliocene, 112

Miocene of Greece, 115

European Miocene, 118

Indian Miocene, 121

European Eocene, 125

N. American Post-Pliocene, 129

N. American Tertiary, 134

of Brazilian caves, 144

S. American Pliocene, 146

Carnivore, classiflcation of, 88 antiquity of, 153

of the Palxaretic region, 182

list of Paluarctic genern of, 240

list of Ethiopian genera of, 302

range of Oriental genera of, 873

list of Australian genern of, 470

Caroline Islands, birds of, 444

Carterodon in Brazilian caves, 145 
C'arus, nud Gerstiteker on chussilicution of inimals, 85

Professor, on classification of the Cutaner, 88

C'ostor, European Pliomene, $11:$

Eurole:an Miocenc, 1:20

rasmyx, N. American Tertiary, 13s

Cathortes, Brazilian caves, $16 t$

Cave-fatuna of Brazil, 14:3

Cuvia, European Miocene, 121

in Brazilian caves, 144

S. American Pliocene, 147

('cbocharus, Enropean Eurenc, 1:13

C'ebus in Brazilian cares, 144

Celebes, plysical features of, 389

mammalia of, 420

birds of, 428

insects of, 434

orivin of fauna of, 436

Centetida, European Miocene, 118

Ceratodus, remarkable dustralian fish, 397

Cercolrubes in Brazilian caves, 14;

Cercopithecus in European Pliocene, 112

Cervide, European Miocene, 120 birth-place and migrations of, 155

Cervis, European Pliocene, 113

Indian Pliocene and Miocene, 122

N. American Post-Pliocene, 130

N. American Tertiary, 138

in Brazilian caves, 144

S. American Pliocene, 147

Cetacea, Eurovean Pliocene, 112

European Miocene, 119

N. Auterican Post-Pliocene, 130

$\mathbf{N}$. American Tertiary, 140

Cetacea, classification of, 89 range of Oriental genus, 374

Ceylon and Malaya, resemblance of insects of, 3.27

Ceylonese sub-region, 326

mammalia of, 327

hirds of, 327

reptiles of, 327

amphibia of, 327

insects of, 327

past history of, as indicated by its fauna, 328

Chaticomys, European Pliocene, 113

Chalicotherium, European Miocene, 119

Indian Mincene, 122

fossil in N. China, 123

Chamceleo, N. American Eocerse, 165

Chamois, figure of, 195

Chatham Islands, birds of, 454

Cholonia classification of, 100

Chelydra, European Pliocene, 165

Chevrotain of Malaya, figure of, 336

Chili should not be placed in the Palaaretic or Nenretic regions, 63

China, fossil mammals in, resembling those of Indian and European Mivcene, 362 North mammalir of, 22:

Chinchillidoe in Brazilian caves, 145

S. American Pliocene, 147

Pliocene of Antilles, 148

Chirontera, classification of, 87

list of Palearctio genern of, 239

list of Ethiopian genera of, 300

range of Oriental genera of, 371

list of Australian genera of, 475

Chiroptera, Eurnpean Encene, 125

in Brazilian caves, 144

Chlamydotherium in Brazilian caves, 145

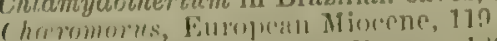

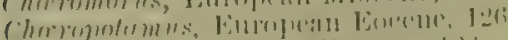

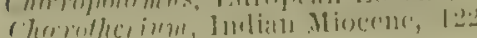

Choneziphius, European Pliocene, 112

Chough, Alpine, flgure of, 19.5

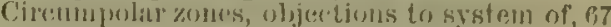

Classiflertion as affecting the study of distrihution, sis

rlonsilir, Eurne, 169

Climate, as a limit to the range of mammalia, 11

gradual change of, before the Glacial epoch, 41

Colenptera, families selected for study, 103

Palaxaretic, 188

number of Palarearetic species, 189

of Central Europe, 196

of the Mediterranean sub-region, 205

of the Cano Verd Islands, 215

of the Ethiopian region, 250

S. African, 268

of Madagascar, 282, 283

of the Oriental region, 319

of Indo-Malay sub-region, 342

of the Australian region, 405

affinity of Australian and South Anerican, 406,407

of Celebes, 435

of New Zealand, 457

Collocalia, European Miocene, 161

Colobus, European Miocenc, 117

Colonoceras, N. American Tertiary, 136

Colossuchelys of Indian Miocene, 123, 165

Colun bx, classification of, 96

range of Palæarctic genera of, 248

range of Ethiopian genera of, 311

range of Oriental genera of, 184

range of Australian genera of, 485

Comoro islands, zoology of, 281

Cuntinents, distribution of, 37 recent changes of, 38

Continental extension in Mesozoic times, 156

Corvus, liropean Miocene, 101

Comphidon, European Eocene, 126

Cosmopolitan groups enumerated, 155

Cricetocion European Miocene, 120

Cricetus, European Fliocene, 113

Crocodiles, Eocene, 165

Crocodilia, classilication of, 100

Crook-billed plovers of New Zealand, 456

Croteh, $\mathrm{Mr}^{2}$, on beetles of the Azores, 209

Crowned-pigeon, figure of, 415

Cryptornis, European Eocene, 163

C'enomys, S. American Pliocene, 147

Cuba, extinct mammalia of, 148

Curculionidium, Oolitic insect, 167

Cuclostoma Eocene, 168

Cyllo sepulta, European Cretaceous, 167

Cyncelurus, in Brazilian caves; 144

Cynovithecus of Celebes, affinities of, 427

Cyotherium, European Eocene, 125

\section{D.}

Tentonzilus, N. American Tertiary, 134

Daro his explanation of the canse of the abundnnce of apterous insects in Madeira, 211

on the relation of flowers and insects, 468

Jasyprocte, European Miocene, 121 in Brazilian caves, 144

Dasypus, in Brazilian caves, 145

\$. American Pliocene, 147

Dosyurus, Anstralian Pust-Tertiary. 15h

David, Pire, his rescarehes in China and Thi. het, 221,222

on birds of $\mathrm{N}$. Chinn, 220 
Deer, fossil in N. American Tertiary formations, 13s

Pals:arctic, 18:

prohable cause of absence of from tropical Africa, 291

Delphinus, European Pliocene, 112

De'ulrocygna, Eunouean Miocene, 162

Desman of S. Russia, figure of, 219

Diceratherinm, N. American Tertiary, 137

Dichobune, European Eocene, $126^{\circ}$

Dicotyles, N. American Post-Pliocene, 130

N. Amerisan Tertiary, 137 .

in Brazilian caves, 144

S. American 'Pliocene, 146

birthpluce and migrations of, 155

Dicrocerus, Enropean Miocene, 120

Didelphys, European Eocene, 126

N. American Post-Pliocene, 130

in Brazilian caves, 145

Didido, 164

Dinocerata, N American Tertiary, 139

Dinoceras, $\mathbf{N}$. American Eocene, 139

Dinoruis, allied form in Eurnpean Eocene, 163 of New Zealaud and Australia, 164

Dinornithide of New Zealand, 164

Dinotherium, Miocene of Greece, 116 European Miocene, 120

Mincene of Perim Island, 123

Dinyctis, N. American Tertiary, 134

Dinylus, European Miocene, 117

Diplacodon, N. American Tertiary, 130

Diprotodon, Australian Pust-Tertiary, 157

Dispersal of auimals, 10

of manimalia, 10

of reptiles and amplibia, 28

Distribution, affected by climate, 5 affected by physical features, 5 contrasts of, in similar climates, 5 similarities of, in diverse climates, 6 brrriers as affecting, 6

study of, dependent on a good classification, 83

of animals an adjunet to geology, 8

of animals requires certain preliminary studies, 8

of animals dependent on physical geograpliy, 35

of animals, as affected by the glncial epoch, 40

of animals, as affected by changes of vegetation, 43

of animals, as affected by organic changes, 44

of animuls, hypothetical illustration of, $46^{3}$

of animals, complexity of the causes affeet ing the, 4.3

of animals, problems in, 51

of plants, as affected by the glacial epoch,

Dodo of Maruitius, 282

Dolichopterus, European Miocene, 162

Dommina, N. Aunerican Tertiary, 134

Dorcutherium, European Miocene, 120

Drenotherinm, Mincene of Grcece, 116 European Miocene, 120

Dresser, Mr. H. E, on northern range of European birds, 193

Dromutherium, N, American Triassic, 134

chlest Antrienm minmul, 160

ngo-shrike, Malayan figme of 840

opilhecus, Eurnjean Miocene, 117
E.

East Africa, geographical features of, 258 wide range of genera and species over, 259 few special types in, 260

East African sub-region, description of, 258 genera and species rangiug over the whole of, 259

mammalia of, 260

birds of, 260

reptiles of, 260

auphibia and fishes of, 260

insects of, 260

few peculiar types in, 260

illustration of zoology of, 261

Enst Australia, peculiar birds of, 440

Eust Thibet, mammalia of, 222

Eaton, Rev. A. Ei, ou insests of Kerguelen Island, 211

Echimyida, in Brazilian caves, 145

Echinogale, European Miocene, 118

Eotognothus, N. American Eocene, 139

Edentata, Miocene of Greece, 116

Europenu Miocene, 121

N. Ainerican Post-Pliccene, 130

N. American Pliocene, 140

of Brazilian caves, 145

S. American Pliocene, 147

Edentata, classification of 90

probable birthplace of, 155

ringe of Ethiopian genera of, 305

range of Oriental genus of, 375

Elephants, fossil of Indian Mincene, 123 fossil in N. Anterican Post-Pliocene formations, 130

birthplace and migrations of 155

Elephaut shrews, S. African, 267

Elephas, Post-Pliocene, 112

fussil in $\mathbf{N}$. China, 123

N. American 'lertiary, 138

Elliot, Mr, his great work on the birds ? paradise, 415

Elornis, Eurovean Miocene, 162

Elotherium, N. American Tertiary, 137, 139

Elwes, Mr., on birds of Persia, 204

on true relations of the birds of Central India, 323

Enbasis, N. American Tertiary, 134

Emu, figure of, 441

Emys, Indian Miocene, 123

Miocene and Eocene, 165

Emydida, Indian Miocene, 123

Enhydrion, Indian Miocene, 121

Eobcusileus, N. American Eoceme, 139

Éocene periorl, 124

fauna of S. Ainerica, 148

Ephemera, from the Lias, 167

Eporeodon, N. American Tertiary, $13 \mathrm{~S}$

Equidre, Europesn Pliocene, 112

Miocene of Greece, 115

European Eocene, 125

Ëquns, European Pliocene, 112

Post-Pliocene, 112

Indian Miocenc, 121

N. Amorican Post-Pliocene, 130

N. American T'ertiary, 135

Brazilian eaves, 144

S. Arrerican Pliocone 146

Freptodon, N. American Post.Pliocene, 130

Lrinacens, European Miocene, 117

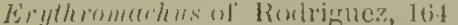

Esthonyx, N. American Wocene, 139

Ethiopian region should not iuclude any part (if furlial, 6:

defined, 7 ,

sillulivisimus ol, $7:$ 
Ethiopian region, general fentures of, 251

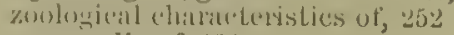
mammalia of, 253

grent speciality of, 253

birds of, 253

reptiles of, 254

amphibia of, 255

fresh-water fish of, 255

summary of vertebrates of, 255

insects of, 255

coleoptera of, 256

terrestrial mollusea of, 257

sub-regions of, 258

Atlantic islands of, 269

the probable past history of, 285

tables of distribution of animals of, 293

Eumys, N. American Tertiary, 140

Euphractus, S. Americnn Pliocene, 147

Europe, recent changes in physical geography of, 39

Miocene fauna of Central, 117 .

Miocene fauna of, allied to existing fauns of tropical Asia and Africa, 124

European sub-region, description of, 191 forests of, 192

mammalia of, 192

birds of, 193

reptiles and amphibia of, 195

fresh-water fish of, 196

insects of, 196

islands of, 197

Euryceros of Madagascar, figure of, 278

Furydon, in Brazilian caves, 145

Eurytherium, European Eocene, 126

Eutatus, S. American Pliocene, 147

Eutelodon, European Eocene, 126

Eutemnodus, S. American Eocene, 148

Extinct mammalian fauna of Europe, general considerations on, 126

mammalia of $\mathbf{N}$. America and Europe, comparison of, 140

mammalia of the Antilles, 148

mammalia of Old and New Worlds, general remarks on, 148

fauna of New Zealand, 459

Extinction of large animals, causes of, 158

\section{F.}

Fauna of Japan, general character and aflinities of, 230

of Palæarctic region, general conclusions as to, 231

extinct, of Madngascar and Mascarene Islands, 282

Malayan, probable origin of, 359

Moluccan, peculiarities of, 419

Timorese, origin of, 422

of Celebes, origin of, 436

of New Zealand, origin of, 460

Felis spelcea, 110

Felis, Miocene of Greece, 115

European Miocene, 118

Indian Miocene, 121

N. American Post-Pliocene, 129

in Brazilian caves, 144

Fernando Po, zoological fertures of, 265

Fiji, Tonga, and Samon Islands, birds of, 443

Fishes, means of dispersal of, 28

classification of, 101

cosmopnlitan groups of, 176

of the Pnlearctic region, 180

of the European sub-region, 196

of the Mediterranean sub-region, 205

of the Manchurian sub-region, 227
Fishes, fresh-water, table of Palrearctic families of, 227

of the Ethiopian region, 255

of South Africa, 208

fresh-water, table of Ethiopian families of, 298

fresh-water, of the Oriental region, 318

of the Indo-Malay sub-region, 341

fresh-water, table of Oriental families of, 369

fresh-water, of the Australian region, 397 fresh-water, resemblance of Australian and S. American, 400

how the transmission may have taken place, 401

fresh-water, of New Zealand, 457

Flamingoes, European Miocene, 162

Flor, of New Zealand, as influenced by scarcity of insects, 462

fossil of Australia, 467

Flower, Professor, on classification of manmalia, 85

classification of camivora, 87

Flying Lemur, Malayan, figure of, 337

Flying Opossum, figure of, 442

Formosa, zoology of, 332

Forests, essential to existence of many European animals, 192

Siberian, greatest extent of, 216

G.

Galapagos, scarcity of insects in, 463

Galecynus, in European Pliocene, 112

Grlera, N. American Post-Pliocene, 130

Galeospalax, European Miocene, 118

Galeotherium, Post-Pliocene, 111

Galethylax, Europern Eocene, 125

Galictis, in Brazilian caves, 144

Gallinæ, classification of, 96

range of Palæarctio, genera of, 248

range of Ethiopian genera of, 511

range of Oriental genera of, 384

range of Australian genera of, 485

Gallus, Miocene of Greece, 116

Gallus bravardi, European Pliocene, 161

Gastornis, Eurnpean Eocene, 163

Genera common to Post-Pliocene and Pliocene faunas of N. America, 132

Geological history of Oriental region, 362

Gibraltar, cave fauna of, 114

Glacial epoch, as afferting the distribution of animals, 40

as a cause of the great change in the fauna of the temperate zones, since Pliocene times, 151

probably simultaneous in both hemispheres, 151

causing a general subsidence of the ocean, 152

Glandina, Eocene, 169

Glossotherium, in Brazilian caves, 145

S. American Pliocene, 147

Glyptodon, S. American Pliocene, 147

Gnothopsis, S. American Pliocene, 147

(ivils, Palandretic, 1s:

Godman, Mr., on Natural History of the Azores, 207

Golden Moles, S. African, 207

Graculourus, N. American Cretaceous, 164

Giallix, arrangement of, 97

peculiar or characteristic Palocarctic genera, 249

peculiar thiopian genera of, 313 
Grallæ, peculiar Oriental genera of; 386 peculiar Australian genera of, $480^{\circ}$

Gray, Dr. J. E., on classification of Cetacea,88

Greecs, Upper Miocene deposits of, 115 summary of Miocene fauma of, 116

Groups peculiar to a region, how defined, 184

Gulick, Rev. J. T., on Achatinellides of the Sandwich Islands, 446

Günther, Dr., his classification of reptiles, 98 his classification of fishes, 101 on gigantic tortoises of Galapagos and the Miscarene Islands, 289 .

on range of Indian reptiles in the Himalayas, 329

\section{H.} Haast, Dr., on extinct birds of New Zealand,

Habitat, defnition of, 4

Hainan, zoology of, 334

Halcyornis, European Eocene, 103

Halitherium, European Pliocene, 112

Europeun Miocene, 119

Helladotherinm, Miocene of Greece, 116 European Miocene, 120

Fatteria of New Zealand, 456

Helictis, Himalayan, figure of, 331

Helix, Eocene, 169

Hemibns, Indian Miocene, 122

Hemicyon, European' Miocene, 118

Herpetotherium, N. American Tertiary, 134

Hesperonys, N. American Tertiary, 140

in Brazilian caves, 145

S. American Pliocene, 147

Hesperornis, N. American Cretaceous, 164

Heterodon, in Brazilian caves, 145

Hexaprotodon, Indian Miocene, 122

Hickman, Mr. John, on a cause of the extinction of large animals, 158

Himalayas, altitude reached by various groups in the, 329,333

Hipparion, European Pliocene, 112

Miocene of Greece, 115

European Miocene, 119

N. American Post-Pliocene, 130

N. American Tertiary, 135

Hippopotamus, Post-Pliocene, 112

Europe «n Pliocene, 113

Indian Pliocene, 122

Hipposyus, N. American Tertiary, 133

Hippotherium, European Miocene, 119 Indian Miucene, 122

Hippotragns, European Miocene, 120

Homalodontotherium, S. American Pliocene, 146

Homalophus, European Mincene, 161

Homocamelus, N. American Tertiary, $13 \mathrm{~s}$

Honeysuckers, birds specially adapted to Australia, 392

Hooker, Dr., on deficiency of odours in New Zealind plants, 464

Hoplocetus, Europenn Pliocene, 112

Hoplophoneus, N. American Tertiary, 134

Horses, fossil, in Indian Miocene, 121 perfect series of ancestral, in N. America, 136 probable hirthplace of, 154

Hutton, Capt. F. W., on origin of New Zealand fnunณ, 461

Huxley, Professor, on zoological regions, 59 division of animal kingdom by, 85

Hycena, Post-Pliocene, 112

Miocene of Greece, 115

European Mioceno, 118
Hycena, Indian Miocene, 121 fossil in $\mathbf{N}$. China, 123

Hycenxrctos in European Pliweene, 112 European Miucene, 118

Indian Miocene, 121

S. American Pliocene, 146

Hycenictis, Miocene of Greece, 115 European Miocene, 118

Hycenidee, European Miocene, 118

Hycenodon, European Miocene, 118 European Eocene, 125

N. American Tertiary, 134

Hyonodontidce, European Miocene, 118

Yydrochnerus, $\mathbb{N}$. American Pnst-Pliocene, 130

Hydrornis, European Miocene, 162

Hyohippus, N. American Tertiary, 135

Hyomoschis, European Miocene, 120

Hyopotamus, European Miocene, 119 N. American Tertiary, 137

Hyopsodus, N. American Tertiary, 133

Hyotherium, European Miocene, 119

Hypertragulus, N. American Tertiary, $13 \mathrm{~s}$

Hypisodus, N. American Tertiary, 138

H "psiprymnus, Australian Post-Tertiary, 157

Hyrachyus, N. American Tertiary, 136

Hyracodon, N. American Tertiary, 136

Hyracoidea, classification of, 90

Palaarctic, 242

Ethiopian, 304

Hyracotherium, supposed, in European Eo. cene, 125

European Eocene, 126

Bystrix, European Pliocene, 113

Miocene of Greece, 116

N. American Tertiary, 140

I.

Ibillipodic, European Miocene, 162 ;

Ibidorhynchus, figure of, 331

Iceland, zoology' of, 198

Icthyornis, N. American Cretaceous, 164

Icticyon in Brazilian caves, 144

Ictitherium, Miocene of Greece, 115

European Miocene, 118

Ictops, N. American Tertiary, 133

India, Miocene fauna of, allied to that of Eurove, 123

geological features of, 328

Indian, sub-region, description of, 321

supposed relation to Ethiopian region, 321

mamnalia of, 322

birds of, 323

reptiles and amphibia of, 326

Indo-Chinese, sub-region, description of, 329

zoological characteristies of, 330

illustration of, 331

reptiles of, 331

amphibia of, 331

insects of, 332

islands belonging to, 333

Indo-Malayan sub-region, description of, 331

mammalia of, 336

illustrations of, 336,339

birds of, 337

remote geographical relations of, 339

reptiles and amphibia of, 340

fishes of, 341

insects of, 341

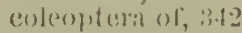

terrestrial mollusen of, 843

zoological relations of islands of, 345

recent geographical chnnges in, 357

probable origin of fauna of, 359

Inscets, means of dispersal of, 32 
Insects, tenacity of life of, 33

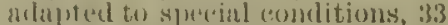

gromins selected for the study of thein geuraty hical distribution, 102

antiquity of the genera of, 160

fussil of Europern Miocene, 160

European Cretaceous, 167

European Wenlclen, 167

Pillituzois: 16 is

Pallaretir, 187

of Central Europe, 196

of the Mediterranean sub-region, 205

of the Siberian sub-region, 220

of the Manchurian sub-region, 227

of the Ethiopian region. 255

of the East African sub-region, 260

of West Africa, 265

S. African, 268

of Madagascar, 282

general remarks on, 284

of tropical Africa and America, probable

cause of similarities in, 291

of Indo-Chinese sub-region, 332

of the Oriental region, 318

of Ceylon, 327

of Indo-Malay sub-region, 341

statistics of collecting in the various

islands of the Malay Archipelago, 34:

of the Australian region, 403

of New Guinea, 417

of the Moluccis, 420

of Timor group, $420^{\circ}$

of Celebes, 454

of New Zealand, 458

scarcity of, in New Zealand, 462

influence of on the flora, 463

Insectivora, European Miocene, 117

N. American Post-Pliocene, 129

N. American Tertiary, 133

Insectivora, classification of, 87

of the Palrearctic region, 181

4. of N. China and E. Thibet, 222

range of Palaarctic genera of, 239

of Madagascar, 273

raucre of Ethiopian genera of, 301

of the Oriental region, 315

range of Oriental genera of, 372

pance of Australian genera of, 476

Isacis, N. American Tertiary, 133

Ischyromys, N. American Tertiary, 140

Islands, N. European, zonlogy of, 197

of the Mectiterranenu sub-region, 206

of the West African sub-region, 265

of Ethiopian region, 269

Mascarene, 280

of the Indo-Chinese sub-region, 333

of Indo-Malay sub-region, 345

Fiji Tonga, and Samoa, 44:

Society and Marquesns. 444

New Caledonia and New Hebricles, 445

Sandwich, 446

of New Zealand sub-region, 453

Norfolk, 453

Lord Howe's, 454

Chatham, 454

Auckland, 455

Issiodromys, European Pliocene, 113

J.

Jaccius, in I3razilian caves, 144

Japan and North China, yhysical features of,

221
southem extremity of perhaps bolongs to thu Orinutal region, 206
Japan, general claracter of the fauna of, 230 former land-ismurxious of, 231

Java, mammalia of, 34!

productions of, well known, 350

birds of, 351

representative species of birds in, 352

origin of the anombalous features of its fauna, 352

Sumatra and Borneo, their geographical contrasts and zoological peculiarities explained, 357

Junonia, European Miocene, 107

\section{K.}

Kakapoe, of New Zenland, 455

Kangaroos, extinct in Australia, 157

Kerguelen Island, apterous insects of, 211 (note)

Kerodon, in Brazilian uaves, 144

S. Annerican Pliocene, 147

King-fisher, racquet tailed, of New Guinea, figure of, 415

Kiwi of New Zealand, 455

Koodoo antelope, figure of, 261

\section{L.}

Lacertilia, classification of, 92

Ladrone Islands, birds of, 444

Lagomys, European Pliocene, 113 European Miocene, 120

Lagosiomus, in Brazilian caves, 115

S. American Pliocene, 147

Lake Baikal, seals of, 218

Land and water, proportions of, 35

Land and fresh-water shells, antiquity of the genera of, 168

Land-shells, Palæozoic, 169

Palæarctic, 190

of Madeira, 209

of the Cape Verd Islands, 215

of the Ethiopian region, 257

of W. Africa, 265

of Madagascar and the Mascarene Islands, 285

of Indo-Malay sub-region, 344

of the Australian region, 407

of Sandwich Islands, 446

of New Zealand, 459

Zanius, European Miocene, 161

Laopithecus, $\$$.American Tertiary, 133

Laomis, N. American Cretaceous, 164

Lemuria, a hypothetical land, 76

Lamuravide, N. American Tertiary, 133

Lemuravus, $\mathbf{N}$. Anerican Tertiary, 133

Lemurido, European Eocene, 124

Lenuroidea, range of Ethiopian genera of, 300 range of Oriental genera of, 371

Lepictis, N. American Tertiary, 133

Lepidoptera, cosmopolitan families of, 177

table of Palaractic fumilies of, $23 \mathrm{~s}$

8. African, 208

talile of Ethiopian families of, 299

of the Oriental region, 318

table of Oriental families of, 369

of the Australian region, 404

table of Australian families of, 472

Lentarchus, N. American Tertiary, 195

Leptanchenia, N. American Tertiary, 138

Leprocherts, $\mathbf{N}$. Auterienn Tertiary, 137

T.eptodon, Miocene of Greece, 116

I.eptomemp, N. American Tertiary, 138

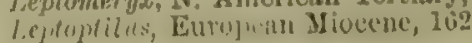


Leptosomus, allied form in European Encene, 168

Leptosolsus of Madiggascar, 2is figure of, 279

Leptotherium, in Brazilian caves, $14 \pm$

Lepus, in Brazilian caves, 145

S. American Pliocene, 147

Lestodon, \$. American Pliocene, 147

Lewis, Mr. George, his collection of Japan insects, 228

Lebellula, from the Lias, 167

Lilljeborg, Professor, on classification of the Rodentia, 90

Limneed, Eocene, 169

European Secondary, 169

Limnatornis, European Miocene, 161

Limnocyon, N. American Tertiary, 134

Limnohyus, N. American Tertiary, 136

Limnotheride, $\mathbf{N}$. American Tertiary, 133

Limnotherium, N. American Tertiary, 133

Listriodon, European Miocene, 119

Lithomys, European Miocene, 120

Lithornis, European Eocene, 163

Lizards, classification of, 99

Tertiary, 165

wide range of a species in Polynesia, 448

Loncheres, in Brazilian caves, 145

Lonchophomes, in Brazilian caves, 145

Lophiodon, European Eocene, 12.5

N. American Tertiary, 136

Iophiotherium, N. American Tertiary, 136

Lord Howe's Island, bircls of, 453

Loxomylus, Pliocene of Antilles, 148

Lund, Dr., his researehes in caves of Brazil, 143

Lutra, European Miocene, 118 Indian Miocene, 121

Lyccend, Miocene of Greece, 115

Lyre-bird, figure of, 441

M.

Macacus, European Pliocene, 112

Miocene of Greece, 115

Indian Miocene, 121

supposed in European Eocene, 125

Machairodus, 110, 111

Miocene of Greece, 115

European Miocene, 118

Indian Miocene, 12]

N. American Tertiary, 134

in Brazilian caves, 144

S. American Pliocene, 146

Macranchenia, S. American Pliocene, 146

Macrotherium, Miocene of Greece, 116 European Miocene, 121

Madagascar, extinct birds of, 164

description of, 272

mammalia of, 272

birds of, 274

reptiles of 2 \% 9

amphibia of, 280

extinct fauna of, 282

general remarks on insect fuuna of, 284

Madeira, birds of, 208

land shells of, 208

beetles of, 210

wingless insects numerous in, 211

how stocked with animals, 219

Malacea, Sumatra, and Borneo, zoological urity of 353

comparigon of maminalia, 354

of birds, 355

Malagnsy sub-region, description of, 272

mammalia of, :

birds of, 274

illustration of zoology of, 278
Malagasy sub-region, reptiles of, 2 \% 9

amphibia of, 280

extinct fauna of, 282,289

insects of, 282

early history of, 286

Malaya and Indo-Malaya, terms defined, 345 (note)

Malavan forms of life reappearing. in West Africa, 263

fauna, probuble origin of, 359

resemblances to that of Madagascar aud Ceylon explained, 361

Malta, Post-Pliocene fauna of, 114

formerly joined to $\Delta$ frica, 201

fossil elephants of, 201

birds of, 206 (note)

Mammalia, means of dispersal of, 10

as limited by climate, 11

as limited by rivers, 12

how far limited by the sea, 13

dispersed by ice-floes and drift-wood, 14

means of dispersal of aquatic, 15

of most importance in determining zoo-

logical regions, 57

classification of 85

birthplace and migrations of some families of, 142,153

cosmopolitan groups of, 176

of the Palæarctic region, 181

of the European sub-region, 192

of the Mediterranean sub-region, 202

of the Siberian sub-region, 217

characteristic of Western Tartary, 218

of the Manchurian sub-region, 222

Palæaretic genera of, in the Manchurian sub-region, 222

Oriental genera of, on borders of same sub-region, 223

peculiar to Japan, 223

characteristic of N. W. Chins and Mongolia, 226

table of Palæarctic families of, 234

range of Palxarctic genera of, 239

of the Ethiopian region, 253

absence of certain important grouns, 253

of the East African sub-region, 260

of West Africa, 262

of $\mathbf{S}$. Africa, 267

of Madagascar, 272

table of Ethiopian families of, 294

table of Ethiopian genera of, 300

of the Oriental region, 315

range of the generd inhabiting the Indian sub-region, 322

of Ceylon, 327

of the Indo-Chinese sub-region, 330

of the Indo-Malayan sub-region, 336

illustration of characteristic Malay an, 336

of the Fhilippine Islands, 345

table of Oriental families of, 365

table of Oriental genera of, 371

of Australian region, 390

of the Papuan Islands, 410

of the Molnceas, 417

of Timner groul, 422

of Celebes, 427

of Australia, 439

illustration of, 439

of New Zealand, 450

iable of families of Australinn, 470

table of genera of Australian, 475

Mammal, the most ancient American, 134

Mammatia, extinct, of Old World, 107

extinct, of historic reriod, 110

extinct, comparative age of in Eurouge, 127

K K 
Mammalice extinct, of the New World, 129 extinct, of N. America and Europe, compared, 141

original birth place of some families and genera, 342, 153

of the secondary period, 160

Manatus, N. American Post-Pliocene, 130

Manchurian sub-region, description of, 220 mammalia of, 222

birds of, 223

reptiles and amphibia of, 227

fresh-water fish of, 227

insects of, 227

coleoptera of, 228

Marquesas Islands, birds of, 443

Marsh, Mr., on improvability of Asiatic and African deserts, 200 on camels and goats as destructive to vegetation, 200

Marsupials, classification of, 91

N. American Post-Pliocene, 130

European Miocene, 121

first migration to America, 155

diversified forms of, 391

of America prove no connexion with Australia, 399

list of Australian genera of, 476

Martes, N. American Tertiary, 135

Mascarene Islands, zoology of, 280

extinct fauna of, 282

gigantic land-tortoises of, 289

Mastodon, European Pliocene, 113

Miocene of Greece, 116

European Miocene, 120

in Brazilian caves, 144

S. American Pliocene, 147

Indian Miocene, 123

N. American Post-Pliocene, 130

N. American Tertiary, 138

Mauritius, zoology of, 280 reptiles of, 281

McCoy, Professor, on Palæontology of Victoria, 466

Mediterranean, recent changes in, 39 sub-region, description of, 109 mammalia of, 202

birds of, 203

reptiles and amphibia of, 204

fresh-water fish of, 205

insects of, 205

islands of, 206

sea not separating distinct faunas, 201

Megacerops, N. American Tertiary, 137

Megalomeryx, N. American Tertiary, 138

Megalocnus, fossil in Cuba, $14 \mathrm{~S}$

Megalonyx, N. American Post-Pliocene, 130

in Brazilian caves, 145

S. American Pliocenre, 147

Megalostomx, Eocene, 169

Megamys, S. Ainerican Eocene, 148

Meguspira, European Tertiary, 169

Megatherido, in Brazilian caves, 145

Megatherium, N. Am rican Pust-Pliocone, 130

in Brazilian caves, 145

S. Ainsrican Plivcene, 147

Melania, European secondary, 169

Meleagris, N. American Miocene, 183

Mellivora, Indian Miocene, 121

Melolonthidium, Oolitic insect, 167

Meniscotherium, N. American Tertiary, 138

Menotherium, N. American Tertiary, 183

Mephitis, in Brazilian caves, 144

Merycius, N. American Tertiary, 188

Merychippus, N. American Tertary, 135

Merychocheeries, N. American Tertiary, 138

Merycodus, N. American Tertiary, 138
Merycopotamus, Indian Miosene, 122

Merycotherium of Biberian drift, 112

Mesacodon, N. American Tertiary, 183

Mesohippus. N. American Tertiary, 135

Mesonyr, N. American Tertiary, 134

Mesopithecus, Miocene of Greece, 115

Meyer, Dr. A. B., on reptiles and amphibia of New Guinea, 415

Microlestes, oldest European mammal, 160

Micromeryx, European Miocene, 120

Microsyops, N. American Tertiary, 133

Microtherium, European Miocene, 120

Middendorf, on extreme northeru birds, 219

Migrating birds, in which region to be placed, 185

Migration of animals, 10

general phenomena of, 18

of birds, 19

of birds in Europe, 19

probable origin of, 22

of birds in India and China, 23

of birds in N. America. 23

changes in extent of, 24

of birds in S. Temperate America, 25 general remarks on, 25

Milvus, European Miocene, 162

Miocene fauna of the Old World, 114

fauna of Greece, 115

fauna of Greece, summary of, 116

fauna of Central Europe, 117

deposits of Siwalik Hills, 121

faunas of Europe and Asia, general observations on, 123

Miohippus, N. American Tertiary, 135

Mivart, Professor, on classification of primates, 86

on classification of insectivora, 87

on classification of ainphibia, 101

Moles almost wholly Palæarctic, 181

Mole-rat, of W. Tartary, 218

Mollusca, means of dispersal of, 30 classification of, 104 groups selected for study, 104

Moliccas, zoology of, 417 birds of, 419 reptiles of, 420 insects of, 420 peculiarities of fauna of, 421

Monkeys on the high Himalayas, 12 fossil in N. American Miocene in $\mathrm{E}$. Thibet, 222

abundance of in the Oriental region, 315

Monotremata, classification of, 91 list of Australian genera of, 477

"More-pork" of Australian figure of, 442

Morotherium, N. American Pliocene, 140

Motacilla, European Miocene, 161

Mound-builders, peculiar Australisn birds 393

Moupin, position and zoology of, 221

Muride, S. American Pliocene, 147

Murray, Mr. Andrew, on zoolo rical region, 60 Mustela, Miocens of Greece, 115 European Miocene, 118

S. American Pliocene, 145

Mustelida, in Brazilian caves, 144

Myloilon, N. American Post-Plioceno, 130

S. Americau Pliocene, 147

Myogule, Euronean Miocena, 118

Myomorphus, fossil in Cuba

Muopotamus, in Brazilian caves, 145

Myoxus, European Miocene, 120 European Eocerre, 126

Miscurachue, European Miocene, 118

Mysops, N. American Eocene, 140

Vyzophagus, N. Amarican Post-Plioc3ne, 130 
N.

Nannhers, N. American Tertiary, 137

Nasua, in Brazilian caves, 114

Nearctic region, defined, 79 subdivisions of, 80 distinct from Palæarctic, 79

Necrornis, Euronean Miocene, 161

Neotropical region, defined, 78 subdivisions of, 78 relations of W. African sub-region with, 265

Nesodon, S. American Pliocene, 147

Newton, Professor, on position of Menuridee and Atrichiidoe, 95

on birds of Iceland, 198

New Caledonia, birds of, 444

New Guinea, zoology of, 409 manmalia of 410

birds of, 411

peeuliarities of its ornithology, 413

illustration of ornithology of, 414

reptiles and amphibia of, 415 insects of, 416

New Zealand, objections to making a primary zoological region, 62

extinct birds of, 164

sub-region, description of, 449

compared with British Isles, 449

mammalia of, 451

islets of, 453

illustration of ornithology of, $4: 5$

reptiles of, 456

amuhibia of 457

fresh-water fish of, 457

insects of, 458

Longicorns of, 458

Myriapoda of, 458

land-shells of, 459

ancient fauna of, 460

origin of fauna of, 460

poverty of insects in, 462

relations of insect-fauna and flora, 472

Nicubar Islands, their zoolngical relutions, 332

Nightiugale, migration of the, 21

Norfolk Island, birds of, 453

North America, remarks on Post-Pliocene fauna of, 130

Post-Pliocene fauna of, partly derived from S. America, 131

extinct birds of, 163

North Africa, zoological relations of, 202

Notharctos, N. American Tertiary, 133

Notornis of New Zealand, 455

Nototherium, Australian Post-Tertiary, 157

0.

Ochctherium, in Brazilian caves, 145

Uetochenticier, s. American I'liocene, 147

Ophiclia, classification of, 99

Oxisthocomus, Brazilian cares, 164

Oxossum, extinct, in Europesn Miocene, 121

Oreodon, N. American Teríary, 138

Oreodontide, N. American Tentiary, 138

Oriental region, defined, 75

subdivisions of, 75

description of, 314

zoological features of, 315

mammalia of, 315

bircls of, 316

reptiles of, 317

annhibia of, 317

fresh-water Jishes of 318

suiumary of vertebrata, 318

insects of, 318

sub-regions of, 321
Oriental region, concluding remarks on, 962 tables of distribution of animals of, 364

Oriental relations of $\mathrm{W}$. African sub-region, 265 Uriental and Palæarctic faunas once identical, 362

Oriental and Ethiopian faunas, cause of their resemblances, 363

Orohippus, N. American Tertiary, 136

Ostrich, Miocene of N. India, 162

Otaria, European Miocene, 118

Ovibos, N. American Post-Pliocene, 130

Oxen, birthplace and migrations of, 155 Palæarctic, 182

Oxyona, N. American Tertiary, 134

Oxygomphus, European Miucene, 118

Oxymycterus, in Brazilian caves, 145

S. American Pliocene, 147

P.

Pachyanna, N. American Tertiary, 134

Pachynolophus, European Eocene, 126

Pachytherium, in Brazilian caves, 145

Palæarctic region, defined, 71

subdivisions of 71

general features of, 180

zoological characteristics of, 181

has few peculiar families, 181

mammalia of, 181

birds of, 182

high degree of speciality of, 184

l'eptiles and amphibia of, 186

frosh-Water fish of, 186

summary of vertebrata of, 186

insects of, 186

coleoptera of, 187

number of coleoptera of, 189

land-shells of, 190

sub-regions of, 190

gcneral conclusions on the fauna of, 231

tables of distribution of animals of, 233

Palceucodcn, N. Ancerican Tertiary, 133

Palceetus, European Miocene, 162

Palogithalus, European Eocene, 162

Palcelodus, European Miocene, 162

Palcecastor, N. American Tertiary, 140

Palococercus, European Miocene, 162

Palceochoerus, European Miocene, 119

Palcuchierax, European Miocene, 162

Palaolagus, N. American Tertiary, 140

Paloeolama, S. American Pliocene, 147

Palocomephitis, European Miocene, 118

Palcomeryja, Eurovean Miocene, 120

Palceomys, Eurupean Miocene, 121

Palacontina oolitica, Oolitic iusect, 167

Palæontology, 107

how best studied in its bearing on geographical distribution, 168

as an introduction to the study of geogranhical distribution, concluding remarks on, 169

Palaonyctis, European Eocene, 125

Palcoperdix, European Miocene, 161

Palceophrynus, European Miocene, 166

Palaoreas, Miocene of Greece, 116

Palcortyx, European Miocene, 161

I'alccoryx, Miocene of Greece, 110

palceosiculax, 111

European Miocene, 117

Palreosyops, N. American Tertiary, 136

Palootherida, European Encene, 125

Palootherium, Europcan Eocene, 125

S. American Eocene, 148

Palocotragus, Mincene of Greece, 110

Paloolringa, N. American Cretaceous, 164 
Palcutcrygidce of New Zealand, 164

Palestine, birds of, 203

Paloplotherium, European Miocene, 119 European Eocene, 125

Paludina, Eocene, 169 European Secondary, 109

Parnpas, Pliocerre deposits of, 146

Panda, of Nepaul and E. Thibet, 222 Himalayan, figure of, 331

Panolax, N. American Tertiary, 140

Papuan Islands, zoology of 409

Paradise-bird, twelve-wired, figure of, 414

Parahippus, N. American Tertiary, 136

Paramys, $\mathbf{N}$. American Eocene, 140

Parroquet, Papuan, figure of, 415

Parrota, classification of, 90

Passeres, arrangement of, 94

range of Palæarctic rencra of, 243

range of Ethiopian genera of, 306 range of Oriental genera of, 375

range of Australian genera of 478

Patriofelis, N. American Tertiary, 134

Peculiar groups, geographically, how dettned, 184

Pelagornis, European Mincene, 162

Pelonax, N. American Tertiary, 138

Peratherium, European Mioceue, 121 European Eocene, 126

Perchoerus, N. American Tertiary, 137

Perim Island, extinct mammalia of, 122 probable southern linit of old Palæarctic land, $36^{\circ}$

Perissodactyla, N. American Tertiary, 135

Persia, birds of, $2 n 4$

Phascolomys, Australian Post-Tertiary, 157

Phasianns, Miocene of Greece, 116 Europenn Post-Pliocene, 161

Pheasants, in European Miocene, 161 golden, of N. China, 226 eured, of Mongolia, 226

Pliencocodus, $\mathbf{N}$ American Tertiary, 138

Philippine Islands, mammals of, 345 birds of, 346 origin of veculiar fauna of, 348

Phocilice, N. American Tertiary, 140

Phyllomys, in Brazilian caves, 145

Phyllostomida, in Brazilian caves, 144

Physical changes affecting distribution, 7

Physeter, European Pliocene, 112

Picariæ, arrangement of, 95

range of Prlaarctic genera of, 247 range of Ethiopian genera of, 309 range of Oriental genera of, 381 range of Australian genera of, 482

Picus, European Miocene, 161

Pigeons, classification of, 96 remarkable development of, in the Augtralian region, 395

crested, of Australia, figure of, 441

Pigs, power of swimming, 13

Pikermi, Miocene faung of, 115

Pittidr, abundant in Borneo, 355

Plagivlophus, European Eocene, 126

planorbis, Europeau Secondary, 169 Eocene, 169

Platycercida, gorgeously-coloured dustralian parrots, 394

Platygonus, N. American Post-Plincene, 130

Plesiarctomys, European Eocene, 126

Plesiomeryx, European Eocene, 126

Plesiosorex, Europena Miocene, 118

Pliocene period, Old World, mammalia of, 112

Pliocene and Post-Pliocene faunas, of Europe, general conclusions from, 118

of N. America, 132

of $\mathrm{S}$. America, 146
Pliocene and Post-Pliocene faunas of dus. tralia, 157

Pliohippus, N. American Tertiary, 185

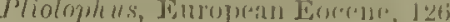

Pliopithecus, European Miocene, 117

Pobrotherium, N. American Tertiary, 138

Polynesian sub-region, description of, 442 birds of, 448 reptiles of, 447

Post-Pliocene, mammalia of Europe, 110 remains imply changes of pliysical geography in Europe, 111

faura of $\mathbf{N}$. America, 129

fauna of N. America, remarks on, 130

Potamogale of West Africa, figure of, 264

Potamotherium, European Miocene, 118

Potto of West Africa, figure of, 264

Praotherium, N. American Post-PJiouene, 130

I'rimates, classification of, 86 probable birthplace of, 153

runge of Palæarctic genera of, 239

range of Ethiopian genera of, 300

range of Oriental genera of, 371

range of Australian genera of, 475

Primates, Eurnpean Pliocene, 112

Miocene of Greece, 115

European Miocene, 117

Indian Mioccne, 121

European Eocene, 124

N. American Tertiary, 132

of Brazilian caves, 144

Prince's Island, birds of, 266

Prionidium, Oolitic insects, 167

Pristiphoca, in European Pliocene, 112

Proboscidea, classification of, 90 range of Ethiopian genus, $3 \cap 3$ range of Oriental genus, 374

Proboscidec, European Pliocene, 113

Miocene of Greece, 116

European Miocene, 120

Indian Miocene, 122

N A merican Post-Pliocene, 130

N. American Tertiary, 138

of Brazilian caves, 144

8. American Pliocene, 147

Procamelus, N. American Post-Pliocene, 130 N. American Tertiary, 138

Procyon, N. American Post-Pliocene, 130

Procyonidce, in Brazilian caves, 144

Promephitis, Mincene of Greece, 115 European Miocene, 118

Promerops of East Africa, figure of, 261

Propalosotherium, European Eocene, 126

Protemnodon, Australian Post-Tertiary, 157

Protohippus, N. American Tertiary, 135

Protomeryx, N. American Tertiajy, 138

Protopithecus, in Brazilian caves, 144

Prototomus, N. American Tertiary, 134

Protornis, European Eocene, 162

Pserdicelurus, Furopean Miocene, 118

Pseridocyon, European Miocene, 118

Psittaci, classificntion of, 96

range of Ethiopian genera of, 811

range of Oriental genera of, 383

range of Australian genera of, 484

Psittacus, Eurovern Mioceno, 161

Pterocles, European Miocene, 161

Pterodon, Europenn Eocene, 125

Pupa, Eocene, 169

P'upa retusta, Palarnzoic, 169

Pythonida, European Miocene, 165

R.

Racoon-dog of N. China, 226

Rana, European Mícene, 160 
Region, the best term for the primary zoological divisions, 68

Arctic, why not adopted, 69

Palæarctic, definecl, 71

Palonuctic, suludivisions of, 71

Ethiopian, defined, 73

Ethiopian, subdivisions of, 73

Oriental, defined, 75

Oriental, subdivisions of, 75

Australian, defined, 77

Australian, subdivisions of, 77

Neotropical, defined, 78 .

Neotropical, subdivisions of, 78

Nearctic, defined, 79

Nearctic, distinct from Palæarctic, 79

Nearctic, subdivisions of, 80

Regions, zoological, j0

zoological, how they should be formed, 53 zoological, may be defined by negative or positive characters, 54

zoological, by what class of animals best determined, 56

for each class of animals, not advisable, $5 \mathrm{~s}$

zoological, proposed since 1857, 58

zoological, Mr. Sclater's, 59

zoological, discussion of those proposed

by various anthors, 61

zoological, proportionate richness of, 64

temperate and tropical, well marked in northern hemisphere, 65

and zones, table of, 66

comparative richness of, 81

and sub-regions, table of, 81

order of succession of the, 173

Representative species, 4

Reptiles, means of dispersal of, 28

classification of, 98

Miocene of Greece, 116

of Indian Miocene deposits, 123

extinct Tertiary, 165

cosmopolitan groups of, 176

peculiar to Yalæarctic region, 186

of Central Europe, 195

of the Mediterrauean sub-region, 204

of Siberiausub-1'egion, 220

of the Manchurian sub-region, 227

table of Palrearctic families of, $236^{\circ}$

of the Ethiopian region, 254

of the East African sub-region, 260

of West Africa, 264

8. African, 268

of Madagascar, 279

table of Ethiopian families of, 297

of the Oriental region, 317

of the Indian sub-region, 326

of Ceylun, 327

of Indo-Chinese sub-region, 331

of Indo-Malay sub-region, 340

table of Oriental families of, 368

of the Anstralian region, 396

of New Guinea, 415

of the Moluceas, $4: 20$

of the Polynesian sub-region, 447

of New Zealand, 456

table of Australian families of, 472

Rhea, in Brazilian caves, 164

Rhinoceros, Post-Pliocene, 112

European Pliocene, 11

Miocene of Greece, 116

Indian Miocene, 122

fossil remains of, at 10,000 feet elevation in 'Tlibet, 122

rossil in N. China, 123

N. American Tertiary, 186

Rhinoceros-hornbill, figure of, 339
Rhinocerotide, N. American Tertiary, 136

River-hng, of West Africa, figure of, 264 of Madagascar, figure of, 278

Rivers, limiting the range of mammalia, 12 limiting the range of birds, 17

River-scene, in West Africa, 264

Rodentia, classification of, 90

range of Palæarctic genera of, 242

range of Ethiopian genera of, 304

range of Oriental genera of, 374

range of Australian genera of, 476

Rodentia, European Pliocene, 113

Miocene of Greece, 116

European Miocene, 120

European Eocene, 126

N. American Post-Pliocene, 130

N. American Tertiary, 139

of Brazilian caves, 144

S. American Pliocene, 147

of 8. American Eocene, 148

Ruff, figure of, 195

S.

Salara, a debatable land, 251

Saiga, aritelope of W. Tartury, 218

Samna Islands, birds of, 443

Sandwich Islands, birds of, 445

prubable past history of, 446

mountain plants of, $\mathbf{4 4 6}$

depth of ocean around, 447

Sand-grouse, Pallas, of Mongolia, 226

Sutyrites Rennesii, European Cretaceous insect, 167

Saunders, Mr. Edward, on the Buprestidx of Japan, 229

Scelidothurium, in Brazilian cares, 145

S. Anerican Pliocene, 147

Schistopleamum, S. American Pliocene, 147

Schweinfurth, Dr., on natural history of Central Africa, 252

on limits of W. African sub-region, 262 (note)

Sciurus, European Miocene, 120

European Eocene, 126

Sciuravus, N. American Eocene, 140

Sclater, Mr., on zoological regions, 59 why his six regions are adopted, 63 on birds of Sandwich Islands, 445

Sen, as a barrier to mammalia, 13

Seals, fossil in European Miocene, 118 of Lake Baikal, 218

Secondary formations, mammalian remains in, 159

Secretary-bird of Africa, figure of, 261

Semnopithecus, European Pliocene, 112

Miocene of Greece, 115

European Miocene, 117

Indian Miocene, 121

Semper, Dr, on Philippine mammalia, 945

Serpentarius, Europeau Miocene, 162

Seychelle Islands, zoology of, 281 amıphibia of, 281

Sharp, Dr., on Japan beetles, 229

Sharpe, Mr. R. B., lis arrangement of Accipitres, 97

on birds of Cape Verd Islands, 215

Shcep, Palæarctic, 182

Siberia, climate of, 217

Siberian sub-region, description of, 216

mammalia of 217

birds of, 219

reptiles and amphibia of, 220

insects of, 220

Simocyon, Miocene of Greece, 115 
Sinoyn, N. Amerienu Tertinry, 134

Sirenia, classification of, so range of Ethiopian genern of, 303 ralige of Oriental genus, 874 range of Australian genus of, 476

Sivenia, European Pliocene, 112 European Miocene, 119

Siratherium, Indian Miocene, 122

Siwalik Hills, Miocene deposits of, 121

Smith, Mr. Frederick, on Hywenoptera of Japan, 230

Snake, nt great elevation in Himalayas, 220

Snakes, classification of, 99

Eocene, 165

large proportion of venomous species in Australia, 396

of New Zealancl, 457

Society Islands, bircls of, 443

Soricictis, European Miocene, 118

Soricida, European Miocene, 118

South African sub-region, description of, 260 mammalia of, 267

birds of, 267

reptiles of, 268

amphibia of, 268

fresh-water fish of, 268

butterflies of, $26 \mathrm{~s}$

coleoptera of, 268

summary of its zoology, 269

South America, fossil fauna of, 143

Pliocene deposits of, 146

supposed land connection with Australia, 398

South Australia, peculiar birds of, 441

Species, representative, 4

Speothos, in Brazilian caves, 144

Spermophilus, European Miocene, 120

Sphenodon, in Brazilian caves, 145

Sphinx, in European Oolite, 167

St. Helena, zoological features of, 269

coleoptera of, 270

landsliells of, 271

St. Thomlas' Island, birds of, 266

Stations, defnition of, 4

Stenenfiber, Europesn Miocene, 120

Sthenurus, Australian Post-Tertiary, 157

Strix, European Miocene, 162

Struthiones, arrangement of, 98 range of Ethiopian genera of, 313 range of Australian genera of, 487

Struthious birds, probable origin of, 287

Stylinodontidcr, N. American Eocene, 139

Stylinodontia, N. American Eocene, 139

Sub-regions, on what principle formed, 80 Palæarctic, 191

Ethiopian, 258

Oriental, 321

Australian, 408

Suido, European Miocene, 119

Sula Islands, fauna of, 483

Sus, European Pliocene, 113

Mjoceue of Greece, 116

European Miocene, 118

Indian Miocene, 122

Swinhoe, Mr., on zoology of Formosa and Hainan, 332

Symborodon, N. American Tertiury, 137

Synaphodus, European Miocene, 119

Synoplotherium, N. American Tertiary, 134

\section{T}

Trbles of distribution of families and genera explained, 177

Tuin $u$, European Miocene, 117
Tapir; fossil in N. China, 128

Tapirs, virthplace and migl ations of, 1 id

Turir, Malayan, figure of, 337

Tapiride, European Eocene, 12

Tapirus, European Plincene, 113

Indian Miocene, 12

iñ Brazilian caves; 144

Tarsier, Malayan, tigure of, 337

Tasmania, comparative zoological poverty of. 441

Taxodon, European Miocene, 118

Telmatobius, $N$. Anterican Cretaceous, 164

Telmatolestes, N. Ainerican Tertiary, 198

Testudo, Miocene of Greece, 116 Indian Miocene, 123

Testudo, great antiquity of the genus, 289

Tetrachus, European Miocene, 117

T'etrao albus, in Italian caverns, 161

Thalassictis, Miocene of Greece, 115 European Miocene, 118

Theridumys, European Miocene, 126 European Eocene, 126

S. American Eocene, 148

Thinohyus, N. American Tertiary, 137

Thinolestes, N. American Tertiary, 133

Thylacinus, Australian Post-Tertiary, 157

Thylacoleo, Australian Post-Tertiary, 157

Tillodontia, N. American Eocene, 139

Tillotheridce, N. American Eocene, 139

Tillotherium, N. American Eocene, 139

Timor, physical features of, 389 group, mammalia of, 422

birds of, 422

origin of fauna of, 424 insects of, 426

Tinoceras, N. American Eocene, 139

Titanomys, European Miocene, 121

Titanotherium, N. American Tertiary, 13\%

Tomarctos, N. American Tertiary, 135

Tnnga Islands, birds of, 443

Tortoises, classification of, 100 of Mascarert Islands and Galapagos, 289

Touraco of W. Africa, tigure of, 264

Toxodon, S. American Pliocene, 137

Toxodontide, 8. American Pliocene, 147

Trachytherium, European Miocene, 119

Tragocerns, Miocene of Greece, 116 European Miocene, 120

Tragopan, Eimalayan, figure of, 331

Tree-shrew of Borneo, figure of, 337

Tree-kangaroo, figure of, 415

Trichechus, N. A merican Post-Pliocene, 130

Trichoglossidæ, birds specially adapted to Australia, 393

Trionyx, Indian Miocene, 123 Miocene and Eocene, 165

Tristan d'Acunha, zoology of, 271

Tristram, Canon, sumnary of the birds of Palestine, 203

Trogon, European Miocene, 161

Trogontherium, Post-Plioceue of Europe, 11]

Trucijelis, N. American Post-Pliocene, 129 Tundras of Siberia, greatest extent of, 216

Tupaidia, European Miocene, 118

Tumer, Mr., on classification of Edentata, 90

Tylodon, European Eocene, 125

Typotherium, S. American Pliocene, 147

U.

Uintacyon, N. Americnn Tertiary, 184

Uintatherium, N. American Eocene, 198

Uintornis, $\mathbf{N}$. American Eocene, 169

Unio, European Secundary, 109

Ungulata, classification of, 89 
Ungulata, antiquity of, 151

of the Palearctic region, 182

range of Paliearctic genera of, 241

range of Ethiopian genera of, 303

range of Oricrital genera of, 374

range of A ustralian genera of, 476

Ungulata, European Pliocene, 112.

Miocene of Greece, 115

European Miocene, 119

Indian Miocene, 121

Eurovean Eocene, 125

N. American Post-Pliocene, 130

N. Anicrican Tertiary, $13 \mathrm{j}$

of Braziliau caves, 144

S. American Pliocene, 146

Urania of Madagascar, 282

Ursidae, N. American Tertiary, 135

in Brazilian caves, 144

Ursitaxus, Indian Miocene, 121

Ursus, Post-Pliocene, 112 Indian Miocene, 121

\section{V.}

Vanga of Madagascar, figure of, 278

Varanus, Miocene of Greece, 116 Indian Miocene, 123

Vertebrata, summary of Palæaretic, 186 summary of Ethiopian, 255 summary of Oriental, 318 summary of Australian, 397

Vespertilio, European Eocene, 125

Viperus, European Miocene, 165

Viverra, European Pliocene, 112 European Miocene, 118

Viverridce, European Miocene, 118 Eurnpean Eocene, 125

\section{W.}

Walden, Viscount, on birds of Philippine Islands, $346^{\circ}$

on birds of Celebes, 428
Washakius, N American Tertiary, 134

Waterhouse, Mr. G. R., on classification of rodentia, 90

on classification of marsupials, 91

West African sub-region, description of, 262 mammalia of, 262

birds of, 262

Oriental or Malayan element in, 263

river scene with characteristic animals, 264 reptiles of, 264

amphibia of, 264

Oriental and Neotropical relations of, 265

insects of, 265

land-shells of, 265

islands of, 265

West Australia, peculiar birds of, 441

Whydah finch of W. Africa, figure of, 264

Wollaston, Mr. T. V., on the coleoptera of the Atlantic Islands, 209

on the wings of the Madeiran beetles, 211 on the origin of the insect fauna of the Atlantic Islands, 214

on coleoptera of the Cape Verd Islands, 215 on beetles of St. Helena, 270

\section{$\mathrm{x}$}

Xenurus, in Brazilian caves, 145

Xiphodontidoe, European Miocene, 119

Z.

Zeuglodontidce, N. American Tertiary, 140

Zonites priscus, Palæozoic, 169

Zoological characteristics of Palæarctic region, 181

Ethiopian region, 252

Oriental region, 315

Australian region, 390

Zoological regions, discussion on, 50

END OF VOL. I. 

-

3 



\section{(2)}

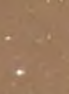

$\because x+x-100$

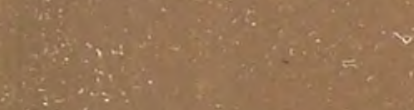

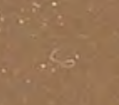

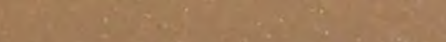

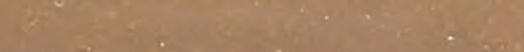

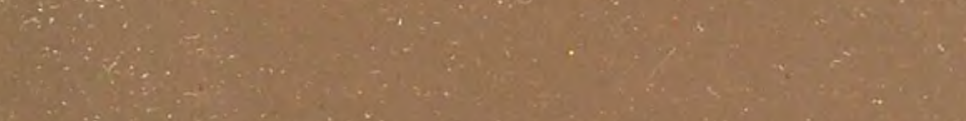

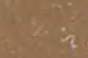
.

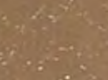
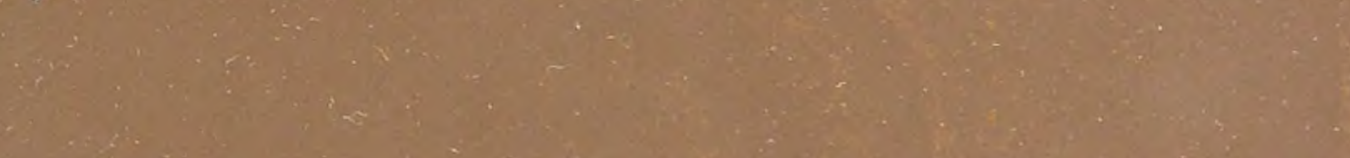

$\sin _{i}$

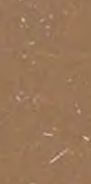

$\therefore \quad \cdots$

$4 x+4$

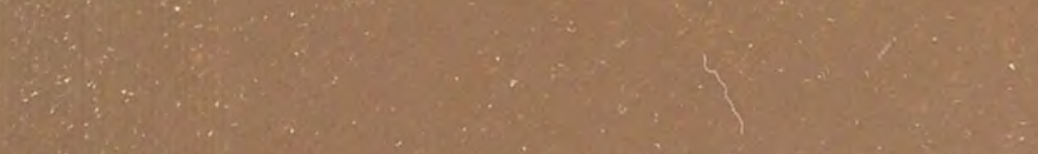

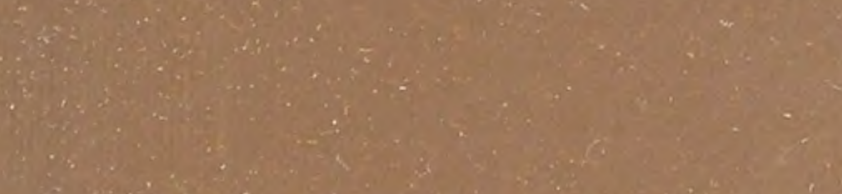

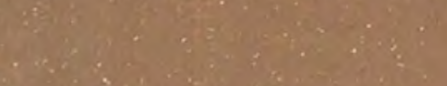

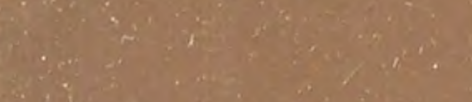

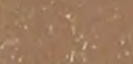

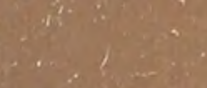

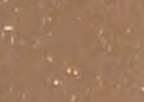

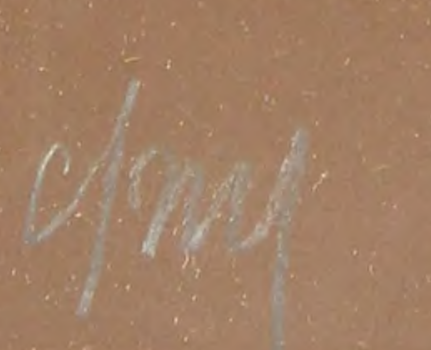

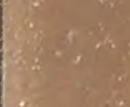

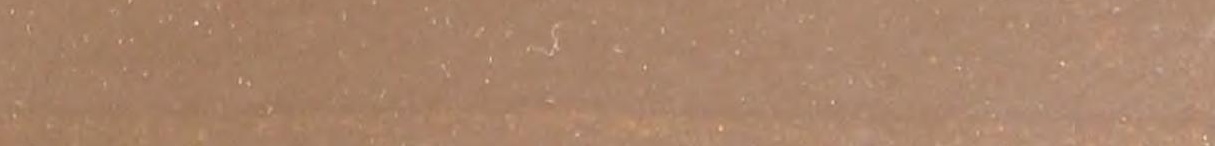


